\title{
OXFORD
}

\section{GROWTH AND POVERTY IN SUB-SAHARAN AFRICA}

\section{Edited by \\ Channing Arndt, \\ Andy McKay, and Finn Tarp}


Growth and Poverty in Sub-Saharan Africa 
United Nations University World Institute for Development Economics Research (UNU-WIDER) was established by the United Nations University as its first research and training centre and started work in Helsinki, Finland, in 1985. The mandate of the institute is to undertake applied research and policy analysis on structural changes affecting developing and transitional economies, to provide a forum for the advocacy of policies leading to robust, equitable, and environmentally sustainable growth, and to promote capacity strengthening and training in the field of economic and social policymaking. Its work is carried out by staff researchers and visiting scholars in Helsinki and via networks of collaborating scholars and institutions around the world.

United Nations University World Institute for Development Economics Research (UNU-WIDER) Katajanokanlaituri 6B, 00160 Helsinki, Finland www.wider.unu.edu 


\section{Growth and Poverty in Sub-Saharan Africa}

Edited by

Channing Arndt, Andy McKay, and Finn Tarp

A study prepared by the United Nations University World Institute for Development Economics Research (UNU-WIDER)

\section{OXFORD}




\section{OXFORD}

\section{UNIVERSITY PRESS}

Great Clarendon Street, Oxford, OX2 6DP,

United Kingdom

Oxford University Press is a department of the University of Oxford.

It furthers the University's objective of excellence in research, scholarship, and education by publishing worldwide. Oxford is a registered trade mark of Oxford University Press in the UK and in certain other countries

(c) United Nations University World Institute for Development Economics Research (UNU-WIDER) 2016

The moral rights of the authors have been asserted

First Edition published in 2016

Impression: 1

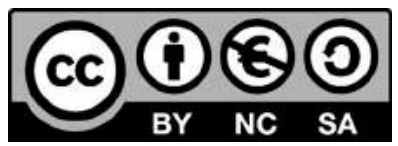

Some rights reserved. This is an open access publication. Except where otherwise noted, this work is distributed under the terms of a Creative Commons Attribution-Non Commercial-Share Alike 3.0 IGO licence (CC BY-NC-SA 3.0 IGO), a copy of which is available at https://creativecommons.org/licenses/by-nc-sa/3.0/igo/.

It is permitted to reuse, share and adapt this work, subject to the following terms:

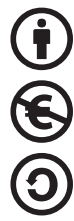

Attribution - appropriate credit is given to the original work, the copyright holder and creator, and any changes made to the work are properly indicated.

Non-Commercial - the work, or any adaptation of the work, may not be used, distributed or reproduced in any format, by any means, for commercial purposes.

Share-Alike - the work, or any adaptation of the work is distributed under the same licence terms as the original, with a URL link provided to the licence.

Enquiries concerning use outside the terms of the Creative Commons licence should be sent to the Rights Department, Oxford University Press, at the above address or to academic.permissions@oup.com.

Published in the United States of America by Oxford University Press 198 Madison Avenue, New York, NY 10016, United States of America

British Library Cataloguing in Publication Data

Data available

Library of Congress Control Number: 2015949595

ISBN 978-0-19-874479-5

Printed in Great Britain by

Clays Ltd, St Ives plc

Links to third party websites are provided by Oxford in good faith and for information only. Oxford disclaims any responsibility for the materials contained in any third party website referenced in this work. 


\section{Foreword}

Despite decades of research and advances in data and methodologies, measuring poverty and reconciling this with patterns of economic growth is a disputatious issue. This contentiousness and the fact that poverty remains widespread in sub-Saharan Africa (SSA) charged UNU-WIDER to launch in 2011 a major research project-the Growth and Poverty Project (GAPP)—-to re-examine SSA's growth, poverty, and inequality trends with three main goals in mind. First, develop new tools to measure monetary poverty in consistent and comparable ways, and make these tools accessible to scholars and analysts in Africa, other developing regions, and beyond. Second, undertake detailed case studies of sixteen of the twenty-four most populous countries in SSA (covering no less than 73.8 per cent of the population in SSA) to measure poverty trends, and 'triangulate' these with other development indicators. Third, develop a macro-micro analytical framework to conduct detailed research in countries where poverty and economic growth trends appear to be inconsistent.

This book holds the essential country-level harvest of this large, multicountry, multi-discipline research project brought to the reader in a condensed form together with a comprehensive synthesis to explore the depths of the unfolding story of the growth-poverty nexus in SSA and to absorb the policy implications. The project team consisted of leading international experts and UNU-WIDER researchers along with some of the African continent's best researchers and data analysts. I hereby sincerely express my appreciation and admiration of the academic and analytical skills of this team and the detailed knowledge of the case countries brought out so clearly in this volume. Our profession does indeed have something sensible to contributeboth in recognizing that growth is in many cases translated into poverty reduction in African countries and in helping to understand why this link is sometimes not as robust as desirable.

UNU-WIDER gratefully acknowledges the Special Programme Contribution (SPC) by the Ministry of Foreign Affairs of Finland for this project and the regular core financial contributions made to its research programme from the governments of Denmark, Finland, Sweden, and the United Kingdom. 



\section{Acknowledgements}

UNU-WIDER's Growth and Poverty Project (GAPP) was implemented between 2012 and 2014 and brought together a highly qualified team of more than forty researchers from Africa and beyond. Without their dedication and professional competence, this book would not have been possible. We wish to express our sincere appreciation to these country teams who produced the case studies in this book. Putting together a volume such as this one is no easy undertaking; and we wish to express our appreciation for all of the high-level academic input, together with the copious goodwill and patience-which were much needed when doing the original groundwork followed by numerous revisions and updates of the individual chapters.

A series of intensive planning meetings, involving many of the authors, helped shape the project; and results were presented at several UNU-WIDER development conferences and many other occasions across African countries. We are grateful to all of those who offered critique and most helpful comments. They include Oxford University Press's Economics Commissioning Editor Adam Swallow and his team, as well as three anonymous referees. Your efforts were essential in helping to sharpen our research questions and approach to addressing one of the most intricate challenges facing the development profession, the African growth renaissance and its impact on poverty reduction.

UNU-WIDER and its dedicated staff provided steady support, including research assistance, which goes far beyond the normal call of duty. Particular thanks go to Dominik Etienne for excellent programming; Anne Ruohonen for consistent project assistance; Lorraine Telfer-Taivainen for all of the careful publication support, including the many contacts with OUP; and Lisa Winkler and the group of copy-editors for helping to put out the many UNU-WIDER working papers produced during the course of the project.

The research project-Reconciling Africa's Growth, Poverty, and Inequality Trends-was generously supported by the governments of Denmark, Finland, Sweden, and the United Kingdom, with a special project contribution additionally provided by the Finnish government. UNU-WIDER gratefully acknowledges this vital research funding. It is our hope that the volume will be of relevance to all of those struggling to end poverty in Africa.

Channing Arndt, Andy McKay, and Finn Tarp Helsinki, January 2016 



\section{Contents}

List of Figures $\quad$ xi

List of Tables $\quad \mathrm{XV}$

List of Boxes $\quad$ xxi

List of Abbreviations $\quad$ xxiii

Notes on Contributors $\quad$ Xxvii

1. Growth and Poverty in Sub-Saharan Africa $\quad 1$

Channing Arndt, Andy McKay, and Finn Tarp

2. Synthesis: Two Cheers for the African Growth Renaissance (but not Three)

Channing Arndt, Andy McKay, and Finn Tarp

\section{Part 1. Rapid Growth and Rapid Poverty Reduction}

3. Poverty in Ethiopia, 2000-11: Welfare Improvements in a Changing Economic Landscape

David Stifel and Tassew Woldehanna

4. Ghana: Poverty Reduction over Thirty Years

Andy McKay, Jukka Pirttilä, and Finn Tarp

5. Did Rapid Smallholder-Led Agricultural Growth Fail to Reduce Rural Poverty? Making Sense of Malawi's Poverty Puzzle

Karl Pauw, Ulrik Beck, and Richard Mussa

6. Growth, Poverty Reduction, and Inequality in Rwanda Andy McKay and Marijke Verpoorten

7. Poverty and its Dynamics in Uganda: Explorations Using a New Set of Poverty Lines

Bjorn Van Campenhout, Haruna Sekabira, and Dede Houeto Aduayom

\section{Part 2. Rapid Growth but Limited Poverty Reduction}

8. Burkina Faso: Shipping around the Malthusian Trap 
9. Mozambique: Off-track or Temporarily Sidelined?

Channing Arndt, Sam Jones, and Finn Tarp

10. Spatial and Temporal Multidimensional Poverty in Nigeria Olu Ajakaiye, Afeikhena T. Jerome, Olanrewaju Olaniyan, Kristi Mahrt, and Olufunke A. Alaba

11. Growth and Poverty Reduction in Tanzania Channing Arndt, Lionel Demery, Andy McKay, and Finn Tarp

12. Assessing Progress in Welfare Improvements in Zambia: A Multidimensional Approach

Gibson Masumbu and Kristi Mahrt

\section{Part 3. Uninspiring/Negative Growth and Poverty Reduction}

13. Slow Progress in Growth and Poverty Reduction in Cameroon 293 Samuel Fambon, Andy McKay, Joseph-Pierre Timnou, Olive Stéphanie Kouakep, Anaclet Désiré Dzossa, and Romain Tchakoute Ngoho

14. The Fall of the Elephant: Two Decades of Poverty Increase in Côte d'Ivoire, 1988-2008

Denis Cogneau, Kenneth Houngbedji, and Sandrine Mesplé-Somps

15. Incomes, Inequality, and Poverty in Kenya: A Long-Term Perspective

Arne Bigsten, Damiano Kulundu Manda, Germano Mwabu, and Anthony Wambugu

16. Utility-Consistent Poverty in Madagascar, 2001-10: Snapshots in the Presence of Multiple Economy-Wide Shocks

David Stifel, Tiaray Razafimanantena, and Faly Rakotomanana

17. Poverty, Inequality, and Prices in Post-Apartheid South Africa Murray Leibbrandt, Arden Finn, and Morné Oosthuizen

\section{Part 4. Low-Information Countries}

18. Growth and Poverty in the Democratic Republic of Congo: 2001 through 2013

Malokele Nanivazo and Kristi Mahrt 


\section{List of Figures}

1.1. Under-five mortality by major world region, 1980-2013 5

1.2. Projected population growth for China, India, and sub-Saharan Africa, 2010-50

1.3. Household final consumption expenditure per capita for sub-Saharan Africa, 1981-2013 (constant 2005 US\$)

3.1. Poverty incidence curves, Ethiopia 2000-11 50

3.2. Poverty incidence curves, Ethiopia 2000-11 51

3.3. Cereal production, Ethiopia 2000-11 56

3.4. Annual infant mortality rates, Ethiopia 1996-2010 60

3.A1. Test of second-order dominance, Ethiopia 2000-11 65

3.A2. Test of third-order dominance, Ethiopia 2000-11 65

4.1. Trends in economic growth, 1960-2012 73

4.2. Inflation in Ghana, 1990-2014 76

4.3. Comparison of food price inflation and overall price inflation 76

4.4. Growth incidence curve for Ghana, 1991/2-2005/6 78

4.5. Growth incidence curve for Ghana, 2005/6-12/13 79

5.1. Maize yields by region: Smallholder summer harvest, 2000/1-11/12 92

5.2. Official poverty headcount rates, 1997/8-2010/11 93

5.3. Consumption distribution functions and poverty estimates 105

6.1. Evolution of real per capita GDP in Rwanda, constant local currency units 113

6.2. Growth incidence curves for Rwanda 122

6.3. Pattern of poverty in Rwanda by district, 2010-11 123

6.4. Changes in poverty in Rwanda between 2005/6 and 2010/11, by district 124

6.5. Scatterplots of 2008 values of income and land against their 2002 values 127

6.6. Self-reported reasons for social mobility between ubudehe categories $\quad 129$

7.1. Regional distribution of households in different poverty dynamics $\begin{array}{ll}\text { categories } & 147\end{array}$

7.2. Time to fetch water in 2005/6 and poverty dynamics 148

7.3. Household size and child dependency ratios in 2005/6 150 
7.4. Distance (in kilometres) to health infrastructure in 2005/6

7.5. Average number of days per year inactive due to illness reported in $2005 / 6$

7.6. Coping with adverse shocks reported in 2005/6

8.1. GDP per capita constant prices

8.2. Sectoral GDP

8.3. Sectoral GDP per capita

8.4. Inflation of food crops compared to the CPI in the long run

8.5. Food imports and population growth

9.1. Average number of consumer goods (out of a maximum of eight) owned by households, 2002/3-8/9, by regions and rural/urban

9.2. Net enrolment rates, primary and secondary schooling by region, 2002/3 and 2008/9

9.3. Share of households with less than forty-five minutes' walk to nearest primary health facility, 2002/3 and 2008/9

9.4. Share of households with access to a safe water source, 2002/3 and 2008/9

9.5. Trends in malnutrition across surveys, percentage of infants, 1996/7-2008/9

9.6. Comparison of malnutrition in IOF08 and MICS08 for survey overlap period, percentage of infants

9.7. International real price indices 206

9.8. Components of the Mozambique CPI 208

9.9. Percentile-specific price indexes by percentiles of nominal per capita consumption

9.10. Evolution of poverty rates by scenario

10.1. Nigeria's real GDP growth rate, 2004-12

10.2. Nigeria's real sectoral GDP growth rates, 2004-11

10.3. Spatial FOD ranking and probability of net domination for national, sectoral, and zonal levels in 1999, 2003, and 2008

11.1. Growth of real local currency per capita GDP in Tanzania

11.2a. Growth incidence curves by strata, 1991/2-2000/1

11.2b. Growth incidence curves by strata, 2001-7

11.2c. Growth incidence curves by strata, 2007-11/12

11.3. Kernel density plots of the logarithm of consumption per adult, 2000/1-7 and 2007-11/12

12.1. GDP and GDP per capita (constant 2005 US\$), 1960-2013

12.2. Value added as a percentage of GDP, 1965-2013 
12.3. Deprivation by welfare indicator and area aggregate, per cent 275

13.1. GDP per capita of Cameroon in constant local currency values 295

13.2. Poverty incidence curve for Cameroon, 1996-2001 305

13.3. Poverty incidence curve for Cameroon, 2001-7 305

13.4. Cameroon growth incidence curve, 1996-2001 310

13.5. Cameroon growth incidence curve, 2001-7 310

14.1. GDP per capita and cash crop income, 1960-2010 322

14.2. Average height stature of males aged 20-59 years, 1900-90 323

14.3. GDP per capita, cash crop income, and oil income, 1988-2008 326

14.4. Cumulative distribution function of consumption per capita across time 328

14.5. Growth incidence curves 329

14.6. Civil conflict 335

14.A1. Real producer prices for cash crops 339

14.A2. Cocoa, coffee, and cotton output 339

15.1. Incomes by source, per cent 348

15.2. Percentage distribution of income by race 349

15.3. Gini coefficients, 1914-76 349

15.4. Income poverty in Kenya (Sen's Index), 1914-76 350

15.5. Relative factor endowments in Kenya, 1964-2000 351

15.6. Indexes of real returns to factors in Kenya, 1964-2000 352

15.7. Factor proportions, 1994-2011 356

16.1. Per capita consumption and GDP since independence in Madagascar 374

16.2. Poverty incidence curves, Madagascar, 2001-10 380

16.3. Poverty incidence curves, Madagascar, 2001-10 381

16.4. Poverty and real per capita GDP, Madagascar, 2001-10 384

16.5. Poverty and real GDP by sector, Madagascar, 2001-10 385

16.6. Annual infant mortality rates, Madagascar, 2000-8 389

17.1. Distributions of income, 1993, 2000, and 2010397

17.2. Lorenz curves, 1993, 2000, and $2010 \quad 399$

17.3. Share of household income from various sources, $2008 \quad 400$

17.4. Impact of prices on poverty as demonstrated by CDFs 405

17.5. Impact of prices on inequality as demonstrated by Lorenz curves 407

17.6. Poor households' exposure to high-inflation expenditure categories, 2005-10

18.1. Evolution of GDP and GDP per capita with marked regime changes and wars, 1960-2013 



\section{List of Tables}

1.1. Average GDP per capita growth of the sixteen selected sub-Saharan African countries (annual percentage) in the 1960s, 1970s, 1980s, 1990s, and 2000s

3.1. Regional poverty lines, Ethiopia 2000-11 46

3.2. Monetary poverty in Ethiopia, 2000-11 49

3.3. Regional poverty in Ethiopia, 2000-11 52

3.4. Inequality in Ethiopia, 2000-11 54

3.5. Production and inflation in Ethiopia, 2000-11 55

3.6. Poverty in select rural communities in Ethiopia, 1994-2009 58

3.7. Stunting rates in Ethiopia, 2000-11 59

3.8. Net school enrolment rates in Ethiopia, 2000-11 60

3.9. Literacy rates in Ethiopia, 1998-2011 61

3.10. Access to public goods in Ethiopia, 2000-11 62

4.1. Growth rates of different national accounts aggregates 74

4.2. Real GDP growth, by expenditure category and sector, 1991, 1999, 2006, and $2013 \quad 75$

4.3. Changes in national poverty headcount for Ghana, and elasticity $\begin{array}{ll}\text { calculations } & 78\end{array}$

4.4. Disaggregated poverty headcount data for Ghana $\quad 80$

4.5. Poverty headcounts by main economic activity 82

4.6. Measures of inequality in Ghana, with a focus on south-north differences $\quad 83$

4.7. Trends in some headline non-monetary indicators in Ghana 84

4.8. Child mortality by regions and education 85

4.9. School attendance by regions 86

5.1. Sectoral GDP growth rates and contributions to change in GDP, 2005-11 92

5.2. Official and revised CPI and inflation estimates 95

5.3. Food, non-food, and overall poverty lines for 2004/5 and 2010/11 101

5.4. Poverty headcount rates and changes in poverty between $2004 / 5$ and 2010/11 
5.5. Changes in subjective well-being, 2004/5-10/11

6.1. Selected non-monetary indicators for Rwanda

6.2. The ratio of indicators between the richest 20 per cent and the poorest 20 per cent of the sample population

6.3. Consumption and consumption poverty by province

6.4. Mobility matrix of self-reported social categories

6.5. Happiness, and mean income, assets, and income change by happiness

7.1. Official poverty headcounts, 2002-12

7.2. Poverty headcounts, 2002-12, using six spatial domains

7.3. Marital status in UNPS $2005 / 6$ and subsequent poverty dynamics

7.4. Most important source of earnings in UNPS 2005/6 and subsequent poverty dynamics

7.5. Education of household head in UNPS 2005/6 and subsequent poverty dynamics

7.6. Shocks experience in the previous five years as reported in UNPS 2005/6 and subsequent poverty dynamics

8.1. Income, income inequality, and income poverty, 1994-2003

8.2. Decomposition of the change in the national headcount index, $\Delta \mathrm{PO}$, Burkina Faso, 1994-2003

8.3. Income, income inequality, and income poverty, 2003-9 173

8.4. Rural and urban population growth 176

8.5. Employment patterns of population aged 15 to 64 (shares), 1994-2007 178

8.6. Cereal and cotton production, 1995-2010 179

8.7. Budget shares and farmers' market integration 182

8.8. Budget shares of general CPI 183

8.9. Indicators of children's malnutrition and mortality, 1993-2010 186

9.1. Official consumption poverty headcounts 192

9.2. Indicators of housing quality, 2002/3 and 2008/9, percentage of households

9.3. Ownership of consumer durables, 2002/3 and 2008/9, percentage of households

9.4. Aggregate production trends for food crops 204

9.5. Total maize production by data source (thousands of tonnes) 204

9.6. Growth in components of GDP 2003/9 for national accounts $\begin{array}{ll}\text { and for model } & 210\end{array}$

9.7. Actual and projected poverty rates 211

10.1. Incidence of poverty by sector and zones, 1980-2010, per cent 222

10.2. Inequality trend by area of residence and zones, 1980-2010 223 
10.3. Income shares distribution, 1986-2010

10.4. Proportion of households not deprived, by welfare indicator and year 228

10.5. Percentage distribution of households by number of deprivations 229

10.6. 1999 DHS static spatial FOD comparisons 230

10.7. 1999 DHS bootstrap spatial FOD comparisons (probabilities) 230

10.8. 2003 DHS static spatial FOD comparisons 230

10.9. 2003 DHS bootstrap spatial FOD comparisons (probabilities) 231

10.10. 2008 DHS static spatial FOD comparisons 231

10.11. 2008 DHS bootstrap spatial FOD comparisons (probabilities)

10.12. Temporal net FOD comparisons, DHS (probabilities)

11.1. Real GDP growth, by expenditure category and sector, 1992, 2001, 2007, and 2012

11.2. Trends in poverty headcounts and growth elasticities of poverty reduction

244

11.3. Poverty headcounts and Gini coefficients for Tanzania 250

11.4. Food shares in Tanzania, 2007 and 2011/12 256

11.5. Households not deprived by welfare indicator, per cent

11.6. Children under five ( $0-4$ years) not deprived by welfare indicator, per cent

259

12.1. Key macroeconomic indicators, annual averages, 1964-2011 266

12.2. Poverty headcount rates by area, 1991-2010 268

12.3. Poverty headcount rates by stratum, 1996-2010 269

12.4. Employment by sector, 2012, per cent 270

12.5. FOD indicators 274

12.6. Per cent of households deprived by indicator and by area 276

12.7. Households by number of deprivations in the five indicators in 2010 and change from 1996, per cent 278

12.8. Temporal net FOD comparisons by aggregate area and province (probabilities)

12.9. Temporal net FOD comparisons by urban and rural strata (probabilities) 280

12.10. Bootstrap spatial FOD comparisons (probabilities), 1996281

12.11. Bootstrap spatial FOD comparisons (probabilities), 2010283

12.12. Area rankings by probability of net domination 284

12.13. Strata rankings by probability of net domination 285

13.1. Contribution of factors to growth in Cameroon 300

13.2. Average consumption in Cameroon in ECAM surveys 303

13.3. Trends in monetary poverty in Cameroon, 1996-2007 304 
13.4. Trends in monetary poverty in urban and rural areas, 1996-2007

13.5. Poverty in Cameroon by region

13.6. Trends in inequality in Cameroon, 1996-2007

13.7. Summary national-level indicators from DHS surveys

13.8. Disaggregated under-five mortality rates for Cameroon

13.9. Percentage of under-three-year-olds with height-for-age $Z$ score less than -2

13.10. Percentage of respondents with secondary education or above

14.1. Daily consumption per capita and poverty measures over time across regions, 1988-2008

14.2. Poverty measures by socioeconomic status of the household head

14.3. Poverty measures in households headed by a farmer

14.4. Decomposition of changes in poverty headcount, 1988-2008

14.A1. School net attendance rates over time

14.A2. Durable goods ownership

15.1. Growth rates (per cent) for 1997-2002 using 1982 and 2001 prices

15.2. GDP growth in new and old series, 1994-2012

15.3. Labour income share in GDP, 1976-2012

15.4. Growth of formal and informal employment and real earnings of formal labour, 1994-2012

15.5. Labour earnings in the formal and informal sectors (KSh per month), 1998/9-2005/6

15.6. Absolute poverty measures (per cent) for Kenya, 1994-2005

15.7. Regional welfare inequality (Gini coefficient) in Kenya, 1994-2005

15.8. Average annual expenditure of rural and urban residents in Kenya, 1994-2005

15.9. Health poverty

15.10. Percentage of people without access to improved drinking water

15.11. Percentage of children under five years classified as malnourished, 1993-2008

15.12. Indicators of access to education

15.13. Literacy rates

16.1. Original and utility-consistent (UC) poverty lines, Madagascar, 2001-10 372

16.2. Production and inflation in Madagascar, 2001-10 376

16.3. Monetary poverty in Madagascar, 2001-10 379

16.4. Regional poverty in Madagascar, 2001-10 382

16.5. Inequality in Madagascar, 2001-10 
16.6. Sectoral distribution of employment and the poor in Madagascar, 2001-10

16.7. Urban labour poverty and rural household consumption in Madagascar, 2001-10

16.8. Stunting rates in Madagascar 388

16.9. Net schooling enrolment rates in Madagascar, 2001-10 390

17.1. South African macroeconomic trends, 1993-2012 394

17.2. Distributional effects of inflation inequality, 2005-10 409

17.3. Patterns of inflation, 2000-13 411

18.1. Consumption poverty headcount in 2005 and 2012, per cent 426

18.2. Children 0-17 not deprived by welfare indicator, per cent

18.3. Children under five not underweight, stunted, or wasting, by gender, per cent

18.4. Children 7-17 who have attended or are currently attending at least primary school, by gender (poverty)

18.5. Children $0-17$ by number of deprivations in the five indicators in 2013 (per cent) and change from 2007

18.6. Temporal net FOD comparisons (bootstrap probabilities)

18.7. 2007 Bootstrap spatial FOD comparisons, children 0-17 (probabilities) 438

18.8. 2013 Bootstrap spatial FOD comparisons, children 0-17 (probabilities) 439

18.9. 2007, 2010, and 2013 area rankings by probability of net domination, children 0-17

18.10. 2001, 2007, 2010, and 2013 area rankings by probability of net domination, children under five 



\section{List of Boxes}

2.1. Measuring inequality 16

$\begin{array}{ll}\text { 2.2. Difficulties in categorization } & 17\end{array}$

2.3. Data collection and analysis 22

2.4. Sources of variation in monetary poverty measures 23

2.5. Agricultural statistics 28

2.6. Price data 29 



\section{List of Abbreviations}

ACLED

ADLI

AERC

AFDB

AGOA

BEAC

CAADP

CBN

$\mathrm{CDF}$

CFAF

CGE

CPI

CSA

$\mathrm{CSO}$

DGOS

DHS

EAP

ECOWAS

EICV

EP

EPM

ERHS

ERP

FAO

FDI

FISP

FISP
Armed Conflict Location and Event Data Project

Agricultural Development-Led Industrialization

African Economic Research Consortium

African Development Bank

African Growth and Opportunity Act

Banque des États de l'Afrique Centrale

Comprehensive African Agricultural Development Programme

Cost of Basic Needs

Cumulative Distribution Function

Communauté Financière Africaine Franc

Computable General Equilibrium

Consumer Price Index

Central Statistical Agency (Ethiopia)

Central Statistical Office (Zambia)

(Belgian) Department for Development Cooperation

Demographic and Health Survey

Enquête Agricole Permanente (Burkina Faso)

Economic Community of West African States

Enquête Intégrale sur les Conditions de Vie des ménages (Rwanda)

Enquêtes Prioritaires

Enquête Périodique auprès des Ménages

Ethiopian Rural Household Survey

Economic Recovery Programme

Food and Agriculture Organization of the United Nations

Foreign Direct Investment

Farm Input Subsidy Programme (Malawi)

Farmer Input Support Programme (formally Fertilizer Input Support

Programme) (Zambia) 


\begin{tabular}{|c|c|}
\hline FOD & First-Order Dominance \\
\hline FRA & Food Reserve Agency \\
\hline GAPP & UNU-WIDER's Growth and Poverty Project \\
\hline GAR & Gross Attendance Ratio (school) \\
\hline GFCF & Gross Fixed Capital Formation \\
\hline GHQ & General Health Questionnaire \\
\hline GHS & General Household Survey \\
\hline GIC & Growth Incidence Curve \\
\hline GLSS & Ghana Living Standards Survey \\
\hline GPRS & Ghana Poverty Reduction Strategy \\
\hline GPRSP & Growth and Poverty Reduction Strategy Paper (DRC) \\
\hline GSGDA & Ghana Shared Growth Development Agenda \\
\hline GSS & Ghana Statistical Service \\
\hline HBS & Household Budget Survey \\
\hline HDI & Human Development Index \\
\hline HICES & $\begin{array}{l}\text { Household Income, Consumption, and Expenditure Survey } \\
\text { (Ethiopia) }\end{array}$ \\
\hline HIPC & Heavily Indebted Poor Country \\
\hline HNLSS & Harmonized Nigeria Living Standard Survey \\
\hline IAF & Inquérito aos Agregados Familiares (Household Budget Survey) \\
\hline IES & Income and Expenditure Survey (South Africa) \\
\hline IHS & Integrated Household Survey (Malawi) \\
\hline IFPRI & International Food Policy Research Institute \\
\hline IMR & Infant Mortality Rate \\
\hline INS & Ivorian National Institute of Statistics \\
\hline INSD & National Institute of Statistics and Demography \\
\hline INSTAT & Institut National de la Statistique (Madagascar) \\
\hline IOF & Inquérito ao Orçamento Familiar (Household Budget Survey) \\
\hline I-PRSP & Interim Poverty Reduction Strategy Paper (DRC) \\
\hline KNBS & Kenya National Bureau of Statistics \\
\hline LCMS & Living Conditions Monitoring Survey \\
\hline LCS & Living Conditions Survey (South Africa) \\
\hline LEAP & Livelihood Empowerment Against Poverty (Ghana) \\
\hline LSMS & Living Standards Measurement Survey (World Bank) \\
\hline MDG & Millennium Development Goal \\
\hline MICS & Multiple Indicator Cluster Survey \\
\hline
\end{tabular}




\begin{tabular}{|c|c|}
\hline MPI & Multidimensional Poverty Index \\
\hline NA & National Accounts \\
\hline NAR & Net Attendance Ratio (school) \\
\hline NBS & National Bureau of Statistics \\
\hline NER & Net Enrolment Rate (school) \\
\hline NIDS & National Income Dynamics Study (South Africa) \\
\hline NSO & National Statistical Office \\
\hline PAMSCAD & $\begin{array}{l}\text { Programme of Actions to Mitigate the Social Costs of } \\
\text { Adjustment (Ghana) }\end{array}$ \\
\hline PCPI & Percentile-Specific Consumer Price Index \\
\hline PEG & Government Economic Programme (DRC) \\
\hline PNVRA & $\begin{array}{l}\text { Programme National de Vulgarisation et Recherche Agricole } \\
\text { (Cameroon) }\end{array}$ \\
\hline PPA & Participatory Poverty Assessment (Rwanda) \\
\hline PPP & Purchasing Power Parity \\
\hline PRGF & Poverty Reduction and Growth Facility (Cameroon) \\
\hline PRSP & Poverty Reduction Strategy Paper \\
\hline PSLSD & $\begin{array}{l}\text { Project for Statistics on Living Standards and Development } \\
\text { (South Africa) }\end{array}$ \\
\hline PSNP & Productive Safety Nets Programme (Ethiopia) \\
\hline QUIBB & Questionnaire des Indicateurs de Base du Bien-être \\
\hline SADC & South African Development Community \\
\hline SAP & Structural Adjustment Programme \\
\hline SEMRY & Société d'Expansion et de Modernisation de la Riziculture de Yagoua \\
\hline SNA & System of National Accounts \\
\hline SSA & Sub-Saharan Africa \\
\hline SWB & Subjective Well-Being \\
\hline TDHS & Tanzania Demographic and Health Survey \\
\hline TFP & Total Factor Productivity \\
\hline TIA & Trabalhos de Inquérito Agricola \\
\hline UBOS & Uganda Bureau of Statistics \\
\hline UNHS & Uganda National Household Survey \\
\hline UNPS & Uganda National Panel Survey \\
\hline WDI & World Development Indicators \\
\hline WHO & World Health Organization \\
\hline WIID & World Income Inequality Database \\
\hline WMS & Welfare Monitoring Survey \\
\hline
\end{tabular}





\section{Notes on Contributors}

Dede Houeto Aduayom, a Togolese and French national, obtained her MSc in Economics from the Paris School of Economics in 2006. After working for IFPRI and the World Bank, she is currently an independent consultant. Her research interests are poverty analysis, impact evaluation, health, and education.

Olu Ajakaiye, a Research Professor of Economics at the Nigerian Institute of Social and Economic Research, is currently Executive Chairman, African Centre for Shared Development Capacity Building, Ibadan, Nigeria. Previously, he was Director-General of NISER and Director of Research at the African Economic Research Consortium, Nairobi, Kenya. He has a PhD in Economics from Boston University.

Olufunke A. Alaba is a researcher and lecturer at the Health Economics Division, University of Cape Town, South Africa. She holds a PhD in Economics, and her major research focuses on applied microeconomics related to poverty, inequality, and health.

Channing Arndt is a Senior Research Fellow at the World Institute for Development Economics Research of the United Nations University. He has substantial research management experience including leadership of interdisciplinary teams. His programme of research has focused on poverty alleviation and growth, agricultural development, market integration, gender and discrimination, the implications of the HIV/ AIDS pandemic, technological change, trade policy, aid effectiveness, infrastructure investment, energy and biofuels, climate variability, and the economic implications of climate change.

Ulrik Beck is a PhD student of Economics at the University of Copenhagen, Denmark. He holds BA and MA degrees in Economics from University of Copenhagen and has been a visiting graduate student at Cornell University and UC-Berkeley. His research interests are development economics using applied microeconomics with a focus on agricultural issues and poverty measurement.

Arne Bigsten is a Professor of Development Economics at the University of Gothenburg and Director of Gothenburg Centre of Globalization and Development. His research has concerned poverty and income distribution, trade and globalization, industrial development, foreign aid, and institutional reform. Bigsten has been involved in major projects on the impact of the coffee boom in the 1970s in Kenya and Tanzania, enterprise development in Africa, the welfare of Ethiopian households, and the impacts of new forms of aid.

Denis Cogneau is a Professor at the Paris School of Economics (PSE) and Senior Research Fellow at the French Research Institute for Development (IRD). His current 
research projects have to do with the economic history of developing regions, the political economy of colonial empires, and the economic development of Africa over the long term.

Lionel Demery is an independent consultant, specializing in development economics. Previously he was Lead Economist in the Africa Region of the World Bank. He has taught in the Economics departments of the University of Warwick and University College Cardiff. He has also worked for the International Labour Organization in Bangkok, and the Overseas Development Institute in London. He holds a Master's degree from the London School of Economics. He has published widely, focusing recently on poverty in Africa.

Anaclet Désiré Dzossa is a research officer at the National Institute of Statistics (NIS) in Cameroon. A demographer and statistician by profession, he holds a DESS/Master in Economic Policy Management. His main fields of work are related to employment, poverty, and other demographic and social statistics. At NIS he has been responsible for coordination of national surveys, including poverty and living standard surveys, employment and informal-sector surveys, and MICS surveys. He also works on data analyses to inform public policy.

Samuel Fambon is an Associate Professor of Economics and Coordinator of the Master's Program in Mathematics and Statistics applied to Social Sciences at the Faculty of Economics and Management, University of Yaoundé II, where he has worked since 1994. He holds a Doctorat d'Etat in economy from University of Yaoundé II. His key research interests include poverty and income distribution issues, pro-poor growth, poverty and inequality measurement, redistribution, econometric modelling, international economics and finance, and development economics. He has published in many journals, notably on poverty, inequality, growth, and health.

Arden Finn is a graduate student at the University of Cape Town and a researcher at the Southern African Labour and Development Research Unit. His research interests include poverty and inequality dynamics, economic mobility, and data quality.

Michael Grimm is a Professor of Development Economics at the universities of Passau and Erasmus Rotterdam. His research is concerned with poverty issues related to education, health, and labour markets. His regional focus is on West Africa. He has published extensively on Burkina Faso and has worked on various projects in that country commissioned by the World Bank, AfD, GIZ, KfW, and the Dutch Ministry of Foreign Affairs among others.

Kenneth Houngbedji is completing his PhD in Economics at the Paris School of Economics. His research interests are in development, environmental economics, economic history, and quantitative methods.

Afeikhena T. Jerome is National Coordinator of the State Peer Review Mechanism in the Nigerian Governors' Forum. Previously he worked with the United Nations as Coordinator for Economic Governance and Management at the African Peer Review Mechanism, Midrand, South Africa, and was a faculty member of the University of Ibadan, Nigeria. He has a PhD in Economics from the University of Ibadan. 
Sam Jones is an Associate Professor of Development Economics at the University of Copenhagen. He has published widely on issues such as foreign aid, economic growth, contract farming, education quality, and tourism. A primary focus of his research is on sub-Saharan Africa. He worked for over seven years as an advisor to the Mozambican government in the Ministry of Planning and Finance and the Ministry of Planning and Development.

Olive Stéphanie Kouakep is a PhD student at the Faculty of Economics and Management of the University of Dschang, Cameroon.

Murray Leibbrandt is the Pro Vice-Chancellor, Poverty and Inequality, at the University of Cape Town, the DST/NRF National Research Chair in Poverty and Inequality, and the Director of the Southern African Labour and Development Research Unit. His research analyses South African poverty, inequality, and labour market dynamics.

Kristi Mahrt is a consultant for the United Nations University World Institute for Development Economics Research (UNU-WIDER). Her research focuses on multidimensional and consumption poverty estimation.

Damiano Kulundu Manda is a Professor of Economics at the University of Nairobi and manages research at the African Economic Research Consortium. His primary research interests are in the fields of labour economics and poverty analysis.

Gibson Masumbu is a Research Fellow at the Zambia Institute for Policy Analysis and Research, where he heads the Human Development Unit. He holds an MA in Economic Policy Management from the University of Zambia. His research interests lie in the area of human development-particularly poverty analysis, employment and unemployment, rural development, and rural finance. His recent research work has been on topics such as youth labour demand constraints, multidimensional poverty analysis, first-order dominance analysis of welfare, self-employment, energy poverty, and employment projection models.

Andy McKay is a Professor of Development Economics at the University of Sussex, where he has worked since 2006. He researches extensively on issues of poverty, inequality, and living standards, in particular on sub-Saharan Africa, and has participated in discussions on the extent of poverty reduction at the continent level. He also works on issues closely linked to poverty, including labour, agriculture, and the distributional impact of policy, and is widely published in these areas. He was an active member of the DFID-funded Chronic Poverty Research Centre from 2000 to 2011 and an Associate Director for 2005-11; more recently in 2015 he became Managing Editor of the Review of Development Economics.

Sandrine Mesplé-Somps is a Research Fellow at the French Research Institute for Development (IRD) within the research centre DIAL (Development, Institutions, and Globalization). Her research focuses on the impact of migration, poverty, and urbanization in Africa and the economic history of developing regions.

Richard Mussa is a Senior Lecturer in Economics at Chancellor College, University of Malawi. He holds a PhD in Economics from the University of Cape Town. He has undertaken research on the Malawian economy with a particular focus on poverty and inequality, nutrition, technical efficiency of agricultural production, non-linear 
pricing in food markets, equity of health care finance, and youth unemployment and child labour.

Germano Mwabu is a Professor of Economics at the University of Nairobi and a resource person at the African Economic Research Consortium. His primary research interests are in the fields of health economics and poverty analysis.

Malokele Nanivazo is a visiting scholar at the University of Kansas in the Department of Economics and consults for the United Nations Economic Commission for Africa. Prior to joining the University of Kansas, she worked as a Research Fellow at the United Nations University World Institute for Development Economics Research (UNUWIDER). Her research focuses on gender, poverty, conflicts, growth, rural transformation, trade, and foreign aid.

Aude Nikiema is a researcher in Geography at the Institut des Sciences des Sociétés in Ouagadougou, Burkina Faso. She was involved in several poverty assessments in Burkina Faso, in particular in collaboration with the Chronic Poverty Research Centre. She is particularly interested in spatial approaches to poverty and local effects.

Olanrewaju Olaniyan is a Senior Lecturer in the Department of Economics, University of Ibadan, Nigeria. He has experience in social policy work in developing countries. His areas of research focus on health economics, economics of education, welfare analysis, and social protection. He holds a PhD in Economics from University of Ibadan.

Morné Oosthuizen is Deputy Director of the Development Policy Research Unit in the School of Economics at the University of Cape Town. His research interests include intergenerational transfers, poverty and inequality, prices and income distribution, and labour market issues.

Karl Pauw is a Research Fellow and Country Program Leader of the Malawi Strategy Support Program of the International Food Policy Research Institute (IFPRI) in Lilongwe, Malawi. He holds a PhD from the University of Cape Town in South Africa. His broad area of interest is development and agricultural policy impact analysis, with a specific focus on better understanding the micro-macro interactions between policies and outcomes using economy-wide and micro-simulation modelling techniques.

Jukka Pirttilä is a Research Fellow at UNU-WIDER. He is on leave from the University of Tampere, where he is a Professor of Economics. He has previously worked for the Labour Institute for Economic Research in Helsinki, and the Bank of Finland. He conducts research on topics related to publicly provided goods, social protection, and tax policy. He has a doctorate in Economics from the University of Helsinki and is a Fellow of the CESifo network and a board member of Uppsala Center for Fiscal Studies.

Faly Rakotomanana is Director of the Household Survey Unit at the National Statistical Institute (INSTAT) of Madagascar. His primary research interests are related to poverty and labour markets.

Tiaray Razafimanantena is a lead economist at the Centre de Recherches, d'Etudes et d'Appui l'Analyse Economique Madagascar (CREAM), and a lecturer at the University of Antananarivo. He was previously Director of the Household Survey Unit at the National Statistical Institute (INSTAT) of Madagascar. His primary research interests are related to poverty, labour markets, and inflation. 
Haruna Sekabira has a Master's in Agricultural and Applied Economics from Makerere University in Uganda, and is currently a research assistant and PhD student at the University Goettingen. A Ugandan national, his main research is on smallholder participation in modern supply chains and impacts on income, poverty, and development.

David Stifel is a Professor of Economics at Lafayette College and Chair of the Lafayette International Affairs Program. His primary research interests are poverty measurement and analysis, rural infrastructure and markets, and agriculture and rural livelihoods.

Finn Tarp is a Professor of Economics at the University of Copenhagen, and Director of UNU-WIDER in Helsinki. He is a leading international expert on development strategy and foreign aid. In addition to his university posts, he has held senior appointments and advisory positions with international organizations and several national governments and is a member of a series of international committees and advisory bodies.

Romain Tchakoute Ngoho holds an MA in Mathematics from the University of Yaoundé I, specializing in numerical analysis; and a Diploma in Statistics from the école nationale de statistique et d'économie appliquée in Abidjan, Côte d'Ivoire. Working at the National Institute of Statistics (NIS), he has been actively involved in data processing and preparing reports for most of the activities undertaken by NIS. His work has involved providing support to double-entry data capture activities and computerassisted personal interviewing (CAPI) activities as part of the ECAM4 and Proxy Means Test surveys.

Joseph-Pierre Timnou is a Senior Lecturer at the University of Yaoundé II, Cameroon. As a demographer, he also deals with data analysis, as well as population and development. His research covers demographic issues, poverty, and corruption matters. He is the head of PODEV-IN, a NGO focusing on population and development in Africa.

Bjorn Van Campenhout, a Belgian national, is a Research Fellow at the International Food Policy Research Institute based in Kampala, Uganda. He holds a PhD in Economics from the University of Leuven, Belgium. Bjorn's main areas of interest are smallholder market participation, commodity market integration, and poverty dynamics.

Marijke Verpoorten is a lecturer at the Institute for Development Policy and Management (IOB), University of Antwerp. She obtained her PhD in Economics from the University of Leuven. Her research focuses on the causes and consequences of armed conflict, on global supply chains, food markets and food security; and more broadly, on the economic and institutional development of sub-Saharan Africa, with a special focus on Rwanda, Benin, and DR Congo. Marijke teaches at the University of Antwerp, at the African School of Economics, and at the Catholic University of Bukavu.

Anthony Wambugu is a Senior Lecturer in Economics at the University of Nairobi. He holds a Bachelor's degree from Kenyatta University, Master's degree from the University of Botswana, and Doctorate from the University of Gothenburg. His research focuses on labour markets and poverty in developing countries.

Claude Wetta is a Professor of Economics at the University of Ouagadougou (Burkina Faso) and research associate of the Centre d'Etudes, de Documentation et Recherches Economiques et Sociales (CEDRES) also at the University of Ouagadougou. He led various 
research projects including Micro Impact of Macro and Adjustment Policies (MIMAP) and the Chronic Poverty Research Project. He is particularly interested in the construction of poverty measures and in the effects of economic policies and shocks on households.

Tassew Woldehanna is an Associate Professor of Economics at Addis Ababa University. He is a development economist whose primary research interests are food security, employment, child welfare and poverty, education, and health. 


\title{
Growth and Poverty in Sub-Saharan Africa
}

\author{
Channing Arndt, Andy McKay, and Finn Tarp
}

\subsection{Introduction}

The recovery and acceleration of economic growth in sub-Saharan Africa (SSA) since about 1995 has been widely recognized. Much less is known about the extent to which this growth has been associated with improvements in welfare for the population in general and with poverty reduction in particular. A recent Afrobarometer survey suggests that 'despite high reported growth rates, lived poverty at the grassroots remains little changed' (Dulani et al. 2013). At the same time, these negative sentiments contrast with a number of notably optimistic (and disputed) assessments that have been published based on internationally available datasets (Young 2012; Pinkovskiy and Salai-Martin 2014).

In addition, concerns have been raised about the quality of available national accounts and other statistics for Africa, even raising a question about the actual scope and extent of the African growth revival. In terms of poverty, serious concerns with respect to the comparability and reliability of bellwether consumption poverty statistics pre-date the more recent broaderbased doubts concerning the African statistical base. This is particularly true of the US $\$ 1.25$ per day statistics compiled by the World Bank, but extends to national line poverty statistics reported in the World Development Indicators (see World Bank 2015), and is a serious concern at country levels.

Amidst these disparate signals, pressing questions related to growth's implications for poverty reduction hang in the balance. This book is dedicated to answering these questions. To do so, we chart an intermediate course between the extremes of the debate with respect to the reliability of African statistics. On the one hand, we (the editors) believe that simply downloading statistics from international databases and then subjecting those to analytical scrutiny 
opens excessive scope for error and misinterpretation. On the other hand, we do not believe that the mass of African statistics are as uninformative as the harsher critics assert. We believe that a proper understanding of the extent to which this growth recovery has or has not translated into poverty reduction can come from (perhaps can only come from) careful country studies conducted by analysts with expert knowledge of the context, based on their best first-hand analysis of the available data and, crucially, knowledge of its relative strengths and weaknesses.

To this end, this volume contains a series of in-depth country studies conducted as part of UNU-WIDER's Growth and Poverty Project (GAPP) in SSA, a project conducted over the period 2012-14. The project undertook case studies of sixteen of the twenty-four most populous countries in Africa (covering 73.8 per cent of the population of the region) and nine of the top ten. The time period considered varied from case to case; generally it covered the last ten to twenty years and so, in most cases, covered the period of the 2008 food, fuel, and financial crisis.

This broad coverage notwithstanding, this book's focus is not on aggregations of figures across countries. Rather, the aim has been to provide a careful understanding of each country case. The chapters focus on presenting observed trends in different welfare measures (monetary and non-monetary poverty as well as inequality) and on seeking to understand linkages to economic growth. In each case, the country authors returned to the primary datasets, applying best techniques in analysis with a strong focus on assuring comparability over time and on recognition of data limitations. The country studies then sought to provide explanations for the observed outcomes. We believe that, with this combination of careful documentation of the evidence alongside rigorous effort to explain the outcomes, this is the most comprehensive and careful assessment of growth and poverty on the subcontinent currently available.

Chapter 2 synthesizes findings from the country studies and presents lessons for the future. The case country studies, grouped broadly in terms of growth and poverty reduction experience, follow. In this introductory chapter, we revert to internationally available data to broadly set the scene. The World Development Indicators (WDI) (World Bank 2015) compile data across the different countries in the world and its major regions, including SSA, and cover a significant period of time. The sources of the data; how comparable it really is between countries; and the extent of and methods used for any interpolation or extrapolation are not always clear. Nonetheless, these data form a useful starting point in trying to summarize the situation for SSA as a whole, and, in that spirit, we make use of these data first to briefly review the growth recovery in SSA and then to consider the evolution of living conditions using both non-monetary and monetary indicators. 


\subsection{The Growth Recovery in Sub-Saharan Africa}

After registering a dismal performance during the mid-1970s to about the mid1990s, the reported constant dollar value of GDP per capita for SSA as a whole has experienced a consistent upward trajectory since 1994, with only a minor and temporary interruption at the time of the financial crisis in 2007-8. This growth has also been widespread across SSA; thirty-nine out of forty-three countries with available data had higher per capita GDP levels in 2013 than in 2000. Coming on the back of the declines registered over the roughly two decades between the mid-1970s and mid-1990s, the past twenty years mark a dramatic change in fortune in the region. The decadal average growth rates for the sixteen focus countries in this book, as reported in the WDI, are presented in Table 1.1. In many of these countries, growth was low or negative in the 1980s, and then higher in the 1990s and often especially in the 2000s, though with some exceptions.

There has been wide discussion of the factors which have underlain this growth recovery, and in policy circles, the beneficial effects of increased commodity prices are often referred to as a key driver. As we discuss in Chapter 2, this explanation is not consistent with case country experience. While some countries experienced improvements in terms of trade, many others have not. The case country experience does indicate that sharp

Table 1.1. Average GDP per capita growth of the sixteen selected sub-Saharan African countries (annual percentage) in the 1960s, 1970s, 1980s, 1990s, and 2000s

\begin{tabular}{lrrrrr}
\hline & $1960 \mathrm{~s}$ & $1970 \mathrm{~s}$ & $1980 \mathrm{~s}$ & $1990 \mathrm{~s}$ & $2000 \mathrm{~s}$ \\
\hline Burkina Faso & 1.73 & 1.35 & 1.16 & 2.28 & 2.25 \\
Cameroon & -0.28 & 4.39 & 0.92 & -2.33 & 0.76 \\
Congo, Dem. Rep. & 0.96 & -2.46 & -0.94 & -8.31 & 0.48 \\
Cote d'Ivoire & 4.38 & 2.81 & -4.07 & -0.40 & -1.08 \\
Ethiopia* & & & -0.82 & -0.60 & 5.12 \\
Ghana & -0.31 & -0.84 & -1.01 & 1.63 & 2.78 \\
Kenya & 2.33 & 3.31 & 0.44 & -0.74 & 0.84 \\
Madagascar & 0.22 & -1.34 & -2.36 & -1.48 & 0.21 \\
Malawi & 2.73 & 2.93 & -2.34 & 2.16 & 1.16 \\
Mozambique & & & -0.58 & 2.59 & 4.24 \\
Nigeria & 0.66 & 4.20 & -3.98 & 0.08 & 6.14 \\
Rwanda & 0.17 & 2.04 & -0.56 & 0.85 & 4.89 \\
South Africa & 3.56 & 1.00 & -0.26 & -0.81 & 2.02 \\
Tanzania** & & & 0.61 & 0.27 & 3.63 \\
Uganda*** & & & -0.45 & 3.43 & 3.65 \\
Zambia & 0.68 & -1.70 & -1.57 & -1.21 & 4.02 \\
Sub-Saharan Africa & 2.04 & 1.29 & -1.10 & -0.85 & 2.35 \\
\hline
\end{tabular}

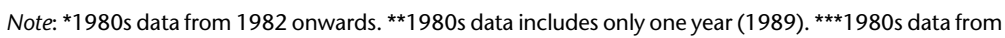
1983 onwards.

Source: World Development Indicators 
movements in terms of trade, such as those that occurred in 2008, can strongly impact welfare levels. At the same time, the diversity of experience in terms of trade and growth indicates essentially no support for the idea that terms of trade effects underpin the growth revival as a whole.

Rather, more durable factors seem to be at work. Radelet (2010) explains the growth recovery in terms of five main factors: more democratic and accountable governments; better economic policies; reduction in debt levels and better donor relations; new technologies; and the emergence of a new generation of policymakers, activists, and business leaders. None of these factors are particularly transitory, and some are the fruit of purposeful and long-term efforts to bring them about. For example, the African Economic Research Consortium (AERC), founded in 1988, has for nearly thirty years explicitly sought to facilitate the emergence of a new generation of policymakers alongside a more capable technical apparatus-both within and outside government-to support economic policymaking. With many senior African policymakers being graduates of AERC programmes alongside manifest improvements in technical economic analysis capacities throughout the subcontinent, the AERC can very plausibly claim (and does claim) that it has played an important role in the emergence of a new generation of policymakers and a consequent improvement in economic policies.

While there is much to celebrate, it is also important to maintain perspective. For sub-Saharan Africa as a whole, the most recent WDI indicates that the constant dollar value of GDP per capita in 1994 was only 78 per cent of what it had been in 1974. The growth renaissance from 1994 only returned GDP per capita to its level of 1974 in 2007. By 2013, GDP per capita in SSA was only 7.7 per cent higher than in 1974. Consistent with the aggregates, just over half of the countries for which WDI data are available had higher per capita GDP in 2007 than they had had in 1974. Hence, a substantial part of the growth recovery amounts to catching up lost ground. Furthermore, while impressive relative to previous experience, the growth rate of per capita GDP in SSA over the period from 1994 to date is still much lower than the average in WDI data for all developing countries, particularly East Asia and the Pacific and South Asia.

All this said, the growth recovery is a dramatic change for the better. Given the low levels of income characterizing many countries in SSA, economic growth is essentially a necessary condition for substantial reductions in monetary poverty and is a facilitator of improvements in non-monetary poverty through, for example, greater tax revenue. However, growth does not always translate effectively into improved living conditions for the majority of the population; hence the key question of this book: have people become better off as a result of the growth recovery? 


\subsection{Evidence on African Development}

We first provide a set of observations about recent developments in SSA by looking at the evolution of different measures of welfare taken from the WDI. The multidimensional nature of human welfare means that a wide range of measures of living conditions need to be taken into account, including both monetary and non-monetary dimensions. We begin here by considering some key non-monetary measures which may be more easily comparable across countries. We then proceed to consider selected monetary measures.

\subsubsection{Non-monetary Measures}

Mortality rates are one of the most fundamental development indicators. The under-five mortality rate for SSA as a whole (see Figure 1.1) shows an impressive and consistent reduction of over 60 per cent over the full period between 1965 and 2013. The rate of reduction visibly slows between about 1975 and 1995, and SSA loses ground relative to other regions of the world during this period. This rate of reduction then picks up again in the most recent period basically converging to the path of reduction elsewhere. Similarly, estimated maternal mortality rates almost halved between 1990 and 2013. While much improved, both indicators remain high, with nearly one child in ten dying before their fifth birthday and more than 500 maternal deaths per 100,000 live births in 2013. These are easily the highest levels registered by any of the major developing regions.

The period from 1990 to date has also seen improvements in drinking water and sanitation facilities in rural areas in particular. The levels remain low, and,

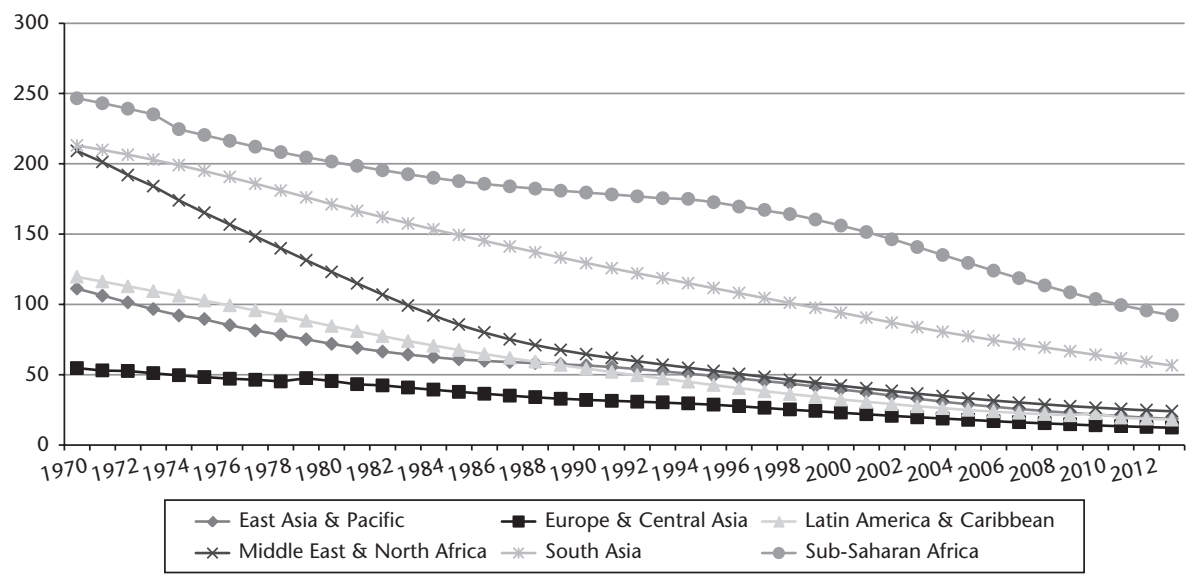

Figure 1.1. Under-five mortality by major world region, 1980-2013 Source: World Development Indicators 
unlike mortality already discussed, SSA is registering a noticeably slower rate of improvement compared with other major regions of the world, even in recent decades. It is not clear why this should be so. Similar to other regions of the world, there are substantial differences in access to these services with provision generally much better in urban areas.

Despite the lagging performance relative to other regions of the world in water and sanitation, SSA has registered a strong performance in reducing childhood malnutrition over the past twenty years. This is an important indicator as it relates to the increased capability of families to deliver the confluence of factors necessary for physical growth and development in early childhood. It thus signifies real improvements on the ground across an array of factors. In addition, mounting evidence points to the importance of early childhood health for welfare and productivity in adulthood (e.g. Hoddinott et al. 2008). Hence, these improvements are a hopeful sign for the future.

Another area where impressive improvement is registered is education. The last twenty years have seen a major focus on trying to extend primary education to all, and some countries have been more successful than others in this. Arguably, it may be that it is the secondary level that is more important in order for education to be transformative. Secondary enrolment rates are still quite low in sub-Saharan Africa, and lower for females than males, yet both have improved consistently over the past twenty years.

One dramatic change in SSA, as elsewhere, over recent years has been the expansion in mobile phones. Mobile phone subscriptions per 100 people increased from 2.5 in 2000 to 66.0 in 2013. As of 2013, the data indicate that mobile phone penetration in SSA lags behind, for example, South Asia, only slightly. This is a remarkable achievement given the rural and dispersed nature of the African subcontinent. It is potentially a very important development.

Finally, while population and population growth are not direct welfare measures, they have a bearing on many other outcomes. As shown in Figure 1.2, population growth in SSA is expected to remain rapid, particularly in comparison with major population centres such as China and India. The UN medium variant population projection indicates that, by 2050, the population of SSA will be larger than that of China and India (individually, not combined). By 2050, more than one in five persons on the globe will reside in SSA, up from a population share of about 12 per cent in 2010. Rapid population growth in SSA is a function of continued high fertility rates. In 2012, the average fertility rate was around five, following a consistent decline over the past thirty years from a figure of about 6.5 in 1980. While SSA has made progress in terms of reducing fertility rates, it strongly lags behind most other regions of the world and, on the whole, continues to leave the benefits of a demographic transition on the table. 


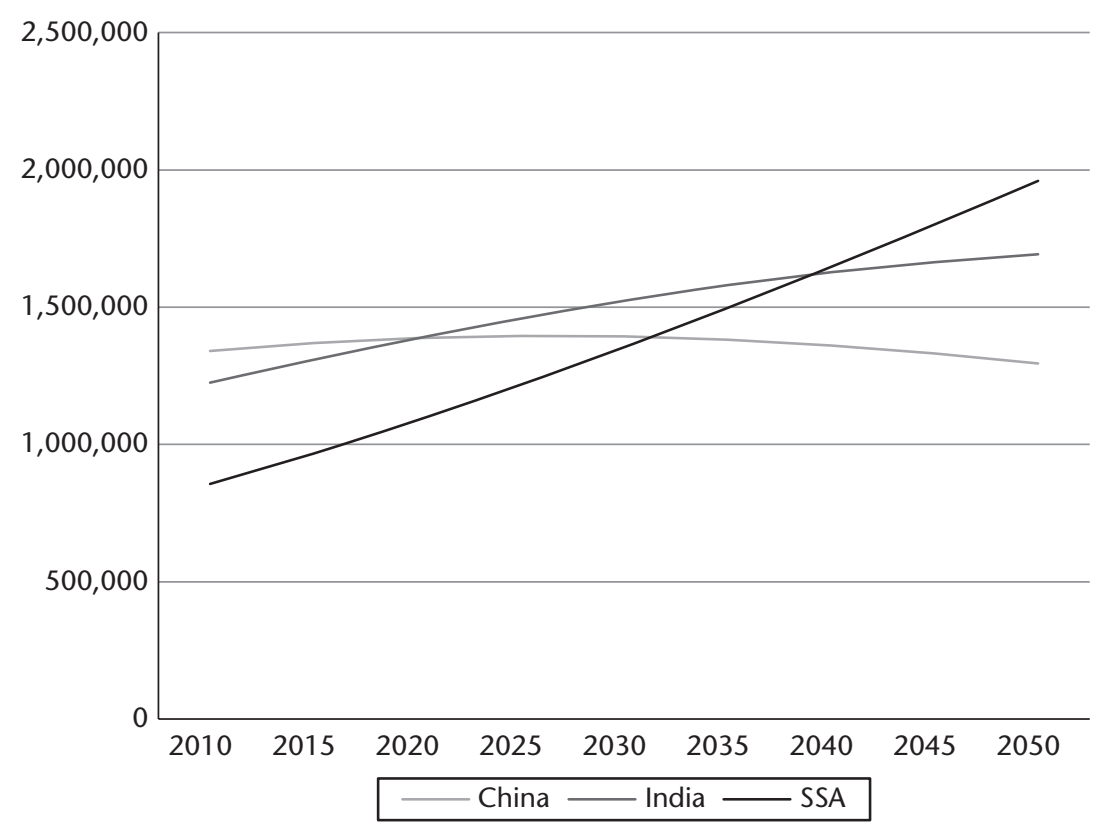

Figure 1.2. Projected population growth for China, India, and sub-Saharan Africa, 2010-50

Source: Population Division of the Department of Economic and Social Affairs of the United Nations Secretariat, World Population Prospects: The 2010 Revision, <http://esa.un.org/unpd/wpp/ index.htm>. For definition of variables, check the link Glossary of Demographic Terms, accessed 29 January 2012

Overall, these various non-monetary poverty indicators show significant progress over the periods considered here-some pre-dating the phase of reestablished growth, and some improving more quickly over this period. SSA generally lags behind other developing regions of the world, with the gap often widening during the period from the mid-1970s to the mid-1990s. From about 1995, the performance of SSA has been, for many non-monetary indicators, roughly on par with other developing regions of the world in terms of rate of improvement, despite slower per capita GDP growth.

The non-monetary indicators presented here are, we believe, both important and relatively robust. They strongly indicate that something is happening on the subcontinent.

\subsubsection{Monetary Measures}

We turn now to monetary measures of welfare, a much trickier challenge. We first consider the evolution of real household consumption per capita in SSA since 1981 (Figure 1.3). Roughly in line with economic growth, this shows a 


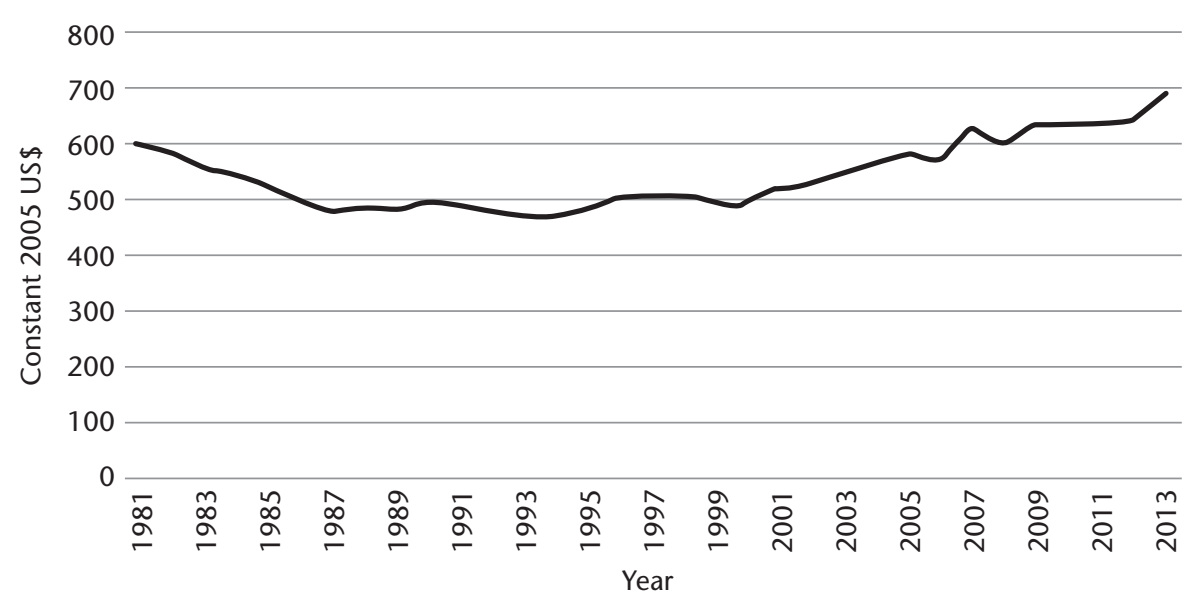

Figure 1.3. Household final consumption expenditure per capita for sub-Saharan Africa, 1981-2013 (constant 2005 US\$)

Source: World Development Indicators

long period of decline/stagnation and then sustained recovery since around 2000. But the implications of this recovery for monetary poverty cannot be judged without assessing the distribution of this consumption growth across households.

Estimating a monetary poverty figure for SSA as a whole requires a common unit of measure. The only available estimates are the global monetary poverty figures produced by the World Bank. The latest available estimates indicate that 51 per cent of the population of SSA was poor in 1981 and 58 per cent in 1999 , relative to the US $\$ 1.25$ poverty line. By 2010 this poverty rate had fallen to 48 per cent. This shows progress in reducing poverty. Consistent with its slower per capita GDP growth, the rate of decrease in the poverty headcount is less than for East and South Asia, including the period since 2000.

As will be made abundantly clear in Chapter 2 and in the country case chapters, these poverty headcounts are at best gross estimations. The regional estimates are amalgamations of country-level estimates, where problems are more evident. These country-level estimates of poverty relative to the US\$1.25 poverty line have the advantage of comprehensiveness of country coverage, at the cost of a number of challenges. For example, data may not be comparable between countries because of differences in the surveys used, or because of differences in the procedures used to adjust for price differences over time or space. The many difficulties encountered in adequately measuring monetary poverty in Nigeria alone (see Chapter 10) should cause any analyst to approach pan-African headcount figures with caution and some degree of scepticism. 
In addition, the methodology for these calculations is not adequately documented in international datasets, making the numbers difficult to interpret. The exchange rate conversions needed to make comparable estimates across all countries are also problematic. Such conversions are made at purchasing power parity (PPP) exchange rates. While significant resources have been put into the computation of PPP exchange rates through the International Comparisons Project, there is widespread disagreement about the adequacy of these adjustments (see e.g. Ackland et al. 2013; Deaton and Aten 2014).

In this volume, the focus is not on cross-country comparison, meaning that national poverty lines, held fixed in real terms, can be used and the conversion problems just noted can be circumvented. Poverty relative to a national line is likely to be the more relevant concern at the country level, and this approach avoids the need for any exchange rate conversion. As noted, the authors of the country studies presented in this volume all have a detailed knowledge of the specific data being used and its strengths and weaknesses.

\subsection{Summing Up}

The aggregate data for SSA as a whole reviewed here suggest that living conditions, measured by both monetary and non-monetary indicators, have improved over the period of re-established growth, with some improvements in non-monetary indicators pre-dating this. It remains the case that the absolute levels of deprivation in SSA continue to be high relative to most other regions of the world. Beyond this, not a lot can be said. These aggregate figures do provide a starting point, but they hide a great deal of country diversity. Chapter 2, to which we now turn, takes on the challenge of synthesizing this diversity and presenting a series of lessons learned.

\section{References}

Ackland, R., S. Dowrick, and B. Freyens (2013). 'Measuring Global Poverty: Why PPP Methods Matter', The Review of Economics and Statistics, 95(3): 813-24.

Deaton, A. and B. Aten (2014). 'Trying to Understand the PPPs in ICP 2011: Why Are the Results So Different?', NBER Working Paper No. 20244, June.

Dulani, B., R. Mattes, and C. Logan (2013). 'After a Decade of Growth in Africa, Little Change in Poverty at the Grassroots', Afrobarometer Policy Brief No. 1, October.

Hoddinott, J., J. Maluccio, J. Behrman, R. Flores, and R. Martorell (2008). 'Effect of a Nutrition Intervention during Early Childhood on Economic Productivity in Guatemalan Adults', The Lancet, 371(9610): 411-16.

Pinkovskiy, M. and X. Sala-i-Martin (2014). 'African Is On Time', Journal of Economic Growth, 19(3): 311-38. 
Radelet, S. (2010). Emerging Africa: How 17 Countries Are Leading the Way. Washington, DC: Center for Global Development.

World Bank (2015). World Development Indicators. Washington, DC: World Bank. See $<$ http://data.worldbank.org/data-catalog/world-development-indicators>.

Young, A. (2012). 'The African Growth Miracle', Journal of Political Economy, 120(4): 696-739. 


\title{
2
}

\section{Synthesis}

\section{Two Cheers for the African Growth Renaissance (but not Three)}

\author{
Channing Arndt, Andy McKay, and Finn Tarp
}

\subsection{Introduction}

This chapter draws from sixteen detailed country case studies, which collectively represent nearly three-quarters of the sub-Saharan African (SSA) population. Attempts at synthesis of something as massive as the African continent south of the Sahara customarily begin with emphasis on the diversity encountered and the consequent perils confronting the generalizer. We will follow suit. Consider four populous countries in focus in the chapters that follow: Nigeria, Democratic Republic of Congo, Ethiopia, and South Africa. These countries contain 41 per cent of the population of the subcontinent, and, as the chapters focused on these countries illustrate, the experiences and development challenges facing them differ enormously. To take only one example, the recent drop in world oil prices by about 50 per cent represents a serious threat to macroeconomic stability to major oil exporters such as Nigeria. At the same time, it is likely to be a boon for large and dispersed structural fuel importers such as Ethiopia. From a development policy perspective, the issues in the fronts of the minds of decision-makers in Nigeria and Ethiopia are, at this moment in time, very different.

Nevertheless, stepping back to a much broader perspective, there is a lot that is shared. Foremost, the peoples of the subcontinent share with each other, and with the people in the rest of the world, a desire for better lives for themselves and for their children. Much has been written about what constitutes a 'better life' and associated issues of measuring whether such a better life 
is being achieved or not. This volume takes a broad view of what constitutes a better life in line with the capabilities approach developed by Sen (1993). Whenever a broad perspective is taken on assessing a better life, the operationalization of this perspective will inevitably encounter limits to its application; and these limits will vary from country to country.

The country chapters in this volume focus principally on the issue of whether the peoples of the sixteen countries in focus are experiencing a better life or not. In light of the diversity of experiences, priorities, and country-level limitations in our capacity to assess trends in well-being, a unified methodology across all countries was not deemed to be the best way to proceed. But the authors of the case chapters were invited to employ approaches that were structurally similar, while allowing for heterogeneity. In particular, authors were encouraged to examine trends in well-being from multiple angles, to compare and contrast across multiple data sources, and to draw upon their indepth experience of the country in question. The aim throughout has been to develop, to the greatest extent possible, a coherent narrative that explains what has been happening with emphasis on the last fifteen to twenty years. In addition, the case countries employ, either implicitly or explicitly, the optic of the poverty, growth, and inequality triangle of Bourguignon (2004) in developing their narratives (see also Bourguignon 2003).

The task of this synthesis chapter is to draw together what can be said from these narratives. A very broad-brush picture already emerges from the aggregate data presented in our Introduction in Chapter 1. Compared with the experience from about 1975 to about 1995, the performance of the subcontinent has, in general, been vastly improved. Unfortunately, this observation does not take us very far for at least three reasons. First, outperforming the period 1975-95 is a remarkably low bar to clear. As emphasized in Chapter 1, development outcomes were dismal. Second, a number of countries, such as Côte d'Ivoire and Zimbabwe, fail to clear even that. Finally, the vast space above the bar set by the 1975-95 period remains unexplored.

To investigate this space, section 2.2 categorizes each country into one of four groups and discusses these allocations. Section 2.3 presents a series of lessons drawn from the case studies, while section 2.4 revisits the risks of a cross-country analysis which does not take account of local knowledge and context. The final section looks forward.

\subsection{Country Typologies}

\subsubsection{The Poverty, Growth, and Inequality Triangle}

Before describing the groups into which we have placed countries for the purpose of this synthesis, some discussion of the poverty, growth, and 
inequality triangle, on which the typologies are motivated, is merited. When a significant share of a population is defined as poor because they live below some given absolute consumption threshold, the poverty rate for that population is a macroeconomic variable. Changes in the poverty rate are linked to other macroeconomic phenomena, not least economic growth. For most African countries, economic growth is a necessary condition for sustained improvement in the welfare of the poor. This assertion falls out of the Bourguignon (2004) poverty, growth, and inequality triangle. In environments characterized by very low GDP, consumption levels are generally low, even if consumption is characterized by perfect equality. To the extent that one moves away from perfect equality of consumption, poverty rates will tend to worsen. By similar logic, if GDP grows, this increment to production must go somewhere. If it accrues as consumption for lower-income populations, then some measure of poverty will improve. If the fruits of the production increment accrue only to upper-income households, then an increase in inequality (by at least some metrics) is to be expected. These relationships comprise the fundamental logic of the triangle.

There are several mechanisms which could 'break' the poverty, growth, and inequality triangle. First, when the poverty metric is the share of the population living below some material welfare threshold (i.e. the poverty headcount), one can easily generate situations where growth occurs, inequality declines, and the poverty headcount remains essentially constant by postulating bizarrely shaped distributions of consumption. For example, if very few households live 'near' the poverty line, then GDP growth could accrue exclusively to households below the poverty line, causing those households to approach the poverty line while not crossing it. In this case, there is GDP growth, a decline in inequality of consumption, and no reduction in the poverty headcount rate. While easy to postulate, these situations are, in our experience, rare.

Two additional mechanisms that can break the poverty, growth, and inequality triangle can be considered using two basic macroeconomic accounting identities. These cases were not considered by Bourguignon (2004) as he uses a household income per adult equivalent as an income metric:

$$
\begin{gathered}
C+I+G+X-M=G D P \\
A b s=C+I+G=G D P+M-X
\end{gathered}
$$

The standard GDP identity using an expenditure optic shown in equation (2.1) can be reformulated to illustrate the definition of absorption (2.2). This is the broadest-based standard measure of economic welfare in the economy. 
Thinking in real terms, the identity in (2.2) states that the real use of goods and services (Abs = absorption) divides itself into three components: consumption (C), investment (I), and government spending (G). The sum represents total usage of goods and services in the economy, which must equal the amount available. Goods and services are produced domestically (GDP) and imported (M). Exports (X) are subtracted from this total. ${ }^{1}$

From equation (2.2), one can straightforwardly identify two additional reasons why the triangle of Bourguignon (2004) might not hold, even in the absence of measurement issues:

1. GDP growth is not proportional across the components of absorption. For example, GDP growth might be translating into growth in investment and government combined with stagnation in per capita consumption.

2. The real trade balance (M-X) shifts such that, for example, the volume of imports declines relative to the volume of exports. One expects this to happen following, for example, a decline in the terms of trade, a reduction in the volume of foreign assistance, or the initiation of debt service payments.

These two factors are serious considerations, particularly given recent experience. In many of the case countries, interest in improving social outcomes has led to substantial growth in state expenditures driven by areas such as education, health, water, and sanitation. This then often translates into improved non-monetary outcomes, and so reduction of some dimensions of poverty, even if monetary poverty improves less. While donor funding has been important in these areas, there have also been concerted efforts to raise tax revenue to support government expenditure in these and other areas. In addition, improved growth performance and prospects combined with better macroeconomic management should also enhance interest in investment. In sum, for a given real trade balance (M-X), the components of absorption are generally shifting, sometimes substantially.

Perhaps more importantly, the period since about 2003 has been characterized by large shifts in global relative prices, with strong implications for the real trade balance. Food and fuel prices, which are major traded items for essentially all African countries, rose dramatically relative to the prices of manufactures and services. For those low-income African countries which are predominantly large net importers of fuels and often food, they were forced to import less or export more of other goods, or borrow, in order to procure the same volume of fuels and food (in the absence of the appearance

\footnotetext{
${ }^{1}$ See Tarp (1993) for a more elaborate overview.
} 
of some new source of foreign exchange). In other words, for these countries, at least part of the increment to production in GDP growth must effectively be shipped overseas in order to purchase even the same volume of imports.

Finally, the triangle may break due to mismeasurement of any one of the components. While much has been made about the weaknesses of African GDP estimates (e.g. Jerven 2014) and fierce debates persist on the proper estimation of monetary poverty (as discussed in Chapter 1 and many of the case studies that follow), the estimation of inequality is almost surely the weakest link in the triangle. As discussed in Box 2.1, with the possible exception of South Africa, none of the case countries has even attempted to implement a statistical system that responds to the specialized requirements for tracking inequality.

In sum, the poverty, growth, and inequality triangle is not an iron rule even in the absence of measurement issues. We also acknowledge a range of complex intertemporal choices and potential trade-offs discussed in detail by Bourguignon (2004). Nevertheless, the simple arithmetic of the triangle provides a useful analytical framework for considering relationships across macroeconomic variables, including measures of monetary poverty. The triangle is also relevant for non-monetary measures of poverty. As noted above, growth in absorption, whether driven by GDP growth or an increase in net imports, permits more consumption, investment, and/or government expenditure. One reasonably expects an expanded government expenditure envelope to result in improvements in the social outcomes targeted by government expenditure even if there may be a lag due to long gestation periods. We apply this optic in the typologies that follow.

\subsubsection{Country Categorization}

We classify countries into one of four groups. These are:

1. Relatively rapid economic growth and corresponding poverty reduction.

2. Relatively rapid economic growth but limited poverty reduction.

3. Uninspiring or negative economic growth and corresponding stagnation or increases in poverty.

4. Low-information countries.

As already noted, it is not difficult to criticize almost any categorization scheme. The difficulties inherent in categorizing economies based on publicly available data, such as the World Development Indicators, are illustrated in Box 2.2. The discussion below provides brief comments on each country case with emphasis on those cases where categorization is, in our view, less clear. 


\section{Box 2.1. MEASURING INEQUALITY}

To begin, it merits mentioning that a specialized system, the system of national accounts (SNA), exists for the measurement of GDP. Similarly, for the measurement of poverty and well-being, specialized surveys, such as Living Standards Measurement (LSMS) and Demographic and Health (DHS) surveys, have been designed and broadly administered. For the measurement of inequality, there are hardly any corresponding systems, tailored to the particular challenges of these measures, in African countries.

This absence is not due to any lack of specialized challenges. In nearly all African countries, it is eminently possible, indeed expected, for a very small share of the population to command a relatively large share of consumption, income, and wealth, with strong implications for many inequality measures such as the Gini coefficient. And the wealthy in developing countries (as elsewhere) are a heterogeneous group with some members earning or consuming considerably more than others. Both of these factors point to a strong need to oversample wealthy households. Yet, the widespread sense is that wealthy households are under-represented in most household surveys, in part reflecting the frequent unwillingness of such households to respond to surveys. This can explain in significant part the tendency for household surveys to often underestimate aggregate consumption relative to national accounts (Ravallion 2003). This undersampling would bias downward inequality measures, perhaps significantly. It also likely contributes to the enhanced volatility of inequality estimates as the number of very wealthy households that are actually included in the sample might vary a lot with strong implications for measured inequality.

A second problematic feature of household surveys in sub-Saharan Africa is that the questionnaire frequently does not vary with circumstance. The same questionnaires designed to capture consumption/income of absolutely poor households are used for wealthier households even though their consumption patterns are very different. As such, the questionnaires administered to wealthy households very often focus on items reflecting trivial expenditure shares while only broadly treating important classes of expenditure, with implications for non-sampling error.

These factors are, in all likelihood, on display in Nigeria where the World Bank's Nigeria Economic Report (2014) lists an implausibly low national Gini coefficient for Nigeria of about 0.33 based on a 5,000 household panel conducted in 2010/11 and 2012/13. This estimate is much lower than any other publicly available national-level estimate and puts Nigeria in the same ballpark as the Republic of Korea. More generally, the variations in alternative inequality measures are vividly on display in the World Income Inequality Database (WIID) at UNU-WIDER.

The profound challenges to adequate inequality measurement, particularly in SSA, would appear to be deeply problematic for the approach of Sala-i-Martin and Pinkovskiy (2010), which makes uncritical use of the available inequality data, not stopping to assess their reliability, to say nothing of the scale of imputations they make for the very large numbers of missing values. This could substantially affect their results.

Countries categorized within the first group, relatively rapid growth and corresponding poverty reduction, are: Ethiopia, Ghana, Malawi, Rwanda, and Uganda. Ethiopia, Ghana, Rwanda, and Uganda all fall comfortably within this group based on experience over the past ten to fifteen years or more. Ghana, with its large rebasing of GDP accounts, is one of the examples of the 


\section{Box 2.2. DIFFICULTIES IN CATEGORIZATION}

Country categorization based on growth and poverty trends is an endeavour likely to generate disagreement. It may seem that a systematic evaluation of available indicators, such as those assembled in the World Bank's World Development Indicators (WDI), should yield reasonably stable categorizations. However, our attempts at classification based on these criteria were strongly sensitive to the choice of poverty measures, time frame, and even the version of the WDI employed.

Consider the case of Tanzania. Based on US $\$ 1.25$ a day poverty headcount figures, Tanzania appears to have achieved significant progress, with poverty falling from 84 per cent in 2000 to 68 and 43 per cent in 2007 and 2012. Further investigation, as discussed in the Tanzania chapter, shows these numbers are not plausible. Looking at national poverty lines suggests a very different scenario, with poverty only declining from 36 to 34 per cent between 2000 and 2007. Further compounding difficulties, these national line figures of 36 and 34 per cent are not comparable to the 2012 poverty estimate of 28 per cent. Hence, they have been withdrawn from the most recent release of the WDI.

In countries such as Cameroon, the choice of time frame can significantly impact the poverty story. Based on national poverty lines, poverty fell from 53 to 40 per cent between 1996 and 2007. However, this gain occurred entirely between 1996 and 2001 and if instead the period 2001-7 were considered, Cameroon would appear to have achieved absolutely no improvements (see Box 2.3).

Finally, methods of computing poverty rates are frequently scrutinized and then revised. For example, the most recent South African poverty estimates, based on national poverty lines, appearing in the WDI indicate a substantial increase in poverty from 38 per cent in 2000 to 57 and 46 per cent in 2006 and 2011 respectively. The WDI is reflecting an official revision from previous estimates, which suggested the opposite, with poverty declining by 15 percentage points to 23 per cent between 2000 and 2006 . The South Africa chapter relies on neither figure, preferring income rather than consumption-related measures due to greater reliability and robustness.

These observations strongly underline the rationale for this book as discussed in the Introduction. Simply plucking figures from the WDI can provide a deeply misleading picture, or at least one that is easily contradicted through alternative choices of indicators (or via release of a revised WDI). They also highlight the difficulties inherent in classification in the volatile contexts that characterize Africa south of the Sahara.

Jerven and Johnston (2015) African Statistical Tragedy; but there is no doubt that it has experienced more than two decades of respectable economic growth, and nearly all welfare indicators, consumption poverty included, point to improvements, often substantial ones. Malawi is perhaps the most controversial placement within this first group. Contrary to the official poverty statistics, the case study presented in this volume finds monetary poverty reductions that are consistent with rapid agricultural growth. Nonmonetary measures also point strongly towards improvement, particularly in relatively recent periods. Nevertheless, even if one accepts that growth has occurred and led to poverty reduction in recent years, the durability of this positive trend remains open to question. The growth and poverty reduction spell in Malawi has been relatively short and has been driven by agricultural 
production, at least partly as a consequence of an input subsidy programme. It remains to be seen whether a more sustainable process has been ignited.

Countries categorized within the second group, relatively rapid growth but limited poverty reduction, are: Burkina Faso, Mozambique, Nigeria, Tanzania, and Zambia. While Burkina Faso fits fairly comfortably within this category, the other countries are somewhat less clear. The case study for Mozambique points to a strong role for temporary factors influencing the most recent poverty assessment; and the authors expect poverty reduction to resume when the next set of data is analysed.

Nigeria could be classified as a low-information economy, given the desultory state of statistics in relation to monetary poverty. For example, the recently released Nigeria Economic Report (World Bank 2014) estimates poverty rates in 2010 and 2012 at much lower levels than the official estimates. However, the report shrinks from making formal comparisons with earlier monetary poverty estimates due to severe comparability issues. Were it possible, application of the same approach to earlier years may yield similarly lower estimates, leaving the conclusion of stagnation or even increase in measured monetary poverty intact. In addition, the analyses undertaken for 2010 and 2012 show only a small decline in poverty over that short period that is clearly statistically insignificant. Finally, the report publishes an implausibly low Gini coefficient of about 0.33 (see Box 2.1). Non-monetary measures appear to be much more reliable, and the Nigeria case chapter conducts considerable original analysis using those data. Viewed broadly, the available evidence summarized in the Nigeria study points reasonably consistently towards broad stagnation in living standards based both on monetary and non-monetary measures, despite fairly rapid GDP growth and a substantial terms of trade boost due to rising oil prices over this specific time period.

For Tanzania, economic growth has probably been overstated. However, the extent of overstatement is likely not so large as to reclassify it to the third group. Tanzania's tepid performance in reducing monetary poverty can be explained by the slow growth of household consumption, reflecting in part slow growth in agriculture, relatively high population growth, and food and fuel price increases. Zambia is a curious case. Official monetary measures point to stagnation in living standards in rural zones and mild improvements in urban zones. The analysis of non-monetary measures conducted in the case study provides exactly the opposite signal with notable improvements in rural zones and stagnation in urban zones. This puzzle remains to be resolved. The constraint appears to be principally the analytical effort required to resolve the puzzle rather than an underlying data constraint (though better data would certainly make the task easier).

Countries categorized within the third group, uninspiring or negative growth and corresponding relative stagnation or increases in poverty, are: 
Cameroon, Côte d'Ivoire, Kenya, Madagascar, and South Africa. Côte d'Ivoire and Madagascar fit comfortably within this group, both plagued by political instability over much of the period and Cote d'Ivoire by extended episodes of conflict. In both cases this was associated with economic decline and often worsening monetary and sometimes non-monetary poverty outcomes. Cameroon and Kenya have had relatively volatile growth records, with some periods of growth but others of stagnation or even recession, and correspondingly limited long-run gains in many welfare indicators.

Growth in South Africa has been tepid relative to many countries on the continent both before and after the end of apartheid. While growth picked up in the middle of the first decade of the 2000s, growth essentially collapsed following the financial crisis of 2008. It has yet to resume at anywhere near the rates required to deliver substantial employment and welfare gains, reinforcing the categorization decided upon here. Essentially stagnant monetary measures of poverty and zero or negative progress in reducing inequality accompany the uninspiring growth performance. With respect to nonmonetary measures, the ample scope for redistribution made available by the fall of apartheid has permitted impressive progress in many measures of non-monetary poverty, representing substantial government investment in sectors such as education and housing over this period. These investments have explicitly sought to target previously disadvantaged groups.

Finally, the Democratic Republic of the Congo (DRC) is securely categorized as a relatively low-information economy, even by the standards of SSA and despite ongoing efforts to improve the information base.

Overall, the recent growth record in these sixteen countries is not one of consistent fast growth across the board. There is a wide range of experience. In terms of the extent to which countries have been able to improve the living conditions of their citizens, there is an even broader range of experience with some relatively fast-growing countries registering disconcertingly few improvements in the welfare of the general population.

\subsection{Lessons}

\subsubsection{Peace and Stability}

During the 1990s, the term 'lost decade' (or 'lost decades' as the aggregate growth hiatus persisted) became increasingly employed to describe the economic experience of SSA since about 1980. The terminology employed evoked a sense of stagnation. Easterly (2001: 135), for example, points out that 'median per capita income growth in developing countries was 0.0 per cent' from 1980 to 1993. The countries of SSA, by and large, sat on the left-hand side of this distribution with negative per capita growth. However, when reading 
the actual case studies, the period in question is almost invariably characterized by massive upheavals as opposed to stagnation. Tanzania 'only' had to transition from a socialist to a market orientation. There are, unfortunately, many at the other end of the spectrum. The Rwandan genocide is well known. Mozambique suffered a devastating decade-long war that killed 1 million, displaced 4 million, literally decimated rural infrastructure, and left it the consensus 'poorest country in the world' by 1992. In general, some period of massive upheaval, almost always punctuated with violence, often severe violence, was the rule almost everywhere.

The importance of political stability and avoidance of conflict for economic and social development is well recognized and clearly evidenced by the more recent experiences of Côte d'Ivoire and Madagascar. In the remaining fourteen of the sixteen case countries, stability as a basic precondition to growth and broad-based poverty reduction is much improved relative to the tumult that characterized the experience of nearly all of the case countries at some point during the 1980s and into the 1990s. An assertion of improvement does not imply that all is well. For example, the 2007-8 electoral crisis in Kenya clearly had a substantial adverse impact on living conditions at the time, as well as illustrating that democratization does not guarantee stability. This is true even in countries where democracy is relatively well embedded, as in the case of Ghana, which has peacefully managed two changes of government since 1992. Nevertheless, even in Ghana, closely contested elections risk creating tensions; and the context of recent oil discoveries may increase this risk. In Ethiopia and Rwanda, political risk reduces the lustre of notably strong objective performances in growth and poverty reduction. Finally, one can recall that, while Côte d'Ivoire was seen as very stable and peaceful in the 1970s and early 1980s, it later descended into large-scale conflict.

It should, in addition, be recognized that our 'sample' of sixteen countries suffers from selection bias. Mali, Sudan, Somalia, and Zimbabwe are not among the cases considered in this volume in large measure because conflict or political instability precludes in-depth analysis of living conditions. Even among our selected sixteen, there is, arguably, not a single case where threats to political stability could be termed very mild or highly unlikely. In cases such as Nigeria with Boko Haram, open conflict is ongoing. With all of this said, the cases often vividly illustrate that governments in SSA in general have been doing a much better job of fulfilling their fundamental role of ensuring peace and security, providing the fundamental stage for the growth acceleration since 1995.

\subsubsection{Data Issues}

Without question, the data situation in SSA has substantially and reasonably consistently improved over the past twenty-five years. In 1990, only a handful 
of countries had data allowing measurement of consumption poverty, and the DHS surveys were only beginning. Since then, the large majority of countries have had multiple DHS surveys, and the majority of countries have now had multiple income and expenditure surveys.

Having said this, all is clearly not well. Massive deficiencies plague almost every case country. The shortcomings of GDP and growth statistics are well known and briefly discussed in Chapter 1 . The desultory state of agricultural statistics is reviewed in Box 2.5; price data are often surprisingly weak (see Box 2.6); and emerging interest in inequality on the subcontinent confronts the functional absence of a system designed specifically to track it in an effective way as discussed in Box 2.1. The weaknesses and confusion that characterize data systems at the country level are at best held constant and more likely magnified when transferred to international datasets as discussed in Box 2.2 (see also the discussion of FAO maize production data in the Mozambique case study).

Doing better is a clear priority. Pluralistic political systems require information in order to function properly. Given the evident very large appetite of global investors for information and given the need for information if there is any hope of developing a well-informed polity, it seems to us deeply unwise to dismiss appropriate data collection and analysis for a later phase of development. Appropriate information is better viewed as a key public good that, in many instances, only government can supply. In short, we agree with the UN Secretary General's High-Level Panel of Eminent Persons on the Post-2015 Development Agenda, ${ }^{2}$ which called for nothing less than a data revolution. Some thoughts on appropriate data collection programmes are included in Box 2.3.

\subsubsection{Volatility of Monetary Poverty}

While the frequency and severity of descent into conflict or macroeconomic collapse has clearly declined on the subcontinent, other sorts of volatility prominently remain. With the accumulation of experience in the estimation of monetary poverty, not least from the cases in this volume, it is becoming increasingly apparent that consumption poverty estimates are volatile. This is true for three reasons, discussed in Box 2.4. Among these reasons is actual variation in levels of consumption (the other two are sampling and nonsampling error). An extensive literature argues that households seek to smooth their consumption and use different predominantly informal ways of doing sosee Case (1995) for a brief overview of an influential symposium. The literature

\footnotetext{
${ }^{2}$ See <http://www.un.org/sg/management/hlppost2015.shtml>.
} 


\section{Box 2.3. DATA COLLECTION AND ANALYSIS}

The broad issue of data collection and analysis is a lot to take on in one box. The points made in other boxes, related to agricultural statistics, price statistics, and inequality, obviously pertain. Here, we simply make four general points based on our experience in pulling together this volume and beyond.

First, the central role of national accounts in data collection and analysis has been substantially neglected in most cases. The national accounts department is obliged to create a macroeconomically coherent whole from a dispersed set of available data sources. Hence, national accounts are a natural location for cross-checking and verification of alternative sources of information. For example, if import plus production information on fertilizer availability does not remotely accord with farm-level data on fertilizer use, then something is wrong in at least one place. National accounts could and should be used more to identify anomalies and then correct them. This implies a more central role for national accounts in country statistical systems.

Second, administrative data, particularly tax data, are frequently underused. In many cases, there is no connection at all between the revenue authorities and statistical authorities. This stands in direct contrast to basic logic and global best practice. These links should be fomented throughout the continent. Use of tax data should put less pressure on the enterprise monitoring programme while simultaneously allowing for cross-checking between administrative and survey-based data sources.

Third, the periodicity of household consumption surveys is very often too infrequent. This follows directly from the observations on volatility made in Box 2.4. It also follows from a capacity development perspective. If the period between surveys is five years or more (as is often the case), the personnel that worked on the previous survey (across the domains of data collection, cleaning/processing, and analysis) have very often moved on by the time the next survey rolls around. One option could be a three-year rolling programme involving a DHS survey (or similar) in year 1, a household-consumptionoriented survey in year 2, and a survey focused on household income sources in year 3 . The last survey would focus more on labour force and informal enterprises in urban areas and agricultural income and off-farm enterprises in rural areas. A three-year rolling programme is convenient in that it easily makes room for a census every tenth year.

Finally, while the many benefits of panel data are clear, and do provide information on volatility, pursuing large-scale, national-level panel surveys does not make sense when very basic items, such as timely and reliable agricultural production statistics, are absent. Given the capacity constraints evident in many statistical services, smaller-scale panel surveys, perhaps pursued within a university context (as in Ethiopia), may be a more productive approach.

also confirms that while households generally try to smooth their consumption they are unable to do so perfectly. Households frequently face major interrelated shocks, such as unusually good or bad harvests, changes in prices of items they purchase or sell, and variations in general economic conditions with implications for income-earning opportunities.

The Burkina Faso case finds that monetary poverty increased by about six percentage points from 1994 to 1998 and then declined by nearly fifteen percentage points from 1998 to 2003. A large drought in 1998 temporarily 


\section{Box 2.4. SOURCES OF VARIATION IN MONETARY POVERTY MEASURES}

In general terms, there are three main sources of variation that need to be distinguished. These are: (i) true variation in the poverty rates, which in turn can be divided into longterm trends and ephemeral shocks; (ii) variation due to sampling error; and (iii) variation due to non-sampling error. Each source of variation is considered in turn.

True variation. It is highly likely that true poverty rates vary substantially through time, particularly for limited geographic areas. For poor African households, food shares represent up to three-quarters of total consumption. Furthermore, in many poor, rural households, home consumption of own production accounts for more than half of food consumption. Given that poor households have relatively few options for stabilizing consumption over time, household consumption becomes highly dependent on agricultural production, food prices, and dependability/availability of income-earning opportunities outside of agriculture. The available evidence indicates strongly that none of these is stable even at relatively high levels of aggregation. Shocks to agricultural production and crucial prices can be expected to influence poverty rates strongly. A negative shock can easily outweigh long-run trend improvement, particularly over short time frames.

Sampling error. When calculated, the confidence intervals on poverty rates can be wide, particularly for subnational regions. For example, in Mozambique, confidence intervals are in the order of plus/minus ten percentage points in many provinces (e.g. a standard error of around five). Sampling error stems from the use of samples; and the likelihood of divergence from the characteristics of the true population declines as the sample sizes increase. Because lower levels of geographical aggregation are associated with smaller samples, sampling error tends to be higher at the provincial level and lower at the national level.

Non-sampling error. Non-sampling error reflects mistakes anywhere along the long chain of events in producing the poverty rates. Enumerators may not pose questions correctly. Respondents may not respond completely or correctly. The declarations of respondents may be improperly noted on the questionnaire. There may be errors in data processing or analysis. These are only a few examples. Non-sampling error is present in all surveys.

In summary, if we could perfectly observe every household in every country through time, we would, in all likelihood, observe that monetary poverty rates vary through time, with favourable conditions pushing poverty rates down and unfavourable conditions pushing poverty rates up. However, as a practical matter, we cannot observe every household, so we are forced to rely on samples and statistical methods to inform our understanding of reality. As a result, sampling error is added to the inherent variation in poverty rates. And error inevitably creeps into our observations of households in the sample. As a result, non-sampling error influences the estimates, adding a third source of variation.

constrained consumption possibilities nationwide. In Mozambique, the stagnation in observed national poverty rates between 2002/3 and 2008/9 was driven by the combined effect of rising/high fuel and food prices, very slow growth in agricultural productivity, and weather shocks in major growing regions, which drove up poverty rates substantially in populous provinces. 
In Ethiopia, results from the Ethiopian Rural Household Survey (ERHS) confirm the power of combined drought and food price shocks. The poverty rate among the nearly 1,500 households followed over successive waves declined from a high mark of 55 per cent in 1995 to 35 per cent in 2004, but increased again to 52 per cent in 2009 following a bad harvest combined with a substantial increase in global food prices (Dercon et al. 2012). A subsequent observation from the ERHS is not yet available; however, a separate nationally representative household survey suggests that national-level poverty reduction resumed in 2010 and 2011.

As these results from Mozambique and the ERHS indicate, volatility of consumption (manifesting itself as volatility in poverty rates) is likely to be more pronounced at regional levels where shocks might be concentrated and in rural areas where consumption smoothing options are more circumscribed. The presence of additional shocks, such as the illness or death of a key household member, ensures that true variations in consumption at the household level are even more pronounced than the already substantial variations suggested by repeated data cross-sections. Finally, from a measurement perspective, the role of sampling and non-sampling error is also more pronounced at lower levels of aggregation, complicating the task of assessing volatility.

Household-level insecurity has long been recognized as a key feature of poverty, as stressed in many qualitative poverty studies and in World Bank (2001). However, the frequently high levels of variability observed in estimated poverty rates even at fairly high levels of aggregation have not yet been adequately internalized. Monetary poverty measures may fail to decline or even rise between two points in time for a host of reasons, including: (i) an ephemeral positive shock in the earlier period; (ii) an ephemeral negative shock in the later period; (iii) a relatively well-off sample in the early period; (iv) a relatively poor sample in the later period; (v) underestimation of poverty in the early period due to non-sampling error; (vi) overestimation of poverty in the late period due to non-sampling error; and finally (vii) actual stagnation or deterioration in underlying living conditions. These observations are particularly pertinent at subnational levels but also apply to national-level monetary poverty estimates.

For these reasons alone, one could conclude that excessive weight is frequently placed on the (normally relatively few) monetary poverty measures available in SSA countries. Non-monetary measures are often more easily measured and more stable, supporting the need for considering a multiplicity of indicators each relating to a different facet of well-being.

These indicators are the subject of section 2.3.4; however, before proceeding, the importance of serious monetary poverty measurement merits highlighting. While the weight accorded to monetary poverty measures is frequently excessive in evaluating country performance, the appropriate 
response is not to allocate fewer resources to the evaluation of monetary poverty. Inadequate consumption or income is a key aspect of poverty, and more frequent observation (i.e. more frequent surveys) is the best way to counteract intrinsic variability.

\subsubsection{Importance of Multidimensional Assessments}

Consistent with the MDGs and with the approach in this volume, it is essential to conceive of and monitor poverty in its different dimensions. Education and health are fundamental human outcomes in their own right (and for many other factors), and premature mortality is clearly the most fundamental form of deprivation. Access to adequate drinking water, sanitation, and information, among other items, are also very important for the realization of human capabilities.

In terms of tracking multiple indicators, the Demographic and Health Surveys (DHS) have been a major achievement. The data are, by and large, of good quality and broadly comparable (over time and between countries), providing solid insights on non-monetary measures of living conditions. They underlie some of the non-poverty measures discussed in the introductory chapter. They are also now being exploited for a number of purposes, one of which is the computation of multidimensional poverty indices as presented in the DRC, Nigeria, and Zambia case studies. Two or more DHS surveys (or DHS-type surveys such as the Mixed Indicators Cluster Survey) are available for every one of the sixteen case countries, including relatively weak data environments such as the DRC, allowing for a perspective on evolution through time.

Helpfully, many key non-monetary indicators are relatively easy to observe (at least compared with estimating per capita consumption for a household). These indicators include child height and weight, possession of assets, access to water, access to sanitation, enrolment in school, distance to public services, use of public services, and child and maternal survival. In addition, with some potential exceptions such as shorter-run malnutrition indicators, nonmonetary indicators tend strongly to evolve in a more stable manner through time compared with consumption per capita. These characteristics ameliorate issues associated with non-sampling error, due to the relative ease of observation; and they ameliorate issues with sampling error, due to the lower variance of the targeted indicators (the width of a confidence interval is proportional to the standard deviation of the variable observed). As such, non-monetary measures are useful in identifying long-run trends.

Finally, many non-monetary outcomes reflect the availability and quality of publicly provided services, in particular for the poor. As such, non-monetary indicators provide important insight into the quality of governance. This 
observation reflects well on most case countries. Consistent with the aggregates presented in Chapter 1 and the observations of Young (2012), nonmonetary indicators exhibit reasonably broad-based improvement in most case countries.

\subsubsection{The Role of Agriculture}

Solid conclusions emerge with respect to the fundamental role of agriculture. Five country cases are classified as exhibiting rapid growth and poverty reduction. These are Ethiopia, Ghana, Malawi, Rwanda, and Uganda. In these cases, an extended period (a decade or more) of broad-based (and sometimes rapid) agricultural growth has been a substantial initial driver of both growth and poverty reduction. ${ }^{3}$ In this context, Ethiopia is a particularly interesting case as it explicitly pursued a strategy of Agricultural Development-Led Industrialization (ADLI). The Ethiopia case study documents very strong efforts by the government of Ethiopia to stimulate agriculture alongside a wide array of indicators pointing to considerable success in fomenting agricultural development. The degree of seriousness of the Ethiopian government is well illustrated by the number of agricultural extension agents hired-some 45,000. Ethiopia now has one of the highest ratios of extension agents to farmers in the world (Davis et al. 2010). Malawi provides a second and somewhat more controversial example. The authors of the Malawi case credit Malawi's Farm Input Subsidy Program as contributing, perhaps substantially, to recent measured poverty reductions despite a series of negative shocks over recent periods.

Historical experience strongly indicates that it is eminently possible to waste substantial resources on poorly designed agricultural interventions. And in an environment with multi-pronged initiatives, such as Ethiopia, it is difficult to know with precision which intervention has contributed the most to their so far successful drive to foment agricultural development. Finally, policies that work in one location may not yield the same results in a different location. For instance, the specificities of the Malawian case may limit the lessons that might be drawn from this experience by other countries. Nevertheless, the message from the experiences of these five countries is that there

\footnotetext{
${ }^{3}$ How long this agricultural growth episode must persist to fuel sustained national-level poverty reduction is an open question whose response likely varies from country to country. For example, Ugandan national accounts do not point to strong growth in agricultural value added during the first decade of the twenty-first century, in contrast to the 1990s (Government of Uganda 2012). Benin et al. (2012) attribute the observed slowdown in reductions in the national poverty rate in the 2000s compared to the 1990s to this more tepid performance in agriculture. In addition, the positive conclusion of national-level growth and poverty reduction is tempered by lagging regions and other equity considerations.
} 
are potentially high returns to effective policies that take agriculture seriously at scale with particular emphasis on upgrading the productive capabilities of small-scale farmers.

The cases of countries with relatively rapid growth and limited poverty reduction-Burkina Faso, Mozambique, Nigeria, Tanzania, and Zambiaprovide an interesting counterpoint. In none of these cases does solid evidence of sustained and substantial growth in agriculture, particularly smallholder agriculture, present itself. ${ }^{4}$ In these cases, substantial agricultural production potential is broadly recognized and is often accompanied by considerable policy rhetoric. In the cases of Burkina Faso, Mozambique, Nigeria, and Tanzania, country authors highlight weak agricultural productivity growth as an underlying factor in the relative stagnation of monetary poverty rates.

The importance of agricultural growth in general and productivity growth within smallholder agriculture in particular is often made but bears repeating here. For countries with large shares of the population mired in lowproductivity subsistence agriculture, agricultural productivity growth among this group remains a powerful lever for achieving poverty reduction and holds out potential from priming sustained growth and poverty reduction over the long run as has been experienced in Asia and elsewhere.

Exhortation to improve agricultural performance is not new. But some countries, notably Ethiopia and Malawi, have clearly moved beyond rhetoric and enacted highly ambitious programmes. And the rhetoric from African policymakers as well as donors has become explicit. Recently, at a Senior Policy Seminar held in March 2015, hosted by the African Economic Research Consortium (AERC) in Maputo, African policymakers reaffirmed the 'critical role of smallholder agriculture in Africa's economic and social transformation' (AERC 2015). Their declaration recognized the Comprehensive African Agricultural Development Programme (CAADP) as well as subsequent commitments such as the Malabo declaration. While commending governments for increasing government budget shares allocated to agriculture, the AERC Maputo declaration also highlighted that 'important gaps remain'. One important gap, the dismal state of agricultural statistics, is highlighted in Box 2.5.

The cases studied in this volume provide further evidence for converting this rhetoric into well-designed programmes to stimulate agriculture, particularly smallholder agriculture, operating at scale.

\footnotetext{
4 The Burkina Faso study finds consistent and sustained growth in agriculture but at a low rate per capita basis. Land expansion, rather than productivity growth, is pointed to as a driving force.
} 


\section{Box 2.5. AGRICULTURAL STATISTICS}

Better agricultural statistics are clearly not a sufficient condition for fomenting agricultural development. They might not even be necessary. After all, the case authors for Ethiopia argue that substantial agricultural growth is occurring in spite of rather broadbased mistrust in Ethiopian official statistics. Nevertheless, the ability of governments to design policies informed by evidence is surely strongly compromised by the stark weaknesses in agricultural statistics that persist in most countries. For example, a great deal of effort has gone into evaluating Malawi's fertilizer input subsidy programme, which has been widely perceived as a potential model across the continent (Jayne and Rashid 2013). The lack of faith in national production and area statistics for major crops in Malawi substantially complicates the task (see Arndt, Pauw, and Thurlow 2015).

Importantly, quality agricultural statistics are not only useful for the purposes of policy formulation and evaluation. Throughout Africa, market prices are meant to provide the appropriate signals to market participants across the value chain from producers to consumers. It is difficult to see how markets can properly price commodities when the quantities existing within a given country or region are so poorly known. When properly gathered and issued in a timely manner, government statistics are known to move agricultural markets. For example, Baur and Orazem (1994: 681) examined the price effects of government orange production forecasts in the United States and found that 'significant price movements occur in response to announced production'. Hence, even in a developed country setting, market participants are not omnisciently capable of efficiently pricing in the information content of official data prior to its announcement, implying that the information provided has significant value. The value of information is very likely to be relatively higher in developing countries given its general paucity.

The success of the Demographic and Health Surveys illustrates that massive improvements within particular data domains are possible. We see no fundamental reason why agricultural statistics could not achieve similar success and a plethora of reasons for striving to achieve that objective. It is impossible to prove definitively that the nearly simultaneous rise of the DHS survey and the gains registered in non-monetary poverty indicators in the large majority of case countries (as discussed in the previous section and in Chapter 1) are related, but it would be unwise to ignore the correlation.

Agriculture is a very different domain from demography and health; hence, applicable 'on-the-ground lessons' from the DHS are limited. Household surveys may not be the best approach to collecting basic agricultural statistics, particularly the timely production information required by market participants. This is especially true of multipurpose household surveys which seek to measure consumption or income and in tandem collect data on agriculture. In our view, approaches based on area, such as area frames, as practised by, for example, the United States and Morocco, merit more serious consideration on the subcontinent (see Davies 2009). Technological advances in location and imaging technologies expand the possibilities set for developing transparent, reliable, and cost-effective approaches that are appropriately tailored to specific country circumstances. One way or another, having better data on agriculture, the most important source of employment in many SSA countries, is a priority.

\subsubsection{Relative Prices}

In many of the case country studies, substantial attention is accorded to the role of shifting relative prices and their implications for poverty and 


\section{Box 2.6. PRICE DATA}

In a number of case countries, household budget surveys allocated inadequate attention to the collection of price data, substantially complicating the task of computing measures of real consumption or income. For example, price data associated with the household consumption survey are either weak or non-existent in the cases of Ghana, Cameroon, and Zambia. In each of these three countries, considerable efforts were made to analyse the household survey data. However, due to difficulties in accessing adequate price information, it was deemed difficult to improve upon or corroborate existing monetary poverty estimates. Hence, the available estimates were employed.

In some cases the price data may be available as part of collection of data for consumer price indices, if these are conducted sufficiently widely across the country, as was the case in Rwanda. In other cases, CPI data have weak geographic coverage, and in at least two case countries (Malawi and Tanzania), published CPI data were inadequate to even capture basic inflation trends. In yet other cases, such as Mozambique, CPI data largely corroborate data from the household surveys. Use of price data from agricultural market information systems also provides a useful coherence check.

One approach is for countries to collect expenditure and quantity information for relatively homogeneous products such as food within the context of the household budget survey such that reliable unit value estimates can be calculated. Challenges occur if respondents are unable to report quantities accurately in standard units. Alternatively, prices may be better collected separately from the survey, but still capturing the spatial variation. In whatever case, this information should be corroborated with contemporaneous village-level pricing surveys, and then further cross-checked using CPI and market information system data.

inequality measures. These price variations must be taken carefully into account in comparing estimates of consumption poverty; and much future work is required to collect relevant price data (Box 2.6). In line with the high levels of volatility discussed in section 2.3 .3 , relative prices can be very different across space (particularly in large countries) and may shift dramatically through time for the same location. Consistent with standard economic theory, the case countries tend to find that changing relative prices influence consumer behaviour, with households tending to shift consumption towards relatively lower-priced products.

These observations relate to long-running debates about the relative merits of consistency versus specificity in the construction of poverty lines based on consumption bundles (Tarp et al. 2002). In a nutshell, it is desirable that the consumption baskets that underlie poverty lines reflect the consumption patterns of the poor. To take an extreme example, it is undesirable to include the price of airline tickets in African poverty line baskets because low-income Africans almost never consume airline tickets. The price of an airline ticket is, as a result, largely irrelevant to the welfare of poor Africans, at least in any direct sense. This is quite straightforward. Other decisions may be less so. As 
emphasized in a number of case countries, staple food consumption can vary quite substantially across regions, even within a relatively small country by area (e.g. Uganda). Simply put, the price of a product is a lot less relevant to populations that consume very little of that product.

However, increasing specificity may come at a cost in terms of consistency. In principle, absolute poverty lines should be linked to some underlying fundamental level of welfare. If poverty analysts are employing multiple consumption bundles to account for consumption specificity across space or through time, how can the analyst be sure that these bundles all reflect a reasonably similar level of welfare? A number of case studies (Ethiopia, Madagascar, Malawi, Mozambique, and Uganda) employ the approach of Arndt and Simler (2010), which is designed to enhance specificity while preserving consistency. The approach applies revealed preference conditions in order to constrain multiple bundles to correspond to reasonably similar welfare levels. The Burkina Faso case also emphasizes relative price movements though an alternative method is employed for coping with the implications.

A few of the case studies address the specific implications of the global food and fuel price crisis of 2007/9. During that period, oil prices spiked to about US\$150 per barrel, compared to about US\$35 per barrel in 2003, and real food prices attained levels not seen since the early 1970s. In large measure because a major national household budget survey was conducted in Mozambique in precisely 2008/9, the Mozambique study devotes considerable attention to the food and fuel price crisis as well as global commodity price trends from 2002/ 3 , when the prior household consumption survey was conducted. The literature on the food and fuel price crisis emphasizes country-specific factors in enhancing or reducing vulnerability (Headey 2013; Swinnen and Squicciarini 2012). Mozambique was particularly vulnerable to the price shocks, and measured poverty rates responded accordingly. As noted in section 2.3.3, strong effects were also observed in the Ethiopian Rural Household Survey, which also was in the field during the 2008/9 period.

Both the South African and Mozambican case studies highlight, in addition, the observation that international price trends from about 2003 have tended to shift the relative prices of basic products (foods and fuels) upwards relative to prices of manufactures and services. Because lower-income people tend to allocate proportionately more consumption expenditures towards basic goods, these movements have potential implications for measured inequality. Indeed, in both countries, the case authors find that ignoring relative price shifts across the income distribution tends to materially underestimate inequality. As these global pricing trends affected all developing countries, it may be that the implications for inequality are more general and extend beyond these two cases. 


\subsubsection{Aid Flows}

While issues of aid and aid effectiveness were not an explicit focus of the case studies, most of the sixteen countries considered received substantial volumes of aid for at least part of the period in reference. It is, as a consequence, much easier to list the countries with notably low aid volumes relative to GDP: Nigeria and South Africa. Aid has been an important consideration in the remaining fourteen case countries. And the contraction of aid volumes in newly declared middle-income countries, such as Ghana and Zambia, is a much-discussed policy issue.

By and large, the outcomes of the case studies in this volume are consistent with a positive developmental impact associated with foreign assistance. ${ }^{5}$ The broad-based improvements in non-monetary indicators are often clearest in relation to education and health. These are services predominantly provided by the public sector, and are therefore a consequence of increased public spending in these areas, more effective and widespread service delivery, or both. Without question, in many case countries, aid has targeted improvements in exactly these areas and has provided often substantial funding and other resources to achieving these objectives.

In sum, it is, in our view, difficult to see how the gains registered in the case countries, particularly the non-monetary gains, could have been achieved with zero or greatly reduced assistance, an observation that is consistent with up-to-date macroeconomic studies of aid impact (see, for example, Arndt, Jones, and Tarp 2015).

\subsection{The Perils of Existing Cross-Country Studies}

Before concluding, we revert to the rationale for undertaking a case study approach in the African context. As a counterpoint, we consider two prominent studies on growth and poverty in SSA: Pinkovskiy and Sala-i-Martin (2014) and Young (2012). These papers, published in leading journals, use internationally available data to suggest that recent changes in living conditions in SSA may be much better than is conventionally understood. Pinkovskiy and Sala-i-Martin (2014) draw on GDP data in purchasing power parity (PPP) values along with available inequality data to claim that monetary poverty reduction has been substantially greater in sub-Saharan Africa than the World Bank and other estimates have reported. Young (2012) uses DHS data from across many African countries to argue that the scale of improvements in non-

\footnotetext{
${ }^{5}$ In a previous case study, Arndt, Jones, and Tarp (2007) examined aid effectiveness for Mozambique and found that aid represented a crucial ingredient to the positive trends observed in development indicators up to that point in time.
} 
monetary measures of well-being suggests that consumption and living standards have been growing much faster than official data suggest.

Pinkovskiy and Sala-i-Martin use inequality data from Chen and Ravallion (2010) containing Gini coefficients and quintile shares, supplemented by data from the UNU-WIDER WIID database, to estimate income distributions, poverty rates, and inequality measures for African countries over the period 1990-2011. They use PPP-adjusted GDP data from the World Bank to anchor the survey mean for this income distribution data, and fit income distribution functions, experimenting with different variants. The functional form is assumed to be the same across all countries and in all years, and is characterized by a scale parameter (reflecting GDP) and a distribution parameter (reflecting inequality). Changes over time manifest themselves in changes in the parameters. The function is fitted to the data, but not before they impute for the substantial number of missing values of inequality-by-year values, using methods explained in the paper. Some countries have no inequality data at all, but imputations are nonetheless made based on neighbouring countries.

The authors then use this as a basis to estimate poverty for each country and for SSA as a whole. The core to their argument that poverty has reduced very rapidly is that the growth in the per capita PPP GDP data is substantially greater than the survey means. It is, however, far from clear that the national accounts data are more accurate than the household survey means, or that price adjustments have been adequately made. As frequently emphasized, the quality of national accounts data has been widely criticized in SSA, and there is plenty of literature to suggest that the household survey estimates may be at least as accurate. Concerns about price adjustments within national surveys (see section 2.3.5) and the quality of PPP adjustments (see Chapter 1) have already been discussed. Second, the appropriate standard used to establish the mean would have been private household consumption per capita, not GDP. Third, the massive scale of imputation of the inequality data suggests that a limited amount of real data in fact underlies these poverty calculations.

Turning to the very carefully conducted study by Young (2012), he uses country-level DHS data on ownership of durables, housing quality, child health and nutrition, household demographics and time use as a basis for estimating real consumption. The basic argument is that these indicators, normalized by the cross-country distribution of per capita consumption from Penn World Tables, have improved at a rapid rate in SSA over the period considered. For SSA, these growth rates are relatively fast compared with the growth in per capita consumption in the national accounts. In other world regions, growth in these indicators aligns more closely with consumption growth, raising a question about the African case. Young then uses educational attainment as a proxy for income, and looks at the relationship between 
education and assets. He argues that the source of the discrepancy in the African case is that there has been faster growth in incomes not picked up in the consumption data. Earlier work by Sahn and Stifel $(2000,2003)$ also pointed out that there had been significantly faster growth in assets than in income poverty, though they did not use this to make such strong claims.

However, even if assets and related measures may function as reasonable proxies for consumption at a point in time, they can be deeply problematic in assessing change over time (Harttgen et al. 2013). Assets are stock measures while consumption is a flow variable. Some variables measured as household assets such as drinking water source may be publicly provided and so are not clearly related to private consumption. Preferences for assets may change over time as they become a more accepted part of normal life; and the relative price and/or quality of assets can change sharply over time. Mobile phones are a clear example of these phenomena. Increased availability of assets over time then is highly likely to overestimate growth in consumption. Thus, this does not appear to be a convincing approach to estimating changes in consumption over time.

In both cases, there appear to be significant problems which raise questions about how much confidence can be placed in these results. Furthermore, the case studies in this volume provide little support for these views. In cases where country authors make adjustments or caveats with respect to GDP growth, it is mainly to adjust them downwards rather than upwards. ${ }^{6}$ For most cases, after careful examination of the full range of available information, authors are able to provide a narrative that reconciles observed trends (both monetary and non-monetary). As discussed in section 2.2.2, one set of countries is doing very well. Others are experiencing either short-term or structural difficulties in translating growth into broad-based welfare gains. Others are simply not growing rapidly enough or are mired in conflict/political turmoil. Taken as a group, these narratives generate a much more nuanced picture and do not support the view that there has been a broad-scale and systematic underestimation of the rate of economic growth and welfare improvement on the subcontinent.

In sum, whatever the contribution of these cross-country approaches, they do not obviate the need for the careful case-by-case country analysis which is the approach taken here. The case study approach enables a much more careful and critical assessment of the available data. It enables expert country knowledge which helps judge the credibility of the findings reported by the

\footnotetext{
${ }^{6}$ A possible exception is South Africa where very recent growth performance has been so poor that some well-informed observers speculate that perhaps national accounts give lower weight to some relatively new and relatively well-performing sectors. However, the assertion that growth is perhaps not quite as dismal as the official numbers suggest is a long way from a growth miracle.
} 
data. And importantly it helps to provide explanations, making the findings more convincing, which is critical from a policy point of view.

\subsection{Summing Up and Looking Forward}

Looking across the sixteen African case countries considered, the development process has been, essentially without exception, highly non-linear. The non-linear nature of the process opens the risk that variability, particularly if one pays greater attention to those countries that are making progress compared to those that are regressing, is mistaken for progress. With this risk accounted for, progress in SSA has been markedly better than almost anyone expected ten or fifteen years ago. Relative to previous periods, macroeconomic management has improved significantly, and important gains have been registered in four key areas: (i) overall political stability; (ii) rates of economic growth; (iii) a large array of non-monetary poverty indicators; and (iv) monetary poverty as measured by household consumption.

This listing is purposefully ordered. At one end of the spectrum, Côte d'Ivoire and Madagascar have failed to achieve political stability and concomitantly failed to achieve appreciable gains in any of the other three areas. At the other end of the spectrum, the five countries that have achieved significant monetary poverty reduction (Ethiopia, Ghana, Malawi, Rwanda, and Uganda) have also enjoyed a sufficient degree of political stability, GDP growth, and gains in non-monetary poverty indicators. In the middle of the spectrum, the tendencies are somewhat less clear. Nevertheless, we classify five examples of reasonable political stability, economic growth, and varying non-monetary poverty reduction, combined with limited monetary poverty reduction. Other permutations are much less frequent. ${ }^{7}$

Looking forward, realistic expectations are required. A development process is in place in SSA; however, it is likely to remain difficult and halting. Even the most basic item of the four, political stability, is not guaranteed in any of the sixteen case countries. While political setbacks are to be expected, these should not completely overshadow the gains. Within just the past twelve months, reasonably peaceful transfers of power have occurred in Malawi, Mozambique, Nigeria, and Zambia.

Overall, gradually improving political stability combined with greatly improved macroeconomic management has created a much firmer platform for growth and broad-based improvements in well-being. Taken as a whole,

\footnotetext{
7 And the exceptions tend to reinforce the rules. For example, South Africa achieved progress in many non-monetary indicators despite uninspiring GDP growth due to the broad scope for redistribution in the post-apartheid period.
} 
the case studies do not point to ephemeral factors, such as firm commodity prices, as supporting the African growth renaissance across the board. Changing commodity prices have created economic opportunities for some countries and economic challenges for others. The recent large drop in oil prices and general reductions in food and other commodity prices move countries between the categories of those with opportunities and those with challenges-however, the varied picture remains.

The fairly broad-based success in improving non-monetary indicators also provides some cause for optimism. Higher school attendance, reduced child mortality, better access to health services, improved access to water and sanitation, and reduced rates of childhood malnutrition are desirable in and of themselves. Improvements in these areas provide hopeful signals in two additional ways. First, and as noted, the frequently substantial state role in delivering these improvements implies that these areas act as a rough indicator of governance. Some state capability is required and is in evidence in most cases. Second, these areas, taken as a whole, also amount to investments in a more productive workforce over the long run. With a decade or more of improvement registered in these areas in many countries, these gains should begin manifesting themselves, helping to firm the basic growth platform. In sum, the basic elements of a self-sustaining development process are starting to come into place.

Nevertheless, the African growth renaissance earns two cheers, not three. The fragility of the gains in stability was highlighted in the previous paragraphs. As discussed in Chapter 1, GDP growth in sub-Saharan Africa is much better than it was, but still lags behind other developing regions of the world on a per capita basis. Population growth rates remain stubbornly high in many countries, forcing these societies to run just to stay in place and forsaking the opportunities that a demographic transition might offer. At the same time, many case countries (e.g. Ethiopia, Ghana, and Rwanda) have begun their demographic transition.

Importantly, key countries on the subcontinent are not among the better performers. Kenya, Nigeria, and South Africa are key economies in Eastern, Central/Western, and Southern Africa respectively. They also account for 29 per cent of the population of the subcontinent. In Kenya, monetary poverty measures as of 2005/6 are not much different from those observed in 1994 and 1997 (above the former and below the latter), and, consistent with the presence of some growth and the absence of poverty reduction, inequality appears to have worsened fairly substantially. Gains have been registered in many though not all non-monetary measures. Overall, Kenya has progressed only slowly, or sometimes stagnated, from the relatively favourable position that it occupied among African nations in the first decades after its independence. 
In Nigeria, growth has been present; however, as noted, evidence of poverty reduction, both monetary and non-monetary, is disconcertingly scarce. Living standards in the Northeast, where Boko Haram has created havoc, are particularly low. The stagnation or even deterioration in important nonmonetary welfare indicators occurred despite a fiscal bonanza due to rising/ high oil prices from 2003 to 2014. Having failed to improve living standards under positive fiscal circumstances, Nigeria confronts serious development and security issues with substantially reduced resources due to recent oil price declines. In short, the new government confronts enormous challenges.

South Africa is both failing to grow and encountering limits to redistribution. The growth hiatus, which began in 2008, is now entering its eighth year, while South Africa's long-standing employment problems continue to fester. Rekindling growth is a policy imperative.

While the fortunes of every country on the continent may not be inextricably tied to the fortunes of their respective regional powerhouse, a broadbased African renaissance surely requires better performance from these three. The international community might usefully ponder their role in helping to bring about this highly desirable outcome. The (so far) peaceful transfer of power following elections in Nigeria in March 2015 is a very positive signal both for Nigeria and the subcontinent as a whole. The gradual institutionalization of mechanisms for the peaceful transfer of power is a positive harbinger. The continuation of this trend is also a key policy priority for the continent as a whole for the foreseeable future.

Two other clear policy priorities emerge from case studies on a continentwide basis. Agriculture is the first. We hope that the rhetoric surrounding agriculture in general and smallholder agriculture in particular is followed by action at scale in a growing number of countries. The second area is information. Information should be seen as a vital publicly provided input into an informed polity in general, into policy formation, and into investment decisions by both public and private actors. Doing better on information systems is crucial to achieving broad-based development goals, not just looking back and tallying the score card. ${ }^{8}$

Finally, we reiterate that the development process is, almost always, a long hard slog involving a challenging process of structural transformation. In this regard, much concern centres around the small and stagnant or even

\footnotetext{
${ }^{8}$ For example, the preceding paragraph calls for aggressive and broad-scale efforts to stimulate agriculture, particularly smallholder productivity. As discussed in section 2.3.4, there are risks associated with these policies. Monitoring and evaluation systems are required to identify poorly functioning initiatives and then make adjustments.
} 
shrinking share of manufactures in GDP on the subcontinent. ${ }^{9}$ Substantial growth in manufacturing value-added and employment creation as a consequence of links by African countries to global value chains would be a very positive outcome. Employment creation goes further than this to other sectors as well. Whether in manufacturing or elsewhere, positive outcomes are more likely if the education system generates the necessary human capital; the agricultural sector is sufficiently productive to simultaneously provide relatively inexpensive food and release labour to rapidly growing, highproductivity sectors; infrastructure underpins development in both agricultural and non-agricultural sectors; information systems are decent; and so on. These issues come on top of the more direct policy concerns within manufacturing, such as reliable and reasonably low-cost power delivery, regulatory burdens, tax burdens, and speed of customs clearance.

In sum, to succeed, African governments must be prepared to accomplish multiple tasks simultaneously. Yes, there are capacity constraints within governments, and state capabilities should be carefully directed with these limitations in mind. At the same time, sustainable development processes demand improvements across multiple dimensions essentially contemporaneously. The subcontinent as a whole has done a much better job of confronting these multi-faceted challenges over the past fifteen to twenty years. While the potential pitfalls are many, there is every reason to aim to achieve three cheers and not just two over the next fifteen to twenty years.

\section{References}

AERC (2015). 'Agriculture in Africa's Transformation: The Role of Smallholder Farmers', Declaration from Senior Policy Seminar XVII, Maputo, Mozambique.

Arndt, C., S. Jones, and F. Tarp (2007). 'Aid and Development: The Mozambican Case', in S. Lahiri (ed.), Theory and Practice of Foreign Aid. Amsterdam: Elsevier, 235-88.

Arndt, C., S. Jones, and F. Tarp (2015). 'Assessing Foreign Aid's Long-Run Contribution to Growth and Development', World Development, 69: 6-18.

Arndt, C., K. Pauw, and J. Thurlow (2015). 'The Economy-Wide Impacts and Risks of Malawi's Farm Input Subsidy Program', American Journal of Agricultural Economics, first published online 24 August 2015, doi:10.1093/ajae/aav048.

Arndt, C. and K. Simler (2010). 'Estimating Utility Consistent Poverty Lines', Economic Development and Cultural Change, 58: 449-74.

Baur, R. F. and P. F. Orazem (1994). 'The Rationality and Price Effects of U.S. Department of Agriculture Forecasts of Oranges', Journal of Finance, 49(2): 681-95.

\footnotetext{
9 See a series of WIDER working papers produced under UNU-WIDER's Learning to Compete Programme of research carried out jointly with Brookings and the African Development Bank (<http://www.wider.unu.edu/research/current-programme/en_GB/L2C-2010/>).
} 
Benin, S., J. Thurlow, X. Diao, A. Kebba, and N. Ofwono (2012). 'Uganda', in X. Diao, J. Thurlow, S. Benin, and S. Fan (eds), Strategies and Priorities for African Agriculture: Economywide Perspectives from Country Studies. Washington, DC: International Food Policy Research Institute, 281-316.

Bourguignon, F. (2003). 'The Growth Elasticity of Poverty Reduction: Explaining Heterogeneity across Countries and Time Periods', in T. Eicher and S. Turnovsky (eds), Inequality and Growth: Theory and Policy Implications. Cambridge, MA: MIT Press, 3-27.

Bourguignon, F. (2004). 'The Poverty-Growth-Inequality Triangle', in Poverty, Inequality and Growth: Proceedings of the AFD-EUDN Conference, 2003. Paris: Agence Française de Développement, 69-111. See <http://www.afd.fr/webdav/site/afd/shared/PUBLICA TIONS/RECHERCHE/Archives/Notes-et-documents/10-notes-documents.pdf>, accessed 29 March 2015.

Case, A. (1995). 'Symposium on Consumption Smoothing in Developing Countries', Journal of Economic Perspectives, 9(3): 81-2.

Chen, S. and M. Ravallion (2010). 'The Developing World Is Poorer than We Thought, but No Less Successful in the Fight against Poverty', Quarterly Journal of Economics, 125(4): 1577-1625.

Davies, C. (2009). 'Area Frame Design for Agricultural Surveys', Report number RDD-09xx. Washington, DC: National Agricultural Statistics Service, United States Department of Agriculture.

Davis, K., B. Swanson, D. Amudavi, D. A. Mekonnen, A. Flohrs, J. Riese, C. Lamb, and E. Zerfu (2010). 'In-Depth Assessment of the Public Agricultural Extension System of Ethiopia and Recommendations for Improvement', IFPRI Discussion Paper 1041. Washington, DC: International Food Policy Research Institute.

Dercon, S., J. Hoddinott, and T. Woldehanna (2012). 'Growth and Chronic Poverty: Evidence from Rural Communities in Ethiopia', Journal of Development Studies, 48(2): 238-53.

Easterly, W. (2001). 'The Lost Decades: Developing Countries' Stagnation in Spite of Policy Reform 1980-1998', Journal of Economic Growth, 6(2): 135-57.

Government of Uganda (2012). 'Statistical Abstract 2012'. Kampala: Uganda Bureau of Statistics.

Harttgen, K., S. Klasen, and S. Vollmer (2013). 'An African Growth Miracle? Or: What Do Asset Indices Tell Us about Trends in Economic Performance?' Review of Income and Wealth, 59, Special Issue: S37-S61.

Headey, D. D. (2013). 'The Impact of the Global Food Crisis on Self-Assessed Food Security'. World Bank Economic Review, 27(1): 1-27.

Jayne, T. S. and S. Rashid (2013). 'Input Subsidy Programs in Sub-Saharan Africa: A Synthesis of Recent Evidence', Agricultural Economics, 44(6): 1-16.

Jerven, M. (2014). 'African Growth Miracle or Statistical Tragedy? Interpreting Trends in the Data over the Past Two Decades', WIDER Working Paper 2014/114. Helsinki: UNU-WIDER.

Jerven, M. and D. Johnston (2015). 'Statistical Tragedy in Africa? Evaluating the Data Base for African Economic Development', Journal of Development Studies, 51(2): 111-15. 
Pinkovskiy, M. and X. Sala-i-Martin (2014). 'African is on time', Journal of Economic Growth, 19(3): 311-38.

Ravallion, M. (2003). 'Measuring Aggregate Welfare in Developing Countries: How Well Do National Accounts and Surveys Agree?', Review of Economics and Statistics, 85(3): 645-52.

Sahn, D. and D. Stifel (2000). 'Poverty Comparisons over Time and across Countries in Africa', World Development, 28(12): 2123-55.

Sahn, D. and D. Stifel (2003). 'Urban-Rural Inequality in Africa', Journal of African Economies, 12(4): 564-97.

Sen, A. (1993). 'Capability and Well-Being', in M. C. Nussbaum and A. Sen (eds), The Quality of Life: A Study Prepared for the World Institute for Development Economics Research (WIDER) of the United Nations University. Oxford: Clarendon Press, 30-53.

Swinnen, J. and P. Squicciarini (2012). 'Global Food Supply: Mixed Messages on Prices and Food Security', Science, 335(6067): 405-6.

Tarp, F. (1993). Stabilization and Structural Adjustment: Macroeconomic Frameworks for Analysing the Crisis in Sub-Saharan Africa. London and New York: Routledge.

Tarp, F., K. Simler, C. Matusse, R. Heltberg, and G. Dava (2002). 'The Robustness of Poverty Lines Reconsidered', Economic Development and Cultural Change, 51(1): 77-108.

World Bank (2001). World Development Report 2000/2001: Attacking Poverty. Washington, DC: World Bank.

World Bank (2014). Nigeria Economic Report No. 2, July. Washington, DC: World Bank. Young, A. (2012). 'The African Growth Miracle', Journal of Political Economy, 120(4): 696-739. 



\section{Part 1}

Rapid Growth and Rapid Poverty

Reduction 



\section{3}

\section{Poverty in Ethiopia, 2000-11}

\section{Welfare Improvements in a Changing Economic Landscape}

David Stifel and Tassew Woldehanna

\subsection{Introduction}

Since the turn of the century, the Ethiopian economy has experienced strong economic growth and structural improvements. Rapid infrastructure growth, increased agricultural production and commercialization, better-functioning food markets, and a strong social safety net programme are all part of the changing economic landscape (Dorosh and Schmidt 2010) that is paying dividends in terms of poverty reduction. Yet measuring these dividends in Ethiopia is complicated by conceptual and practical data-related issues. This is not surprising given the complexity of measuring poverty in a manner that is consistent over time and space, yet is also sensitive to local conditions.

The purpose of this chapter is to analyse poverty in Ethiopia between 2000 and 2011, using nationally representative household consumption and expenditure surveys, and applying to those surveys Arndt and Simler's (2010) utility-consistent approach to calculating cost of basic needs (CBN) poverty lines. This method involves calculating region-specific poverty lines based on consumption patterns of the poor in each of the regions to reflect local perceptions of poverty (i.e. specificity). But to ensure that each of the consumption bundles in the region-specific CBN poverty lines also represents the same level of utility (i.e. consistency), a maximum entropy approach is then employed to reconcile cases where revealed preference conditions are violated. These consistent yet specific poverty lines, along with consumption aggregates calculated from the household surveys, form the basis of the poverty analysis in this chapter. 
To disentangle the long-term poverty trends from the short-term shocks that may affect poverty estimates based on nationally representative household surveys in particular years, we place the monetary poverty measures in context by comparing them to other macro- and microeconomic indicators, some of which are collected with more frequency. These indicators suggest that survey-based poverty estimates for Ethiopia are largely a reflection of long-term trends characterized by broad-based growth and improved welfare. While comparability issues related to the main data sources used in this analysis warrant care in interpreting the degree to which poverty fell, the overall body of evidence paints a picture of substantive improvements in living standards over the course of the first decade of the twenty-first century in Ethiopia.

The structure of this chapter is as follows. In section 3.2, we describe the primary data sources and discuss the poverty lines estimated from these data. Section 3.3 provides a description of the economic context during which the surveys took place to better understand the long-term trends. In section 3.4, we present the estimates of poverty and inequality based on the utilityconsistent approach to calculating poverty lines, and triangulate these results with other monetary and non-monetary indicators. Section 3.5 provides concluding remarks.

\subsection{Data and Poverty Lines}

In this section, we briefly describe the primary data sources and the regional poverty lines that are consistent over time and space, and which are specific to local consumption patterns and norms.

\subsubsection{Data}

The primary data sources used in this analysis are the 1999/2000 (hereafter 2000), 2004/2005 (hereafter 2005), and 2010/2011 (hereafter 2011) Ethiopia Household Income, Consumption and Expenditure Surveys (HICES) and Welfare Monitoring Surveys (WMS). The WMS and HICES, conducted by the Central Statistical Agency (CSA), are nationally representative stratified and clustered surveys that contain information on household characteristics, expenditure, activities, and infrastructure. The WMS were conducted mainly to assess non-income dimensions of poverty, whereas the main objective of the HICES was to provide data on levels, distributions, and patterns of household income, consumption, and expenditure. In each of the three years, the HICES interviewed a representative subset of the households that were interviewed in the WMS. 
The HICES are used to construct the household consumption aggregates for the analysis of monetary poverty. As such, it is important to be aware of comparability issues related to them. Coverage of the three surveys is similar (major urban areas, rural regions, and other urban areas), and although the sample sizes grew from 17,332 to 21,274 to 27,830 , for the 2000, 2005, and 2011 surveys, respectively, this is unlikely to affect the comparability of the welfare measures over time. There are, however, other differences in the data collection method that may be problematic. First, although the questionnaires are nearly identical, the item codes used for the expenditure/consumption recall differed for each of the three years. For example, the numbers of food codes used in the data collection process were 252, 872, and 653 in the 2000, 2005, and 2011 surveys, respectively. Evidence that more detailed lists of commodity items are associated with higher levels of reported consumption from household surveys (Pradhan 2000) warrants care in interpreting changes in poverty given that the household consumption aggregates may not be entirely comparable.

Second, the change in the data collection period complicates comparability due to issues of seasonality and inflation. The 2000 and 2005 surveys were conducted in two relatively short and similarly timed rounds (July-August and January-February) during low inflation periods, whereas the 2011 survey was conducted over the course of a year (8 July 2010 to 7 July 2011) that was characterized by inflation of over 30 per cent. ${ }^{1}$ Although we do temporally deflate the food consumption aggregate quarterly for the 2011 data using price indices calculated from unit prices in the data to address inflation, ${ }^{2}$ even within-quarter inflation may be problematic due to the high rate at which prices rose. Further, it is difficult to gauge the consequences that seasonal variation in consumption patterns may have on the comparability of the 2011 consumption aggregate relative to the aggregates from the earlier surveys. As a form of sensitivity analysis, we estimated poverty lines on the subset of the sample of households in the 2011 survey who were interviewed in the same quarters as those in the 2000 and 2005 surveys. Although the poverty estimates from this subsample do not differ substantively from those of the full sample, we remain cautious about interpreting the magnitudes of the changes in poverty between these surveys.

\subsubsection{Regional Cost of Basic Needs Poverty Lines}

The utility-consistent regional poverty lines estimated from the HICES (Table 3.1) show that between 2000 and 2011, the costs of basic needs rose

\footnotetext{
1 Headey et al. (2012) document a rapid rise in urban food prices for the poor during the 2011 survey period that outpaced the growth of urban nominal wages.

2 See Arndt and Simler (2010) for more details.
} 
Table 3.1. Regional poverty lines, Ethiopia 2000-11

\begin{tabular}{|c|c|c|c|c|c|c|}
\hline \multicolumn{7}{|c|}{ Birr per person per day } \\
\hline & \multicolumn{3}{|c|}{ Urban } & \multicolumn{3}{|c|}{ Rural } \\
\hline & 2000 & 2005 & 2011 & 2000 & 2005 & 2011 \\
\hline Addis Ababa & 3.22 & 2.27 & 8.86 & & & \\
\hline Afar & 3.27 & 2.68 & 8.00 & 3.07 & 3.09 & 8.89 \\
\hline Amhara & 2.78 & 3.31 & 8.52 & 2.52 & 3.84 & 7.77 \\
\hline Benishangul & 2.83 & 3.99 & 7.41 & 2.66 & 4.54 & 6.77 \\
\hline Dire Dawa & 3.42 & 2.69 & 9.19 & 3.58 & 4.07 & 8.68 \\
\hline Gambella & 2.80 & & 7.22 & 2.79 & & 7.76 \\
\hline Harari & 3.48 & 2.87 & 9.10 & 3.48 & 2.87 & 9.10 \\
\hline Oromiya & 2.43 & 3.20 & 8.00 & 2.26 & 3.94 & 7.52 \\
\hline SNNP & 2.62 & 3.31 & 6.93 & 2.36 & 3.73 & 5.57 \\
\hline Somali & 3.43 & 2.83 & 8.69 & 2.90 & 3.05 & 8.31 \\
\hline Tigray & 3.10 & 2.94 & 8.86 & 2.84 & 3.44 & 9.17 \\
\hline
\end{tabular}

Source: Authors' calculations from HICES (2000, 2005, 2011)

by over 130 per cent (an average of 9.0 per cent per year). Most of this increase, however, occurred between 2005 and 2011 as costs actually fell between 2000 and 2005 in many regions (most markedly in Addis Ababa where basic needs costs were 30 per cent lower in 2005 than in 2000). In some regions, such as Oromiya and rural Tigray, the cost of living for the poor rose even further over the decade (230 per cent). Throughout the survey periods, the changes in prices for both food and non-food items contributed to overall changes in costs of basic needs, though non-food costs rose slightly faster than food costs between 2005 and 2011. The poverty lines in Table 3.1 also illustrated substantial variation in costs of basic needs. For example, in 2000 the rural Oromiya poverty line was 30 per cent below the Addis Ababa poverty line, while the rural Dire Dawa poverty line was 11 per cent higher than in Addis Ababa. These different poverty lines and the differential changes in these poverty lines lend credence to the need for specificity in constructing poverty lines.

\subsection{Context}

During the 2000-11 period, Ethiopia witnessed persistent weather shocks, high rates of inflation in the latter half of the decade, and a post-election crisis in 2005. Nonetheless, this period is predominantly characterized by what Dorosh and Schmidt (2010) refer to as 'Ethiopia's changing economic landscape'. In short, fundamental structural changes took place in the economy led by the Ethiopian government's deliberate strategy of Agricultural Development-Led Industrialization (ADLI). In an effort to facilitate 'rapid agricultural growth as a means of accelerating economic transformation and 
reducing poverty' (MoFED 2008), the government invested substantial resources towards increasing agricultural productivity through the use of modern inputs, and towards developing growth linkages with the rest of the economy through improved roads and other types of infrastructure.

Although increases in agricultural production over the last decade appear to be driven largely by the expansion of cultivated land (Dercon and Hill 2009; Seyoum Taffesse et al. 2013), and overall use of modern agricultural inputs remains low, changes did take place that likely resulted in productivity gains. For example, the Ethiopian government expanded the agricultural extension system to such a degree that by 2010, some 45,000 extension agents were placed in villages. With roughly three extension agents available per kebele (ward), Ethiopia now has one of the highest extension agent per farmer ratios in the world (Davis et al. 2010). Further, there is evidence that the use of modern inputs that are distributed through government-established cooperatives increased over the course of the decade. The gains in modern cereal seed use were largely confined to maize (Spielman et al. 2011), though more improved teff (cereal) seeds were also being rapidly adopted by the end of the decade (Minten etal. 2012). Finally, chemical fertilizer use grew to about 650,000 tons in 2012, as the amount of fertilized land dedicated to cereal production more than doubled over the course of the decade (Rashid et al. 2013).

Improving the physical infrastructure has been a central component of the Ethiopian government's development strategy. In 1997, the government embarked on a large road investment programme (the Road Sector Development Program), with a resulting impressive increase in spatial connectivity. By 2011, all-weather surfaced roads connected most of the capitals of the regions, as the length of these roads more than doubled in the fifteen years between 1993 and 2008, from an estimated 19,000 km to 44,300 km, respectively. As a consequence, in 2007 only 12 per cent of the total population were more than ten hours away from a city compared to 31 per cent in 1997, and 38 per cent were over five hours away in 2007 compared to 82 per cent in 1997 (Schmidt and Kedir 2009). Minten et al. (2012) find that this type of road development had important effects on the spatial integration of agricultural markets in the country, as travel times between different wholesale markets in the country and the Addis wholesale market fell on average by 20 per cent over the last decade, from ten hours to eight hours, and transportation costs fell by 50 per cent.

Infrastructure investments were not limited to roads, however. Public resources that poured into the construction of hydroelectric dams prior to 2000 began to pay off in the latter half of the decade. The increase in total generating capacity from 477 megawatts (7 watts per person) at the turn of the century to 1917 megawatts (21 watts per person) by the end of the decade 
(Dorosh and Schmidt 2010) laid the foundation for significant increases in productivity and output (see, for example, Ayele et al. 2009). Further, communication infrastructure reached a larger segment of the population as fixed telephone lines more than doubled from 405,000 in 2003, and as mobile subscriptions rose exponentially from 50,000 in 2003 to over 10 million in 2011 (Dorosh and Schmidt 2010; Telegraphy 2012). Minten et al. (2012) find that the increased access to telecommunications played an important role in reducing marketing margins in the improved food marketing system.

Finally, in 2005, the Ethiopian government and a consortium of donors began implementation of the Productive Safety Nets Programme (PSNP) in response to chronic food insecurity in rural Ethiopia. With the objective of providing 'transfers to the food-insecure population in chronically foodinsecure woredas (districts) in a way that prevents asset depletion at the household level and creates assets at the community level' (Government of Ethiopia 2004), the PSNP targets food-insecure rural households and provides them compensation for their labour on labour-intensive projects designed to build community assets. For labour-scarce households, direct support is provided in the form of cash or food transfers, though this accounts for less than 5 per cent of total transfers. The programme is well targeted (Coll-Black et al. 2011) and participants with access to both the PSNP and packages of agricultural support provided through the Other Food Security Program are more likely to be foodsecure (Gilligan et al. 2009), have shorter hungry seasons, and own more livestock (Berhane et al. 2014). Programmes such as the PSNP appear to have helped reduce food insecurity, and hence poverty, in rural areas since 2005.

\subsection{Poverty and Inequality in the 2000s}

It is in this context of steady structural changes in the economic landscape of Ethiopia that we analyse snapshots of poverty and inequality in Ethiopia from 2000 to 2011. The general story that emerges from the data is one of steady but uneven progress, with urban areas witnessing the greatest gains in the first half of the decade, and rural areas benefitting more in the latter half. Moreover, while slightly more muted, other monetary and non-monetary measures of well-being confirm the general pattern of persistent improvements.

\subsubsection{Monetary Poverty and Inequality}

Poverty rates in Ethiopia at the turn of the century were high, but fell substantially by 2011 (Table 3.2). In 2000, 46.8 per cent of the population was poor, compared to 23.8 per cent in 2011. Most of the decline, however, occurred between 2005 and 2011 as the poverty rate fell by just under one 
Table 3.2. Monetary poverty in Ethiopia, 2000-11

\begin{tabular}{|c|c|c|c|c|c|c|}
\hline & \multicolumn{3}{|c|}{ Levels } & \multicolumn{3}{|c|}{ Changes } \\
\hline & 2000 & 2005 & 2011 & $2000-5$ & 2005-11 & $2000-11$ \\
\hline \multicolumn{7}{|l|}{ National } \\
\hline $\begin{array}{l}\text { Headcount ratio }\left(P_{0}\right) \\
\text { Depth of poverty }\left(P_{1}\right) \\
\text { Severity of poverty }\left(P_{2}\right) \\
\text { Urban }\end{array}$ & $\begin{array}{r}46.8 \\
12.6 \\
4.8\end{array}$ & $\begin{array}{r}46.0 \\
12.3 \\
4.5\end{array}$ & $\begin{array}{r}23.8 \\
6.3 \\
2.4\end{array}$ & $\begin{array}{l}-0.7 \\
-0.3 \\
-0.3\end{array}$ & $\begin{array}{r}-22.3 \\
-6.0 \\
-2.0\end{array}$ & $\begin{array}{r}-23.0 \\
-6.3 \\
-2.3\end{array}$ \\
\hline $\begin{array}{l}\text { Headcount ratio }\left(P_{0}\right) \\
\text { Depth of poverty }\left(P_{1}\right) \\
\text { Severity of poverty }\left(P_{2}\right)\end{array}$ & $\begin{array}{r}39.0 \\
10.8 \\
4.1\end{array}$ & $\begin{array}{r}22.7 \\
4.7 \\
1.5\end{array}$ & $\begin{array}{r}13.3 \\
3.2 \\
1.3\end{array}$ & $\begin{array}{r}-16.3 \\
-6.1 \\
-2.6\end{array}$ & $\begin{array}{l}-9.4 \\
-1.5 \\
-0.3\end{array}$ & $\begin{array}{r}-25.6 \\
-7.6 \\
-2.9\end{array}$ \\
\hline \multicolumn{7}{|l|}{ Rural } \\
\hline $\begin{array}{l}\text { Headcount ratio }\left(P_{0}\right) \\
\text { Depth of poverty }\left(P_{1}\right) \\
\text { Severity of poverty }\left(P_{2}\right)\end{array}$ & $\begin{array}{r}48.0 \\
12.9 \\
4.9\end{array}$ & $\begin{array}{r}50.0 \\
13.5 \\
5.0\end{array}$ & $\begin{array}{r}25.9 \\
6.9 \\
2.7\end{array}$ & $\begin{array}{l}2.0 \\
0.7 \\
0.1\end{array}$ & $\begin{array}{r}-24.1 \\
-6.6 \\
-2.3\end{array}$ & $\begin{array}{r}-22.2 \\
-5.9 \\
-2.2\end{array}$ \\
\hline
\end{tabular}

Note: Poverty measures are multiplied by 100.

Source: Authors' calculations from HICES $(2000,2005,2011)$

percentage point between 2000 and 2005. Poverty is largely a rural phenomenon, with 48.0 per cent of the rural population below the poverty line in 2000 , compared to 39.0 per cent in urban areas. Although the rural headcount ratio fell by a remarkable 25.6 percentage points, urban areas as a whole saw even greater declines in poverty, as the urban poverty rate fell to under 14 per cent by 2011. Most of the decline in urban poverty took place in the first half of the decade, falling by just over sixteen percentage points. Conversely, rural poverty rose marginally during this period, with all of the gains occurring after 2005.

The more distribution-sensitive measures of poverty (depth and severity) are generally consistent with the trends in the headcount ratios, though the magnitude of the declines in the severity of poverty are not as large. The poverty incidence curves shown in Figure 3.1 illustrate this graphically, as the poorest of the poor were no better off in 2011, or in 2005, than they were in 2000. As for the other 95 percent of the population, although there was virtually no difference in the distributions of real per capita household consumption levels (temporally and spatially deflated by the poverty lines to convert all values to 2011 Addis Ababa values) between 2000 and 2005 (the thick solid line overlapping the thin solid line), they rose substantially between 2005 and 2011 (the thick dashed line substantially below the other lines). In short, while the well-being of most of the Ethiopian population improved significantly, extremely poor households were not as fortunate. ${ }^{3}$

\footnotetext{
3 The overlapping of the 2005 and 2011 distributions indicates that tests of first-order dominance are rejected. Further, because the overlap is at the lower end of the household consumption distribution, this also results in rejection of tests of second- and third-order dominance (see Appendix Figures 3.A1 and 3.A2).
} 


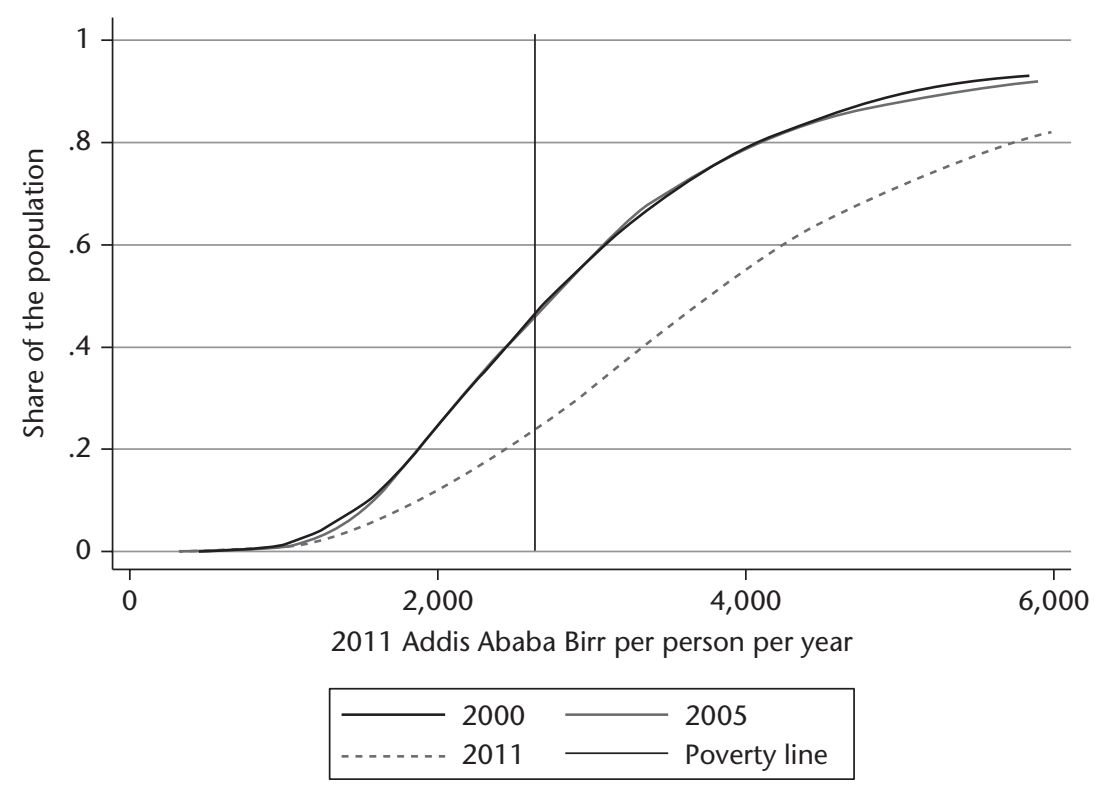

Figure 3.1. Poverty incidence curves, Ethiopia 2000-11

Source: Authors' calculations from HICES $(2000,2005,2011)$

The dramatic fall in urban poverty between 2000 and 2005 is clearly illustrated in Figure 3.2a by the across-the-board increase in real household consumption levels (the thick line below the thin line at all consumption levels). The vertical gap between the poverty incidence curves for these two years indicates that the sixteen percentage point decrease in the poverty rate shown in Table 3.2 is not sensitive to the real poverty line. A whole host of possible poverty lines, ranging from less than 2,000 Birr (2011 Addis Ababa prices) per person per year to over 6,000 Birr, would result in estimates of similar magnitudes. ${ }^{4}$ This is not the case for the $2005-11$ period, however. During this period, most of the urban population also experienced increased real consumption levels, but the gains were not as large (9.4 percentage point decrease in poverty), nor were they distributed as uniformly. In fact, the poorest 10 per cent of the urban population experienced no real change in their consumption levels, despite nominal incomes rising.

Figure $3.2 \mathrm{~b}$ shows that all of the improvements in rural well-being occurred between 2005 and 2011. Although consumption levels fell rather uniformly

4 2,000 Birr is equivalent to US\$117.6 and 6,000 Birr is equivalent to US\$352.9 at the 2011 average exchange rate (17 Birr/US\$). 
a. urban

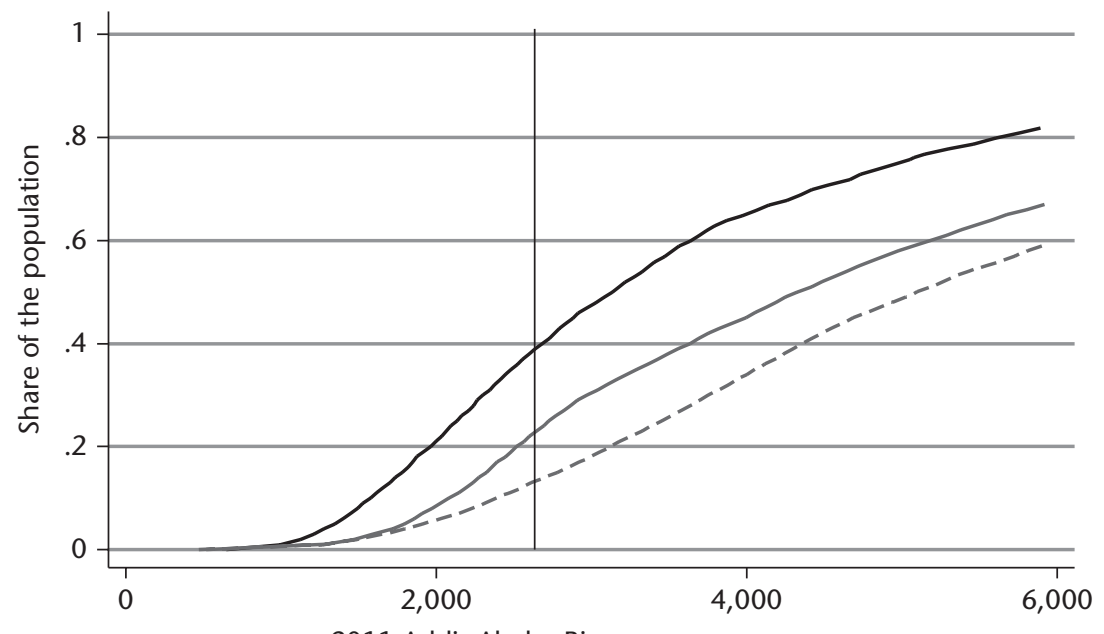

2011 Addis Ababa Birr per person per year

\begin{tabular}{|ll|}
\hline 2000 & 2005 \\
-----2011 & Poverty line \\
\hline
\end{tabular}

b. rural

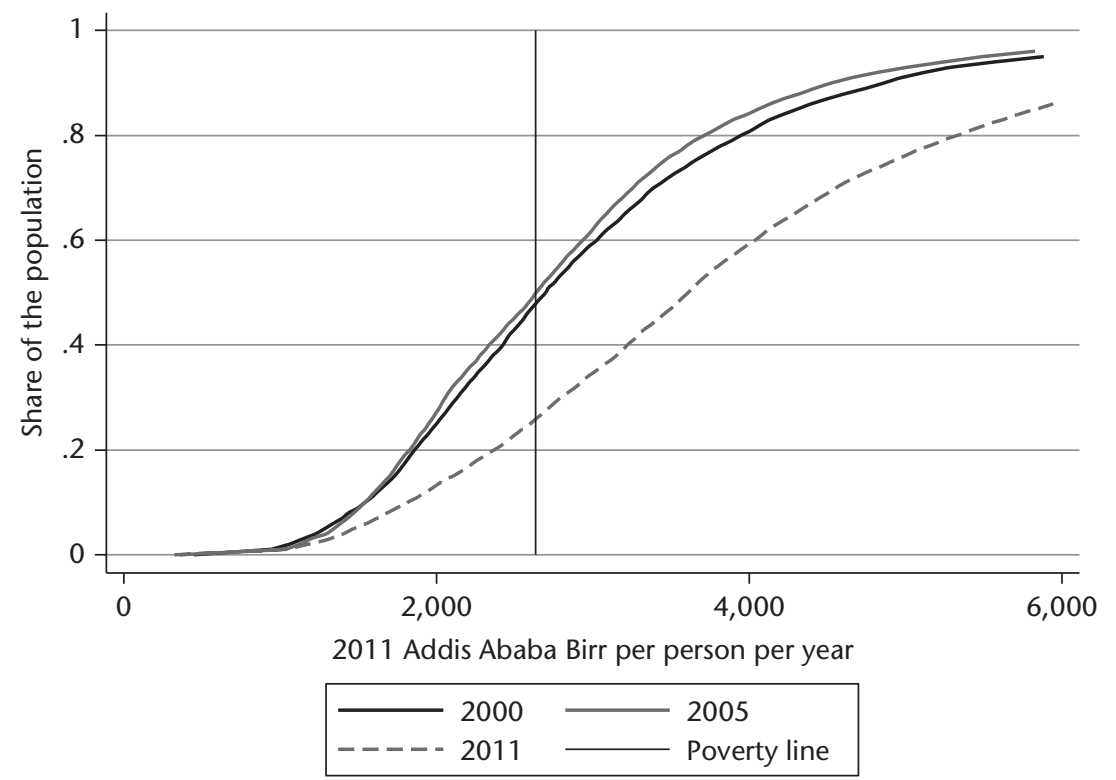

Figure 3.2. Poverty incidence curves, Ethiopia 2000-11

Source: Authors' calculations from HICES $(2000,2005,2011)$ 
between 2000 and 2005 (the thick line almost everywhere above the thin line), the declines were moderate, with at most a five percentage point increase in headcount ratios, depending on the value of the poverty line chosen. The positive and large shift in the 2011 poverty incidence curve to the right for the top 95 per cent of the rural population illustrates the twenty-two percentage point decrease in rural poverty along with the six point decrease in the depth of poverty (Table 3.2). The smaller two point reduction in the severity of poverty follows from the poorest 5 per cent of the rural population being no better off in 2011 than in 2000 or 2005.

Further disaggregation of poverty by region reveals some interesting messages (Table 3.3). First, in 2000, urban poverty rates in all of the regions were lower than the poverty rates in all of the rural areas, except for rural Oromiya and Amhara. The headcount ratio in rural Oromiya (37.9 per cent) was in fact lower than all urban areas other than Addis Ababa (34.6 per cent), Oromiya (35.1 per cent), and Benishangul-Gumuz (36.6 per cent). That rural Amhara has marginally less poverty (52.6 per cent) compared to urban Somali (52.7 per cent) is more of a reflection of the high rate of poverty in the latter, than of the low poverty in the former.

Table 3.3. Regional poverty in Ethiopia, 2000-11

\begin{tabular}{|c|c|c|c|c|c|c|}
\hline & \multicolumn{3}{|c|}{ Percent poor } & \multicolumn{3}{|c|}{ Changes } \\
\hline & 2000 & 2005 & 2011 & $2000-5$ & 2005-11 & 2000-11 \\
\hline Addis Ababa & 34.6 & 10.9 & 10.7 & -23.7 & -0.3 & -24.0 \\
\hline Afar (rural) & 79.6 & 39.1 & 42.7 & -40.5 & 3.6 & -36.9 \\
\hline Afar (urban) & 39.7 & 12.4 & 15.2 & -27.3 & 2.8 & -24.5 \\
\hline Amhara (rural) & 52.6 & 51.2 & 33.2 & -1.4 & -18.0 & -19.5 \\
\hline Amhara (urban) & 38.9 & 31.1 & 14.8 & -7.8 & -16.3 & -24.1 \\
\hline Benishangul (rural) & 63.1 & 57.5 & 21.3 & -5.6 & -36.2 & -41.8 \\
\hline Benishangul (urban) & 36.6 & 32.8 & 13.7 & -3.9 & -19.1 & -22.9 \\
\hline Dire Dawa (rural) & 70.7 & 66.2 & 14.7 & -4.5 & -51.5 & -56.0 \\
\hline Dire Dawa (urban) & 44.2 & 16.6 & 22.2 & -27.6 & 5.5 & -22.1 \\
\hline Gambella (rural) & 63.7 & & 19.7 & & & -44.0 \\
\hline Gambella (urban) & 38.7 & & 24.1 & & & -14.7 \\
\hline Harari & 41.9 & 17.7 & 7.5 & -24.2 & -10.3 & -34.4 \\
\hline Oromiya (rural) & 37.9 & 47.4 & 25.1 & 9.5 & -22.3 & -12.7 \\
\hline Oromiya (urban) & 35.1 & 23.3 & 15.9 & -11.7 & -7.4 & -19.2 \\
\hline SNNP (rural) & 53.4 & 52.2 & 15.1 & -1.2 & -37.1 & -38.3 \\
\hline SNNP (urban) & 40.9 & 35.6 & 8.8 & -5.4 & -26.8 & -32.2 \\
\hline Somali (rural) & 59.2 & 40.8 & 33.8 & -18.4 & -7.0 & -25.4 \\
\hline Somali (urban) & 52.7 & 21.3 & 14.6 & -31.4 & -6.7 & -38.1 \\
\hline Tigray (rural) & 63.0 & 53.6 & 39.3 & -9.4 & -14.3 & -23.7 \\
\hline Tigray (urban) & 60.2 & 24.8 & 12.3 & -35.4 & -12.5 & -47.9 \\
\hline Urban & 39.0 & 22.7 & 13.3 & -16.3 & -9.4 & -25.6 \\
\hline Rural & 48.0 & 50.0 & 25.9 & 2.0 & -24.1 & -22.2 \\
\hline National & 46.8 & 46.0 & 23.8 & -0.7 & -22.3 & -23.0 \\
\hline
\end{tabular}

Source: Authors' calculations from HICES $(2000,2005,2011)$ 
Second, in 2000, the poverty rates were lowest in Addis Ababa, ${ }^{5}$ which is not surprising given that it is the national capital as well as the commercial hub of the country. The poorest regions, with more than twice as much poverty as the least poor, are located in the rural areas of Dire Dawa and Afar. The former, situated in drought-prone lowlands inhabited by pastoralist Somali tribes, and the latter, situated in lowland pastoralist areas, are both repeatedly affected by droughts and periodic tribal conflicts.

Third, although poverty fell in all of the regions between 2000 and 2011, the changes in poverty were not uniform, nor were they necessarily consistent with the observed changes at the more aggregated urban and rural levels. For example, while urban areas generally exhibited greater declines in poverty between 2000 and 2005 than did most rural areas, the rural areas in Afar experienced the greatest decline in poverty among all of the regions as a result of 2000 being a particularly bad year and 2005 being a good year there. Further urban poverty in Benishangul-Gumuz declined only moderately during this period, but fell substantially in the latter half of the decade. Finally, some regions did remarkably better than others in terms of poverty reduction. For example, poverty rates in rural Dire Dawa and urban Tigray fell by forty-eight percentage points or more over the course of the decade, while poverty rates in urban Gambella and rural Oromiya fell by less than fifteen percentage points-which is still quite good. As a consequence of these differential experiences, rural Afar continues to have the highest level of poverty, while Addis Ababa no longer has the lowest.

Clearly, the differing poverty rates indicate that not all regions in Ethiopia are equal. We now turn to how the differing consumption levels for different regions translate into overall inequality of household consumption in the country as well as in urban and rural areas. The first thing to note is that the degree of inequality in Ethiopia is in the low range for African countries (World Bank 2011), as the Gini coefficient was 0.29 in 2000 (Table 3.4). Second, inequality rose over the course of the decade as indicated by the Gini coefficient increasing from 0.29 in 2000 to 0.32 in 2011, and the Theil index rising from 0.16 to 0.21 . This is not surprising, given the observation in Figure 3.1 that the poorest 5 per cent of the population did not fare as well as the rest.

The degree of inequality in urban areas was considerably higher than in rural areas throughout the decade. Further urban inequality initially rose between 2000 and 2005, and fell back to nearly the same level in 2011 as in 2000. While the Gini coefficients from 2000 and 2011 are both roughly 0.38 ,

\footnotetext{
5 Because all areas in Addis Ababa were categorized as urban in the 2011 survey, no distinction is made between urban and rural areas for Addis Ababa for all three survey years.
} 
Table 3.4. Inequality in Ethiopia, 2000-11

\begin{tabular}{lccc}
\hline & 2000 & 2005 & 2011 \\
\hline Gini coefficient & & & \\
$\quad$ National & 0.289 & 0.326 & 0.321 \\
$\quad$ Urban & 0.384 & 0.438 & 0.387 \\
$\quad$ Rural & 0.263 & 0.254 & 0.282 \\
Theil Index & & & \\
$\quad$ National & 0.158 & 0.259 & 0.208 \\
$\quad$ Urban & 0.279 & 0.460 & 0.317 \\
$\quad$ Rural & 0.122 & 0.117 & 0.141 \\
Percentage due to ... & & & \\
$\quad$ Within-group inequality & 95.1 & 80.2 & 88.9 \\
$\quad$ Between-group inequality & 4.9 & 18.8 & 11.1 \\
\hline
\end{tabular}

Source: Authors' calculations from HICES $(2000,2005,2011)$

the Theil index for 2011 (0.32) is slightly larger than for 2000 (0.28). Conversely, rural inequality fell slightly by 2005, before rising in 2011 .

Despite urban consumption levels being roughly 50 per cent higher on average than in rural areas in 2000, 95 per cent of total inequality in 2000 was due to within-group inequality (Table 3.4). This follows largely from the rural population accounting for over 85 per cent of the national population. As with poverty, rural inequality largely drives national inequality. Nonetheless, the more rapid growth experiences in urban areas as a whole compared to rural areas contributed to the overall rise in national inequality. This is illustrated by the contribution of between-group inequality to overall inequality rising from 4.9 per cent in 2000 to 11.1 per cent in 2011.

\subsubsection{Poverty, GDP, and Inflation}

National poverty rates in 2000, 2005, and 2011 are consistent with trends in real per capita GDP over the decade, suggesting that at the more aggregated levels, the declines in poverty capture long-term growth trends in Ethiopia rather than short-term shocks. As illustrated in Table 3.5, growth of real GDP per capita in the first half of the decade was punctuated by periods of droughtinduced negative growth in 2002 and 2003. As such, despite otherwise respectable growth rates in other years, per capita GDP was only 18 per cent higher in 2005 than in 2000. By the end of the decade, however, overall growth remained high, as per capita income increased by 50 per cent over the 2005 level. This shadows the poverty rates that fell by 7.5 percentage points between 2000 and 2005, and even further by 14.5 percentage points between 2005 and 2011.

A sectoral breakdown in GDP is instructive vis-à-vis the differential impact of the sources of growth. First, with the exceptions of 2001 and 2002, the real 


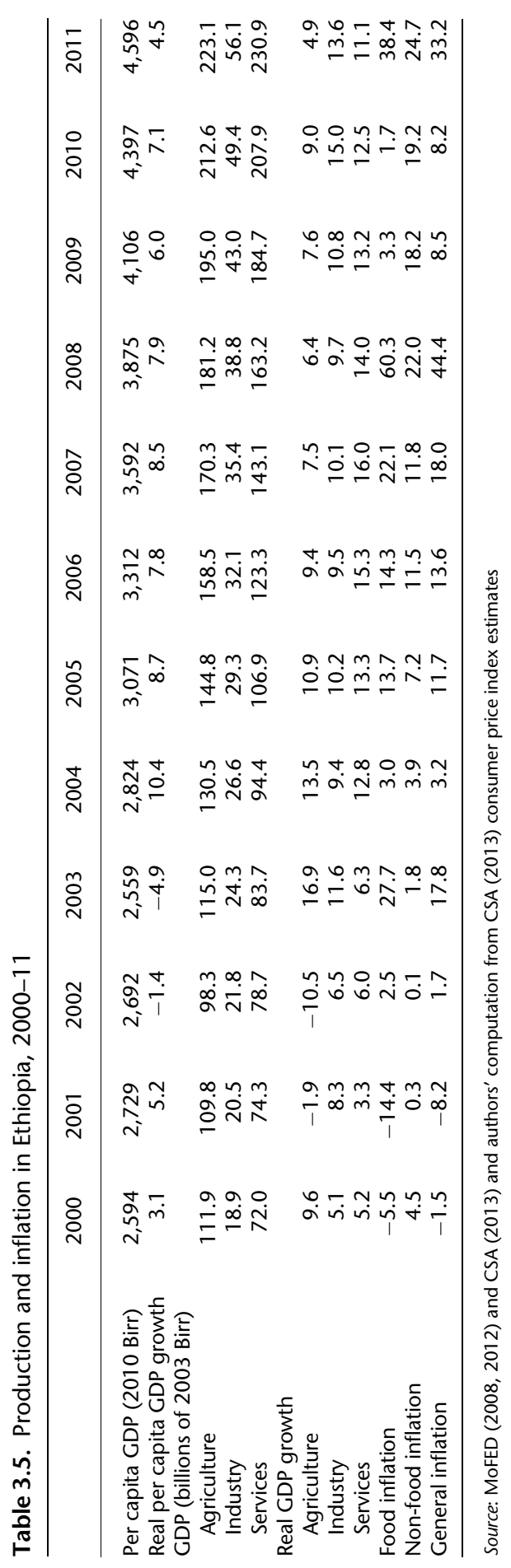




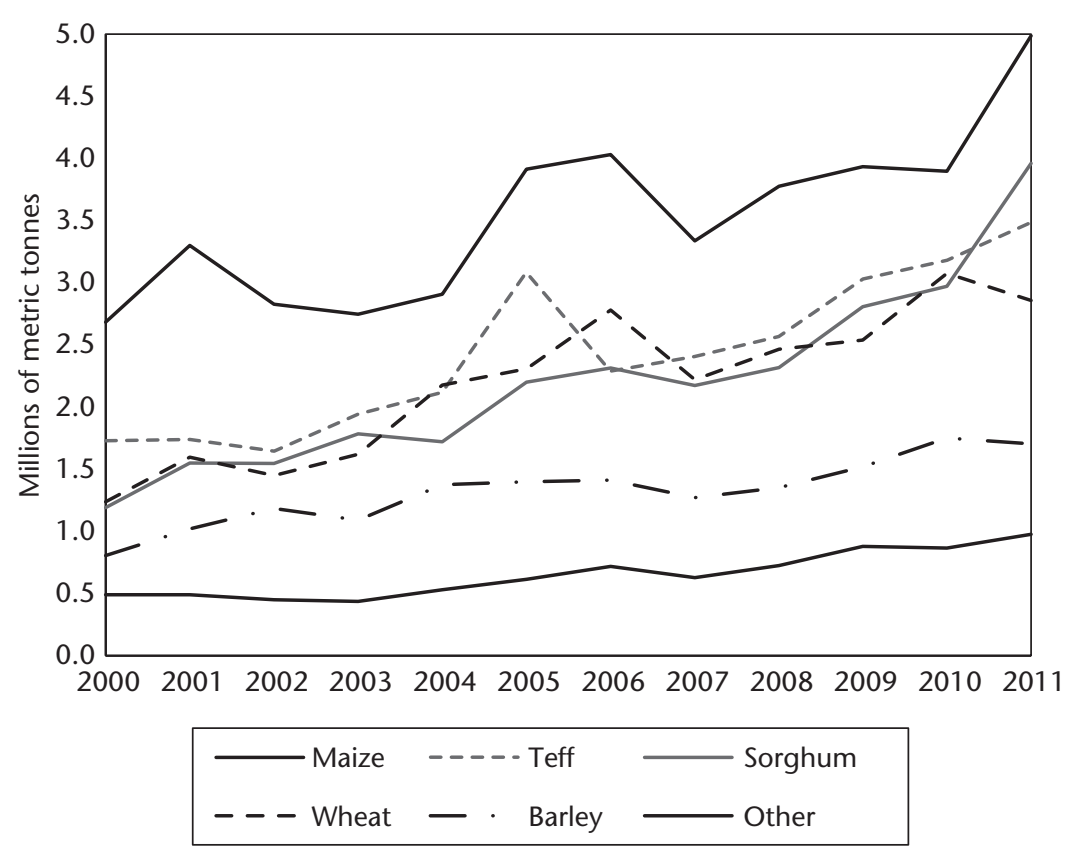

Figure 3.3. Cereal production, Ethiopia 2000-11

Source: MoFED $(2008,2012)$

value of agricultural production in Ethiopia grew by roughly 9 per cent per year on average. Given the dominance of agriculture in the livelihoods of rural dwellers, the doubling of real agricultural GDP between 2000 and 2011 (Table 3.5) was an important driver of rural poverty reduction. Much of this growth was driven by increases in the production of cereals, which account for three-quarters of the cultivated area (Dorosh and Schmidt 2010). As illustrated in Figure 3.3, production of all major cereal crops grew steadily over the course of the decade. In the 1990s, despite stagnating yields, increases in areas cultivated drove increases in cereal production. In the 2000s, however, yields grew by 3.5 per cent per year and contributed to the 7 per cent annual growth in cereal production during this time period (Dorosh and Schmidt 2010). This type of growth was a key objective of the government's ADLI strategy.

Although the population remains largely rural, with some 80 per cent employed in agriculture, the service sector grew so much over the decade (12 per cent per year on average) that by 2011 it accounted for a greater share of GDP than agriculture. With financial services, real estate, and wholesale and retail trade leading the way, especially between 2005 and 2011 (MoFED 2012), urban dwellers are the most likely beneficiaries. Further, given that much of the growth in the service sector occurred in the latter half of the decade (average annual growth of 13.6 per cent compared to 7.8 per cent in the first 
half), the performance of this sector is consistent with the greater decrease in urban poverty observed during this period. Finally, industrial production more than doubled over the decade, but it started from such a low base that it accounted for only 10 per cent of GDP by 2011.

Inflation and price volatility are problems that faced Ethiopian households during this period, and created challenges for accurately measuring poverty. While non-food inflation was low between 2000 and 2005, it rose steadily over the latter half of the decade, reaching as high as 25 per cent in 2011. However, the major source of uncertainty for poor households, who spend more than half of their incomes on food, was related to food prices. During the period between 2000 and 2011, food prices were volatile ${ }^{6}$ and at times rose substantially. Following annual average declines in the beginning of the decade, food prices swung upward and food price inflation reached peaks of 28 per cent in 2003, 60 per cent in 2008, and 38 per cent in 2011. As such, it is surprising that poverty fell to the degree shown in Table 3.2. This is especially the case for urban areas where poor households are primarily net buyers of food. In rural areas as well, inflation may have negatively affected the poor, as the detrimental effect of food price inflation tends to dominate the effect of rising producer prices given that the poor are generally net food buyers (Ticci 2011).

In terms of accurately measuring poverty, the high rate of inflation (33 per cent for general inflation and 38 per cent for food inflation) during the yearlong data collection for the 2011 HICES may have contributed to overly inflated consumption aggregates for households surveyed later in the year compared to those surveyed earlier. Although we did deflate the food consumption component of the household consumption aggregate by a quarter during the data collection period, we warn that the poverty estimates for this year may be too low due to intra-quarter inflation and non-food inflation, and that the magnitude of the fall in poverty may be smaller than that reported in Table 3.2.

\subsubsection{HICES Poverty and Other Data Sources on Monetary Poverty}

Although the HICES are the only nationally representative surveys for which monetary poverty in Ethiopia can be assessed, there are other smaller surveys that can be used to describe poverty in specific localities. One example is the Ethiopian Rural Household Survey (ERHS) conducted by the Department of

\footnotetext{
${ }^{6}$ Bellemare et al. (2013) also document the seasonal volatility of food prices and find that households in select rural communities are willing to pay 6-32 per cent of their income to eliminate price volatility, though the welfare gains from price stability accrue disproportionately to the non-poor.
} 
Table 3.6. Poverty in select rural communities in Ethiopia, 1994-2009

\begin{tabular}{ccccc}
\hline & $\begin{array}{l}\text { Median consumption } \\
\text { per capita }\end{array}$ & $\begin{array}{l}\text { Headcount } \\
\text { ratio }\left(\mathrm{P}_{0}\right)\end{array}$ & $\begin{array}{l}\text { Depth of } \\
\text { poverty }\left(\mathrm{P}_{1}\right)\end{array}$ & $\begin{array}{l}\text { Severity of } \\
\text { poverty }\left(\mathrm{P}_{2}\right)\end{array}$ \\
\hline 1994 & 51.9 & 0.48 & 0.21 & 0.12 \\
1995 & 45.3 & 0.55 & 0.24 & 0.14 \\
1997 & 70.1 & 0.33 & 0.12 & 0.06 \\
1999 & 64.3 & 0.36 & 0.13 & 0.06 \\
2004 & 65.7 & 0.35 & 0.13 & 0.06 \\
2009 & 48.6 & 0.52 & 0.20 & 0.11 \\
\hline
\end{tabular}

Source: Dercon et al.'s (2012) calculations from the ERHS

Economics of Addis Ababa University in collaboration with the International Food Policy Research Institute (IFPRI) and Oxford University. This survey followed 1,450 households from fifteen rural villages for seven rounds $(1989,1994,1995,1997,1999,2004$, and 2009) and focuses largely on Ethiopian highland farming systems that are often drought-stricken. It does not include the pastoral areas.

The observed trends in poverty among the ERHS households are not exactly the same as those from the HICES (Table 3.6), but are not entirely inconsistent either. Dercon et al. (2012) find that although poverty in the ERHS villages did fall significantly between 1994 and 2004 (for example, the headcount poverty fell from 48 per cent to 35 per cent, respectively), it rose again sharply between 2004 and 2009 (to 52 per cent poor), contrary to the patterns found in the HICES. Two factors contributed to the very high levels of poverty measured in 2009 , and hence the rise in poverty in these villages-year-specific short-term weather and food price shocks that were not experienced at the time of the HICES. First, more than half of the villages are located in drought-prone areas and were negatively affected by droughts in the year leading up to the survey. Second, most households in the ERHS villages are net food buyers and were hit hard by the food price hikes in 2008 (Dercon et al. 2012). It is thus important to be cautious when comparing the poverty estimates from the ERHS with those of the HICES because (a) the latter are nationally representative and the former are not, and (b) surveys taken in a particular year may reflect timespecific shocks, rather than overall long-term trends.

\subsubsection{Poverty and Non-monetary Measures of Well-being}

The Demographic and Health Surveys (DHS) for Ethiopia provide a nationally representative set of non-monetary indicators that complement the poverty estimates from the HICES. The collection of these data coincides with the HICES and provides a sense of consistency between the patterns of the changes in monetary poverty measured in the HICES and long-term trends 
Table 3.7. Stunting rates in Ethiopia, 2000-11

\begin{tabular}{|c|c|c|c|c|c|c|}
\hline & \multicolumn{3}{|c|}{ Levels } & \multicolumn{3}{|c|}{ Changes } \\
\hline & 2000 & 2005 & 2011 & $2000-5$ & 2005-11 & 2000-11 \\
\hline $\begin{array}{l}\text { National } \\
\text { Gender }\end{array}$ & 51.3 & 46.4 & 38.6 & -4.8 & -7.8 & -12.6 \\
\hline $\begin{array}{l}\text { Male } \\
\text { Female }\end{array}$ & $\begin{array}{l}52.0 \\
50.6\end{array}$ & $\begin{array}{l}47.2 \\
45.6\end{array}$ & $\begin{array}{l}39.3 \\
38.0\end{array}$ & $\begin{array}{l}-4.7 \\
-5.0\end{array}$ & $\begin{array}{l}-8.0 \\
-7.6\end{array}$ & $\begin{array}{l}-12.7 \\
-12.6\end{array}$ \\
\hline Residence & & & & & & \\
\hline $\begin{array}{l}\text { Urban } \\
\text { Rural }\end{array}$ & $\begin{array}{l}41.7 \\
52.4\end{array}$ & $\begin{array}{l}31.8 \\
47.6\end{array}$ & $\begin{array}{l}25.8 \\
40.4\end{array}$ & $\begin{array}{l}-9.8 \\
-4.8\end{array}$ & $\begin{array}{l}-6.0 \\
-7.2\end{array}$ & $\begin{array}{l}-15.9 \\
-11.9\end{array}$ \\
\hline
\end{tabular}

Note: Sample of children under age five

Source: Authors' calculations from DHS $(2000,2005,2011)$

in overall welfare. Consider, for example, child under-five stunting rates over the three survey years (Table 3.7). The high level of malnutrition in 2000, with over half of all young children stunted, is consistent with the high poverty rates in the country at the time, when over half of all individuals were poor. Further, the declines in stunting were substantial (12.6 percentage points between 2000 and 2011), though they were not as large as the fall in poverty (21.9 percentage points). As with poverty, stunting rates are lower in urban areas, and they fell by more there than in rural areas. Moreover, urban stunting rates fell by more in the first half of the decade than in the latter half, whereas they fell by more in the latter half of the decade in rural areas. These patterns are remarkably similar to the patterns of change in poverty.

Birth history data collected in the DHS enable us to construct retrospective estimates of infant (under age one) mortality rates (IMR) for each of the eight years prior to, but not including, the survey year (Figure 3.4). The plot of these IMRs shows two things. First, mortality rates are high, which is not surprising given high monetary poverty in Ethiopia. For example, in 2000, roughly 100 children per 1,000 live births died before they reached their first birthday. Second, there is evidence of a long-term trend of improvements consistent with the stunting and poverty data. But unlike the stunting data, because we estimate IMR for each year, not just the survey years, the longer-term trend is more obvious. In this case, IMR declined on average by four deaths per thousand live births each year, such that by 2011, the IMR was 60 .

As with the other non-monetary measures of well-being, net primary schooling enrolment rates calculated from the WMS data showed persistent improvements between 2000 and 2011 (Table 3.8) that are consistent with the decreases in monetary poverty. For example, the net primary enrolment rate rose from 33.8 per cent in 2000 to 62.4 per cent in 2011 . Although primary enrolment rates rose faster in rural areas than in urban areas, the levels are much lower in rural areas (59.2 per cent) than in urban areas (84.8 per cent) in 2011. In line with the 


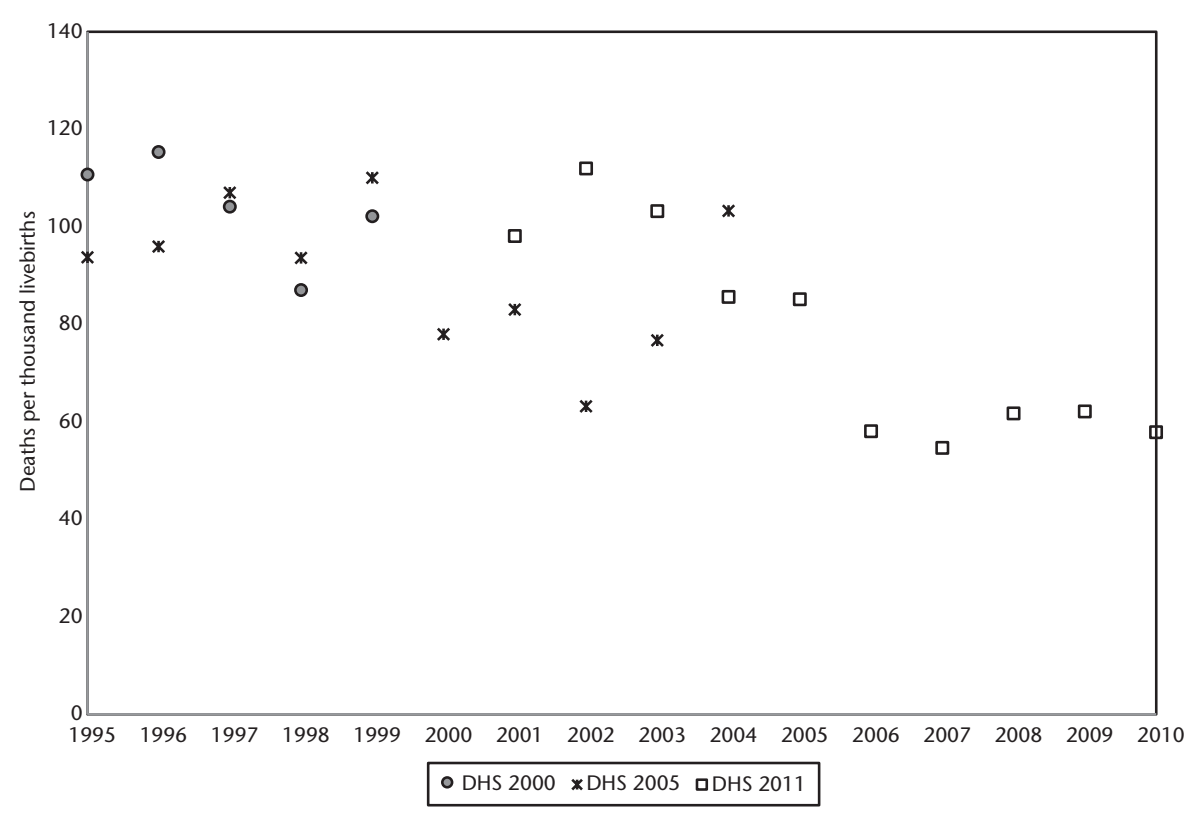

Figure 3.4. Annual infant mortality rates, Ethiopia 1996-2010 Source: Authors' calculations from DHS data

Table 3.8. Net school enrolment rates in Ethiopia, 2000-11

\begin{tabular}{|c|c|c|c|c|c|c|}
\hline & \multicolumn{3}{|c|}{ Primary } & \multicolumn{3}{|c|}{ Secondary } \\
\hline & 2000 & 2005 & 2011 & 2000 & 2005 & 2011 \\
\hline National & 33.8 & 37.8 & 62.4 & 11.6 & 14.5 & 10.8 \\
\hline Male & 35.8 & 38.9 & 60.7 & 12.2 & 16.6 & 11.4 \\
\hline Female & 31.6 & 36.8 & 64.3 & 10.9 & 12.4 & 11.1 \\
\hline Rural & 28.0 & 32.8 & 59.2 & 3.9 & 8.3 & 4.9 \\
\hline Male & 30.7 & 34.2 & 57.3 & 5.0 & 10.6 & 5.6 \\
\hline Female & 25.2 & 31.2 & 61.2 & 2.6 & 5.9 & 4.2 \\
\hline Urban & 72.9 & 77.2 & 84.8 & 48.4 & 44.5 & 35.7 \\
\hline Male & 76.0 & 78.8 & 85.4 & 52.2 & 50.1 & 39.4 \\
\hline Female & 70.2 & 75.8 & 84.1 & 45.3 & 40.1 & 32.9 \\
\hline
\end{tabular}

Source: Authors' calculations from WMS (2000, 2005, 2011)

Millennium Development Goal of equal access to education for girls, primary enrolment rates for girls rose faster than for boys over the decade. In fact, by 2011, girls' primary enrolment rates were higher than for boys in rural areas, and girls nearly made up the 6 percentage point difference in primary enrolment rates that existed at the beginning of the decade in urban areas.

These comparisons are complicated by the fact that the structure of primary education changed after the 2005 survey. Primary school now includes grades 
1-8 rather than grades $1-6$. This is likely to result in estimates of both primary and secondary enrolment rates that are lower, or at least no higher, than would have been the case had the change not occurred. This follows from dropout rates increasing as children get older, which is illustrated by the degree to which enrolment rates dropped between primary and secondary school in the 2000 and 2005 data (33.8 per cent to 11.6 per cent, respectively in 2000, and 27.8 per cent to 14.5 per cent, respectively in 2005). As such, the measured increase in primary school enrolment rates between 2005 and 2011 likely represent lower bounds.

Secondary school net enrolment rates, which are much lower than primary school enrolment rates (10.8 per cent compared to 62.4 per cent in 2011, respectively), exhibited ambiguous changes. Although they rose from 11.6 per cent in 2000 to 14.5 per cent in 2005, they appear to have fallen below the 2000 level to 10.8 per cent in 2011. Part of this is likely a consequence of the official restructuring of primary and secondary schooling. As such, we do not read too much into the apparent drop in enrolments. Nonetheless, the restructuring does not explain the decline in secondary enrolment rates in urban areas between 2000 and 2005. Finally, although urban secondary enrolment rates (35.7 per cent in 2011) are higher than in rural areas (4.9 per cent in 2011), they remain very low and girls have yet to catch up to boys.

A broad-based measure of basic educational attainment that is not sensitive to the change in the schooling structure-the literacy rate-shows considerable improvements over the decade (Table 3.9). While less than 30 per cent of the over-ten population could read in 2000, this number rose to 46.7 per cent by 2011 . This increase is particularly noteworthy because general literacy rates change more slowly than enrolment rates, given that literacy rates are a measure of the stock educational attainment of the population, while changes

Table 3.9. Literacy rates in Ethiopia, 1998-2011

\begin{tabular}{rccc}
\hline & National & Urban & Rural \\
\hline Total & & & \\
2000 & 29.2 & 69.9 & 21.7 \\
2005 & 37.9 & 74.2 & 30.9 \\
2011 & 46.7 & 77.9 & 39.7 \\
Male & & & \\
2000 & 39.7 & 81.8 & 32.8 \\
2005 & 49.9 & 86.2 & 43.4 \\
2011 & 56.2 & 87.6 & 49.7 \\
Female & & & \\
2000 & 19.4 & 60.6 & 11.0 \\
2005 & 26.6 & 64.4 & 18.7 \\
2011 & 37.6 & 69.6 & 30.0 \\
\hline
\end{tabular}

Note: For all persons ten years of age and older.

Source: CSA (2013) 
in these rates take place mostly at the margin among children in school, not among adults who are out of school.

Literacy increased over time in both rural and urban areas, and for both males and females. Most of the increase in literacy took place in rural areas (eighteen percentage point increase, compared to eight percentage points in urban areas) where rates were very low to begin with (21.7 per cent in 2000). Although there remains a roughly 20 percentage point difference in literacy rates between men and women, the gap did close by about two percentage points over the decade as a consequence of more girls enrolling in schools (Table 3.7).

\subsubsection{Poverty and Access to Public Goods}

A final set of indicators that can be used to triangulate the monetary poverty estimates are measures of access to public goods, such as electricity, drinking water, and sanitation (Table 3.10). Access to each of these types of public goods increased over the decade in a manner consistent with improved wellbeing. As with the non-monetary measures, however, the improvements are generally more muted than those of poverty.

As noted in section 3.3, Ethiopia's electricity-generating capacity improved substantially since 2000, with most of the gains taking place after 2005. This is clearly evident in Table 3.10, where the very low initial level of access into the home of less than 5 per cent in 2000, increased to over 9 per cent in

Table 3.10. Access to public goods in Ethiopia, 2000-11

\begin{tabular}{|c|c|c|c|c|c|c|c|c|c|}
\hline & \multicolumn{3}{|c|}{ National } & \multicolumn{3}{|l|}{ Urban } & \multicolumn{3}{|l|}{ Rural } \\
\hline & 2000 & 2005 & 2011 & 2000 & 2005 & 2011 & 2000 & 2005 & 2011 \\
\hline $\begin{array}{l}\text { Electricity access } \\
\text { Drinking water }\end{array}$ & 4.9 & 5.7 & 9.1 & 31.6 & 34.3 & 44.9 & 0.6 & 0.4 & 2.1 \\
\hline $\begin{array}{l}\text { Piped } \\
\text { Communal tap } \\
\text { Protected well } \\
\text { Low-quality* }\end{array}$ & & $\begin{array}{r}7.1 \\
14.3 \\
11.3 \\
67.3\end{array}$ & $\begin{array}{r}8.7 \\
20.3 \\
19.3 \\
51.7\end{array}$ & & $\begin{array}{r}40.4 \\
47.4 \\
4.4 \\
5.2\end{array}$ & $\begin{array}{r}48.6 \\
40.6 \\
5.0 \\
5.8\end{array}$ & & $\begin{array}{r}0.8 \\
8.1 \\
12.6 \\
78.4\end{array}$ & $\begin{array}{r}0.7 \\
16.4 \\
22.1 \\
60.8\end{array}$ \\
\hline Toilet facilities & & & & & & & & & \\
\hline $\begin{array}{l}\text { Flush } \\
\text { Pit latrine } \\
\text { No facility }\end{array}$ & $\begin{array}{r}1.7 \\
15.7 \\
82.5\end{array}$ & $\begin{array}{r}2.4 \\
27.1 \\
70.5\end{array}$ & $\begin{array}{r}1.8 \\
65.7 \\
32.5\end{array}$ & $\begin{array}{r}6.9 \\
64.4 \\
28.6\end{array}$ & $\begin{array}{r}8.7 \\
71.6 \\
19.7\end{array}$ & $\begin{array}{l}10.2 \\
76.8 \\
13.0\end{array}$ & $\begin{array}{r}0.8 \\
7.7 \\
90.7\end{array}$ & $\begin{array}{r}1.1 \\
18.9 \\
79.9\end{array}$ & $\begin{array}{r}0.2 \\
63.5 \\
36.3\end{array}$ \\
\hline
\end{tabular}

Note: *Low-quality drinking water is unprotected well, river, lake, pond, or rainwater.

Source: Authors' calculations from WMS (2000, 2005, and 2011) 
2011, with the bulk of the increase being realized between 2005 and 2011. Most access to electricity is in urban areas, rather than in rural areas (45 per cent compared to 2 per cent in 2011). As such, most of the gains were realized there as well (10 percentage point increase between 2005 and 2011).

Access to clean sources of drinking water also improved. Since information on sources of drinking water was not collected in the 2000 WMS, our analysis is limited to the 2005-11 period. Nonetheless, the improvements over this period are substantial. Although more than half of the population had access to only low-quality sources of drinking water (unprotected wells, rivers, lakes, ponds, or rainwater) in 2011, this is a vast improvement from the more than two thirds of the population in the same situation in 2005. Patterns of improved access to clean sources of drinking water were markedly different in urban and rural areas. For example, in urban areas, where nearly 90 per cent of the population had access to communal taps or direct piped water, the gains were made in the form of eight percentage points more households with piped water. These households were generally those who previously relied on communal taps in 2005, but had since gained access to piped water. In rural areas, where the percentage of households with access to only low-quality sources of water fell from 78 per cent to 61 per cent, the gains were in the form of newly built protected wells and communal taps. Piped water in rural areas is effectively non-existent.

Finally, access to sanitation facilities improved substantially, and along with greater access to clean sources of drinking water, is likely to have contributed to the lower stunting and mortality rates discussed previously. Whereas 82.5 per cent of the population had no toilet facilities in 2000, by 2011 , only 32.5 per cent were in a similar situation. Almost all of these gains follow from the construction of pit latrines (15.7 per cent in 2000 to 65.7 per cent in 2011) as a result of the implementation of the health extension system, which allocates two health extension workers per kebele (ward), especially in rural areas where more than half of the population benefitted. Flush toilets effectively only exist in urban areas with one in ten individuals having access in 2011.

\subsection{Concluding Remarks}

In this chapter, we analyse poverty in Ethiopia in 2000, 2005, and 2011 using Arndt and Simler's (2010) utility-consistent approach to calculating 
CBN poverty lines. This method involves calculating region-specific poverty lines based on consumption patterns of the poor in each of the urban and rural areas in the nine provinces (regional states) and two city administrations to reflect local perceptions of poverty (i.e. specificity). To ensure that each of the consumption bundles used to construct the region-specific CBN poverty lines also represents the same level of utility (i.e. consistency), a maximum entropy approach is employed to reconcile cases where revealed preference conditions are violated. These consistent yet specific poverty lines, along with consumption aggregates calculated from nationally representative household surveys, form the basis of the monetary poverty analysis in this chapter.

The general story that emerges from the data is one of steady but uneven progress, with urban areas witnessing the greatest gains in the first half of the decade, and rural areas benefitting more in the latter half. According to our estimates, national poverty fell remarkably from 51.9 per cent in 2000, to 44.5 per cent in 2005, and finally to 30.0 per cent in 2011 . Poverty is considerably higher in rural areas (53.7 per cent) where more than 80 per cent of the population lives, compared to urban areas (40.8 per cent). Although the rural headcount ratio fell by a remarkable 20.5 percentage points, urban areas as a whole saw even greater declines in poverty, as the urban poverty rate fell to just under 14 per cent by 2011.

These patterns of declining poverty took place in the context of what Dorosh and Schmidt (2010) describe as 'Ethiopia's changing economic landscape', in which fundamental structural changes took place in the economy. Improvements in the country's physical infrastructure, better access to improved agricultural inputs, and widespread social safety nets have created an environment that is conducive to poverty reduction. Moreover, other monetary and non-monetary measures of well-being confirm the general pattern of persistent welfare improvements. These indicators suggest that the poverty estimates for Ethiopia are largely a reflection of long-term trends characterized by broad-based growth and improved welfare. Although data comparability issues warrant care in determining the degree to which monetary poverty fell, the broader body of evidence paints a picture of substantive welfare improvements over the decade. 


\section{Appendix}

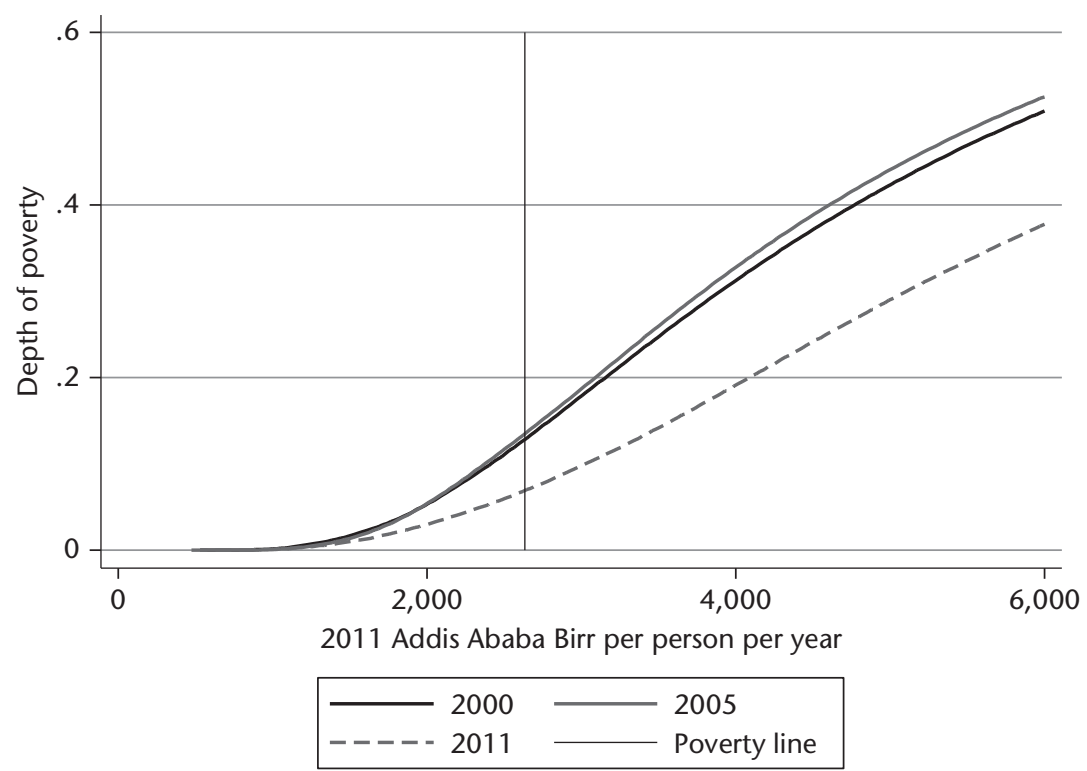

Figure 3.A1. Test of second-order dominance, Ethiopia 2000-11

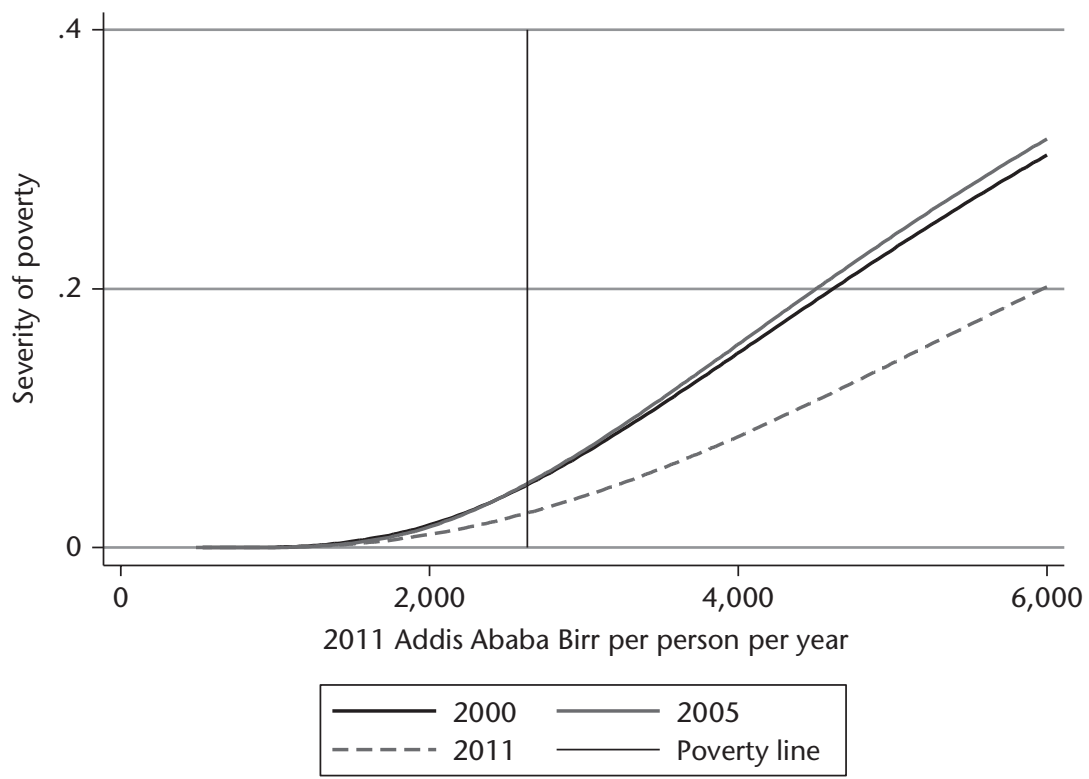

Figure 3.A2. Test of third-order dominance, Ethiopia 2000-11 


\section{References}

Arndt, C. and Kenneth Simler (2010). 'Estimating Utility-Consistent Poverty Lines with Applications to Egypt and Mozambique', Economic Development and Cultural Change, 58(3): 449-74.

Ayele, G., Jordan Chamberlin, Lisa Moorman, Kassu Wamish, and Xiaobo Zhang (2009). 'Infrastructure and Cluster Development: A Case Study of Handloom Weavers in Ethiopia', ESSP II Working Paper 1. Addis Ababa, Ethiopia: International Food Policy Research Institute/Ethiopia Strategy Support Program II.

Bellemare, M., Christopher Barrett, and David Just (2013). 'The Welfare Impacts of Commodity Price Volatility: Evidence from Rural Ethiopia', American Journal of Agricultural Economics, 95(4): 877-99.

Berhane, G., Daniel O. Gilligan, John Hoddinott, Neha Kumar, and Alemayehu Seyoum Taffesse (2014). 'Can Social Protection Work in Africa? The Impact of Ethiopia's Productive Safety Net Programme', Economic Development and Cultural Change, 63(1): 1-26.

Central Statistical Agency (CSA) (2013). Data. Available at <http://imis.csa.gov.et/ bineth/RpWebEngine.exe/Portal?LANG=eng>.

Coll-Black, S., Daniel Gilligan, John Hoddinott, Neha Kumar, Alemayehu Seyoum Taffesse, and William Wiseman (2011). 'Targeting Food Security Interventions When "Everyone Is Poor": The Case of Ethiopia's Productive Safety Net Programme', ESSP II Working Paper 24. Addis Ababa, Ethiopia: International Food Policy Research Institute/Ethiopia Strategy Support Program II.

Davis, K., Burton Swanson, David Amudavi, Daniel Ayalew Mekonnen, Aaron Flohrs, Jens Riese, Chloe Lamb, and Elias Zerfu (2010). 'In-depth Assessment of the Public Agricultural Extension System of Ethiopia and Recommendations for Improvement', IFPRI Discussion Paper 1041. Washington, DC: International Food Policy Research Institute.

Demographic and Health Surveys (DHS) (2000, 2005, and 2011). Dataset. Central Statistical Agency of Ethiopia and ORC Macro. Available at <http://www. dhsprogram.com/data/available-datasets.cfm>.

Dercon, S. and Ruth Vargas Hill (2009). 'Growth from Agriculture in Ethiopia: Identifying Key Constraints'. Paper prepared as background for a study on agriculture and growth in Ethiopia. Oxford: University of Oxford. Available at <users.ox.ac.uk/ reconstd/policy_ethiopiaagriculturework.htm>, accessed 26 August 2014.

Dercon, Stefan, John Hoddinott, and Tassew Woldehanna (2012). 'Growth and Chronic Poverty: Evidence from Rural Communities in Ethiopia', Journal of Development Studies, 48(2): 238-53.

Dorosh, P. and Emily Schmidt (2010). 'The Urban-Rural Transformation in Ethiopia', ESSP II Working Paper 13. Addis Ababa, Ethiopia: International Food Policy Research Institute/Ethiopia Strategy Support Program II.

Ethiopia Rural Household Survey (ERHS) (1989-2009, 2011). Dataset. Washington, DC: International Food Policy Research Institute (IFPRI) (datasets). 
Gilligan, D., John Hoddinott, and Alemayehu Seyoum Taffesse (2009). 'The Impact of Ethiopia's Productive Safety Net Programme and its Linkages', Journal of Development Studies, 45(10): 1684-1706.

Government of Ethiopia (2004). Productive Safety Net Programme: Programme Implementation Manual. Addis Ababa, Ethiopia: Ministry of Agriculture and Rural Development.

Headey, D., Fantu Nisrane, Ibrahim Worku, Mekdim Dereje, and Alemayehu Seyoum Taffesse (2012). 'Urban Wage and Food Price Inflation: The Case of Ethiopia', ESSP II Working Paper 41. Addis Ababa, Ethiopia: International Food Policy Research Institute/Ethiopia Strategy Support Program II.

Household Income, Consumption and Expenditure Survey (HICES) (2000, 2005, and 2011). Datasets. Available at <http://microdata.worldbank.org/index.php/catalog/1068>.

Minten, B., David Stifel, and Seneshaw Tamru (2012). 'Structural Transformation in Ethiopia: Evidence from Cereal Markets', ESSP II Working Paper 39. Addis Ababa, Ethiopia: International Food Policy Research Institute/Ethiopia Strategy Support Program II.

MoFED (Ministry of Finance and Economic Development) (2008). Dynamics of Growth and Poverty in Ethiopia (1995/96-2004/05). Addis Ababa, Ethiopia: Development Planning and Research Department, Ministry of Finance and Economic Development.

MoFED (Ministry of Finance and Economic Development) (2012). Ethiopia's Progress towards Eradicating Poverty: An Interim Report on Poverty Analysis Study (20010/11). Addis Ababa, Ethiopia: Development Planning and Research Department, Ministry of Finance and Economic Development.

Pradhan, M. (2000). 'How Many Questions Should Be in a Consumption Questionnaire? Evidence from a Repeated Experiment in Indonesia', Working Paper 112. Ithaca, NY: Cornell Food and Nutrition Policy Program, Cornell University.

Rashid, S., Negussie Tefera, Nicholas Minot, and Gezahegn Ayele (2013). 'Can Modern Input Use Be Promoted Without Subsidies? An Analysis of Fertilizers in Ethiopia', Agricultural Economics, 44(6): 595-611.

Schmidt, E. and Mekamu Kedir (2009). 'Urbanization and Spatial Connectivity in Ethiopia: Urban Growth Analysis Using GIS', ESSP II Working Paper 3. Addis Ababa, Ethiopia: International Food Policy Research Institute/Ethiopia Strategy Support Program II.

Seyoum Taffesse, A., Paul Dorosh, and S. A. Gemessa (2013). 'Crop Production in Ethiopia: Regional Patterns and Trends', in P. Dorosh and S. Rashid (eds), Food and Agriculture in Ethiopia: Progress and Policy Challenges. Philadelphia, PA: University of Pennsylvania Press, 53-83.

Spielman, D., Dawit Kelemwork, and Dawit Alemu (2011). 'Seed, Fertilizer, and Agricultural Extension in Ethiopia', ESSP II Working Paper 20. Addis Ababa, Ethiopia: International Food Policy Research Institute/Ethiopia Strategy Support Program II.

Telegraphy (2012). 'Ethio Telecom Mobile Base Tops 17.26m at End-June'. Available at $<$ https://www.telegeography.com/products/commsupdate/articles/2012/09/20/ethiotelecom-mobile-base-tops-17-26m-at-end-june/>. 
Ticci, E. (2011). 'Can Inflation Be a Good Thing for the Poor? Evidence from Ethiopia', Development in Practice, 21(4-5): 629-41.

Welfare Monitoring Surveys (WMS) (2000, 2005, and 2011). Addis Ababa, Ethiopia: Central Statistical Agency.

World Bank (2011). World Development Indicators 2011. Washington, DC: World Bank Publications. 


\title{
4
}

\section{Ghana}

\section{Poverty Reduction over Thirty Years}

\author{
Andy McKay, Jukka Pirttilä, and Finn Tarp
}

\subsection{Introduction}

Ghana has by now experienced solid growth for almost thirty years. In the late 1980s and early 1990s when much of sub-Saharan Africa saw economic decline, Ghana stood out as one of a small number of exceptions with positive growth. It undertook major economic reforms from 1984 onwards, and is regularly held up as an example of successful implementation of adjustment policies. They came with substantial aid inflows; and in recent years growth has accelerated even further, in part with the discovery of oil and the start of its production.

While the rate of growth has varied over time, growth in per capita GDP was positive in every single year between 1985 and 2013. Per capita GDP grew at 1.7 per cent from 1985 to 1994; by 2.0 per cent from 1995 to 2004; and it reached 5.3 per cent over 2005-13, in part due to 12 per cent growth experienced in 2012. This period also saw Ghana joining the group of lower-middle countries. Accordingly, Ghana has widely been seen as an African growth success story, and growth is projected to remain strong over the medium-term future.

Turning to the poverty impacts of this growth, Ghana has over the years benefitted from having a variety of sources of data. Not only have there been six different rounds of the national household living conditions survey (the last four at least being comparable), there have also been five waves of the Demographic and Health Survey (DHS). A number of insightful studies of poverty in Ghana therefore exist, starting with an analysis based on one of the very first household surveys conducted in Africa, the first round of the Ghana Living Standards Survey (GLSS), conducted in 1987/8 (Boateng et al. 
1992), with many other more in-depth studies following. A consistent message of these studies is that growth has been accompanied by progress in reducing monetary poverty.

At the official level, the Ghana Statistical Service (GSS) has also published important studies of poverty in Ghana. Its 2007 study (GSS 2007) describes poverty developments between 1991 and 2006 in detail, and a recently published poverty report compares the situation in 2005/6 with that revealed by the latest survey in 2012/13 (GSS 2014). Both reviews show impressive progress over these periods in terms of reducing consumption poverty, but also that inequality has been on the rise.

Among academic studies, Aryeetey and McKay (2007) look at the relationship between economic growth and poverty reduction in Ghana as a study done as part of a multi-country project analysing pro-poor growth. Coulombe and Wodon (2007) provide a thorough study of poverty, its relation to growth, and the determinants of poverty between 1991 and 2006. They note that the GDP deflator increased more than the CPI, which implies that poverty reduction has been further underpinned with relatively strong real consumption growth. They also decompose changes in the mean level of consumption per adult equivalent of households over time into changes due to differences in household characteristics and changes due to differences in the returns to these characteristics. The results from this exercise suggest that the reductions in poverty due to declines in household size, which occurred both in rural and urban areas, are important, and also that the impact was much larger in urban areas. They also calculate that, if inequality had not increased between 1991 and 2006, poverty would have fallen by four percentage points more than it actually did during this period.

Duclos et al. (2006) examine multidimensional poverty in three African countries, including Ghana. Their chosen indicators are consumption and children's height for age scores (a good measure of nutrition). For the country as a whole, such measured multidimensional poverty is greater in rural than in urban areas. It also appears that in some geographical regions this pattern unexpectedly does not hold. Annim et al. (2012) study district-level inequality using GLSS3-5, and find that the contribution of within-district inequality to national inequality is higher than inequality between districts.

Two papers specifically focus on the linkages between inflation, an important challenge in Ghana, and poverty. Cudjoe et al. (2010) examine food price transmission between regional markets, using the $2007-8$ food price crisis as an example. They combine econometric analysis of food price correlations with consumer demand system-based simulations. While they find that domestic grain prices are highly correlated with world market prices, the food crisis had only a modest impact on consumer welfare on average because of the relatively diverse consumption patterns within the country. They also argue that some 
subgroups of the population, namely the poorest households in urban areas, suffered considerably due to food price increases. Coleman (2012), in turn, investigates the persistence properties of inflation across regions and sectors in Ghana. He finds some regions (Ashanti, Central, and Eastern) demonstrate inflation persistence, implying that a nationwide policy shock will have longer-lasting effects in these three compared to the other regions.

This chapter revisits and updates all of this evidence on growth and poverty in Ghana, taking into account the results of the most recently conducted household survey in 2012/13. Insights are also provided using different nonmonetary indicators from the Demographic and Health Surveys for the four latest available rounds. While Ghana is undoubtedly an African success in many respects, we also raise a number of issues, in particular in relation to the more recent record and in terms of the inclusiveness of the growth pattern.

The chapter proceeds as follows. Section 4.2 sets out the historical background to Ghana's period of three decades of sustained growth and outlines some of the policies and reforms related to growth and poverty reduction. Then in section 4.3 we review the macroeconomic picture in terms of growth and other outcomes, looking in more detail at the composition of growth and its likely implications for changes in poverty. The record in terms of monetary poverty and inequality, and the responsiveness of these to growth, is reviewed in section 4.4, after which section 4.5 discusses the record in terms of nonmonetary dimensions of poverty. Section 4.6 concludes.

\subsection{Economic Developments and Policies Implemented to Reduce Poverty}

At Independence in 1957 Ghana had a per capita income level comparable to countries like South Korea and Malaysia, and much higher than Thailand, India, and most other African countries. The government of the time (with Kwame Nkumah as prime minister during 1957-60 and president from 1960 to 1966) pursued several policies and programmes to enhance economic growth and to reduce poverty, focusing on removing constraints to industrialization. This included, among other things, policies to construct a modern road network, to modernize and enlarge the main ports (Takoradi and Tema), to diversify agricultural production and to achieve significant progress in education and health.

In reality though, the history of Ghana's first twenty-five years of independence is a case of largely self-inflicted decline (Huq 1989). The period between the toppling of the Nkrumah government in 1966 and December 1983 when Flight Lieutenant Jerry Rawlings took power for the second time saw substantial political instability (with eight different regimes in this period, some 
military and many short-lived) and major inconsistencies in policy implementation. In addition, the economy was hit by several shocks, including the sharp oil price rises in the 1970s, severe droughts during 1975-7 and 1981-3, and the repatriation of Ghanaians from Nigeria in 1983 (Gockel and Amu 2003). The government ended up in 1983 having no other alternative than to seek assistance from the IMF and the World Bank through the Economic Recovery Programme (ERP) (Aryeetey et al. 2000).

The ERP is described by Aryeetey and Tarp (2000). They detail the many different market-oriented policy reform measures, which were involved, and assess the initial performance. The programme helped relaunch growth and was associated with improved fiscal performance; although the fact already noted that the ERP was accompanied by substantial aid inflows makes it challenging to disentangle the relative importance of the different factors in accounting for re-establishing growth. Furthermore, in some respects economic performance remained poor, in particular in relation to private investment and control of inflation. Political liberalization followed economic liberalization with a transition to democracy in 1992; and this process has been both popular in Ghana and successful as demonstrated by two peaceful changes of political regime in elections in 2000 and 2008. Democracy though also creates challenges, with rising fiscal deficits associated with election periods. Effective fiscal management remains a major issue, alongside high inflation, which has been a continued problem.

Concern about the poverty consequences of the reform measures being undertaken led the government to adopt its Programme of Actions to Mitigate the Social Costs of Adjustment (PAMSCAD) in 1989 as a kind of buffer for the vulnerable groups in the country (Leite et al. 2000). More effective focus on alleviating poverty was introduced through a set of later initiatives, including Vision 2020, which sought to propel the economy to middle-income status within twenty-five years. Its replacement, the first Ghana Poverty Reduction Strategy (GPRS I), the first phase of which accompanied Ghana's application for the Enhanced HIPC facility in 2001, followed. Concerns were nonetheless expressed that the poor did not participate actively in the growth process (Osei and Domfe 2008). Hence the second Growth and Poverty Reduction Strategy (GPRS II) was launched in 2006 to continue the poverty reduction efforts. One key poverty reduction project under GPRS II, borne out of the evaluation of the GPRS I, was the cash transfer programme called the Livelihood Empowerment Against Poverty (LEAP). GPRS II ended in 2009 and was replaced by the Ghana Shared Growth Development Agenda (GSGDA), which has now entered a second phase.

An important recent economic development in Ghana is the discovery of significant quantities of oil in 2007 with production starting on a modest scale towards the end of 2010. This has now become a significant source of export 
revenue for Ghana, adding to its traditional important exports of gold and cocoa. Oil production is intended to provide a source of revenue for government; however, it is still too early to judge the impact of oil production on the economy and certainly on poverty. Recent macroeconomic difficulties caused by expenditure overshooting, which caused Ghana to approach the IMF once again, underline the importance of prudent management of natural resource income.

\subsection{The Macroeconomic Environment}

Three phases can be discerned from the economic growth trends from 1960 to 2013. The first, spanning the period 1960-83, saw growth averaging close to zero with very large variability (Figure 4.1). The dismal growth performance for this period has been attributed to many factors, including economic mismanagement, political instability, the severe droughts referred to in section 4.2, adverse shifts in the country's terms of trade, and the oil shocks of the 1970s (Killick 2010; Lloyd, Morrissey, and Osei 2001). The second phase spans the economic recovery period until the early 2000s. These years of restoration recorded positive growth on average with relatively low variability, reflecting greater economic and political stability in combination with a much stronger macroeconomic performance in general (including continued inflows of

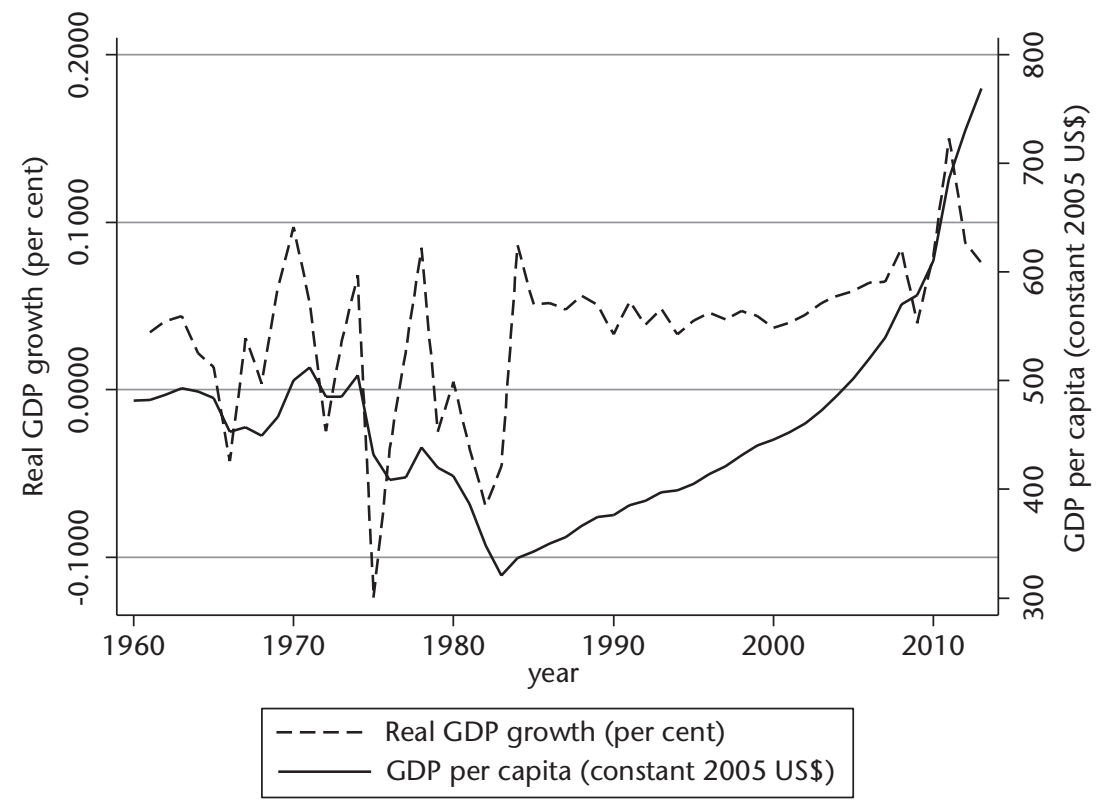

Figure 4.1. Trends in economic growth, 1960-2012

Source: World Development Indicators 2014 
Table 4.1. Growth rates of different national accounts aggregates

\begin{tabular}{|c|c|c|c|}
\hline & \multicolumn{3}{|c|}{ Mean growth rates per annum } \\
\hline & $1991-9$ & 1998-2005 & $2007-13$ \\
\hline Real GDP growth, \% & 4.4 & 4.8 & 8.3 \\
\hline GDP per capita growth, annual \% & 1.8 & 2.2 & 5.8 \\
\hline Final consumption expenditure, etc., annual \% growth & 4.8 & 4.9 & 6.3 \\
\hline $\begin{array}{l}\text { General government final consumption expenditure, annual \% } \\
\text { growth }\end{array}$ & 7.0 & 8.4 & 18.1 \\
\hline Household final consumption expenditure, annual \% growth & 4.6 & 4.4 & 5.5 \\
\hline Gross capital formation, annual \% growth & 11.7 & 8.1 & 11.4 \\
\hline External balance on goods and services, annual \% growth & -23.6 & -12.0 & 1.0 \\
\hline Exports of goods and services, annual \% growth & 12.8 & 7.7 & 18.5 \\
\hline Imports of goods and services, annual \% growth & 13.3 & 7.7 & 11.1 \\
\hline Agriculture, real growth rate, $\%$ & 3.0 & 5.1 & 3.4 \\
\hline Industry, real growth rate, $\%$ & 12.0 & 4.2 & 14.5 \\
\hline Manufacturing, real growth rate, $\%$ & 4.8 & 3.9 & 0.1 \\
\hline Services, etc., real growth rate, $\%$ & 2.5 & 4.9 & 8.6 \\
\hline
\end{tabular}

Source: World Development Indicators 2014

foreign aid). The last phase covers the period from the mid-2000s to date, where the beginnings of accelerated growth could be witnessed. Economic growth between 2002 and 2008 averaged about 6.1 per cent per annum. In the year 2011, the economy grew at an unprecedented rate of 14.4 per cent. This growth, though, was principally driven by oil production, which started during the last quarter of 2010.

According to the more detailed information available from Table 4.1 (see also Table 4.2), private consumption (and investment) grew faster than the GDP during the period 1991-9, made possible through increasing deficits in the external balance. In the latest period shown, 2007-13, after the rebasing of the GDP, consumption growth has lagged behind GDP growth, while investment growth has remained high.

The sectoral decomposition of growth shows how the agricultural sector lagged behind overall growth in the 1990s, then experienced a faster growth rate until the rebasing of GDP in 2006. After that, the share of agriculture in total GDP remained fairly small, and agricultural growth has been modest. This stands in comparison with the much faster growth of the service sector and especially non-manufacturing industries in the period from 2007 onwards.

The sluggish development of the manufacturing sector stands out. Jedwab and Osei (2012) note that income changes in Ghana during 1960-2010 were mainly driven by changes in the productivity of specific sectors rather than by a shift of resources from low- to high-productivity areas. This was particularly the case before 1992. Nevertheless, the authors argue that Ghana has slowly transitioned into a more efficient economy, with structural change becoming a more significant factor of productivity growth. Indeed, Osei (2012) cautions 
Table 4.2. Real GDP growth, by expenditure category and sector, 1991, 1999, 2006, and 2013

\begin{tabular}{lcccc}
\hline & \multicolumn{4}{c}{ Shares } \\
\cline { 2 - 5 } & 1991 & 1999 & 2006 & 2013 \\
\hline Final consumption expenditure, etc., \% of GDP & 92.7 & 96.5 & 93.9 & 81.0 \\
General government final consumption expenditure, \% of GDP & 9.5 & 10.8 & 11.2 & 16.6 \\
Household final consumption expenditure, etc., \% of GDP & 83.2 & 85.7 & 82.7 & 64.4 \\
Gross capital formation, \% of GDP & 15.9 & 21.0 & 21.6 & 24.1 \\
External balance on goods and services, \% of GDP & -8.6 & -17.5 & -15.5 & -5.1 \\
Exports of goods and services, \% of GDP & 17.0 & 32.1 & 25.2 & 42.2 \\
Imports of goods and services, \% of GDP & 25.5 & 49.6 & 40.7 & 47.2 \\
Total & 100 & 100 & 100 & 100 \\
Agriculture, value added, \% of GDP & 45.6 & 39.9 & 30.4 & 21.9 \\
Industry, value added, \% of GDP & 17.0 & 28.4 & 20.8 & 28.5 \\
Manufacturing, value added, \% of GDP & 9.3 & 10.1 & 10.2 & 5.8 \\
Services, etc., value added, \% of GDP & 37.5 & 31.7 & 48.8 & 49.6 \\
Total & 100 & 100 & 100 & 100 \\
\hline
\end{tabular}

Source: The World Bank

that the growth-enhancing type of structural change needs to be sustained particularly if the country is to avoid the oil curse. Other potential concerns that could mitigate the growth-enhancing potential of structural change in Ghana are the increasingly fragile nature of the government's fiscal situation and the challenges in the country's energy sector. In terms of the fiscal policy, the country has recently again needed a fiscal rescue package from the IMF (see IMF 2015). On the energy sector the frequent disruptions to power means that firms rely increasingly on their own power generation (mainly by use of diesel generators), which invariably makes them less competitive, limiting the scope to develop an industrial sector.

A key factor lurking behind poverty estimates is inflation, especially food price inflation. Figure 4.2 demonstrates the large fluctuations in the inflation rate over the entire time period discussed here. In Figure 4.3, food price inflation is compared with overall consumer price inflation for the period for which comparable information is available. While food prices increased rapidly during the food price crisis around 2008, the overall inflation rate was also high and remained above food price inflation. In any case, the rates shown underline the need for great care when deflating nominal figures to arrive at real consumption estimates.

\subsection{The Record on Consumption Poverty}

The analysis of consumption poverty in Ghana is enabled by the four rounds of the Ghana Living Standards Survey (GLSS, rounds 3 to 6), concurred in 


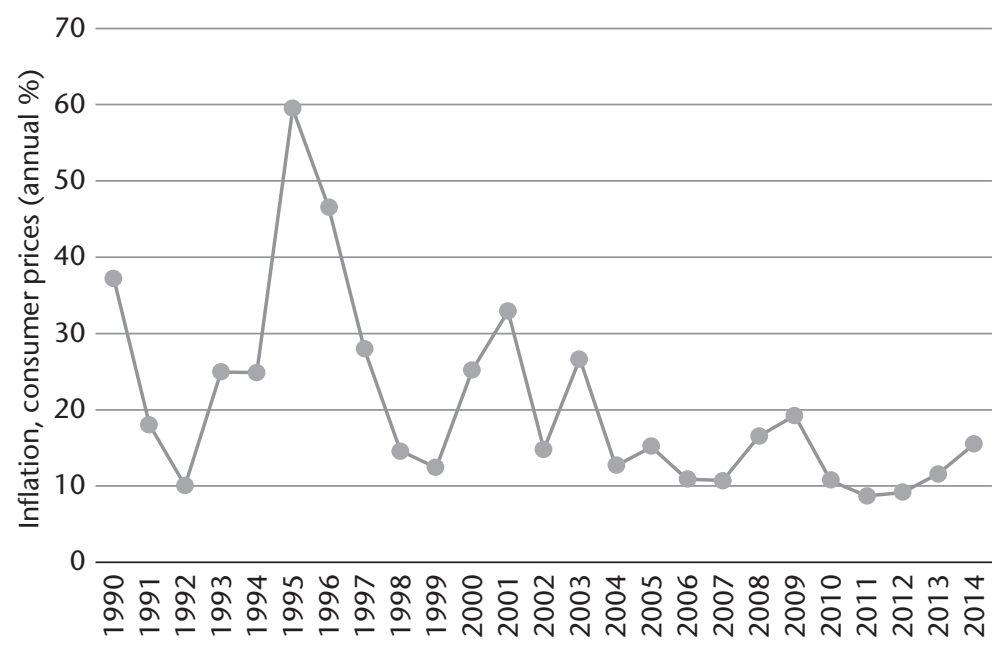

Figure 4.2. Inflation in Ghana, 1990-2014

Source: World Bank

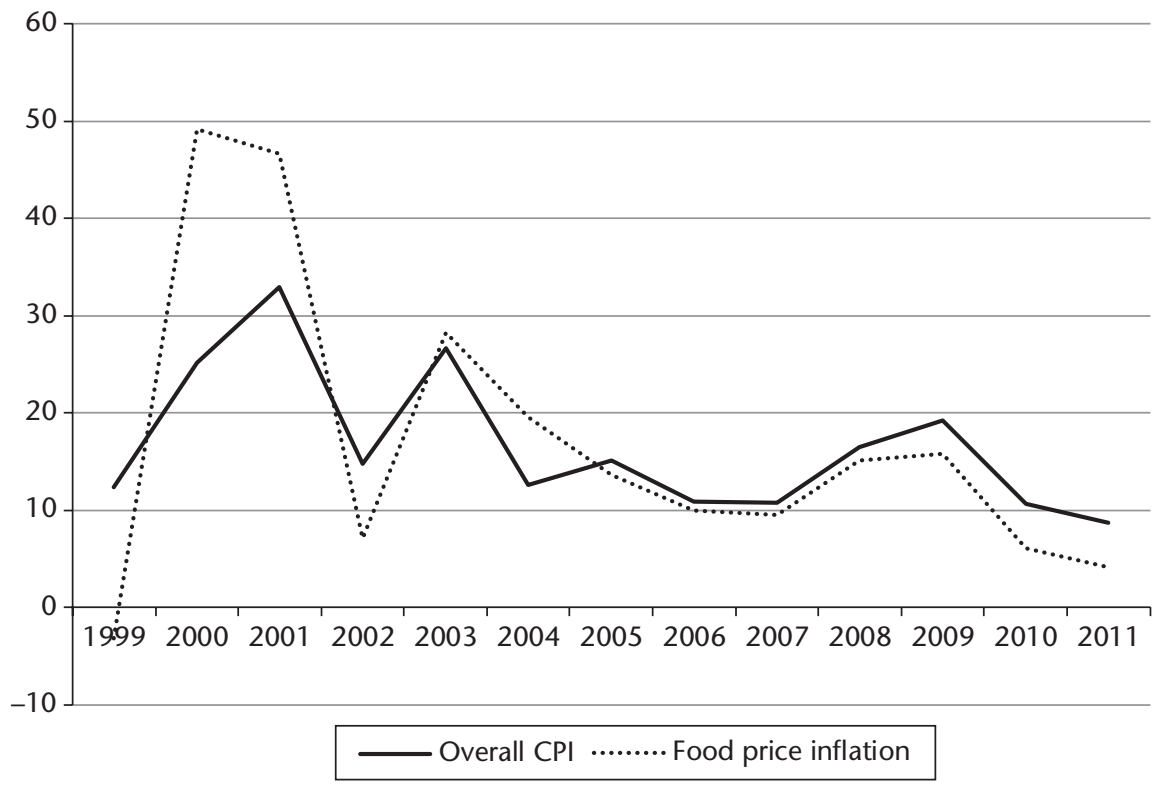

Figure 4.3. Comparison of food price inflation and overall price inflation Source: Authors' calculations based on Ghana Statistical Service data 
1991-2, 1998-9, 2005-6, and 2012-13. These are comparable surveys which enable total real household consumption expenditure per adult equivalent to be computed, using price data which can take account of differences across space and over time between one round and another. A national poverty line is used. The Ghana Statistical Service has published a poverty report based on the first three of these rounds (GSS 2008), and more recently a poverty study based on the latest two rounds, the latter using a revised consumption measure and poverty line (GSS 2014). ${ }^{1}$

The mean values of household consumption from the last four household surveys, expressed in the constant prices of January 2013, are summarized in Table 4.3. It demonstrates rising average consumption at quite fast rates over this period. Over the full period from $1991 / 2$ to $2012 / 13$, consumption per adult equivalent grew at a very respectable annual average rate of 3.1 per cent. While growth was faster in the periods between the GLSS3 and 4 and GLSS4 and 5 surveys than over the GLSS5 to 6 years, even in this last period consumption still grew at an average rate of 2.5 per cent per year.

Figures 4.4 and 4.5 show the distributional pattern of this growth by plotting growth incidence curves for the GLSS3 to 5 and GLSS5 to 6 periods respectively. These figures show the higher average rate of growth in the first period compared to the second. They also show that in the first period growth in consumption was significantly higher at the top end of the distribution than at the bottom, indicating that inequality rose over this period. Growth between the GLSS5 and 6 periods was less uneven, though still slightly higher at the top end of the distribution.

What these growth incidence curves also indicate is a consistent history of reduction in monetary poverty over this period. Poverty headcount data from the four most recent GLSS surveys at the national level are presented in Table 4.3, drawing on official, published data. The data for the GLSS3 to GLSS5 surveys are directly comparable. Small revisions were made to the computation of the poverty line (and consumption aggregate) in the analysis of the GLSS6 survey, resulting in revised estimates for GLSS5, which are also presented in this table. While the revised poverty line, which took into account more recent consumption patterns, gives higher poverty numbers for the $2005 / 6$ period, the patterns are not fundamentally different from the previous figures. The headline story remains one of a large reduction in the poverty headcount between 1991/2 and 1998/9, and again between 1998/9

\footnotetext{
1 An earlier study by Coulombe and McKay (1995) compared poverty over the first three rounds of the Ghana Living Standards Survey from 1987/8 to 1991/2, a comparison which was made difficult by a significant change in the way of collecting consumption data between the second and third rounds of the survey. Nonetheless, attempting to correct for the effects of this change, Coulombe and McKay estimated that poverty had fallen over this period.
} 
Table 4.3. Changes in national poverty headcount for Ghana, and elasticity calculations

\begin{tabular}{|c|c|c|c|c|}
\hline & $1991-2$ & $1998-9$ & $2005-6$ & $2012-13$ \\
\hline Poverty headcount & 51.7 & 39.5 & 28.5 & \\
\hline Proportionate change in poverty & & -0.236 & -0.278 & -0.241 \\
\hline Real GDP per capita (2006 values) & 634.8 & 714 & 837.2 & $1,228.2$ \\
\hline Real consumption per capita (2006 values) & 539.3 & 590.1 & 685.5 & 711.9 \\
\hline $\begin{array}{l}\text { Real survey consumption per capita (est. } 2006 \\
\text { values) }\end{array}$ & 294.8 & 382.8 & 479.2 & \\
\hline Real survey consumption per capita (2013 values) & & & 2,511 & 3,002 \\
\hline Proportionate change in per capita GDP & & 0.125 & 0.173 & 0.467 \\
\hline $\begin{array}{l}\text { Proportionate change in per capita consumption } \\
\text { (national accounts) }\end{array}$ & & 0.094 & 0.162 & 0.039 \\
\hline $\begin{array}{l}\text { Proportionate change in per adult household } \\
\text { consumption (survey) }\end{array}$ & & 0.216 & 0.272 & 0.192 \\
\hline Growth elasticity of poverty (GDP) & & -1.89 & -1.61 & -0.52 \\
\hline $\begin{array}{l}\text { Growth elasticity of poverty (national accounts } \\
\text { consumption) }\end{array}$ & & -2.51 & -1.72 & -6.26 \\
\hline Growth elasticity of poverty (survey consumption) & & -1.09 & -1.02 & -1.26 \\
\hline
\end{tabular}

Note: The levels of consumption from the third household survey in 2006 values cannot be compared with those in 2013 values because of significant revisions in the $\mathrm{CPI}$ data used for these calculations. But comparisons along the row to compute growth rates are valid.

Source: Authors' computations based on data from World Development Indicators and Ghana Living Standards Survey data

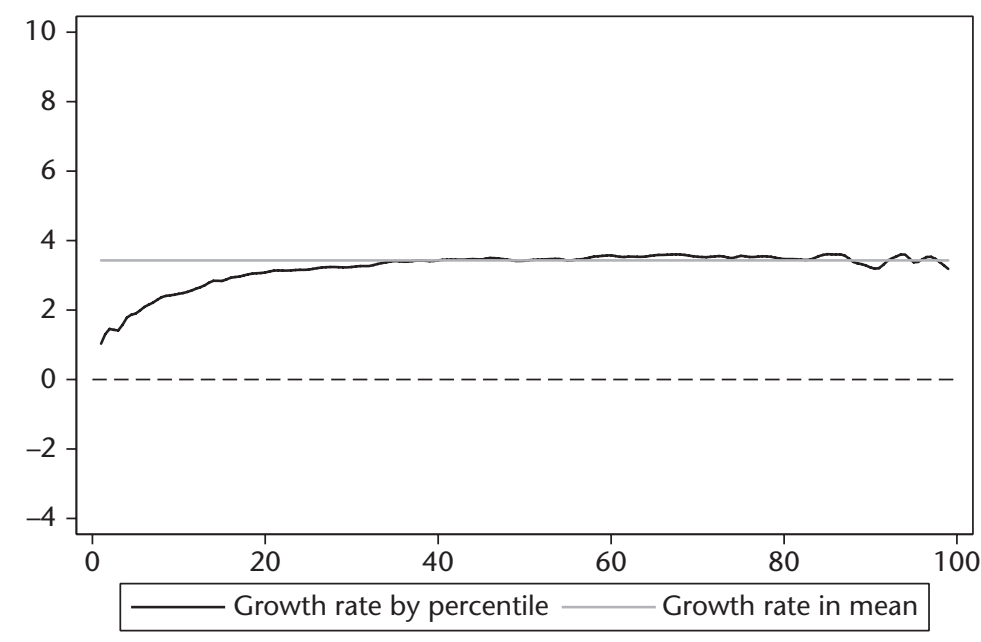

Figure 4.4. Growth incidence curve for Ghana, 1991/2-2005/6

Source: Authors' computations based on Ghana Living Standards Survey data

and 2005/6. Poverty continued to fall between 2005/6 and 2012/13 (based on the comparable data), even if the percentage point reduction was smaller.

The rest of the table examines the responsiveness of poverty to growth by computing the growth elasticity of poverty reduction, based on different definitions of growth. The first calculations are done relative to per capita GDP, the growth rate of which increased over time. The figures suggest that 


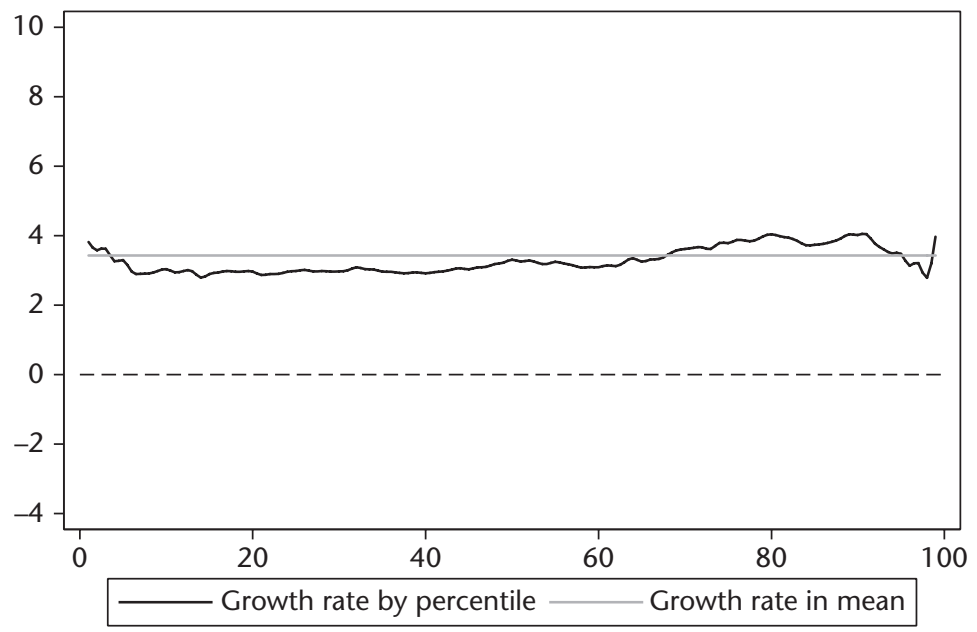

Figure 4.5. Growth incidence curve for Ghana, 2005/6-12/13

Source: Authors' computations based on Ghana Living Standards Survey data

the growth elasticity with respect to GDP falls from -1.9 between 1992 and 1998/9 (a respectable figure) to a much less respectable -0.5 between 2005/6 and 2012/13. In other words, the recent faster growth in GDP would not appear to have been associated with significant poverty reduction. Monetary poverty is, however, more directly linked to private consumption; and the elasticity with respect to the national accounts estimate of private consumption is -2.5 in the first period, -1.7 in the second period, and -6.3 in the third period. The last figure would seem to be an anomaly and raises questions about the reliability of the associated private consumption estimate in the national accounts. Its growth rate may well have been underestimated. We now finally turn to the estimated growth elasticities of poverty computed using the household-based consumption measure, which shows significantly faster growth between 2005/6 and 2012/13 than does the national accounts aggregate. Here the growth elasticities of poverty are both more stable and more modest; -0.8 between 1991/2 and 1998/9, -1.1 between 1998/9 and $2005 / 6$, and -1.2 between $2005 / 6$ and $2012 / 13$. This is perhaps the best measure of the responsiveness of poverty to growth and shows disappointing progress in poverty reduction, given the consumption growth rate achieved. As will be seen, rising inequality over much of this period will be part of the explanation.

While the above review concerns national-level poverty, a disaggregated analysis of the poverty headcount is presented in Table 4.4. Significant diversity is evident in both levels and trends. Poverty levels are much higher in rural than in urban areas; yet both show falling levels of poverty. In both urban and 
Table 4.4. Disaggregated poverty headcount data for Ghana

\begin{tabular}{lrrrrr}
\hline & $1991-2$ & $1998-9$ & $2005-6$ & $2005-6$ & $2012-13$ \\
\hline All Ghana & 51.7 & 39.5 & 28.5 & 31.9 & 24.2 \\
Urban & 27.7 & 19.4 & 10.7 & 12.4 & 10.6 \\
Rural & 63.6 & 49.5 & 39.3 & 43.7 & 37.9 \\
Accra (GAMA) & 23.1 & 3.8 & 10.6 & 12 & 3.5 \\
Urban Coastal & 28.3 & 24.2 & 5.5 & 6.4 & 10.1 \\
Urban Forest & 25.8 & 18.2 & 7.0 & 8.7 & 9.9 \\
Urban Savannah & 37.8 & 43.0 & 26.9 & 30.1 & 26.4 \\
Rural Coastal & 52.5 & 45.2 & 23.9 & 27.2 & 30.3 \\
Rural Forest & 61.6 & 38.0 & 27.9 & 33.1 & 27.9 \\
Rural Savannah & 73.0 & 70.0 & 60.3 & 64.2 & 55 \\
Western & 59.6 & 27.3 & 18.6 & 22.9 & 20.9 \\
Central & 44.3 & 48.4 & 19.9 & 23.4 & 18.8 \\
Greater Accra & 25.8 & 5.2 & 11.8 & 13.5 & 5.6 \\
Eastern & 48.0 & 43.7 & 31.7 & 37.3 & 33.8 \\
Volta & 57.0 & 37.7 & 14.7 & 17.8 & 21.7 \\
Ashanti & 41.2 & 27.7 & 20.5 & 24 & 14.7 \\
Brong Ahafo & 65.0 & 35.8 & 29.7 & 34 & 27.9 \\
Northern & 63.4 & 69.2 & 52.2 & 55.7 & 50.4 \\
Upper West & 88.4 & 83.9 & 70.5 & 72.9 & 44.4 \\
Upper East & 66.9 & 88.2 & 87.9 & 89.1 & 70.7 \\
North & 68.8 & 76.6 & 62.7 & 65.6 & 52.4 \\
South & 47.9 & 31.3 & 19.8 & 23.3 & 18.5 \\
Male & 54.9 & 41.0 & 31.5 & 34.9 & 25.9 \\
Female & 43.1 & 35.2 & 19.0 & 22.1 & 19.1 \\
\hline & & & & & \\
\hline
\end{tabular}

Source: Authors' computations based on Ghana Living Standards Survey data

rural areas, poverty reduction was less over the $1991 / 2$ to $2005 / 6$ period in the savannah ecological zone compared to the forest and coastal zones. The savannah is also the zone with the highest poverty levels by far in both urban and rural areas.

There are some differences though in the patterns of change between 2005/6 and 2012/13 compared to the earlier period. In this period the poverty reductions in percentage point terms are higher in the savannah zone than elsewhere, and poverty in fact increases in the coastal zones outside of Accra (as well as in the urban forest zone). What is clear is that over this latest period the urban poverty reduction is completely accounted for by Accra, while poverty in other urban areas in fact rises. It is also the case that measured poverty in Accra has been exceptionally volatile over time, falling sharply between 1991/2 and 1998/9 before rising to a significant extent between then and 2005/6 and then falling again from then to 2012/13. Whether this volatility reflects something about the data collection or is a real phenomenon is difficult to confirm from the available data.

In rural areas poverty in the savannah zone fell slowly between 1991/2 and 1998/9, and then more quickly between 1998/9 and 2005/6 and again between 2005/6 and 2012/13. Savannah remains the zone where poverty 
levels are by far the highest in Ghana. This zone only accounted for 20.5 per cent of the population in 2012/13 but 40.8 per cent of national poverty according to the headcount measure. Poverty in the rural forest zone fell very quickly between 1991/2 and 2005/6 and it continued to fall between $2005 / 6$ and 2012/13. As noted above, poverty rose in the rural coastal zone between $2005 / 6$ and 2012/13, in contrast to the sharp falls seen in the years leading up to this. This increased poverty in the coastal zone is the most striking finding of the analysis of the latest round of the GLSS surveys, a point acknowledged though not explained in the government's official poverty report.

An analysis by the ten main regions of Ghana covering the 1991/2 to 2005/ 6 period shows a pattern of generally significantly better progress in the seven southern or transition regions compared to the three northern regions; these are grouped together as 'south' and 'north' in Table 4.4. The poverty headcount for the three northern regions increased between 1991/2 and 1998/9, and by $2005 / 6$ poverty here was only 6.1 percentage points less than it had been in 1991/2. By contrast, the seven regions in the south had reduced their collective poverty headcount by 28.1 percentage points. In $2005 / 6$ the poverty headcount for the three northern regions was more than three times that for the seven southern regions. Between 2005/6 and 2012/13 poverty fell faster in the north than in the south, narrowing this gap, but it remains very large. The north-south gap in Ghana, a characteristic shared by other West African countries including Côte d'Ivoire and Nigeria, stands out as an important policy challenge in Ghana and a continually sensitive political issue.

Looking at the specific regions shows some diversity. In the north, sharp reductions in poverty between $2005 / 6$ and 2012/13 happened predominantly in the Upper West and especially the Upper East region, with poverty reduction being less in the Northern region. While the poverty headcount was much higher in the Upper West compared to the other regions in the north, in terms of accounting for the numbers in poverty, it was the Northern region which contributed much more, reflecting its higher population. Nearly 18 per cent of the poor in Ghana in 2012/13 were located in the Northern region. Similar diversity exists regarding poverty reduction in the south. The Ashanti and Brong Ahafo regions have shown consistent progress in poverty reduction over all the periods considered here. In other regions there has been a bit more variability. The Western and Volta regions showed impressive poverty reduction between 1991/2 and 2005/6, but much slower progress or slight regress respectively between 2005/6 and 2012/13. Poverty decreased much more slowly in the Eastern region, which from 2005/6 onwards was the poorest among the seven regions outside the north.

Computation of the $P_{2}$ Foster-Greer-Thorbecke poverty index (not presented here), which places much more emphasis on the depth of poverty, 
Table 4.5. Poverty headcounts by main economic activity

\begin{tabular}{lccccc}
\hline & $1991-2$ & $1998-9$ & $2005-6$ & $2005-6$ & $2012-13$ \\
\hline Public employees & 34.7 & 22.7 & 7.8 & & \\
Private formal employees & 30.3 & 11.3 & 10.2 & & \\
Private informal employees & 38.6 & 25.2 & 17.1 & & \\
Export farmers & 64.0 & 38.7 & 24.1 & & \\
Food crop farmers & 68.1 & 59.4 & 45.7 & & \\
Non-farm self-employed & 38.4 & 28.6 & 16.7 & & \\
Non-working & 18.8 & 20.4 & 13.0 & 9.0 & 7.1 \\
Public employee & & & & 14.3 & 10.8 \\
Private employee & & & 17.0 & 12.8 \\
Self-employed (non-agric.) & & & & 45.1 & 39.2 \\
Self-employed (agriculture) & & & & 20.0 & 28.1 \\
Unemployed & & & & 38.1 & 4.7 \\
Retired & & & & 38.6 & 23.6 \\
Other non-active & & & & \\
\hline
\end{tabular}

Source: Authors' computations based on Ghana Living Standards Survey data

highlights even more sharply the north-south differential in Ghana. In 2005/6 the $P_{2}$ value for the three regions in the north collectively was 0.176 compared to 0.020 in the south. While the ratio of these two figures had narrowed by 2012/13 there was still a difference of a factor of 5.6. The $P_{2}$ indices for the Upper West region were 0.328 in $2005 / 6$ and 0.188 in 2012/13. These values highlight that the relatively remote Upper West region is by far the poorest in Ghana.

Looking at poverty by the economic activity status of the household (Table 4.5) shows that the highest levels of poverty by far are among those reliant on agriculture for their primary economic activity. In all years this is consistently the group among which poverty levels are the highest. At the same time, the level of poverty in this group (as in most others) fell significantly over each of the sub-periods. Poverty levels are much lower among those self-employed in non-farm activities, and they too experience significant reductions in poverty over these periods. The group among which poverty seems to be falling less or even increasing in recent years is some of the households in which no one works. This group can be disaggregated in more detail for the last two rounds. This shows that the non-active and unemployed are the second poorest groups in 2005/6 and 2012/13, and poverty among the unemployed group increases quite sharply over this period.

Summary inequality indices are presented for Ghana for the same period in Table 4.6. The Gini coefficient at national level was 0.397 in 1991/2, and this rose in each following year to 0.407 in $1998 / 9,0.411$ in 2005/6, and 0.418 in $2012 / 13$. This pattern is as expected from the growth incidence curves seen in Figures 4.4 and 4.5 . The two members of the generalized entropy inequality indices presented here, the relative mean deviation and the Theil Index, show 
Table 4.6. Measures of inequality in Ghana, with a focus on southnorth differences

\begin{tabular}{lccc}
\hline & Gini & GE0 & GE1 \\
\hline 1991-2 & 0.373 & 0.231 & 0.249 \\
North & 0.382 & 0.243 & 0.255 \\
South & 0.363 & 0.216 & 0.237 \\
Share of between-group inequality &.. & 0.045 & 0.038 \\
1998-9 & 0.388 & 0.255 & 0.259 \\
North & 0.375 & 0.230 & 0.269 \\
South & 0.362 & 0.219 & 0.226 \\
Share of between-group inequality &.. & 0.135 & 0.111 \\
2005-6 & 0.406 & 0.286 & 0.301 \\
North & 0.424 & 0.303 & 0.312 \\
South & 0.378 & 0.237 & 0.265 \\
Share of between-group inequality &.. & 0.126 & 0.102 \\
2012-13 & 0.409 & 0.288 & 0.296 \\
North & 0.423 & 0.306 & 0.330 \\
South & 0.391 & 0.257 & 0.270 \\
Share of between-group inequality &.. & 0.079 & 0.066 \\
\hline
\end{tabular}

Source: Authors' computations based on Ghana Living Standards Survey data

the same pattern of change over time. Given the apparent importance of the north-south differential seen in Table 4.4, Table 4.6 presents values of the inequality indices for the north and the south of the country separately. What is clear from this is that the north of Ghana is not only much poorer, it is also more unequal, except perhaps in 1998/9. These decomposable generalized entropy indices can be used to identify the relative share of betweenand within-locational inequality. It is clear that in 1998/9 and 2005/6, more than 10 per cent of national inequality was accounted for by the difference in average consumption between the south and north of the country. This share had fallen by 2012/13, but the contribution of the north-south differential to national inequality remains substantial. At the same time, substantial inequality within each of these groups continues, and that inequality is especially high within the north.

\subsection{Progress in Non-monetary Indicators}

Table 4.7 reports various non-monetary indicators for the country as a whole, from 1993 (1988 for some indicators) to 2008. The indices reveal a similar pattern: infant and under-five mortality rates have declined remarkably well (although the level for a country with Ghana's GDP per capita is still on the high side); and secondary school attendance rates increased at the same time when income poverty went down. Access to services has also improved. 
Table 4.7. Trends in some headline non-monetary indicators in Ghana

\begin{tabular}{|c|c|c|c|c|c|c|}
\hline & & 1988 & 1993 & 1998 & 2003 & 2008 \\
\hline Infant mortality rate & & 77 & 66 & 57 & 64 & 50 \\
\hline Under-five mortality rate & & 155 & 119 & 108 & 111 & 80 \\
\hline$\%$ with $\mathrm{HFA}<-2 \mathrm{sd}$ & & 33.6 & 32.3 & 30.3 & 35.0 & 26.8 \\
\hline$\%$ with WFH $<-2$ sd & & 8.9 & 13.7 & 9.9 & 8.4 & 8.7 \\
\hline$\%$ with WFA $<-2$ sd & & 22.6 & 23.3 & 19.5 & 17.7 & 13.5 \\
\hline \multirow[t]{2}{*}{ Education level: Completed secondary or higher } & Male & & 10.8 & 45.7 & 40.6 & 47.7 \\
\hline & Female & & 5.7 & 33.4 & 32.5 & 38.1 \\
\hline Has electricity: Yes & & & 30.6 & 42.6 & 48.3 & 60.5 \\
\hline$\%$ with adequate drinking water source & & & 67.0 & 73.7 & 79.7 & 80.0 \\
\hline$\%$ within 15 minutes of water source & & & 60.9 & 56.6 & 61.8 & 67.4 \\
\hline$\%$ with flush or pit toilet & & & 69.4 & 79.4 & 78.2 & 80.5 \\
\hline$\%$ having received all vaccinations & & & 54.8 & 62.0 & 69.4 & 79.0 \\
\hline
\end{tabular}

Source: DHS, various years

The only indicator where progress is not so clear is the weight-for-height indicator for children. This measure captures short-term deficiencies in nutrition, and its development may have been influenced by improvements in child survival.

Heterogeneity in child mortality developments is examined in Table 4.8. The drop in both infant and under-five mortality has been especially pronounced in the rural areas, although the levels remain higher in the rural areas and in the poorer administrative regions. Regions where child mortality rates are high include Upper West and Northern regions, and also the Central region, despite it being located not too far from Accra.

A similar picture emerges from the differences between child mortality when classified based on mothers' education. Children with more educated mothers face a lower risk of death, but the situation has also improved for children of uneducated mothers.

Educational attainment has increased across all regions (Table 4.9), and if one looks at, for example, the age group 16-18, where there was more variance in the first period, some more backward areas have done exceptionally well: attendance increased by seventy-seven percentage points in the Upper East region. While gender gaps have declined, they still persist, for example in the Northern region, but also in Accra. One needs to remember, however, that improvements in the male-female ratio among older students take some time to materialize.

All in all, the monetary poverty developments and non-monetary indicators convey a similar story: while poverty has decreased and well-being increased, the differences across the country continue to be large. The same regions, predominantly in the north, where monetary poverty is persistent, also fare worse in terms of the non-monetary indicators. 
Table 4.8. Child mortality by regions and education

\begin{tabular}{|c|c|c|c|c|c|c|c|c|}
\hline & \multicolumn{4}{|c|}{ Infant mortality } & \multicolumn{4}{|c|}{ Under-five mortality } \\
\hline & 1993 & 1998 & 2003 & 2008 & 1993 & 1998 & 2003 & 2008 \\
\hline \multicolumn{9}{|l|}{ Residence } \\
\hline Urban & 54.9 & 42.6 & 55 & 49 & 89.9 & 76.8 & 93 & 75 \\
\hline $\begin{array}{l}\text { Rural } \\
\text { Region }\end{array}$ & 82.2 & 67.5 & 70 & 56 & 149.2 & 122 & 118 & 90 \\
\hline $\begin{array}{l}\text { Region } \\
\text { Western }\end{array}$ & 76.3 & 68.0 & 66.0 & 51 & 131.8 & 109.7 & 109.0 & $65^{*}$ \\
\hline Central & 71.6 & 83.8 & $50 *$ & $73^{*}$ & 128 & 142.1 & $90^{*}$ & $108^{*}$ \\
\hline Greater Accra & 58.4 & 41.4 & 45 & $36^{*}$ & 100.2 & 62 & 75 & $50^{*}$ \\
\hline Volta & 77.8 & 53.8 & 75 & $37^{*}$ & 116.4 & 98 & 113 & $50^{*}$ \\
\hline Eastern & 55.9 & 50.2 & 64 & $53^{*}$ & 93.2 & 89.1 & 95 & $81^{*}$ \\
\hline Ashanti & 65.2 & 41.9 & 80 & 54 & 97.6 & 78.2 & 116 & 80 \\
\hline Brong Ahafo & 48.7 & $77.3^{*}$ & 58 & $37^{*}$ & 94.6 & $128.7^{*}$ & 91 & $76^{*}$ \\
\hline Northern & 113.7 & 70.1 & 69 & 70 & 237 & 171.3 & 154 & 137 \\
\hline Upper West & $84.5^{*}$ & 70.6 & 33 & 97 & $187.7^{*}$ & 155.6 & 208 & $142^{*}$ \\
\hline Upper East & 105 & 81.6 & 105 & $46^{*}$ & 180.1 & 155.3 & 79 & $78^{*}$ \\
\hline \multicolumn{9}{|l|}{ Mother's education } \\
\hline No education & 87.1 & 69.3 & 66 & 61 & 165.7 & 130.8 & 125 & 102 \\
\hline Primary & 85.8 & 45.4 & 76 & 55 & 141.2 & 112.5 & 120 & 88 \\
\hline Middle/JSS & 55.4 & 39.9 & 60 & 46 & 89 & 91.3 & 92 & 68 \\
\hline Secondary/Higher & $28.2^{*}$ & $36.8^{*}$ & $29 *$ & $49 *$ & $40.7^{*}$ & $59.8^{*}$ & $34^{*}$ & $64 *$ \\
\hline Total & 74.7 & 61.2 & 64 & 50 & 132.8 & 110.4 & 111 & 80 \\
\hline
\end{tabular}

Note: *Figures are based on $250-499$ births.

Source: DHS data, various years

\subsection{Conclusions}

In many ways Ghana stands out as one of the most notable success stories in sub-Saharan Africa. It has had consistent growth in per capita GDP for thirty years; it has managed a successful, popular, and peaceful democratic transition; it has maintained political stability; and it has achieved impressive progress in monetary and non-monetary poverty reduction over the past twenty-five years. In many ways it is an impressive model.

While all this remains true, there are a number of important concerns in both the past record and perhaps especially in terms of risks for the future. Ghana has continually struggled with effective macroeconomic and fiscal policy management, the recent IMF loan being testament to this. Ghana has always struggled in managing inflation; it has not had a particularly strong record in private investment. Its manufacturing sector performance has been poor and it has made slow progress in transforming the economy. Oil has contributed to faster recent growth but may carry significant risks for the future performance of the Ghanaian economy.

And while Ghana has consistently reduced monetary and non-monetary poverty, the rate of responsiveness of the former to growth has not been very 
Table 4.9. School attendance by regions

\begin{tabular}{|c|c|c|c|c|c|c|c|c|}
\hline \multirow{3}{*}{$\begin{array}{l}\text { Survey } \\
\text { Sex }\end{array}$} & \multicolumn{8}{|c|}{ Age range $12-15$ years } \\
\hline & \multicolumn{2}{|c|}{$1991 / 2$} & \multicolumn{2}{|c|}{$1998 / 9$} & \multicolumn{2}{|c|}{$2005 / 6$} & \multicolumn{2}{|c|}{$2012 / 13$} \\
\hline & Male & Female & Male & Female & Male & Female & Male & Female \\
\hline Western & 83.2 & 75.5 & 93 & 84.3 & 98.9 & 94.5 & 98.6 & 96.9 \\
\hline Central & 83.3 & 71.4 & 89.1 & 81.6 & 99.6 & 97.7 & 96.9 & 96.6 \\
\hline Greater Accra & 93.2 & 77.7 & 87.3 & 85.4 & 98.1 & 97.4 & 99.7 & 98.3 \\
\hline Eastern & 90.4 & 81.1 & 87.1 & 77.4 & 98.6 & 96.8 & 98.8 & 98 \\
\hline Volta & 82.7 & 81.5 & 84.6 & 82 & 97.6 & 85.5 & 94.9 & 96.9 \\
\hline Ashanti & 94 & 76 & 85.4 & 78.3 & 98 & 94.1 & 98 & 96.9 \\
\hline Brong Ahafo & 83.3 & 82.5 & 88.7 & 82.3 & 95.3 & 91.8 & 96.2 & 95.8 \\
\hline Northern & 63.3 & 31.5 & 71.9 & 46.1 & 63.7 & 57.9 & 74.6 & 73.1 \\
\hline Upper West & 30.8 & 35.5 & 62.6 & 71.6 & 68.9 & 69.3 & 88.9 & 93.2 \\
\hline Upper East & 44.8 & 34.1 & 60.2 & 47.2 & 58.3 & 67.7 & 93.1 & 90.4 \\
\hline \multirow[t]{2}{*}{ All } & 81.5 & 70.8 & 83.8 & 76.8 & 90.4 & 88.5 & 95.1 & 94.7 \\
\hline & \multicolumn{8}{|c|}{ Age range $16-18$ years } \\
\hline Survey & \multicolumn{2}{|c|}{$1991 / 2$} & \multicolumn{2}{|c|}{$1998 / 9$} & \multicolumn{2}{|c|}{$2005 / 6$} & \multicolumn{2}{|c|}{$2012 / 13$} \\
\hline Sex & Male & Female & Male & Female & Male & Female & Male & Female \\
\hline Western & 60.3 & 47.3 & 50.1 & 41.1 & 95.5 & 92.2 & 98.2 & 94.7 \\
\hline Central & 61 & 51.7 & 49.2 & 32.5 & 100 & 96.5 & 93.9 & 97.8 \\
\hline Greater Accra & 65.9 & 52.5 & 68.4 & 43.4 & 97.7 & 93.7 & 99.2 & 92.1 \\
\hline Eastern & 57.1 & 36.5 & 46.1 & 42.8 & 94.8 & 95.5 & 99.1 & 98 \\
\hline Volta & 63.5 & 31.8 & 57.9 & 50.1 & 93.7 & 89.3 & 92.9 & 89.6 \\
\hline Ashanti & 55 & 36.3 & 40.1 & 43.4 & 97.4 & 94.4 & 97 & 97.8 \\
\hline Brong Ahafo & 65.9 & 53.6 & 55.6 & 37.9 & 87.3 & 92.8 & 94.3 & 91.5 \\
\hline Northern & 40.9 & 22.6 & 38.6 & 32.1 & 52.7 & 54.8 & 78 & 65.4 \\
\hline Upper West & 42.1 & 33.3 & 62.9 & 68.7 & 65.5 & 66.7 & 90.3 & 93.1 \\
\hline Upper East & 14.3 & 15 & 59.9 & 18.5 & 64.9 & 56.4 & 91.9 & 92.3 \\
\hline All & 56.9 & 41.1 & 51.9 & 41.8 & 87.6 & 87.3 & 94.2 & 92.1 \\
\hline
\end{tabular}

Source: GLSS

fast and inequality has consistently risen over the past twenty years. Poverty levels are much higher among those working in agriculture; the agricultural sector has also shown significantly slower growth. It has not been seen as a sufficient policy priority.

One aspect of this inequality has been the significant spatial diversity in the achievements in both monetary and non-monetary poverty. One dimension of this has been the significant disadvantage of the north of the country compared to the transition zone and the south, despite different policy measures to try to address this. There is a tension between this and the need to develop an effective manufacturing sector (McKay and Perge 2015), which is more likely to be located in the south to take advantage of transport links and agglomeration benefits. But a stronger policy focus on agriculture and enabling freer trade should benefit the north. However, there is also quite 
a high level of inequality within the north, and the spatial diversity has other aspects than just the north-south difference. Recent years show increasing poverty in the coastal zone and increasing urban poverty, some of which is linked to those without work. The limited employment creation in Ghana has been another important deficiency.

Thus, while there is much to applaud, Ghana will face increasing challenge in sustaining its poverty reduction record over the coming years.

\section{Acknowledgements}

We are grateful for survey data analysis relating to the latest household survey rounds undertaken by Edgar Cooke on which this chapter draws, as well as his advice. Part of the research for this chapter was conducted when Jukka Pirttilä visited ISSER in 2014. He wishes to express his gratitude to ISSER for all the hospitality extended on that occasion. The authors also acknowledge three unpublished overview papers on the Ghanaian economy prepared by respectively Charles Ackah, Johnson Wilson Appiah Kubi, Robert Darko Osei, Isaac Osei-Akoto, and Jukka Pirttilä; Samuel Kobina Annim and William Gabriel Brafu-Insaidoo; and Wisdom Akpalu under the UNU-WIDER Growth and Poverty Project (GAPP). The chapter draws on general insights from these papers. The authors are grateful for excellent research assistance provided by Sinikka Parviainen and Risto Rönkkö.

\section{References}

Annim, S., S. Mariwah, and J. Sebu (2012). 'Spatial inequality and household poverty in Ghana', Economic Systems, 36: 487-505.

Aryeetey, E., J. Harrigan, and M. Nissanke (eds) (2000). Economic Reforms in Ghana: The Miracle and the Mirage. Oxford: James Curry Press.

Aryeetey, E. and A. McKay (2007). 'Ghana: The Challenge of Translating Sustained Growth into Poverty Reduction', in T. Besley and L. Cord (eds), Delivering on the Promise of Pro-Poor Growth: Insights and Lessons from Country Experiences. Basingstoke and Washington, DC: Palgrave Macmillan and World Bank, 147-68.

Aryeetey, E. and F. Tarp (2000). 'Structural Adjustment and After: Which Way Forward? Economic Reforms in Ghana', Academy of Management Review, 12(1): 67-75.

Boateng, E. O., K. Ewusi, R. Kanbur, and A. McKay (1992). 'A Poverty Profile of Ghana, 1987-88', Journal of African Economies, 1(1): 25-58.

Coleman, S. (2012). 'Where Does the Axe Fall? Inflation Dynamics and Poverty Rates: Regional and Sectoral Evidence for Ghana', World Development, 40: 2454-67.

Coulombe, H. and A. McKay (1995). 'An Assessment of Trends in Poverty in Ghana 1988-1992', PSP Discussion Paper Series, No. 81, November. Washington, DC: World Bank. 
Coulombe, H. and Q. Wodon (2007). 'Poverty, Livelihoods and Access to Basic Services in Ghana'. Washington, DC: World Bank.

Cudjoe, G., C. Breisinger, and X. Diao (2010). 'Local Impacts of a Global Crisis: Food Price Transmission, Consumer Welfare and Poverty in Ghana', Food Policy, 35: 294-302.

Duclos, J.-Y., D. Sahn, and S. Younger (2006). 'Robust Multidimensional Spatial Poverty Comparisons in Ghana, Madagascar, and Uganda', World Bank Economic Review, 20: 91-113.

GSS (Ghana Statistical Service) (2007). 'Pattern and Trends of Poverty in Ghana'. Accra: Ministry of Finance and Economic Planning.

GSS (Ghana Statistical Service) (2008). 'Report on Ghana Living Standard Surveys'. Accra: Ministry of Finance and Economic Planning.

GSS (Ghana Statistical Service) (2014). 'Poverty Profile of Ghana, 2005 to 2013'. Accra: Ministry of Finance and Economic Planning.

Gockel, A. F. and N. Amu (2003). 'Financial Sector Liberalization and the Labour Market in Ghana'. Legon, Accra: Economics Department, University of Ghana.

Huq, M. M. (1989). The Economy of Ghana: The First Twenty-Five Years since Independence. London: Macmillan.

International Monetary Fund (2015). 'Ghana', IMF Country Report No. 15/103, Washington, DC.

Jedwab, R. and R. Osei (2012). 'Structural Change in Ghana 1960-2010', Institute for International Economic Policy Working Paper, September. Washington DC: Institute for International Economic Policy, George Washington University.

Killick, T. (2010). Development Economics in Action: A Study of Economic Policies in Ghana, Second edition. London: Taylor \& Francis.

Leite, S. P. A., L. Zanforlin, G. Begashaw, S. Fabrizio, and J. Harnack (2000). 'Ghana: Economic Development in a Democratic Environment', IMF Occasional Paper 199. Washington, DC: International Monetary Fund.

Lloyd, T., O. Morrissey, and R. Osei (2001). 'Aid, Exports and Growth in Ghana', CREDIT Research Paper (01/01), Centre for Research in Economic Development and International Trade, University of Nottingham.

McKay, A. and E. Perge (2015). 'Spatial Inequality and its Implications for GrowthPoverty Reduction Relations', in A. McKay and E. Thorbecke (eds), Economic Growth and Poverty Reduction in Sub-Saharan Africa: Current and Emerging Issues. Oxford: Oxford University Press.

Osei, R. D. (2012). 'Aid, Growth and Private Capital Flows to Ghana', WIDER Working Paper No. 2012/22. Helsinki: UNU-WIDER.

Osei, R. D. and G. Domfe (2008). 'Oil Production in Ghana: Implications for Economic Development', Real Instituto Elcano, ARI 104/2008. 


\section{5}

\section{Did Rapid Smallholder-Led Agricultural Growth Fail to Reduce Rural Poverty? Making Sense of Malawi's Poverty Puzzle}

Karl Pauw, Ulrik Beck, and Richard Mussa

\subsection{Introduction}

Poverty reduction is a primary development goal in Malawi. While a variety of policy interventions and strategies have sought to reduce poverty, the most significant policy intervention in recent years has been the Farm Input Subsidy Programme (FISP). FISP provides heavily subsidized fertilizer and other farm inputs to between 1.5 and 2 million poor smallholders at a cost of around 3 per cent or more of annual GDP. Although the programme is primarily designed to address food security through increasing maize yields, its significant burden on public resources has meant that the programme's wider impact on growth and poverty reduction has also been closely scrutinized as it is believed to crowd out other government interventions.

Malawi's recent growth performance has been remarkable. Official national accounts data reveal strong growth across all Malawi's economic sectors during 2005-11, with per capita GDP growth averaging 3.5 per cent per annum (NSO 2012b). Growth was particularly robust in the agricultural sector, which government attributes to FISP (GoM 2012). Since a large majority of the poor are rural smallholder farmers, and since about half of these farmers were explicitly targeted by the subsidy programme, the expectation was always that Malawi's growth trajectory during this period would be highly propoor, even if poverty reduction was not necessarily a primary goal of the subsidy programme.

Prior to the release of official poverty estimates in 2012, a heated debate had already developed over the desirability, sustainability, and overall impact of 
input subsidy programmes in Malawi and elsewhere in the continent (see, for example, Chirwa and Dorward 2013; Jayne et al. 2013; Lunduka et al. 2013; Arndt et al. 2015). Although initially praised globally as a bold and resoundingly successful initiative, emerging survey evidence was beginning to cast doubt on the ability of FISP to raise maize yields enough for direct benefits to outweigh programme costs, while official crop production estimates which underlie GDP estimates were also being questioned (see Pauw and Thurlow 2014).

The FISP 'success story' unravelled further when official poverty estimates suggested that purported economic growth had in fact not been accompanied by rapid poverty reduction as expected: using the latest two rounds of Integrated Household Surveys (IHSs), the National Statistical Office (NSO 2012a) reported that the poverty headcount rate declined only marginally from 52.4 per cent in 2004/5 (IHS2) to 50.7 per cent in 2010/11 (IHS3). Even more disconcerting was the fact that rural poverty had apparently increased marginally over the period despite the introduction and scaling up of FISP during this time.

This growth-poverty puzzle justifies further investigation. One possibility is that economic growth, and particularly agricultural growth, is overstated in national accounts; another is that the structure of growth was such that it did not benefit those close enough to the poverty line to be lifted out of poverty. However, it is equally possible that poverty estimates understate the reduction in poverty. We focus on the latter and undertake our own consumption-based poverty analysis using the same datasets as in the official poverty analysis conducted by Malawi's National Statistical Office (NSO).

Several methodological advances distinguish our approach from that of the NSO. First, we allow the consumption bundles from which poverty lines are derived to change over time as consumers near the poverty line adjust their spending patterns in response to relative price changes. Second, rather than relying on a national poverty line only, we construct regional poverty lines that account for variations in consumption preferences, prices, and non-food consumption shares. In doing so we return to the tradition of using regional poverty lines in Malawi in the late 1990s (see Mukherjee and Benson 2003).

Third, we adopt a slightly revised version of Ravallion's (1998) iterative procedure to devise consumption bundles and poverty lines that more closely represent actual consumption preferences of the poor, as well as an entropybased method by Arndt and Simler (2010) that ensures that poverty bundles are utility-consistent. Finally, we use a revised set of conversion factors (Verduzco-Gallo et al. 2014) for converting non-standard food consumption into standard units. This may influence unit costs of foods and hence the estimate of household consumption spending or the poverty line. 
In contrast to the official poverty estimate, our analysis reveals large declines in regional and national poverty in Malawi between 2004/5 and 2010/11. Poverty declined by 7.5 and 10.3 percentage points in rural and urban areas respectively, which is more consistent with the economic growth trajectory reported in the national accounts as well as reported improvements in several non-monetary dimensions of welfare. Although weaknesses in Malawi's economic statistics compel us to remain cautious in our conclusions, and while we do not explicitly test causality, our results ultimately corroborate a much more positive narrative about FISP and its impact on growth and poverty reduction compared to the more pessimistic view held by many.

The chapter is structured as follows. Section 5.2 further explores the official evidence on economic growth and poverty trends in Malawi. Section 5.3 describes, in simplistic terms, the method for constructing utility-consistent regional poverty lines for Malawi and contrasts this with the method used by the NSO. Section 5.4 presents our consumption-based poverty results as well as trends in non-monetary poverty; and finally, section 5.5 concludes and highlights areas for further research.

\subsection{Recent Evidence of Growth and Poverty Trends in Malawi}

Rain-fed smallholder maize production accounts for around one quarter of agricultural GDP in Malawi. The agricultural sector, in turn, accounts for 30 per cent of the economy (Benin et al. 2012). This high dependence on a single, large agricultural subsector is a major reason for Malawi's highly erratic economic growth path. Since around 2006, however, favourable weather combined with the introduction of the Farm Input Subsidy Programme (FISP) has contributed to robust and more stable agricultural growth led by rapidly rising maize yields (see Figure 5.1). The initial success of Malawi's FISP created renewed interest globally in fertilizer subsidies as a tool for promoting growth while at the same time ensuring food security and reducing poverty.

Increased yields achieved under FISP led to a significant increase in maize production. Although FISP was also associated with relative declines in maize prices, these were found to be fairly small (Ricker-Gilbert 2014), and as a result agricultural GDP still grew strongly. The first three columns of Table 5.1 report average sector-level and national GDP growth rates for different sub-periods (i.e. 2005-7, 2005-11, and 2007-11). Agricultural growth was particularly rapid during the first years of FISP (2005-7) but then slowed down as the potential for further yield gains through input subsidies was exhausted. The years 2010 and 2011 were exceptionally troublesome years for the important tobacco sector, which faced large declines in international prices and domestic sales volumes. However, despite these setbacks, the average agricultural 


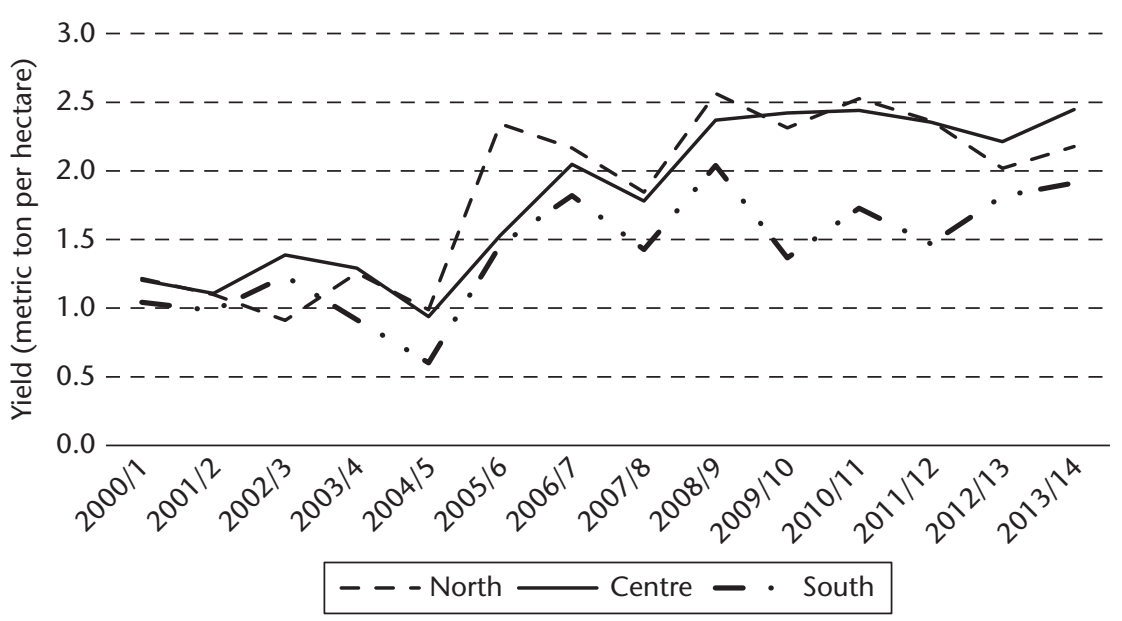

Figure 5.1. Maize yields by region: Smallholder summer harvest, 2000/1-11/12 Source: Authors' calculations using data from MoAFS (2013)

Table 5.1. Sectoral GDP growth rates and contributions to change in GDP, 2005-11

\begin{tabular}{|c|c|c|c|c|c|c|c|}
\hline & \multicolumn{3}{|c|}{ Average growth rates (\%) } & \multirow{2}{*}{$\begin{array}{l}\text { Value added } \\
\text { share } \\
2005-11(\%)\end{array}$} & \multicolumn{3}{|c|}{ Contribution to change (\%) } \\
\hline & $2005-7$ & 2007-11 & $2005-11$ & & $2005-7$ & 2007-11 & 2005-11 \\
\hline Agriculture & 15.9 & 7.3 & 10.1 & 30.0 & 54.7 & 26.4 & 34.2 \\
\hline $\begin{array}{l}\text { Mining, industry, and } \\
\text { construction }\end{array}$ & 3.0 & 11.4 & 8.5 & 16.7 & 6.3 & 22.7 & 18.2 \\
\hline Trade and transport & 5.5 & 6.1 & 5.9 & 21.2 & 15.3 & 15.2 & 15.2 \\
\hline Private services & 7.6 & 11.7 & 10.3 & 18.8 & 16.6 & 25.8 & 23.3 \\
\hline Government services & 4.1 & 6.4 & 5.6 & 13.3 & 7.2 & 9.9 & 9.2 \\
\hline National GDP & 6.2 & 7.5 & 7.1 & 100.0 & 100.0 & 100.0 & 100.0 \\
\hline
\end{tabular}

Source: Authors' calculations based on data from NSO (2012b)

growth rate over the whole FISP period remained above 10 per cent per annum. Malawi's growth path can be described 'broad-based', with strong growth also in non-agricultural sectors. The final columns show sector-level value added shares and average contributions to national GDP. As expected, given its size and high rate of growth, agriculture remained a major driver of growth during the FISP period, with a contribution of 34.2 per cent to overall GDP expansion.

These results paint a very positive story about Malawi's recent economic performance and the role of agriculture. Growth far outstripped population growth of around 3.3 per cent per annum. Moreover, growth was driven to a large extent by smallholder maize production increases, a crop cultivated by the vast majority of farmers. Since around 90 per cent of Malawians live in 


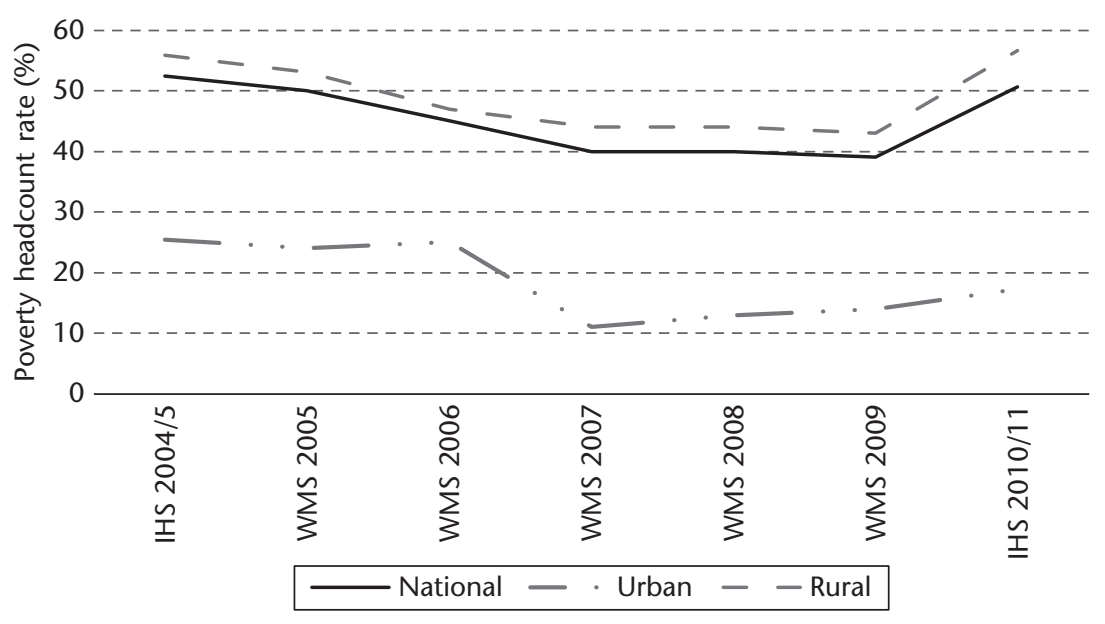

Figure 5.2. Official poverty headcount rates, 1997/8-2010/11

Source: Authors' calculations based on NSO $(2005,2010,2012 a)$

predominantly poor, rural farm households (Benin et al. 2012), one would very legitimately expect that the level and structure of growth would have had a significant impact on rural poverty.

The most recently released poverty trends in Malawi are based on the comparison of per capita consumption welfare aggregates from two rounds of household surveys (i.e. the IHS2 in 2004/5 and the IHS3 in 2010/11). During the inter-survey period, the NSO also published a series of poverty estimates based on imputed consumption from several rounds of Welfare Monitoring Surveys (WMSs). The imputations, which were necessary because the WMSs did not include a detailed expenditure module, were done on the basis of an econometric model fitted to the IHS2 data, with right-hand side variables including household demographics, health, education, employment, housing conditions, and amenities that are included in both the IHS2 and WMSs. The poverty trend from these WMSs showed a sharp decline in poverty to around 39 per cent in 2009 (NSO 2010) (see Figure 5.2), which at the time created the expectation that the imminent poverty rates from the IHS3 would be of a similar magnitude.

The WMS poverty trend also seemed entirely consistent with national accounts data available at the time. For example, using a general equilibrium model for Malawi, Pauw et al. (2011) replicate the reported agricultural production and economic growth trends for 2005-10. The model yields a poverty rate of about 40 per cent by 2010, which is remarkably close to the estimate in the WMS 2009. However, contrary to expectations, the official poverty figures for 2010/11, which were finally released in 2012 after much delay, were a major disappointment. Although urban poverty declined sharply from 25.4 to 
17.3 per cent, the biggest concern was the increase in rural poverty from 55.9 to 56.6 per cent. National poverty declined only marginally from 52.4 to 50.7 per cent over the period.

One possible explanation for this unexpected result is that the production effect of FISP and hence estimates of economic growth may have been vastly overstated (see Jayne et al. 2008; Chirwa and Dorward 2013). Another is that growth did not trickle down to the rural poor, which is unlikely given overwhelming evidence that growth is generally associated with declines in poverty (Dollar et al. 2013), and that agricultural growth in particular is strongly pro-poor (Diao et al. 2010). However, the rising rural-urban income divide and an overall increase in inequality as measured by the Gini coefficient (i.e. from 0.39 to 0.45 ) (NSO 2012a) does seem to suggest that growth may have disproportionately benefitted wealthier sections of the population. Yet another possibility is that the decline in poverty has been understated in the official estimates. The remainder of this chapter focuses on this third possible explanation for the growth-poverty puzzle in Malawi; particularly, we explore how the NSO estimated their poverty rates and provide alternative estimates of our own that are based on a method that introduces some advances over the one used by the NSO.

\subsection{Constructing Regional Poverty Lines for Malawi}

In this section we briefly, and in largely non-technical terms, explain the method adopted to estimate regional poverty lines for Malawi. As far as possible, we compare this against the NSO method to provide a simplistic explanation of possible sources of difference between our estimates and those of the NSO. For a more comprehensive and technical discussion please refer to Pauw et al. (2014).

\subsubsection{Poverty and Prices}

In its official assessment of poverty in 2004/5 the NSO followed a cost of basic needs approach to estimate national food and non-food poverty lines. However, in coming up with a new set of poverty lines for 2010/11, they opted not to follow this approach, arguing that the standard of living implied by any newly estimated consumption bundle would not necessarily be utilityconsistent with the IHS2 bundle (NSO 2012a). This may be true, but as we explain in this section there are approaches in the literature that allow us to overcome this problem.

NSO's approach was to estimate an inflation rate they believed to be representative of price changes faced by the poor. The $2004 / 5$ poverty line(s) were 
then multiplied by the inflation rate to arrive at the new lines for 2010/11. Rather than using the implicit prices contained in the two household surveys to estimate inflation, the NSO opted to derive an inflation estimate on the basis of a revised consumer price index (CPI). The official CPI traditionally used to monitor rural and urban inflation was thought to understate the true extent of price increases over the analysis period, and hence this revision was carried out with technical assistance from South Africa's statistics agency and the World Bank. The original and revised CPI series are shown in Table 5.2.

One particular oddity about the NSO's approach is that although the revised CPI suggests significantly higher inflation for food products compared to nonfood products, both the food poverty line (representing 'ultra-poverty') and the overall poverty line (food plus non-food) were adjusted by the same 'poverty line inflation rate' (i.e. by 128.9 per cent). Their own data also show large differences in rural and urban food and non-food inflation rates, but in the interest of maintaining a single national poverty line this difference was disregarded.

The last section of Table 5.2 shows a 'true' estimate of inflation based on the revised price indexes for urban and rural food and non-food items. Essentially, in doing this exercise, we assume that the food and non-food indexes as reported, and hence their reported inflation rates, are correct; but we then use actual food/non-food consumption shares of relatively poor householdsdefined for simplicity as those below the median per capita consumption

Table 5.2. Official and revised CPI and inflation estimates

\begin{tabular}{|c|c|c|c|c|c|c|c|c|c|}
\hline & \multicolumn{3}{|c|}{ National } & \multicolumn{3}{|c|}{ Urban } & \multicolumn{3}{|c|}{ Rural } \\
\hline & $\begin{array}{l}\text { All } \\
\text { items }\end{array}$ & Food & $\begin{array}{l}\text { Non- } \\
\text { food }\end{array}$ & $\begin{array}{l}\text { All } \\
\text { items }\end{array}$ & Food & $\begin{array}{l}\text { Non- } \\
\text { food }\end{array}$ & $\begin{array}{l}\text { All } \\
\text { items }\end{array}$ & Food & $\begin{array}{l}\text { Non- } \\
\text { food }\end{array}$ \\
\hline \multicolumn{10}{|c|}{ (a) Official estimates } \\
\hline CPI 2004/5 & 178.0 & 161.1 & 201.3 & 192.1 & 183.9 & 196.6 & 171.8 & 155.9 & 205.4 \\
\hline CPI 2010/11 & 315.6 & 276.3 & 370.0 & 379.7 & 425.9 & 354.7 & 287.8 & 242.7 & 383.5 \\
\hline Inflation (\%) & 77.3 & 71.5 & 83.8 & 97.6 & 131.6 & 80.4 & 67.5 & 55.6 & 86.7 \\
\hline \multicolumn{10}{|c|}{ (b) Revised estimates } \\
\hline CPI 2004/5 & 212.7 & 220.5 & 201.9 & 199.5 & 202.5 & 197.9 & 218.4 & 224.5 & 205.3 \\
\hline CPI 2010/11 & 488.1 & 543.8 & 411.0 & 457.9 & 549.6 & 408.1 & 501.4 & 542.5 & 413.7 \\
\hline Inflation (\%) & 128.9 & 146.7 & 103.6 & 128.9 & 171.4 & 106.2 & 128.9 & 141.7 & 101.5 \\
\hline \multicolumn{10}{|c|}{ (c) 'True' inflation } \\
\hline CPI 2004/5 & 213.4 & 220.5 & 201.9 & 200.7 & 202.5 & 197.9 & 217.2 & 224.5 & 205.3 \\
\hline CPI 2010/11 & 499.0 & 543.8 & 411.0 & 494.8 & 549.6 & 408.1 & 499.5 & 542.5 & 413.7 \\
\hline Inflation (\%) & 133.8 & 146.7 & 103.6 & 146.5 & 171.4 & 106.2 & 130.0 & 141.7 & 101.5 \\
\hline
\end{tabular}

Note: CPI 2004/5 represents the average index value for the period March 2004-March 2005, which is the period during which the IHS2 was conducted. Similarly, CPI 2010/11 represents the average index value for March 2010-March 2011. The 'true' inflation rates are obtained by averaging food and non-food inflation rates using actual consumption shares of relatively poor households.

Source: Official CPI estimates from NSO website (<http://www.nsomalawi.mw/>); revised CPI estimates obtained from NSO as supplementary material to IHS3 report (NSO 2012a) 
level-to construct new weighted average indexes for 'all items'. This is done separately for rural and urban as well as at national level. As can be seen, these index values, and hence their associated inflation estimates, are quite different from the 128.9 per cent estimate of NSO. We are only able to (roughly) replicate the NSO's national 'all item' index values of 212.7 in 2004/5 and 488.1 in 2010/11 and hence their national inflation rate of 128.9 per cent using the 2004/05 consumption weights for all households (i.e. poor and non-poor) in both years 2004/05 and 2010/11. Our contention is that the NSO's inflation rate is not necessarily representative of the inflation faced by the poor and fails to account for differences in food and non-food inflation in urban and rural areas.

\subsubsection{Regions, Preferences, and Utility Consistency}

Although official poverty estimates have always been reported at a regional level in Malawi, region-specific poverty lines were last constructed using the first Integrated Household Survey (IHS1) of 1997/8 (Mukherjee and Benson 2003; NSO 2010). Following the IHS1 approach we include four regions of Malawi: rural areas are divided along the three administrative regions, namely 'south rural', 'centre rural', 'north rural', while a fourth region comprises all major urban centres, including Mzuzu in the north, Lilongwe in the centre, and Blantyre and Zomba in the south. The rationale for having a regional disaggregation is to capture regional differences in consumption preferences, relative prices of commodities or their changes over time (i.e. regional inflation rates), and demographic composition which affects calorie needs. Taking account of regional and temporal differences in prices and preferences tends to have a significant impact on estimated poverty lines (Tarp et al. 2002).

As is common in the literature we use consumption expenditure rather than income in our poverty estimation, mainly because consumption expenditure provides a smoother, less lumpy measure of welfare through time. The consumption aggregate used in the official poverty assessment is publicly available and consists of food and non-food components, with the latter consisting of expenditure on non-durable goods, estimated use value of durable consumer goods, and the rental value of housing. Whereas we adopt the NSO non-food consumption measure for our own analysis, we construct a new food consumption component.

Total quantity of food consumed in a household is the sum of purchased food, own production, and gifts. Food consumption is based on a seven-day recall period. In order to carry out meaningful analysis, quantity units of measurement-these include standard (metric) and non-standard units (e.g. plates, cups, bags, or pails) — need to be converted into grams using conversion factors typically supplied with household expenditure survey data. Conversion 
factors take into account the volume of the measurement unit but also the weight density of the particular food product. The quality of conversion factors is crucial for determining unit costs of food consumption baskets.

We use versions of the official conversion factors for IHS2 and IHS3 that were systematically checked for errors and cleaned by Verduzco-Gallo et al. (2014) to construct both our consumption aggregate and estimated poverty lines. This explains at least some of the differences between our consumption aggregate and the one used in the official poverty assessment. The differences in conversion factors also affect poverty lines through the composition and cost of the poverty line food bundle, although since we use regional poverty lines as opposed to a national one, regional differences in prices and consumption patterns also influence the final results.

Since respondents provide estimates of both the cost and quantity of purchased food, this data can be used to estimate unit values for different food items. The valuation is carried out in the same way as the NSO describe their valuation. If a household reports to have consumed a food item not purchased in the last week (e.g. gifts, own production, or food purchased earlier), the median unit value from its cluster is used to value that consumption. If no other household in that cluster consumed the same item, or if there were not enough observations to obtain a reliable unit value, the median unit value from the next geographical level within which the household resides was used to estimate the value of that consumption. Total food expenditure for each household is calculated by multiplying the unit values by the quantity consumed. In principle, the use of revised conversion factors should be the only factor that may cause our food consumption estimate to differ from the official one.

Once a consumption aggregate has been estimated, it is necessary to construct a poverty line, or in our case, several regional poverty lines. The total poverty line for each region is the sum of the food and non-food poverty lines. The poverty line and its subcomponents reflect value judgements about basic food and non-food needs, and are set in terms of a level of per capita consumption expenditure that is deemed consistent with meeting those basic needs at prevailing prices. The level at which the food poverty line is set is crucial to our understanding of poverty since poor households allocate such a significant proportion of their spending to food. The non-food poverty line, on the other hand, recognizes that the poor also allocate a non-trivial proportion of their total consumption to non-food items.

For each of the four regions a food poverty line is constructed by determining the food energy (caloric) availability for the reference population (i.e. the poor), the caloric content of the typical diet of the poor in that region, and the average cost (at local prices) of calories when consuming that diet. Thus, the food poverty line, expressed in this instance in Malawi Kwacha (MWK) per 
person per day, is the area-specific cost of meeting the minimum caloric requirements when consuming a food bundle comprised of goods that the poor in a particular area typically consume. Essentially, the caloric requirement is a way of anchoring the estimated poverty line at a specific welfare level. We therefore opt to use the same caloric requirement as the NSO, namely 2,400 kilocalories per person per day (NSO 2005, 2012a).

The first step in our poverty line estimation is to establish reasonable cost estimates of commonly consumed food commodities. Following Arndt and Simler (2010), we assume the most common food items consumed by the poor to be those that account for 90 per cent of their food expenditure. On average, we find that these bundles represent about 95 per cent of caloric availability. The values of these area-specific food bundles are then scaled to equal 100 per cent of calorie requirements. Each household's food consumption bundle therefore essentially excludes less common (and often more expensive) sources of calories. A set of household-specific prices is then calculated (i.e. amount spent divided by quantity in grams). The median unit values of these price distributions will eventually be used in valuing regional bundles.

In order to ensure that our poverty lines reflect preferences and prices faced by poor people, we adopt and modify an iterative process described by Ravallion (1998). In the original procedure, households are first ranked by consumption per capita, and then the bottom $x_{1}=60$ per cent of households is at first arbitrarily identified as the relatively poor. This means $x_{1}$ may be regarded as a preliminary estimate of the poverty headcount rate. These 'poor' households' food quantities and prices are then evaluated to estimate the cost of the calories they obtain. Preliminary poverty line calculations are made using the minimum caloric requirement as the basis, and the nominal consumption values are converted into real terms by taking into account region-specific differences in the cost of acquiring the basic needs bundle. This gives a preliminary poverty headcount ratio $x_{2}$. Households are then re-ranked using this first approximation of consumption per capita in real terms, and the bottom $x_{2}$ per cent of this ranking identified as the relatively poor. Observed consumption patterns and prices in this subsample are calculated, producing a second estimate of poverty lines. This gives another preliminary poverty headcount ratio $x_{3}$. Again households are ranked by their real expenditure, and the iterative process continues until the poverty line converges, meaning that the same, or nearly the same, subsample of households are identified as the poor.

Applying this procedure to Malawi yielded a very low poverty line and hence a very low poverty rate. Therefore, we adopt a slightly modified version of the iterative procedure in that the poorest 60 per cent of the population was used in each iteration. Between each iteration the consumption aggregate was deflated by the estimated poverty lines only. Since poverty lines were 
estimated at the regional level, this procedure allowed the final consumption baskets to be calculated based on the consumption of the 60 per cent poorest in terms of real consumption. This is, however, still a deviation from the approach taken by the NSO where the poverty line was based on the fifth and sixth consumption deciles.

The above procedure should reduce poverty rate bias; however, there is no guarantee that the estimated poverty lines are consistent across time and space. Arndt and Simler (2010) found that in both Mozambique and Egypt poverty lines based on such traditional iterative methods produced biased poverty estimates. This study therefore adopts the methodological advancement first proposed by Arndt and Simler (2010) to ensure that poverty lines are utility-consistent. The method is not described in detail here, but essentially entails use of an entropy-based approach that makes small adjustments to budget shares until imposed constraints-in this instance, utility consistency-are satisfied. The method ensures that the information content in the original budget shares is preserved to the greatest degree possible. Spatial utility consistency is ensured if the regional bundles satisfy revealed preference conditions. This means that the 2010/11 bundle of domain A is not manifestly of higher quality than the 2010/11 bundle of domain B (and vice versa); similarly, the 2004/5 bundle of domain A is not manifestly of higher quality than the 2010/ 11 bundle of domain $\mathrm{A}$ (and vice versa).

The next step is to estimate a non-food poverty line. Similar to the approach adopted by the NSO, this is taken as a weighted average of non-food expenditure for people with food expenditure at between 80 and 120 per cent of the food poverty line. A triangular weighting scheme is used where the closer a household's food expenditure is to the poverty line, the higher the weights. The sum of the non-food and food poverty lines is the total poverty line, which is the basis for calculating initial poverty rates.

Having derived the poverty lines, the next step is to estimate poverty rates. Since expenditure data are collected at the household level, we assume a uniform intra-household distribution such that each household member has the same per capita expenditure level. In keeping with the popular poverty literature, we use poverty measures proposed by Foster et al. (1984):

$$
P(z, \alpha)=\frac{1}{N} \sum_{i=1}^{N}\left(\frac{z-y_{i}}{z}\right)^{a} I\left(y_{i}<z\right)
$$

In equation (5.1), $y_{\mathrm{i}}$ is per capita consumption expenditure of person $i$ drawn from a sample of size $N, z$ is a poverty line, $a$ is a measure of poverty aversion, and $I($.$) is an indicator function equal to one if the condition y_{i}<z$ holds, and zero otherwise. The parameter $a$ takes on values of 0,1 , or 2 to measure the poverty headcount rate, poverty gap, and squared poverty gap respectively. 
Specifically, when $\alpha=0$, we have the poverty headcount index. This gives the percentage of the population who are, based on consumption, poor. The headcount is easy to interpret; however, it has some limitations. It neither takes into account how close or far the consumption levels of the poor are to the poverty line, nor the distribution among the poor. When $\alpha=1$, we have the poverty gap index. It measures the extent of the difference between the poverty line and the average consumption of poor households. This measure captures changes in poverty that the poverty headcount index does not detect. For instance, if the consumption of the poor increases without necessarily crossing the poverty line, the headcount will not detect this change, while the poverty gap will. For $\alpha=2$, we have the squared poverty gap index. It measures the severity of poverty, and also takes into account inequality changes among the poor. A transfer from a poor person to somebody less poor may leave unaffected the headcount or the poverty gap but will increase this measure. Our analysis focuses on the poverty headcount rate $(\alpha=0)$.

\subsection{Results and Analysis}

\subsubsection{Monetary Poverty Analysis}

In this section we present our estimates of changes in monetary (or consumptionbased) poverty in Malawi between 2004/5 and 2010/11. Throughout we compare our estimates with the official poverty estimates of the NSO. Differences between our poverty results and those of the NSO reflect differences in poverty lines as well as differences in the distribution of the consumption aggregates used in the respective poverty analyses.

Our estimated poverty lines are reported in Table 5.3 and compared with the official food, non-food, and national poverty lines used by the NSO. All poverty lines are converted to Malawi Kwacha (MWK) per person per day. In order to facilitate the comparison, we present, in addition to our regional poverty lines, population-weighted national average poverty lines, which can be compared against the NSO's national poverty lines. We also estimate an average rural poverty line in the same manner. Given the approach adopted here, our poverty lines may vary by region, while, more importantly, the implied inflation rate faced by the poor-we refer to it here as the "poverty line inflation rate' - may also vary by region and for food or non-food items.

While both food and non-food poverty lines of the urban and rural northern regions as well as the non-food poverty line for the central rural region are above the official estimates, the food poverty lines of rural south and rural central as well as the non-food poverty line of rural south are below the official estimates. We estimate a national poverty line of MWK 43.2 per person per day, which is about 2.4 per cent below the official estimate of MWK 44.3. In 
Table 5.3. Food, non-food, and overall poverty lines for $2004 / 5$ and $2010 / 11$

\begin{tabular}{|c|c|c|c|c|c|c|c|c|c|}
\hline & \multicolumn{6}{|c|}{ Poverty lines (Malawi Kwacha/person/day) } & \multicolumn{3}{|c|}{ Poverty line inflation rates } \\
\hline & \multicolumn{3}{|c|}{ IHS2 (2004/5) } & \multicolumn{3}{|c|}{ IHS3 (2010/11) } & & & \\
\hline & Food & $\begin{array}{l}\text { Non- } \\
\text { food }\end{array}$ & Total & Food & $\begin{array}{l}\text { Non- } \\
\text { food }\end{array}$ & Total & Food & $\begin{array}{l}\text { Non- } \\
\text { food }\end{array}$ & Total \\
\hline National & 26.0 & 17.2 & 43.2 & 59.4 & 33.1 & 92.5 & 128.2 & 92.5 & 114.0 \\
\hline Urban & 30.3 & 26.7 & 57.0 & 65.4 & 62.1 & 127.5 & 116.1 & 132.5 & 123.8 \\
\hline Rural & 25.5 & 16.0 & 41.5 & 58.3 & 28.0 & 86.2 & 128.8 & 74.8 & 108.0 \\
\hline North rural & 29.7 & 16.3 & 46.1 & 64.7 & 31.0 & 95.4 & 117.5 & 89.5 & 108.0 \\
\hline Centre rural & 26.1 & 17.6 & 43.8 & 59.8 & 28.7 & 88.4 & 128.8 & 62.6 & 102.1 \\
\hline South rural & 23.8 & 14.4 & 38.2 & 55.0 & 26.4 & 81.3 & 131.0 & 83.5 & 113.1 \\
\hline $\begin{array}{l}\text { NSO poverty line } \\
\text { (national) }\end{array}$ & 27.5 & 16.8 & 44.3 & 62.9 & 38.5 & 101.4 & 128.9 & 128.9 & 128.9 \\
\hline
\end{tabular}

Note: Poverty lines are estimated for each of the four regions. Estimates for 'national' and 'rural' poverty lines are population-weighted averages of the region-specific poverty lines.

Source: NSO (2012a) and authors' estimates based on IHS2 and IHS3

2010/11 all food and non-food poverty lines of the rural regions are lower than the official lines, except the food poverty line in the rural north, which is slightly higher. As in 2004/5 the urban food poverty line and in particular the non-food poverty line are above the official lines. The overall poverty line of MWK 92.5 per person per day is about 8.8 per cent lower than the official poverty line of MWK 101.4. Our estimated national poverty line inflation rate is 114.0 per cent, which is somewhat lower than the 128.9 per cent estimated by the NSO. We therefore concur that the official inflation estimate of 77.3 per cent (see Table 5.2) understates actual inflation faced by the poor, but at the same time inflation faced by the poor may not have been as high as 128.9 per cent.

Importantly, there is some regional variation in our inflation estimates. Consistent with the 'true' inflation estimates shown in Table 5.2, our urban poverty line inflation rate (123.8 per cent) is significantly above the rural poverty line inflation rate (108.0 per cent). While there is some variation among rural areas, there is a much more pronounced difference between the urban and rural inflation rates, particularly as far as non-food inflation rates are concerned: whereas urban non-food inflation was 132.5 per cent, the rural inflation rate is only 74.8 per cent. This may reflect significant welfare effects associated with the subsidy programme: the commercial value of the full subsidy package of two bags of fertilizer, distributed to half of rural farm households, is equivalent to over 20 per cent of our estimated non-food rural poverty line (see Arndt et al. 2015). Another likely factor is a sharp reduction in clothing and footwear prices linked to a dramatic rise in subSaharan Africa's importation of inexpensive used clothing from developed countries (see Baden and Barber 2005). The NSO's revised CPI data shows that 
clothing and footwear prices increased only about half as much as the overall consumption basket, allowing households to drastically reduce spendingthe CPI weight for clothing and footwear items have recently been adjusted downwards from 20.3 to 6.4 per cent of non-food expenditure-yet there is an equally sharp rise in the proportion of households that feel their clothing is 'adequate' (see Table 5.5 and related discussion in section 5.4.2).

Perhaps the most important methodological difference between our approach and that of the NSO is that our inflation rate is based on flexible consumption bundles. This means that we account for observed changes in the non-food share of expenditure, whereas the NSO fix the non-food expenditure share in both survey years at 38 per cent. Since the non-food poverty line is estimated on the basis of non-food expenditures of households close to the food poverty line, different choices of food poverty lines will mean that nonfood poverty lines are estimated on the basis of the observed expenditures of different subsets of the population; hence, the level and share of non-food expenditures may be sensitive to the choice of poverty line.

We find several interesting results in this regard. Firstly, if Engel's Law holds, the estimates of non-food expenditure shares would rise as we move to higher poverty lines, simply because given the estimation procedure we would then be evaluating non-food expenditures of slightly wealthier households. It appears this only holds for urban households in 2004/5. In all other instances the non-food share declines or is constant as we evaluate non-food expenditure at higher notional food poverty lines, which suggests extra income earned by the poor is initially spent on more (or better-quality) food rather than non-food expenditures. We can reasonably assume that many households with food expenditure at or below the food poverty line are not satisfying their caloric needs; for example Verduzco-Gallo et al. (2014) estimate a calorie deficiency rate of 40 per cent in 2004/5. Hence, it is quite plausible to think that additional income will be spent on food until they reach a desired level and quality of food intake. Non-food shares therefore only start to rise at relatively high food poverty lines. The relatively low rural non-food inflation rate also means that poor households are able to divert household income normally reserved for essential non-food items to food spending because of significant savings on non-food items.

Secondly, while NSO assumed a constant non-food expenditure share of 38 per cent, we find this rate to be reasonably close to our own non-food shares in 2004/5 only in central and southern rural areas. The rural north has a lower non-food share, while in urban areas the share is well above 38 per cent. This is consistent with the literature where urban households are often found to consume fewer and more expensive calories (Tarp et al. 2002). This finding should therefore also be reflected in the estimated poverty line for the urban areas. In summation, the regional and time-specific approach to poverty line 
estimation appears to be important in the present setting: consumption patterns, even those represented by crude non-food shares, differ substantially across regions.

Table 5.4 reports our estimated poverty headcounts and compares them with official numbers. We calculate and report 95 per cent confidence intervals to accompany the percentage point changes in poverty rates between 2004/5 and 2010/11. If the confidence interval value exceeds the absolute value of the percentage point change in poverty, the change is considered statistically insignificant.

Whereas we estimate a slightly lower rural poverty rate in 2004/5 (48.2 per cent) to that of the NSO (55.9 per cent), our urban poverty rate (37.6 per cent) is substantially higher than the official rate (25.4 per cent). Since our estimates of rural poverty are at a somewhat lower level than those of the NSO for both surveys and our estimates of urban poverty are somewhat higher, we will focus our discussion on the changes in poverty over time rather than their absolute levels. By 2010/11 our rural poverty rate (40.6 per cent) is substantially lower than in 2004/5 (48.2 per cent), i.e. we estimated a significant 7.5 percentage point decline in rural poverty compared to the NSO's estimate of a small 0.7 percentage point increase. We also report substantial declines across all rural

Table 5.4. Poverty headcount rates and changes in poverty between $2004 / 5$ and $2010 / 11$

\begin{tabular}{|c|c|c|c|c|c|c|}
\hline \multicolumn{4}{|c|}{ Poverty headcount rate (\%) } & \multirow{2}{*}{\multicolumn{2}{|c|}{$\begin{array}{l}\text { Percentage point change } \\
(2004 / 5 \text { to } 2010 / 11) \text { and } \\
95 \% \text { confidence intervals }\end{array}$}} & \multirow{3}{*}{$\begin{array}{l}\text { Change in } \\
\text { poverty (fixed } \\
\text { non-food } \\
\text { share) }\end{array}$} \\
\hline \multicolumn{2}{|c|}{ 2004/5 (IHS2) } & \multicolumn{2}{|c|}{ 2010/11 (IHS3) } & & & \\
\hline $\begin{array}{l}\text { Regional } \\
\text { poverty } \\
\text { estimates }\end{array}$ & $\begin{array}{l}\text { NSO } \\
\text { poverty } \\
\text { estimate }\end{array}$ & $\begin{array}{l}\text { Regional } \\
\text { poverty } \\
\text { estimates }\end{array}$ & $\begin{array}{l}\text { NSO } \\
\text { poverty } \\
\text { estimate }\end{array}$ & $\begin{array}{l}\text { Change in } \\
\text { poverty }\end{array}$ & $\begin{array}{l}\text { NSO } \\
\text { change in } \\
\text { poverty }\end{array}$ & \\
\hline
\end{tabular}

\section{Normal poverty}

\begin{tabular}{|c|c|c|c|c|c|c|c|c|c|}
\hline National & 47.0 & 52.4 & 38.6 & 50.7 & -8.4 & \pm 2.8 & -1.7 & \pm 2.4 & -4.1 \\
\hline Urban & 37.6 & 25.4 & 27.3 & 17.3 & -10.3 & \pm 9.4 & -8.1 & \pm 6.8 & -11.6 \\
\hline Rural & 48.2 & 55.9 & 40.6 & 56.6 & -7.5 & \pm 2.9 & 0.7 & \pm 1.4 & -2.3 \\
\hline North rural & 59.4 & 56.3 & 48.0 & 59.9 & -11.4 & \pm 6.8 & 3.6 & \pm 6.5 & -8.8 \\
\hline Centre rural & 40.0 & 46.7 & 33.7 & 48.7 & -6.3 & \pm 4.4 & 2.0 & \pm 4.2 & 0.6 \\
\hline South rural & 53.1 & 64.4 & 45.1 & 63.3 & -8.0 & \pm 4.5 & -1.1 & \pm 3.7 & -3.5 \\
\hline \multicolumn{10}{|c|}{ Extreme poverty } \\
\hline National & 17.1 & 22.3 & 17.9 & 24.5 & 0.8 & \pm 2.0 & 2.1 & \pm 2.2 & - \\
\hline Urban & 9.0 & 7.5 & 4.7 & 4.3 & -4.2 & \pm 3.6 & -3.2 & \pm 3.4 & - \\
\hline Rural & 18.1 & 24.2 & 20.2 & 28.1 & 2.1 & \pm 2.2 & 3.9 & \pm 2.4 & - \\
\hline North rural & 30.1 & 25.9 & 25.6 & 29.0 & -4.5 & \pm 6.7 & 3.0 & \pm 6.4 & - \\
\hline Centre rural & 11.8 & 16.1 & 16.1 & 21.5 & 4.3 & \pm 2.8 & 5.4 & \pm 3.2 & - \\
\hline South rural & 21.1 & 31.5 & 22.6 & 34.2 & 1.6 & \pm 3.8 & 2.7 & \pm 4.0 & - \\
\hline
\end{tabular}

Note: The confidence interval is used to determine the statistical significance of the difference in the poverty rate between $2004 / 5$ and $2010 / 11$. Since the distribution of the poverty rate is unknown we follow Simler and Arndt (2007) in defining the confidence interval as plus or minus twice the standard error. The change in the poverty headcount rate is considered statistically insignificant if zero is within the confidence interval around the estimate.

Source: NSO (2012a) and authors' estimates based on IHS2 and IHS3 
regions, which stands in contrast to the NSO's estimates of increases in poverty in the rural north and centre. On the other hand, consistent with NSO's estimate, we find a substantial decrease in urban poverty, i.e. by 10.3 percentage points compared to the 7.4 percentage points estimated by the NSO. Overall, we estimate a statistically significant 8.4 percentage point decline in national poverty, which stands in sharp contrast to the NSO's statistically insignificant decline of 1.7 percentage points.

Table 5.4 also presents results for changes in extreme poverty. Households are deemed extremely poor or 'ultra-poor' when their total per capita consumption falls below the food poverty line. Consistent in direction with the NSO estimates, we find that urban extreme poverty declines by 4.2 percentage points, while rural extreme poverty increases by 2.1 percentage points. At the national level we estimate a small and insignificant increase in extreme poverty (0.8 percentage points) compared to the NSO's increase of 2.1 percentage points, which is also statistically insignificant. It appears Malawi's economic policies, while benefitting those close to the poverty line, may have failed to benefit the rural ultra-poor.

At least one important methodological question raised earlier is whether an assumption of fixed non-food consumption shares is reasonable. To investigate how such an assumption would affect our poverty estimates, we estimate regional food poverty lines as before, but then assume that essential non-food spending in 2010/11 is a fixed share of food spending, with the share determined by the 2004/5 non-food shares. The final column of Table 5.4 reports the resulting change in poverty. The results now show a slightly higher reduction in urban poverty (i.e. by 11.6 percentage points), but a much smaller decline in rural poverty (i.e. by 2.3 percentage points). Poverty estimates are therefore sensitive to the choice of flexible or fixed non-food shares, and our estimates are closer to that of the NSO when we fix the non-food budget share.

Figure 5.3 provides a visual picture of how the cumulative distribution functions of our consumption aggregates compare with the official welfare aggregates. The solid lines represent our newly calculated consumption aggregates, while the dashed line represents that of the NSO. Poverty lines (logarithmic values) are indicated by vertical lines, which are also dashed or solid to match the cumulative distribution function. The point at which a poverty line intersects the relevant cumulative distribution function indicates the associated poverty level (vertical axis). These values are comparable with those shown in Table 5.4 .

While our consumption aggregates for urban households are similar to those of the NSO in both 2004/5 and 2010/11, our urban poverty lines are much higher, and hence our estimated poverty rates in urban areas are higher. The 2004/5 panel for rural areas shows that our cumulative distribution 

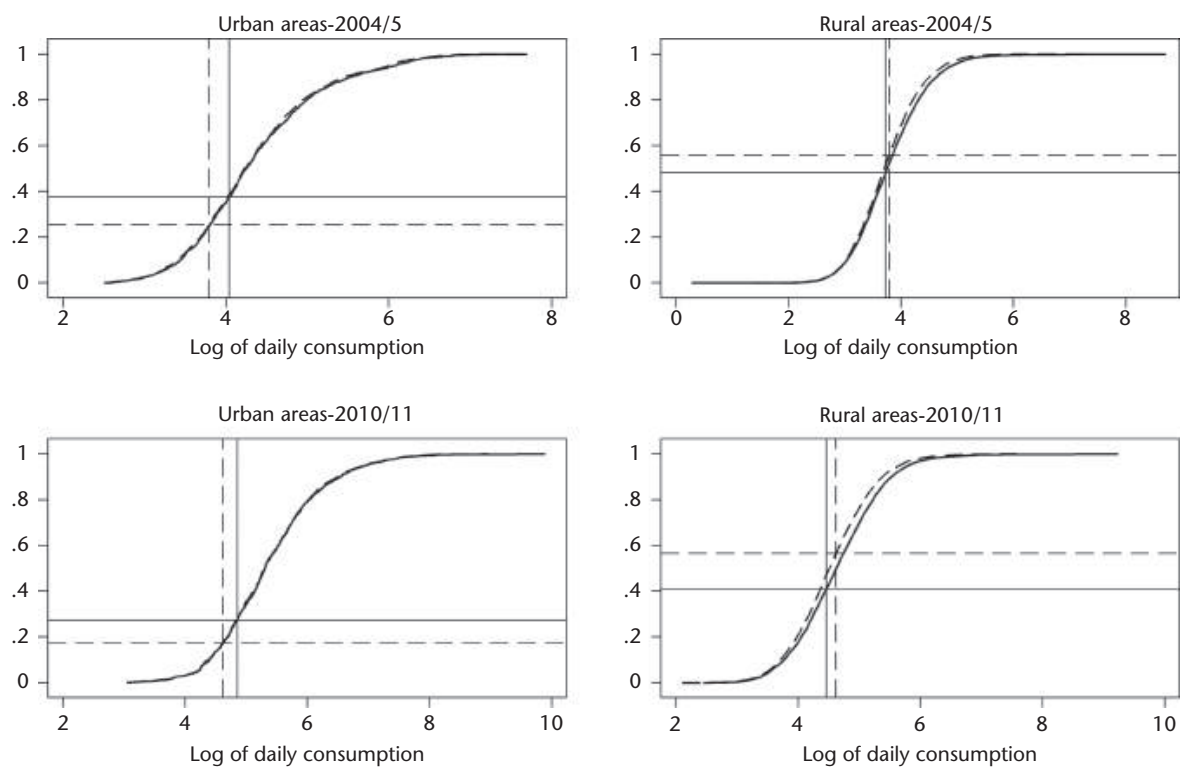

New consumption - - - - - NSO consumption

Figure 5.3. Consumption distribution functions and poverty estimates Source: Authors' estimates based on IHS2 and IHS3

function lies slightly to the right of the NSO's function, which implies that our consumption estimate is higher over most of the distribution; however, our poverty line is slightly lower, which explains why we get a lower estimate of rural poverty compared to that of the NSO. In 2010/11, our rural poverty line is again lower than that of the NSO, but our consumption estimate is once again to the right of that of the NSO, thus yielding a much lower poverty estimate than the NSO. These visual inspections lead us to conclude, with some circumspection, that differences in our poverty line estimates are the most important factor in explaining differences in poverty rates and their changes over time between the respective studies.

\subsubsection{Non-monetary Poverty Analysis}

The preceding discussion has focused on estimates of monetary poverty whereby consumption expenditure is used as an indicator of welfare. The rationale for a consumption-based approach to identifying the poor is that there is a strong correlation between 'means' (i.e. income or consumption levels) and 'ends' such as adequate levels of health, education, or freedom. An individual above the monetary poverty line is thought to possess sufficient purchasing power to acquire the bundle of attributes yielding a level of 
well-being sufficient to function in society, thus providing a rationale for a consumption-based approach to poverty analysis.

However, given the often weak relationship between income and welfare-this may be due to incomplete markets, presence of externalities, or provision of public goods-money-metric measures are not always good indicators of welfare. Besides, there is no guarantee that households with incomes at or above a poverty threshold would use their incomes to purchase those 'basic needs' considered necessary for achieving an acceptable level of well-being. Decision-makers in the household may, for example, instead choose to satisfy wants for, say, alcohol and tobacco at the expense of satisfying the minimum caloric requirements of their children. In the money-metric approach such households would be classified as non-poor when in reality at least some of their members are deprived of some basic needs (Thorbecke 2005).

Consequently, Sen (1985) argues that the measurement of poverty should, where possible, go beyond income or consumption and look at other dimensions of well-being such as health, education, empowerment, and freedom of association, among others. Income and consumption expenditure are instrumentally important as a means of achieving the other dimensions of well-being, but the other dimensions of well-being are in and of themselves intrinsically significant. Thus, these dimensions are equally important and deserve recognition and measurement in their own right. Moreover, trends in non-monetary dimensions of wellbeing can be used to validate or challenge observed trends in monetary poverty.

This section looks at levels and trends of non-monetary dimensions of wellbeing in Malawi between 2004/5 and 2010/11. Although we omit some results due to space considerations - a full set of results can be found in Pauw et al. (2014) — we find overwhelming evidence of improvements in non-monetary welfare measures. Specifically, we note significant improvements in housing quality, access to clean water, and ownership of consumer durables, which are consistent with the finding of rising incomes and declining poverty. School enrolment has increased, while Malawians appear to have become better educated over time in terms of academic qualifications achieved. Nutritional outcomes reveal a somewhat mixed picture, with declines in stunting and underweight children, but an increase in wasting (see Verduzco-Gallo et al. 2014 for a more in-depth discussion with regards to food and nutrition security outcomes).

The IHS2 and IHS3 also include several questions related to subjective wellbeing vis-à-vis adequacy of food consumption, housing, clothing, and health care. We treat households that report access to be 'less than adequate' as being deprived, while those that report 'just adequate' or 'more than adequate' are 
Table 5.5. Changes in subjective well-being, 2004/5-10/11

\begin{tabular}{|c|c|c|c|c|c|c|}
\hline & \multicolumn{3}{|c|}{ Prevalence of food inadequacy } & \multicolumn{3}{|c|}{ Prevalence of housing inadequacy } \\
\hline & $\begin{array}{l}2004 / 5 \\
(\mathrm{IHS} 2) \\
(\%)\end{array}$ & $\begin{array}{l}2010 / 11 \\
(\mathrm{IHS} 3)(\%)\end{array}$ & $\begin{array}{l}\text { Percentage } \\
\text { point change } \\
\text { (\%) }\end{array}$ & $\begin{array}{l}2004 / 5 \\
\text { (IHS2) } \\
(\%)\end{array}$ & $\begin{array}{l}2010 / 11 \\
(\mathrm{IHS} 3)(\%)\end{array}$ & $\begin{array}{l}\text { Percentage } \\
\text { point change } \\
\text { (\%) }\end{array}$ \\
\hline Urban & 48.1 & 26.7 & -21.5 & 44.2 & 31.5 & -12.6 \\
\hline Rural & 58.5 & 40.4 & -18.1 & 56.8 & 44.5 & -12.3 \\
\hline North & 35.3 & 29.8 & -5.5 & 36.4 & 39.0 & 2.6 \\
\hline Centre & 59.1 & 33.8 & -25.3 & 60.3 & 40.4 & -19.9 \\
\hline South & 63.8 & 49.2 & -14.6 & 58.7 & 49.9 & -8.8 \\
\hline \multirow[t]{3}{*}{ Total } & 57.3 & 38.5 & -18.9 & 55.4 & 42.8 & -12.5 \\
\hline & \multicolumn{3}{|c|}{ Prevalence of clothing inadequacy } & \multicolumn{3}{|c|}{ Prevalence of health care inadequacy } \\
\hline & $\begin{array}{l}2004 / 5 \\
(\mathrm{IHS} 2) \\
(\%)\end{array}$ & $\begin{array}{l}2010 / 11 \\
\text { (IHS3) (\%) }\end{array}$ & $\begin{array}{l}\text { Percentage } \\
\text { point change } \\
\text { (\%) }\end{array}$ & $\begin{array}{l}2004 / 5 \\
\text { (IHS2) } \\
(\%)\end{array}$ & $\begin{array}{l}2010 / 11 \\
(\mathrm{IHS} 3)(\%)\end{array}$ & $\begin{array}{l}\text { Percentage } \\
\text { point change } \\
\text { (\%) }\end{array}$ \\
\hline Urban & 54.5 & 49.3 & -5.2 & 51.8 & 28.1 & -23.7 \\
\hline Rural & 74.9 & 58.5 & -16.4 & 62.0 & 34.5 & -27.5 \\
\hline North & 52.3 & 55.3 & 3.0 & 43.1 & 27.8 & -15.3 \\
\hline Centre & 84.2 & 54.7 & -29.5 & 65.4 & 39.3 & -26.1 \\
\hline South & 71.8 & 62.1 & -9.7 & 63.6 & 31.1 & -32.5 \\
\hline Total & 72.6 & 57.0 & -15.5 & 60.9 & 33.4 & -27.5 \\
\hline
\end{tabular}

Source: Authors' computation using IHS2 and IHS3

considered not deprived. The corresponding prevalence rates of deprived households are reported in Table 5.5. We note substantial reductions in the percentage of households reporting to be deprived in terms of access to food (-18.9 per cent), housing ( -12.5 per cent), clothing ( -15.5 per cent), and health care (-27.5 per cent), which is largely consistent with our corresponding finding of a large decline in national poverty. Equally significant declines in deprivation rates are observed in most regions of Malawi.

\subsection{Conclusion}

Malawi experienced rapid economic growth during the period 2005-11. Although growth was broad-based and originated from several sectors, the most important contribution came from the large and rapidly growing agricultural sector, which enjoyed significant support in the form of fertilizer input subsidies during the period. On average, and somewhat remarkably, this sector purportedly grew at an average annual rate of 10.1 per cent per year, while overall GDP expanded at a rate of 7.1 per cent per year, far exceeding 
population growth, and thus allowing per capita GDP to grow at roughly 3.5 per cent per year on average during the period.

A reasonable expectation was that rapid smallholder-led agricultural growth would have a significant impact on poverty. However, the official poverty estimates based on the IHS3, which were released in 2012, suggested national poverty had declined only marginally by 1.7 percentage points between 2004/5 and 2010/11, while rural poverty increased by 0.7 percentage points. This raised several questions, including whether reported maize production and agricultural GDP growth estimates were in fact accurate. Others speculated about whether or not the poor were excluded from the benefits of rapid growth. The sharp rise in inequality measured by the Gini coefficient $(0.39$ to 0.45 ) supported the 'no trickle-down effect' hypothesis to some extent, but the puzzling question remained: how could Malawi have had no reduction in rural poverty after investing so heavily in poor smallholder agriculture and seemingly reaping rewards from the subsidy programme in terms of economic growth?

While recognizing that poverty measurement is challenging and poverty results are extremely sensitive to the assumptions made, this study notes two major concerns about the official poverty analysis conducted by the National Statistical Office (NSO). The first relates to the revision of the official consumer price index (CPI). Our analysis concurs that the official 2004-11 inflation rate (77.3 per cent) is indeed an underestimation, and that revision was justified. However, our estimate of the national average poverty line inflation rate (114.0 per cent) is somewhat lower than that of the NSO (128.9 per cent). The NSO approach of applying the same inflation rate to the food and overall poverty lines in both urban and rural areas is another source of significant bias in their estimated poverty rates. Our analysis suggests that urban poverty line inflation was higher (123.8 per cent) and rural poverty line inflation somewhat lower (108.0 per cent) than the national average. This, coupled with significant shifts in consumption patterns, makes an approach that adopts regional poverty lines and flexible but utility-consistent consumption bundles more appropriate.

Second, as pointed out by Verduzco-Gallo et al. (2014), there are several inconsistencies contained in the official sets of consumption conversion factors. Even minor adjustments to conversion factors, especially for important food commodities, may significantly alter estimates of poverty. There is need for a consultative process to agree on a final set of conversion factors that can be used in all ongoing and future poverty or nutrition analyses.

In contrast to the official poverty estimate, our own analysis reveals large and statistically significant declines in poverty between 2004/5 and 2010/11. The poverty rate declines by 7.5 percentage points in rural areas, with a particularly large decline in the rural north. Urban poverty also declines by 
10.3 percentage points, which is slightly higher than the official estimate of 8.1 percentage points. At national level, we find that poverty dropped by 8.4 percentage points. These results are consistent with the purported economic growth trajectory of Malawi, as well as evidence of significant improvements across a range of non-monetary dimensions of welfare in recent years.

While these results corroborate a much more positive narrative about FISP and its impact on growth and poverty reduction, it still appears as if FISP, and possibly other economic policies in Malawi, continue to neglect the ultrapoor. We find a borderline statistically significant increase in rural extreme poverty (2.1 percentage points), and a more sizable and statistically significant decline in urban areas (i.e. by 4.3 percentage points). The direction of these changes is consistent with the findings of the NSO. Many among the ultrapoor are landless or labour-constrained households, and would make ideal candidates for other forms of social support such as cash transfers, which are currently being scaled up in Malawi.

There are some areas that require further analysis. We concur that the official CPI series understates inflation in Malawi. The implication is that the GDP deflator currently used to estimate real GDP levels may also be understated, leading to economic growth estimates that are too optimistic. At present, GDP estimates are available up until 2012, but all estimates beyond 2007 are subject to revision. In order to truly understand the growth-poverty puzzle, more up-to-date national accounts data is needed, while supporting data for estimation of agricultural GDP, such as crop estimates, need to be strengthened. A more likely growth-poverty narrative for Malawi is probably that growth was lower but that the poverty outcome was significantly more optimistic than what official estimates suggest, particularly in rural areas. Extreme poverty, however, may have increased slightly, suggesting that the most vulnerable in Malawi's society have been excluded from the benefits of economic policy and growth.

\section{References}

Arndt, C., K. Pauw, and J. Thurlow (2015). 'The Economy-wide Impacts and Risks of Malawi's Farm Input Subsidy Program', American Journal of Agricultural Economics, forthcoming, doi: 10.1093/ajae/aav048.

Arndt, C. and K. Simler (2010). 'Estimating Utility Consistent Poverty Lines', Economic Development and Cultural Change, 58: 449-74.

Baden, S. and Barber, C. (2005). The Impact of the Second-hand Clothing Trade on Developing Countries. Oxford: Oxfam.

Benin, S., J. Thurlow, X. Diao, C. McCool, and F. Simtowe (2012). 'Malawi', in X. Diao, J. Thurlow, S. Benin, and S. Fan (eds), Strategies and Priorities for African Agriculture: 
Economy-wide Perspectives from Country Studies. Washington, DC: International Food Policy Research Institute, 245-79.

Chirwa, E. and A. Dorward (2013). Agricultural Input Subsidies: The Recent Malawi Experience. Oxford: Oxford University Press.

Diao, X., P. Hazell, and J. Thurlow (2010). 'The Role of Agriculture in African Development', World Development, 38(10): 1375-83.

Dollar, D., T. Kleineberg, and A. Kraay (2013). 'Growth Still Is Good for the Poor', Policy Research Working Paper No. 6568. Washington, DC: World Bank.

Foster, J., J. Greer, and E. Thorbecke (1984). 'A Class of Decomposable Poverty Measures', Econometrica, 52: 761-6.

GoM (Government of Malawi) (2012). 'The Malawi Growth and Development Strategy II (MGDS II), 2011-2016'. Lilongwe: Government of Malawi.

Jayne, T. S., A. Chapoto, I. Minde, and C. Donovan (2008). 'The 2008/09 Food Price and Food Security Situation in Eastern and Southern Africa: Implications for Immediate and Longer Run Responses', International Development Working Paper. East Lansing: Michigan State University.

Jayne, T., D. Mather, N. Mason, and J. Ricker-Gilbert. (2013). 'How Do Fertilizer Subsidy Programs Affect Fertilizer Use in Sub-Saharan Africa? Crowding Out, Diversion, and Benefit/Cost Assessments', Agricultural Economics, 44: 687-703.

Lunduka, R., J. Ricker-Gilbert, and M. Fisher (2013). 'What are the farm-level impacts of Malawi's farm input subsidy program? A critical review', Agricultural Economics, 44: 563-79.

MoAFS (Ministry of Agriculture and Food Security) (2013). 'Agricultural Production Estimates Survey (APES), 2001-2012'. Lilongwe: Government of Malawi.

Mukherjee, S. and T. Benson (2003). 'The Determinants of Poverty in Malawi', World Development, 31: 339-58.

NSO (National Statistics Office) (2005). 'Integrated Household Survey 2004-2005, vol. I: Household Socio-economic Characteristics'. Zomba, Malawi: National Statistics Office. NSO (National Statistics Office) (2010). 'Report Welfare Monitoring Survey 2009', July. Zomba, Malawi: National Statistics Office.

NSO (National Statistics Office) (2012a). 'Integrated Household Survey 2004-2005. Household Socio-economic Characteristics Report'. Zomba, Malawi: National Statistics Office.

NSO (National Statistics Office) (2012b). 'Quarterly Statistical Bulletin', September. Zomba, Malawi: National Statistics Office.

Pauw, K., U. Beck, and R. Mussa (2014). 'Did Rapid Smallholder-Led Agricultural Growth Fail to Reduce Rural Poverty? Making Sense of Malawi's Poverty Puzzle', WIDER Working Paper No. 2014/123, October. Helsinki: United Nations University-World Institute of Development Economics Research.

Pauw, K., O. Ecker, and J. Mazunda (2011). 'Agricultural Growth, Poverty, and Nutrition Linkages in Malawi', Malawi Strategy Support Program Policy Note 8. Washington, DC: International Food Policy Research Institute.

Pauw, K. and J. Thurlow (2014). 'Malawi's Farm Input Subsidy Program: Where Do We Go from Here?', Malawi Strategy Support Program Policy Note 18. Washington, DC: International Food Policy Research Institute. 
Ravallion, M. (1998). 'Poverty Lines in Theory and Practice', Living Standards Measurement Study Working Paper No. 133. Washington, DC: World Bank.

Ricker-Gilbert, J. (2014). 'Wage and Employment Effects of Malawi's Fertilizer Subsidy Program', Agricultural Economics, 45: 337-53.

Sen, A. K. (1985). Commodities and Capabilities. Amsterdam: North Holland.

Simler, K. and C. Arndt (2007). 'Poverty Comparisons with Absolute Poverty Lines Estimated from Survey Data', Review of Income and Wealth, 53(2): 275-94.

Tarp, F., K. Simler, C. Matusse, R. Heltberg, and G. Dava (2002). 'The Robustness of Poverty Profiles Reconsidered', Economic Development and Cultural Change, 51(1): 77-108.

Thorbecke, E. (2005). 'Multi-Dimensional Poverty: Conceptual and Measurement'. Paper prepared for the Many Dimensions of Poverty International Conference, UNDP International Poverty Centre, Brasilia, 29-31 August.

Verduzco-Gallo, I. E. Ecker, and K. Pauw (2014). 'Changes in Food and Nutrition Security in Malawi: Analysis of Recent Survey Evidence', MaSSP Working Paper 6, July, Malawi Strategy Support Program, International Food Policy Research Institute. 


\section{6}

\section{Growth, Poverty Reduction, and Inequality in Rwanda}

Andy McKay and Marijke Verpoorten

\subsection{Country Context and Economic Performance}

Rwanda has many features which make it unique and of interest to analysts. It has the highest population density in Africa. Even more than many subSaharan African countries, it is very highly dependent on agriculture, but its originally fertile soils face a continued risk of environmental degradation, and average farm size is rapidly falling (the average farm size is now only 0.7 ha, with much of this land not being easy to cultivate). Without doubt, the country needs to diversify out of agriculture, but finding these alternative activities has been and remains a major challenge.

Rwanda has also attracted international attention because of its disastrous period of violent conflict in the early to mid-1990s. ${ }^{1}$ Also well known, though, is the impressive economic growth it has experienced since. Per capita GDP in local currency values since 1970 is presented in Figure 6.1. What this shows is consistent sustained growth from 1995 onwards, in sharp contrast to the stagnation of GDP in the 1980s and early 1990s. By 2006, GDP per capita had reached its highest level to date, and by 2012, it was about 50 per cent larger than GDP per capita prior to the armed conflicts of the 1990s. Growth seems to be even faster in recent years. All productive sectors have grown consistently over this period, agriculture and industry included, but according to national accounts data the fastest growth has been in the services sector, especially in wholesale and retail trade and transport, storage, and

\footnotetext{
1 Poverty and land scarcity added to the intensity of the conflict (Verpoorten 2012), but the root causes lay elsewhere (Ingelaere and Verpoorten 2014).
} 


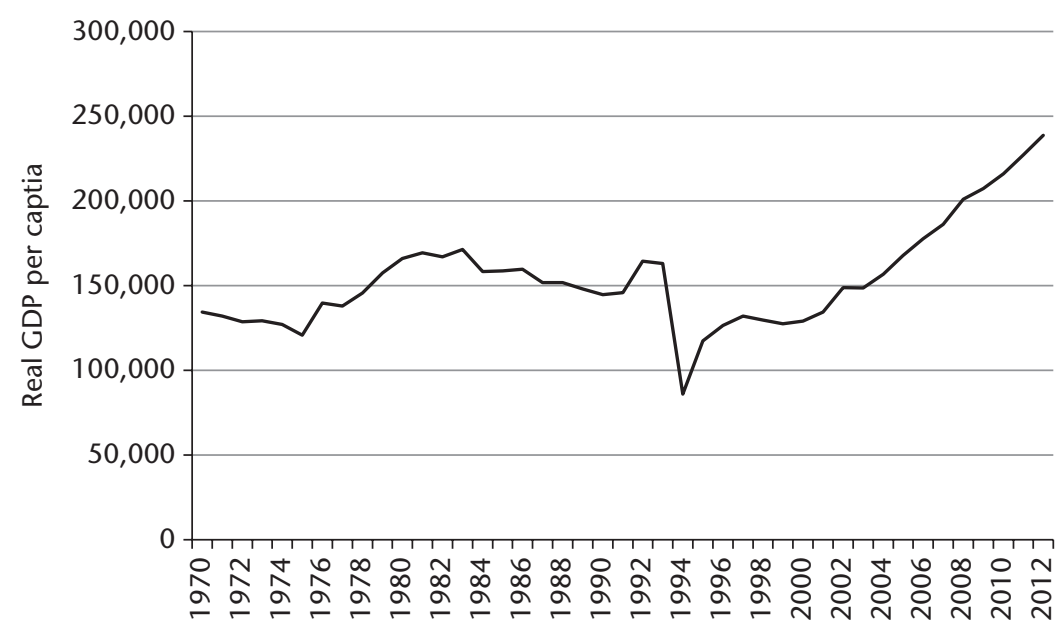

Figure 6.1. Evolution of real per capita GDP in Rwanda, constant local currency units Source: World Development Indicators (2014)

communications. In addition, there is evidence of significant improvements in living conditions over recent years.

Population growth was historically high in Rwanda, doubling between 1970 and 1990 (growing at an average of 3.3 per cent a year). Population growth has been slower in the post-war period at around 2.6 per cent per annum, but the momentum of past growth means that the population continues to increase at a fast rate, and in an increasingly land-scarce environment.

There are different views among analysts about the factors underlying Rwanda's recent economic success story. Important elements often discussed include post-war catch-up; massive aid inflows; increased budget shares for health, education, and agriculture; the fertility transition; and the rise in international commodity prices. Booth and Golooba-Mutebi (2012: 387) stress the aspect of governance, arguing that Rwanda is a developmental authoritarian state that actively promotes private-sector development and keeps the most detrimental forms of rent-seeking in check with 'a set of arrangements for managing economic rents in a centralized way and deploying them with a view to the long term'.

Even if aid and post-war catch-up may be important, it is impossible to deny the role of government policy in Rwanda. Numerous policy changes have been made, including among others the 1999 new inheritance law that grants equal rights to male and female children; the new constitution of 2003 that introduces gender quotas at all levels of decision-making; free and mandatory primary education; major changes in agricultural and land policy; the introduction of performance-based financing for health care centres in 2006 as well as performance contracts between each district and the central government 
(imihigo); an intense family planning campaign in 2007; and mandatory health insurance in 2008.

Many studies have looked at these policy changes to determine how they have contributed to the Rwandan success story. Guariso et al. (2012) discuss the transformation of the Rwandan coffee sector; Ayalew et al. (2011) study the impact of land tenure regularization on investment, maintenance of soil conservation measures, and women's land access; Basinga et al. (2010), Kalk (2008), and Kalk etal. (2010) study the impact of the introduction of performance-based financing in the health care sector; Nkurunziza et al. (2012) analyse the introduction of free primary education; Saksena et al. (2011) study the introduction of mutual health insurance; and Westoff (2012), Kabano et al. (2013), and Muhoza et al. (2013) look at the fertility transition.

Identifying causality remains, however, a challenge in these studies; and many policies still need to be properly evaluated. At the same time, some policies, for instance in relation to agricultural and land policy, have been criticized by many researchers, using mainly qualitative methods (Ansoms 2011; Huggins 2009; Newbury 2011).

The data, though, continues to indicate impressive growth performance. The focus of this chapter is to consider the distributional pattern of this growth and its impact on poverty. In section 6.2 we consider evidence on the evolution of many non-monetary indicators from the Demographic and Health Surveys for which several rounds have been conducted between 1992 and 2010. Section 6.3 focuses on consumption poverty and inequality, primarily based on surveys which have been conducted since 2000, though with a brief discussion of evidence dating back to 1990 as well as a brief first review of available qualitative evidence. Then in section 6.4 we draw on a small-scale panel dataset which enables an examination of mobility and consideration of other issues, while section 6.5 presents an extended discussion and synthesis while also discussing unresolved issues.

\subsection{The Evolution of Non-monetary Measures of Well-being}

As noted above, we first focus on trends in non-monetary indicators as revealed by the Demographic and Health Surveys (DHS), of which there were five rounds in 1992, 2000, 2005, 2007, and 2010. The first two surveys bracket a period of armed conflicts, namely the 1991-4 civil war, the 1994 genocide, and the 1994-8 refugee crisis and (counter-)insurgency operations. The more recent surveys were implemented in a period in which various government interventions took place in the health and education sector. The questionnaire design is broadly similar across the survey rounds, though 
the 2007 round was smaller and collected data on a more limited number of indicators. The first four surveys were designed to be representative at the level of the twelve provinces (in place before the 2006 administrative reform), while the latest survey is representative at the level of the thirty districts created during later administrative reform. The analysis here and in section 6.3 uses population weights, and focuses throughout on indicators which are comparable across the different survey rounds. Table 6.1 summarizes time trends in the average outcomes for a range of health, fertility, education, and housing indicators.

The infant mortality rate, as calculated from the five-year period preceding the survey, dropped dramatically from 109 in 2000 to 83 in 2005 to 50 in 2010. In contrast, in the period of armed conflict the same indicator had increased from 85 in 1992 to 109 in 2000. Under-five mortality shows a similar trend and similar dramatic reduction from 2000. This falling mortality went hand in hand with improvements in child nutritional indicators, with stunting and wasting decreasing over the period 2005-10, and with reduced prevalence of diarrhoea and especially fever for under-fives in the two weeks preceding the survey. These improvements may in part reflect a better outreach of basic preventive health care measures. Vaccination coverage was always high but bed net ownership increased sharply and consistently from only 6.6 per cent of households in 2000 to 82.7 per cent in $2010 .^{2}$

Another big change over this period is the fall in the fertility rate between 2005 and 2010 from 6.1 to 4.6 respectively. From 1992 to 2005, the rate had not fallen and this is potentially a very important change. In line with this, the same 2005-10 period saw a marked increase in the use of contraceptives, and the unmet need for contraceptives declined considerably, from 37.9 per cent in 2005 to 20.8 per cent in 2010. Between 2005 and 2010, there were also sharp increases in delivery at a health facility (instead of at home), from below 30 per cent in and prior to 2005 to almost 80 per cent in 2010; and in the number of births assisted by trained medical staff. The maternal mortality ratio remains high in Rwanda, but shows a steady decline over the period 2000-10. It stood at 476 deaths per 100,000 live births in the 2010 DHS, down from 1,071 in 2000, again demonstrating impressive progress.

Education has been a major policy and donor focus, and both attendance and attainment have improved substantially over time. The share of men (aged 6 years or more) with no formal education fell from 29.4 per cent in 1992 to 24.9 per cent in 2000 to 19.4 per cent in 2005 and 13.0 per cent in 2010. The corresponding figures for women are 40.4 per cent, 32.6 per cent, 27.7 per cent, and 20.2 per cent. The mean years of education of the active

2 The ownership of bed nets was not recorded in 1992. 
Table 6.1. Selected non-monetary indicators for Rwanda

\begin{tabular}{|c|c|c|c|c|c|}
\hline DHS survey round & 1992 & 2000 & 2005 & $2007-8$ & 2010 \\
\hline \multicolumn{6}{|l|}{ Mortality rate } \\
\hline infant mortality & 85 & 109 & 83 & 64 & 50 \\
\hline under-five mortality & 151 & 196 & 152 & 103 & 76 \\
\hline \multicolumn{6}{|l|}{ Nutritional status } \\
\hline height-for-age (\% below -2 sd) & 56.8 & 48.3 & 51.1 & n.a. & 44.2 \\
\hline weight-for-height (\% below - 2 sd) & 5.0 & 8.3 & 4.7 & n.a. & 2.8 \\
\hline weight-for-age (\% below -2 sd) & 24.3 & 19.5 & 17.5 & n.a. & 11.4 \\
\hline \multicolumn{6}{|l|}{ Health condition past two weeks (age $0-5$ ) } \\
\hline diarrhoea (\%) & 22.0 & 17.2 & 14.4 & 13.9 & 13.3 \\
\hline fever $(\%)$ & 42.1 & 31.0 & 26.6 & 21.9 & 15.9 \\
\hline All vaccinations (\% children $12-23$ months) & 86.3 & 76.0 & 75.2 & 80.4 & 90.1 \\
\hline $\begin{array}{l}\text { Households owns mosquito net (any type, } \\
\%)\end{array}$ & n.a. & 6.6 & 18.2 & 59.2 & 82.7 \\
\hline Total fertility rate ${ }^{a}$ & 6.2 & 5.8 & 6.1 & 5.5 & 4.6 \\
\hline \multicolumn{6}{|l|}{ Use of contraception ${ }^{\mathrm{b}}$} \\
\hline any modern method (\%) & 12.9 & 5.7 & 10.3 & 27.4 & 45.1 \\
\hline unmet need for family planning (\%) & 38.9 & 35.6 & 37.9 & 100.0 & 20.8 \\
\hline Delivery at health care facility (\%) & 26.3 & 25.7 & 29.7 & 53.7 & 78.3 \\
\hline Assistance of trained personnel (\%) & 28.3 & 31.3 & 38.6 & 52.1 & 69.0 \\
\hline Maternal mortality rate ${ }^{\mathrm{d}}$ & n.a. & 1071 & 750 & n.a. & 476 \\
\hline \multicolumn{6}{|l|}{ Educational level } \\
\hline no education, men (\%, >6 year) & 29.4 & 24.9 & 19.4 & n.a. & 13.0 \\
\hline no education, women (\%, >6 year) & 40.4 & 32.6 & 27.7 & n.a. & 20.2 \\
\hline mean years of education, men 15-65 & 3.9 & 4.1 & 4.1 & n.a. & 4.6 \\
\hline mean years of education, women 15-65 & 3.0 & 3.3 & 3.4 & n.a. & 4.0 \\
\hline \multicolumn{6}{|l|}{ Net attendance ratio ${ }^{\mathrm{e}}$} \\
\hline primary school, total & 61.5 & 72.0 & 80.6 & n.a. & 87.5 \\
\hline secondary school, total & 5.7 & 4.9 & 4.0 & n.a. & 14.4 \\
\hline \multicolumn{6}{|l|}{ Gross attendance ratio ${ }^{f}$} \\
\hline primary school, total & 84.6 & 104.5 & 134.2 & n.a. & 142.4 \\
\hline secondary school, total & 16.6 & 7.9 & 8.2 & n.a. & 26. \\
\hline \multicolumn{6}{|l|}{ Housing characteristics } \\
\hline has electricity (\%) & 2.3 & 6.2 & 4.8 & 6.0 & 9.7 \\
\hline finished floor (\%) & 11.0 & 13.1 & 13.0 & 14.6 & 16.9 \\
\hline \multicolumn{6}{|l|}{ Household durable goods } \\
\hline radio $(\%)$ & 32.3 & 35.2 & 45.8 & 58.2 & 62.6 \\
\hline television (\%) & n.a. & 2.4 & 2.3 & 3.4 & 5.3 \\
\hline bicycle (\%) & 6.4 & 7.6 & 11.0 & 12.2 & 15.2 \\
\hline motorcycle (\%) & 0.7 & 0.7 & 0.5 & 0.9 & 1.1 \\
\hline
\end{tabular}

Notes and source: Authors' calculations from DHS data, except for the fertility and mortality rates, under-five mortality rate, nutritional status, and health insurance which are taken from the DHS reports and gross attendance ratio which is taken from the DHS reports for 2000, 2005, and 2010, and from the WDI for 1992. ${ }^{\mathrm{F}}$ For the three years preceding the survey and the percentage of women $15-49$ currently pregnant. ${ }^{b}$ Among married women. ${ }^{c}$ Of live births in the last three years preceding the survey. ${ }^{\mathrm{d}}$ Per 100,000 live births, for the period of $0-4$ years prior to the survey. ${ }^{\mathrm{e}}$ The NAR for primary school is the percentage of the primary-school-age (7-12 years) population that is attending primary school. The NAR for secondary school is the percentage of the secondary-school-age (13-18 years) population that is attending secondary

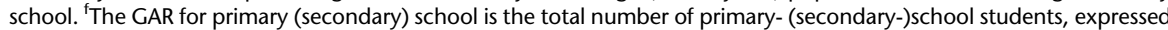
as a percentage of the official primary- (secondary-)school-age population. If there are significant numbers of over-age and under-age students at a given level of schooling, the GAR can exceed 100 per cent.

population (aged 15-65) increased from 3.9 in 1992 to 4.6 in 2010 for men, and from 3.0 in 1992 to 4.0 in 2010 for women.

The net attendance ratio (NAR) for primary school increased over the period 1991-2000 from 61.5 to 72.0, despite the violent conflicts, then increased 
further to 80.1 in 2005 and 87.5 in 2010. The NAR for secondary school is much lower and fell in the period of conflict (Guariso and Verpoorten 2013), but it then increased by more than ten percentage points during 2005-10. Gross attendance ratios (GAR) though are much higher, a result of slow grade progression during armed conflict (and so many over-age children). Gross attendance ratios for primary school increased greatly from 84.6 in 1992 to around 100 in 2000, close to 130 in 2005, and to approximately 140 in 2010. The GAR for secondary school decreased from 16.6 in 1992 to 7.9 in 2000, but then recovered to 8.2 in 2005 and further to 26.1 in 2010.

Finally the DHS surveys also collect data on housing characteristics and household assets. There were improvements over time in the two comparable housing indicators: electricity in the home and the construction material of the floor. This is especially apparent across the latest three rounds $(2005,2007$, 2010). Household ownership of durable goods also increased over time, with 62.6 per cent of households owning a radio in 2010, compared to 32.3 per cent in 1992. Likewise, bicycle ownership almost doubled over the period 1992-2010, from 6.4 per cent to 15.2 per cent, though ownership of a television or motorcycle remained low in 2010 despite small increases.

This analysis, though, focuses on average outcomes across the entire sample, where almost all indicators show improvements, often substantial improvements, over the period. But it is also important to look at heterogeneity: to what extent do poorer households share in these improvements? In the absence of income data, poverty is proxied on the basis of an asset index constructed using principal component analysis (Filmer and Pritchett 2001). ${ }^{3}$ Table 6.2 then looks at eight indicators across rich and poor, showing the ratio of the indicator for the top asset quintile to that of the lowest asset quintile. The disparity is smallest and most stable over time for primary school enrolment and vaccination coverage. For the other indicators, the general pattern is one of sharply increasing disparities during the period of armed conflict (1992-2000), followed in most cases by sharp reductions in disparities since 2000. The absolute levels of disparities are still large in some cases, notably for the secondary NAR, but in six out of the eight cases inequality in these outcomes fell, often sharply between 2000 and 2010; in the other two cases the disparity scarcely changed. The evidence suggests that poorer households shared in the improvements in these non-monetary indicators. A similar analysis comparing rural and urban areas shows the same pattern of disparity increasing during 1992-2000 and falling during 2000-10 (not reported).

\footnotetext{
3 The resulting indices are given by Measure DHS for each round, and are constructed on the basis of a set of variables that vary across survey rounds. For instance, the 2005 and 2010 indices include information on mobile phone ownership, a variable that was only introduced in 2005 . In addition, for some variables the answer categories varied between rounds, e.g. source of drinking water and type of toilet facilities.
} 
Table 6.2. The ratio of indicators between the richest 20 per cent and the poorest 20 per cent of the sample population

\begin{tabular}{|c|c|c|c|c|c|}
\hline DHS survey round & 1992 & 2000 & 2005 & $2007-8$ & 2010 \\
\hline Use of contraception ${ }^{a}$ & \multicolumn{5}{|c|}{$\begin{array}{l}\text { Ratio of indicator between top and bottom wealth } \\
\text { quintile }\end{array}$} \\
\hline any method (\%) & 1.45 & 3.26 & 2.88 & 1.79 & 1.32 \\
\hline any modern method (\%) & 1.53 & 6.19 & 3.72 & 1.78 & 1.29 \\
\hline Delivery at health care facility (\%) & 2.11 & 3.97 & 3.36 & 1.62 & 1.28 \\
\hline Assistance of trained personnel (\%) & 1.95 & 3.08 & 2.44 & 1.65 & 1.40 \\
\hline All vaccinations ( $\%$ children $12-23$ months) & 1.05 & 1.08 & 1.00 & 1.02 & 1.10 \\
\hline Households owns mosquito net (any type, \%) & n.a. & 26.01 & 7.35 & 1.71 & 1.20 \\
\hline \multicolumn{6}{|l|}{ Net attendance ratio ${ }^{c}$} \\
\hline primary school, total & 1.39 & 1.18 & 1.10 & n.a. & 1.19 \\
\hline secondary school, total & 4.86 & 12.88 & 24.24 & n.a. & 4.74 \\
\hline
\end{tabular}

Notes and source: Authors' calculation from the DHS data. aAmong married women. ${ }^{\mathrm{b}}$ Of live births in the last three years preceding the survey. ${ }^{\mathrm{C}}$ The NAR for primary school is the percentage of the primary-school-age (7-12 years) population that is attending primary school. The NAR for secondary school is the percentage of the secondary-school-age (13-18 years) population that is attending secondary school.

In sum, the overall pattern revealed by almost all of the DHS indicators is of big improvements in health, education, assets, and housing conditions between 2000 and 2010, and of improvements in which rural areas and the poor appear to share equally. In most cases this is in sharp contrast to the pattern in Rwanda over the years of conflict in the 1990s.

This raises the question of the causes of these improvements in nonmonetary outcomes. The period from 2000 onwards saw major policy initiatives and changes in relation to education and especially health. Compulsory and free primary education was introduced; large numbers of schools were constructed or refurnished in this period, and many who had missed school in the years of conflict attended later. As seen above, a very high rate of attendance was achieved. There were many initiatives in the health sector, including the introduction of performance-based financing and of compulsory health insurance; and all sectors were affected by the imihigo performance contracts described above. The intense family planning campaign and a big increase in contraceptive availability are likely to have contributed to the falling fertility rates. To decisively attribute the improved outcomes to these policies, more rigorous evaluations are needed.

\subsection{Trends in Consumption Poverty and Inequality}

The available data to assess consumption poverty primarily concern the postconflict period. Three comparable household surveys are available since 2000 and these are the main focus of this section; an earlier rural survey collecting 
data on income from 1990 will be briefly reviewed at the end of this section, despite concerns about comparability.

The three household surveys used here are the Household Living Conditions Survey-Enquête Intégrale sur les Conditions de Vie des ménages (EICV), in French-of 2000/1, 2005/6, and 2010/11. These were multi-purpose household surveys collecting among other things detailed data to enable the estimation of household consumption and income, based on short-period recall data for consumption. The first survey used the 1991 census as a sampling frame, but substantially complemented by a socioeconomic survey conducted in $1996 / 7$ because of the substantial population changes since 1991; the second and third rounds used the 2002 population census for the sample frame, which was also used ex post to revise the weights from the first survey. Sample sizes were 6,420 in 2000/1, 6,900 in 2005/6, and 14,298 in 2010/11. The larger sample frame in the last case was designed to give data which would be representative at the new district level, following a reform in the structure of local government in 2006.

The three surveys were identical in terms of how they collected consumption data, and were used to estimate household consumption for each of the rounds. The measure of household consumption encompasses annualized estimates of purchases of food and non-food as well as consumption of home-produced food and non-food. In addition, consumption aggregates include spending on education, frequent health expenses, expenses on housing and utilities (electricity, water), the value of wages received in kind, the estimated value of services derived from durable goods, and the value of transfers received in kind from other households. An adult equivalence scale commonly used in Rwanda was used to express household consumption on a per equivalent adult basis, so taking account of differences in the size and composition of households. The detailed methodology is described in the appendix to the National Institute of Statistics of Rwanda's poverty report (GoR 2012a).

In analysing consumption poverty it is also important to take account of price differences between geographic locations, between months of the year, and between the periods of the different surveys. Very good price data was available in this case. The agriculture ministry had since 1999 been collecting frequent and consistent food price data on a large number of commodities across a large number of markets in Rwanda. This was used to estimate a food price index capturing all the spatial and temporal differences, using commodity weights from the survey data. A similar non-food index was constructed using the raw price data collected for the consumer price index in more urbanized areas and the two were combined into an overall cost-of-living index, which was used to deflate the consumption data computed from the survey. The index shows important differences by month, location, and between the survey rounds (GoR 2012a). 
Table 6.3. Consumption and consumption poverty by province

\begin{tabular}{|c|c|c|c|c|c|c|c|c|c|}
\hline & \multicolumn{3}{|c|}{$\begin{array}{l}\text { average consumption per } \\
\text { adult }\end{array}$} & \multicolumn{3}{|c|}{ poverty incidence } & \multicolumn{3}{|c|}{ poverty depth } \\
\hline & $2000 / 1$ & $2005 / 6$ & $2010 / 11$ & $2000 / 1$ & $2005 / 6$ & $2010 / 11$ & $2000 / 1$ & $2005 / 6$ & 2010/11 \\
\hline Kigali City & 253.2 & 289.5 & 324.8 & 0.227 & 0.208 & 0.168 & 0.366 & 0.346 & 0.284 \\
\hline Southern Province & 68.5 & 71.6 & 106.8 & 0.655 & 0.667 & 0.565 & 0.422 & 0.416 & 0.340 \\
\hline Western Province & 76.6 & 87.4 & 92.9 & 0.623 & 0.604 & 0.484 & 0.396 & 0.395 & 0.340 \\
\hline Northern Province & 73.4 & 76.1 & 110.0 & 0.642 & 0.605 & 0.428 & 0.431 & 0.400 & 0.340 \\
\hline Eastern Province & 71.4 & 89.9 & 104.5 & 0.593 & 0.521 & 0.426 & 0.415 & 0.357 & 0.302 \\
\hline RWANDA & 90.6 & 99.7 & 123.9 & 0.589 & 0.567 & 0.449 & 0.414 & 0.393 & 0.329 \\
\hline
\end{tabular}

Source: Government of Rwanda (2012a)

An absolute local currency poverty line was used in the analysis, of RwF118,000 per adult equivalent per year in 2010/11 prices (RwF64,000 January 2001 prices). This line had been set with reference to a minimum food consumption basket identified in 2000/1, judged to offer the number of calories required for a Rwandan who was likely to be involved in physically demanding work, along with an allowance for non-food consumption. An extreme poverty line was also set as the cost of buying the food consumption basket if nothing was spent on non-food at all, corresponding to RwF83,000 (RwF45,000 January 2001 prices). The consumption basket was an austere one, reflecting widespread levels of poverty at the time of the EICV1 survey.

The average level of consumption and estimates of poverty headcount and poverty depth (the average shortfall of the poor below the poverty line) are presented in Table 6.3, disaggregated across the five provinces of Rwanda. Average real household consumption per adult equivalent increased from RwF90,601 in 2000/1 to RwF99,749 in 2005/6, an annualized rate of increase of 1.9 per cent; between $2005 / 6$ and 2010/11 it increased at an annualized rate of 4.5 per cent to reach RwF 123,891 in 2010/11. The data show a very sharp differential in the levels of consumption between Kigali and the other provinces. The four remaining provinces have much more similar average consumption levels. The provinces mostly show similar trends over time.

The poverty incidence figures show at the national level a modest reduction in poverty of 2.2 percentage points, between 2001/1 and 2005/6. But there is then a sharp reduction of 11.8 percentage points between 2005/6 and 2010/ 11. A broadly similar pattern of change over time in poverty is seen in each province, except that in the Southern province poverty actually increased slightly between $2000 / 1$ and $2005 / 6$. There is a particularly sharp reduction in poverty in the Northern province between 2005/6 and 2010/11. All the province-level reductions in poverty between 2005/6 and 2010/11 are statistically significant at the 1 per cent level, though the changes between 2000/1 and 2005/6 are often not significant. Comparing levels of poverty between 
provinces it is very clear always that the levels of poverty are much lower in Kigali compared to the other four provinces. To a large extent this reflects urban-rural differences as the provinces outside Kigali are predominantly rural while Kigali province is predominantly urban. The depth of poverty shows similar patterns. It falls modestly between 2000/1 and 2005/6 and more between 2005/6 and 2010/11. The difference in the depth of poverty in Kigali and other provinces is much less than was the case for the incidence of poverty. In other words, those who are poor in Kigali are almost as poor on average as are the poor in other provinces.

It is equally important to look at inequality. At the national level, the Gini coefficient for Rwanda is high compared to neighbouring countries and internationally. It was 0.51 in $2000 / 1$ and increased modestly to 0.52 in 2005/6, but then fell to 0.49 in 2010/11. Other inequality indices such as the ratio of the 90th to the 10th percentile show the same pattern of change. But the nature of the change of inequality is also highlighted visually through growth incidence curves for the 2000/1-2005/6 and 2005/6-2010/11 periods (Figures 6.2a and 6.2b). These show the growth in household consumption by percentile. What is clear is that for the first sub-period, consumption growth was higher at the top of the distribution than at the bottom, consistent with the increase in inequality. In the second sub-period though, growth was faster at the bottom of the distribution than at the top, again consistent with inequality falling. Thus in the first period, poverty reduction was modest because the growth in consumption was slower and it was associated with increasing inequality. In the second period, poverty fell much more, both because growth was faster and because inequality fell. It still remains the case in 2010/11 though that the level of inequality is high in Rwanda.

In summary, the pattern revealed by the survey data shows two very distinct periods. In the first period, over which GDP growth was also more modest (per capita GDP actually fell in 2001-2), consumption growth was also modest, inequality rose, and the incidence and depth of poverty only fell slightly, to an extent which was not statistically significant. In the second period, GDP growth was higher and consumption growth was much higher. Inequality also fell and there was a significant growth at the bottom of the distribution. Reflecting all this, both the incidence and depth of poverty fell significantly, indeed by a large magnitude.

As noted, the 2010/11 sample was large enough to permit indicators to be estimated at the district level. Figure 6.3 shows a map of Rwanda indicating district-level poverty estimates with darker colours representing higher poverty levels. It is very clear from this that poverty is lowest in Kigali (the lightshaded districts in the centre of the map) and in Musanze district in the north; it is also clear that it is in the districts in the south and west that poverty levels are highest. These are historically poorer areas of Rwanda, and they are often 
(a) Growth incidence curve $1999 / 2001$ to $2005 / 6$

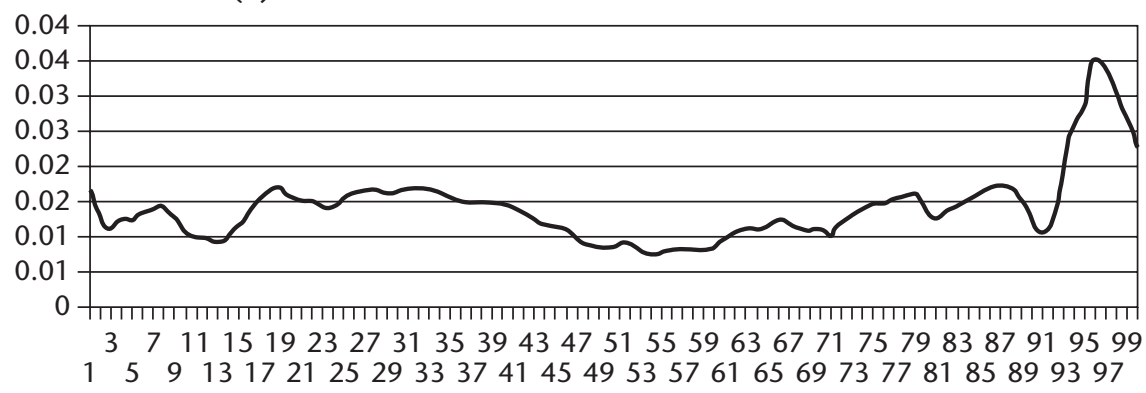

(b) Growth incidence curve $2005 / 6$ to $2010 / 11$

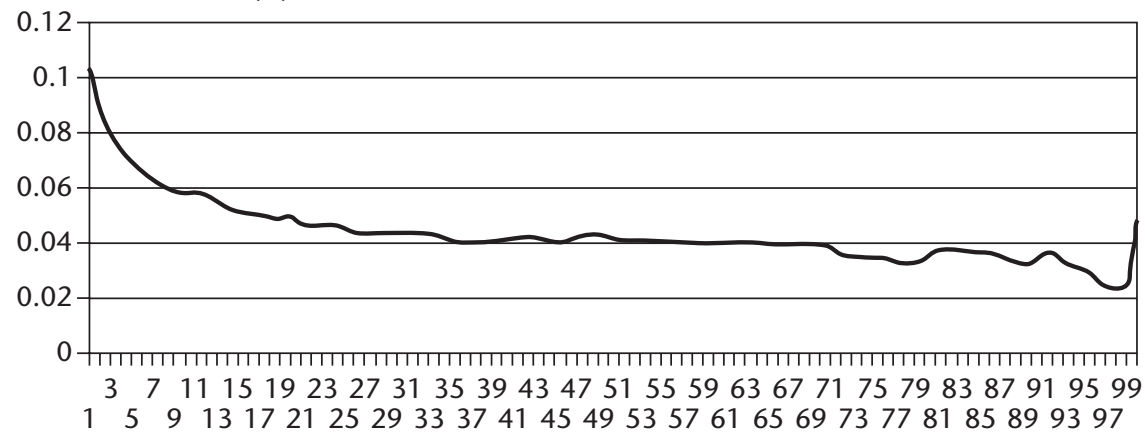

Figure 6.2. Growth incidence curves for Rwanda

Source: Government of Rwanda (2012a: 22)

also less urbanized and more remote. Figure 6.4 then shows changes in poverty between 2005/6 and 2010/11. Not all these changes are statistically significant but all in the lightest colour category are; what this map seems to suggest is much greater poverty reduction in districts located closer to borders with neighbouring countries (even some very poor ones in the south) and much less reduction or even increases in locations further from borders and often more remote. Cross-border trade may have been a factor contributing to this poverty reduction, but this needs further investigation.

An analysis looking at poverty in relation to a household's economic activities shows that those undertaking non-farm activity, either as wage work or self-employment, are much less poor than average; and that those reliant on farming activity are much poorer than average. The period between 2005/6 and 2010/11 showed an increase in the proportion of households in the survey reliant on non-farm activities, consistent with the overall poverty reduction over this period. In both years, among households reliant on farming it is those that are substantially reliant on farm wage work who are poorest 


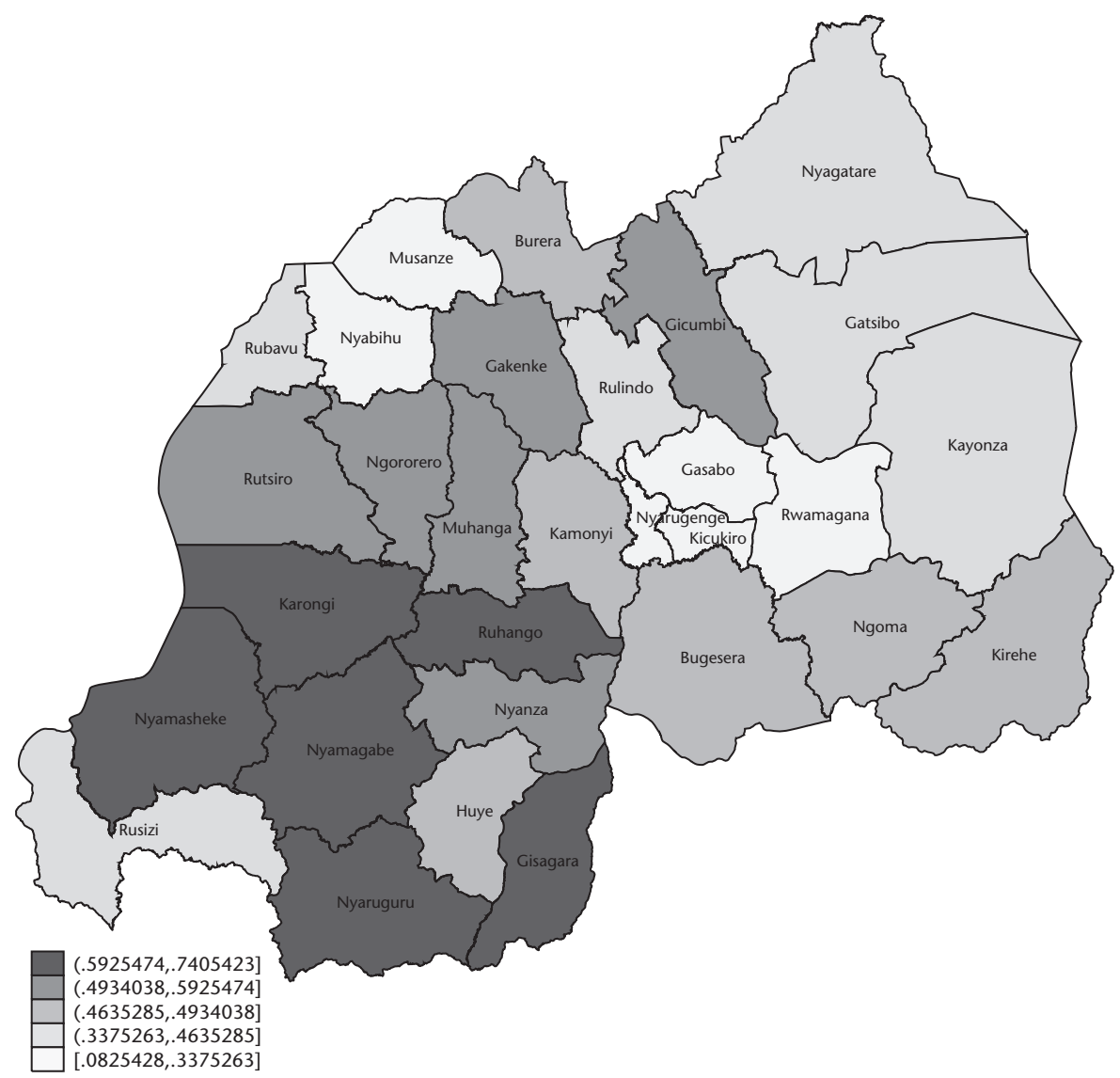

Figure 6.3. Pattern of poverty in Rwanda by district, 2010-11 Source: Government of Rwanda (2012a: 17)

of all. In 2005/6 and 2010/11 around 4 per cent of households get more than half their income from farm wage work, and 7 per cent and 8 per cent get at least 30 per cent of their household income from this source. This work is very badly paid and these households are among the poorest of all.

The consumption poverty results suggest that there has been substantial poverty reduction between $2005 / 6$ and 2010/11; this is also the sub-period where the DHS indicators showed the fastest improvement. But these results need to be explained; and they need to be considered against local-level qualitative field research which gives a very different picture (Ansoms et al. 2010; Sommers 2012) as well as highly critical evaluations or assessments of a number of policy measures put in place by the government (e.g. villagization: Newbury 2011; land consolidation and crop intensification policies: Ansoms et al. 2010; Huggins 2009). 


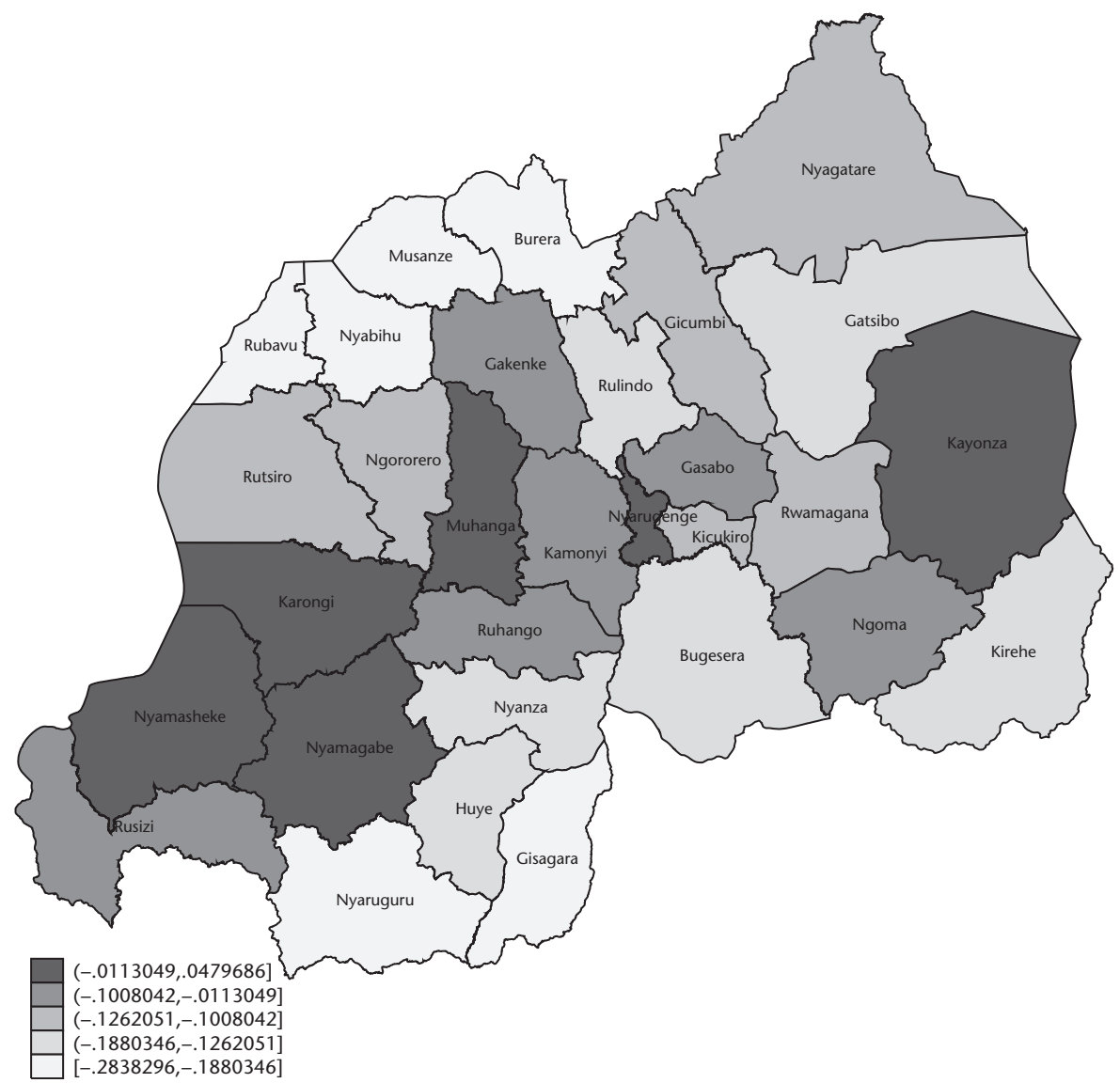

Figure 6.4. Changes in poverty in Rwanda between 2005/6 and 2010/11, by district Source: Authors' computation from the Rwanda EICV survey database

In seeking to explain the results, it is important first to bear in mind that poverty results reflect the economic conditions of the time period over which the data was collected, and can reflect exceptional circumstances in these years. To some extent, the relatively disappointing harvest in 2005/6 could partly explain both the lack of progress between 2000/1 and 2005/6 and the faster progress between 2005/6 and 2010/11 as well as the attendant changes in inequality. The period covered by the second and third surveys was one over which agricultural production is reported to have increased substantially. The production of cereals, pulses, and roots was reported to have increased between 2005/6 and 2010/11 by 135 per cent, 21 per cent, and 95 per cent, respectively (World Bank 2013). The survey data also show that agricultural commercialization was higher in 2010/11 than 2005/6. Reyntjens (2012: 115) argues this point, stating that 'the consumption figures are a snapshot that 
might be determined by the output, strongly influenced by climate of the agricultural season preceding the survey'. Further potential support to this is given by the fact that total annual rainfall in 2010 was 50 per cent higher than in 2005 (1,200 $\mathrm{mm}$ compared to $800 \mathrm{~mm}$ ) (SSEE 2011).

Other factors though undoubtedly contributed to poverty reduction. One is the increased number of households able to undertake non-agricultural activities (though this may to some extent also be affected by the good agricultural performance), including an increase in available wage work opportunities (GoR 2012b). Smaller family size is another factor which will have had a positive impact on poverty reduction. Improved education and health outcomes, as evidenced in section 6.2 , are also likely to have contributed to improved economic outcomes for households.

But in terms of whether and which policies contributed to poverty reduction, the same point made above in relation to social sectors applies even more emphatically here. Given the lack of proper impact evaluations, nothing contained in this consumption poverty analysis can be decisively attributed to the different policies which have been put in place (e.g. agricultural and land policies; social protection; the Economic Development and Poverty Reduction Strategy itself).

Besides the absence of rigorous assessments, another issue is how to interpret 'improvements'. Some argue that they reflect the 'cosmetic upgrading of rural life' which 'hides the true extent of poverty and inequality' (Ansoms 2011: 247). This criticism is based on the coercion that accompanies many of the developmental measures, institutionalized in a system of fines-for not sending children to school, for walking bare-footed, or for consulting a traditional healer without authorization, among others. ${ }^{4}$ Ingelaere (2011: 73) argues that these fines may make rural dwellers 'look' less poor, even though they are likely to 'be and feel' as poor, or even poorer, than before. The issue of people's perceptions in relation to poverty will be revisited in section 6.4.

The comparisons on which this section focuses have been based on surveys conducted since 1994, and these are not properly comparable with earlier surveys. However, in terms of trying to make a pre-war comparison, a survey in 1990 collected quite detailed data on incomes of rural households, and McKay and Loveridge (2005) sought to compare this with income data collected from rural households in the 2000/1 EICV survey. Differences in methodology mean that considerable care is needed in making this comparison. The authors sought to define comparable concepts of income, and could also compare child anthropometric outcomes between the two surveys. Anthropometric outcomes for under-five children had improved slightly

\footnotetext{
${ }^{4}$ Following criticism of the fines, among others by donors, their actual implementation may have decreased in recent years (personal correspondence with Bert Ingelaere).
} 
between 1990 and 2000/1, despite a significant reduction in the average land size cultivated over the period; and average household income in 2000/1 had risen above its 1990 value (a result consistent with other data on agricultural production for this period). But there also appeared to be increasing inequality over this period (in line with the pattern observed in the DHS data); the richest 30 per cent of the sample in 2000/1 were significantly better off, but the remaining 70 per cent were in fact worse off in income terms, though not in terms of anthropometric outcomes. The latter paradox may be explained by changes in cultivation patterns over the period (e.g. more cultivation of cassava, less of cash crops) and reductions in sales of output over the period.

There may then have been progress also during 1990-2000. But the results for the post-2000 period are clearly more robust.

\subsection{Analysing Household Mobility Based on a Small Panel Dataset}

Panel data enables an analysis of economic mobility which cannot be done with the repeated cross-sectional data analysed above. The analysis in this section is based on a small panel data conducted in 2002 and 2008 in two locations in Rwanda, the former provinces of Gikongoro and Gitarama (now mainly in the Southern or Western provinces). It is interesting to note that much of this area was seen to have made less progress in consumption poverty in section 6.3. This survey was a follow-up of the same 1990 survey discussed in the previous section, but the analysis here focuses on the 2002 and 2008 rounds. The 2002 round was collected as part of a study for the Belgian Department for Development Cooperation (DGOS), and collected data from 258 households on themes including subsistence production, crop sales, livestock production, non-farm income, beer brewing, transfers, land ownership, household composition and schooling, war-related shocks, other adverse income shocks, and household consumption shortfalls. For a detailed description, see Verpoorten and Berlage (2007). The 2008 round used a similar design and was collected on a grant from the Rwandan government and LICOSCenter for Institutions and Economic Performance (University of Leuven). It sought to interview and collect similar information from all 258 households, but in the end interviewed 241 because the remaining households could not be found or could not be considered to be the same. Analysing attrition across the 2002 and 2008 rounds, we find little evidence that household characteristics drive attrition.

The data can be used to estimate household income as a welfare measure, and data are also available on land, livestock, and other assets. There is strong growth in average income between 2002 and 2008, with real income per adult 

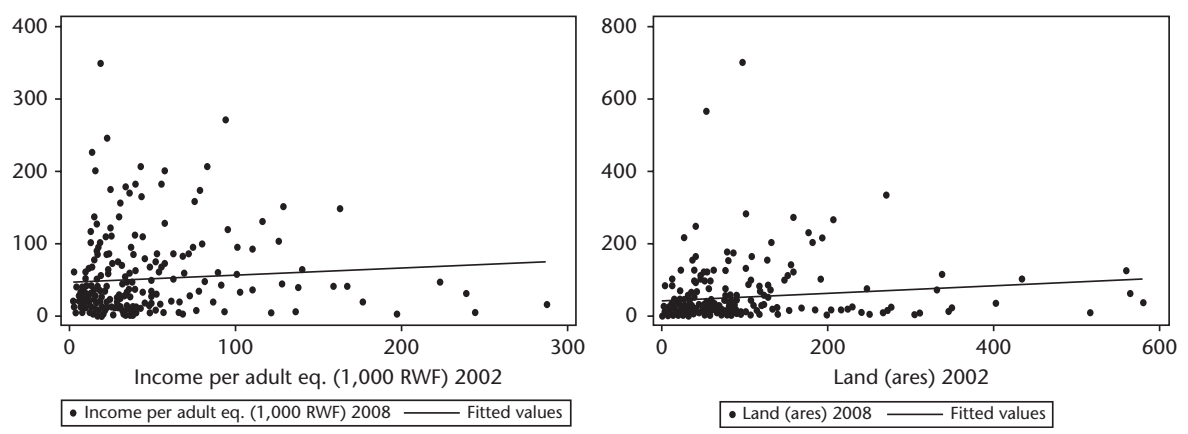

Figure 6.5. Scatterplots of 2008 values of income and land against their 2002 values Source: Computed from DGOS/Government of Rwanda/LICOS panel dataset; see text

equivalent (in prices of 2008) increasing from RwF54,614 in 2002 to RwF60,725 in 2008, a 11.2 per cent increase over the six-year period. This happened despite a sharp drop in average farm sizes from 0.89 ha in 2002 to 0.54 ha in 2008. Livestock ownership, expressed in TLU (tropical livestock units), was very similar in both years. There is a very small rise over the period in the contribution of non-farm wage employment (7.2 per cent to 7.6 per cent) and non-farm self-employment (9.4 per cent to 10.1 per cent). More important is the fact that agricultural productivity would seem to have increased, which may reflect the increased use of fertilizer as highlighted by the World Bank (2013), or simply better agricultural weather conditions. The data again highlight substantial inequality with the Gini coefficient of net income per adult equivalent being 0.56 and 0.55 in 2002 and 2008 respectively.

Of particular interest in a panel dataset is to look at mobility. Figure 6.5 presents scatterplots of income and land in 2008 compared to their 2002 values. The land scatterplot shows reductions in the large majority of cases, including some very large reductions. The income plot shows much greater heterogeneity, with many increases but also a large number of reductions. A regression analysis, based on a production function approach, of the level of income found that there were large, positive, and significant returns to land and labour. In addition, income in 2008 depends positively and significantly on income in 2002 and on changes in labour and land between 2002 and 2008 (Verpoorten 2014).

The 2008 survey also classified households into six widely used social categories that emerged from the 2001 nationwide participatory poverty assessment (PPA, ubudehe). ${ }^{5}$ The categories range from 'the abject poor'

\footnotetext{
5 The PPA was implemented nationwide in a sample of administrative sectors. In each sector, facilitators consulted with a large number of community members (about 300), aiming to identify different social categories as seen by Rwandans themselves. The characteristics of these groupings
} 
Table 6.4. Mobility matrix of self-reported social categories

\begin{tabular}{|c|c|c|c|c|c|c|c|}
\hline & & \multicolumn{6}{|c|}{ Categories in 2008} \\
\hline & & $\begin{array}{l}\text { umutindi } \\
\text { nyakujya }\end{array}$ & umutindi & umukene & $\begin{array}{l}\text { umukene } \\
\text { wifashije }\end{array}$ & umukungu & umukire \\
\hline \multirow[t]{11}{*}{$\begin{array}{c}\text { Categories } \\
\text { in } 2002\end{array}$} & umutindi nyakujya & $\begin{array}{c}6 \\
85.7\end{array}$ & $\begin{array}{l}0 \\
0.0\end{array}$ & $\begin{array}{c}1 \\
14.3\end{array}$ & $\begin{array}{l}0 \\
0.0\end{array}$ & $\begin{array}{l}0 \\
0.0\end{array}$ & $\begin{array}{l}0 \\
0.0\end{array}$ \\
\hline & umutindi & 0 & 19 & 8 & 4 & 0 & 0 \\
\hline & & 0.0 & 61.3 & 25.8 & 12.9 & 0.0 & 0.0 \\
\hline & umukene & 1 & 4 & 70 & 27 & 0 & 0 \\
\hline & & 1.0 & 3.9 & 68.6 & 26.5 & 0.0 & 0.0 \\
\hline & umukene wifashije & 0 & 4 & 8 & 66 & 2 & 0 \\
\hline & & 0.0 & 5.0 & 10.0 & 82.5 & 2.5 & 0.0 \\
\hline & umukungu & 0 & 0 & 1 & 5 & 11 & 0 \\
\hline & & 0.0 & 0.0 & 5.9 & 29.4 & 64.7 & 0.0 \\
\hline & umukire & 0 & 0 & 0 & 0 & 1 & 1 \\
\hline & & 0.0 & 0.0 & 0.0 & 0.0 & 50.0 & 50.0 \\
\hline
\end{tabular}

Source: Small DGOS/Government of Rwanda/LICOS panel dataset; see text

(umutindi nyakujya) to 'the money rich' (umukire). The intermediate categories are 'the very poor', 'the poor', 'the resourceful poor', and 'the food rich' (umutindi, umukene, umukene wifashije, umukungu). These categories are described in more detail in the Appendix to this chapter. The 2008 survey also asked households to report their ubudehe status in 2002. The social categories reported by respondents correlate quite strongly with the income, land, and livestock data available from the survey.

This then gives an alternative, self-reported measure of mobility to the income and land-based measures above, and a mobility matrix is reported in Table 6.4. In this matrix, nearly 70 per cent of households remain in the same category between these two years, but where there is mobility it is mostly upward, especially people moving out of categories 2 and 3 to typically the next highest group. Howe and McKay (2007) in an earlier analysis interpreted the first three categories as being likely to include a substantially higher number of chronically poor households, but even some of these appear to have been able to move up into a higher group. In 2002, we find about 13 per cent in the second category and 43 per cent in the third category, compared to 11 per cent and 37 per cent in 2008 . While the lowest three categories make up almost 59 per cent of the sample in 2002, their share stands at 51 per cent in 2008, thus marking a decline in poverty.

The survey also asked respondents directly about the reasons for upward and downward mobility in terms of these categories (Figure 6.6). Once again, production factors figure large here, with a good harvest, better and more land,

were defined as well as the reasons for moving up or down the social ladder and for being stuck in poverty (<http://www.rgb.rw/governance-innovations/ubudehe/>). 


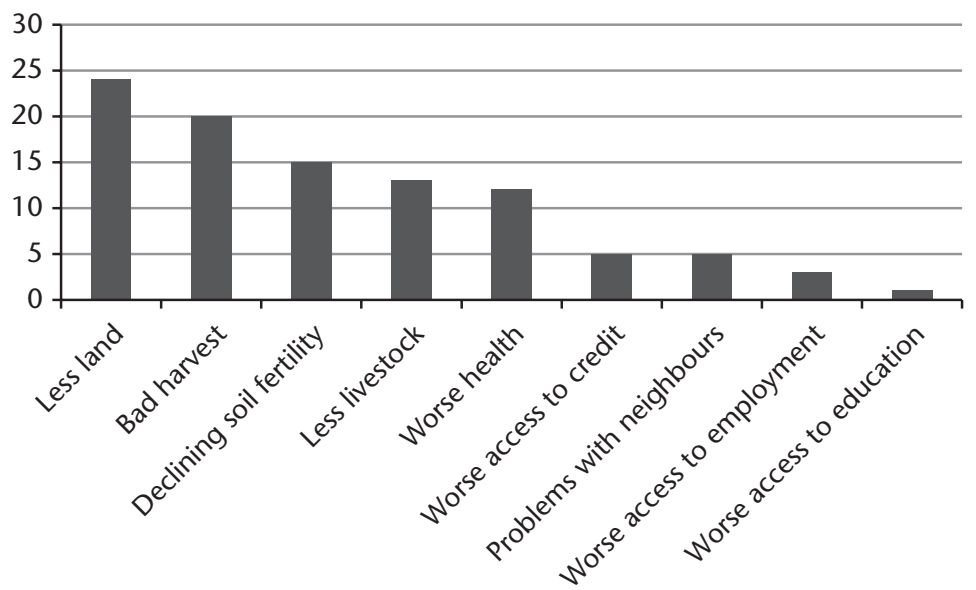

Figure 6.6. Self-reported reasons for social mobility between $u b u d e h e$ categories Source: Computed from DGOS/Government of Rwanda/LICOS panel dataset; see text

and more livestock being reported as the most important factors behind upward mobility; and the opposite factors being the main reasons behind downward mobility.

Finally and importantly the 2008 round of the panel data set also asked household heads the twelfth question of the GHQ-12, the General Health Questionnaire, developed by Goldberg and Blackwell (1970): 'Have you recently been feeling reasonably happy all things considered?' (Goldberg and Blackwell 1970), with the following response categories: 'strongly agree', 'agree', 'disagree', and 'strongly disagree'. About 10 per cent of household heads strongly agree, 57 per cent agree, 21 per cent disagree, and 12 per cent strongly disagree (see Table 6.5). These responses suggest that close to one out of three household heads felt unhappy. Looking at the distribution of income, assets, and mobility across the answer categories, happiness is weakly positively correlated with income, but strongly correlated with relative income mobility (both measured and self-reported): those who moved more upward feel more happy. Strikingly, however, even the unhappy experienced a positive absolute change in average income ( $+21,000$ vs $+85,000$ for the happy), suggesting that it is not levels nor absolute changes in income that matter, but

\footnotetext{
6 The GHQ has been translated into many languages. It was cross-culturally validated as part of a World Health Organization project on mental illness conducted in both developing and developed countries (Goldberg et al. 1997). During the preparation phase of the 2008 round of the panel data, we let the GHQ-12 be translated from English to Kinyarwanda and then back from Kinyarwanda to English by two different translators (double-blinded). We compared the retranslated English version with the original one to spot problems, which were then discussed in detail with both translators until a consensus on an accurate translation was reached. We acknowledge input from Pieter Serneels in this process.
} 
Table 6.5. Happiness, and mean income, assets, and income change by happiness

Have you recently been feeling reasonably happy all things considered?

\begin{tabular}{|c|c|c|c|c|c|c|c|c|c|}
\hline & $\mathrm{Nr}$ & $\%$ & $\begin{array}{l}\text { Cum } \\
\%\end{array}$ & $\begin{array}{l}\text { Income/ } \\
\text { ae } 08\end{array}$ & $\begin{array}{l}\text { Land } \\
08 \\
\text { (ares) }\end{array}$ & $\begin{array}{l}\text { Livestock } \\
08 \text { (TLU) }\end{array}$ & $\begin{array}{l}\text { Female } \\
\text { head } \\
08\end{array}$ & $\begin{array}{l}\text { Income } \\
\text { change } \\
02-08\end{array}$ & $\begin{array}{l}\text { Self-reported } \\
\text { mobility: } \\
\text { 'better' }\end{array}$ \\
\hline strongly disagree & 29 & 11.6 & 11.6 & 77,897 & 33.33 & 0.93 & 0.59 & 15,146 & 0.21 \\
\hline disagree & 52 & 20.8 & 32.4 & 47,820 & 40.45 & 0.86 & 0.51 & 26,078 & 0.24 \\
\hline agree & 143 & 57.2 & 89.6 & 61,961 & 62.92 & 1.24 & 0.46 & 69,011 & 0.31 \\
\hline strongly agree & 26 & 10.4 & 100 & 70,134 & 81.47 & 1.39 & 0.19 & 183,623 & 0.42 \\
\hline
\end{tabular}

Source: Small DGOS/Government of Rwanda/LICOS panel dataset; see text

relative changes. Happiness also strongly correlated with land ownership. Those who report being happy have about 75 per cent more land than 'the unhappy' (0.65 ha versus $0.38 \mathrm{ha}$ ). The average decline in landholdings was also significantly larger among the unhappy than among the happy (0.53 ha vs $0.25 \mathrm{ha}$, not reported).

The importance of relative wealth for subjective well-being has also been underlined in many other studies including Luttmer (2005), Kingdon and Knight (2007), and Fafchamps and Shilpi (2008), among others. The importance of relative landholdings aligns well with the findings of Van Landeghem et al. (2011) who study the subjective well-being (SWB) of farm households in the context of land reform in Moldova.

The fact that happiness is not strongly correlated with the level of material well-being is an important finding, and may help explain something of the difference between the indicators reported in the survey-based results and the results of the qualitative fieldwork. Progress in terms of levels of monetary and non-monetary indicators does not necessarily mean that people feel better off, certainly when others are also making progress, at a faster rate.

\subsection{Conclusions}

In many respects Rwanda has made very impressive progress in the period since 1994, showing sustained growth at fast rates, even accelerating in recent years. This represents a substantial change from the pre-1994 situation of no, or at best, low and unsustained growth. This chapter has examined the changes in living conditions which have taken place alongside this growth. It shows substantial progress in both non-monetary indicators of well-being and consumption poverty, with faster progress since around 2005 in each case. The 2002-8 panel survey also suggests that people have become better off in income terms and in terms of their own self-assessment (in terms of the 
ubudehe categories). There is therefore strong evidence of improving living conditions alongside the economic growth.

In the case of consumption or income, given the typical fluctuations in such variables over time, the results of the comparisons between two or more years can be quite sensitive to the precise timing of the surveys. Hence the comparisons of these variables may or may not indicate longer-term trends. But many non-monetary measures vary much less over time, rather evolving more gradually and consistently. The non-monetary measures considered here mostly show improvement which is just as impressive as that in consumption poverty. Mortality rates have fallen consistently since 2000 , access to health care has much improved, education levels have increased, asset holdings and housing conditions have improved, and these improvements have happened for the poor as much as for the non-poor. While complete explanations of these changes are currently lacking, these changes are beyond mere post-war catch-up.

Because of the various channels of multi-way causation between income, health, education, and other outcomes, it is not surprising that the improvements in human development outcomes as inferred from the DHS data are in line with the poverty and inequality trends that emerge from data on consumption expenditures. But how can this evidence of pro-poor growth be reconciled with the much more pessimistic findings of mostly qualitative fieldwork at the local level?

The analysis of dynamic and subjective measures of household well-being based on the small panel dataset may provide some clues. Respondents' happiness levels turned out to be very weakly related to income levels, but correlated much more strongly with relative income changes and landholdings. These findings suggest that subjective measures of well-being do not necessarily align well with objective measures of well-being; and that the mismatch may be considerable in Rwanda as a result of rapid and profound economic and social transformations. This creates uncertainty; it leads to winners and losers (in relative terms); and it affects traditional land- and subsistence-based livelihoods. In particular, peasants have often had great difficulty in responding to many of the policies introduced-for example, in relation to land consolidation and monocropping - and the speed of the implementation makes this more difficult.

It is very difficult also to say to what extent the improvements have been due to the many different government policy interventions which have been put in place over the period. Many of these interventions are quite recent; but more importantly they mostly have not been properly evaluated. Thus, for example, it is not yet possible to know whether changes in land and agricultural policy can account for the significantly increased production levels in the sector. The requirement for increased upward accountability from the 
local to the central government level via performance contracts or imihigo (Ingelaere 2011) might have played a role in improvements in health and education (or even economic growth), but this has not been evaluated. The massive increase in health care spending (increasing by a factor of 2.5 between 2004 and 2010), coupled with the introduction of performance-based financing, is nonetheless likely to be an important factor behind the improved health outcomes (Basinga et al. 2010). A similar comment applies in the education sector. Aid would seem to have played an important role here, as it probably has in stimulating growth more widely. But there is currently insufficient information to assess the relative role of public policy measures, greater effectiveness of policy implementation, aid, and other factors in accounting for the observed outcomes in terms of living conditions.

Although the technically capable government is well underway to reach several of the Millennium Development Goals, Rwanda's path to development remains controversial, because of the sharp contrast between the impressive economic progress and the standstill in 'voice and accountability', one of the six Kaufmann et al. (2010) governance indicators. These allegations cast a shadow over the regime's economic successes and leave the scholar and donor community deeply divided on how to approach Rwanda, and what to expect-can the lack of progress on 'voice and accountability' pose a risk to the sustainability of the achievements to date? If anything, Rwanda's history should make observers especially attentive to evolutions in social, political, and economic exclusion (Ingelaere and Verpoorten 2014).

Another point of concern highlighted in this analysis is the continued high level of inequality in Rwanda, even if this has fallen recently and has become an important government priority. Inequality in Rwanda is higher than in most or all other countries in Eastern Africa and this must be a concern for cohesion and sustainability, exacerbated by the above concerns about voice and accountability. The extent of the gap between Kigali and the rest of the country remains an important dimension of this, though there are also large levels of inequality within provinces. 


\section{Appendix: Rwandan Social Categories}

\begin{tabular}{|c|c|}
\hline Social category & Characteristics \\
\hline $\begin{array}{l}\text { Umutindi nyakujya (those in } \\
\text { abject poverty) }\end{array}$ & $\begin{array}{l}\text { Those who need to beg to survive. They have no land or livestock } \\
\text { and lack shelter, adequate clothing, and food. They fall sick often } \\
\text { and have no access to medical care. Their children are } \\
\text { malnourished and they cannot afford to send them to school. }\end{array}$ \\
\hline Umutindi (the very poor) & $\begin{array}{l}\text { The main difference between the umutindi and the umutindi } \\
\text { nyakujya is that this group is physically capable of working on } \\
\text { land owned by others, although they themselves have either no } \\
\text { land or very small landholdings, and no livestock. }\end{array}$ \\
\hline Umukene (the poor) & $\begin{array}{l}\text { These households have some land and housing. They live on their } \\
\text { own labour and produce; though they have no savings, they can } \\
\text { eat, even if the food is not very nutritious. However, they do not } \\
\text { have a surplus to sell in the market, their children do not always } \\
\text { go to school, and they often have no access to health care }\end{array}$ \\
\hline $\begin{array}{l}\text { Umukene wifashije (the } \\
\text { resourceful poor) }\end{array}$ & $\begin{array}{l}\text { This group shares many of the characteristics of the umukene, but in } \\
\text { addition they have small ruminants and their children go to } \\
\text { primary school. }\end{array}$ \\
\hline Umukungu (the food rich) & $\begin{array}{l}\text { This group has larger landholdings with fertile soil and enough to } \\
\text { eat. They have livestock, often have paid jobs, and can access } \\
\text { health care. }\end{array}$ \\
\hline Umukire (the money rich) & $\begin{array}{l}\text { This group has land and livestock, and often has salaried jobs. } \\
\text { They have good housing, often own a vehicle, have enough money } \\
\text { to lend, and get credit from banks. Many migrate to urban } \\
\text { centres. }\end{array}$ \\
\hline
\end{tabular}

Source: Government of Rwanda (2002)

\section{References}

Ansoms, A. (2011). 'Rwanda's Post-Genocide Economic Reconstruction: The Mismatch between Elite Ambitions and Rural Realities', in S. Straus and L. Waldorf (eds), Remaking Rwanda: State Building and Human Rights after Mass Violence. Madison, WI: University of Wisconsin Press, 240-51.

Ansoms, A., A. Verdoodt, and E. Van Ranst (2010). 'A Green Revolution for Rural Rwanda: Reconciling Production Growth with Small-Scale Risk Management'. A paper prepared for the Ten Years of War Against Poverty conference, 8-10 September, Manchester, UK, <http://www.chronicpoverty.org/uploads/publication_files/ ansoms_et_al_rwanda.pdf $>$.

Ayalew, A. D., K. Deininger, and M. Goldstein (2011). 'Environmental and Gender Impacts of Land Tenure Regularization in Africa: Pilot Evidence from Rwanda', World Bank Policy Research Working Paper No. 5765. Washington, DC: World Bank.

Basinga, P., P. J. Gertler, A. Binagwaho, A. L. B. Soucat, J. R. Sturdy, and C. M. J. Vermeesch (2010). 'Paying Primary Healthcare Centers for Performance in Rwanda', World Bank Policy Research Working Paper No. 5190. Washington, DC: World Bank. 
Booth, D. and F. Golooba-Mutebi (2012). 'Developmental Patrimonialism? The Case of Rwanda', African Affairs, 111(444): 379-403.

DHS (Demographic and Health Surveys) (1992, 2000, 2005, 2007, 2010). MEASURE DHS project, obtained from ICF Macro, <http://www.measuredhs.com>.

Fafchamps, M. and F. Shilpi (2008). 'Subjective Welfare, Isolation, and Relative Consumption', Journal of Development Economics, 86: 43-60.

Filmer, D. and L. Pritchett (2001). 'Estimating Wealth Effects without Expenditure Data-or Tears: An Application to Educational Enrollments in the States of India', Demography, 38: 115-32.

Goldberg, D. P. and B. Blackwell (1970). 'Psychiatric Illness in General Practice: A Detailed Study Using a New Method of Case Identification', British Medical Journal, 1: 439-43.

Goldberg, D. P., R. Gater, N. Sartorious, T. Ustun, M. Piccinelli, O. Gueje, and C. Rutter (1997). 'The Validity of Two Versions of the GHQ in the WHO Study of Mental Illness in General Healthcare', Psychological Medicine, 27(1): 191-7.

GoR (Government of Rwanda) (2002). 'The Government of Rwanda Poverty Reduction Strategy Paper', National Poverty Reduction Programme, Ministry of Finance and Economic Planning, June. Available at <http://siteresources.worldbank.org/ INTPRS1/Resources/Country-Papers-and-JSAs/Rwanda_PRSP.pdf $>$.

GoR (Government of Rwanda) (2012a). 'The Evolution of Poverty in Rwanda from 2000 to 2011: Results from the Household Surveys (EICV)', National Institute of Statistics of Rwanda.

GoR (Government of Rwanda) (2012b). 'EICV 3 Thematic Report: Economic Activity', National Institute of Statistics of Rwanda.

Guariso, A., C. J. Ngabitsinze, and M. Verpoorten (2012). 'The Rwandan Coffee Sector: Out of the Ordinary', in F. Reyntjens, S. Vandeginste, and M. Verpoorten (eds), L'Afrique des grands lacs: Annuaire 2011-2012. Paris, L'Harmattan, 397-426.

Guariso, A. and M. Verpoorten (2013). 'Armed Conflict and Schooling in Rwanda: Digging Deeper', LICOS Discussion Papers 343, LICOS—Centre for Institutions and Economic Performance, KULeuven.

Howe, G. and A. McKay (2007). 'Combining Quantitative and Qualitative Methods in Assessing Chronic Poverty: The Case of Rwanda', World Development, 35(2): 197-211.

Huggins, C. (2009). 'Agriculture Policies and Local Grievances in Rural Rwanda', Peace Review, 21(3): 296-303.

Ingelaere, B. (2011). 'The Ruler's Drum and the People's Shout: Accountability and Representation on Rwanda's Hills', in S. Straus and L. Waldorf (eds), Remaking Rwanda: State Building and Human Rights after Mass Violence. Madison, WI: University of Wisconsin Press, 67-78.

Ingelaere, B. and M. Verpoorten (2014). 'Rwanda: Could State-Led Mass Killings Ever Happen Again?', African Arguments, 2 June. Available at <http://africanarguments. org/2014/06/02/rwanda-could-state-led-mass-killings-ever-happen-again-by-bertingelaere-marijke-verpoorten/>.

Kabano, I. H., A. Broekhuis, and P. Hooimeijer (2013). 'Fertility Decline in Rwanda: Is Gender Preference in the Way?', International Journal of Population Research, vol. 2013, Article ID 787149, 9 pp. 
Kalk, A. (2008). 'Rwanda's Health System: Some Concerns', The Lancet, 372: 1729.

Kalk, A., F. A. Paul, and E. Grabosch (2010). 'Payment for Performance in Rwanda: Does it Pay Off?', Tropical Medicine and International Health, 15(2): 182-90.

Kaufmann, D., A. Kraay, and M. Mastruzzi (2010). 'The Worldwide Governance Indicators: Methodology and Analytical Issues', World Bank Policy Research Working Paper 5430. Washington, DC: World Bank.

Kingdon, G. G. and J. Knight (2007). 'Community, Comparisons and Subjective Well-being in a Divided Society', Journal of Economic Behavior \& Organization, 64: 69-90.

Luttmer, E. F. P. (2005). 'Neighbours as Negatives: Relative Earnings and Well-being', Quarterly Journal of Economics, 120(3): 963-1002.

McKay, A. and S. Loveridge (2005). 'Exploring the Paradox of Rwandan Agricultural Household Income and Nutritional Outcomes in 1990 and 2000', Michigan State University Staff Paper 2005-06, March.

Muhoza, D. N., P. C. Rutayisire, and A. Umubyeyi (2013). 'Measuring the Success of Family Planning Initiatives in Rwanda: A Multivariate Decomposition Analysis', DHS Working Paper No. 49.

Newbury, C. (2011). 'High Modernism at the Ground Level: The Imidugudu Policy in Rwanda', in S. Straus and L. Waldorf (eds), Remaking Rwanda: State Building and Human Rights after Mass Violence. Madison, WI: University of Wisconsin Press, 223-39.

Nkurunziza, J., A. Broekhuis, and P. Hooimeijer (2012). 'Free Education in Rwanda: Just One Step towards Reducing Gender and Sibling Inequalities', Education Research International, 2012, Article ID 396019, 11 pp.

Reyntjens, F. (2012). 'Elite Ambitions: Engineering a New Rwanda and New Rwandans', in C. Panella (ed.), Lives in Motion, Indeed: Interdisciplinary Perspectives on Social Change in Honour of Danielle de Lame (Studies in Social Sciences and Humanities 174). Tervuren, Belgium: Royal Museum for Central Africa Publishers, 93-120.

Saksena, P., A. F. Antunes, K. Xu, L. Musango, and G. Carrin (2011). 'Mutual Health Insurance in Rwanda: Evidence on Access to Care and Financial Risk Protection', Health Policy, 99(3): 203-9.

SSEE (Smith School of Enterprise and Environment) (2011). 'Rwanda's Climate: Observations and Projections', July, University of Oxford.

Sommers, M. (2012). Stuck: Rwandan Youth and the Struggle for Adulthood. Athens, GA: University of Georgia Press.

Van Landeghem, B., J. Swinnen, and L. Vranken (2011). 'Land and Happiness: Land Distribution and Subjective Well-being in Moldova', Eastern European Economics, 51 (1): 61-85.

Verpoorten, M. (2012). 'Leave None to Claim the Land: A Malthusian Catastrophe in Rwanda?', Journal of Peace Research, 49(4): 547-63.

Verpoorten, M. (2014). 'Growth, Poverty and Inequality in Rwanda: A Broad Perspective', WIDER Working Paper 2014/138. Helsinki: UNU-WIDER.

Verpoorten, M. and L. Berlage (2007). 'Economic Mobility in Rural Rwanda: A Study of the Effects of War and Genocide at the Household Level', Journal of African Economies, 16: 349-92. 
Westoff, C. (2012). 'The Recent Fertility Transition in Rwanda', Population and Development Review, 38 (Supplement): 169-78.

World Bank (2013). 'Rwanda Economic Update: Maintaining Momentum, with a Special Focus on Rwanda's Pathway out of Poverty', Working Paper No. 78229. Washington, DC: World Bank.

World Bank (2014). 'World Development Indicators'. Washington, DC: World Bank. 


\title{
7
}

\section{Poverty and its Dynamics in Uganda}

\author{
Explorations Using a New Set of Poverty Lines
}

Bjorn Van Campenhout, Haruna Sekabira, and Dede Houeto Aduayom

\subsection{Introduction}

During the past few decades, Uganda has experienced substantial economic growth. Since 1986, when the National Resistance Movement took over government, real gross domestic product (GDP) has grown at an annual rate of 6.8 per cent, making its economy one of the fastest growing in Africa. This growth has been attributed to the new government that has implemented a farreaching economic reforms agenda, transforming Uganda into one of the most liberal economies in Africa south of the Sahara. Indeed, as argued in World Bank (1993: 22), the government 'liberalized the trade regime by abolishing export and import licensing; dismantled all price controls, which were few to begin with; repealed the Industrial Licensing Act, promulgated a new investment code, returned properties expropriated by the Amin regime and commenced privatizing public industrial enterprises; made important strides in abolishing export and distribution monopolies; embarked upon a major overhaul of the civil service; restructured the tax system and improved tax administration; and has made an impressive start in restructuring public expenditures towards critical economic and social services'. Such policy changes were seen as essential preconditions for sustainable economic growth.

The growth has been accompanied by equally impressive declines in the levels of poverty as reported by the government. While aggregate headcount poverty stood at about 57 per cent in the early 1990s, the most recent official estimate puts 19.5 per cent of the population below the official poverty line. ${ }^{1}$

\footnotetext{
${ }^{1}$ For the most recent official estimate, we take the poverty estimate based on the 2012/13 Uganda National Household Survey (UNHS). The data on which these estimates are based were
} 
But despite these successes at the aggregate level, researchers warn that this growth has not been shared equally. For instance, marked spatial heterogeneity in poverty reductions means that differences in the standard of living between locations are often much higher now than they used to be.

Apart from the observed heterogeneity in terms of poverty and poverty reduction, the figures themselves have been called into question as well. Some argue that the lack of progress on assets accumulation and nonmonetary well-being proxies suggests much more modest poverty reductions, raising suspicion about the poverty lines and the welfare indicator used by the government of Uganda (Daniels and Minot 2015; Kakande 2010). Some scholars have also been questioning the spatial pattern of poverty as reported in official documents, arguing that a single national food poverty line is likely to overstate poverty in some areas while underestimating poverty in others (Appleton 2003; Jamal 1998).

In this chapter, we want to update existing knowledge about the state of poverty and its dynamics in Uganda, while at the same time addressing some of the problems with the official figures that have been identified in recent studies. To account for differences in diets in different locations, we will construct different poverty thresholds for different spatial domains using the latest available nationally representative household survey. We will then use these new poverty lines to look at the evolution of poverty, using the recently released Uganda National Panel Survey (UNPS), a yearly panel survey collected by the Uganda Bureau of Statistics (UBOS) supported by the World Bank's Living Standards Measurement Study (LSMS) project that tracks about 3,000 households.

Finally, we will use the panel nature of this survey to study how many households are chronically poor and investigate how their characteristics differ from other groups, such as households that successfully escaped poverty. In other words, we will construct a detailed poverty profile that takes dynamic aspects into account, defining groups based on poverty transitions instead of a simple dichotomous poor/non-poor status (Boateng et al. 1992). As for the characteristics we contrast within each group, we confine ourselves to those that change only slowly over time, and we look at the 'initial conditions' at the start of the panel. We hope that this can enlighten us on the preconditions that need to be in place to be in a particular poverty dynamics group.

obtained from the Uganda Bureau of Statistics (UBOS) in August 2014. As is mostly the case with UNHS data obtained from UBOS, the dataset came with a compiled welfare aggregate based on consumption expenditure and a set of official poverty lines. Using the same methods we used to replicate official poverty figures in previous rounds of the UNHS, we estimate national headcount poverty to be 19.5 per cent in the UNHS 2012/13. This is lower than official poverty estimates at the time of the UNHS 2012/13 dissemination and reported in the press (22.1 per cent). 
The remainder of this chapter is structured as follows. We first give an overview of poverty in the past few decades and look at the current official poverty estimates in Uganda. We also review some studies that point out shortcomings in official poverty measurement. In section 7.3 , we briefly explain the reasoning behind the use of spatially disaggregated poverty lines, as well as the methodology we use to construct them. Section 7.4 presents poverty estimates using the new poverty lines and using household consumption expenditure data from 2005 up to 2013. Section 7.5 then looks at poverty dynamics and relates households with differing poverty dynamics to a selection of characteristics. A final section concludes.

\subsection{Poverty in Uganda: Trends and Controversies}

During the 1990s, poverty in Uganda decreased substantially, falling by almost 40 per cent at the national level (Appleton 2003). However, there were significant spatial differences in both levels and changes in poverty. The urban areas and central region reduced poverty the fastest. The northern region, already starting from high levels of poverty, was relatively unsuccessful in bringing down the number of people living below the poverty line. In addition, studies that exploit the panel nature of the data find that in some regions, poverty was particularly persistent (Deininger and Okidi 2003). Also puzzling is a sudden drop between 1997/8 and 1999/2000. Although it took five years for poverty to decrease by 20 per cent between 1992 and 1997, it took only two years to decrease another 20 per cent at the turn of the century. This may be due to inconsistent underlying welfare indicator data that were obtained from different surveys.

One controversy we will also address in this chapter pertains to the fact that the official poverty estimates are based on poverty lines that are rooted in a single national food consumption bundle, derived from 1993/4 Monitoring Survey data. In particular, a single food basket was identified at the national level with twenty-eight of the most frequently consumed food items by households with less than the median income. The items in this food basket were then converted into caloric equivalents and scaled to generate 3,000 calories per adult equivalent per day using the World Health Organization (WHO) estimates for an 18-30-year-old male as a reference. Next, a non-food allowance was added. Non-food requirements were estimated as the average non-food expenditure of those households whose total expenditure was around the food poverty line. The non-food allowance does allow for spatial heterogeneity, as separate averages were calculated for urban and rural locations interacted with the four regions (central, eastern, northern, and western), using the method described in Ravallion and Bidani (1994). These 
poverty lines have since been updated by the official inflation figures each time a new household survey came out.

Appleton (2003) and Jamal (1998) argue that Uganda is unusual in its dietary diversity. Indeed, Uganda has five different staples-matooke, maize, sweet potatoes, cassava, and millet-that are more or less important within the diet depending on the region. This may not matter very much if the diets are equally cost-effective in obtaining the same level of basic needs as defined in kilocalories. However, the staple food of choice for a large part of the population, both in the western and the central regions, is matooke, a highly localized staple. ${ }^{2}$ Appleton (2003) calculates that, at least in 1993-4, matooke appeared to be a very expensive source of calories, compared to what people in, for instance, the north consume. When Appleton (2003) and Jamal (1998) account for this in their analysis, they come to the conclusion that poverty is more pronounced in the western region than found in official statistics. Even after correcting for income difference, as regions that consume more expensive calories may do so simply because they have higher incomes, Appleton (2003) comes to the conclusion that the western region, rather than the northern region, emerges as the poorest.

Progress in fighting poverty reported by the government of Uganda and UBOS in the first decade of the new millennium is equally impressive. Table 7.1 shows that poverty at the national level kept falling during the first decade, shaving another 50 per cent off of headcount poverty. At the same

Table 7.1. Official poverty headcounts, 2002-12

\begin{tabular}{lrrrr}
\hline & $2002 / 3$ & $2005 / 6$ & $2009 / 10$ & $2012 / 13$ \\
\hline Uganda & 38.80 & 31.10 & 24.50 & 19.50 \\
Urban & 14.40 & 13.70 & 9.10 & 9.60 \\
Rural & 42.70 & 34.20 & 27.20 & 22.40 \\
Central & 22.30 & 16.40 & 10.70 & 5.10 \\
Eastern & 46.00 & 35.90 & 24.30 & 24.10 \\
Northern & 63.00 & 60.70 & 46.20 & 43.70 \\
Western & 32.90 & 20.50 & 21.80 & 7.60 \\
Kampala & 4.70 & 4.40 & 3.90 & 0.80 \\
Central 1 & 22.00 & 18.80 & 11.10 & 3.90 \\
Central 2 & 30.00 & 19.70 & 13.60 & 7.90 \\
East Central & 42.60 & 32.70 & 21.40 & 24.10 \\
Eastern & 48.40 & 39.20 & 26.50 & 24.10 \\
Mid-northern & 57.40 & 61.10 & 40.40 & 35.60 \\
Northeastern & 82.80 & 79.30 & 75.80 & 74.50 \\
West Nile & 62.80 & 55.30 & 39.70 & 42.00 \\
Mid-western & 37.90 & 23.20 & 25.30 & 9.50 \\
Southwestern & 29.00 & 18.70 & 18.40 & 5.80 \\
\hline
\end{tabular}

Source: Calculated from respective Uganda National Household Surveys

\footnotetext{
${ }^{2}$ Matooke is a variety of starchy banana, commonly referred to as cooking bananas.
} 
time, differential progress in poverty reduction in different regions persists, too. For instance, by 2012/13, poverty was more than eight times higher in the northern region than in the central region. In 2002/3, the north was only 2.7 times poorer than the central region. The more disaggregated the numbers, the starker the contrasts become. In the northeast, a semi-arid area with low rainfall inhabited by the Karamajong, an agro-pastoralist ethnic group, poverty remains stubbornly high, while in the central and western regions of the country, poverty has been almost eradicated.

The official poverty figures and their evolution over time have been questioned in recent years for being overly optimistic. Daniels and Minot (2015) use Demographic and Health Survey (DHS) data and methods related to poverty mapping and small area estimation to look at poverty trends across Uganda from 1995 to 2010. They use the 2005/6 UNHS survey to estimate regressions that correlate poverty to a range of household characteristics that also appear in the DHS (four such surveys have been carried out between 1995 and 2009/10). They then use the DHS surveys to predict poverty in each of the DHS survey years. They find that poverty indeed reduced over time, but much slower than official figures suggest. While their national estimate of headcount poverty in 2006 is 33 per cent and thus very close to the official estimate of 2005/6, the rate still stands at 30 per cent using the 2009 DHS, about six percentage points higher than the 2009/10 UNHS estimate.

This view is shared among many researchers and opinion makers in Uganda. Byekwaso (2010) calls officially reported poverty changes 'a fiction'. Kakande (2010) admits that qualitative findings on poverty trends suggest there was a decrease in well-being despite the drop in poverty rates. Recently, an unpublished manuscript has been circulating that compares Uganda to other African countries on six non-monetary poverty indicators, such as literacy rates and access to piped water. This admittedly partial analysis also points to a much higher incidence of poverty than officially reported.

\subsection{Utility-Consistent Poverty Lines Using Revealed Preferences}

From section 7.2, we learn that one of the main weaknesses of the official poverty measures is that they are based on a poverty line that is constructed using a single food commodity bundle for the entire country. In addition, this food basket was constructed in 1993 and has not been updated since, apart from accounting for inflation using the consumer price index. However, it is well known that in many instances-for example, if relative prices of basic commodities vary by region (or through time) and preferences permit substitution - the use of a single consumption bundle may yield inconsistent poverty comparisons (Tarp et al. 2002). While differences in prices in different 
locations are usually incorporated in poverty measurement by adjusting the welfare indicator to reflect prices used in the construction of the poverty lines (or by adjusting the poverty lines to reflect prices used in the construction of the welfare indicator), it is becoming more and more common to also account for spatial heterogeneity in consumption bundles in an effort to increase the specificity of poverty lines (e.g. Mukherjee and Benson 2003; Ravallion and Lokshin 2006).

While differences in consumption baskets are interesting in their own right, they become relevant only in the context of poverty measurement and analysis, as we relate a welfare indicator to the cost of these basic needs. Indeed, different diets may provide the same basic needs (usually a given amount of kilocalories per day) at significantly different costs, which complicates poverty comparisons between units (regions, households, individuals, and so forth) with different diets. It is especially in this regard that Uganda provides an interesting case. Matooke, the main ingredient in the diet of households in the west, may be more or less expensive per energy unit than, for example, sorghum, the main staple in the north. As such, it would be misleading to compare the west with the north on the basis of a single food poverty line, even after allowing for spatial price heterogeneity.

But how can we be sure that two different consumption bundles provide the same basic needs? Or, in the language of Ravallion and Bidani (1994), how do we ensure consistency ${ }^{3}$ The theory underlying absolute poverty lines is grounded in welfare economics and constrained utility maximization. In this context, the fixed standard of living represented by the poverty line is viewed as a level of utility associated with the minimally acceptable standard of living. In other words, two bundles of goods are consistent if they yield the same utility.

We follow Ravallion and Lokshin (2006), who argue that the theory of revealed preferences provides a suitable framework for answering these questions. The idea uses the rationality assumption that economic agents that derive utility from consumption always prefer consuming more to less. A representative consumer in a particular spatial domain will choose only that bundle that minimizes expenditure. Thus, any other bundle that yields the same level of utility should be equally expensive as or more expensive than the chosen bundle. No bundle can cost less than the chosen one yet yield that same utility, because then the rational consumer should have chosen that one. Or, as in Gibson and Rozelle (2003), if the cost of a bundle from another domain would be cheaper if bought in a specific domain, this means it must have lower utility than the bundle in that specific domain, as otherwise the

${ }^{3}$ A poverty measure is consistent if two individuals at the same welfare level are considered equally poor. 
rational consumer would have picked the bundle from the other domain. We use a minimum cross-entropy approach to adjust expenditure shares such that they meet revealed preference conditions (Arndt and Simler 2010). More information on the rationale behind utility-consistent poverty lines and the estimation using minimum cross-entropy can be found in Van Campenhout et al. (2014).

\subsection{A Reassessment of Poverty and its Evolution in Uganda}

For our reassessment of poverty in Uganda using spatially disaggregated poverty lines, we will calculate welfare using the four waves of the Uganda National Panel Survey (UNPS). ${ }^{4}$ The UNPS is a multi-topic panel household survey started by UBOS in 2009/10. However, the 2009/10 sample was essentially a subset of 3,123 households that were interviewed as part of the 2005/6 Uganda National Household Survey (UNHS 2005/6), a nationally representative survey that covered 6,775 households. As such, the first wave of the panel comprises the UNHS 2005/6 data of this subsample of 3,123 households. After the second wave of 2009/10, the survey was repeated annually. Currently data are available for a third round covering the 2010/11 agricultural year and a fourth round covering the 2011/12 agricultural year. ${ }^{5}$ The UNPS is conducted in two visits to better capture agricultural outcomes associated with the two cropping seasons of the country.

For the construction of the utility-consistent poverty thresholds elaborated on in the previous section, we will use the 2012/13 Uganda National Household Survey (UNHS 2012/13). Like the UNHS 2005/6, the UNHS 2012/13 is nationally representative, covering 6,888 households. We choose this survey because it is the most recent one available, and the construction of utilityconsistent poverty lines requires a sufficiently large sample, with sufficient observations in each spatial domain. After some experimentation, we ended up using six spatial domains (Kampala, Rural Central, Rural East, Rural North, Rural West, and Other Urban). The results are presented in Table 7.2.

The poverty headcounts we obtain using six spatial domains are much higher than the official ones. While part of the divergence may be explained by various differences between approaches (e.g. official estimates scale household consumption expenditure by adult-equivalent units, while we use per capita expenditures; we use a much more recent dataset underlying the poverty line estimates, etc.), spatial disaggregation seems to make the largest

\footnotetext{
${ }^{4}$ We use consumption expenditure per capita as a proxy for welfare, as is common in poverty measurement and analysis.

5 No UNPS survey was done in 2012/13.
} 
Table 7.2. Poverty headcounts, 2002-12, using six spatial domains

\begin{tabular}{|c|c|c|c|c|c|c|c|c|c|c|}
\hline & \multicolumn{2}{|c|}{$2005 / 6$} & \multicolumn{2}{|c|}{$2009 / 10$} & \multicolumn{2}{|c|}{ 2010/11 } & \multicolumn{2}{|c|}{$2011 / 12$} & \multicolumn{2}{|c|}{$2012 / 13$} \\
\hline & PO & contr & PO & contr & PO & contr & PO & contr & PO & contr \\
\hline Uganda & 0.423 & 1.000 & 0.381 & 1.000 & 0.370 & 1.000 & 0.359 & 1.000 & 0.315 & 1.000 \\
\hline Rural & 0.476 & 0.938 & 0.431 & 0.951 & 0.413 & 0.959 & 0.408 & 0.943 & 0.360 & 0.879 \\
\hline Urban & 0.158 & 0.062 & 0.117 & 0.049 & 0.108 & 0.041 & 0.121 & 0.057 & 0.167 & 0.121 \\
\hline Central & 0.291 & 0.213 & 0.231 & 0.187 & 0.143 & 0.098 & 0.146 & 0.089 & 0.149 & 0.123 \\
\hline Eastern & 0.374 & 0.219 & 0.295 & 0.188 & 0.389 & 0.282 & 0.379 & 0.337 & 0.355 & 0.328 \\
\hline Northern & 0.670 & 0.273 & 0.603 & 0.285 & 0.489 & 0.306 & 0.529 & 0.308 & 0.567 & 0.374 \\
\hline Western & 0.463 & 0.295 & 0.485 & 0.340 & 0.473 & 0.314 & 0.379 & 0.266 & 0.231 & 0.175 \\
\hline
\end{tabular}

Note: 'PO' means headcount poverty; 'contr' means contribution to national poverty.

Source: Calculated from the respective UNHS and UNPS waves

difference. In Van Campenhout et al. (2014), we compare poverty lines and poverty estimates based on the 2012/13 data, contrasting figures generated using one and six spatial domains. We find that our method using one spatial domain actually leads to a lower poverty estimate than the official one, while allowing for spatial disaggregation leads to substantially higher estimates of poverty. ${ }^{6}$ The reductions in poverty over time also seem more modest than the official ones, with an overall reduction in poverty between 2005/6 and 2012/13 of about one-quarter, echoing concerns raised by Daniels and Minot (2015), who argue that the original 1993 poverty lines may have increased too little to keep pace with inflation. We also see that the largest reduction of the number of people living below the poverty line happened between 2011/12 and 2012/13.

If we disaggregate between rural and urban poverty, we see that most of the poverty reduction has been happening in rural areas. Over the years, poverty in rural areas has steadily fallen from almost 50 per cent to 36 per cent. This is different from what has been happening in urban areas. While between 2005/6 and 2010/11 urban poverty was on the decline, it started rising again afterwards. A marked acceleration in urban poverty between 2011/12 and 2012/13 together with a steady decline in rural poverty reduced the contribution of rural poverty to overall poverty from about 94 per cent to 88 per cent in 2012/13. The evolution of official figures is in line with our findings, except that we find a much stronger rebound of urban poverty.

Finally, we disaggregate poverty by region. We find that in the northern region, which is the poorest, poverty has decreased by 15 per cent over the

\footnotetext{
6 Technically, this can be explained by the fact that poverty lines are based on the consumption patterns of the poorest households (e.g. the poorest 50 per cent). If poverty lines are constructed at higher aggregate levels, such as the national level, all the poor are lumped together and the poverty line is calculated on the basis of the poorest of the poor in society at large, leading to a single low poverty line. If some degree of spatial disaggregation is allowed for, these poor are likely to be distributed over spatial domains, generally leading to higher poverty lines.
} 
entire period. However, the evolution was far from linear. Especially between 2009/10 and 2010/11, there was a strong reduction in poverty. But since then, poverty in the northern region has been rising again. Official poverty figures report a reduction of 28 per cent between 2005/6 and 2012/13 in headcount poverty. The western region is, just as in the official estimates, the secondrichest region. However, it is now 55 per cent poorer than the richest region. This gap between the western and central regions is significantly larger than in the official statistics, where poverty rates in the western region are 33 per cent higher than in the eastern region. Thus, while we do not observe the reversal in the rankings observed by Appleton (2003), our results are consistent with the finding that the west is poorer than official figures suggest.

The central region, already the least poor region at the start of the panel, reduced headcount poverty by half between 2005/6 and 2012/13 according to our estimates using six spatial domains. Again, official estimates record higher poverty reductions (almost 70 per cent). Inequality in poverty headcount has also increased over time. While the northern region initially contributed 27 per cent to overall poverty, this has increased to 37 per cent in 2012/13. The contribution of the eastern region also has increased substantially. If we disaggregate the 2012/13 data further, we find that most poverty is found in the northeast, where over 80 per cent of the individuals live in poverty. This is followed by West Nile, a distant second with 60 per cent of the population living in poverty.

To summarize, we feel that these poverty estimates are more credible, both from a theoretical and an empirical point of view. The continued use of outdated poverty lines based on a single food basket is likely to lead to inconsistent poverty estimates, especially in a country where different regions have widely varying diets. Indeed, most of the staples in these diets are effectively non-tradables, deriving their price from local demand and supply conditions. The result is that the cost of basic needs, even though anchored in a single caloric requirement, may vary significantly.

\subsection{A Profile Based on Poverty Dynamics}

Now that we have developed a new set of poverty lines, in this section we will use the Uganda National Panel to construct profiles for different categories of households based on the evolution of their poverty status over time. We will start by defining five different categories. The first category consists of households that are identified as being poor in all four waves of the UNPS. We will refer to these households as the chronic poor. Second, we will identify the households that were never poor in any of the waves. These households will be grouped in the non-poor group. Next, we delineate a group of households 
that are escaping poverty. These are households that are poor in all past waves but non-poor in all subsequent waves. ${ }^{7}$ A fourth group will then consist of those households that are falling into poverty. ${ }^{8}$ These are households that are non-poor in all past waves but poor in all subsequent waves. Finally, there is a category for the rest. These households, repeatedly moving in and out of poverty, are labelled as vulnerable in our analysis.

Looking at poverty transitions using the above typology, we find that only about 257 of the 2,195 households that appear in all four waves are poor in each wave. This amounts to only 11.7 per cent of the households being chronic poor. However, if we weigh these households by population weights, the number of chronic poor individuals increases to 12.3 per cent. This suggests that the chronic poor tend to live in larger households. At the other extreme, we find that 833 households, or 37.9 per cent of the households, are never poor, corresponding to about 35.8 per cent when using weights. Next, 387 households have escaped poverty and 198 have fallen into poverty, corresponding to 19.0 and 8.2 per cent of the population, respectively. Finally, there is a sizable class of about 520 vulnerable households, or almost a quarter of the population, that moves into or out of poverty, possibly multiple times, over the four waves.

We will now relate these four categories of households to various household characteristics to come up with a profile, similar to poverty profiles in a static analysis of poverty. Since we are interested in the likely causes of poverty transitions, we will look at characteristics of the household at the first wave of the panel in 2005/6. In other words, the profile may help us understand whether households have fared differently in terms of poverty status because of a different past. As such, we will also concentrate on characteristics that change only slowly over time, as opposed to those that may change significantly from year to year, such as crops cultivated. In a way, we will try to identify the preconditions at the household level associated with different poverty transition trajectories.

\subsubsection{Location}

Location and well-being are often found to be correlated. In virtually all cases, poverty is found to be higher in rural areas than in urban. More in general, remote areas tend to be poorer for a myriad of reasons. For instance, one

\footnotetext{
7 This group comprises households that are poor in 2005/6 and non-poor in all subsequent rounds, those that are poor in 2005/6 and 2009/10 and non-poor in 2010/11 and 2011/12, and those that are poor in 2005/6, 2009/10, and 2010/11 and non-poor in 2011/12.

8 This group comprises household that are non-poor in 2005/6 and poor in all subsequent rounds, those that are non-poor in $2005 / 6$ and $2009 / 10$ and poor in 2010/11 and 2011/12, and those that are non-poor in 2005/6, 2009/10, and 2010/11 and poor in 2011/12.
} 
prominent economic reason is that in sparsely populated areas with a thin road network that is often in bad shape, transaction costs are high, affecting economic activity (Stifel and Minten 2008). Dercon et al. (2012) find that chronic poverty in Ethiopia is significantly correlated to 'remoteness' in terms of distance to town or poor roads. Bird et al. (2010) note that agroecology; institutional, political, and governance failures; service delivery; stigma and exclusion; crime and insecurity; and communication, media, and information and communication technologies are all factors that are mediated by remoteness and as such likely to contribute to spatial poverty traps.

We first look at the location of households in the five classes in terms of being in urban or rural areas. Of all the chronic poor, 97.7 per cent live in rural areas. Of all the non-poor, this is only 71.9 per cent. For Uganda as a whole, 86.7 per cent report to be living in rural areas. Going one step further, we look at the three groups by region. This is visualized in the mosaic plot in Figure 7.1. The figure clearly shows that chronic poverty is concentrated in the northern region. Here, 45.5 per cent of all the chronic poor can be found.

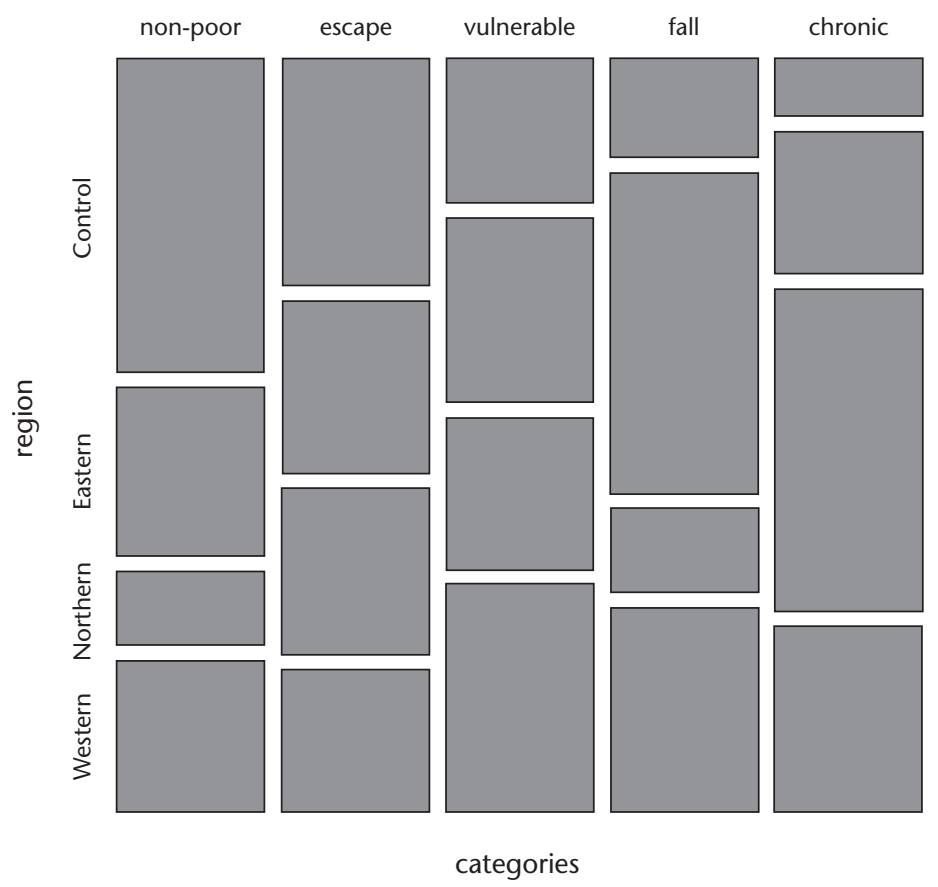

Figure 7.1. Regional distribution of households in different poverty dynamics categories

Source: Authors' calculations from the UNPS 
On the other end, the households that have never experienced poverty are disproportionately located in the central region-more than 44 per cent of the people that are always above the poverty threshold live there. If one lives in the eastern region, one has a relatively higher chance of falling into poverty. People living in the western region seem to be moving in and out of poverty more than people living in other regions. While the northern region has a large group of chronic poor, the good news is that the relative share of people escaping poverty is larger than the share that falls into poverty. This is different in the eastern region, where the large share of individuals sliding into poverty happens simultaneously with relatively few people escaping poverty. Finally, it is worth noting that, despite the already high presence of non-poor in the central region, many poor households have escaped poverty over time and very few households have slipped back into poverty.

As mentioned, location also affects access to services, such as safe drinking water. Figure 7.2 provides kernel density plots for time reported to fetch drinking water, including waiting time. You can see that respondents cluster their answers around two hours and four hours. We find that, in general, the

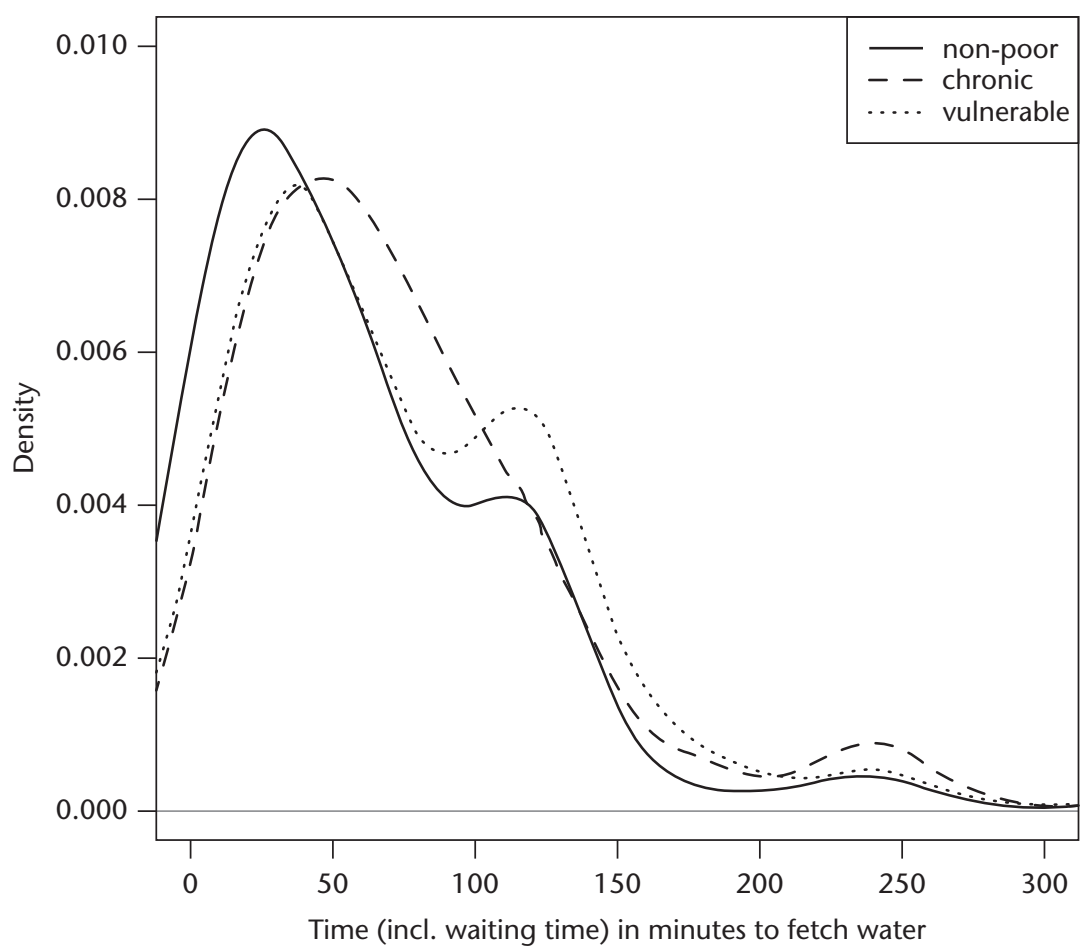

Figure 7.2. Time to fetch water in $2005 / 6$ and poverty dynamics Source: Authors' calculations from the UNPS 
non-poor need to spend less time fetching water, except maybe for some non-poor that spend about two hours. The median for the non-poor is about fifty minutes, as opposed to about sixty minutes for the chronic poor. The respective means are sixty-three minutes for the non-poor and seventy-seven for the poor. This is also illustrated by the fact that the chronic poor have higher densities at the extreme right of the distribution-for instance, around four hours or 240 minutes. The vulnerable have a high density around two hours.

\subsubsection{Household Demographics}

The size and composition of the household are also variables that often feature in poverty regressions. It is thought that increased competition for a given food stock reduces consumption. However, Lanjouw and Ravallion (1995) argue that the negative correlation disappears as one takes economies of scale in household food consumption into account. In terms of production, a larger household may mean more and cheaper labour is available, but Van Campenhout (2014) finds that especially mothers in larger households devote a significant amount of time to non-productive activities. This last feature may be captured better when relating the different types of household in terms of poverty dynamics to dependency ratios.

Female-headedness is also often found to be a good predictor of poverty. The underlying reasons should be sought in differences between male-headed and female-headed households in terms of access to secure land tenure, labour, credit, technology, and extension services (e.g. Quisumbing and Pandolfelli 2010). One of the consequences is that female-headed households employ fewer inputs, such as improved seeds and fertilizer, which has been shown to reduce productivity (e.g. Udry et al. 1995). We will also look at marital status as an alternative way to look at gender-based agricultural gaps. This will enable us to see if, for instance, widowhood is associated with chronic poverty (van de Walle 2013).

We find that indeed, chronic poor households are more likely to be headed by a female. In addition, households that were never poor in our panel, as well as households that are escaping poverty over time, are more likely to be headed by a male. For the other categories, we do not find big differences between male- and female-headed households. We also looked at the age of the household head. We find that average age of the household head is around 40 for households that are chronic poor or have been sliding into poverty. Households that have never been poor or that have moved out of poverty are on average about four years older.

Figure 7.3 gives an idea of the distribution household size and child dependency ratios conditional on the poverty dynamics group of the household. In 

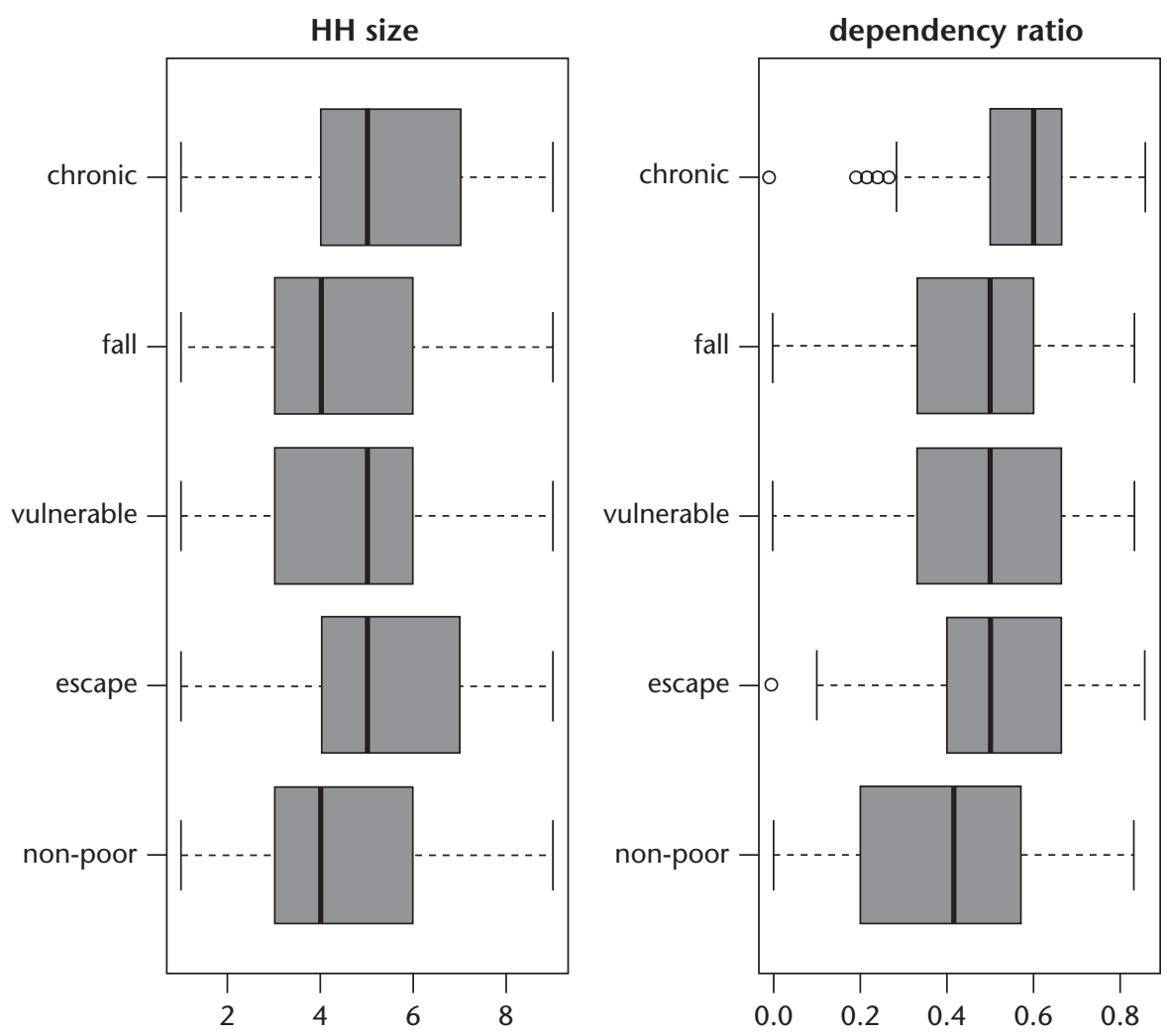

Figure 7.3. Household size and child dependency ratios in 2005/6 Source: Authors' calculations from the UNPS

the left panel (1), we plot box plots for household size for each of the five poverty dynamics classes. In the right panel (2) we do the same for child dependency ratios. For each household we calculate the share of children under the age of 15 within the total household and use this to plot box plots by poverty dynamics category. We find that higher child dependency is associated with chronic poverty, while the non-poor have the lowest median child dependency ratio. Looking at both of the charts together, the chronic poor have relatively large households and high dependency ratios. Those that have never been poor have small households and low dependency ratios. Households that slide below the poverty threshold and those that are vulnerable have a surprisingly high dependency ratio given the relatively smaller households. These may be households where one of the parents has died or has left the household. Large households with a high dependency ratio also escape poverty. These may be households that start to benefit from the additional cheap labour provided by children. 
Table 7.3. Marital status in UNPS $2005 / 6$ and subsequent poverty dynamics

\begin{tabular}{lccccc}
\hline & Non-poor & Escape & Vulnerable & Fall & Chronic \\
\hline Married monogamously & 0.367 & 0.192 & 0.230 & 0.086 & 0.125 \\
Married polygamously & 0.348 & 0.152 & 0.299 & 0.081 & 0.119 \\
Divorced & 0.420 & 0.238 & 0.169 & 0.077 & 0.096 \\
Widowed & 0.272 & 0.246 & 0.293 & 0.071 & 0.118 \\
Never married & 0.517 & 0.125 & 0.139 & 0.029 & 0.190 \\
All & 0.358 & 0.190 & 0.247 & 0.082 & 0.123 \\
\hline
\end{tabular}

Source: Authors' calculations from the UNPS

For marital status of the household head, respondents could choose from five mutually exclusive types of marriage: married monogamously, married polygamously, divorced, widow or widower, and never married. The results are presented as a table of proportions where the rows sum to 1 (Table 7.3). This allows us to judge the fraction of the total in each type of marriage accounted for by each of our poverty transition groups. Thus, although the chronic poor account for only about 12.3 per cent of the population, they account for almost 20 per cent of individuals living in households where the head has never been married. However, at the same time, households where the head has never married are clearly more likely to be non-poor, as are households where the head has divorced. We also see that widowed households are under-represented in the non-poor segment. In addition, households headed by widows appear to have a hard time keeping consumption smooth, as is evident by the large proportion classified as vulnerable. Divorced household heads have been more successful in moving out of poverty and are under-represented in the group of chronic poor households. Polygamously married households have been less successful in escaping poverty. Just like widowed household heads, they seem to have a hard time keeping consumption smooth between the different years.

\subsubsection{Activity}

Table 7.4 looks at what households report to be their major source of earnings at the beginning of the panel. While in general 35.8 per cent of Ugandans fall into the non-poor category, only 25.7 per cent of the Ugandan subsistence farmers are in the non-poor subgroup. It seems the group of vulnerable households is disproportionately represented within the group of subsistence farmers. Subsistence farming is indeed a very risky activity, and subsistence farmers have few assets to insure against adverse shocks such as bad weather outcomes or disease. Individuals that are living in households that report to be engaged in commercial farming appear more likely to be nonpoor. Wage employment also seems to be an activity that is prevalent among 
Table 7.4. Most important source of earnings in UNPS 2005/6 and subsequent poverty dynamics

\begin{tabular}{lccccc}
\hline & Non-poor & Escape & Vulnerable & Fall & Chronic \\
\hline Subsistence farming & 0.257 & 0.211 & 0.293 & 0.089 & 0.150 \\
Commercial farming & 0.563 & 0.160 & 0.258 & 0.019 & 0.000 \\
Wage employment & 0.513 & 0.145 & 0.152 & 0.094 & 0.097 \\
Non-agricultural enterprise & 0.535 & 0.159 & 0.160 & 0.060 & 0.086 \\
Property income & 0.865 & 0.035 & 0.037 & 0.064 & 0.000 \\
Transfers & 0.555 & 0.207 & 0.168 & 0.048 & 0.021 \\
Organizational support & 0.172 & 0.132 & 0.290 & 0.057 & 0.349 \\
All & 0.358 & 0.190 & 0.247 & 0.082 & 0.123 \\
\hline
\end{tabular}

Source: Authors' calculations from the UNPS

the non-poor. But among the wage-employed, there is also an overrepresentation in the group of people that have fallen into poverty.

Ugandans engaged in non-agricultural enterprises are also likely to fall into the non-poor category. The clearest results are for those who mention their main source of income is property-virtually all are non-poor. People that depend on transfers are also non-poor. Transfers are likely to correlate with social capital, and hence the lower probability that such households fall into the vulnerable group or in the group that falls into poverty. Finally, a significant group of people reported to be depending on handouts. As expected, these are especially the chronic poor or individuals that are vulnerable. It is, however, also interesting to note that 17.2 per cent of the individuals that report organizational support as their main source of income are never poor in the four-wave panel.

\subsubsection{Education}

In traditional poverty profiles, the education level of the household head is often significant. Indeed, skills are important for the self-employed, and schooled labour is likely to be better rewarded. It is less obvious how schooling affects poverty dynamics in the short run. Lack of education has been linked to intergenerational poverty (Harper et al. 2003). Education is also among the initial characteristics associated with chronic poverty in rural communities in Ethiopia (Dercon et al. 2012).

Table 7.5 looks at the highest education level reported by the household head. We see that 17.6 per cent of all Ugandan household heads have never attended school. However, within the group of individuals in households that have always been poor, the share of households that are headed by someone without formal education is 37 per cent. On the other hand, the share of households with heads without schooling in the subgroup of the non-poor is only 7.8 per cent. In the second row, we see that the majority of household 
Table 7.5. Education of household head in UNPS 2005/6 and subsequent poverty dynamics

\begin{tabular}{lrrrrrrr}
\hline & Non-poor & Escape & Vulnerable & Fall & Chronic & All \\
\hline No schooling & 0.078 & 0.190 & 0.227 & 0.142 & 0.366 & 0.176 \\
Primary & 0.425 & 0.648 & 0.627 & 0.642 & 0.583 & 0.554 \\
Post-primary training/certificate & 0.085 & 0.026 & 0.024 & 0.032 & 0.010 & 0.045 \\
Secondary & 0.297 & 0.119 & 0.114 & 0.175 & 0.041 & 0.177 \\
Post-secondary training/certificate & 0.086 & 0.016 & 0.006 & 0.009 & 0.000 & 0.036 \\
Above & 0.029 & 0.000 & 0.002 & 0.000 & 0.000 & 0.011 \\
\hline
\end{tabular}

Source: Authors' calculations from the UNPS

heads have finished primary education. Primary education also seems insufficient to keep the household permanently out of poverty. Everything above primary education leads to a higher-than-average chance to be in the nonpoor class.

\subsubsection{Health}

Illness and health shocks have been reported to affect poverty dynamics. For instance, Barrett et al. (2006) note that serious human health shocks causing permanent injury or illness or death were among the most frequently cited reasons for households falling into poverty in quantitative data from Madagascar and Kenya. But the bidirectional nature of the poverty relationship between poverty and health may trap households in persistent poverty, as ill health can be a catalyst for poverty spirals and in turn poverty can create and perpetuate poor health status (Grant 2005).

Health status is likely to be a function of the distance to the nearest health facility. Figure 7.4 reports on distance to the nearest health facility. By health facility we mean either a private clinic, a government or non-governmental health unit, or hospital. There seems to be some pattern in the data. Households that are never poor in any of the waves of the panel dataset reported lowest median distance to health facilities. At the other extreme, we find that households that live in chronic poverty reported highest median distance to health facilities. Distance to health facilities likely reflects location, as we have seen that the chronic poor tend to live in more remote areas.

Figure 7.5 looks at average days that household heads reported being inactive due to illness in the last six months in the 2005/6 UNPS wave conditional on subsequent poverty transitions. For most of the categories, the number of days lost is on average about 8.5 days. We see that people that have lost relatively few days due to illness are more likely to be in the subgroup that subsequently escapes poverty. On the other hand, the households that report the highest number of days lost by the household head due 


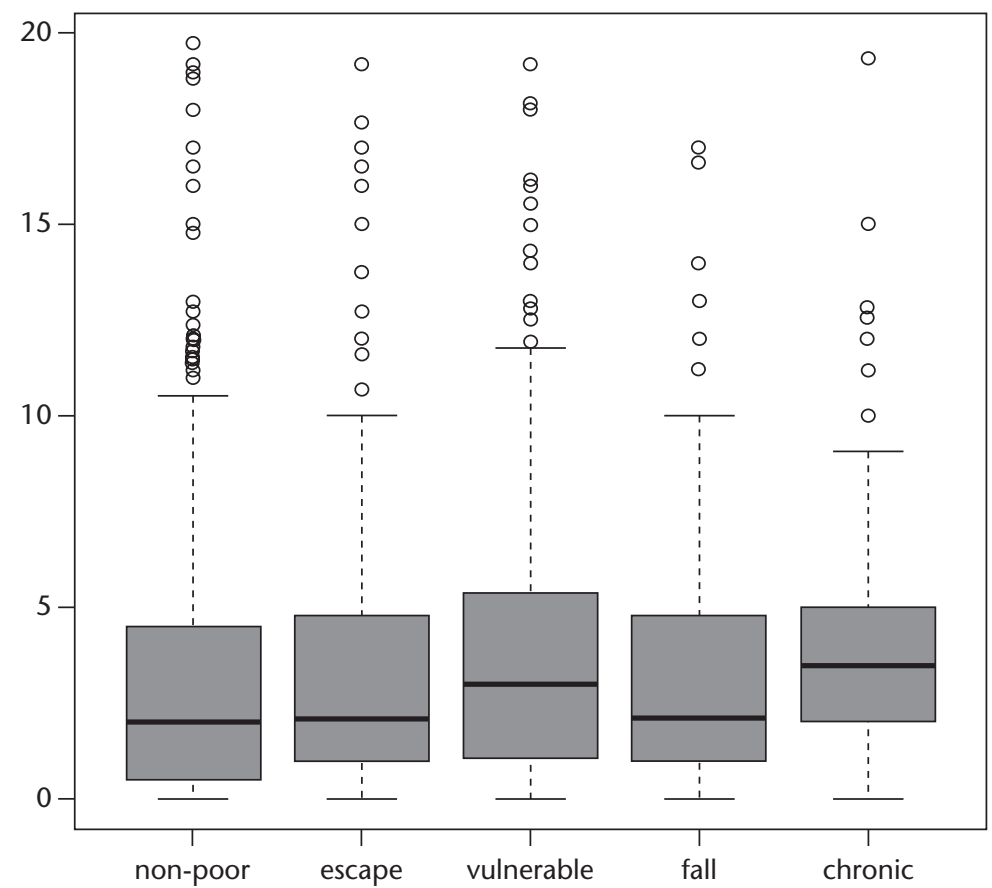

Figure 7.4. Distance (in kilometres) to health infrastructure in 2005/6 Source: Authors' calculations from the UNPS

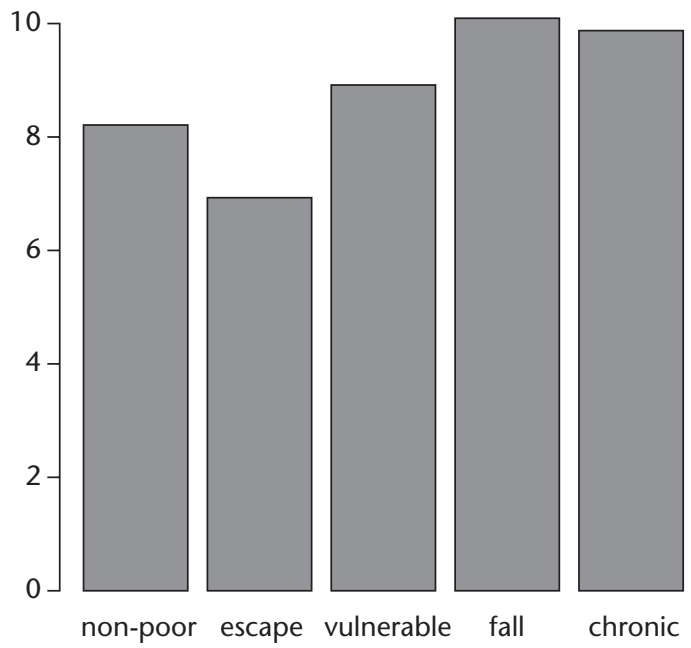

Figure 7.5. Average number of days per year inactive due to illness reported in 2005/6 Note: Includes household heads that did not report illness with days inactive set to zero. Source: Authors' calculations from the UNPS 
to illness are those that are in the subgroup of households that eventually fall into poverty or are living in chronic poverty.

\subsubsection{Shocks and Coping}

The poor are known to be more vulnerable to shocks, due to their lower ability to insure (Dercon 2004). Shocks can have lasting effects if they destroy productive assets, such as when droughts reduce livestock or health shocks destroy human capital. If households are left with too few productive assets to replenish the gap left by shocks, they are likely to fall into an asset-based poverty trap (Carter and Barrett 2006). We also look at how the households deal with shocks ex post, conditional on their wealth dynamics category.

Table 7.6 looks at shocks reported at the onset of the panel. More particularly, respondents were asked if they experienced any of a series of shocks in the previous five years. We again report column percentages. Hence, while 35 per cent of all shocks are drought-related, this increases to almost 40 per cent in the group of the chronic poor. Still, drought also features prominently in the group that subsequently escapes poverty. A substantial share of the nonpoor report to have been exposed to drought shocks, but this share is only about five percentage points lower than the overall share that reports droughtrelated shocks. Floods, hailstorms, and also pest reports do not seem to differ too much between the different groups.

Bad seed quality is reported more among the non-poor than average, although care needs to be taken as relatively few farmers report bad seed quality as a shock. This may be because especially farmers that are always above the poverty line are more commercially oriented and buy seed, instead of recycling seeds. As such, they are also more prone to counterfeit seeds. But

Table 7.6. Shocks experience in the previous five years as reported in UNPS 2005/6 and subsequent poverty dynamics

\begin{tabular}{lcccccc}
\hline & Non-poor & Escape & Vulnerable & Fall & Chronic & All \\
\hline Drought & 0.302 & 0.383 & 0.369 & 0.350 & 0.388 & 0.350 \\
Floods/hailstorm & 0.125 & 0.135 & 0.136 & 0.114 & 0.129 & 0.129 \\
Pest attacks & 0.098 & 0.086 & 0.084 & 0.098 & 0.082 & 0.090 \\
Bad seed quality & 0.035 & 0.011 & 0.023 & 0.021 & 0.018 & 0.024 \\
Livestock epidemic & 0.065 & 0.067 & 0.042 & 0.047 & 0.061 & 0.057 \\
Fire accident & 0.018 & 0.021 & 0.036 & 0.024 & 0.038 & 0.027 \\
Civil strife & 0.037 & 0.059 & 0.074 & 0.051 & 0.123 & 0.064 \\
Robbery/theft & 0.102 & 0.055 & 0.075 & 0.098 & 0.063 & 0.081 \\
Death of HH head & 0.022 & 0.041 & 0.023 & 0.028 & 0.023 & 0.026 \\
Death of other family member & 0.139 & 0.097 & 0.107 & 0.123 & 0.038 & 0.108 \\
Injury from accidents & 0.033 & 0.011 & 0.010 & 0.024 & 0.010 & 0.019 \\
Other & 0.024 & 0.032 & 0.020 & 0.021 & 0.025 & 0.024 \\
\hline
\end{tabular}

Source: Authors' calculations from the UNPS 
probably the most significant result in this table is the disproportionate number of people within chronically poor households that report being affected by civil strife. Poverty that is associated with civil war seems to be very persistent (Goodhand 2003). The non-poor clearly faced different shocks. They report more than average losses related to robbery and theft. This category also shows up relatively more in the category of households that slide into poverty. The death of a family member is also disproportionately mentioned among those that fall into poverty over the period covered by the panel.

Finally, the dot chart in Figure 7.6 shows how the different categories of households reportedly dealt with shocks. The top of the chart shows that the

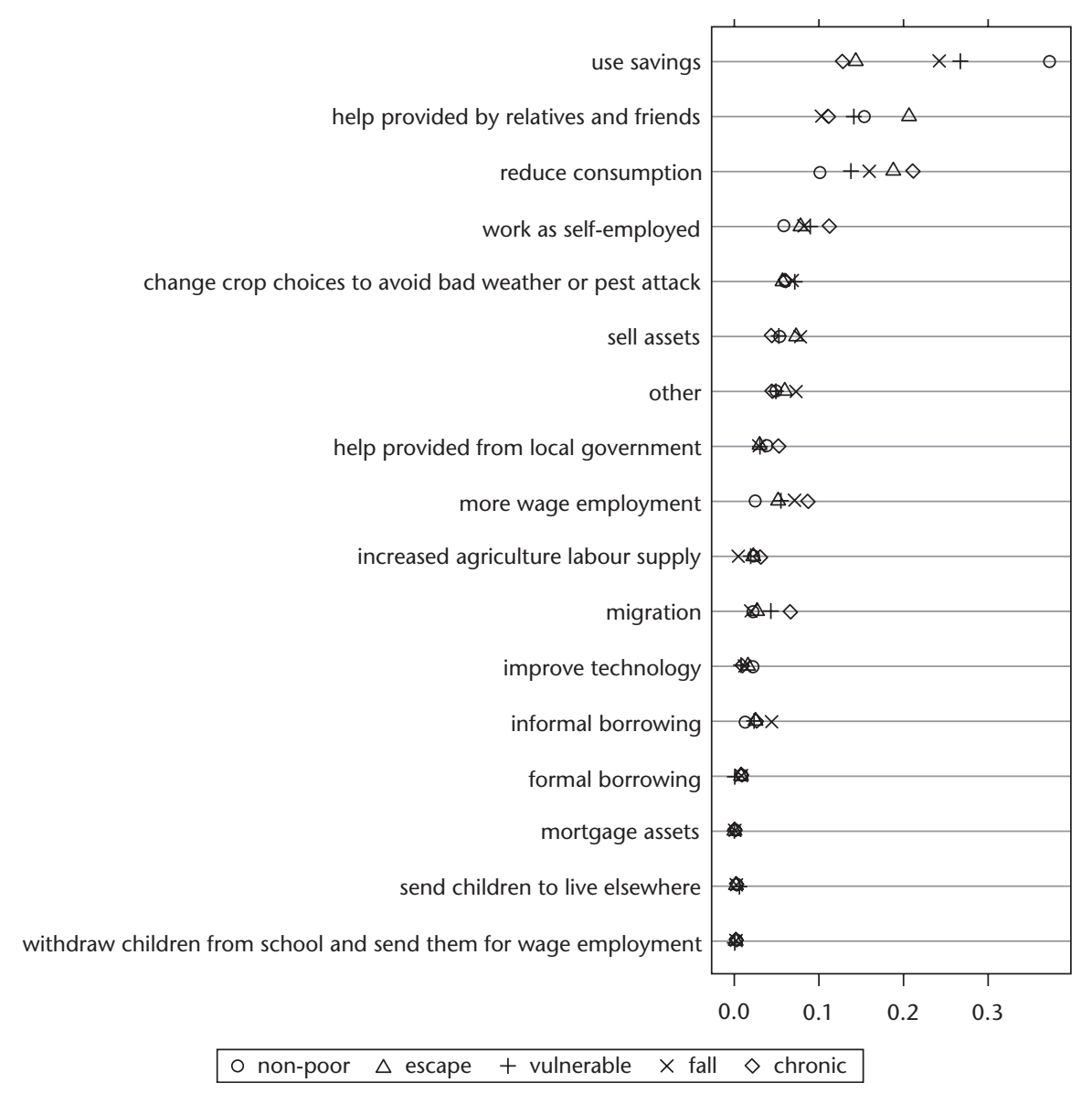

Figure 7.6. Coping with adverse shocks reported in 2005/6

Source: Authors' calculations from the UNPS. Points are proportions of households reporting item as main way to cope with shocks 
non-poor most often used savings to cope with shocks. This is also reported as a main source of ex post insurance for a substantial part that have slid into poverty over the course of the panel. The chronic poor deal in a completely different way with shocks. For instance, they cannot rely on savings to deal with shocks. Instead, the poor seem to rely on employment and migration, but most of all simply have no choice but to reduce consumption. The graph also shows the importance of social capital to deal with shocks for vulnerable households. There is also some indication that informal borrowing during the first round of our panel is associated with an increase in the chance that households descend into poverty.

\subsection{Conclusion}

In this chapter, we reassess the evolution of poverty over the past ten years in Uganda. Official figures suggest substantial poverty reduction, but independent researchers note that the benefits of economic growth have been shared unequally. In addition, casual observation does not correspond to the rosy picture that official figures suggest. Other indicators that define well-being in a broader way, such as adult literacy and maternal health, also put Uganda at a much lower level than what would correspond to officially disseminated well-being.

One possible explanation for this divergence lies in the poverty line. The poverty line that is currently in use to estimate official poverty in Uganda was constructed more than a decade ago, using data from a 1993/4 survey. In addition, this poverty line relies on a single food consumption basket for Uganda, despite the fact that Uganda consists of a diverse set of regions, each with their own diets. These diets are also exceptional in their difference in cost to obtain a certain level of kilocalories. Lumping all regions together and assuming they require the same amounts of each commodity disregards the cultural and agro-climatic diversity that typifies Uganda. We therefore follow Arndt and Simler (2010), and construct poverty lines that better reflect local diets, which results in poverty estimates and patterns that are more realistic than the official ones. For instance, they are much more in line with the levels and evolution of other non-monetary poverty indicators. A case in point is the nutritional status of children in the west, a region highly dependent on the cost-inefficient non-tradable food crop matooke. According to the Uganda Demographic Household Survey 2011, height-for-age scores are worst in the western region, except for the Karamoja district. Ssewanyana and Kasirye (2010) also find that the highest rates of stunting are in the southwestern sub-region. This at least indicates that the situation in terms of poverty is less rosy than official figures suggest. 
We then use panel data to look at changes in poverty over time. While our analysis shows the situation has improved over time in the northern region, a disturbingly large proportion of the chronic poor remain. In addition, a substantial proportion of vulnerable households resides in the northern region. In the western region, relatively few households are escaping poverty and relatively more households are falling into poverty. This is in contrast to the central region, where, despite the already high presence of non-poor, many poor households have escaped poverty over time and very few households have slipped back into poverty.

We also investigate how poverty dynamics are correlated with household demographics, We find that chronic poor households are more likely to be headed by a female. Higher child dependency is also associated with chronic poverty. Households headed by widows appear to have a hard time keeping consumption smooth and households where the head has never married are more likely to be better off. Divorced household heads have been more successful in moving out of poverty.

If we look at the main source of income at the start of the panel, we find a significant group of people that reported to be depending on handouts. As expected, these are especially the chronic poor. It seems the group of vulnerable households is disproportionately represented within the group of subsistence farmers, underlining the riskiness of rain-fed agriculture. Ugandans engaged in commercial agriculture or non-agricultural enterprises are likely to be better off.

We then look at education and health. We find that households that live in chronic poverty reported highest median distance to health facilities. Another striking feature is that long periods of illness (in terms of days lost due to illness) are correlated with sliding into poverty. Finally, we find some interesting results with respect to shocks and how households subsequently deal with these shocks. While the chronic poor seem to have no other option than to reduce consumption, the non-poor draw on savings. Social networks also seem important for vulnerable households.

\section{References}

Appleton, S. (2003). 'Regional or National Poverty Lines? The Case of Uganda in the 1990s', Journal of African Economies, 12(4): 598-624.

Arndt, C. and K. R. Simler (2010). 'Estimating Utility-Consistent Poverty Lines with Applications to Egypt and Mozambique', Economic Development and Cultural Change, 58(3): 449-74.

Barrett, C. B., P. P. Marenya, J. McPeak, B. Minten, F. Murithi, and W. Oluoch-Kosura (2006). 'Welfare Dynamics in Rural Kenya and Madagascar', Journal of Development Studies, 42(2): 248-77. 
Bird, K., A. McKay, and I. Shinyekwa (2010). 'Isolation and Poverty: The Relationship between Spatially Differentiated Access to Goods and Services and Poverty', ODI Working Paper 322. London: Overseas Development Institute.

Boateng, E. O., K. Ewusi, R. Kanbur, and A. McKay (1992). 'A Poverty Profile for Ghana, 1987-1988', Journal of African Economies, 1(1): 25-58.

Byekwaso, N. (2010). 'Poverty in Uganda', Review of African Political Economy, 37(126): 517-25.

Carter, M. R. and C. B. Barrett (2006). 'The Economics of Poverty Traps and Persistent Poverty: An Asset-Based Approach', Journal of Development Studies, 42(2): 178-99.

Daniels, L. and N. Minot (2015). 'Is Poverty Reduction Overstated in Uganda? Evidence from Alternative Poverty Measures', Social Indicators Research, 212(1): 115-33.

Deininger, K. and J. Okidi (2003). 'Growth and Poverty Reduction in Uganda, 1999-2000: Panel Data Evidence', Development Policy Review, 21(4): 481-509.

Dercon, S. (ed.) (2004). Insurance Against Poverty. Oxford: Oxford University Press.

Dercon, S., J. Hoddinott, and T. Woldehanna (2012). 'Growth and Chronic Poverty: Evidence from Rural Communities in Ethiopia', Journal of Development Studies, 48(2): 238-53.

Gibson, J. and S. Rozelle (2003). 'Poverty and Access to Roads in Papua New Guinea', Economic Development and Cultural Change, 52(1): 159-85.

Goodhand, J. (2003). 'Enduring Disorder and Persistent Poverty: A Review of the Linkages between War and Chronic Poverty', World Development, 31(3): 629-46.

Grant, U. (2005). 'Health and Poverty Linkages: Perspectives of the Chronically Poor', Background Paper for the Chronic Poverty Report 2008-09. Chronic Poverty Research Centre.

Harper, C., R. Marcus, and K. Moore (2003). 'Enduring Poverty and the Conditions of Childhood: Lifecourse and Intergenerational Poverty Transmissions', World Development, 31(3): 535-54.

Jamal, V. (1998). 'Changes in Poverty Patterns in Uganda', in H. B. Hansen and M. Twaddle (eds), Developing Uganda. Kampala: Fountain Publishers, 73-97.

Kakande, M. (2010). 'Poverty Monitoring', in F. Kuteesa, E. Tumusiime-Mutebile, A. Witworth, and T. Williamson (eds), Uganda's Economic Reforms: Insider Accounts. Oxford: Oxford University Press, 226-45.

Lanjouw, P. and M. Ravallion (1995). 'Poverty and Household Size', Economic Journal, 105(433): 1415-34.

Mukherjee, S. and T. Benson (2003). 'The Determinants of Poverty in Malawi, 1998', World Development, 31(2): 339-58.

Quisumbing, A. R. and L. Pandolfelli (2010). 'Promising Approaches to Address the Needs of Poor Female Farmers: Resources, Constraints, and Interventions', World Development, 38(4): 581-92.

Ravallion, M. and B. Bidani (1994). 'How Robust Is a Poverty Profile?', World Bank Economic Review, 8(1): 75-102.

Ravallion, M. and M. Lokshin (2006). 'Testing Poverty Lines', Review of Income and Wealth, 52(3): 399-421.

Ssewanyana, S. N. and I. Kasirye (2010). 'Food Security in Uganda: A Dilemma to Achieving the Millennium Development Goal', Research Series 113614. Kampala: Economic Policy Research Centre. 
Stifel, D. and B. Minten (2008). 'Isolation and Agricultural Productivity', Agricultural Economics, 39(1): 1-15.

Tarp, F., K. R. Simler, C. Matusse, R. Heltberg, and G. Dava (2002). 'The Robustness of Poverty Profiles Reconsidered', Economic Development and Cultural Change, 51(1): 77-108.

Udry, C., J. Hoddinott, H. Alderman, and L. Haddad (1995). 'Gender Differentials in Farm Productivity: Implications for Household Efficiency and Agricultural Policy', Food Policy, 20(5): 407-23.

Van Campenhout, B. (2014). 'Fertility, Agricultural Labor Supply, and Production: Instrumental Variable Evidence from Uganda', IFPRI Discussion Paper 1406. Washington, DC: International Food Policy Research Institute.

Van Campenhout, B., H. Ssekabira, and D. H. Aduayom (2014). 'Consumption Bundle Aggregation in Poverty Measurement: Implications for Poverty and its Dynamics in Uganda', WIDER Working Paper WP/2014/150. Helsinki: UNU-WIDER.

van de Walle, Dominique (2013). 'Lasting Welfare Effects of Widowhood in Mali', World Development, 51: 1-19.

World Bank (1993). 'Uganda: Growing out of Poverty', World Bank Country Study 12029. Washington, DC: World Bank. 
Part 2

Rapid Growth but Limited Poverty

Reduction 



\title{
8
}

\section{Burkina Faso}

\section{Shipping around the Malthusian Trap}

\author{
Michael Grimm, Claude Wetta, and Aude Nikiema
}

\subsection{Introduction}

More and more people seem to think that the time has come for sub-Saharan Africa (SSA) to take off. This optimism is based on high rates of economic growth indicated by national accounts data (see, for example, Pinkovskiy and Sala-i-Martin 2014), and by a rather positive development in asset ownership revealed by household surveys (Young 2012). Burkina Faso, a resource-poor, landlocked country in West Africa with a very low level of human development, ${ }^{1}$ is no exception in this regard. According to its national accounts, it has experienced remarkable rates of growth in gross domestic product (GDP) over the past twenty years. However, according to official poverty estimates and people's perceptions, the level of poverty has not changed much over this period. Indeed, the growth elasticity of poverty - that is, the rate by which poverty declines for each per cent of GDP per capita growth-is, at -0.54 , very low, both in absolute terms and in comparison with countries that have recently shifted large parts of their population out of poverty. ${ }^{2}$

We show that in Burkina Faso growth had basically two sources: first, a massive migration of people from the rural agricultural sector to the urban informal sector, and second, agricultural production of food crops and cotton, both fuelled by a massive expansion of cultivable land. Both sources are

\footnotetext{
1 The country ranks 181st out of 187 countries in the United Nations Human Development Index ranking; see <http://hdr.undp.org/en/data/trends/>.

2 This elasticity can, for instance, be compared to growth elasticities of poverty reported in Besley and Cord (2007) for a larger set of countries. The sample average is well beyond 1 .
} 
unsustainable. Structural changes that would allow urban workers to move from low- to high-productivity jobs and increases in land productivity are virtually absent. Given the stagnation of agricultural productivity, the limits to further land expansion, and the massive population growth-population size has doubled since 1985-the country is experiencing a steady rise in food prices, which erodes the purchasing power of the population and hence prevents significant reductions in poverty from materializing. Food price inflation is so substantial that child malnutrition and mortality rates are still very high and, temporarily, even on the rise. Taming these Malthusian forces will be a major challenge for Burkina Faso in the decade to come. We believe the findings from this case study are also relevant to many other parts of SSA.

The remainder of this chapter is organized as follows. Section 8.2 briefly describes the relevant context. Section 8.3 provides a detailed assessment of growth, inequality, and poverty dynamics since the early 1990s. Section 8.4 investigates the underlying forces with a focus on changes in population size, migration, and productivity development. Section 8.5 concludes.

\subsection{Country Context and Background}

In Burkina Faso almost 80 per cent of the population live in rural areas. As a mainly agricultural and cotton-exporting country, its economic performance depends heavily on climatic conditions and the world market price for cotton; even though more recently gold (the most important export product since 2009) and a few other metals have also became important export products. In urban areas the majority of the workforce operate in the informal sector. Public revenue is for a large part financed through external aid. In the late 1980s the country started to make reforms in accordance with the International Monetary Fund (IMF) and the World Bank. The first Structural Adjustment Programme (SAP) was signed in $1991 .^{3}$ Given that Burkina Faso, due to its participation in the CFA franc zone, ${ }^{4}$ already showed relatively modest public expenditure and monetary stability, the most important element of the SAP was the liberalization and privatization of the economy. However, despite the SAP (or because of it), real GDP per capita declined between 1991-3 by approximately 3.8 per cent per year. Finally, the failure of the internal adjustment strategy, not only in Burkina Faso but also in

\footnotetext{
3 The government had already undertaken 'auto-adjustment programmes' to stabilize the economy at the end of the 1960s and in 1983.

${ }^{4}$ Franc de la Communauté Financière d'Afrique is the name of the local currency. The currency union is called the CFA franc zone.
} 


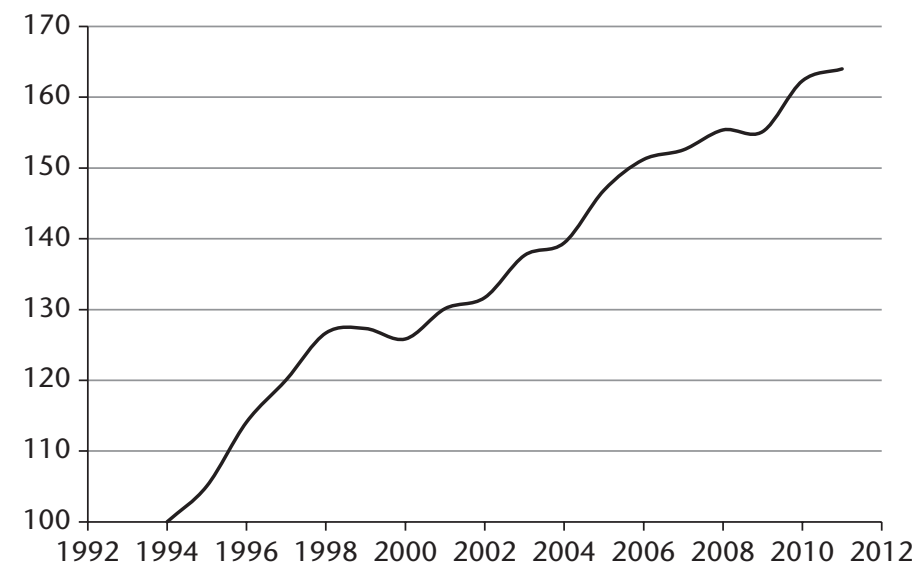

Figure 8.1. GDP per capita constant prices $(1994=100)$

Source: INSD (National Accounts various years; see $<$ www.insd.bf $>$ )

several other countries of the CFA franc zone and especially in Côte d'Ivoire, led to a 50 per cent devaluation of the CFA franc parity in relation to the French franc in January 1994. After the devaluation, real GDP per capita growth began to rise and averaged at approximately 6.1 per cent per year between 1994-8 (see Figure 8.1). This growth was furthermore encouraged by a favourable development of the world market price for cotton and a multiplication of the amount of land used for cotton production.

In the following years, Burkina Faso pursued its efforts for structural reforms, in particular concerning price and trade liberalization. Burkina Faso established its first Poverty Reduction Strategy Paper (PRSP) in May 2000 (Ministry of Finance and Economic Affairs 2000) and the country reached its completion point in the Heavily Indebted Poor Country (HIPC) II Initiative in April 2002. In the 2000s, GDP per capita growth was rather moderate and adversely affected by the Ivorian crisis and the resulting, albeit temporary, return migration of many Burkinabè, adverse rainfall conditions, and a volatile international price for cotton.

Between 2003 and 2010, real GDP per capita grew on average by 2.3 per cent annually. The entire period was marked by a general rise in the prices of basic food items, in particular domestically produced cereals and imported rice, and a high volatility of these prices, with important peaks in 2005 and 2008. During the 2008 food crisis, prices for the main food crops rose by $40-70$ per cent. Urban dwellers additionally suffered from high prices for cooking energy and fuel. Wodon et al. (2008) estimate that the price increase for rice, bread, oil, sugar, and milk alone increased poverty by about $1-2$ percentage points. The actual increase must have been much higher as the study ignored the 
price hikes for the most important food crops of millet, sorghum, and maize. ${ }^{5}$ In response to the food crisis, the government suspended taxes on a number of consumer products between March and September 2008, with a view to protecting the welfare of the most vulnerable groups. Energy prices were also contained, and some petroleum products subsidized. However, an IMF report that looked at these interventions more closely concluded that these measures were not well targeted as 80 per cent of the benefits accrued to the top 60 per cent in terms of income distribution (Arze del Granado and Adenauer 2011). Regarding fuel subsidies alone, the authors show that less than 16 per cent of the benefits reached the poorest 40 per cent of households. Not surprisingly, these measures were phased out in late 2008. In 2008, but in particular in spring 2011, people took to the streets of Ouagadougou to protest against the soaring prices of basic foods. Other spontaneous and largely unexpected civilian protests and military looting followed. President Blaise Compaoré intensified the dialogue with representatives of student and military groups. He replaced the prime minister, defence chief, and security service chiefs and appointed new governors in all thirteen regions. However, a large part of the population seems to share the view that their standard of living has not changed much over the past two decades. ${ }^{6}$ Hence, in late 2014 when Compaoré made an attempt to change the constitution again and extend his twenty-seven-year rule, violent protests followed and eventually forced him to resign. A transitional government was formed to guide the country to elections in 2015.

Official estimates do indeed suggest that poverty has not reduced much since the implementation of structural reforms. The first survey that measures poverty in a representative way dates back to the mid-1990s. It has been repeated since then every four to six years. The fourth survey was undertaken in 2009. According to the official poverty figures provided by National Institute of Statistics and Demography (INSD), ${ }^{7}$ the poverty rate has fluctuated since 1994 at around 45 per cent: 44.5 per cent in 1994, 45.3 per cent in 1998, 46.4 per cent in 2003, and 43.9 per cent in 2009 (IMF 2012; INSD 1997, 2000a, 2003). These numbers have been challenged by several authors (Grimm and Günther 2004, 2007a; World Bank 2004). Grimm and Günther (2004, 2007a) show that if one accounts for differences in the survey design over time, ensures a computation of a time-coherent expenditure aggregate, and allows the poverty line to reflect changes in prices acceding to the consumption

\footnotetext{
5 The second-order effects of such price hikes on children's school enrolment have been analysed by Grimm (2011).

6 In the QUIBB surveys for instance, 86 per cent of all respondents in 2005 and 71 per cent in 2007 , respectively, reported that they thought that the economic situation in their community had not changed or had even worsened over the previous twelve months.

7 Institut National de la Statistique et de la Démographie.
} 
habits of poor people, then poverty actually increased between 1994 and 1998, in particular as a result of a severe drought in 1997, and declined between 1998 and 2003 with a national poverty rate in 2003 even somewhat lower than it had been in 1994 . The 2009 poverty rate was published first in 2010, but then withdrawn as there was a fear that it would lead to social unrest. It was only in 2012 that the (same) figure was issued again-in a report published by the IMF (2012).

\subsection{Growth, Inequality, and Poverty Dynamics}

For Burkina Faso, representative cross-sectional household living standard measurement surveys (so-called Enquêtes Prioritaires) are publicly available for the years 1994, 1998, and 2003. These surveys were undertaken by the INSD with financial support by the World Bank, among others. The sample size in each is around 8,500 households. A fourth round of data was collected in 2009 , but these data are not yet publicly available. Hence, we first analyse the period 1994-2003 for which we have detailed data, and then the period 2003-9 for which the information is more scattered.

\subsubsection{Growth, Inequality, and Poverty Dynamics over the Period}

\section{4 to 2003}

Given Burkina Faso's macroeconomic performance, one would have expected poverty to also have substantially declined. Indeed, as shown in Table 8.1, over the entire period the growth rate of household expenditure per capita (here deflated by the general consumer price index (CPI)) had a similar order of magnitude than the growth rate of real GDP per capita. ${ }^{8}$ If the Gini coefficient is computed for this expenditure aggregate, one finds an almost constant coefficient; 0.47 in 1994 and 0.45 in 1998 and 2003. This in turn implies that expenditures by the poor must have more or less followed the average growth rate. However, as shown in Grimm and Günther (2007a), this is not necessarily the case, if, for instance, the relevant price index of the poor evolved differently than the general CPI and the deflator of GDP.

As can be seen in Table 8.1, the nominal poverty line ${ }^{9}$ increased between 1994 and 1998 much more than the CPI, suggesting that the poor lost in

\footnotetext{
8 There are, of course, differences in levels between GDP per capita and household expenditure per capita (used as a proxy for income) due to conceptual differences between national accounts (NA) and household surveys and there is also measurement error on both levels.

9 We deviate from the official poverty line used by INSD, since the official poverty line only accounts for the price increase of the food component (based on the price of the 2,283 per kilocalories (kcal) per day provided by millet, sorghum, maize, and rice, which are the main
} 
Table 8.1. Income, income inequality, and income poverty, 1994-2003

\begin{tabular}{|c|c|c|c|c|}
\hline & 1994 & 1998 & 2003 & $\begin{array}{l}\text { 1994-2003 } \\
\text { (change } \\
\text { per annum, \%) }\end{array}$ \\
\hline \multicolumn{5}{|l|}{ Income and income inequality } \\
\hline $\begin{array}{l}\text { Real GDP per capita }{ }^{a} \text { (in 1,000 CFA } \\
\text { francs, } 1994 \text { prices) }\end{array}$ & 120,821 & 135,434 & 148,195 & 2.30 \\
\hline $\begin{array}{l}\text { Real household expenditure per } \\
\text { capita, survey-based (CPI deflated, } \\
1994 \text { prices) }\end{array}$ & 78,772 & 85,540 & 99,153 & 2.59 \\
\hline Inequality (Gini coefficient) & 0.47 & 0.45 & 0.45 & -0.01 \\
\hline \multirow{2}{*}{ Poverty line $(\text { nominal })^{c}(1994=100)$} & 53,219 & 82,885 & 82,672 & \\
\hline & 100 & 155.74 & 155.34 & 5.02 \\
\hline For comparison: CPI $(1994=100)$ & 100 & 123.57 & 133.07 & 3.23 \\
\hline $\begin{array}{l}\text { Real household expenditure per } \\
\text { capita, survey-based (poverty line } \\
\text { deflated, } 1994 \text { prices) }\end{array}$ & 78,772 & 67,871 & 84,938 & 0.84 \\
\hline \multicolumn{5}{|l|}{ Poverty national } \\
\hline FGT Poverty headcount index $(P 0)^{d}$ & $\begin{array}{c}0.555 \\
{[0.54 ; 0.57]}\end{array}$ & $\begin{array}{c}0.618 \\
{[0.61 ; 0.61]}\end{array}$ & $\begin{array}{c}0.472 \\
{[0.46 ; 0.49]}\end{array}$ & -1.78 \\
\hline FGT Poverty gap index $(\mathrm{P} 1)^{d}$ & $\begin{array}{c}0.209 \\
{[0.20 ; 0.22]}\end{array}$ & $\begin{array}{l}0.229 \\
{[0.22 ; 0.24]}\end{array}$ & $\begin{array}{l}0.160 \\
{[0.15 ; 0.17]}\end{array}$ & -2.92 \\
\hline \multicolumn{5}{|l|}{ Poverty urban } \\
\hline FGT Poverty headcount index $(P 0)^{d}$ & $\begin{array}{c}0.147 \\
{[0.13 ; 0.17]}\end{array}$ & $\begin{array}{c}0.273 \\
{[0.26 ; 0.30]}\end{array}$ & $\begin{array}{c}0.203 \\
{[0.18 ; 0.22]}\end{array}$ & 3.65 \\
\hline FGT Poverty gap index (P1) ${ }^{d}$ & $\begin{array}{l}0.039 \\
{[0.03 ; 0.05]}\end{array}$ & $\begin{array}{c}0.083 \\
{[0.07 ; 0.09]}\end{array}$ & $\begin{array}{l}0.057 \\
{[0.05 ; 0.06]}\end{array}$ & 4.31 \\
\hline \multicolumn{5}{|l|}{ Poverty rural } \\
\hline FGT Poverty headcount index $(P 0)^{d}$ & $\begin{array}{c}0.634 \\
{[0.61 ; 0.65]}\end{array}$ & $\begin{array}{c}0.687 \\
{[0.67 ; 0.70]}\end{array}$ & $\begin{array}{c}0.533 \\
{[0.52 ; 0.55]}\end{array}$ & -1.91 \\
\hline FGT Poverty gap index (P1) ${ }^{d}$ & $\begin{array}{c}0.241 \\
{[0.23 ; 0.25]}\end{array}$ & $\begin{array}{c}0.258 \\
{[0.25 ; 0.27]}\end{array}$ & $\begin{array}{c}0.183 \\
{[0.18 ; 0.19]}\end{array}$ & -3.01 \\
\hline \multicolumn{5}{|l|}{ Inequality } \\
\hline Gini coefficient, price-adjusted ${ }^{e}$ & 0.47 & 0.50 & 0.47 & \\
\hline
\end{tabular}

Notes: ${ }^{a}$ Deflated by GDP deflator (INSD, National Accounts). ${ }^{b}$ In prices of Ouagadougou. ${ }^{\mathrm{c}}$ The poverty lines are taken from Grimm and Günther (2007a). ${ }^{d} 95$ per cent confidence intervals in brackets. ${ }^{e}$ To adjust for the effect of change in relative prices, the Gini coefficient is computed over expenditure distributions, where the deflation to 1994 is done using urban/rural and decile-specific price deflators.

Source: Grimm and Günther (2007a), and own computations based on National Accounts and EP $(1994,1998,2003)$

components of the nutritional intake of the poor) but not for the non-food component. In the official poverty line, the non-food component is simply calculated as a share of the nominal food component. Because this component has been altered over time-it slightly decreased from 1994-8 (from approximately 35 per cent to 30 per cent) and strongly increased from 1998-2003 (from approximately 30 per cent to 50 per cent)—the price index implicit in the official poverty line does not correspond to a true Laspeyres index. Therefore, Grimm and Günther (2004, 2007a) decided to calculate a new poverty line using constant real weights of food and non-food items over the period 1994-2003. More precisely, they took the nominal value of the official poverty line for 2003 (to have a common reference point with the official statistics), and the cereal food, otherfood, and non-food budget shares as they were observed in the 2003 household survey in the first two quintiles of the expenditure distribution. The cereal food component, which accounts for roughly 37 per cent of per capita household expenditure, was then deflated to 1998 and to 1994 using the observed price changes for the corresponding cereals. The remaining food and non-food components were deflated using the corresponding CPI components. 
purchasing power relative to the representative household underlying the CPI. Indeed, if deflated using the implicit price index of the poverty line, household expenditure per capita declined between 1994 and 1998, but increased between 1998 and 2003, in the end even to a level higher than in 1994. The increase in the poverty line was mainly driven by a droughtinduced rise in the prices of the three main cereals: sorghum, millet, and maize. This drought reduced cereal production in 1998 by more than 20 per cent in relation to $1996 / 7$ levels. ${ }^{10}$ Applying the poverty line shown in Table 8.1 thus implies the following development of poverty over time: the national headcount index (P0) increased from 1994-8 from 55.5 per cent to 61.8 per cent and then decreased quite substantively from 1998-2003 to 47.2 per cent-that is, to a level lower than in 1994. It is safe to say that probably any year would look better than 1998 if the comparison could be done-that is, if household survey data were available.

In rural areas we find the same dynamic, but at a higher level (63.4 per cent to 68.7 per cent to 53.3 per cent). In urban areas throughout all three survey years poverty remained significantly lower than in rural areas: the respective numbers are 14.7 per cent (1994), 27.3 per cent (1998), and 20.3 per cent (2003). Hence, urban poverty also increased from 1994-8 and decreased from 1998-2003. However, and in contrast to rural areas, urban poverty in 2003 was still substantially higher than in 1994. The poverty gap-that is, the average distance to the poverty line (where this distance is set to zero for the non-poor) - relative to the poverty line broadly follows the movement of the poverty rate. ${ }^{11}$

Two main messages emanate from this analysis. First, poverty in Burkina Faso is highly responsive to food prices and therefore very volatile across time. Second, over the entire period 1994-2003, poverty declined by about nine percentage points - that is, one point per year. This decline was even more pronounced in rural areas. Again, these estimates are different from the official estimates, because of different assumptions about the poverty line and because of a different concept used to construct the expenditure aggregate. ${ }^{12}$ These changes also affect the assessment of inequality. As can be seen at the bottom of Table 8.1, accounting for differential inflation shows that inequality did in fact increase between 1994 and 1998 (by three percentage points) and decline afterwards, but not below the 1994 level. This is quite different from the assessment that is obtained by simply using nominal expenditures, since scale invariance does not apply if inflation rates differ across the income distribution.

10 Based on data of the Enquête Permanente Agricole (1995-2002).

11 Computation as in Foster et al. (1984).

12 For details, the interested reader can refer to Grimm and Günther (2004, 2007a). 
Since the change in relative prices, or in other words the phenomenon of differential inflation-that is, loss of purchasing power that varies systematically across the income distribution-is so crucial to understanding Burkina Faso's growth, inequality, and poverty nexus, we illustrate this issue further by decomposing the changes in poverty into a growth and distributional component. We use Datt and Ravallion's (1992) method, but extend it by a third component as suggested by Günther and Grimm (2007) that will measure the contribution of differential inflation.

Datt and Ravallion's decomposition (Datt and Ravallion 1992) can be written as follows:

$$
\Delta P_{t}=\left[P\left(\mu_{t}, L_{t-1}, z\right)-P\left(\mu_{t-1}, L_{t-1}, z\right)\right]+\left[P\left(\mu_{t-1}, L_{t}, z\right)-P\left(\mu_{t-1}, L_{t-1}, z\right)\right]+R,
$$

where $P\left(\mu_{t}, L_{t}, Z\right)$ is the poverty measured with a mean income of $\mu_{t}$, a Lorenz curve $L_{t}$, and a poverty line $z$ which is constant in real terms. The first component corresponds to the change in poverty explained by the growth effect. The second component corresponds to the change in poverty explained by the distribution effect. $R$ is the calculated residual, representing the interaction effect of changes in the mean income and changes in inequality. ${ }^{13}$ To ensure that such a decomposition is consistent, the implicit price deflator of the poverty line and the one applied to deflate household expenditures have to be the same: typically the CPI is used for that purpose. However, in our case, as we have just shown, the development of the CPI and the inflation experienced by the poor are very different, hence we use the implicit price deflator of the poverty line. Moreover, to illustrate the poverty impact of that 'differential' inflation, it is possible, as shown by Günther and Grimm (2007), to add a 'relative price shift' or 'poverty line' component to Datt and Ravallion's (1992) decomposition and to derive the following 'triple' poverty decomposition:

$$
\begin{aligned}
& \Delta P_{t}=\left[P\left(\mu_{t} L_{t-1}, z_{t-1}\right)-P\left(\mu_{t-1}, L_{t-1}, z_{t-1}\right)\right]+\left[P\left(\mu_{t-1}, L_{t}, z_{t-1}\right)-P\left(\mu_{t-1}, L_{t-1}, z_{t-1}\right)\right] \\
& +\left[P\left(\mu_{t-1}, L_{t-1}, z_{t}\right)-P\left(\mu_{t-1}, L_{t-1}, z_{t-1}\right)\right]+R
\end{aligned}
$$

where the third component corresponds to the change in poverty explained by the inflation difference between the poverty line and the national CPI, in a

13 The magnitude of both components and the residual depend on the decomposition paththat is, it depends on whether the initial or the final year is taken as the reference period. In our case, the decomposition results are averaged over the two possible decomposition paths-first the initial year is taken as the reference year for the computation of the components, and then the final year is taken as the reference year, and in a last step for each component the average over the two decomposition paths is calculated. 
growth- and distributional-neutral case. The poverty line $z_{t+1}$ is calculated by inflating $z_{t}$ with the inflation rate of the consumption basket underlying the poverty line relative to the inflation rate of the CPI between $t$ and $t+1$. In this 'triple' decomposition, the growth component has to be interpreted a bit differently than in a 'dual' decomposition. It represents the change in poverty that would have occurred with the observed growth rate given that the poor had experienced the same increase in cost of living as the CPI. The 'poverty line' component represents the change in poverty that can be explained by relative price shifts between the goods consumed by the poor and the goods consumed by the non-poor.

Table 8.2 shows the results of that decomposition. It can be noted that the impact of the 'poverty line' component on changes in poverty can be significantly negative (as from 1994-8 and 1994-2003) as well as positive (as from 1998-2003) and might in some cases even outweigh the impact of the growth as well as the redistribution component. This implies that relative price changes heavily contributed to the poverty increase that could be observed between 1994 and 1998. Poverty would have decreased by almost eighteen percentage points between 1994 and 2003 if the prices of the goods of the poor had experienced the same inflation rates as the prices of the goods of the non-poor. However, the high relative price shifts offset the positive effects of general growth rates and redistribution by over nine percentage points. Obviously, the 'true' relative price shift effect might in reality have been somewhat lower if households had been able to substitute the items that became relatively more expensive. Our data do not allow for the examination of such a substitution in detail as the survey only reports values and not unit prices and quantities. However, we have good reasons to believe, as we will explain in more detail in section 8.4.3, that the relevant substitution effects are very limited. The main reason is that the price increase concerns not only the main food items of the poor but also the items with by far the lowest price per kcal, even after accounting for the price increase of these goods.

Table 8.2. Decomposition of the change in the national headcount index, 4 P0, Burkina Faso, 1994-2003

\begin{tabular}{lrcc}
\hline Year & $1994-98$ & $1998-2003$ & $1994-2003$ \\
\hline$\Delta$ P0 & 0.063 & -0.146 & -0.083 \\
Growth effect & -0.044 & -0.091 & -0.131 \\
Redistribution effect & -0.023 & -0.013 & -0.048 \\
Poverty line effect & 0.129 & -0.045 & 0.091 \\
Residual & 0.001 & 0.002 & 0.005 \\
\hline
\end{tabular}

Source: EP 1994, 1998, 2003; Günther and Grimm (2007) 
8.3.2 Growth, Inequality, and Poverty Dynamics over the Period 2003 to 2009

Given that the Enquête Prioritaire 2009 is not yet publicly accessible (and probably never will be), it is not possible to simply extend the analysis presented in the previous section up to 2009 . We rely instead on the recently published official poverty estimates based on that same survey and check the credibility of these estimates against other evidence.

The official poverty line and the estimated poverty headcount index for 2009 are shown in Table 8.3. Recall we had used the official 2003 poverty line as a reference point to recompute the poverty lines for 1994 and 1998, therefore the 2003 poverty line in Table 8.3 is identical to the one in Table 8.1. This poverty line was increased by the INSD by 31 per cent to reach a nominal value of 108,374 CFA francs per person per year in 2009 or about 454 \$PPP (or 1.24 \$PPP per day). ${ }^{14}$ Based on this poverty line and the distribution of household per capita consumption expenditure drawn from the 2009 survey, INSD estimates that the poverty headcount index declined to 43.9 per cent, which corresponds to a reduction of 2.4 percentage points or 0.4 points per year since 2003. If this estimate could be confirmed, it would mean that the positive trend over the entire period 1994-2003 continued, but that the pace of poverty reduction slowed down further. As will be seen, there is indeed a lot of evidence supporting this conclusion. Before we discuss this further, we will first take a closer look at the implied growth rate in household consumption per capita and the implied inflation rate experienced by the poor.

INSD increased the poverty line by 31 per cent over the six years between 2003 and 2009. The general CPI during that period increased by 23 per cent, the GDP deflator by 18 per cent, and the deflator of private consumption in the national accounts by 28 per cent (see Table 8.3). The prices of the three main food staples consumed by the poor showed the following price dynamics: sorghum +29 per cent, millet +15 per cent, and maize +40 per cent. The price of rice, which, because of its high cost per kcal, is not consumed as much by the poor, increased by 68 per cent. If we extrapolate the Grimm/Günther poverty line used above to 2009, we get 102,667 CFA francs which implies an increase relative to 2003 of 24 per cent. This is slightly less than the INSD estimate. But it is sufficiently close to conclude that the increase inherent in the method used by INSD is in line with the facts.

142009 Purchasing Power Parity from Penn World Tables 7.0, <http://www.rug.nl/research/ ggdc/data/pwt/pwt-7.0>. 
Table 8.3. Income, income inequality, and income poverty, 2003-9

\begin{tabular}{|c|c|c|}
\hline & 2003 & 2009 \\
\hline \multicolumn{3}{|l|}{ INSD official estimates } \\
\hline Poverty line (nominal) & 82,672 & 108,374 \\
\hline Poverty headcount index (P0) & 0.463 & 0.439 \\
\hline \multicolumn{3}{|l|}{ INSD (National Accounts) } \\
\hline Inflation rate $\mathrm{CPI}$ & \multicolumn{2}{|c|}{0.23} \\
\hline Inflation rate GDP deflator & \multicolumn{2}{|c|}{0.18} \\
\hline Inflation rate private consumption deflator & \multicolumn{2}{|c|}{0.28} \\
\hline Inflation rate CPI sorghum & \multicolumn{2}{|c|}{0.29} \\
\hline Inflation rate CPI millet & \multicolumn{2}{|c|}{0.15} \\
\hline Inflation rate CPI maize & \multicolumn{2}{|c|}{0.40} \\
\hline Inflation rate $\mathrm{CPI}$ rice & \multicolumn{2}{|c|}{0.68} \\
\hline Growth rate of real GDP per capita & \multicolumn{2}{|c|}{0.13} \\
\hline Growth rate of real private consumption per capita & \multicolumn{2}{|c|}{-0.002} \\
\hline \multicolumn{3}{|l|}{ Own computations } \\
\hline Implied inflation rate of INSD poverty line & \multirow{2}{*}{\multicolumn{2}{|c|}{$\begin{array}{l}0.31 \\
0.06\end{array}$}} \\
\hline Implied real household expend growth rate of the poor ${ }^{\mathrm{a}}$ & & \\
\hline CPI-inflated poverty line & \multicolumn{2}{|c|}{101,773} \\
\hline PO using CPI-inflated poverty line and INSD income level & \multicolumn{2}{|r|}{0.426} \\
\hline Poverty line extrapolating Grimm/Günther 2004 line & \multicolumn{2}{|r|}{102,667} \\
\hline Implied inflation rate & \multirow{2}{*}{\multicolumn{2}{|c|}{$\begin{array}{l}0.24 \\
0.431\end{array}$}} \\
\hline PO using Grimm/Günther line and INSD income level ${ }^{a}$ & & \\
\hline Poverty line inflated with inflation of private consumption & \multicolumn{2}{|r|}{105,820} \\
\hline P0 using priv. consumption inflated pov. line and INSD income level ${ }^{\mathrm{a}}$ & \multicolumn{2}{|r|}{0.453} \\
\hline
\end{tabular}

Note: ${ }^{\text {a }}$ Assuming no distributional change in nominal incomes between 2003 and 2009.

Source: EP (2003), INSD, National Accounts (various years); IMF (2012); own computations

Based on this poverty line and assuming (for the moment) that the distribution of relative incomes did not change between 2003 and 2009, we can compute the implicit mean growth rate of household consumption expenditures per capita. It is simply the growth rate with which we have to multiply all household consumption expenditures in the 2003 distribution to get a poverty headcount index of 43.9 per cent given the new poverty line. This procedure yields a rate of 6 per cent (Table 8.3). Depending on the true distributional change, the true mean growth rate might be a bit higher or lower than 6 per cent. Six per cent is about half of the growth rate in GDP per capita, but significantly more than the per capita adjusted growth rate in real private consumption in the national accounts. In section 8.4, we further investigate the discrepancy between growth in GDP and growth in household expenditure per capita.

To further check the robustness of the official poverty estimate, we recomputed the poverty headcount, applying the growth rate of real household expenditure per capita implied by the INSD estimates to the 2003 distribution for alternative poverty lines-again assuming the absence of any distributional shift between 2003 and 2009. The results are shown in Table 8.3. If we 
use a CPI-inflated poverty line, we find a poverty headcount index of 42.6 per cent; if we use the extrapolated Grimm/Günther line, we find 43.1 per cent; and if we use the inflation rate implied by the private consumption deflator (national accounts), we find 45.3 per cent.

We conclude that the official estimate is relatively robust to alternative poverty lines and it seems safe to state that the relative number of poor people decreased between 2003 and 2009, but very modestly and at a slower pace than between 1994 and 2003.

\subsection{An Analysis of the Underlying Driving Forces}

In what follows we investigate in more detail the driving forces of the growth, inequality, and poverty trends already discussed. We start by unpacking aggregate growth into sectoral growth and analyse how it affected households' disposable income and employment in urban and rural areas. We then focus on the agricultural sector, which accommodates almost 90 per cent of the poor, and link the supply and demand side of food. Throughout, special attention is given to the role of population growth and the urban-rural divide of that growth.

\subsubsection{Sectoral Analysis}

In this section we disaggregate growth of real GDP per capita by sector in order to investigate the sources of aggregate growth. Figure 8.2 shows GDP growth according to three broad sectors: agriculture (primary sector), industry (secondary sector), and trade and services (tertiary sector). It can be seen that the level of total GDP is highest in the tertiary sector, followed by the primary sector and then the secondary sector. In terms of growth, the figure suggests that real growth in total GDP was also highest in the tertiary sector; it even gained pace over the observation period. In the primary and secondary sectors, growth of GDP was a bit less impressive, but still positive and relatively steady over the entire period.

Yet, regarding the implied leverage on poverty, what matters is obviously growth of GDP per capita. As has already been shown, given the continuing high population growth in Burkina Faso, aggregate real growth rates differed substantially from per capita growth rates. Regarding the sectoral analysis, it would be a mistake to simply discount the aggregate population growth rate, since the primary sector is mainly related to the rural population, whereas the secondary and tertiary sectors are mainly related to the urban population and population growth rates are very different in rural and urban areas. Although natural population growth was higher in rural areas compared to urban 


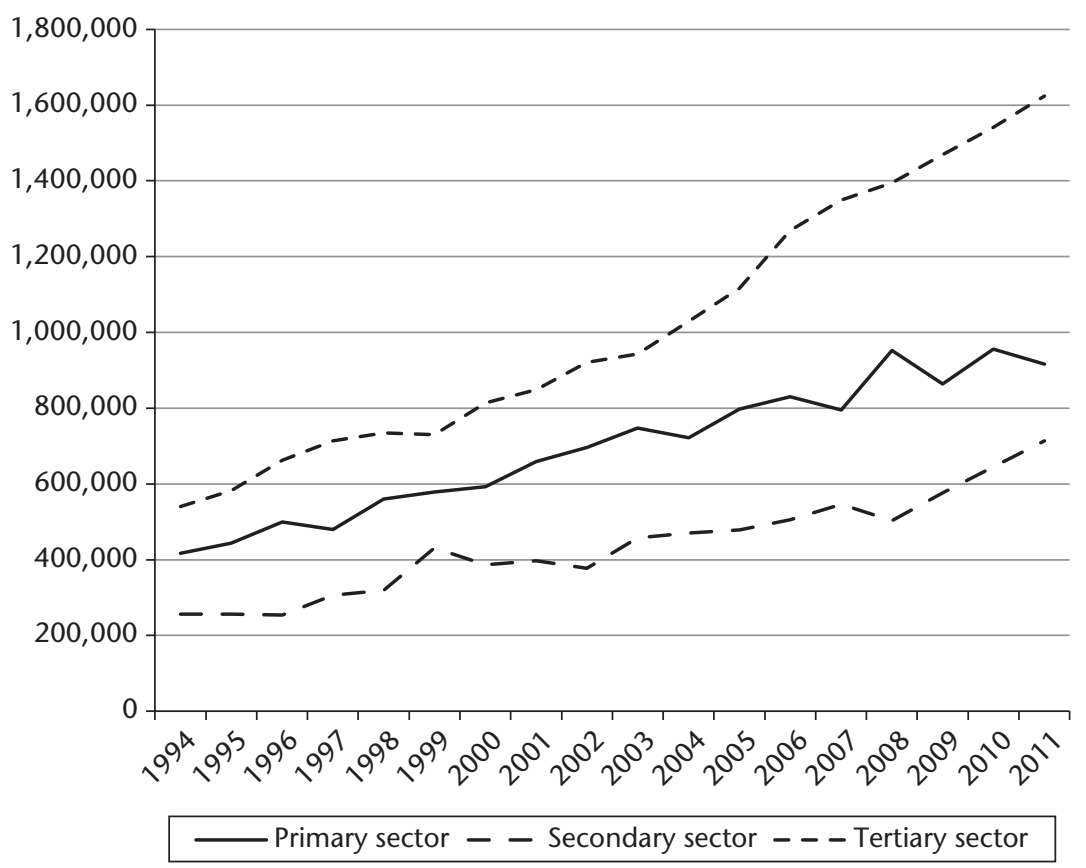

Figure 8.2. Sectoral GDP (constant prices 1999, in million CFA francs) Source: INSD (www.insd.bf); own computations

areas, ${ }^{15}$ total growth in urban areas was in fact much higher than in rural areas due to the intensive rural-urban migration. This can be seen in Table 8.4, which shows population estimates for the census years and the implied growth rates over the periods in between. For instance, over the period 1996-2006, the urban population grew at a rate of more than 7 per cent per year, whereas the rural population 'only' grew at a rate of 2.2 per cent per year. Some of the urban growth was due to villages that surpassed the threshold of 5,000 inhabitants and hence got the status of a city, but the bulk related to population growth in already existing cities, including Ouagadougou and Bobo-Dioulasso, the country's two major cities.

Hence, Figure 8.3 shows sectoral GDP per capita, where GDP in the primary sector has been related to the rural population and GDP in the secondary and

15 According to the last Demographic and Health Survey undertaken in 2010, the estimated total fertility rate-that is, the number of children a woman would have over her fertile years if she was exposed to the currently observed age-specific fertility rates-was 3.9 in urban areas and 6.7 in rural areas (INSD 2012a). According to the same data, the crude birth rate-the number of births relative to the total population-was 33.9 per 1,000 in urban areas and 43.3 per 1,000 in rural areas (INSD 2012a). 
Table 8.4. Rural and urban population growth

\begin{tabular}{lcccc}
\hline & 1985 & 1996 & 2006 & 2011 (proj.) \\
\hline Rural (count) & $6,912,367$ & $8,711,441$ & $10,835,295$ & $12,084,150$ \\
Mean annual growth rate over period & & 0.021 & 0.022 & 0.022 \\
Urban (count) & $1,052,338$ & $1,601,168$ & $3,181,967$ & $4,485,647$ \\
Mean annual growth rate over period & & 0.039 & 0.071 & 0.071 \\
of which & & & & \\
Ouagadougou (count) & 465,969 & 750,398 & $1,475,223$ & $1,475,223$ \\
Mean annual growth rate over period & & 0.044 & 0.070 & 0.070 \\
Bobo-Dioulasso (count) & 228,668 & 309,771 & 489,967 & 489,967 \\
Mean annual growth rate over period & & 0.028 & 0.047 & 0.047 \\
Other cities (count) & 357,701 & 540,999 & $1,216,777$ & $1,216,777$ \\
Mean annual growth rate over period & & 0.038 & 0.084 & 0.084 \\
Total (count) & $7,964,705$ & $10,312,609$ & $14,017,262$ & $16,571,808$ \\
Mean annual growth rate over period & & 0.024 & 0.031 & 0.034 \\
\hline
\end{tabular}

Note: Settlements with a population of 5,000 and above are considered urban.

Source: INSD (www.insd.bf)

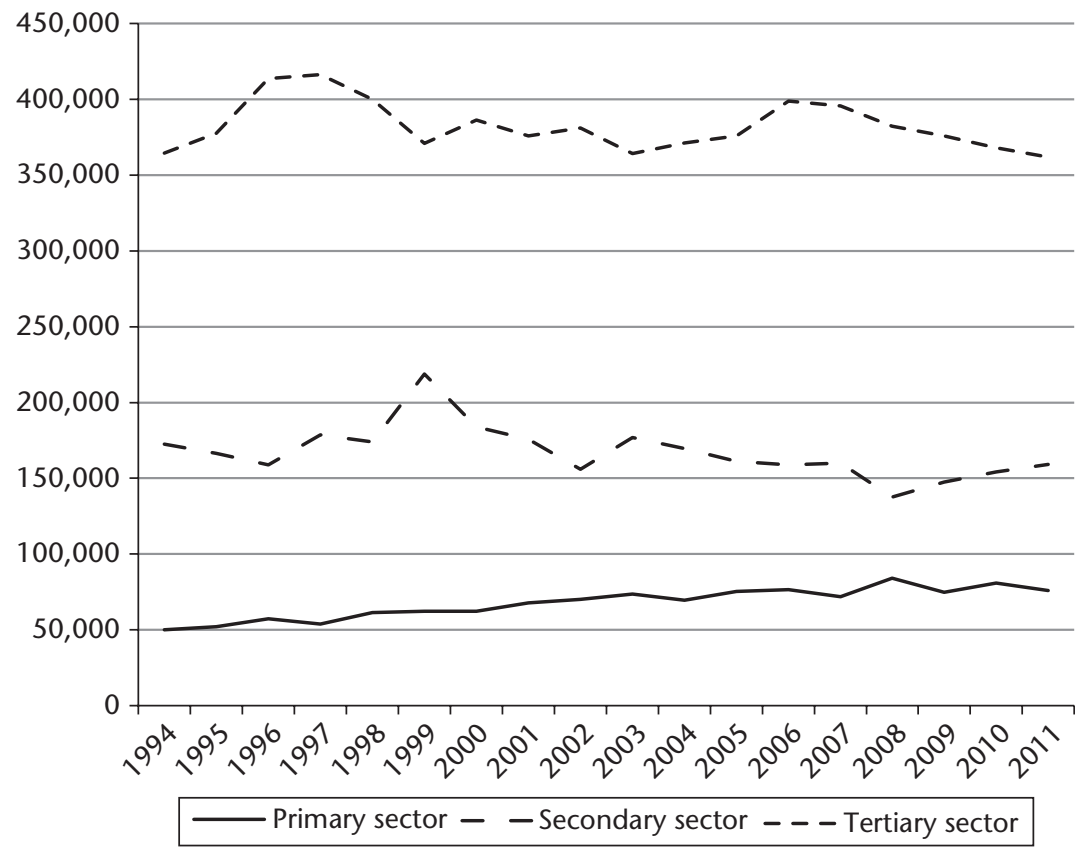

Figure 8.3. Sectoral GDP per capita (constant prices 1999)

Note: In 1,000 CFA francs

Source: INSD (www.insd.bf); own computations 
tertiary sectors to the urban population. ${ }^{16}$ The message that we get now is completely different. The sectoral differences in GDP per capita widened. Moreover, and more importantly, these figures show that aggregate growth was, to a large extent, the result of urbanization or the migration of rural dwellers from low-paid activities to better-paid activities in urban areas. Whereas GDP per capita in the primary sector was between 50 and 100 thousand CFA francs (in 1999 prices), it was between 200,000 and 250,000 CFA francs in the secondary sector and 350,000 to 400,000 CFA francs in the tertiary sector. Hence, at least on average, migrants increased their income quite substantially. However, as Figure 8.3 clearly shows, in terms of growth, the performance in the secondary and tertiary sector was, as a consequence of that massive influx, very weak. The secondary sector only saw positive growth rates in the second half of the 1990s, but thereafter growth was negative in most years and real GDP per capita in 2011 was lower by about 30 per cent than in 1999. The negative growth performance in the tertiary sector started in the mid-1990s and was only interrupted by a short boom in the mid-2000s. By 2011, GDP per capita was more or less at the same level as it had been in 1994. Thus the only sector that experienced growth in per capita terms over the entire period was the agricultural sector. In the agricultural sector, real GDP per capita in 2011 was about 50 per cent higher than in 1994. Cash crops, in particular cotton, played an important role in that growth, but the bulk is related to food crops (see also Table 8.6). So, relative to the other two sectors, the primary sector showed the best performance in per capita terms. In this sector the massive outflow of people prevented GDP per capita from declining. However, even there growth was volatile and in the end was also relatively weak: 50 per cent over 17 years is equivalent to a yearly growth rate of roughly 2.5 per cent. This dynamic also perfectly fits our own poverty estimates for the period 1994 to 2003 (Table 8.1), which suggest that poverty declined in rural areas but increased in urban areas.

A look at employment patterns in rural and urban areas confirms that the massive urbanization was not accompanied by any significant structural change within the urban economy. Table 8.5 shows the distribution of the active population over five different socioeconomic groups. The data are drawn from the same household surveys as above. In addition, for 2005 we used the so-called QUIBB survey (Questionnaire des Indicateurs de Base du Bienêtre), which is an extremely shortened version of the Enquête Prioritaire. QUIBB does not collect any information on household expenditure or household

16 Obviously, to the extent that households in urban areas still engage in agriculture, the procedure applied here exaggerates demographic growth in the secondary and tertiary sectors and underestimates it in the primary sector. However, the 2003 household survey shows that only 8.3 per cent of the urban workforce (population aged 15-64 years) had agriculture as their primary activity, hence the simplification we are making here seems acceptable. 
Table 8.5. Employment patterns of population aged 15 to 64 (shares), 1994-2007

\begin{tabular}{|c|c|c|c|c|c|}
\hline & 1994 & 1998 & 2003 & 2005 & 2007 \\
\hline \multicolumn{6}{|l|}{ Rural } \\
\hline Public sector worker & 0.007 & 0.006 & 0.006 & 0.005 & . \\
\hline Private (formal) sector worker & 0.002 & 0.002 & 0.006 & 0.006 & . \\
\hline Informal sector (independent/dependent) & 0.042 & 0.025 & 0.038 & 0.049 & . \\
\hline Subsistence agriculture & 0.727 & 0.702 & 0.621 & 0.599 & . \\
\hline Cotton agriculture & 0.114 & 0.195 & 0.208 & 0.252 & . \\
\hline Inactive & 0.107 & 0.070 & 0.121 & 0.089 & . \\
\hline \multicolumn{6}{|l|}{ Urban } \\
\hline Public sector worker & 0.068 & 0.072 & 0.076 & 0.068 & . \\
\hline Private (formal) sector worker & 0.074 & 0.099 & 0.109 & 0.085 & . \\
\hline Informal sector (independent/dependent) & 0.222 & 0.208 & 0.231 & 0.232 & . \\
\hline Subsistence agriculture & 0.172 & 0.206 & 0.169 & 0.160 & . \\
\hline Cotton agriculture & 0.001 & 0.003 & 0.006 & 0.010 & . \\
\hline Inactive & 0.463 & 0.411 & 0.408 & 0.445 & . \\
\hline Households involved in cotton production & 0.103 & 0.167 & 0.182 & 0.188 & 0.154 \\
\hline
\end{tabular}

Source: EP (1994, 1998, 2003); QUIBB 2004 and 2007 in INSD (2007); own computations

income, but has information about occupations. This survey is also available for the year 2007, but the information on occupations is not reliable, hence for that year we only use the information related to whether a household was involved in cotton production. The data on occupational patterns from the 2009 survey are not yet available. Table 8.5 shows two striking results. There was no substantial change in the employment structure with respect to the allocation of workers between the private formal and informal sectors. Still, in 2005 in urban areas fewer than 10 per cent of the population aged 15-64 years declared having a job in a private formal firm. There was also no increase in public sector employment over time. Given that earnings in the informal sector are significantly lower than in the private formal and public sectors (Grimm and Günther 2004, 2007b), there is nothing that would suggest substantial income gains in urban areas over the entire period. In rural areas, employment in subsistence agriculture declined significantly over the period 1994-2005, while the share of the workforce involved in cotton farming doubled. As mentioned above, the expansion of cotton farming and theover most of the period-favourable development of the international cotton price was certainly one of the most important drivers of rural poverty reduction. However, the producer price paid to farmers declined between 2004 and 2008 and even in 2009 it did not reach its 2004 level, thus explaining why the share of households involved in cotton production declined again after 2005. This is then also consistent with the slower pace of poverty reduction between 2003 and 2009 compared to the period between 1994 and 2003. In the following section we further unpack the sources of agricultural growth by examining the development of land, production, and productivity. 
8.4.2 The Development of Land Use, Production, and Productivity in Food and Cotton Production

The data used in this section have been drawn from the Enquete Agricole Permanente (or 'EAP'), an annual agricultural survey that has been undertaken by the agriculture ministry since the mid-1990s. In principle, it interviews the same sample of households every year and collects basic sociodemographic information and information about agricultural production and income from farming. However, the survey does not collect information about livestock and non-farm income (see Wetta et al. 2011). We use these data to answer the following question: to what extent was agricultural growth, albeit moderate, in particular in per capita terms, the result of land expansion, a rise in land productivity, and price movements? We undertake this analysis separately for food crops and cotton, the main cash crop in Burkina Faso. Table 8.6 shows that the land used for food crop production increased on average by 2.1 per cent per year and the land used for cotton production by 7.6 per cent per year (the growth rate for the period 1995 to 2002 was substantially higher, for both food crops and cotton). However, comparing both, the absolute area used for cotton is relatively small compared to that used for food crops. In 1995 only 5 per cent of agricultural land was used for cotton production. Due to the favourable development of the cotton producer price, this share increased to 10 per cent in 2003. During that period, the producer price could be kept high due to the favourable international price dynamic and the devaluation of the CFA franc relative to the French franc in 1994, which temporarily increased

Table 8.6. Cereal and cotton production, 1995-2010

\begin{tabular}{|c|c|c|c|c|c|c|}
\hline & \multicolumn{3}{|c|}{ Food crops } & \multicolumn{3}{|c|}{ Cotton } \\
\hline & ha & ton & $\mathrm{kg} / \mathrm{ha}$ & ha & ton & $\mathrm{kg} / \mathrm{ha}$ \\
\hline $1995 / 6$ & $2,694,493$ & $2,296,382$ & 852 & 145,418 & 150,451 & 1,035 \\
\hline $1996 / 7$ & $2,692,899$ & $2,470,971$ & 918 & 200,768 & 202,630 & 1,009 \\
\hline $1997 / 8$ & $2,838,530$ & $2,002,800$ & 706 & 276,911 & 343,106 & 1,239 \\
\hline $1998 / 9$ & $2,969,359$ & $2,642,334$ & 890 & 334,770 & 324,557 & 969 \\
\hline $1999 / 2000$ & $2,940,876$ & $2,686,548$ & 914 & 211,931 & 257,121 & 1,213 \\
\hline $2000 / 1$ & $2,645,351$ & $2,268,474$ & 858 & 209,113 & 212,545 & 1,016 \\
\hline $2001 / 2$ & $3,194,448$ & $3,096,769$ & 969 & 345,578 & 395,031 & 1,143 \\
\hline $2002 / 3$ & $3,296,616$ & $3,110,176$ & 943 & 412,138 & 439,247 & 1,066 \\
\hline $2003 / 4$ & $3,566,360$ & $3,555,542$ & 997 & 443,739 & 471,945 & 1,064 \\
\hline $2004 / 5$ & $3,073,117$ & $2,892,905$ & 941 & 521,466 & 535,367 & 1,027 \\
\hline $2005 / 6$ & $3,227,040$ & $3,641,728$ & 1,129 & 621,748 & 712,707 & 1,146 \\
\hline $2006 / 7$ & $3,043,932$ & $3,671,174$ & 1,206 & 569,858 & 759,858 & 1,333 \\
\hline $2007 / 8$ & $3,302,871$ & $3,095,966$ & 937 & 378,536 & 377,364 & 997 \\
\hline $2008 / 9$ & $4,167,474$ & $4,338,972$ & 1,041 & 535,325 & 720,675 & 1,346 \\
\hline $2009 / 10$ & $3,585,683$ & $3,600,539$ & 1,004 & 406,278 & 483,865 & 1,191 \\
\hline Mean annual growth rate & 0.021 & 0.033 & 0.012 & 0.076 & 0.087 & 0.010 \\
\hline
\end{tabular}

Source: Economic accounts for the agricultural sector, based on the EPA (1995-2010) 
the competitiveness of Burkinabè products on international markets—see, for example, Kaminski (2011: 115, figure 6.5).

In terms of output, food crop production increased by about 3.3 per cent annually, cotton production by about 8.7 per cent annually-more or less one-to-one with the expansion of land-implying that land productivity did not change much during the observation period. Indeed, over the entire period, output per hectare increased annually by 1.2 per cent in the food crop sector and 1.0 per cent in the cotton sector. Hence, the agricultural growth documented in the previous subsection was to a very large extent driven by land expansion and an increase in prices, and not by an increase in land productivity. Agricultural growth was also overproportionally driven by cotton production, in particular in terms of the value of output.

The data also shows that among food crop farmers the usage rate of fertilizer was only 20 per cent of all households, at least in 1994 and 1998, and therefore not very widespread (data not presented in Table 8.6). It is only in 2003 that the usage rate increased to 57 per cent. Among cotton farmers the usage rate was much higher, 80-90 per cent. This is due to the fact that cotton farmers had access to credits and fertilizer through a cotton marketing board. ${ }^{17}$ They typically also used their fertilizer for their food crops. Less than 5 per cent of all food crop farmers made use of credits. The absence of any systematic and large-scale support through seeds (at least till 2000), fertilizer, and other extension services can explain why there was more or less no increase in productivity in the food crop sector. The agricultural sector still operates in a very traditional fashion. Although some promising technologies exist, adoption and diffusion rates are low (see also Kaminski 2011).

Due to the lack of space we do not discuss here in detail the development of livestock production and forestry. Livestock production is relatively important in terms of its share of GDP in the primary sector (about 30 per cent), but is regionally more concentrated (mainly in the Sahelian north). According to national accounts, this subsector grew more or less one-to-one with the primary sector as a whole. The forestry sector in turn increased its share in total primary output and is today responsible for almost 25 per cent of total agricultural GDP. However, the forestry sector is dominated by a few larger companies and is therefore less important in terms of poverty reduction.

\footnotetext{
17 The institutional set-up of the cotton sector, and in particular the organization of the marketing board, was subject to substantial reform in the 2000s. In particular the state-owned marketing board SOFITEX was split into several parts and partly privatized. For details, see Kaminski et al. (2010).
} 


\subsubsection{Food Price Dynamics}

As has been shown in section 8.4.2, in the period under consideration, productivity growth in the food crop sector was very low, land expansion hit its limits, and population growth was intense. Moreover, these dynamics have to be seen in a context of a rather weakly integrated cereal market, both nationally and regionally, and in a context of internationally rising food prices. Hence, it is not surprising that the relative price of cereals—by far the most important single consumption item for the Burkinabè population-increased steadily; this is shown in Figure 8.4. Although the development was very volatile, given the boosts and busts in agriculture induced by variations in rainfall, the trend was clearly that prices were increasing. This steady inflation of food had a sizeable impact on the purchasing power of the population, in particular poor households who spent a very high share of their income on food. Table 8.7 shows that in 1994 in rural areas in the lowest quintile of the expenditure per capita distribution, almost a third of the budget was spent on millet, sorghum, and maize. In line with the relative price movement of these items, this share increased over time. It was particularly high in 1998, just after the massive drought, when cereals were particularly expensive. Table 8.7 further shows that in the richest quintile, again in rural areas, the share of income spent on these items was still at 20 per cent in 2003 and also significantly higher than in 1998. Remarkably, the CPI has a cereal component of

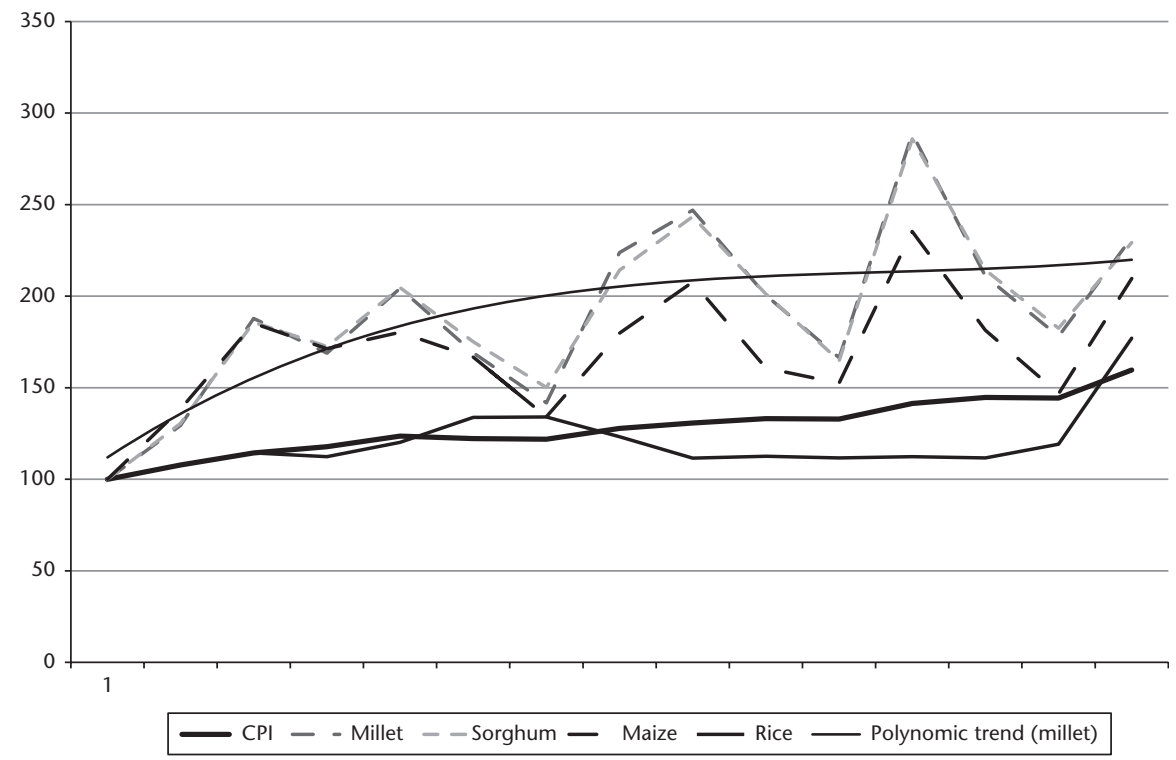

Figure 8.4. Inflation of food crops compared to the CPI in the long run Source: INSD (www.insd.bf); own computations 
Table 8.7. Budget shares and farmers' market integration

\begin{tabular}{|c|c|c|c|c|c|c|c|c|c|}
\hline \multirow[t]{2}{*}{ Rural } & \multicolumn{3}{|c|}{1994} & \multicolumn{3}{|c|}{1998} & \multicolumn{3}{|c|}{2003} \\
\hline & All & Q1 & Q5 & All & Q1 & Q5 & All & Q1 & Q5 \\
\hline Food crops & 0.23 & 0.27 & 0.18 & 0.43 & 0.48 & 0.31 & 0.30 & 0.38 & 0.22 \\
\hline millet/sorghum & 0.16 & 0.24 & 0.09 & 0.33 & 0.40 & 0.21 & 0.22 & 0.30 & 0.15 \\
\hline maize & 0.04 & 0.03 & 0.04 & 0.06 & 0.06 & 0.06 & 0.04 & 0.05 & 0.03 \\
\hline rice & 0.03 & 0.01 & 0.05 & 0.03 & 0.02 & 0.04 & 0.04 & 0.03 & 0.04 \\
\hline Other food items & 0.28 & 0.33 & 0.25 & 0.20 & 0.20 & 0.19 & 0.26 & 0.29 & 0.23 \\
\hline Rent and utilities & 0.01 & 0.01 & 0.01 & 0.01 & 0.01 & 0.01 & 0.01 & 0.01 & 0.01 \\
\hline Education & 0.07 & 0.03 & 0.10 & 0.03 & 0.02 & 0.05 & 0.04 & 0.01 & 0.06 \\
\hline Health & 0.08 & 0.13 & 0.05 & 0.06 & 0.11 & 0.04 & 0.06 & 0.10 & 0.05 \\
\hline Transfers made & 0.04 & 0.01 & 0.06 & 0.04 & 0.01 & 0.08 & 0.03 & 0.00 & 0.05 \\
\hline Other & 0.29 & 0.22 & 0.35 & 0.24 & 0.17 & 0.32 & 0.30 & 0.20 & 0.39 \\
\hline Total & 1.00 & 1.00 & 1.00 & 1.00 & 1.00 & 1.00 & 1.00 & 1.00 & 1.00 \\
\hline Households producing food crops (share) & 0.90 & & & 0.94 & & & 0.90 & & \\
\hline Households selling food crops (share) & 0.16 & & & 0.15 & & & 0.30 & & \\
\hline Share of purchased food crops & 0.15 & & & 0.49 & & & 0.33 & & \\
\hline \multirow[t]{2}{*}{ Urban } & \multicolumn{3}{|c|}{1994} & \multicolumn{3}{|c|}{1998} & \multicolumn{3}{|c|}{2003} \\
\hline & All & Q1 & Q5 & All & Q1 & Q5 & All & Q1 & Q5 \\
\hline Food crops & 0.10 & 0.18 & 0.06 & 0.15 & 0.35 & 0.06 & 0.13 & 0.25 & 0.06 \\
\hline millet/sorghum & 0.03 & 0.11 & 0.01 & 0.05 & 0.21 & 0.01 & 0.03 & 0.10 & 0.01 \\
\hline maize & 0.02 & 0.03 & 0.01 & 0.05 & 0.10 & 0.02 & 0.04 & 0.08 & 0.02 \\
\hline rice & 0.05 & 0.04 & 0.04 & 0.05 & 0.04 & 0.04 & 0.06 & 0.07 & 0.03 \\
\hline Other food items & 0.24 & 0.27 & 0.20 & 0.20 & 0.21 & 0.16 & 0.22 & 0.28 & 0.19 \\
\hline Rent and utilities & 0.03 & 0.03 & 0.03 & 0.04 & 0.04 & 0.04 & 0.04 & 0.04 & 0.04 \\
\hline Education & 0.09 & 0.06 & 0.10 & 0.06 & 0.03 & 0.07 & 0.06 & 0.02 & 0.07 \\
\hline Health & 0.12 & 0.18 & 0.10 & 0.11 & 0.15 & 0.10 & 0.15 & 0.14 & 0.15 \\
\hline Transfers made & 0.04 & 0.01 & 0.07 & 0.07 & 0.01 & 0.13 & 0.03 & 0.00 & 0.05 \\
\hline Other & 0.38 & 0.27 & 0.44 & 0.36 & 0.22 & 0.44 & 0.37 & 0.27 & 0.44 \\
\hline Total & 1.00 & 1.00 & 1.00 & 1.00 & 1.00 & 1.00 & 1.00 & 1.00 & 1.00 \\
\hline Households producing food crops (share) & 0.26 & & & 0.25 & & & 0.24 & & \\
\hline Households selling food crops (share) & 0.02 & & & 0.01 & & & 0.04 & & \\
\hline Share of purchased food crops & 0.83 & & & 0.91 & & & 0.86 & & \\
\hline
\end{tabular}

Source: EP (1994, 1998, 2003); own computations

only 10 per cent (Table 8.8). The total food component of the CPI stands at 34 per cent. However, on average, rural households spend 50-60 per cent of their budget on food.

In urban areas the share of cereal and food components in total consumption was obviously lower than in rural areas, but they were still substantial and also rose over time. In urban areas in the lowest quintile the share spent on cereals (sorghum, millet, maize) stands at 18 per cent, 35 per cent, and 25 per cent, in 1994, 1998, and 2003 respectively. In these three years, the total food component amounted to 45 per cent, 55 per cent, and 53 per cent of total expenditure respectively. This shows again that the CPI is an inadequate price 
Table 8.8. Budget shares of general CPI

\begin{tabular}{ll}
\hline & Share \\
\hline Food crops & 0.10 \\
Other food items & 0.24 \\
Rent and utilities & 0.11 \\
Education & 0.03 \\
Health & 0.04 \\
Transport & 0.16 \\
Other & 0.33 \\
Total & 1 \\
\hline
\end{tabular}

Source: INSD (www.insd.bf)

deflator for the poor population, also in urban areas. It is important to note that the possibilities to substitute were very limited for these households, since the relative price shift concerns all three cereals: sorghum, millet, maize. Rice in turn was hardly an alternative for the rural population; although the price of rice increased less, it remained substantially more expensive per kcal than the other three cereals. ${ }^{18}$

From a theoretical point of view, one could argue that the rural population should benefit from rising cereal prices as this improves their terms of trade. However, as was shown to be the case in many poor countries during the 2008 world food crisis, the market integration of Burkinabè food crop farmers is surprisingly low. Table 8.7 shows that although 90 per cent of all rural households produced cereals, only 15-30 per cent of these households sold cereals on the market; the others just produced for their own consumption. ${ }^{19}$ But more importantly, almost all households had to purchase additional cereals from the market. The share of purchased cereals relative to the total value of cereals consumed was 15 per cent in 1993, 49 per cent in 1998, and 33 per cent in 2003. This low market integration had to do with a lack of market access due to bad infrastructure, lack of information, and a lack of adequate storage facilities (see Gräb and Grimm 2011; Grimm and Günther 2004, 2007b; Kaminski 2011). Even those farmers who sold some of their cereals were often obliged to sell them right after the harvest when prices were low and to purchase later during the lean season when prices were high. The need for cash after a long, lean season is a further factor that often pushed households to sell quite early.

\footnotetext{
18 For instance in 2010, the price of a kilogram of rice was almost 400 CFA francs whereas the price of millet, sorghum, and maize was between 150 and 200 CFA francs per kilo. This difference does not make up the difference in kcal per kilo (rice: 3,680; maize: 3,680; sorghum: 2,990; and millet: 2,650) (see Wetta et al. 2011).

19 It needs to be seen whether the rising trend of households selling cereals that was observed between 1998 and 2003 is confirmed in 2009 data.
} 


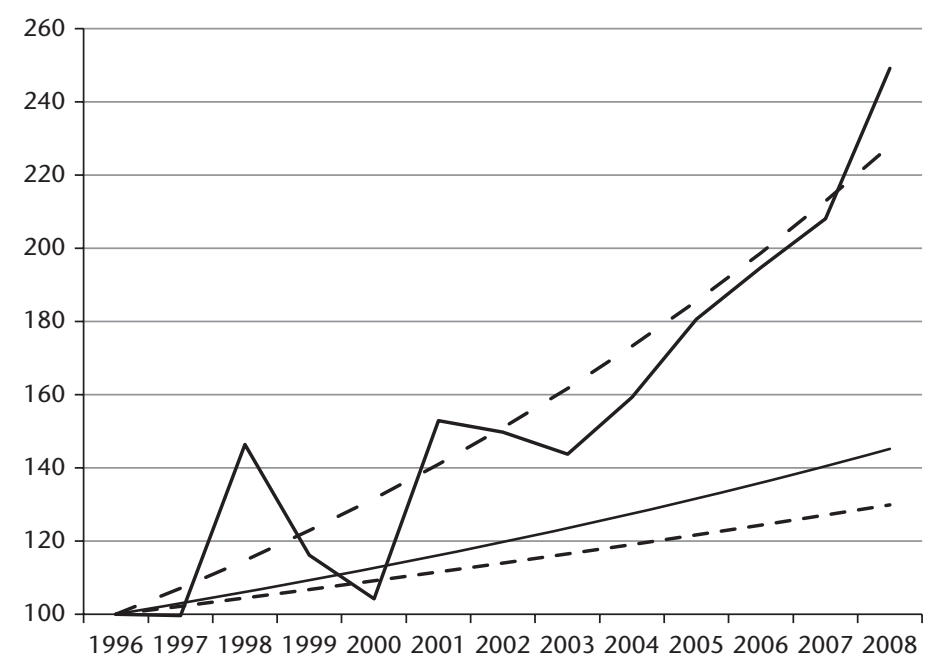

— Food imports _— Population total $\_-$Population rural - Population urban

Figure 8.5. Food imports and population growth $(1996=100)$

Note: Food includes all vegetarian products, food oil and fat products, processed food (vegetarian and animal-based) and all drinks. Unprocessed animal products are not included.

Source: INSD (www.insd.bf)

To conclude, the absolute and relative increase of cereal prices substantially eroded the purchasing power of the Burkinabè population and in particular of the poor population. This again fits in with the Malthusian framework. Productivity improvements and better market integration could in principle turn the price dynamic into rising living standards in rural areas, but so far production has not been able to keep up with the rising demand. Figure 8.5 provides another illustration of this phenomenon-food imports increase almost one-to-one with the growth rate of the urban population.

Obviously, food price inflation will not only erode the purchasing power of the population; it can potentially also have direct health effects as it may increase malnutrition and mortality, in particular in children. This is what we investigate next.

\subsubsection{Undernutrition and Child Mortality}

To investigate the dynamics of malnutrition and child mortality we make use of the Demographic and Health Surveys (DHS) which are available for the years $1993,1998 / 9,2003$, and $2010 .^{20}$ The data are also nationally

${ }^{20}$ See <www.measuredhs.com>. 
representative and have also been collected by the INSD. The sample size in each round is about 9,000 households. Regarding children's malnutrition we consider wasting and stunting. Wasting refers to a low weight-for-height ratio and is a sign of short-term undernutrition. Stunting refers to a low height-forage ratio and is a sign of a continuous shortage of food; children end up shorter when they are adults (WHO 2009). We use the standard WHO (World Health Organization) concept-that is, compute the share of children for whom weight-for-height and height-for-age respectively is inferior by two standard deviations of the median in the reference population. We have computed these indicators throughout all years using the new WHO standard (WHO 2009).

Table 8.9 shows that between 1993 and 1998 wasting was almost stable in both rural and urban areas and even increased after 1998, in particular in rural areas. Only after 2003 did malnutrition decline a bit. In rural areas malnutrition was in 2010 almost identical to the level observed in 1998; in urban areas it was slightly higher. We find more or less the same evolution if we use the old WHO standard (results not shown in the table) instead of the new WHO standard. Hence, in 201014 per cent of all Burkinabè children under five were wasting. Stunting in urban areas is more or less constant throughout the entire observation period with 25 per cent of all children under five concerned. In rural areas the share increases between 1994 and 1998, followed by a modest decline in 2003 and a more significant decline in 2010, reaching in that year a level five percentage points below the 1993 level. To summarize, despite the improvements in consumption and poverty over the entire period 1993-2009, there is almost no change in malnutrition rates_between 1993 and 2003 malnutrition even increased.

Infant and child mortality decreased also only modestly over the observation period 1993-2010. Child mortality even increased between 1994 and 1998. This is thus in line with the trends in child malnutrition.

To summarize, malnutrition and child mortality temporarily increased and are still at a relatively high level. This suggests a direct link between the performance in the food crop sector, food prices, and nutrition. Thus, recurrent droughts and the rising long-term trend in food prices seem to have direct health effects through undernutrition and premature mortality.

\subsection{Conclusion and Policy Perspectives}

Although we find that over the past twenty years poverty has declined a bit faster than official estimates suggest, the overall reduction has been relatively modest and, due to the vulnerability of the country, also quite volatile. Over the entire twenty-year period the country achieved a meagre growth elasticity 
Table 8.9. Indicators of children's malnutrition and mortality, 1993-2010

\begin{tabular}{|c|c|c|c|c|}
\hline & 1993 & 1998 & 2003 & 2010 \\
\hline \multicolumn{5}{|c|}{ Share of children under five, weight-for-height (wasting) $<2$ StDev } \\
\hline all & 0.130 & 0.140 & 0.194 & 0.139 \\
\hline urban & 0.094 & 0.101 & 0.133 & 0.122 \\
\hline rural & 0.148 & 0.147 & 0.207 & 0.144 \\
\hline \multicolumn{5}{|c|}{ Share of children under five, height-for-age (stunting) $<2$ StDev } \\
\hline all & 0.366 & 0.436 & 0.427 & 0.343 \\
\hline urban & 0.253 & 0.259 & 0.257 & 0.242 \\
\hline rural & 0.424 & 0.471 & 0.461 & 0.372 \\
\hline \multicolumn{5}{|c|}{ Infant mortality per 1,000 live births } \\
\hline all & 108 & 109 & n.a. & n.a. \\
\hline urban & 76 & 67 & 70 & 61 \\
\hline rural & 113 & 113 & 95 & 81 \\
\hline \multicolumn{5}{|c|}{ Under-five mortality per 1,000 live births } \\
\hline all & 205 & 224 & n.a. & n.a. \\
\hline urban & 148 & 129 & 136 & 104 \\
\hline rural & 214 & 235 & 202 & 156 \\
\hline
\end{tabular}

Notes: Stunting and wasting have been computed using the raw data that can be downloaded from the DHS webpage. The new 2006 standard has been used for all years, such that the indicators are fully comparable over time. Mortality rates are taken from the published survey reports.

Source: Own computations based on DHS $(1993,1998,2003,2010)$ and officially published survey reports (INSD 1994, 2000b, 2004, 2012b)

of poverty of less than -0.6 per cent. This is very low by international standards and means that Burkina Faso may still need a long time to eradicate poverty. In fact, a doubling of the population since 1985, in conjunction with rapid urbanization and the absence of any substantial structural change to the economy, leaves the country today with about 6.5 million people below the poverty line; this is about 1 million more than in 1994. Agricultural growth was almost uniquely generated through land expansion and more labour, and not much through modernization and the adoption of new technologies, such as irrigation, machinery, and improved seeds. In urban areas, per capita growth was hindered by a massive population influx which, however, was not accompanied by any form of industrialization or significant creation of jobs in the formal sector. Although those who migrated improved their income position relative to those who stayed in the countryside, overall there has been hardly any increase in real earnings within the urban informal economy.

Due to the limited growth in agricultural productivity, in conjunction with high population growth, food prices increased continuously. We show that food price inflation not only eroded the purchasing power of the poor, but seems to have temporarily also increased malnutrition and premature mortality. To some extent Burkina Faso fits what Galor and Weil (2000) call the postMalthusian equilibrium, which is characterized by high demographic and 
low economic growth. In Galor and Weil's model this equilibrium is unstable. If educational investments and technology adoption take off, a country can switch to a modern growth regime. If not, it risks falling back into the Malthusian low equilibrium. Since Burkina Faso can hardly expand the amount of its cultivable land further (on the contrary, land is becoming scarce and much land is becoming infertile due to the extensive use of fertilizers in cotton production), and given the decline of the cotton sector (partly due to a less favourable international environment and also to a degradation of soils) and the lack of any substantial industrialization, population growth can fully unfold its adverse effects. Without substantial change, the country will not be in a position to absorb the 0.3 to 0.5 million men and women that enter the labour force each year. If change can be made, the country has a chance to turn the demographic burden into a demographic gift.

More generally, this study hopes to contribute to the general debate on poverty trends in SSA. We identified (endogenous) food price inflation as a major driver of poverty. Obviously, its adverse effects on the poor would have remained largely unnoticed if we had, as in Pinkovskiy and Sala-i-Martin (2014), used an approach that uniquely focuses on GDP, GDP deflators, and nominal expenditure distributions. This is also true for all approaches that focus on asset ownership, as for instance in Young (2012), since these approaches ignore shifts in relative prices-the fact that in many regions food becomes more and more expensive relative to durables. This makes it unlikely that the income elasticity of asset demand stays constant over longer periods of time.

\section{References}

Arze del Granado, J. and I. Adenauer (2011). 'Burkina Faso: Policies to Protect the Poor from the Impact of Food and Energy Price Increases', IMF Working Paper 11/202. Washington, DC: International Monetary Fund.

Besley, T. and L. J. Cord (2007). Delivering on the Promise of Pro-poor Growth: Insights and Lessons from Country Experiences. Washington, DC: Palgrave Macmillan and World Bank.

Datt, G. and M. Ravallion (1992). 'Growth and Redistribution Components of Changes in Poverty Measures: A Decomposition with Applications to Brazil and India in the 1980s', Journal of Development Economics, 38: 275-95.

Foster, J. E., J. Greer, and E. Thorbecke (1984). 'A Class of Decomposable Poverty Measures', Econometrica, 52: 761-76.

Galor, O. and D. N. Weil (2000). 'Population, Technology, and Growth: From Malthusian Stagnation to the Demographic Transition and Beyond', American Economic Review, 90(4): 808-28. 
Gräb, J. and M. Grimm (2011). 'Inequality in Burkina Faso: To What Extent Do Household, Community and Regional Factors Matter?', Journal of the Royal Statistical Society: Series A (Statistics in Society), 174(3): 759-84.

Grimm, M. (2011). 'Does Household Income Matter for Children's Schooling? Evidence for Rural Sub-Saharan Africa', Economics of Education Review, 30(4): 740-54.

Grimm, M. and I. Günther (2004). 'How to Achieve Pro-Poor Growth in a Poor Economy: The Case of Burkina Faso'. Report prepared for the 'Operationalizing Pro-Poor Growth' project sponsored by the World Bank, DFID, AFD, GTZ, and KFW. Eschborn: GTZ.

Grimm, M. and I. Günther (2007a). 'Growth and Poverty in Burkina Faso: A Reassessment of the Paradox', Journal of African Economies, 16: 70-101.

Grimm, M. and I. Günther (2007b). 'Pro-Poor Growth in Burkina Faso: The Role of Price Shocks', in M. Grimm, A. McKay, and S. Klasen (eds), Determinants of Pro-Poor Growth: Analytical Issues and Findings from Country Cases. London: Palgrave Macmillan, 135-63.

Günther, I. and M. Grimm (2007). 'Measuring Pro-Poor Growth When Relative Prices Shift', Journal of Development Economics, 82(1): 245-56.

INSD (Institut National de la Statistique et de la Démographie) (1994). Enquête de Démographie et de Santé 1993. Burkina Faso: INSD.

INSD (1997). EPI: Profil de la Pauvreté au Burkina Faso. Burkina Faso: INSD.

INSD (2000a). EPII: Profil et Évolution de la Pauvreté au Burkina Faso. Burkina Faso: INSD. INSD (2000b). Enquête de Démographie et de Santé 1998-99. Burkina Faso: INSD.

INSD (2003). Analyse des Résultats de l'Enquête Burkinabè sur les Conditions de Vie des Ménages. Burkina Faso: INSD.

INSD (2004). Enquête de Démographie et de Santé 2003. Burkina Faso: INSD.

INSD (2007). Analyse des Analyse des Résultats de l'Enquête Annuelle sur les Conditions de Vie des Ménages en 2007. Burkina Faso: INSD.

INSD (2012a). Burkina Faso DHS, 2010_Final Report. Burkina Faso: INSD.

INSD (2012b). Enquête de Démographie et de Santé 2010. Burkina Faso: INSD.

IMF (International Monetary Fund) (2012). 'Burkina Faso: Strategy for Accelerated Growth and Sustainable Development 2011-2015', Country Report 12/123. Washington, DC: IMF.

Kaminski, J. (2011). 'Cotton Dependence in Burkina Faso: Constraints and Opportunities for Balanced Growth', in P. Chuhan-Pole and M. Angwafo (eds), Yes Africa Can: Success Stories from a Dynamic Continent. Washington, DC: World Bank, 107-24.

Kaminski, J., C. D. Headey, and C. T. Bernard (2010). 'Institutional Reform in the Burkinabè Cotton Sector and its Impact on Incomes and Food Security: 1996-2006', in D. Spielman and R. Pandya-Loch (eds), Technical Compendium of the 'Millions Fed' Project. Washington, DC: IFPRI, 317-48.

Ministry of Finance and Economic Affairs (2000). Burkina Faso: Poverty Reduction Strategy Paper. Burkina Faso: Ministère de l'Economie et des Finances.

Pinkovskiy, M. and X. Sala-i-Martin (2014). 'Africa Is On Time', Journal of Economic Growth, 9(3): 311-38.

Wetta, C., S. Kaboré, L. Kibora, A. Nikièma, M. Koné, M. Kondé, M.-E. Malgoubri, P. M. F. Zida, A. Sawodogo, and H. Ouedraogo (2011). Pauvreté Chronique et Transitoire 
au Burkina Faso: Une Analyse de La Dynamique à Partir de Données Agricoles. Manchester: Chronic Poverty Research Centre, University of Manchester.

Wodon, Q., C. Tsimpo, P. Backiny-Yetna, G. Joseph, F. Adoho, and H. Coulombe (2008). 'Potential Impact of Higher Food Prices on Poverty: Summary Estimates for a Dozen West and Central African Countries', Policy Research Working Paper 4745. Washington, DC: World Bank.

World Bank (2004). 'Burkina Faso: Reducing Poverty through Sustained Equitable Growth. Poverty Assessment', PREM 4, Africa Region, Report 29743-BUR. Washington, DC: World Bank.

World Health Organization (WHO) (2009). WHO Child Growth Standards and the Identification of Severe Acute Malnutrition in Infants and Children. A Joint Statement by the World Health Organization and the United Nations Children's Fund. Geneva: WHO.

Young, A. (2012). 'The African Growth Miracle', Journal of Political Economy, 120(4): 696-739. 


\title{
9
}

\section{Mozambique}

\section{Off-track or Temporarily Sidelined?}

\author{
Channing Arndt, Sam Jones, and Finn Tarp
}

\subsection{Introduction}

The past four decades in Mozambique have been tumultuous by almost any standard. Unlike many African countries that gained independence during the 1960s, the struggle in Mozambique for political independence from the colonial Portuguese power lasted until 1974. The decade prior to independence was marked by increasing violence coexisting with a policy of settlement on the part of the Portuguese. Independence occurred following the Carnation Revolution in Portugal and the subsequent decision to withdraw support to the colonies. Once in power in Mozambique, the ruling Frelimo party initiated a Marxist economic and social regime. Simultaneously, a mass exodus of nearly all of the approximately 200,000 Portuguese settlers removed the vast bulk of skilled people. While macroeconomic collapse was avoided during the second half of the 1970s, the limitations of the collectivist economic strategy became increasingly evident. Before alternative policies could be put in place, armed struggle broke out with the National Resistance Movement of Mozambique (Renamo) in the early 1980s, strongly abetted by the racist regimes in Rhodesia (now Zimbabwe) and South Africa.

The war that ensued was brutal and lasted for a decade. During the 1980s, more than 1 million people were killed and about 5 million displaced. The stresses of war, including the difficulties in enacting economic reforms under a wartime footing, led inexorably to economic collapse, in spite of the signing of the Nkomati Accord with South Africa in 1984. In 1986, Mozambique formally embarked on an Economic Rehabilitation Programme controlled by the Bretton Woods institutions. However, without peace, few 
reforms were actually possible. Coincident with the release of Nelson Mandela from prison in 1990, peace talks began in earnest and culminated with the signing of a peace agreement in 1992. This was followed by general elections in 1994, when the Frelimo party took firm control, and by the fairly rapid implementation of an essentially standard structural adjustment programme.

In the more than two decades that have passed since democratic elections ushered in a new era in Mozambique, a great deal has been accomplished with nearly all development indicators registering improvements-often substantial—relative to the miserable levels posted in the mid-1990s. Headline economic growth has been among the most rapid in the world; enormous efforts have been made in improving access to education with complete primary education now in sight; and infant mortality rates have declined dramatically from about 175 deaths per 1,000 live births in 1975 to about 70 deaths per 1,000 live births in 2011. Moreover, the inherent potential for Mozambique to continue to register rapid economic and social progress is large. Recent major natural resource finds expand the possibilities set.

In this chapter, we assess whether Mozambique is on- or off-track. Section 9.2 focuses on the record from the mid-1990s to about 2009. This period saw three major efforts to take stock of living conditions and to relate those to trends in the macro economy. Section 9.3 synthesizes the available information and notes that a reasonably coherent picture emerges from the record presented in section 9.2. Unfortunately, perspectives from 2009 to the present are less clear due in particular to a lack of comprehensive data on how the fruits of continued rapid economic growth are being distributed. Nevertheless, the final section 9.4 considers recent economic and social trends drawing from the available information base and provides some perspectives looking forward.

\subsection{The Record from the mid-1990s to 2009}

\subsubsection{Growth and Monetary Measures of Poverty}

As noted in the Introduction, economic growth has been rapid at approximately 7 per cent per annum since 1994 . At this rate, the volume of goods and services produced domestically at the end of 2014 would be about four times greater than the (low) levels achieved in 1994. This expansion is spread across a larger population. The 1997 and 2007 censuses estimated the population at about 16.9 and 21.8 million respectively, implying a population growth rate of about 2.5 per cent per annum. In addition, a share of the GDP growth has been concentrated in highly capital-intensive activities (such as aluminium production and gas extraction) with substantial foreign ownership and very light tax burdens. These activities influenced the headline macroeconomic 
statistics during the 1996/2009 years, but had very limited implications for the living standards of the population. If we accept that about one percentage point of growth has been related directly to these island sectors, we end up with a rough estimate of per capita growth in GNP of around 3.5 per cent per annum. This implies, in turn, a rough doubling of goods and services produced whose incomes accrue to Mozambican nationals over the twenty-year period from 1994 to 2014.

With increased production, one would expect increased consumption, and this is indeed observed. Data on consumption patterns, growth, and distribution are derived principally from household budget surveys. Three major surveys have been undertaken: 1996/7, 2002/3, and 2008/9. A fourth survey, 2014/15, is currently in the field (Ministry of Planning and Finance/DNPO 1998, 2004; Ministry of Planning and Development/DNEAP 2010). These surveys are employed for a vast array of purposes including rebasing national accounts and estimation of inequality. However, they are designed principally for the estimation of absolute poverty rates. Table 9.1 presents the official headcount results for consumption poverty at the national level and for rural and urban zones.

The story from $1996 / 7$ to $2002 / 3$ is reasonably straightforward. Economic growth was accompanied by a substantial reduction in consumption poverty. About 15 per cent of the population passed from poor to non-poor status. Gains occurred in both rural and urban zones and the gains in rural zones were somewhat more pronounced. Consistent with the poverty, growth, and inequality triangle of Bourguignon (2004), measured inequality remained roughly constant.

Furthermore, as documented in the second national poverty assessment (Ministry of Planning and Finance/DNPO 2004), this reasonably welldistributed GDP and consumption growth occurred in tandem with improvements across a large array of measures, including real agricultural incomes, estimated production levels, anthropometrics, child mortality rates, and a

Table 9.1. Official consumption poverty headcounts

\begin{tabular}{|c|c|c|c|c|c|}
\hline & & & & \multicolumn{2}{|c|}{ Difference (\% points) } \\
\hline & \multicolumn{3}{|c|}{ Levels (\%) } & $1996 / 7$ to & $2002 / 3$ to \\
\hline & $1996 / 7$ & $2002 / 3$ & $2008 / 9$ & $2002 / 3$ & $2008 / 9$ \\
\hline National & 69.4 & 54.1 & 54.7 & -15.3 & 0.6 \\
\hline Urban & 62.0 & 51.5 & 49.6 & -10.5 & -1.9 \\
\hline Rural & 71.3 & 55.3 & 56.9 & -16 & 1.6 \\
\hline
\end{tabular}

Source: Ministry of Planning and Finance/DNPO (1998, 2004); Ministry of Planning and Development/ DNEAP (2010) 
variety of social indicators. These improvements are all relative to the very low levels observed in the mid-1990s. Hence, the progress realized reflects some combination of a development process coming into place and a natural snapback from the deeply depressed conditions prevailing in the immediate postwar period.

The next period, from 2002/3 to 2008/9, presents a different story. Even though published GDP growth rates continued at roughly similar rates, no progress was realized in reducing absolute consumption poverty rates. With increasing population, this implies a growing number of absolutely poor people. Stagnation occurred in both urban and rural zones though the point estimate declines in the urban zone and increases in the rural. None of these changes is statistically significant. Furthermore, inequality, measured in exactly the same way as in 1996/7 and 2002/3, again remained essentially constant. Hence, at face value, the growth, poverty, and inequality triangle presents a conundrum. More is being produced and the measured distribution of consumption remains constant; yet the poverty rate is not declining. ${ }^{1}$ Section 9.3 is dedicated principally to analysing this conundrum. Before considering this, we present non-monetary measures of welfare with a focus on the $2002 / 3$ to $2008 / 9$ period.

\subsubsection{Non-monetary Poverty Measures}

\subsubsection{ASSETS}

The quality of a household's shelter or housing is a widely accepted indicator of material wealth. Housing often represents the single largest category (by value) of investments in durable assets made by individuals over the course of their lifetime. Households will often need to save or access credit facilities in order to make housing investments, meaning that such investments typically reflect a temporal dimension of material well-being. Thus, they are a reasonable proxy for longer-run income (typical/average individual income). Crude differences in housing quality are also relatively easily observed, making them less prone to measurement error.

Table 9.2 reports changes over time in four measures of housing quality. Each measure is represented as a dummy variable, which takes the value of one if a household's home has the characteristic indicated and zero otherwise. Accordingly, the average of such a dummy variable for a population subgroup gives the share of households in that group with that characteristic. The results show that, on average, all characteristics of housing improved from

\footnotetext{
1 Poverty gap measures stagnate as well, indicating that the mean distance to the poverty line for those living below it has also remained roughly constant.
} 
Table 9.2. Indicators of housing quality, 2002/3 and 2008/9, percentage of households

\begin{tabular}{|c|c|c|c|c|c|c|c|c|}
\hline & \multicolumn{2}{|c|}{ Durable roofing } & \multicolumn{2}{|c|}{ Durable walls } & \multicolumn{2}{|c|}{ Electric lighting } & \multicolumn{2}{|c|}{ Toilet/latrine } \\
\hline & IAF02 & IOF08 & IAF02 & IOF08 & IAF02 & IOF08 & IAF02 & IOF08 \\
\hline National & 25.8 & 30.2 & 14.2 & 17.9 & 6.9 & 13.3 & 11.2 & 16.0 \\
\hline Urban & 57.8 & 65.6 & 36.9 & 43.2 & 21.7 & 41.8 & 32.5 & 41.6 \\
\hline Rural & 12.2 & 15.6 & 4.5 & 7.5 & 0.6 & 1.6 & 2.1 & 5.5 \\
\hline
\end{tabular}

Note: IAF02 = 2002/3 Budget Survey; IOF08 = 2008/9 Budget Survey

Source: Ministry of Planning and Development/DNEAP (2010) using data from the 2002/3 and 2008/9 budget surveys

$2002 / 3$ to 2008/9. The share of families that have roofs made of a durable material (concrete, zinc, or fibrous cement) increased by 4.4 percentage points, and the share using electricity, a generator, or solar energy for lighting almost doubled from 6.9 per cent to 13.3 per cent of households.

It bears emphasizing that, while the trends in housing are positive, the levels remain low. Nationally, 65 per cent of the population in 2008/9 reported living in housing with none of the four improvements in focus in Table 9.2 (down from 71 per cent in 2002/3). It is also useful to look at patterns of ownership of durable consumer goods. These typically represent lumpy investments that require a minimum level of income to purchase and sustain (for example, batteries to play a radio). Again, measures of this kind incorporate a temporal dimension to material well-being that may not be fully reflected in the consumption poverty measures.

Table 9.3 summarizes trends in ownership for eight different goods, differentiated by urban and rural areas. Figure 9.1 then plots the average number of these goods owned by each household (ranging from zero to eight), which represents a simple composite non-monetary poverty indicator. Whichever way one looks, the trends are unambiguously positive. Perhaps the only exception is ownership of radios in urban areas; however, this is offset by the large increase in ownership of TVs and phones (driven by cell phones), which suggests some substitution between these goods.

Four more specific points can be made. First, as with housing, while the trends are positive, the levels are low, particularly in rural areas. Rural households owned, on average, about 1.36 goods in 2008/9. Not surprisingly, the use value of durable goods represents a small share of total consumption with a median value of about 1.2 per cent in rural areas and 3.1 per cent in urban areas in $2008 / 9$. The small number of durables available, particularly to rural households, and their relatively small value illustrate the limits of consumer durable ownership as a reliable indicator of welfare as well as the limits of asset sales as a means to smooth consumption. 
Table 9.3. Ownership of consumer durables, 2002/3 and 2008/9, percentage of households

\begin{tabular}{|c|c|c|c|c|}
\hline & & Urban & Rural & National \\
\hline \multirow[t]{3}{*}{ Bicycle } & $2002 / 3$ & 19.4 & 31.8 & 28.1 \\
\hline & $2008 / 9$ & 24.1 & 43.8 & 38.1 \\
\hline & change & 4.7 & 12.0 & 10.0 \\
\hline \multirow[t]{3}{*}{ Car } & $2002 / 3$ & 4.3 & 0.4 & 1.6 \\
\hline & $2008 / 9$ & 5.0 & 0.6 & 1.8 \\
\hline & change & 0.7 & 0.2 & 0.3 \\
\hline \multirow[t]{3}{*}{ Motorbike } & $2002 / 3$ & 2.3 & 0.7 & 1.2 \\
\hline & $2008 / 9$ & 5.2 & 2.9 & 3.6 \\
\hline & change & 2.9 & 2.2 & 2.4 \\
\hline \multirow[t]{3}{*}{ Radio } & $2002 / 3$ & 54.9 & 41.5 & 45.5 \\
\hline & $2008 / 9$ & 47.7 & 44.9 & 45.8 \\
\hline & change & -7.1 & 3.5 & 0.3 \\
\hline \multirow[t]{3}{*}{ TV } & $2002 / 3$ & 19.5 & 0.7 & 6.3 \\
\hline & $2008 / 9$ & 35.9 & 2.8 & 12.4 \\
\hline & change & 16.4 & 2.1 & 6.1 \\
\hline \multirow[t]{3}{*}{ Telephone } & $2002 / 3$ & 13.1 & 0.5 & 4.3 \\
\hline & $2008 / 9$ & 53.7 & 11.4 & 23.7 \\
\hline & change & 40.7 & 10.8 & 19.4 \\
\hline \multirow[t]{3}{*}{ Bed } & $2002 / 3$ & 62.1 & 22.3 & 34.2 \\
\hline & $2008 / 9$ & 64.1 & 28.8 & 39.0 \\
\hline & change & 2.0 & 6.5 & 4.9 \\
\hline \multirow[t]{3}{*}{ Fridge } & $2002 / 3$ & 12.2 & 0.3 & 3.9 \\
\hline & $2008 / 9$ & 18.4 & 0.6 & 5.8 \\
\hline & change & 6.2 & 0.3 & 1.9 \\
\hline Average & change & 8.3 & 4.7 & 5.7 \\
\hline
\end{tabular}

Source: Ministry of Planning and Development/DNEAP (2010) using data from the 2002/ 3 and 2008/9 budget surveys

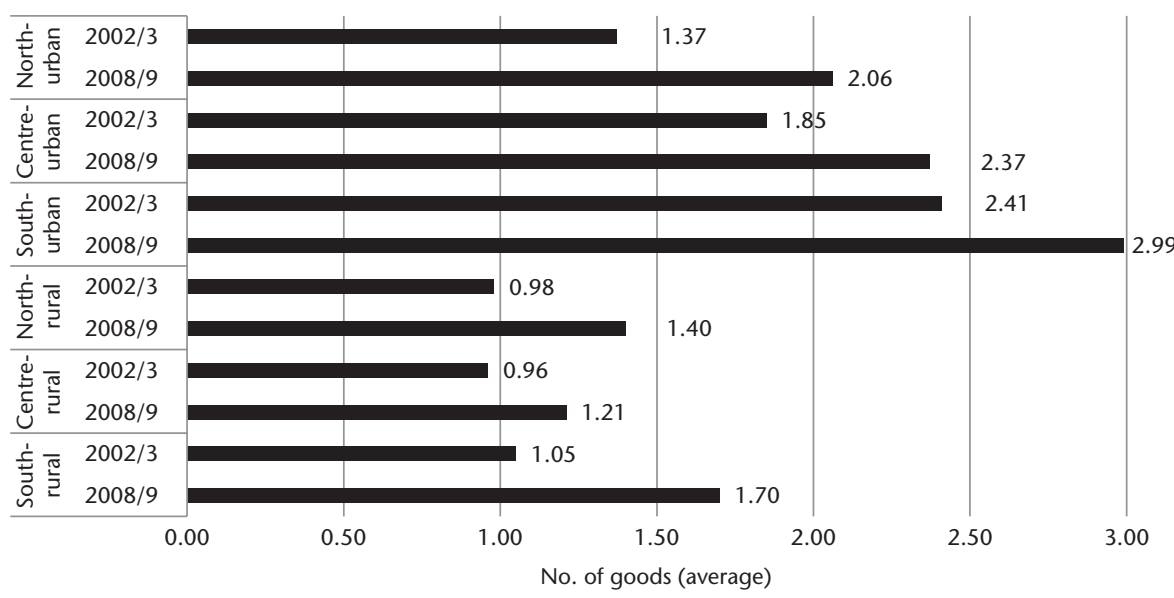

Figure 9.1. Average number of consumer goods (out of a maximum of eight) owned by households, 2002/3-8/9, by regions and rural/urban

Note: Included goods are those listed in Table 9.3.

Source: Ministry of Planning and Development/DNEAP (2010) using data from the 2002/3 and 2008/9 budget surveys 
Second, as expected, one finds much greater levels of asset ownership in urban compared to rural areas (excluding bicycles). Third, the change in the share of households owning consumer durables has been moderately larger in urban areas for many goods, contributing to a growing rural-urban divide in asset ownership, at least in absolute terms. The average number of goods owned by rural households increased from 0.98 to 1.36 (or by 0.38 ) goods over the 2002/3 to $2008 / 9$ period; in urban areas the increase was from 1.88 to 2.54 (or by 0.66 ) goods. ${ }^{2}$ Finally, we see from Figure 9.1 that the increase in ownership of consumer durables has been stronger in the south, particularly in comparison to rural parts of the central region of the country.

\subsubsection{ACCESS TO EDUCATION}

As indicated in the Introduction, Mozambique has achieved significant gains in increasing citizens' access to basic public services, especially education. Trends in this domain can be assessed using the net enrolment rate (NER). This is defined as the share of all children of official school age ${ }^{3}$ who are enrolled in a school whose official age range corresponds to the child's age. The NER gives the share of children of a given official school age enrolled at their 'expected' level.

The NER for primary schooling is shown in panel (a) of Figure 9.2, distinguished by regions and urban/rural. The NER for secondary schooling is given in panel (b). The two panels show unambiguous increases for both ratios across virtually every region. At the national level, in 2008/9 we find that 76.5 per cent of all children aged 6-13 attended primary school, up from 66.8 per cent in 2002/3. Similarly, the secondary school NER more than doubled (from a relatively low base) to 22.0 per cent from 8.2 per cent. National-level results mask even larger gains in specific areas. Access to primary schooling increased most where it was lowest, thereby reducing regional educational inequality. In the rural north, the primary NER rose to 67.5 per cent compared to 52.2 per cent in $2002 / 3$. Also, increases in the secondary NER were spectacular in rural areas; previously net enrolment rates were below 1 per cent in the rural north and centre and below 4 per cent in the south in $2002 / 3$. In 2008/9 they stood at 6.4 per cent and 17.2 per cent, respectively. The conclusion is that expansion of the school network and access to education has been impressive.

\subsubsection{ACCESS TO HEALTH SERVICES AND CLEAN WATER}

Here, we consider indicators of public health. Two indicators are employed here: (a) walking distance to the nearest primary health facility, measured in

\footnotetext{
${ }^{2}$ In terms of rate of growth, the rural rate is slightly faster than the urban rate.

${ }^{3}$ Primary school ages are 6-13 years; secondary school ages are 14-18 years.
} 
(a) Primary NER

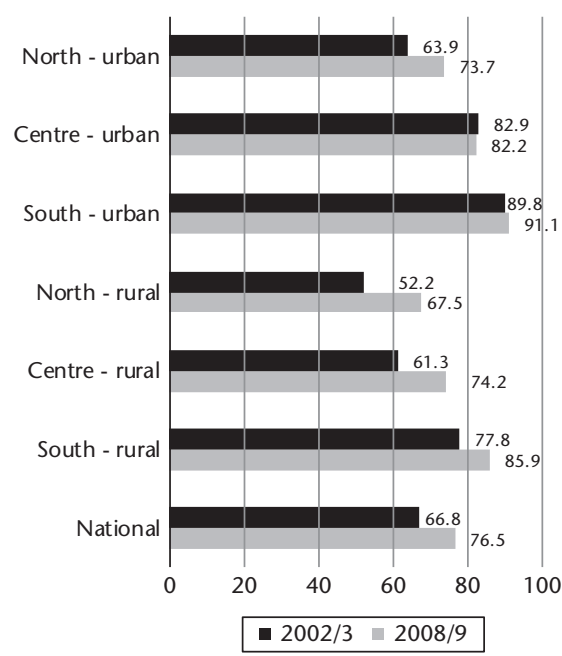

(b) Secondary NER

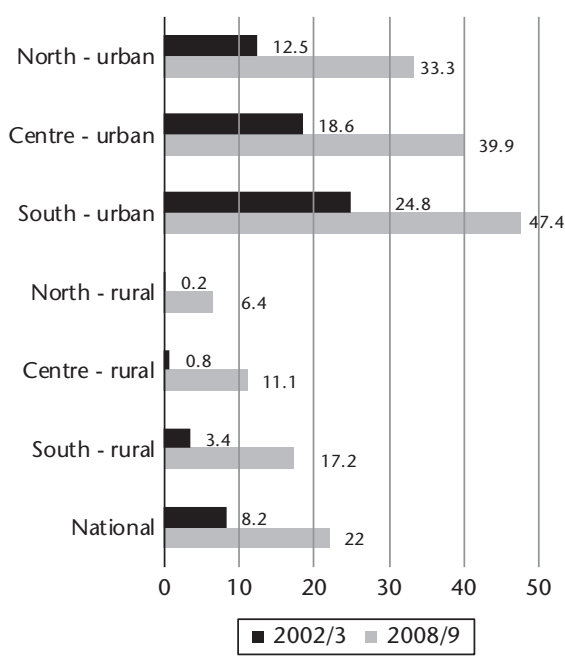

Figure 9.2. Net enrolment rates, primary and secondary schooling by region, 2002/3 and $2008 / 9$

Notes: NER is defined as the share of all children of official school age (primary: 6-13 years; secondary: 14-18 years) who are enrolled in a school whose official age range corresponds to the child's age; secondary school includes technical schools.

Source: Ministry of Planning and Development/DNEAP (2010) using data from the 2002/3 and 2008/9 budget surveys

time taken; and (b) access to a safe water source, defined as potable water of some form. Figures 9.3 and 9.4 provide summary results for these two measures, respectively.

With respect to distance to the nearest primary health facility, the most important finding is a large improvement in rural areas. In 2008/9 in the rural north, 69.7 per cent of households could access such a facility within a fortyfive-minute walk compared to only 31.5 per cent in $2002 / 3$. Access in the rural centre and south also improved, though not quite so quickly. Interestingly, access in urban areas to primary health facilities appears to have worsened, as a slightly smaller share of households report they were able to reach a facility on foot within forty-five minutes. This may be due to a number of factors such as urbanization, with higher population growth in the periphery of cities where access to public facilities is lower; and a greater reliance on hospitals and other medical facilities in urban areas, reducing demand for basic primary facilities.

Evidence concerning access to safe water is probably the least impressive of the non-monetary indicators. As Figure 9.4 shows, the only unambiguous increase in access to safe water occurred in the urban south, where access 


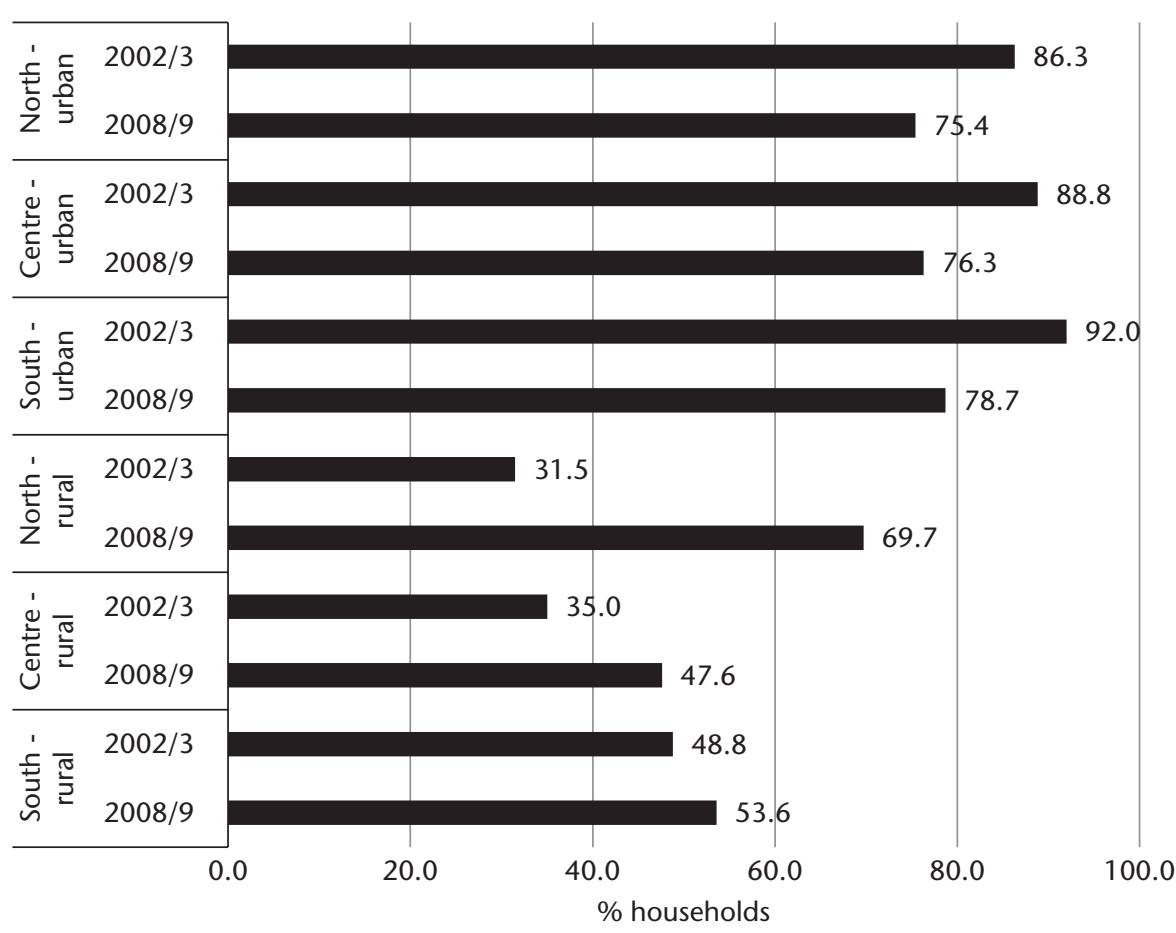

Figure 9.3. Share of households with less than forty-five minutes' walk to nearest primary health facility, 2002/3 and 2008/9

Source: Ministry of Planning and Development/DNEAP using the 2008/9 and 2002/3 budget surveys

was already relatively good. In 2008/9, less than one-third of all households in the rural centre and rural north of the country had access to a safe water source.

\subsubsection{ANTHROPOMETRIC MEASURES OF WELL-BEING}

This subsection examines the well-being of the population from the point of view of the nutritional status of children under five years old. The risks and implications of poor nutrition are particularly critical for young children, as nutritional deficiencies can exert a strong influence on their subsequent growth and development. Assessing the nutritional status of children is a first step in fighting against malnutrition and is an important broad indicator of well-being. In addition to the 2008/9 household survey, a number of previous studies provide useful information about the nutritional status of children. These include: (a) the 1996/7 household budget survey (IAF96), which included a survey of anthropometric data; 


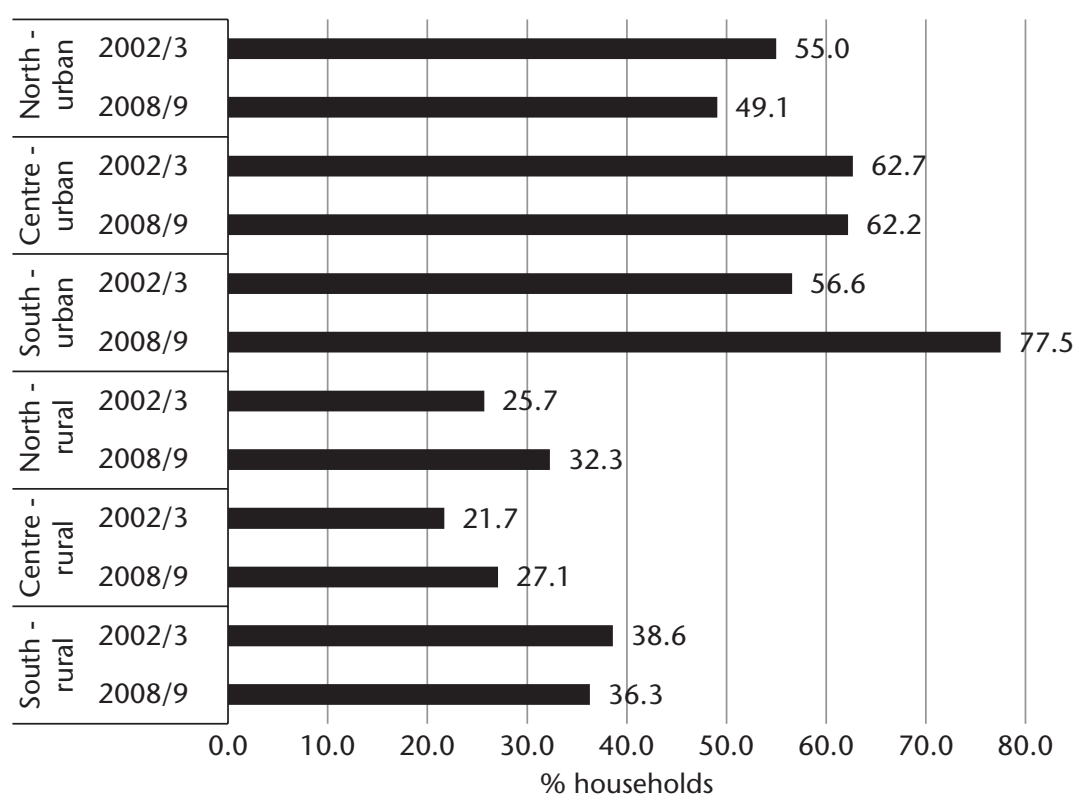

Figure 9.4. Share of households with access to a safe water source, 2002/3 and 2008/9 Source: Ministry of Planning and Development/DNEAP using the 2008/9 and 2002/3 budget surveys

(b) the 2003 Demographic and Health Survey (DHSO3); and (c) the 2008 Multiple Indicator Cluster Survey (MICS08). In general, these studies indicate that the prevalence of malnutrition in Mozambique decreased slowly over time; yet remains high in absolute terms. These trends are illustrated in Figure 9.5.

The jump in malnutrition between the MICS08 and the IOF08 is notable even though portions of the two surveys were in the field contemporaneously. The increase might be indicative of a generally less well-off sample selected in IOF2008/9, which might help explain the stagnation in consumption poverty rates shown in Table 9.1. To test this, we consider only households surveyed during the same period of 2008 (the MICS was conducted between September and November 2008 while IOF ran from September 2008 to August 2009). The results are shown in Figure 9.6. It indicates much smaller differences between the national averages for the three indicators. While the full sample stunting rate for IOF08 is 46.4, the rate for the comparable sample period is 44.7. If the September to November 2008 malnutrition indicators from IOF08 are lower than the full sample average, this implies that the December 2008 to August 2009 malnutrition indicators must be higher than the full sample average. 


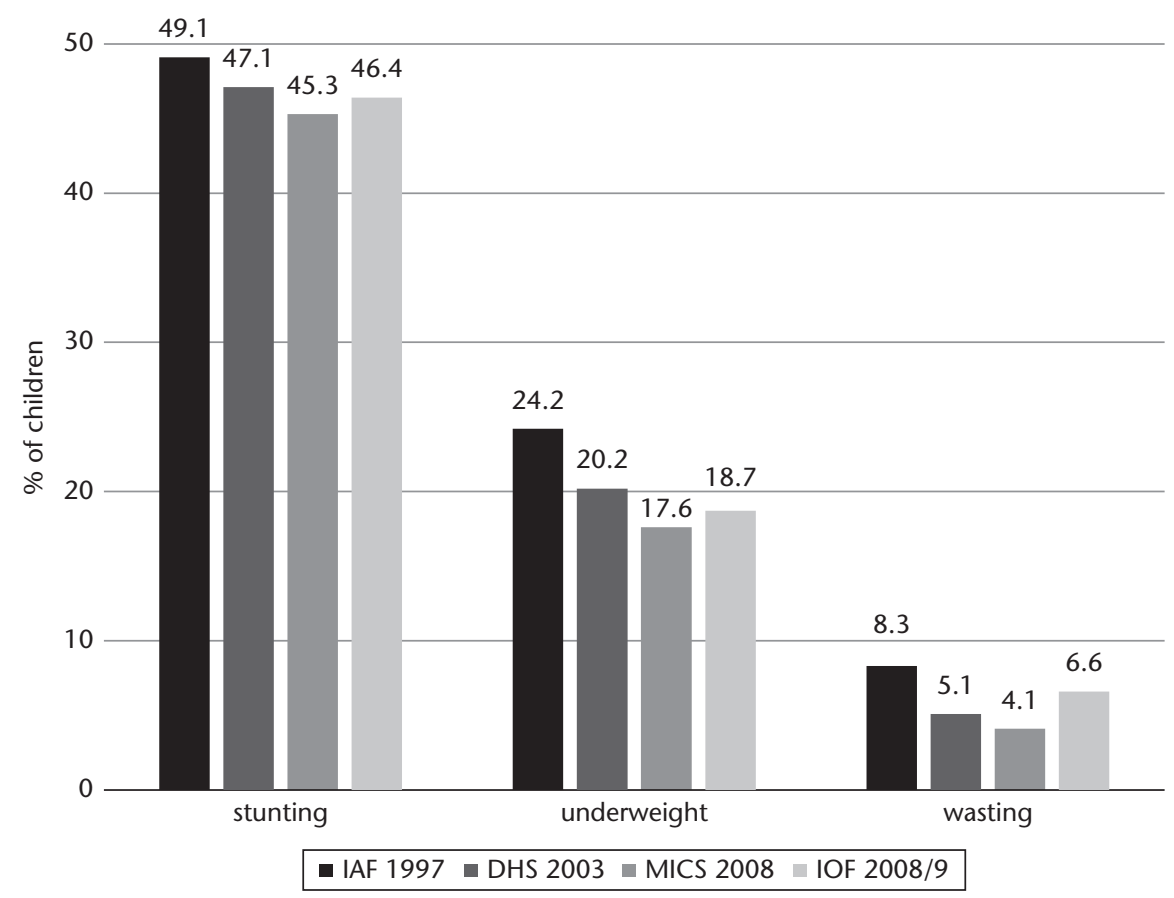

Figure 9.5. Trends in malnutrition across surveys, percentage of infants, 1996/7-2008/9 Source: Ministry of Planning and Development/DNEAP (2010) using data from the 1996/7 and 2008/9 budget surveys as well as 2003 Demographic and Health Survey (National Institute of Statistics 2005) and the 2008 Mixed Indicators Cluster Survey (MICS) (National Institute of Statistics 2009)

\subsection{Macroeconomic Consistency}

\subsubsection{Basic Accounts}

A principal concern is whether the story that emerges with respect to trends in consumption poverty can be squared with other macroeconomic variables. As discussed, the official statistics point to economic growth and a steady distribution of consumption in combination with no poverty reduction. The fundamental issues can be considered using two basic macroeconomic accounting identities.

$$
\begin{gathered}
C+I+G+X-M=G D P \\
A b s=C+I+G=G D P+M-X
\end{gathered}
$$

The standard GDP identity using an expenditure optic shown in equation (9.1) can be reformulated to illustrate the definition of absorption. This is the 


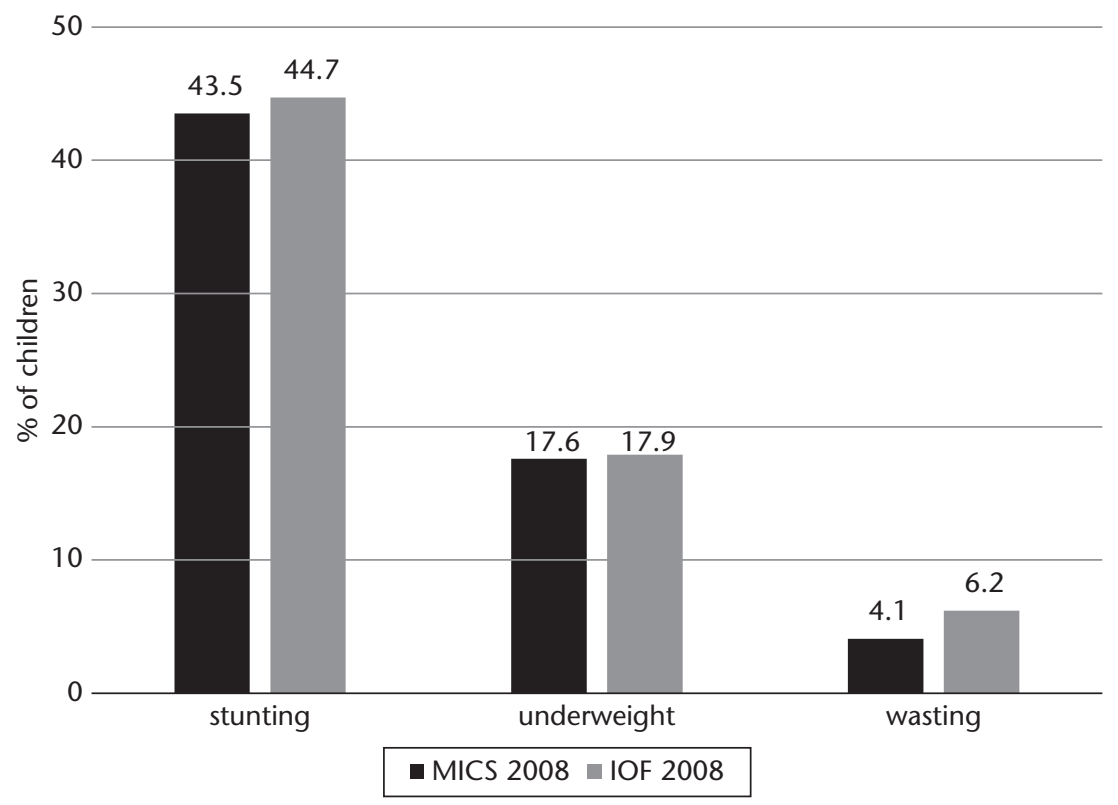

Figure 9.6. Comparison of malnutrition in IOF08 and MICS08 for survey overlap period, percentage of infants

Source: Ministry of Planning and Development/DNEAP (2010) using data from the 2008/9 budget survey and the 2008 Mixed Indicators Cluster Survey (National Institute of Statistics 2009)

broadest-based measure of economic welfare in the economy. Thinking in real terms, the identity in equation (9.2) states that real use of goods and services (Abs=absorption) divides itself into three components: consumption (C), investment (I), and government $(\mathrm{G})$. The sum represents total usage of goods and services in the economy, which must equal the amounts available. Goods and services are produced domestically (GDP) and imported (M). Exports (X) are subtracted from this total.

From equation (9.2), one can identify a series of possible reasons why the poverty, growth, and inequality triangle of Bourguignon (2004) might not hold for Mozambique based on published data. They include:

(a) GDP growth is not as rapid as stated in national accounts. There are actually fewer goods to distribute.

(b) GDP growth is not translating proportionally across the components of absorption. So, consumption, government, and investment are growing at different rates. Rapid GDP growth might be translating into even more rapid growth in investment and government and consequently less growth in consumption. 
(c) The real trade balance shifts such that the volume of imports declines relative to the volume of exports. A decline in the terms of trade would have this effect.

(d) The inequality estimates are incorrect. The distribution of consumption is in fact worsening.

(e) The poverty estimates are incorrect. There should be more poverty reduction than the estimates suggest.

\subsubsection{Consumption Poverty Headcount Estimates}

Let us begin with the last of the possible explanations-the consumption poverty rate estimates should be lower in 2008/9 and/or higher in 2002/3. A great deal of effort has been expended in examining the relevant consumption data in order to corroborate (or not) the official estimates cited above. As illustrated by Alfani et al. (2012), it is possible to employ a method for estimating poverty that generates a decline in poverty over the $2002 / 3$ to $2008 / 9$ period. However, the fundamental result of a rapid decline in poverty rates between 1996/7 and 2002/3 and then a substantial slowdown in the 2002/3 to 2008/9 period remain. In addition, the regional pattern of the slowdown, particularly measured increases in poverty rates in rural provinces in the centre of the country, are present in all analyses conducted to date. We now turn to the remaining four possibilities listed in section 9.3.1 to consider whether those factors alone can explain the observed stagnation in poverty rates over the more recent $2002 / 3$ to $2008 / 9$ period.

\subsubsection{GDP Growth}

Issues with GDP growth calculations begin with agriculture. Before going to growth, it is necessary to highlight the importance of agricultural production for the well-being of the majority of Mozambican households. According to the 2008/9 budget survey, 70 per cent of households are located in rural areas and virtually all of these (96 per cent) are engaged in agriculture in some way, with the vast majority of these pointing to agriculture as their principal livelihood. As shown in Jones and Tarp (2013), agriculture represents the principal occupation of a plurality of urban households. Additionally, consumption of food accounts for two-thirds or more of total consumption of poor households. These figures are essentially unchanged compared to 2002/3 and suggest a strong relationship between trends in agriculture and aggregate trends in poverty reduction.

On this basis, the series of Agricultural Surveys (Trabalhos de Inquérito Agricola, TIAs) provides an important complement to the household budget 
surveys (Ministry of Agriculture/DE 2010). Official estimates from the series of TIAs have been published by the Ministry of Agriculture. The TIAs are based on outcomes as reported by large, representative samples of households. As such, they represent the most consistent and rigorous database of production by agricultural households over time. Full TIAs were conducted in 1996, 2002, 2005, and 2008. They attempt to estimate total household income for the production year. Limited TIAs, which focus on agricultural production, were conducted focusing on the harvests of 2003, 2006, and 2007.

For the period 2002-8, four main findings from the TIAs can be highlighted. First, the TIAs confirm the continued importance of agriculture for households' well-being. From 2002 to 2008 the number of small- and medium-sized farms grew by 19 per cent, consistent with population growth, and the area under cultivation grew by 34 per cent. Importantly, however, the vast majority of farms are small-the average size is around 1.5 hectares, with many farms operating on one hectare or less. Second, all indicators concerning access to and use of productivity-enhancing inputs, such as pesticides and fertilizers, are at very low levels and show no unambiguously positive trends. From 2002 to 2008 the share of farming households receiving extension information declined from 13.5 per cent to 8.3 per cent. Similarly, use of pesticides fell from 6.8 per cent to 3.8 per cent. The point estimate for the share of farms using chemical fertilizer rose slightly from 3.8 per cent in 2002 to 4.1 per cent in 2008. Only about one in thirty-five farm households received credit of any sort (Ministry of Planning and Development/DNEAP 2010) with no discernible trend over the period. In short, all productivity indicators were at best stuck at very low levels over the period with some showing negative trends.

Third, consistent with stagnation in technology trends, agricultural production shows only weak growth on aggregate. Per capita production of all the principal staple crops (for example, maize, sorghum, cassava, rice) was lower in 2008 than in 2002 (Ministry of Planning and Development/DNEAP 2010). Table 9.4 provides aggregated figures for staple food crop production, calculated using caloric values of the individual crops as weights. ${ }^{4}$ These caloric values remain constant over time and can be used to derive a total production index. When calculated on a per capita basis, the total calorie value of staple crop production has been at best stagnant and possibly falling. For example, total calorie availability per person per day was 2,000 calories in 2008 compared to 2,135 in 2002 (based on national agricultural production alone). These mild declines in per capita staple food production are highly consistent with the national picture of stagnant rural poverty over the same period.

\footnotetext{
${ }^{4}$ The caloric values are the same as those used in the household survey analysis and are based on internationally recognized benchmarks.
} 
Table 9.4. Aggregate production trends for food crops

\begin{tabular}{|c|c|c|c|c|c|c|c|c|}
\hline $\begin{array}{l}\text { Aggregate measures } \\
\text { (using calories) }\end{array}$ & 2002 & 2003 & 2005 & 2006 & 2007 & 2008 & $\begin{array}{l}\text { Change } \\
2002-8\end{array}$ & $\begin{array}{l}\text { Coeff. of } \\
\text { variation }\end{array}$ \\
\hline $\begin{array}{l}\text { Total production } \\
\text { index }\end{array}$ & 100.0 & 124.2 & 111.3 & 140.9 & 128.6 & 113.8 & 13.8 & 12.1 \\
\hline Productivity (kcal/ha) & 2,307 & 2,643 & 1,935 & 2,424 & 2,189 & 1,961 & -15.0 & 12.2 \\
\hline $\begin{array}{l}\text { Calories per person/ } \\
\text { day }\end{array}$ & 2,135 & 2,583 & 2,103 & 2,717 & 2,422 & 2,000 & -6.3 & 12.5 \\
\hline
\end{tabular}

Source: Ministry of Planning and Development/DNEAP (2010)

Table 9.5. Total maize production by data source (thousands of tonnes)

\begin{tabular}{llrc}
\hline & TIA/AE & FAOStat & \% Difference \\
\hline 2002 & 1,115 & 1,115 & $0.0 \%$ \\
2003 & 1,181 & 1,179 & $-0.2 \%$ \\
2004 & NA & 1,060 & \\
2005 & 942 & 942 & $0.1 \%$ \\
2006 & 1,396 & 1,418 & $1.6 \%$ \\
2007 & 1,134 & 1,582 & $39.5 \%$ \\
2008 & 1,214 & 1,676 & $38.1 \%$ \\
2009 & NA & 1,612 & \\
2010 & NA & 2,090 & \\
2011 & NA & 2,179 & $0.0 \%$ \\
2012 & 1,177 & 1,177 & $35.1 \%$ \\
2013 & 1,207 & 1,631 & \\
\hline
\end{tabular}

Source: Ministry of Agriculture/DE (2010), National Institute of Statistics (2014, 2013, and 2012), and Food and Agriculture Organization (2015)

An additional point is one of production volatility. The last column of Table 9.4 reports the coefficient of variation, which is the standard deviation of the series of annual values divided by their mean. It indicates the expected change per year as a percentage of the average value. Total calorie availability (per person/day) can be expected to vary by 12 per cent from one year to the next. Production volatility is much larger at the regional level given that differential regional performances offset each other to some extent, leading to smoother national trends. Large variability in agricultural production is an indicator (among many) of the high level of vulnerability of rural populations.

Despite these repeated findings from the TIA surveys and despite the massive weight of the family sector and food in overall agricultural production, national accounts estimated growth in agricultural value added (agricultural GDP at factor cost) at 7.9 per cent per annum from 2003 to 2009 . Outside observers can be excused for falling into massive confusion over this statistical disconnect. Table 9.5 provides some insights into the issues by illustrating comparisons of maize production statistics between TIAs, which have recently 
been the official source for agricultural production data as published in the Statistical Yearbook and an international data site-in this case, FAOStat.

In a nutshell, up until about 2008, official agricultural statistics relied upon data obtained from the food security unit located within the agriculture ministry. This unit was set up in the immediate post-war period and essentially employed rapid appraisal-type techniques to estimate agricultural production. These data became the official source of data for agriculture by force of the fact that there was no alternative. From 1996, these data coexisted with data from the TIAs for the years when the TIAs went into the field. From about 2002, reasonably regular TIA surveys began to take place. In 2005, production data from the TIA showed a wide-scale drought. This finding diverged massively from the estimations of the food security unit, which found a normal year and continuation of rapid agricultural growth. A careful examination of these competing data sources in general and the 2005 crop year in particular by Kiregyera et al. (2008) shone a harsh light on the then official data source. The food security unit had completely missed a massive drought, and the TIA was highlighted as a far more reliable data source for production statistics.

Following the publication of the Kiregyera et al. (2008) report, the National Institute of Statistics switched the official source of agricultural statistics to the TIA. As shown in Table 9.5, FAOStat applies the TIA data from 2002 to 2006. Curiously, FAOStat then reverts to another source (presumably the food security unit data) in 2007 and 2008. It is then unencumbered by any TIA data in 2009, 2010, and 2011. In 2012, it reverts back to exactly the data published in the Statistical Yearbook, the source for official data, before diverging from the official source once again in 2013.

Two observations are pertinent here. First, many of the salient elements in the FAOStat series derive from movement between data sources. The production collapse from 2011 to 2012 is particularly striking. Second, and more relevant to the point in focus here, national accounts have been almost impossibly trapped with respect to estimating growth and value added in agriculture. The survey-based data are, even in positive circumstances, deeply inconvenient to use as they arrive well after the regular planning cycle for government. The national accounts department is obliged to provide GDP estimates for the cycle; hence, they are forced to use the more timely food security unit estimates. Worse, survey-based estimations of agricultural production do not happen every year. The 2012 Statistical Yearbook provides maize production figures for 2008 (a number slightly greater than the one in Table 9.5) and for 2012 (exactly the number in Table 9.5). The years in between are pointedly blank (National Institute of Statistics 2013). So, just at the time that the official data source for production of major crops switched to a survey-based instrument, that instrument ceased to produce data for three years running. Faced with this situation, national accounts have not yet 
moved from the old data series-which looks similar to FAOStat in trends-to the new official agricultural production series, which is vastly more credible. Note that, with FAOStat, maize production grows by 50 per cent from 2002 to 2008, or 7 per cent per year. With the more credible survey-based estimates, production of maize-the most important staple food in the country-is basically flat, which implies a mild decline on a per capita basis. As agriculture represents around 20 per cent of GDP, significantly slower growth in agriculture implies slower growth in overall GDP.

\subsubsection{Components of Absorption}

This brings us to point (b) in our list. A large reduction in the estimated growth rate of agriculture has strong implications for exactly one component of absorption, consumption (C). Increases in agricultural production are not likely to be absorbed by the government or investment accounts. Hence, reductions in the estimated rate of agricultural growth imply reductions in consumption (assuming the trade statistics are left alone, which is sensible).

\subsubsection{Terms of Trade}

Point (c) is also relatively straightforward. Over the period 2002/3 to 2008/9, a great deal was happening in international commodity markets, as shown in Figure 9.7. World food prices spiked significantly in real terms, with the peak attained in mid-2008. During the 2008/9 survey period, world food prices

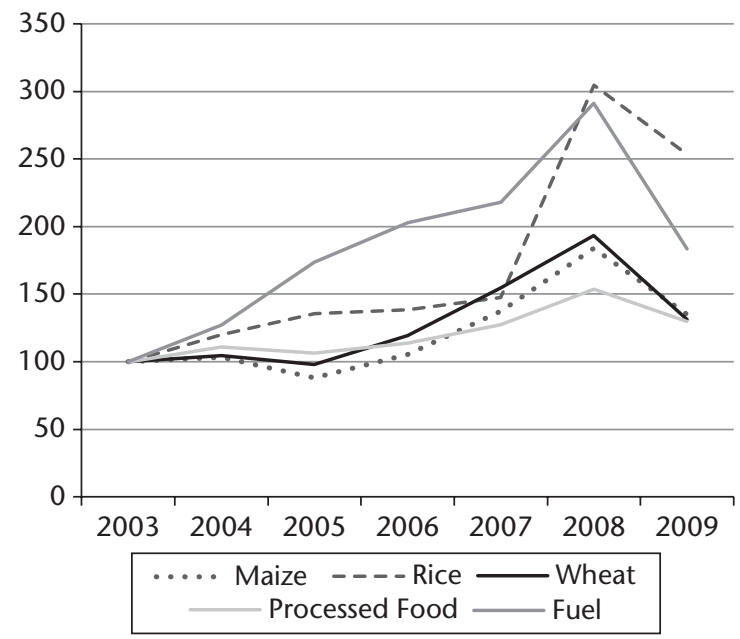

Figure 9.7. International real price indices

Source: International Monetary Fund (2011) and Council of Economic Advisers (2010) 
declined to levels significantly below their peaks of mid-2008, but still well above levels registered in 2002 and 2003. In addition, fuel prices rose almost continuously from 2002 to a peak in mid-2008 that was nearly five times the average level observed in 2002/3. Like food, oil prices declined in the second half of 2008 and remained at levels well above those observed in 2002/3. Hence, the observed decline in per capita production of food crops in 2008 essentially coincided with a very strong spike in international food prices. Increases in fuel prices raised the cost of delivering food to Mozambique (even after the international food price had been paid), as well as the costs of distributing imports within the country and distributing whatever surplus domestic agricultural production might have existed.

All five of the items shown in Figure 9.7 are significant import items for Mozambique, with fuel particularly prominent in the import basket. As Mozambique did not enjoy similar price increases for its exports, its terms of trade declined nearly continuously over the $2002 / 3$ to $2008 / 9$ period. For a given level of foreign finance, Mozambique was forced to export more in order to import the same volume of goods (particularly fuels and food).

\subsubsection{Inequality}

Finally, with respect to point (d), inequality, properly measured, appears to have increased as well. In most poverty assessments (including those conducted for Mozambique), inequality is calculated on the basis of nominal consumption or consumption adjusted by a spatial price index in order to take spatial variation in price levels into account. The spatial adjustment typically reduces inequality as it is normally less expensive to attain a minimum standard of food consumption and housing in rural areas. Hence, the typically more limited nominal consumption expenditures in rural areas have more real purchasing power per currency unit compared with urban zones. While accounting for spatial differences, the measures employed implicitly assume constant relative prices across the income distribution. When this constant relative price assumption does not hold, inequality can be affected. As stated by Muellbauer (1974: 32), if "the prices of "luxuries" and "necessities" move differently, then different groups are differently affected'. In Mozambique, as in other poor countries, lower-income consumers dedicate about half their overall budget to basic or core food products. Non-foods account for about one-third of expenditure. The remaining budget share, about 15 per cent, is allocated to a catch-all food category-non-core foods-which include processed foods and other more expensive items that would not be considered as core sources of calories or other nutrients.

At the upper end of the consumption scale, consumption patterns differ. Upper-income consumers purchase a much lower share of basic foods, a much 
higher share of non-core foods, and a much higher share of non-foods (Arndt et al. 2014). If the relative prices for goods in these categories shift, there are potential implications for real consumption inequality.

Figure 9.8 illustrates the trajectory of subcomponents of the consumer price index (CPI) for Mozambique divided between core foods, non-core foods, and non-foods over the period 2004 to 2009. The figure shows that, coincident with the world price spike of 2007 and 2008, the price of foods had risen substantially relative to the price of non-foods. For Mozambique, the CPI data are limited to three major urban zones. Arndt et al. (2014) extend the analysis (to the extent possible) to rural zones and to the full time frame between 2002/3 and 2008/9, using the price data available for the household budget survey combined with existing CPI data. They find even greater separation than shown in Figure 9.8. Specifically, prices of core food, non-core foods, and non-food rise 2.34, 1.92, and 1.51 times, respectively, from 2002/3 to 2008/9. Arndt et al. (2014) use these three price indices combined with consumption share information for the three categories of expenditure for each household in the consumption surveys to construct a household-specific price index. The resulting household-specific price indices, averaged per percentile of nominal consumption, are shown in Figure 9.9. The figure shows that the cost of living increased substantially more for lower-income consumers (who consume more basic foods) than for upper-income consumers (who consume more non-food). When this household-specific deflator is used to deflate nominal consumption in 2008/9, measured inequality increases by about 2.5 Gini points from $2002 / 3$ to $2008 / 9$. This inequality increase holds whether

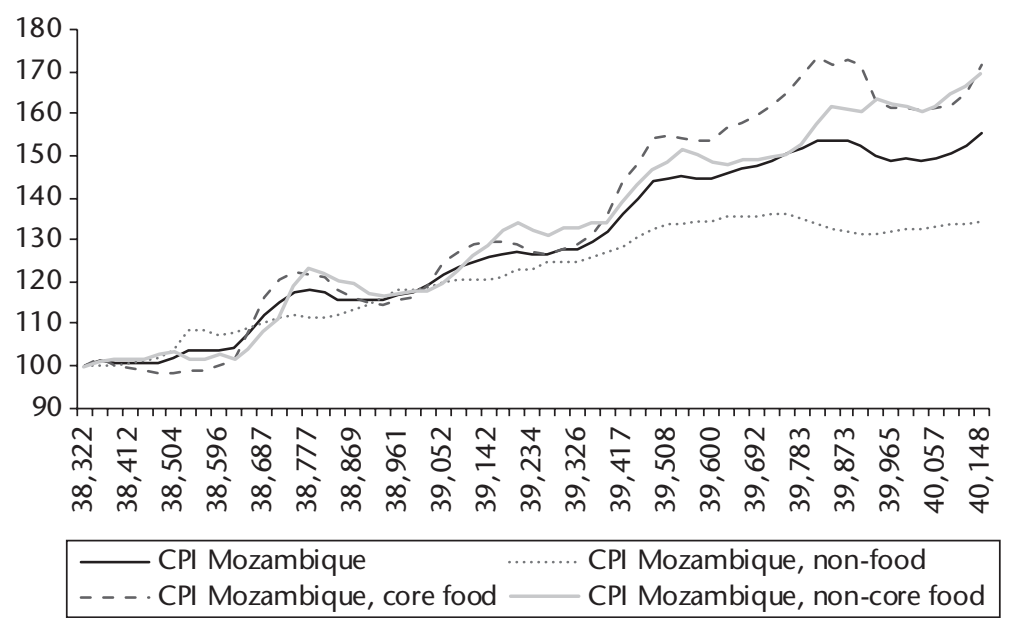

Figure 9.8. Components of the Mozambique CPI

Source: Authors' calculations 


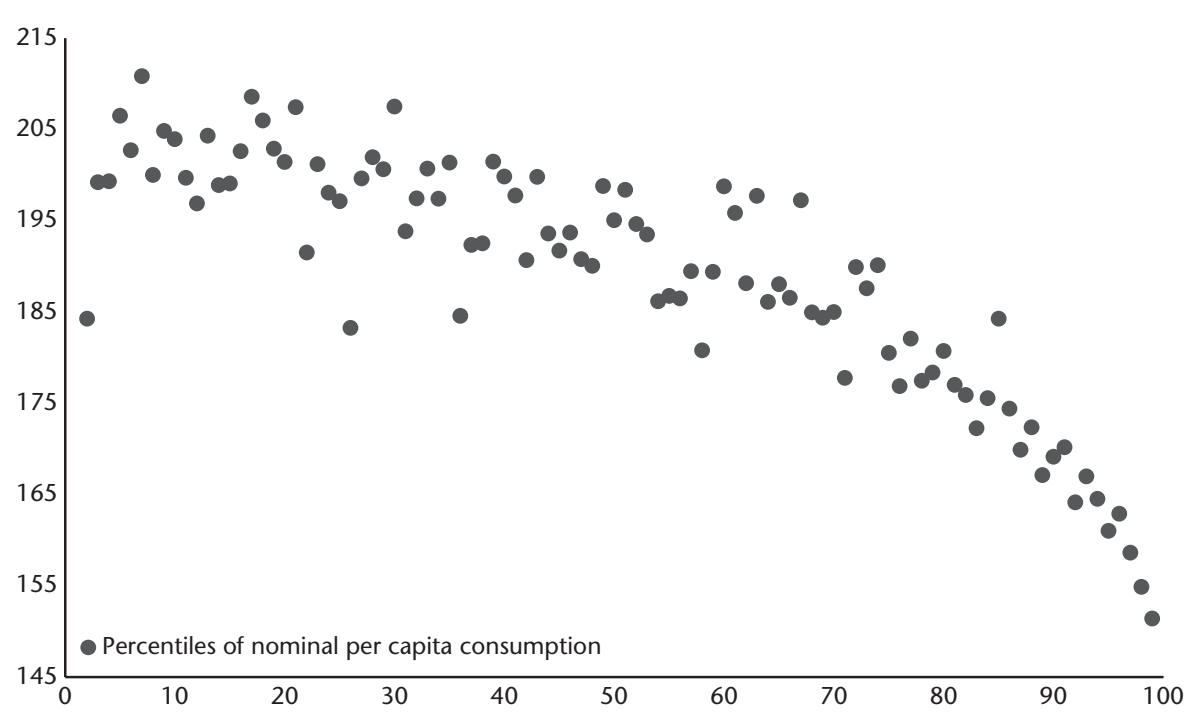

Figure 9.9. Percentile-specific price indexes by percentiles of nominal per capita consumption

Note: Percentile-specific price indices were obtained computing the median of household-specific price indices (HPIs) for each percentile of nominal per capita consumption. The 1st and 100th percentiles are excluded from the figure. The HPI takes a value of 100 in 2002/3.

Source: Authors' calculations

or not one deflates nominal consumption to account for spatial differences in the cost of living.

\subsubsection{Formal Assessment of Macroeconomic Factors}

Hence, all the factors (a) to (d) listed at the end of section 9.3.1 are present, and we note that all of them are likely to exert upward pressure on poverty in Mozambique. Nevertheless, it is not clear which factors are the most important or whether they combine to result in stagnant poverty rates. To assess this, Arndt et al. (2012) used a dynamic economy-wide model of the Mozambican economy linked to a poverty module. They begin with a baseline scenario, labelled 2003 Baseline, and present a projection of economic growth and poverty rates in 2008/9, using assumptions that would have reasonably pertained had the projection been made in early 2004. Hence, they use standard assumptions for growth in the labour force (near the population growth rate), an optimistic projection of agricultural productivity growth, and constant world prices for imports and exports.

They then present five successive scenarios labelled: Education, Agriculture, Food, Fuel, and Weather. The scenarios are cumulative with each new scenario 
Table 9.6. Growth in components of GDP 2003/9 for national accounts and for model

\begin{tabular}{|c|c|c|c|}
\hline & & National & \\
\hline & 2003 Share & Accounts & Model \\
\hline GDP & 100 & 7.6 & 6.5 \\
\hline \multicolumn{4}{|l|}{ Production optic } \\
\hline Agriculture & 26 & 7.9 & 3.4 \\
\hline Industry & 23 & 6.3 & 7.8 \\
\hline Services & 51 & 8.3 & 7.4 \\
\hline \multicolumn{4}{|l|}{ Expenditure optic } \\
\hline Consumption & 89 & 5.9 & 4.5 \\
\hline Investment & 22 & 4.5 & 5.8 \\
\hline Government & 13 & 7.7 & 8.5 \\
\hline Exports & 26 & 11.0 & 10.2 \\
\hline Imports & -50 & 4.7 & 5.2 \\
\hline
\end{tabular}

Source: Arndt et al. (2012). Reproduced under Creative Commons license terms

adding a particular set of changes to the earlier one. The changes bring the projection in line with what actually happened over the period. The Education scenario relates to the increased tendency for children to remain in school. As a result, the labour force as a whole grew at about 0.4 per cent per annum. This is significantly less than the rate of population growth and the assumed rate of growth of the labour force in the baseline scenario (both of which are about 2.5 per cent per annum). ${ }^{5}$ Agricultural productivity growth was in fact close to zero (Agriculture scenario). As noted in section 9.3.5, world prices diverged dramatically. This is divided between two scenarios, Food and Fuel, corresponding to their respective price increases. The final scenario, Weather, incorporates shocks to agricultural production related to weather, and represents the total cumulative effect of all changes from the 2003 Baseline.

We begin with macroeconomic outcomes from this final weather scenario. Table 9.6 illustrates the growth in the components of GDP from both a production and an expenditure perspective by sector between 2003 and 2009 as (i) published in national accounts and (ii) projected by the dynamic computable general equilibrium (CGE) model for the final cumulative scenario Weather. The table also illustrates the shares of each sector in value added as well as expenditure shares in 2003. Sectors are divided between the broad categories of agriculture, industry, and services.

We note that, for industry and services, actual growth in value added is reasonably close to the growth in value added projected by the CGE model; however, the projected rate of growth of agriculture is substantially lower than

\footnotetext{
5 The composition of the labour force does shift towards more skilled labour.
} 
Table 9.7. Actual and projected poverty rates

\begin{tabular}{|c|c|c|c|c|c|c|}
\hline & \multicolumn{2}{|c|}{ National } & \multicolumn{2}{|c|}{ Rural } & \multicolumn{2}{|c|}{ Urban } \\
\hline & Actual & Model & Actual & Model & Actual & Model \\
\hline Aggregate & 54.7 & 54.3 & 56.6 & 55.3 & 49.6 & 52.3 \\
\hline Semester 1 & 57.3 & 57.4 & 60.1 & 57.8 & 50.5 & 56.5 \\
\hline Semester 2 & 52.3 & 51.3 & 53.8 & 52.8 & 48.6 & 48.0 \\
\hline
\end{tabular}

Source: Arndt et al. (2012). Reproduced under Creative Commons license terms

the rate estimated by national accounts. Consequently, overall GDP growth differs between the estimations of national accounts ( 7.6 per cent per annum) and the projections of the model (6.5 per cent per annum). About 90 per cent of the difference in the overall GDP growth rate is due to the difference in the growth rate of agriculture, particularly food crops, which represented more than two-thirds of agricultural value added in 2003. Even with this correction to the estimated overall GDP growth rate, per capita GDP is still estimated to have grown by about 4 per cent per annum (6.5 per cent GDP growth rate minus about 2.5 per cent annual population growth rate) over the period 2003 to 2009. However, the rate of private consumption growth is lower than GDP growth in both the model and in national accounts. Real consumption is growing in the model at about 4.5 per cent per annum in total or about 2 per cent per annum per capita. Hence, returning to our list of factors at the end of section 9.3.1 that might cause measured poverty to stagnate despite real GDP growth, we have accounted for the first two factors (a) and (b). Do these two factors, combined with terms of trade effects (which relate to point (c)), result in stagnant poverty?

The answer is 'yes'. Table 9.7 compares poverty rates derived from the 2008/ 9 survey with projected poverty rates using the economy-wide model. Before comparing the rates, it is helpful to note that the CGE model is annual while the household survey spans 2008 and 2009. To deal with this issue, we assume that the first semester of the survey corresponds to the model year 2008 while the second semester of the survey corresponds to the model year 2009. When comparing the full 2008/9 survey with the model results, we take the simple average of results for 2008 and 2009.

The model results are strikingly close to the estimates from the survey. At the national level and for the full survey period, the 2008/9 budget survey estimates 54.7 per cent of the population consumes below the poverty line. The corresponding model estimate is 54.3 per cent of the population. The model results are also very close to IOF estimated rates in rural zones both for the full survey period and by semester. The only rates that do not lie very close to one another between the model projection (based on the 2002/3 survey and 


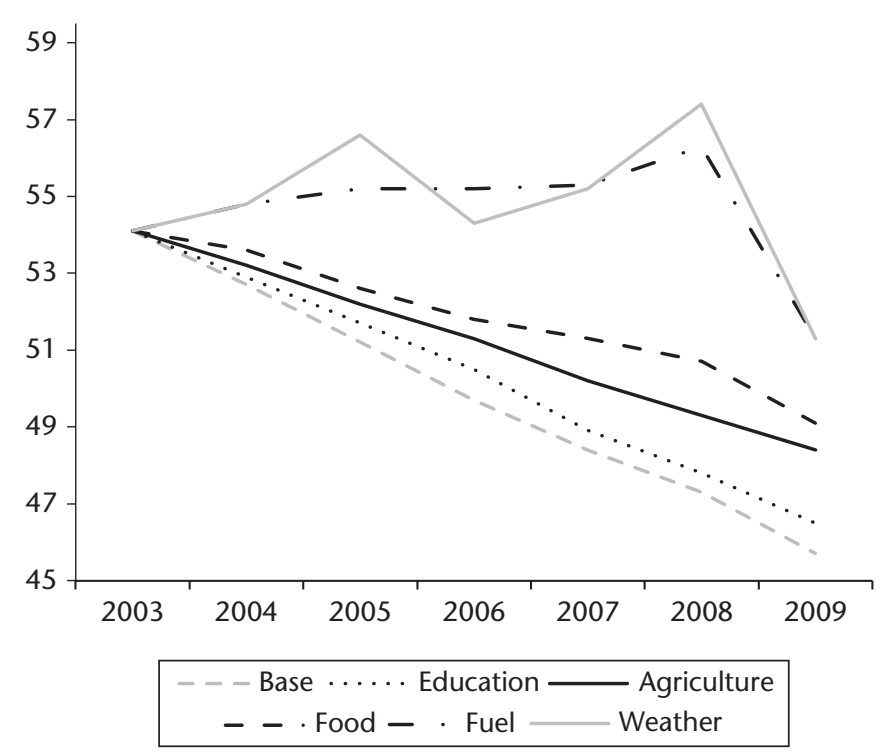

Figure 9.10. Evolution of poverty rates by scenario

Notes: Base is the Baseline 2003. Education applies observed labour force growth rates. Agriculture applies low productivity growth rates. Food applies world price shifts in food products to exports and imports. Fuel applies world price shifts in fuels and related products (plastics and fertilizers). Weather applies shocks to agricultural production related to weather events.

Source: Arndt et al. (2012). Reproduced under Creative Commons license terms

the CGE model) and the 2008/9 survey are the first semester in urban zones. The difference between these two rates is about six percentage points. Overall, the 2008/9 survey results appear to be strongly consistent with the evolution of macroeconomic variables.

A significant advantage of economy-wide models is that they allow the analyst to decompose complex phenomena, such as the evolution of poverty rates through time, in order to provide insights into the driving forces behind results. So far, we have considered only results from the final scenario, Weather, which includes all of the effects discussed in the preceding subsection. Figure 9.10 shows the evolution of poverty rates through time for each of the scenarios: 2003 Baseline, Education, Agriculture, Food, Fuel, and Weather. Recall that the scenarios are cumulative. Hence, the scenario Agriculture differs from the 2003 Baseline both in terms of rates of productivity growth in agriculture and the rate of growth of the labour force by skill class.

A number of useful observations emerge. First, the goal, established in 2004, of a 45 per cent poverty rate by 2009 was reasonable. As discussed at the start 
of this section, the 2003 Baseline scenario provides a projection of poverty rates based on information available in 2004. In this scenario, the labour force grows at plausible rates, agricultural productivity growth is relatively rapid, world prices are held constant, and no weather events occur. Under this scenario, a poverty rate of 45.7 per cent is attained in 2009 .

The principal factors driving the observed stagnation in poverty are: (i) the combination of low productivity growth in agriculture (particularly food crops), substantial increases in world food prices, and a weather shock in 2008; and (ii) the nearly continuous increase in fuel prices over the 2003-9 period. In 2008, when fuel prices were at their peak, they contributed the most to the increases in poverty above the 2003 Baseline scenario. In 2009, with the decline in fuel prices but relative firmness of food prices, the combination of low agricultural productivity growth and food price increases contributed the most to the increase in poverty.

The strength of the fuel price effect merits further mention. This effect is consistent with earlier analysis (Arndt et al. 2008). Net imports of fuel and derived products represent a substantial share of total imports-about 18 per cent in 2003. Because fuel use is difficult to economize on, particularly in the short run, fuel price increases imply a need either to increase exports or reduce imports for any given level of foreign exchange availability from external sources. This terms of trade loss amounts to a reduction in the quantity of goods available to the economy.

Changes in fuel prices then influence relative prices throughout the economy. Mozambique is a large dispersed country with relatively low population density. Driven in part by this geography, the existence of large differences between farm-gate agricultural prices and consumer prices is well established. Transport costs, of which fuel is a substantial component, account for a large share of this difference. Other things being equal, higher fuel prices simultaneously lower farm-gate prices and increase consumer prices because they expand the marketing wedge between producers and consumers (Tarp et al. 2002). The costs of distributing imported products - especially food, which is bulky and relatively low value-increases. Finally, direct transport costs such as for buses or minibuses, which are often particularly important for urban residents, also tend to rise.

The model can also be used to assess inequality. Because the model contains household groups by income quintile, it will capture (some of ) the differential impact of the observed shifts in relative prices across the income distribution. In the model, the Gini coefficient, looking across results for 2008 and 2009, rises to about two points higher than the estimate from 2002/3. This is in the same range as the 2.5 point increase estimated in Arndt et al. (2014). 
In summary, a coherent story emerges. At the macroeconomic level, the stagnation observed in absolute poverty rates is consistent with the best available data on agricultural production, corrected GDP growth, and world price shifts. $^{6}$

\subsection{Current Perspectives}

Due to the current absence of sufficient data to conduct a detailed assessment beyond 2009, the best approach is to extrapolate forward on the basis of the trends observed up to 2008/9 and new factors entering the calculus. On this basis, both optimists and pessimists have items to point to. On the positive side, optimists can point to the following:

- While consumption poverty rates did not decline, a number of related welfare measures registered improvement, including the quality of the housing stock and ownership of durable goods. While still at very low levels, some accumulation processes are in place in Mozambique.

- Education investments should begin to pay off. As discussed in section 9.3, the net effect of retaining children in school (reduction in the labour force where labour force is defined as economically active individuals over 14 years old) outweighed the positive effect of increased levels of human capital over the $2002 / 3$ to $2008 / 9$ period. Over time, the impacts of education should tilt decisively towards benefits from a better-educated population. This assumes that the education sector is actually conferring skills of value; and available cross-section evidence indicates that, while returns to education have declined somewhat, particularly for low levels of education, they are still firmly positive (Ministry of Planning and Development/DNEAP 2010).

- Other enhancements to human capital are being registered. Child malnutrition remains alarmingly high and is declining at a slow rate; however, it has been declining over time. People should also benefit from improved access to health posts and safe water.

- In contrast to the period leading up to $2008 / 9$, there is a growing sense of at least pockets of rapid growth in small-scale commercial agriculture. Credible national-level statistics are scarce; however, Smart and Hanlon

\footnotetext{
${ }^{6}$ Space constraints prevent a complete exposition of how changes in poverty observed by region correlate with other observables; see Ministry of Planning and Development/DNEAP (2010) for such detail.
} 
(2014), for example, document the emergence of a viable poultry sector value chain with links back to local feedstock producers.

- Importantly, the persistent terms of trade declines experienced over the $2002 / 3$ to $2008 / 9$ period have ceased. Some of these, notably oil prices, have recently reversed themselves.

- As noted in the Introduction, recent major natural resource finds open both new possibilities for growth as well as new risks. As with existing large investments in Mozambique, natural resource exploitation, which is concentrated in coal, natural gas, and hydropower, is expected to be highly capital-intensive in nature with very substantial foreign ownership. Once in operation, a principal linkage to the domestic economy will be government revenue. Substantial and reasonably regular revenues from royalties and income taxes are only likely to kick in ten years or more into the future. However, during the ongoing investment phase, linkages to the domestic economy are clearly visible as natural resource exploitation companies set up operations. This includes extensive investment in rail and port infrastructure.

On the negative side, pessimists can point to the following:

- The survey-based agricultural production data for major food crops remains disconcerting, at least through 2013. And, use of improved technologies by the family sector remains very low.

- Job creation by the enterprise sector has also been disappointing. As a consequence, job opportunities tend to be strongly concentrated in agriculture and services, where productivity is often very low.

- Social fissures remain. In the first half of 2014, the principal opposition party Renamo, retreated into the bush and actively sought to split the country in two by closing traffic on the main north/south road through military means. Fortunately, an agreement was reached and Renamo participated in the general elections held in November 2014. Nevertheless, these events can hardly be taken as a positive sign either from the perspective of evaluating recent performance or looking forward.

Overall, and despite poor performance on some key welfare metrics during the 2002-9 period, we conclude that while poverty reduction in Mozambique was temporarily sidelined in the 2000s, development is not fundamentally off-track. Rather, a series of shocks, especially the fuel and food price crisis of 2008 , combined with poor underlying productivity growth in the family agricultural sector and a weather shock in 2008 contributed substantially to undermining progress in these key areas. As most of these shocks have ceased or gone into reverse, we expect measured progress in consumption poverty reduction to resume. 
At the same time, these shocks also exposed genuine weaknesses in development strategies and programmes as implemented. These weaknesses persist, and it is evident that the new Mozambican government that took office in January of 2015 is faced with many complex challenges. Prominent policy challenges include that poverty remains very high; and future prospects in smallholder agriculture and the informal sector will be of fundamental importance to achieving rapid and sustained poverty reduction.

Looking further ahead, the existing pattern of employment creation indicates that the infrastructure and business environment remain weak and skewed against labour-intensive manufacturing exports and household firms. Meanwhile, Mozambique has to 'run' just to keep up due to the existing demographic dynamics. Nearly half the population is under 15 years of age. How they will be absorbed into the labour market in a productive manner will be critical to the success or failure of the Mozambican socioeconomic transformation process in the years to come. In sum, there is little doubt that Mozambique has the potential to achieve rapid and broad-based economic and social progress. With key reforms and success in maintaining peace and stability, it will.

\section{References}

Alfani, F., C. Azzarri, M. d'Errico, and V. Molini (2012). 'Poverty in Mozambique: New Evidence from Recent Household Surveys', World Bank Policy Research Working Paper. Washington, DC: World Bank.

Arndt, C., M. Azhar Hussain, S. Jones, V. Nhate, F. Tarp, and J. Thurlow (2012). 'Explaining Poverty Evolution: The Case of Mozambique', American Journal of Agricultural Economics, 94(4): 854-72.

Arndt, C., R. Benfica, N. Maximiano, A. Nucifora, and J. Thurlow (2008). 'Higher Fuel and Food Prices: Impacts and Responses for Mozambique', Agricultural Economics, 39(1): 497-511.

Arndt, C., S. Jones, and V. Salvucci (2014). 'When Do Relative Prices Matter for Measuring Income Inequality? The Case of Food Prices in Mozambique', WIDER Working Paper 2014/129. Helsinki: UNU-WIDER.

Bourguignon, F. (2004). 'The Poverty-Growth-Inequality Triangle', Indian Council for Research on International Economic Relations Working Paper 125. New Delhi: Indian Council for Research on International Economic Relations.

Council of Economic Advisors (2010). 'Council of Economic Advisors: Economic Report of the President, 2009'. Washington, DC: United States Government Printing Office.

Food and Agriculture Organization (2015). 'Electronic Data from FAOStat', <http:// faostat3.fao.org/browse/Q/QC/E>, accessed 6 February 2015.

International Monetary Fund (2011). 'Primary Commodity Prices Database 2010', <www.imf.org/external/np/res/commod/index.asp>, accessed 9 March 2015. 
Jones, S. and F. Tarp (2013). 'Jobs and Welfare in Mozambique', WIDER Working Paper 2013/045. Helsinki: UNU-WIDER.

Kiregyera, B., D. Megill, D. Eding, and B. José (2008). 'A Review of the National Agricultural Information System in Mozambique', Discussion Paper 64E. Maputo: National Directorate for Studies and Policy Analysis, Ministry of Planning and Development.

Ministry of Agriculture/DE (2010). Agriculture Statistical Yearbook. Maputo: Ministry of Agriculture.

Ministry of Planning and Development/DNEAP (2010). 'Poverty and Wellbeing in Mozambique: Third National Poverty Assessment'. Maputo: Ministry of Planning and Development/DNEAP.

Ministry of Planning and Finance/DNPO (1998). 'Understanding Poverty and Wellbeing in Mozambique: The First National Assessment, 1996-97'. Maputo: Ministry of Planning and Finance/DNPO.

Ministry of Planning and Finance/DNPO (2004). 'Poverty and Wellbeing in Mozambique: Second National Poverty Assessment'. Maputo: Ministry of Planning and Finance/DNPO.

Muellbauer, J. (1974). 'Prices and Inequality: The United Kingdom Experience', Economic Journal, 84(333): 32-55.

National Institute of Statistics (2005). 'Mozambique: Demographic and Health Survey 2003 (DHS03)'. Maputo: National Institute of Statistics.

National Institute of Statistics (2009). 'Mozambique: Multiple Indicator Cluster Survey 2008 (MICS08)'. Maputo: National Institute of Statistics.

National Institute of Statistics (2012). Statistical Yearbook, 2011. Maputo: National Institute of Statistics.

National Institute of Statistics (2013). Statistical Yearbook, 2012. Maputo: National Institute of Statistics.

National Institute of Statistics (2014). Statistical Yearbook, 2013. Maputo: National Institute of Statistics.

Smart, T. and J. Hanlon (2014). Galinhas e Cerveja: Uma Receita Para o Crescimento. Maputo: Kapicua.

Tarp, F., C. Arndt, H. T. Jensen, S. Robinson, and R. Heltberg (2002). 'Facing the Development Challenge in Mozambique: An Economy-wide Perspective', IFPRI Research Report 126. Washington, DC: IFPRI. 


\section{0}

\section{Spatial and Temporal Multidimensional Poverty in Nigeria}

Olu Ajakaiye, Afeikhena T. Jerome, Olanrewaju Olaniyan, Kristi Mahrt, and Olufunke A. Alaba

\subsection{Introduction}

Nigeria, no doubt, typifies a country that has had rapid economic growth but worsening poverty. The economy grew strongly at an average annual rate in excess of 6 per cent over the last decade, even during the global financial crisis (IMF 2013), ranking Nigeria as one of the fastest growing economies globally. In spite of this strong growth performance, the poverty incidence has remained high, rising from 42.7 per cent in 1992 to 65.6 per cent in 1996, with an all-time high of 69 per cent in 2010, according to data from the National Bureau of Statistics (NBS 2012). Furthermore, the benefit of growth has not been equitably shared as the Gini coefficient, a standard measure of income inequality increased from 0.42 per cent in 2004 to 0.45 per cent in 2010. Therefore, the theoretical arguments and empirical evidence from the literature that associate faster economic growth with poverty reduction seem to be failing in the Nigerian context. Not surprisingly, major issues in policy debates include how to proffer explanations and reconcile this paradoxical trend, and the need to investigate the key mechanisms through which growth can be translated into sustainable poverty reduction. This, no doubt, would require adequate measurement of poverty, an issue to which researchers and policymakers have given much prominence in recent years.

This chapter seeks to contribute to the debate by estimating non-monetary multidimensional poverty in Nigeria, across time and space within Nigeria's six geopolitical zones and the rural and urban sector. Using the first-order dominance (FOD) method recently developed by Arndt et al. (2012), we are able to compare these subpopulations using multiple-ordinal, discrete measures of poverty without imposing weighting schemes or making assumptions 
about the preferences for each indicator. The FOD method allows multidimensional welfare comparisons based on the simple criterion that it is better to be non-deprived than deprived in any indicator. Furthermore, while the welfare indicators are ordinal in nature, the application of bootstrap sampling produces probabilities of one population performing better than another, which enables population ranking across time and space.

This chapter makes a distinct contribution to the literature. This is the first application of the FOD methodology to non-monetary multidimensional poverty in Nigeria. Moreover, few studies exist on multidimensional poverty in Nigeria. It complements earlier studies by Oyekale et al. (2009) which used the fuzzy set approach to assess the poverty profile of rural households in Nigeria based on the 2006 Core Welfare Indicator Survey data and Adetola and Olufemi (2012), which employed the Alkire and Foster (2007) counting approach to examine child poverty in rural Nigeria using the 2008 Demographic and Health Survey (DHS) data.

The remainder of the chapter is structured as follows. Section 10.2 reviews the poverty and poverty situation in Nigeria, drawing on available data from the DHS, while section 10.3 presents the methodology. The results are presented in section 10.4, and section 10.5 concludes.

\subsection{Situation Analysis of Growth, Poverty, and Inequality in Nigeria}

\subsubsection{Economic Growth}

Nigeria is the most populous country in Africa with a population of 168.8 million in 2012, distributed as 50.9 per cent urban and 49.1 per cent rural (World Statistics Pocketbook 2014). The country comprises of thirty-six states and the Federal Capital Territory, Abuja. The thirty-six states have been classified into six geopolitical zones based on a number of criteria, including location, cultures, ethnic composition, and common history. ${ }^{1}$

The depth and persistence of Nigeria's economic failure is well recognized. After a brief spurt of growth in the 1960s, the concurrence of political instability, an inert economic structure, and chronic levels of poverty despite huge hydrocarbon reserves have been a recurrent theme. Economic stagnation, declining welfare, and social instability have undermined development

\footnotetext{
1 These zones are: South East = Anambra, Enugu, Ebonyi, Imo, and Abia states; South South = Edo, Delta, Rivers, Bayelsa, Cross-River, and Akwa-Ibom states; South West = Lagos, Ogun, Oyo, Osun, Ondo, and Ekiti states; North Central = Kwara, Kogi, Plateau, Nassarawa, Benue, Niger, and FCT; North East = Taraba, Adamawa, Borno, Yobe, Bauchi, and Gombe states; North West = Sokoto, Zamfara, Kebbi, Kaduna, Katsina, Kano, and Jigawa states.
} 


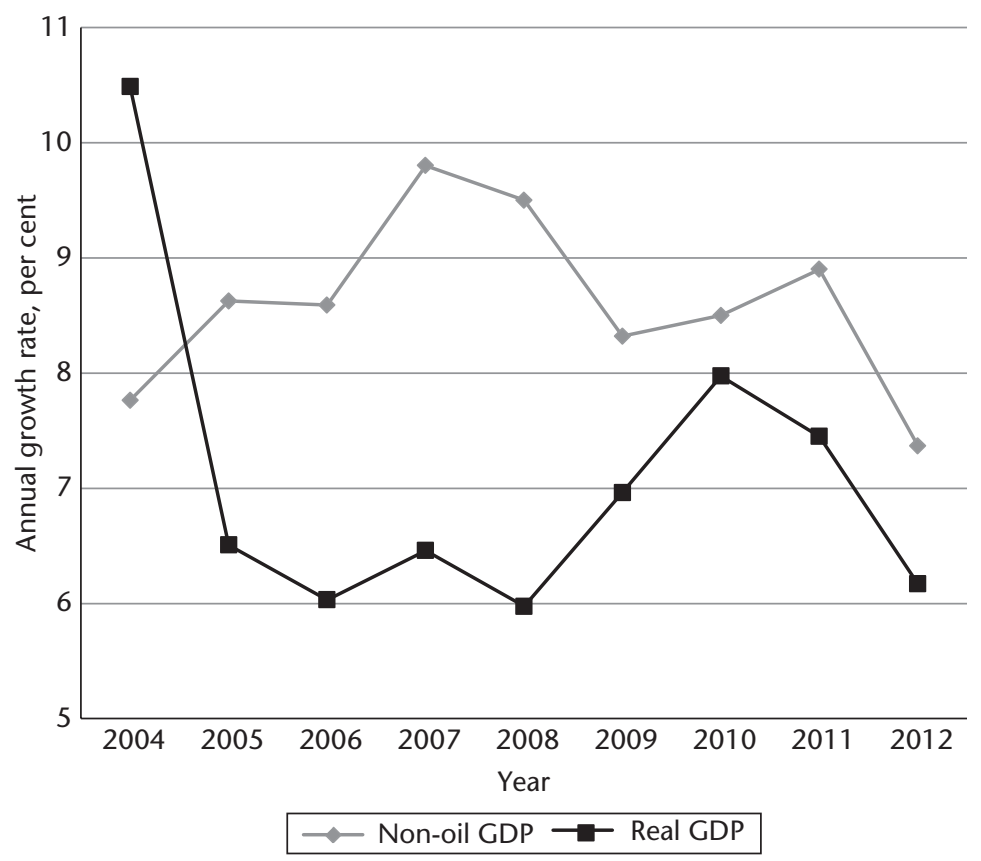

Figure 10.1. Nigeria's real GDP growth rate, 2004-12

Source: Underlying data based on Central Bank of Nigeria (2012)

for most of the post-independence period despite generating about US $\$ 500$ billion as oil revenues in the past three decades (Ajakaiye and Jerome 2011).

Over the last ten years, Nigeria has attempted to turn the corner, implementing an ambitious reform agenda. Sound macroeconomic policies combined with structural reforms, aimed at increasing the supply responsiveness of the economy, ushered in sustained high growth averaging 7.6 per cent over the last decade and one of the highest in Africa (see Figure 10.1). ${ }^{2}$ The performance of the economy continues to be underpinned by favourable improvements in the non-oil sector, with recently rebased real GDP growth of 5.3 per cent, 4.2 per cent, and 5.5 per cent in 2011, 2012, and 2013, respectively.

The profile of the Nigerian economy must consider the differential roles of the oil and non-oil sectors. The oil sector is the major export earner for the country as well as the largest revenue-earning sector for government. Figures 10.1 and 10.2 indicate that growth in the oil sector has been lagging behind growth in the non-oil sector in recent years. The drop in crude-oil

\footnotetext{
2 The rebasing of Nigeria's GDP in April 2014, to better reflect the structure of the economy, saw it surge after South Africa to become Africa's largest economy with a revised GDP estimate of US\$454 billion in 2012 and US\$510 billion in 2013 (compared with the US\$259 billion and US\$270 billion that were previously reported), confirming Nigeria's lead as the continent's largest economy.
} 


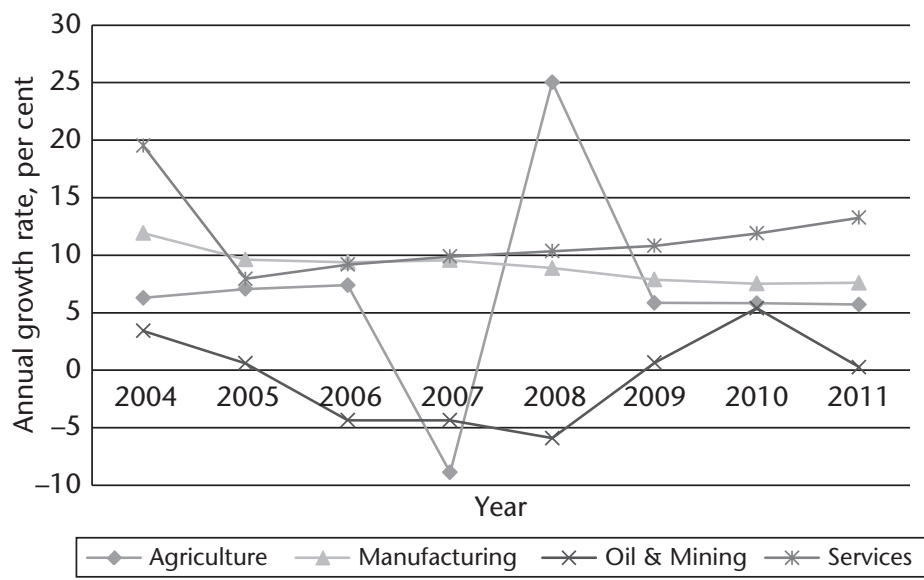

Figure 10.2. Nigeria's real sectoral GDP growth rates, 2004-11

Source: Underlying data based on Central Bank of Nigeria (2012) Statistical Bulletin

production was a result of large-scale oil theft ${ }^{3}$ and other operational constraints experienced by some of the oil-producing companies. Within the non-oil sector, agriculture and services, especially the communication sector, are the main growth drivers. Agriculture has maintained its dominant role in the Nigerian economy, though it is still essentially rain-fed, while farmers have suffered tremendous crop failure as a result of climate variability.

While data on the geographic distribution of growth in Nigeria are still scanty, it does seem that growth has a very high geographic concentration and varies remarkably at the subnational level as the World Bank (2013) rightly observes. Lagos state, for example, which accounts for about 35 per cent of the national GDP, is experiencing exceptionally rapid growth, which enabled it to reduce its poverty headcount from an estimated 44 per cent of the population to 23 per cent between 2004 and 2010.

\subsubsection{Poverty}

Poverty is widespread in Nigeria no matter the method used in computing it, and the incidence has been on the rise over the last ten years. ${ }^{4}$ Using food

\footnotetext{
3 A recent study by Katsouris and Sayne (2013) estimated that an average of 100,000 barrels per day was stolen in the first quarter of 2013.

4 The NBS periodically conducts the Harmonized Nigeria Living Standard Survey (HNLSS), which is used, among other things, to determine poverty and inequality trends in the country. The HNLSS uses four different approaches in the computation of poverty indicators: relative poverty, which is defined by reference to the living standards of the majority in a given society and separates the poor from the non-poor; absolute poverty, which reflects the minimal requirements necessary to afford minimal standards of food, clothing, health care, and shelter; the basic needs approach, which measures the proportion of those living on the less than US\$1 per day poverty line; and subjective
} 
Table 10.1. Incidence of poverty by sector and zones, 1980-2010, per cent

\begin{tabular}{lcccccc}
\hline Levels & 1980 & 1985 & 1992 & 1996 & 2004 & 2010 \\
\hline National & 27.2 & 46.3 & 42.7 & 65.6 & 54.4 & 69.0 \\
Urban & 17.2 & 37.8 & 37.5 & 58.2 & 43.2 & 61.8 \\
Rural & 28.3 & 51.4 & 46.0 & 69.3 & 63.3 & 73.2 \\
Geopolitical zones & & & & & & \\
North Central & 32.2 & 50.8 & 46.0 & 64.7 & 67.0 & 67.5 \\
North East & 35.6 & 54.9 & 54.0 & 70.1 & 72.2 & 76.3 \\
North West & 37.7 & 52.1 & 36.5 & 77.2 & 71.2 & 77.7 \\
South East & 12.9 & 30.4 & 41.0 & 53.5 & 26.7 & 67.0 \\
South South & 13.2 & 45.7 & 40.8 & 58.2 & 35.1 & 63.8 \\
South West & 13.4 & 38.6 & 43.1 & 60.9 & 43.0 & 59.1 \\
\hline
\end{tabular}

Source: NBS $(2009,2012)$

energy intake to measure poverty, the 2010 Nigeria Poverty Profile Report reveals that poverty incidence rose from 27.2 per cent in 1980 to 69.0 per cent in 2010 (NBS 2012). ${ }^{5}$ Urban poverty has been consistently lower than rural poverty; hence while 61.8 per cent of urban residents were considered poor in 2010, more than 73 per cent of rural dwellers fell into the same category (Table 10.1).

Poverty also appears to be more prevalent in the northern part of the country with the highest rates hovering between the North East and North West zones. The high poverty rate had even become more pronounced by 2010 as virtually all the zones of the country had over 60 per cent poverty incidence (see Table 10.1).

A recent assessment by the World Bank using the NBS General Household Surveys (GHS) for 2010/2011 and 2012/2013 estimated the national poverty rate at 35.2 per cent and 33.1 per cent respectively, which are significantly lower than earlier NBS estimates using the HNLSS. The new GHS analysis also estimated rural poverty at 46.3 per cent and 44.9 per cent in 2010/2011 and 2012/2013 respectively compared to 69 per cent in the HNLSS 2009/2010 estimates by the NBS. The new living standards estimates also imply an even stronger divide between the North and South in Nigeria than do previous figures, with the North experiencing significantly higher poverty. In addition, a large number of Nigerians are clustered around the poverty line, implying a high degree of vulnerability for a large part of the population (World Bank 2014a).

In addition to poverty incidence, income inequality has been consistently high in the country although with some reduction in 1992 and 2004 (NBS

poverty, which is based on opinions from respondents on whether or not they consider themselves poor.

5 Concerns have been expressed about the comparability of surveys through time. The figures presented in Tables 10.1, 10.2, and 10.3 should be interpreted with this in mind. 
Table 10.2. Inequality trend by area of residence and zones, 1980-2010

\begin{tabular}{|c|c|c|c|c|c|}
\hline Levels & 1985 & 1992 & 1996 & 2004 & 2010 \\
\hline National & 0.43 & 0.41 & 0.49 & 0.42 & 0.45 \\
\hline Urban & 0.49 & 0.38 & 0.52 & 0.41 & 0.43 \\
\hline Rural & 0.36 & 0.42 & 0.47 & 0.42 & 0.44 \\
\hline \multicolumn{6}{|c|}{ Geopolitical zones } \\
\hline North Central & 0.41 & 0.39 & 0.50 & 0.44 & 0.42 \\
\hline North East & 0.39 & 0.40 & 0.49 & 0.41 & 0.45 \\
\hline North West & 0.41 & 0.43 & 0.47 & 0.40 & 0.41 \\
\hline South East & 0.44 & 0.40 & 0.39 & 0.38 & 0.44 \\
\hline South South & 0.48 & 0.39 & 0.46 & 0.39 & 0.43 \\
\hline South West & 0.43 & 0.40 & 0.47 & 0.41 & 0.41 \\
\hline
\end{tabular}

Source: NBS $(2009,2012)$

Table 10.3. Income shares distribution, 1986-2010

\begin{tabular}{|c|c|c|c|c|}
\hline \multirow[t]{2}{*}{ Year } & \multicolumn{2}{|c|}{ Income share held by the rich } & \multicolumn{2}{|c|}{ Income share held by the poor } \\
\hline & $10 \%$ & $20 \%$ & $10 \%$ & $20 \%$ \\
\hline 1986 & 28.2 & 45.0 & 2.5 & 6.0 \\
\hline 1992 & 31.5 & 49.4 & 1.4 & 4.0 \\
\hline 1996 & 37.1 & 52.1 & 1.9 & 5.0 \\
\hline 2004 & 29.9 & 46.1 & 2.2 & 5.6 \\
\hline 2010 & 32.8 & 48.9 & 2.2 & 5.4 \\
\hline
\end{tabular}

Source: WORLD Bank (2014b)

2012). Using the Gini coefficient, income inequality in the country increased between 1985 and 2010. Although national income inequality fell between 1985 and 1992, it rose in 1996, declined in 2004, and rose again in 2010 (Table 10.2). With the exception of 1985 and 1996, inequality has been higher in the rural areas relative to the urban areas, which is probably accounted for by the structure of employment and income in the rural areas. The agricultural sector has consistently been neglected until recently due to the dominance of the oil sector in the economy. Faced with the inability to invest in skills acquisitions like those in the urban areas, the predominantly rural population has become more vulnerable to poverty. Considering zones, in 2010 income inequalities were highest in the North East and lowest in the North West and South West.

Income inequality is further demonstrated in the share of income held by the top richest and the bottom poorest in the country. As revealed in Table 10.3, there is a very high disparity between the income of the richest and poorest deciles of the population. The income share of the richest 10 and 20 per cent increased from 28 and 45 per cent respectively in 1986 to 37 and 52 per cent in 1996, declined to 32 and 49 per cent in 2004, and then jumped to 38 and 54 per cent in 2010 . This clearly defines Nigeria's paradoxical status 
as a rich country with poor people; a country whose richest 20 per cent controlled 54.01 per cent of income in 2010 while most of the remaining 80 per cent were poor and struggled to live. A more equal distribution of Nigeria's income would assist greatly in curbing the increases in poverty rate.

\subsection{Methodology}

\subsubsection{Approach}

There is widespread agreement that poverty is a complex phenomenon with multidimensional properties and effects (Sen 1973). Thus, there has been a shift from the conventional one-dimensional approaches to measuring poverty, inequality, and welfare, using monetary values such as household income or expenditure per capita, to a multidimensional concept where both monetary and non-monetary measures of deprivation are integrated or applied independently.

More advanced approaches have evolved over time to assess living standards and make comparisons within a multidimensional framework since the pioneering efforts of Tsui (2002) and Bourguignon and Chakravarty (2003). The challenge, however, has been to empirically define and aggregate relevant attributes, as well as determine the minimum thresholds that can capture differences in levels of deprivation rather than choices and tastes (Layte et al. 2001).

Some approaches that have been adopted to handle the aggregation problem $^{6}$ are axiomatic and extensions of unidimensional poverty indices (Tsui 2002; Atkinson 2003; Bourguignon and Chakravarty 2003). Other nonaxiomatic approaches in the literature include the fuzzy set approach (Cerioli and Zani 1990; Cheli and Lemmi 1994; Chiappero-Martinetti 2006), the distance function method (Lovell et al. 1994; Anderson et al. 2005), the information theory approach (Maasoumi 1993; Deutsch and Silber 2005; Maasoumi and Lugo 2008), the inertia approach and factor analysis (Klasen 2000; Sahn and Stifel 2003), and methods from the psychometric literature (Wagle 2005; Di Tommaso 2007; Krishnakumar and Ballon 2008).

Batana and Duclos (2008) draw attention to the concern that the arbitrary nature of assumptions involved in choosing poverty thresholds and in aggregating across welfare dimensions and individuals may diminish the robustness of results. The multidimensional dominance approach provides a methodology that is robust to each of these choices.

\footnotetext{
${ }^{6}$ See Batana (2008) for a good overview and summary of the different applications.
} 
As noted elsewhere in this volume, the FOD approach does not impose a weighting scheme or ad hoc simplifying assumptions on the social welfare function. No assumptions are made about preferences for one indicator over another. The only criterion the method imposes is that it is better to be non-deprived than deprived in any indicator (Sonne-Schmidt et al. 2008; Arndt et al. 2012). This is the approach adopted in this study to investigate multidimensional poverty in Nigeria over time and space.

The FOD approach is a simple form of stochastic ordering applied in decision situations characterized by a probability distribution over possible binary outcomes. The approach describes the criterion in which one distribution can be ranked unambiguously 'better' than another, allowing us to make welfare comparisons between two populations on the basis of a series of discrete, ordinal welfare indicators without imposing arbitary weighting schemes or conditions on the social welfare function (Arndt et al. 2012).

This approach is well established in the theory of one-dimensional ${ }^{7}$ and multidimensional FOD. ${ }^{8}$ It allows for comparison between populations over time, on the basis of a series of binary ordinal welfare indicators. Therefore, the binary variables were created for each indicator, where ' 1 ' is the good outcome (non-deprived) and ' 0 ' is the bad outcome (deprived). Therefore, the outcome $(0,0,0,0,0)$ indicates deprivation in all indicators of well-being while the outcome $(1,1,1,1,1)$ means non-deprivation in all of the dimensions.

FOD is operationalized through the principles of the linear programming. To ameliorate the lack of information inherent in indeterminate outcomes of dominance, a bootstrapping approach is applied. In comparing repeated bootstrap samples, the empirical probability of domination provides an estimate of the extent to which one population dominates another. Furthermore, the probability of net domination (the probability a population dominates all other populations minus the probability that a population is dominated by all other populations) can be interpreted as a measure of welfare, which provides the basis to rank populations. Bootstrapping is a computational non-parametric technique for resampling and enables conclusions to be drawn based on the characteristics of the population. We ran the bootstrap analysis with 100 replications.

The analysis captured both spatial and temporal welfare domination for geopolitical zones and rural/urban sectors. Temporal FOD analysis measures domination of one time period over another in the same

\footnotetext{
7 See Østerdal (2010) and Arndt et al. (2012) for detailed discussion.

8 See Lehmann (1955), Strassen (1965), Levhari et al. (1975), Grant (1995) (cross reference from Arndt et al. 2012).
} 
population. We define three possibilities of temporal domination for each population (states, geopolitical zones, and rural/urban sectors) as follows:

0 : neither $t+s$ FOD $t$ nor $t$ FOD $t+s$

1: $\mathrm{t}+\mathrm{s}$ FOD $\mathrm{t}$

$-1:$ t FOD $t+s$

where $t$ is a year such as 1999 and $s$ is greater than or equal to one. These possible outcomes are averaged over all bootstrap iterations.

\subsubsection{Data Sources}

The study utilized the Nigeria Demographic Health Surveys (DHS) of 1999, 2003, and 2008 for the analysis. The 1999, 2003, and 2008 DHS are nationally representative surveys covering both urban and rural households. The surveys follow a stratified cluster sampling design. Details of the research design can be found in the final reports (NPC and ORC Macro 1999, 2004, and NPC and ICF Macro 2009). As indicated in the surveys, 7,647, 7,225, and 34,070 households were surveyed in 1999,2003 , and 2008, respectively. Due to the removal of missing values, 7,354, 7,121 , and 32,896 households in 1999, 2003, and 2008 were utilized for the analysis.

\subsubsection{Choice of Welfare Indicators}

Poverty can be reflected in various broad dimensions. The welfare indicators used in this study are education, water, sanitation, shelter, and energy. All are binary variables (1: not deprived 0: deprived). The indicators are defined as follows:

Water: a household is not deprived if the household's water source is piped water, well water, or rainwater.

Sanitation: a household is not deprived if the household uses a flush toilet, an improved, ventilated pit latrine, or a composting toilet.

Access to electricity: a household is not deprived if the household has access to electricity.

Shelter: a household is not deprived if the household has flooring made of a material other than dirt, sand, or dung.

Education: a household is not deprived if any household member has completed three or more years of schooling at the primary level or above.

\subsection{Results and Discussion}

The analyses were conducted at the national, zonal, and sectoral (rural and urban) levels. Five binary indicators were selected, as mentioned in section 
10.3.3, and the number of possible welfare combinations is $2^{5}=32$, giving us 32 comparator subgroups. The national, zonal, and sectoral results are based on the 1999, 2003, and 2008 DHS datasets. ${ }^{9}$

\subsubsection{Households According to Welfare Indicators}

Table 10.4 presents the proportion of Nigerian households that are not deprived by the five different welfare indicators at national, zonal, and sectoral levels based on the 1999, 2003, and 2008 DHS datasets. Nationally, the table indicates a positive change in welfare indicators between 1999 and 2008 with the exception of education, which had a small negative change. However, the proportion of Nigerian households that had access to electricity declined from 51 per cent in 2003 to 48 per cent in 2008 and a similar decrease can be observed for shelter (64 per cent in 2003 and 62 per cent in 2008).

The change in deprivation levels from 1999 to 2008 varies across welfare indicators and areas. Both the urban and rural sectors experienced deterioration in two indicators between 1999 and 2008-water and electricity for urban populations and shelter and education for rural areas. The North Central zone performed the worst with negative changes in all welfare indicators except sanitation.

\subsubsection{Share of Households in Multidimensional Welfare Combinations}

Table 10.5 shows the percentage share of Nigerian households by the combination of welfare indicators for the nation, zones, and sectors from the 1999, 2003, and 2008 DHS surveys. The number of deprivations in the welfare indicators range from 0 to 5 where 0 signifies zero deprivation (a case of nondeprivation in any indicator $(1,1,1,1,1)$ ) and 5 implies acute deprivation (deprivation in all welfare indicators $(0,0,0,0,0)$ ). Between the two extremes are the various combinations of welfare indicators. However, our discussion will only consider the two extremes, i.e. acute deprivation and zero deprivation.

Nationally, the share of households experiencing acute deprivation (deprived in all indicators) was 3.3 per cent in 1999. It declined to 2.4 per cent in 2003, but increased to 3.1 per cent in 2008, although it remained below the 1999 level. Substantial improvement can be observed in the percentage of households with no deprivation (zero), with a 5.5 percentage point improvement from 13.4 to 18.9 per cent over the ten-year period. In the urban sector, only 0.4 per cent of households experienced acute deprivation in 2008 compared to 4.4 per cent in the rural sector. The share of rural households not

${ }^{9}$ Population weights are used throughout the analysis. 


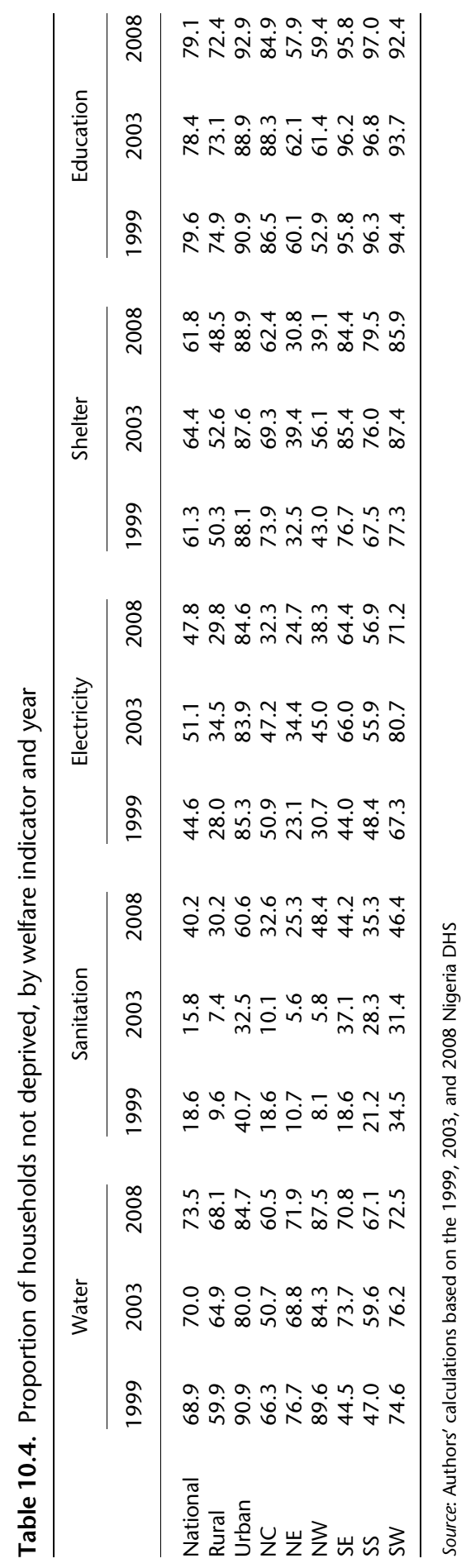


Table 10.5. Percentage distribution of households by number of deprivations

\begin{tabular}{lrrrrrrrrr}
\hline & National & Urban & Rural & NC & NE & NW & SE & SS & SW \\
\hline 1999 & & & & & & & & & \\
0 & 13.4 & 36.1 & 4.1 & 9.9 & 7.2 & 3.7 & 11.9 & 16.5 & 30.8 \\
1 & 20.3 & 38.5 & 12.9 & 29.3 & 7.6 & 16.0 & 15.2 & 18.6 & 30.2 \\
2 & 19.7 & 14.1 & 21.9 & 25.9 & 14.1 & 19.9 & 28.6 & 18.9 & 12.9 \\
3 & 22.6 & 7.9 & 28.6 & 20.0 & 28.7 & 26.8 & 30.3 & 23.5 & 10.8 \\
4 & 20.7 & 3.2 & 27.9 & 11.9 & 37.0 & 28.8 & 13.1 & 20.0 & 12.9 \\
5 & 3.3 & 0.2 & 4.6 & 3.0 & 5.5 & 4.9 & 1.0 & 2.5 & 2.4 \\
2003 & & & & & & & & & \\
0 & 12.7 & 27.3 & 5.4 & 6.7 & 3.9 & 4.5 & 31.0 & 24.2 & 25.9 \\
1 & 21.8 & 40.1 & 12.5 & 18.0 & 10.9 & 21.4 & 27.5 & 18.8 & 45.8 \\
2 & 21.9 & 17.8 & 24.0 & 30.9 & 19.9 & 24.5 & 18.5 & 20.6 & 11.5 \\
3 & 22.0 & 9.0 & 28.6 & 25.4 & 27.0 & 23.5 & 15.8 & 23.5 & 7.7 \\
4 & 19.2 & 4.4 & 26.6 & 16.7 & 33.5 & 23.9 & 6.5 & 11.8 & 6.9 \\
5 & 2.4 & 1.3 & 3.0 & 2.3 & 4.8 & 2.2 & 0.7 & 1.1 & 2.2 \\
2008 & & & & & & & & & \\
0 & 18.9 & 42.5 & 7.3 & 14.7 & 4.3 & 9.8 & 27.2 & 23.8 & 35.5 \\
1 & 23.5 & 36.6 & 17.1 & 16.7 & 13.7 & 20.4 & 30.9 & 27.5 & 32.0 \\
2 & 19.6 & 13.5 & 22.6 & 22.0 & 17.1 & 23.4 & 22.9 & 20.1 & 12.2 \\
3 & 20.3 & 5.1 & 27.7 & 24.9 & 26.6 & 27.3 & 13.0 & 18.5 & 8.7 \\
4 & 14.7 & 1.9 & 20.9 & 16.5 & 30.1 & 17.0 & 5.2 & 9.3 & 9.2 \\
5 & 3.1 & 0.4 & 4.4 & 5.1 & 8.3 & 2.1 & 0.8 & 0.7 & 2.4 \\
\hline
\end{tabular}

Source: Authors' calculations based on the 1999, 2003, and 2008 Nigeria DHS

deprived in any indicator marginally improved by 3.2 percentage points over the ten-year period.

Among the geopolitical zones, acute deprivation ranged from 1.0 per cent in the South East to 5.5 per cent in the North East zone in 1999. The proportion of households in the North East experiencing acute deprivation increased by over one-half from 5.5 per cent in 1999 to 8.3 per cent in 2008 , while zero deprivation declined by almost one-half in the same period, 7.2 per cent and 4.3 per cent in 1999 and 2008, respectively. Generally, the northern zones are characterized by a higher share of acute deprivation and a marginal share in zero deprivation compared to the southern zones.

\subsubsection{Domination Comparisons: Spatial Analyses}

Spatial FOD static and bootstrap comparisons from the 1999, 2003, and 2008 DHS for the nation, zones, and sectors are reported in Tables 10.6-10.11. These are FOD comparisons across populations at a given point in time. In each table, the row (column) averages indicate the probability that a population dominated (is dominated by) other populations. In other words, a relatively large row and column average implies a relatively well-off population and a relatively poor population respectively. 
Table 10.6. 1999 DHS static spatial FOD comparisons

\begin{tabular}{lllllllllll}
\hline Area & National & Rural & Urban & NC & NE & NW & SE & SS & SW & Avg. \\
\hline National & & 1 & & & & & & & & 0.13 \\
Rural & & & & & & & & & & \\
Urban & 1 & 1 & & 1 & 1 & 1 & & & 0.00 \\
NC & & 1 & & & & & & & & 0.63 \\
NE & & & & & & & & & & 0.13 \\
NW & & & & & & & & & & 0.00 \\
SE & & & & & & & & & & 0.00 \\
SS & & & & & & & & & & 0.00 \\
SW & & 1 & & & & & & & & \\
Average & 0.13 & 0.50 & 0.00 & 0.13 & 0.13 & 0.13 & 0.00 & 0.00 & 0.00 & 0.11 \\
\hline
\end{tabular}

Source: Authors' calculations based on the 1999 Nigeria DHS

Table 10.7. 1999 DHS bootstrap spatial FOD comparisons (probabilities)

\begin{tabular}{|c|c|c|c|c|c|c|c|c|c|c|}
\hline Area & National & Rural & Urban & NC & NE & NW & SE & SS & SW & Avg. \\
\hline National & & 1 & & & 0.02 & & & & & 0.13 \\
\hline Rural & & & & & & & & & & 0.00 \\
\hline Urban & 1 & 1 & & 0.9 & 1 & 0.79 & & & 0.01 & 0.59 \\
\hline NC & 0.01 & 0.6 & & & 0.04 & & & & & 0.08 \\
\hline NE & & & & & & & & & & 0.00 \\
\hline NW & & & & & 0.03 & & & & & 0.00 \\
\hline SE & & & & & & & & & & 0.00 \\
\hline SS & & 0.02 & & & & & & & & 0.00 \\
\hline SW & 0.26 & 0.83 & & 0.12 & 0.22 & & 0.01 & 0.06 & & 0.19 \\
\hline Average & 0.16 & 0.43 & 0.00 & 0.13 & 0.16 & 0.10 & 0.00 & 0.01 & 0.00 & 0.11 \\
\hline
\end{tabular}

Source: Authors' calculations based on the 1999 Nigeria DHS

Table 10.8. 2003 DHS static spatial FOD comparisons

\begin{tabular}{lllllllllll}
\hline Area & National & Rural & Urban & NC & NE & NW & SE & SS & SW & Avg. \\
\hline $\begin{array}{l}\text { National } \\
\text { Rural }\end{array}$ & & 1 & & & 1 & & & & & 0.25 \\
Urban & 1 & 1 & & 1 & 1 & & & & & 0.00 \\
NC & & & & & & & & & & 0.50 \\
NE & & & & & & & & & & 0.00 \\
NW & 1 & 1 & & 1 & 1 & & & & & 0.00 \\
SE & 1 & & & & & & & & & 0.50 \\
SS & 1 & 1 & & 1 & 1 & & & & & 0.00 \\
SW & 1 & & & & & & & & \\
Average & 0.38 & 0.50 & 0.00 & 0.38 & 0.50 & 0.00 & 0.00 & 0.00 & 0.00 & 0.19 \\
\hline
\end{tabular}

Source: Authors' calculations based on the 2003 Nigeria DHS

The urban sector consistently had the highest probability of dominating in all the three periods and strongly dominated the rural sector in all three years. On the other hand, the average probability of the rural sector being dominated steadily increased from 43 per cent in 1999 to 50 per cent in 2008 in the bootstrapped results (Tables 10.7 and 10.11). Performance among the zones 
Table 10.9. 2003 DHS bootstrap spatial FOD comparisons (probabilities)

\begin{tabular}{|c|c|c|c|c|c|c|c|c|c|c|}
\hline Area & National & Rural & Urban & $\mathrm{NC}$ & NE & NW & SE & SS & SW & Avg. \\
\hline National & & 0.94 & & & 0.61 & & & & & 0.19 \\
\hline Rural & & & & & 0.09 & & & & & 0.01 \\
\hline Urban & 0.94 & 0.94 & & 0.42 & 0.98 & 0.09 & & & & 0.42 \\
\hline NC & & 0.01 & & & 0.01 & & & & & 0.00 \\
\hline NE & & & & & & & & & & 0.00 \\
\hline NW & & & & & 0.2 & & & & & 0.03 \\
\hline SE & 0.59 & 0.84 & & 0.87 & 0.7 & 0.01 & & 0.14 & & 0.39 \\
\hline SS & 0.02 & 0.13 & & 0.29 & 0.11 & & 0.01 & & & 0.07 \\
\hline SW & 0.56 & 0.79 & & 0.48 & 0.86 & 0.01 & 0.01 & & & 0.34 \\
\hline Average & 0.26 & 0.46 & 0.00 & 0.26 & 0.45 & 0.01 & 0.00 & 0.02 & 0.00 & 0.16 \\
\hline
\end{tabular}

Source: Authors' calculations based on the 2003 Nigeria DHS

Table 10.10. 2008 DHS static spatial FOD comparisons

\begin{tabular}{|c|c|c|c|c|c|c|c|c|c|c|}
\hline Area & National & Rural & Urban & $\mathrm{NC}$ & NE & NW & SE & SS & SW & Avg. \\
\hline National & & 1 & & & 1 & & & & & 0.25 \\
\hline Rural & & & & & & & & & & 0.00 \\
\hline Urban & 1 & 1 & & 1 & 1 & & & & 1 & 0.63 \\
\hline $\mathrm{NC}$ & & & & & & & & & & 0.00 \\
\hline NE & & & & & & & & & & 0.00 \\
\hline NW & & & & & 1 & & & & & 0.13 \\
\hline SE & & 1 & & 1 & & & & & & 0.25 \\
\hline SS & & & & 1 & & & & & & 0.13 \\
\hline SW & & 1 & & 1 & 1 & & & & & 0.38 \\
\hline Average & 0.13 & 0.50 & 0.00 & 0.50 & 0.50 & 0.00 & 0.00 & 0.00 & 0.13 & 0.19 \\
\hline
\end{tabular}

Source: Authors' calculations based on the 2008 Nigeria DHS

Table 10.11. 2008 DHS bootstrap spatial FOD comparisons (probabilities)

\begin{tabular}{|c|c|c|c|c|c|c|c|c|c|c|}
\hline Area & National & Rural & Urban & $\mathrm{NC}$ & NE & NW & SE & SS & SW & Avg. \\
\hline National & & 1 & & & 0.67 & & & & & 0.21 \\
\hline Rural & & & & & 0.03 & & & & & 0.00 \\
\hline Urban & 1 & 1 & & 1 & 1 & 0.1 & & & 0.6 & 0.59 \\
\hline $\mathrm{NC}$ & & & & & & & & & & 0.00 \\
\hline $\mathrm{NE}$ & & & & & & & & & & 0.00 \\
\hline NW & & & & & 0.68 & & & & & 0.09 \\
\hline SE & 0.09 & 0.83 & & 0.97 & 0.32 & & & & & 0.28 \\
\hline SS & & 0.23 & & 0.71 & 0.1 & & & & & 0.13 \\
\hline SW & 0.17 & 0.97 & & 0.98 & 0.54 & & & & & 0.33 \\
\hline Average & 0.16 & 0.50 & 0.00 & 0.46 & 0.42 & 0.01 & 0.00 & 0.00 & 0.08 & 0.18 \\
\hline
\end{tabular}

Source: Authors' calculations based on the 2008 Nigeria DHS 


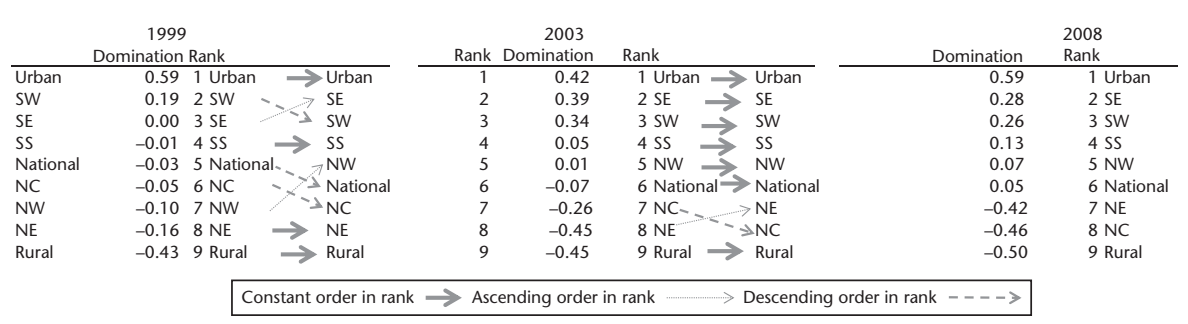

Figure 10.3. Spatial FOD ranking and probability of net domination for national, sectoral, and zonal levels in 1999, 2003, and 2008

Source: Authors' calculations based on the 1999, 2003, and 2008 Nigeria DHS

indicated that southern zones had higher probabilities of dominating compared to the northern zones. Notably, the South West zone almost doubled its probability of dominating over the ten-year period. However, the probability of the North Central and North East zones being dominated increased considerably from 13 and 16 per cent in 1999 to 46 and 42 per cent in 2008 (Table 10.7 and 10.11). This implies that the rural sector, North Central, and North East geopolitical zones are relatively poor while South West and the urban sector are relatively wealthy.

\subsubsection{Net Dominance and Inequality}

Net dominance is the difference between the average probability of dominating and being dominated by all other areas, i.e. the column average minus the row average. Net dominance is an indicator of the strength of domination over others and allows populations to be ranked. It is also an indicator of inequality. While positive figures indicate a high dominancy level and negative figures show low dominancy, an increase(decrease) in these values over time is related to increase(decrease) in inequality across the different populations. Figure 10.3 presents the change in dominance and ranks the populations (national, rural, and urban sectors, and the six geopolitical zones) across time.

The national net domination was -0.03 and -0.07 in 1999 and 2003 respectively but moved to marginal positive net dominance (0.05) in 2008. While the urban sector consistently maintained the highest ranking, the rural sector had the lowest ranking throughout the ten years. A significant change in rankings could be observed within the populations between 1999 and 2003, but between 2003 and 2008 the movement was not dramatic with North East moving up by one point to the seventh position and North Central falling in ranking to the eighth position in 2008.

\subsubsection{Temporal FOD Comparisons}

The net temporal domination score is the average of the three possible outcomes in comparing one year to another, i.e. the average that one year 
Table 10.12. Temporal net FOD comparisons, DHS (probabilities)

\begin{tabular}{|c|c|c|c|c|c|c|}
\hline & \multicolumn{2}{|c|}{2003 FOD 1999} & \multicolumn{2}{|c|}{2008 FOD 1999} & \multicolumn{2}{|c|}{2008 FOD 2003} \\
\hline & Static & Boot & Static & Boot & Static & Boot \\
\hline NC & & -0.04 & & & & \\
\hline NE & & -0.01 & & & & \\
\hline NW & & 0.02 & & 0.07 & & \\
\hline National & & 0.01 & & 0.15 & & \\
\hline Rural & & 0.03 & & 0.04 & & \\
\hline SE & 1 & 0.36 & & 0.38 & & 0.05 \\
\hline SS & 1 & 0.4 & 1 & 0.6 & & 0.24 \\
\hline SW & & & & 0.03 & & 0.01 \\
\hline Urban & -1 & -0.37 & & & 1 & 0.45 \\
\hline
\end{tabular}

Source: Authors' calculations based on the 1999, 2003, and 2008 Nigeria DHS

dominates (1), neither dominates nor is dominated by (0), or is dominated by $(-1)$ another year over all bootstraps. Net domination scores for the nation, zones, and sectors are presented in Table 10.12.

Nationally, the temporal results show that 2003 dominated 1999 by a very low probability of 0.01 ; a slightly higher probability of 0.15 net domination can be observed between 2008 and 1999; and neither 2008 dominates 2003 nor 2003 dominates 2008. However, these are very low probabilities indicating little evidence of advancement over the years. Among the zones, North Central and North East experienced 1999 dominating 2003 while South East, South South, and South West experienced positive probability of dominance between 2008 and 2003 with the highest chance in the South South (0.24). In the sectors, the urban sector displays some probability of decline between 1999 and 2003 but had a high probability of 2008 dominating 2003 with 0.45 .

\subsection{Conclusion}

This study set out to appraise non-monetary multidimensional poverty in Nigeria using the FOD approach. The methodology is quite robust and lends credence to the general observation that the distribution of positive economic performance in Nigeria has not translated positively to improvements in welfare/poverty in the country over time. This is consistent with the lack of pro-poor growth observed by Ichoku et al. (2012).

The results indicate that Nigeria registered few gains in non-income poverty over the decade from 1999 to 2008 . While there was a decrease in the percentage of the population experiencing acute deprivation between 1999 and 2003, an increase was observed between 2003 and 2008, which resulted in a total decline of merely -0.25 percentage points between 1999 and 2008 . 
An examination of the performance of the five indicators over the decade indicates that only sanitation recorded a substantial positive change; education had a negative change; and the rest had an improvement of less than 10 per cent. The results indicate that the country has not achieved broad-based progress across a number of welfare indicators for different populations especially in indicators like water, education, and electricity that are directly accruable from public expenditure.

The spatial FOD comparisons indicate that regional inequalities remain profound with huge disparities mirrored also in the results for states. ${ }^{10}$ The FOD temporal results indicate that the probability of experiencing welfare improvement between any two years was low. South East, South South, South West zones, and the urban sector were the only areas with positive probability of advancement between 1999 and 2008; however, the probabilities for South South and South West zones were virtually zero.

It is imperative that Nigeria finds a recipe for making growth inclusive while alleviating poverty in a larger part of the country, recognizing that poverty rates appear to be geographically concentrated in some zones and rural areas.

\section{References}

Adetola, A. and P. Olufemi (2012). 'Determinants of Child Poverty in Rural Nigeria: A Multidimensional Approach', Global Journal of Human Social Science Arts \& Humanities, 12(12): 38-52.

Ajakaiye, O. and A. Jerome (2011). 'The Role of Institutions in the Transformation of the Nigerian Economy'. Paper presented at the 52nd Annual Conference of the Nigerian Economic Society. Covenant University, Ota, Nigeria, 13-15 September.

Ajakaiye, O., A. Jerome, O. Olaniyan, K. Mahrt, and O. Alaba. (2014). 'Multidimensional Poverty in Nigeria: First Order Dominance Approach', UNU-WIDER Research Paper WP2014/143, Working Paper Series, World Institute for Development Economic Research (UNU-WIDER).

Alkire, S. and J. Foster (2007). 'Counting and Multidimensional Poverty Measurement', Working Paper 7. Oxford: Oxford University, Oxford Poverty \& Human Development Initiative.

Anderson, G., I. Crawford, and A. Liecester (2005). 'Statistical Tests for Multidimensional Poverty Analysis'. Paper presented at the International Conference on the Many Dimensions of Poverty. Brasilia, Brazil: Carlton Hotel, 29-31 August.

Arndt, C., R. Distante, M. A. Hussain, L. P. Østerdal, P. Huong, and M. Ibraimo (2012). 'Ordinal Welfare Comparisons with Multiple Discrete Indicators: A First Order

\footnotetext{
${ }^{10}$ A detailed result of state analyses can be found in Ajakaiye et al. (2014).
} 
Dominance Approach and Application to Child Poverty', World Development, 40(11): 2290-301.

Atkinson, A. B. (2003). 'Multidimensional Deprivation: Contrasting Social Welfare and Counting Approaches', Journal of Economic Inequality, 1(1): 51-65.

Batana, Y. M. (2008). 'Multidimensional Measurement of Poverty in Sub-Saharan Africa', Working Paper 13. Oxford: Oxford University, Oxford Poverty \& Human Development Initiative.

Batana,Y. M. and J.-Y. Duclos (2008). 'Multidimensional Poverty Dominance: Statistical Inference and an Application to West Africa', CIRPEE Working Paper 08-08. Montreal: Centre interuniversitaire sur le risque, les politiques economiques et l'emploi.

Bourguignon, F. and S. Chakravarty (2003). 'The Measurement of Multidimensional Poverty', Journal of Economic Inequality, 1(1): 25-49.

Cerioli, A. and S. Zani (1990). 'A Fuzzy Approach to the Measurement of Poverty', in C. Dagum and M. Zenga (eds), Income and Wealth Inequality and Poverty. Berlin: Springer-Verlag, 272-84.

Central Bank of Nigeria (2012). Statistical Bulletin, vol. 23, December. Abuja: Central Bank of Nigeria.

Cheli, B. and A. Lemmi (1994). 'A Totally Fuzzy and Relative Approach to the Multidimensional Analysis of Poverty', Economic Notes, 24(1): 115-34.

Chiappero-Martinetti, E. (2006). 'Capability Approach and Fuzzy Set Theory: Description, Aggregation and Inference Issues', in A. Lemmi, and G. Betti (eds), Fuzzy Set Approach to Multidimensional Poverty Measurement. New York: Springer-Verlag, 93-113.

Di Tommaso, M. L. (2007). 'Children Capabilities: A Structural Equation Model for India', Journal of Socio-Economics, 36(3): 436-50.

Deutsch, J. and J. Silber (2005). 'Measuring Multidimensional Poverty: An Empirical Comparison of Various Approaches', Review of Income and Wealth, International Association for Research in Income and Wealth, 51(1): 145-74.

Grant, S. (1995). 'A Strong (Ross) Characterization of Multivariate Risk Aversion', Theory and Decision, 28: 131-52.

Ichoku, H. E., C. Agu, and J. E. Ataguba (2012). 'What Do We Know about Pro-Poor Growth and Regional Poverty in Nigeria?', International Journal of Economic Sciences and Applied Research, 5(3): 147-72.

IMF (International Monetary Fund) (2013). 'Nigeria: 2012 Article IV Consultation', Country Report 13/116. Washington, DC: IMF.

Katsouris, C. and A. Sayne (2013). Nigeria's Criminal Crude: International Options to Combat the Export of Stolen Oil. London: Chatham House.

Klasen, S. (2000). 'Measuring Poverty and Deprivation in South Africa', Review of Income and Wealth, 46(1): 33-58.

Krishnakumar, J. and P. Ballon (2008). 'Estimating Basic Capabilities: A Structural Equation Model Applied to Bolivia', World Development, 36(6): 992-1010.

Layte, R., B. Nolan, and C. T. Whelan (2001). 'Reassessing Income and Deprivation Approaches to the Measurement of Poverty in the Republic of Ireland', Economic and Social Review, 32(3): 239-61.

Lehmann, E. L. (1955). 'Ordered Families of Distributions', Annals of Mathematical Statistics, 26: 399-419. 
Levhari, D., J. Paroush, and B. Peleg (1975). 'Efficiency Analysis for Multivariate Distributions', Review of Economic Studies, 42: 87-91.

Lovell, C. A. K., S. Richardson, P. Travers, and L. Wood (1994). 'Resources and Functionings: A New View of Inequality in Australia', in W. Eichhorn (ed.), Models and Measurement of Welfare and Inequality. Heidelberg: Springer-Verlag, 707-807.

Maasoumi, E. (1993). 'A Compendium to Information Theory in Economics and Econometrics', Econometric Reviews, 12(2): 137-81.

Maasoumi, E. and M. A. Lugo (2008). 'The Information Basis of Multivariate Poverty Assessments', in N. Kakwani and J. Silber (eds), Quantitative Approaches to Multidimensional Poverty Measurement. New York: Palgrave Macmillan, 1-29.

NBS (National Bureau of Statistics) (2009). Annual Abstract of Statistics. Abuja, Nigeria: National Bureau of Statistics.

NBS (National Bureau of Statistics) (2012). Nigeria Poverty Profile 2010. Abuja, Nigeria: National Bureau of Statistics.

NPC (National Population Commission) (Nigeria) and ORC Macro (1999). 'Nigeria Demographic and Health Survey, 1999'. Calverton, MD: National Population Commission and ORC Macro.

NPC (National Population Commission) and ORC Macro (2004). 'Nigeria Demographic and Health Survey, 2003'. Calverton, MD: National Population Commission and ORC Macro.

National Population Commission (NPC) (Nigeria) and ICF Macro (2009). 'Nigeria Demographic and Health Survey, 2008'. Abuja, Nigeria: National Population Commission (NPC) (Nigeria) and ICF Macro.

Østerdal, L. P. (2010). 'The Mass Transfer Approach to Multivariate Discrete First Order Stochastic Dominance: Direct Proof and Implications', Journal of Mathematical Economics, 46: 1222-8.

Oyekale, T. O., F. Y. Okunmadewa, B. T. Omonona, and O. A. Oni (2009). 'Fuzzy Set Approach to Multidimensional Poverty Decomposition in Rural Nigeria', Journal of Agricultural Economics, 6(3-4): 7-44.

Sahn, D. and D. Stifel (2003). 'Exploring Alternative Measures of Welfare in the Absence of Expenditure Data', Review of Income and Wealth, 49(4): 463-89.

Sen, A. K. (1973). On Economic Inequality. Oxford: Clarendon Press.

Sen, A. K. (2004). 'Dialogue: Capabilities, Lists and Public Reasons: Continuing the Conversation', Feminist Economics, 10(3): 77-80.

Sonne-Schmidt, C., F. Tarp, and L. P. Østerdal (2008). 'Ordinal Comparison of Multidimensional Deprivation: Theory and Application', Discussion Paper 08-33. Copenhagen: University of Copenhagen, Department of Economics.

Strassen, V. (1965). 'The Existence of Probability Measures with Given Marginal', Annals of Mathematical Statistics, 36: 423-39.

Tsui, K. (2002). 'Multidimensional Poverty Indices', Social Choice and Welfare, 19(1): 69-93. Wagle, U. (2005). 'Multidimensional Poverty Measurement with Economic Wellbeing, Capability, and Social Inclusion: A Case from Kathmandou, Nepal', Journal of Human Development, 6: 301-28.

World Bank (2013). 'Nigeria: Economic Report, No. 1'. Washington DC: World Bank. Available at <http://documents.worldbank.org/curated/en/2013/05/17708026/ nigeria-economic-report>. 
World Bank (2014a). 'Nigeria: Economic Report No. 2'. Washington, DC: World Bank. Available at <http://documents.worldbank.org/curated/en/2014/07/19883231/ nigeria-economic-report-no-2>.

World Bank (2014b). World Development Indicators. Available at <data.worldbank. org >, accessed 28 October 2014.

World Statistics Pocketbook, 2014 edition (Series V, No. 38), <http://data.un.org/ CountryProfile.aspx?crName=Nigeria $>$, accessed 10 February 2015. 


\title{
11
}

\section{Growth and Poverty Reduction in Tanzania}

\author{
Channing Arndt, Lionel Demery, Andy McKay, and Finn Tarp
}

\subsection{Introduction}

Tanzania is the fifth largest country in sub-Saharan Africa in terms of population, accounting for around 5 per cent of the region's people. It is a major economy in East Africa and an active member of the East African Community. Tanzania is also actively involved in Southern African discussions, being a member of the Southern African Development Community (SADC).

Julius Nyerere, the first President of Tanzania from shortly after its independence in 1962 until 1985, pursued a development policy based on a vision of African socialism, in particular between 1967 and the late 1970s. The economy deteriorated sharply over this period, leaving Tanzania as one of the poorest and most aid-dependent countries in the world. At the same time, Tanzania made progress in many aspects of social development. From the 1970s onwards, Tanzania increasingly borrowed from the IMF and the World Bank; and after Nyerere's departure in 1985, the country started to undertake reforms in order to pursue more market-oriented policies. Over time, better economic performance followed, though growth remained slow even in the 1990s. Since around 2000, Tanzania has reported an improved economic growth performance.

Tanzania is also by now well known for not having been able to translate this growth into a significant reduction in monetary poverty. This apparent contrast, which has dominated recent literature on Tanzania's economic performance, is an important focus of this chapter. Authors who have also addressed this conundrum include Atkinson and Lugo (2010), Demombynes and Hoogeveen (2007), Hoogeveen and Ruhinduka (2009), Kessy et al. (2013), Mashindano et al. (2011), Mkenda et al. (2010), Osberg and Bandara (2012), Arndt et al. (2013), and World Bank (2007, 2012, 2013). The general conclusion 
from these studies is that growth and consumption-based poverty are in several respects 'delinked' (Pauw and Thurlow 2011). The GDP elasticity of poverty reduction of around -0.21 for the period 2001-7 illustrates this weak effect. While more recent data suggest a possible improvement (the elasticity increasing to -0.80 during the period 2007-12), the available data continue to point to a weak link between economic growth and monetary poverty reduction.

Reflecting the above observation, this chapter begins by analysing the recent pattern of growth in Tanzania and considers the likely consequences of this for poverty reduction, over a period characterized by large increases in the prices of food and fuel. The first part of the chapter focuses on the record in terms of monetary poverty and its seeming unresponsiveness to growth. Much of the focus is on the period since 2000 when the seeming disconnect arises. The 1990s were characterized by limited growth and limited poverty reduction between 1991/2 and 2001 (from 38.6 per cent to 35.7 per cent). As noted, the national accounts data report improved growth in per capita GDP and average per capita private consumption since around 2000, while the rate of monetary poverty reduction has continued to be slow. Four main household surveys are used for the analysis, the Household Budget Surveys (HBS) conducted in 1991/2, 2000/1, 2007, and 2011/12. ${ }^{1}$ We also draw on Demographic and Health Surveys (DHS) to assess progress in non-monetary domains.

Key to understanding the difficulties in analysing how growth and poverty interact in Tanzania is the fact that there are serious issues with the underlying data. These concern both the national accounts estimates of economic growth (Jerven 2011) and the household survey evidence on poverty trends (Eele et al. 2000; World Bank 2015). Both are decidedly questionable in tracking changes over time, which is a central concern addressed in this chapter. To add to that, the national accounts were then rebased in November 2014 (an issue not addressed in detail here), but this does not change the overall growth story from the national accounts. This data uncertainty is one key feature of this chapter. Nevertheless, both the surveys and the national accounts suggest a somewhat slower growth in real private consumption which is then somewhat less out of line with the progress in relation to monetary poverty. Importantly, the non-monetary indicators show reasonably good progress since 1991.

The chapter first presents in section 11.2 the economic growth story over a longer period of time and then in more detail over the period covered by the four Household Budget Surveys. A discussion of the macroeconomic

1 See World Bank (2015) for the latest World Bank report. 
composition of growth considers the likely implications for progress in poverty reduction. The responsiveness of poverty to growth is discussed in detail in section 11.3. This discussion highlights major differences between the national-accounts-based measures of growth and the growth in average household consumption from the household surveys. How responsive poverty is to growth depends critically on how growth is measured. Section 11.4 then looks at the nature of consumption poverty reduction in more detail. While results for the more recent period might suggest a more positive poverty reduction record, concerns about data comparability and the adequacy of price adjustments raise the question of how robust this finding is. Evidence on selected, more straightforwardly measured non-monetary indicators of deprivation is briefly reviewed in section 11.5 , after which section 11.6 concludes.

\subsection{The Recent Pattern of Growth in Tanzania}

The data presented in this section precede the rebasing of the national accounts in November 2014. Though the data rebased in 2007 are now available, currently available data do not provide information before 2007 and so do not enable a longer-term consideration of growth. We use the original data here, though comment on any points of difference over the 2007-12 period evident in the rebased data; these are generally small.

Data from World Development Indicators on real GDP in local currency values from 1988 to 2013 (prior to the rebasing) are presented in Figure 11.1. This chart confirms that the 1990s were characterized by at best modest growth, as well as some periods of decline. By contrast since 2001 annual growth in real per capita GDP averaged 3.9 per cent a year, and was never less than 2.9 per cent, which occurred in 2009 following the financial, food, and fuel crises.

A more detailed presentation of the national accounts is set out in Table 11.1 corresponding to the periods covered by the four Household Budget Surveys (HBS). This confirms the difference between the 1990s and the period since 2000. Real GDP in 2001 prices grew at an average rate of 3.8 per cent per annum between 1992 and 2001, by 7.2 per cent per annum between 2001 and 2007, and 6.6 per cent between 2007 and 2012 (6.2 per cent in 2007 prices using the rebased data). Population growth averaged 2.9 per cent over the 1992-2012 period, so this translates into slow per capita GDP growth in the 1990s, and then more satisfactory, though by no means impressive, growth in real per capita GDP since 2001.

A disaggregation of the overall growth rate provides important clues about its expected poverty reduction impacts. Looking first at GDP by expenditure 


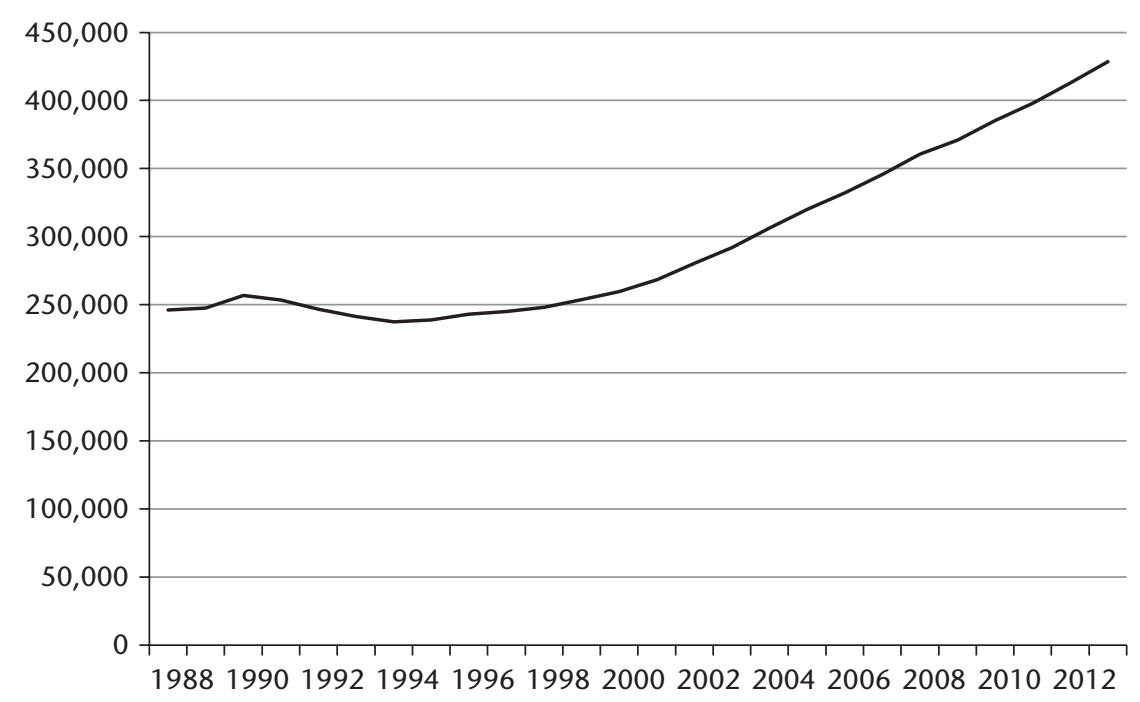

Figure 11.1. Growth of real local currency per capita GDP in Tanzania Source: World Development Indicators, 2014

component, the national accounts estimate of private consumption grew by only 0.9 per cent per annum between 1991 and 2001; but by 6.6 per cent and 6.9 per cent per annum over the periods $2001-7$ and 2007-12 respectively (5.7 per cent between 2007 and 2012 with the rebased data). Private consumption therefore fell in per capita terms between 1991 and 2001. Importantly, public consumption grew much faster than private consumption over each of these periods.

There were also very large increases in investment over each of these subperiods, generally at much faster rates than consumption. Available data do not enable a public-private disaggregation for the 1992-2001 years. The government predominantly accounted for the investment growth between 2001 and 2007, while between 2007 and 2012 private investment dominates, including investment for natural resource exploitation.

It is also clear that Tanzania had a sharply negative balance of trade throughout this period. Imports supported this consumption and investment growth. In 1991 net exports were -5.8 per cent of GDP; by 2007 and 2012 this figure had reached -15.0 and -26.8 per cent respectively. The trade deficit growth from 1991 to 2007 probably reflects aid, while the deficit in 2007-12 is likely related to offshore natural gas and other resource investments (predominantly undertaken by the private sector).

The investments that have taken place form part of the explanation of the faster growth in the 2000s. The increased public consumption, and public investment in the first period, have implications for non-monetary outcomes 
Table 11.1. Real GDP growth, by expenditure category and sector, 1992, 2001, 2007, and 2012

\begin{tabular}{|c|c|c|c|c|c|c|c|}
\hline & \multicolumn{3}{|c|}{ Mean growth rates per annum } & \multicolumn{4}{|c|}{ Shares } \\
\hline & 1992-2001 & $2001-7$ & $2007-12$ & 1991 & 2001 & 2007 & 2012 \\
\hline \multicolumn{8}{|l|}{ By expenditure category } \\
\hline Real GDP (2001 prices) & 3.8 & 7.2 & 6.6 & 100.0 & 100.0 & 100.0 & 100.0 \\
\hline Consumption & $2.0^{*}$ & 8.0 & 8.0 & 99.7 & 86.8 & 90.7 & 94.9 \\
\hline Public & $14.8^{*}$ & 15.0 & 12.0 & 4.2 & 11.9 & 18.1 & 23.2 \\
\hline Private & $0.9^{*}$ & 6.6 & 6.9 & 95.8 & 75.0 & 72.6 & 71.7 \\
\hline Investment & 17.4 & 13.3 & 14.0 & 5.9 & 17.4 & 24.3 & 31.9 \\
\hline Gross fixed capital formation & & 13.5 & 14.0 & 5.8 & 17.0 & 24.0 & 31.5 \\
\hline Government & & 26.0 & 5.5 & & 3.2 & 8.4 & 8.7 \\
\hline Private & & 9.4 & 18.3 & & 13.8 & 15.6 & 22.8 \\
\hline Change in stocks & & 1.8 & 12.2 & 0.1 & 0.4 & 0.3 & 0.4 \\
\hline Net exports & & 32.2 & 24.6 & -5.8 & -4.3 & -15.0 & -26.8 \\
\hline \multicolumn{8}{|l|}{ By sector } \\
\hline Agriculture and fishing & & 4.4 & 3.9 & 44.7 & 30.7 & 26.2 & 22.8 \\
\hline Crops & & 4.7 & 4.2 & 32.9 & 21.4 & 18.6 & 16.5 \\
\hline Livestock & & 3.1 & 3.1 & 6.3 & 5.0 & 4.0 & 3.3 \\
\hline Forestry and hunting & & 3.4 & 3.4 & 3.0 & 2.5 & 2.0 & 1.7 \\
\hline Fishing & & 5.8 & 2.7 & 2.6 & 1.7 & 1.6 & 1.3 \\
\hline Industry and construction & & 9.9 & 7.7 & 15.1 & 18.0 & 20.9 & 21.8 \\
\hline Mining and quarrying & & 15.4 & 3.3 & 1.0 & 1.8 & 2.7 & 2.3 \\
\hline Manufacturing & & 8.8 & 8.4 & 7.6 & 8.4 & 9.2 & 9.9 \\
\hline Electricity and water & & 6.2 & 6.1 & 1.4 & 2.6 & 2.5 & 2.4 \\
\hline Electricity & & 6.5 & 6.3 & 1.3 & 2.2 & 2.1 & 2.0 \\
\hline Water & & 4.9 & 5.6 & 0.2 & 0.5 & 0.4 & 0.4 \\
\hline Construction & & 11.3 & 9.0 & 5.0 & 5.2 & 6.5 & 7.3 \\
\hline Services & & 7.9 & 7.9 & 37.5 & 45.5 & 47.3 & 49.9 \\
\hline Trade, hotels, and restaurants & & 7.7 & 7.8 & 14.8 & 15.8 & 16.2 & 17.0 \\
\hline Trade and repairs & & 8.3 & 8.3 & 0.0 & 13.0 & 13.8 & 14.8 \\
\hline Hotels and restaurants & & 4.6 & 4.9 & 0.0 & 2.8 & 2.4 & 2.2 \\
\hline $\begin{array}{l}\text { Transport and } \\
\text { communication }\end{array}$ & & 8.7 & 11.6 & 4.8 & 6.6 & 7.2 & 9.0 \\
\hline Transport & & 6.3 & 6.7 & 0.0 & 5.4 & 5.1 & 5.1 \\
\hline Communication & & 16.9 & 20.8 & 0.0 & 1.2 & 2.1 & 3.9 \\
\hline Finance intermediation & & 10.2 & 11.0 & 3.4 & 1.5 & 1.8 & 2.2 \\
\hline Real estate and business serv. & & 7.0 & 6.8 & 5.9 & 10.3 & 10.2 & 10.2 \\
\hline Public administration & & 9.5 & 6.1 & 6.0 & 7.0 & 8.0 & 7.7 \\
\hline Education & & 4.7 & 7.0 & 1.0 & 2.1 & 1.8 & 1.8 \\
\hline Health & & 8.4 & 6.7 & 0.6 & 1.3 & 1.4 & 1.4 \\
\hline $\begin{array}{l}\text { Other social and personal } \\
\text { serv. }\end{array}$ & & 2.8 & 3.3 & 1.1 & 0.9 & 0.7 & 0.6 \\
\hline
\end{tabular}

Note: *relates to period 1991-2001 instead of 1992-2001 due to missing data for 1992.

Source: World Bank and authors' computation from HBS datasets

for which government provision is important and help to set the stage for faster growth in the domestic economy. The relatively slow increase in aggregate private consumption taking place over much of this period suggests that slower progress in reducing monetary poverty might be expected. 
While data are not available to analyse the sectoral pattern of the growth in real GDP from 1992 to 2001, data in current prices for this period suggest faster growth in industry/construction and services compared with agriculture. The detailed pattern of real growth is available for the second and third sub-periods in Table 11.1. Particularly fast-growing subsectors over these periods include first and foremost communications, followed by financial intermediation, construction, transport and communication, manufacturing, trade and repairs, and in the earlier sub-period mining and quarrying. All showed significant growth rates. Again agriculture grew much more slowly over this period. Growth performance seems to have been better in urban areas than in rural areas, where poverty is concentrated.

The above review relies on aggregate macroeconomic figures. Both the expenditure composition of growth, which is oriented more to investment and government spending as opposed to private consumption, and its sectoral pattern, which is oriented towards urban sectors, suggest slower progress in reducing consumption-based poverty than might be presumed from headline GDP growth.

\subsection{Micro-Level Evidence on Consumption Poverty in Tanzania and its Responsiveness to Growth}

In this section, we turn to household-level data. Microeconomic analysis is possible based on the four Household Budget Surveys, conducted by the National Bureau of Statistics in 1991/2, 2000/1, 2007, and 2011/12. These are nationally representative surveys of the mainland Tanzania population. Among other things, they collect the data to estimate household consumption, which can then be used to measure living standards as total real household consumption per adult equivalent. There were some differences in the survey questionnaires used through time. Some revisions in 2011/12 compared with earlier rounds are of particular relevance. As a result, there were methodological differences in the analysis conducted across the two latest surveys, compared with the analysis originally done on the first three surveys. For this reason, two different estimates of poverty in 2007 have been made here in order to compare like with like.

The summary national-level poverty headcount estimates from these data, as published by the National Bureau of Statistics (1991/2-2007) (Government of Tanzania 2009) and the World Bank (2007-2011/12) are presented in Table 11.2. The poverty headcount in 1992 was 38.6 per cent. Estimates for 2000/1 and 2007, based on consumption measures constructed to be as comparable as possible, showed poverty headcounts of 35.7 per cent and 33.6 per cent respectively. Progress in reducing the poverty headcount over 


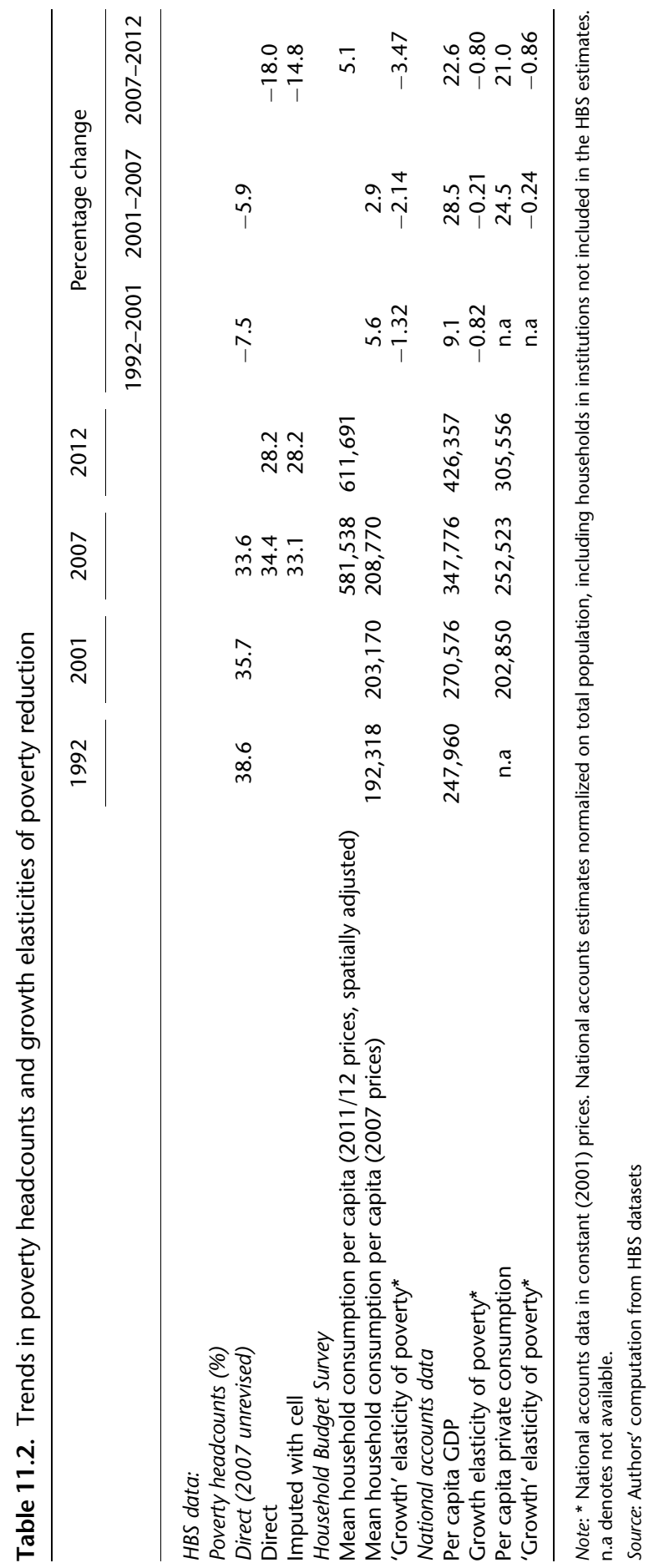


this fifteen-year period therefore appears to be quite slow, and the absolute numbers of poor people rose by an estimated 3.3 million. Between 2007 and $2011 / 12$ the poverty headcount is estimated to have fallen from a revised estimate of 34.4 per cent in 2007 to 28.2 per cent in 2011/12. This corresponds to a reduction in the absolute numbers of poor people by around 670,000.

Given the concern expressed at the beginning at the lack of responsiveness of poverty to growth, these figures are used next as a basis for estimating the growth elasticity of poverty reduction. Their construction for the three subperiods under consideration here is reported in Table 11.2. Two ways of doing this are pursued: one based on national accounts aggregates, and secondly an approach using the estimated growth in household consumption from the survey data.

In using national accounts data, the growth elasticity can be computed with respect to growth in per capita GDP or growth in per capita private consumption. With respect to per capita GDP, the elasticities are low, all less than one, and especially low between 2001 and 2007 when growth was fast (per capita GDP increased by 28.5 per cent) and poverty reduction was very modest, falling by only 2.9 percentage points or 5.9 per cent. The elasticity is higher between 2007 and 2011/12, when poverty reduction was faster and growth slightly slower, yet it was still only -0.80 . The elasticity with respect to per capita consumption is only slightly higher than the elasticities with respect to per capita GDP for the full period between 2001 and 2012.

Such statistics feed concerns about the poverty-reducing impact of growth in Tanzania. The values are low compared with several other African countries studied in this volume, to say nothing of some East Asian countries. This raises the question of what it is about the growth experience of Tanzania that results in such poverty outcomes, and what might be done to improve it in future.

When these same calculations are done in relation to the household-surveybased measure of consumption, the results paint a different picture. The growth in per capita consumption reported by the household survey data is generally much less, especially in the 2000s. Compared with the estimates of 24 and 21 cumulative per cent changes in real per capita private consumption expenditure over the 2001-7 and 2007-12 periods from the national accounts, the household surveys suggest cumulative changes over these periods of 2.9 per cent and 5.1 per cent respectively. The assessment of whether growth is effective in reducing poverty then critically depends on which of the two measures of aggregate real consumption one takes as the basis of analysis.

In Table 11.2, when we took the 'growth' denominator to be the percentage change in real private consumption per capita from the national accounts, the consumption growth elasticity of poverty reduction (based on changes between 2007 and 2012) was just -0.86. If instead we measured 'growth' using the percentage change in mean real household consumption per capita from the 
two household budget surveys, the estimated 'growth' elasticity of poverty increases to -3.5 . The elasticity estimated using household consumption is also significantly higher between 2000/1 and 2007. Poverty appears to be relatively unresponsive to growth only if the latter is measured from the national accounts. Using consumption measured in the HBSs (which is also used in the measurement of poverty itself) leads to a more optimistic assessment in terms of responsiveness-poverty did respond to much more limited 'growth'-but a less optimistic assessment in terms of consumption growth. In this view, the core issue underlying the limited poverty reduction is the lack of growth in real household consumption.

With this background, it is important to ask which measure of consumption should be considered more reliable. At the outset, it is important to recognize that there are differences between the two approaches to estimating consumption. The national accounts measure of private consumption is a macro-founded indicator, while the household-survey-based measure is a micro-founded indicator computed primarily for purposes of poverty analysis. In addition, the estimates are obtained in very different ways. Typically, the national accounts estimate of private consumption is obtained as a residual, once absorption by firms and government is accounted for. Surveys obtain their estimates directly from household interviews, based on respondent recall or diary keeping. There are strengths and weaknesses to both; yet the underlying concepts certainly overlap closely enough to suggest that similar estimates of levels and growth rates should emerge in general.

The observation that national accounts and household-survey-based estimates of consumption can differ significantly is not an issue unique to Tanzania; rather it is an issue which has been quite widely studied. Ravallion (2001: 5) concludes, 'it is evident that when the levels or growth rates from these two data sources differ there can be no presumption that the NAS [national accounts] is right and the surveys are wrong, or vice versa, since they are not really measuring the same thing, and both are prone to errors'. While these differences can be considered a problem, they also do have an advantage, in that each source can serve to triangulate the other. Ravallion (2001) finds that the divergence between the national accounts and survey estimates of consumption is greater when surveys centre on measuring income, rather than consumption. The general practice in African surveys to rely mainly on measuring consumption would reduce the divergence between the two sources. Deaton (2005), for example, finds that the average ratio of household consumption (measured in seventy-four surveys in sub-Saharan Africa) and private consumption from the national accounts is unity. ${ }^{2}$

\footnotetext{
2 Sub-Saharan Africa also exhibits a high variance in this ratio. Globally, the ratio of householdbased to national-accounts-based estimates is typically less than one.
} 
The household-survey-based approach is in many ways more closely related to the analysis of poverty-indeed, that is the purpose for which they were designed. In Tanzania's case, there is a challenge caused by a change in survey methodology between the 2007 and 2011/12 surveys. While the approach taken to measuring consumption was better in 2011/12 than in 2007, this change creates the risk that comparing the average consumption estimates from these two surveys with each other may overestimate the growth in consumption.

So, the key question is: Why are estimates of real consumption growth from the national accounts so much greater than those of the HBS? To start to explore this, we first compare nominal estimates of per capita household consumption between the national accounts and the household survey in the years of the latest two household surveys, 2007 and 2011/12. The survey estimates of average nominal consumption per capita were 306,072 TSh in 2007 and 611,691 TSh in 2011/12, while the national accounts estimates of private consumption per capita were 358,591 TSh in 2007 and 694,340 TSh in 2012. This implies annual growth rates of 14.9 per cent and 12.8 per cent respectively. Both the nominal levels of per capita consumption and their growth rates over the period are quite close despite the very different sources.

For welfare analysis, it is necessary to track changes in real consumption over time; and it is here the two approaches part company. When the series are deflated (the national accounts using a consumption component of the GDP deflator and the survey using survey-based prices and weights, both employing a single country-wide inflation estimate), there are significant differences in estimated changes in real consumption. The national accounts report a real per capita private consumption growth of 3.9 per cent per annum between 2007 and 2012, whilst the survey gives a growth in per capita household consumption of just 1.0 per cent per annum. Whereas in nominal terms the two consumption measures correspond reasonably well, when expressed in real terms, there is little correspondence between them; and they imply completely different growth and poverty scenarios.

So a major issue is the choice and reliability of the price deflators. In Tanzania, the implicit national accounts private consumption deflator indicates that prices rose by only 51 per cent between 2007 and 2012. This is marginally lower than the deflator for GDP as a whole (54 per cent). In contrast, according to the 2007 and 2011/12 HBS data, consumer prices faced by households on average rose by 90 per cent in the period. This makes a massive difference to the time trend in real household consumption. ${ }^{3}$ A similar issue arises between 2001 and 2007, and is discussed in the studies of poverty by Mkenda et al.

\footnotetext{
3 The CPI records price inflation of 75 per cent during this period-that is, somewhere between the national accounts consumption deflator and the HBS data.
} 
(2010) and Atkinson and Lugo (2010). That earlier period saw a bigger divergence between the private consumption deflator and the GDP deflator (Atkinson and Lugo 2010). But again, the key difference there is that between the national accounts deflator (which implied that prices increased by around 60 per cent over this period) and the survey data deflator (which implied that prices increased by 93 per cent).

The reliability of price data in Tanzania has been reviewed and analysed in detail by Adam et al. (2012). Concerns that the Consumer Price Index (CPI) underestimates inflation in Tanzania have been a long-standing issue. A major revision of the CPI computation was made in the mid-2000s, after an IMF review found that procedures of handling seeming outliers and other technical errors were creating a large downward bias. A World Bank study (World Bank 2007) argued that there was still some downward bias in the series. The analysis conducted by Adam et al. (2012) showed a significantly higher level of food price inflation than the NBS series, and moreover their estimates were much closer to the pattern of world price changes converted into Tanzanian Shilling values. A similar issue seems to arise for non-food. They take this as strongly suggestive evidence that the CPI was a downwardly biased measure of inflation in Tanzania, at least through 2007.

The inconsistency between the national accounts and survey consumption evidence is graphically illustrated by Sandefur (2013). Dealing with the period 2000-7, he contrasts the marginal decline in poverty based on HBS data (as seen above, 2.1 percentage points) with the significant decline in PPPUS\$1/day poverty (16.7 percentage points). Since both estimates are based on the same survey evidence, the difference has to be attributed to the price series used to obtain real values, the CPI being used for the PPPUS\$1/day estimate. He recalculated the PPPUS\$1/day measure using instead a price deflator derived from the HBS, and obtained a much less dramatic poverty decline (just 3.5 percentage points). This shows that the price series used to establish trends in well-being and poverty plays a critical role, and explains in large measure the inconsistency between the national accounts and survey-based narratives. Sandefur (2013) clearly favours the price series obtained from the surveys. These prices are obtained directly from the household questionnaires, and reflect the prices actually paid by Tanzanian households; and they are derived from the same data used to compute the poverty indicators. Official inflation estimates (such as the CPI) are based on surveys of local urban markets only, which may not reflect the prices actually paid by most rural households; and they face the problems already identified by Adam et al. (2012).

It is also important to recognize that the CPI is normally a macro-weighted index, which gives rich household consumption baskets a large weight. The index based on the household survey places more weight on the consumption 
patterns of poorer households, meaning that basic items have a higher weight. Consistent with world price increases over the period, one would expect more rapid inflation in the household-survey-based index, which is more relevant for the measurement of the monetary poverty rate.

There are therefore several reasons for arguing that, for analysing the economic well-being of the population, the survey-based price data are to be preferred. A corollary question may be whether the price indices used for measuring growth (i.e. either the GDP deflators or CPI estimates) give too favourable a view of recent economic growth. In other words, are official estimates of real GDP (and private consumption) open to question?

In sum, using the best available data to assess changes over 2001-12, the main issue is not so much why Tanzania's reported fast growth led to so little poverty reduction-rather, it is why real household consumption has grown so slowly.

\subsection{The Pattern of Poverty Change in Tanzania and an Evaluation of its Robustness}

In assessing the monetary poverty results in greater detail for Tanzania, it is very important to review underlying measurement issues. There are two major challenges which must be taken account of in this assessment: the issue of the comparability of the latest two of the surveys used and the adequacy of price data. On survey comparability, the data for the four available years all come from HBSs conducted by the National Bureau of Statistics. The first three surveys are considered to be largely comparable with each other. As already noted, a set of improvements in survey design and methodological approach were introduced with the 2011/12 survey (World Bank 2015), creating potential issues of comparability with earlier work. For the comparison between 2007 and 2011/12, the World Bank (2015) for its recent Poverty Assessment recomputed the consumption aggregates for 2007 on a comparable basis to the $2011 / 12$ estimate. ${ }^{4}$ This revised 2007 estimate is then not directly comparable with the earlier series; that comparison needs to be made based on the original 2007 estimate. On prices, the data available from the surveys may give a better assessment of inflation over the period between the surveys, but they are still quite inadequate for adjusting for the differences in the prices faced by different households. These issues are revisited again later in this section; to begin with we discuss the available results at face value.

${ }^{4}$ Differences in sampling and survey methodology remain. 
Table 11.3. Poverty headcounts and Gini coefficients for Tanzania

\begin{tabular}{|c|c|c|c|c|c|}
\hline Location & $1992 / 3$ & $2000 / 1$ & 2007 & 2007 & $2011 / 12$ \\
\hline $\begin{array}{l}\text { National headcount } \\
\text { By stratum }\end{array}$ & 38.6 & 35.7 & 33.6 & 34.4 & 28.2 \\
\hline Dar es Salaam & 28.1 & 17.6 & 16.4 & 14.1 & 4.0 \\
\hline Other urban & 28.7 & 25.8 & 24.1 & 22.7 & 21.5 \\
\hline Rural & 40.8 & 38.7 & 37.6 & 39.4 & 33.4 \\
\hline Gini coefficient (national) & 0.343 & 0.356 & 0.353 & 0.373 & 0.342 \\
\hline
\end{tabular}

Source: Authors' computation from HBS datasets

The analysis in this section relies on national poverty lines. Data for the poverty headcount by survey stratum (Dar es Salaam, Other Urban and Rural) in mainland Tanzania are presented in Table 11.3, with the two different figures for 2007 reflecting the above observation. It is clear that poverty is consistently lower in urban areas than rural areas, and that over the entire period much faster progress in poverty reduction has been experienced in Dar es Salaam compared with other strata. In particular, there were quite large poverty reductions in Dar between 1991/2 and 2000/1 and between 2007 and 2011/12. Over these periods, average real consumption in Dar grew by 4.5 per cent and 3.3 per cent per annum respectively, while the consumption growth rates were much slower elsewhere. In urban areas outside Dar, the poverty headcount fell very slowly between each survey. The same happened in rural areas between 1991/2 and 2007, while poverty seems to have fallen more in rural areas between 2007 and 2011/12. An analysis of extreme poverty, covering those households whose consumption lies below the food poverty line, shows very similar patterns and trends (not presented here).

The same table also provides estimates of national-level Gini coefficients. Here, the striking features seem to be its relatively low level (compared with neighbouring countries such as Kenya, Rwanda, and Uganda) and its relative constancy over time. The only change in the Gini coefficient happens with the recalculated 2007 consumption data, and even that change is relatively small. This finding of a moderate and stable level of inequality may seem surprising given, among other things, the faster progress shown by Dar es Salaam over this period relative to the rest of the country. We highlight that it is always a concern in household surveys that wealthier households are not adequately captured.

The nature of these changes over time can be further explored by considering growth incidence curves for the strata between each pair of years (Figures 11.2a-c). Between 1991/2 and 2000/1 the national pattern shows slow growth throughout most of the distribution, except at the very bottom and at the top (Figure 11.2a). The stratum level curves again show that growth over this period was much faster in Dar than elsewhere. While the growth 

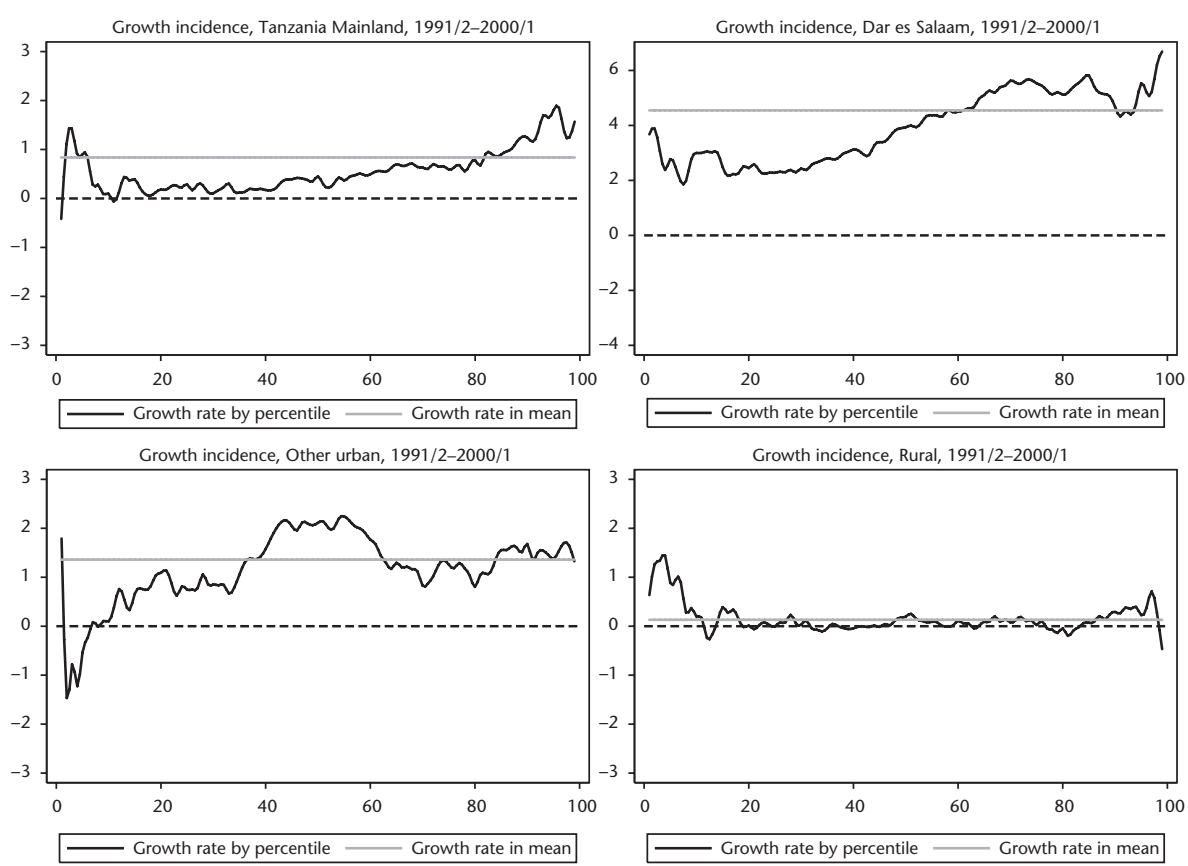

Figure 11.2a. Growth incidence curves by strata, 1991/2-2000/1

Source: Authors' computations from 1992/3 and 2000/1 survey data

rate in Dar generally increased with the consumption level over this period, there was positive growth also at the bottom of the distribution, consistent with the poverty reduction seen there over this period. There was slower growth in other urban areas, but generally not at the bottom of the distribution where the poor are concentrated. In rural areas, consumption growth was very slow over this period, even if according to available data it was slightly higher at the bottom of the distribution.

Growth incidence curves for the 2000/1 to 2007 period show very little growth overall (Figure 11.2b). ${ }^{5}$ There appears to be no significant change in inequality over the period; if anything, growth over this period was marginally faster at the bottom of the distribution.

The stratum-level GICs over the 2007 to 2011/12 period again show much faster growth in Dar es Salaam than the other strata, and in both other urban and rural areas, mean real consumption actually falls over this period (Figure 11.2c). The distributional pattern of the curves is now one where the

\footnotetext{
5 The fact that the growth rate is higher in the national GIC than in any of the others is explained by significant population shifts over the period, with the population in the (poorer on average) rural areas falling from 80.4 per cent in 2000/1 to 74.8 per cent in 2007 .
} 

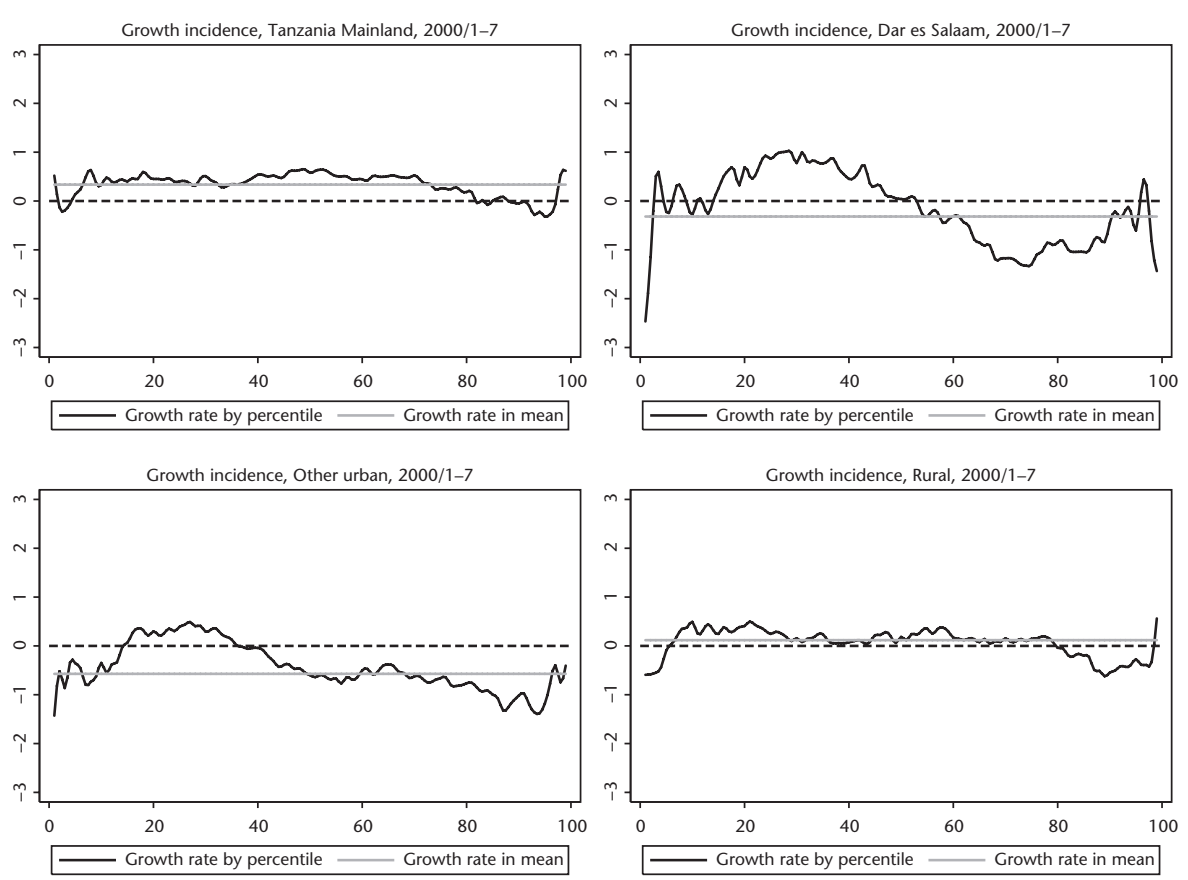

Figure 11.2b. Growth incidence curves by strata, 2001-7

Source: Authors' computations from 2000/1 and 2007 survey data

growth rate falls as households become better off. Reported growth is relatively faster at the bottom of the distribution, though the absolute magnitude of change is still quite small. The same pattern is seen in each of the strata.

As another representation of this, kernel density plots comparing the logarithm of consumption per adult for 2007 and 2011/12 are presented in Figure 11.3, with a similar plot comparing 2000/1 and 2007. The 2000/1 and 2007 curves are very close to each other, with the 2007 curve very slightly to the right throughout much of the distribution. The difference between the 2007 and 2011/12 curves is observed at the bottom of the distribution only; there are fewer observations at lower values of per adult consumption in 2011/ 12 than was the case in 2007. This underlies the shape of the growth incidence curves seen above. This seeming change in the distributional pattern of growth raises the question of whether this is picking up a real phenomenon or whether it could reflect more effective collection of the data at the bottom of the distribution in 2011/12.

While the 2007 and 2011/12 data used here were computed on as comparable a basis as possible, there are still differences in the way the data were collected. It is possible that improvements in the design and implementation of HBS 2011/12 resulted in better capture of consumption by poorer 

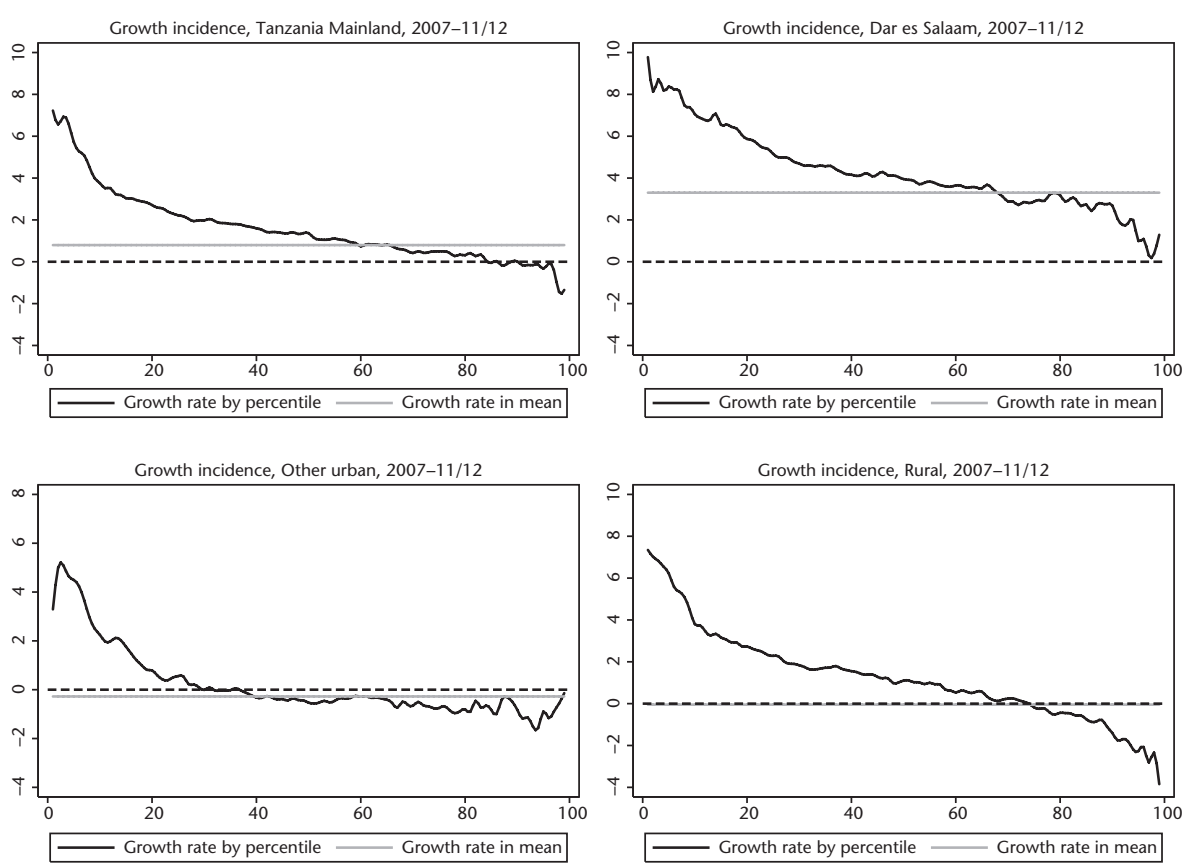

Figure 11.2c. Growth incidence curves by strata, 2007-11/12

Source: Authors' computations from 2007 and 2011/12 survey data

households. ${ }^{6}$ In both rounds, food consumption was collected in a fairly similar way using a diary which the interviewers monitored on a daily basis; it is not possible though to verify whether this monitoring was more carefully done in the 2011/12 survey compared with the 2007 survey. There was potentially a bigger change in how the non-food data were collected, in that in 2011/12 respondents were asked about items individually one by one while in 2007 they were asked about broader categories of goods and asked to specify items from a list. This might create a risk of fewer non-food items being reported in 2007 compared with 2011/12. The food consumption data in principle ought to be more comparable.

However, this does not seem to explain the observed outcome, in that if growth incidence curves are generated for food consumption only (which may be more comparable) for the 2007 to $2011 / 12$ period, a similar distributional pattern of change is observed at the national level and in each stratum.

${ }^{6}$ It is important first to note that in absolute terms the gains we measure among the poorer groups are not particularly large. For the poorest five deciles, increases in consumption amount to only around 4,000 TSh (in 2011/12 prices) per month, and appear significant in relative terms only because of the low levels of consumption that characterize the bottom half of the consumption distribution in Tanzania. 


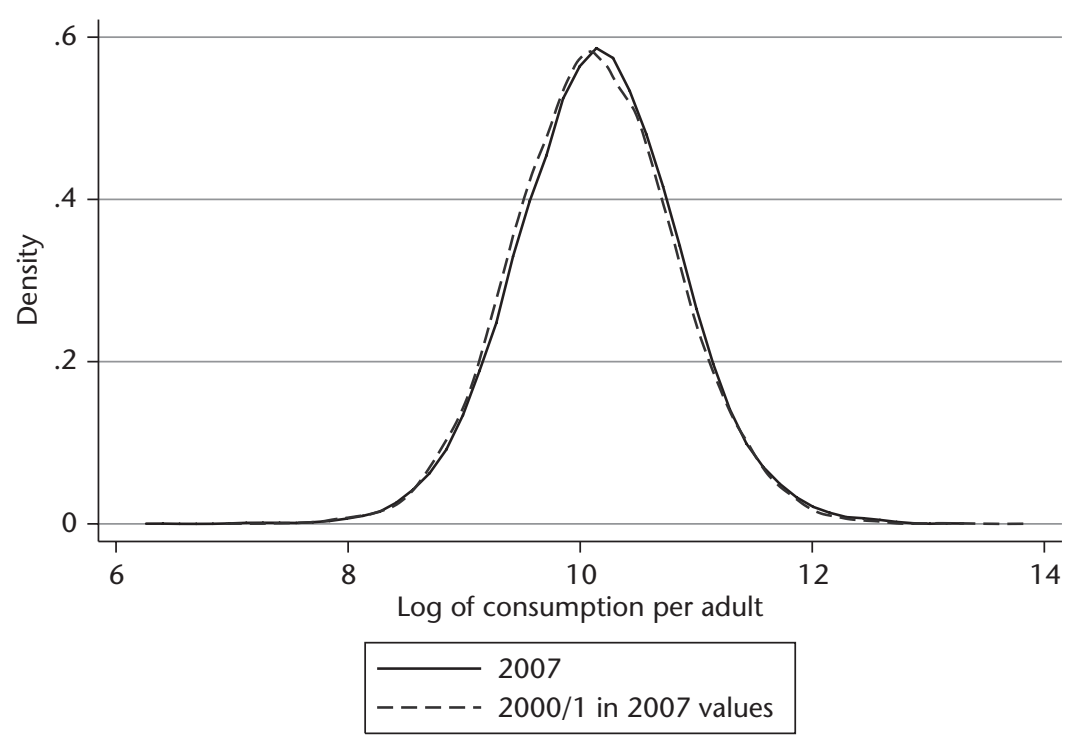

kernel $=$ epanechnikov, bandwidth $=0.0962$

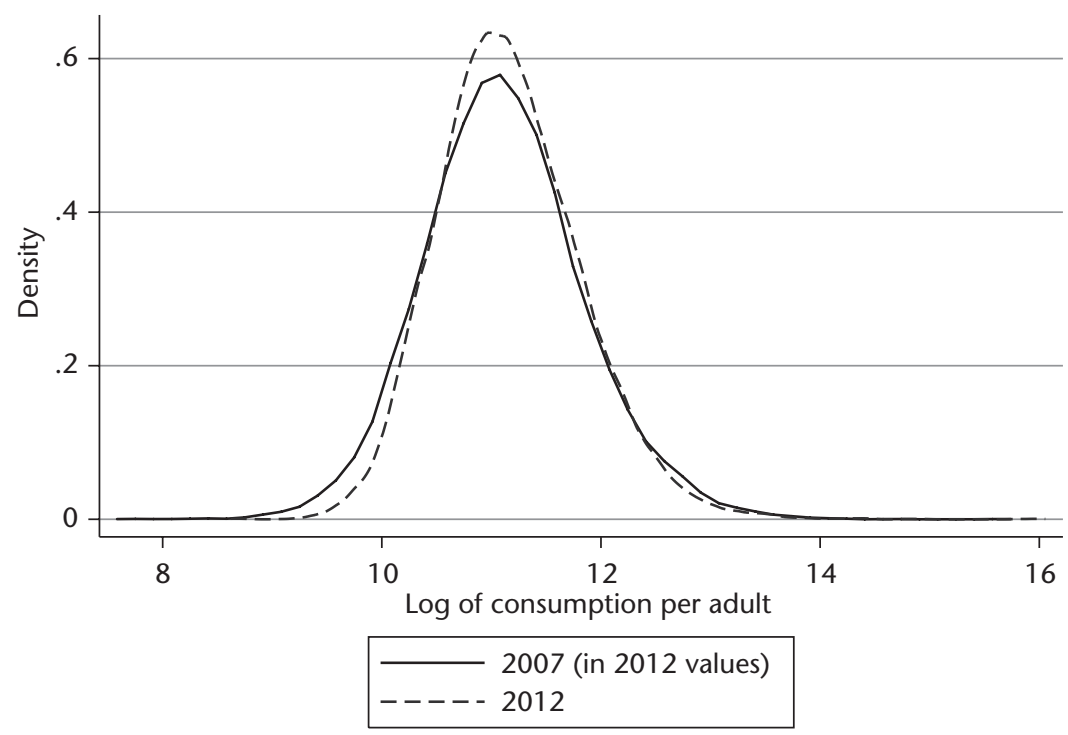

kernel $=$ epanechnikov, bandwidth $=0.0971$

Figure 11.3. Kernel density plots of the logarithm of consumption per adult, 2000/1-7 and 2007-11/12

Source: Authors' computation from HBS dataset 
As a further check on whether consumption measurement issues are responsible for the shape of these GICs, we use imputed estimates of consumption for 2007 (thus avoiding any use of measured consumption in 2007). For this, household consumption per capita in 2011/12 was regressed on ownership of assets and household characteristics, selecting only characteristics and assets available in the 2007 survey. These 2007 regressors were then used to predict consumption in 2007, allowing for the random error component. One hundred simulations were run for each household in 2007. The percentile points were identified for each one of these simulations, and in conjunction with the 2011/12 percentile points were used to compute 100 estimates of the change in consumption for each percentile which were then averaged. The results based on these simulations show that the GICs are downward-sloping through most of the range, and this also suggests relatively more rapid consumption growth among lower percentiles.

Another major concern is about the inadequate price data available for this analysis. The survey used a single deflator for inflation for all households in Tanzania between 2007 and 2011/12, whereas it is highly likely that inflation rates would have differed spatially or by income group. It is certainly plausible that poor households may have faced higher inflation overall in this period, given the greater share of food in their consumption baskets combined with the fact that food price inflation was higher over this period. If so, this would affect estimates of both poverty and inequality (Arndt et al. 2015). ${ }^{7}$ While there is not sufficient information to be able to assess this, it underlines the need for considerable caution in deriving strong conclusions from the data.

Alternatively, the GICs may be representing a real pattern of change. One possible explanation might be that it captures a genuine reduction in consumption by the poorest in 2007. Comparing food shares across the four HBS surveys, it is the 2007 food share which stands out as being most different (Table 11.4). If poorer households did reduce their level of food consumption in response to, for example, sharply rising food prices in 2007 then the shape of the GIC between 2007 and 2011/12 may represent catch-up by the poorest households.

Another possible interpretation of the pattern of the GICs could be positive changes made by households over the period. The national accounts data suggest that growth in agriculture was not faster in the 2007-12 period compared with the 2001-7 period, so this is unlikely to be a major part of the story. The survey data do suggest some movement out of agriculture in rural areas over this period into wage work (potentially with a higher return); and, within

\footnotetext{
${ }^{7}$ What is less clear is whether poorer households would also have faced higher food price inflation as well; this would need to be the case to conclude that the food consumption GICs were also misrepresenting the pattern of change.
} 
Table 11.4. Food shares in Tanzania, 2007 and 2011/12

\begin{tabular}{lcc}
\hline Location & 2007 & $2011 / 12$ \\
\hline National & 0.575 & 0.63 \\
By stratum & & \\
Dar es Salaam & 0.597 & 0.662 \\
Other urban & 0.528 & 0.581 \\
Rural & 0.481 & 0.516 \\
By quintile & & \\
Lowest & 0.630 & 0.708 \\
Second & 0.607 & 0.677 \\
Third & 0.600 & 0.661 \\
Fourth & 0.563 & 0.614 \\
Highest & 0.477 & 0.498 \\
\hline
\end{tabular}

Source: Authors' compilation based on the 1992 and 2010 TDHS (National Bureau of Statistics and Macro International 1993, 2011)

agriculture, some increase in the number of households cultivating cash crops (who tend to be better off). There was evidence of an increase in asset ownership among the poorest 40 per cent (livestock and especially cell phones); and also evidence of an increase in access to community infrastructure (electricity, roads). It is, however, not obvious why this should affect poorer households more; one might argue that better-off households are restraining consumption levels and increasing their saving and investment in both rural and urban areas. But, these explanations are speculative and remain to be rigorously assessed.

Overall, the change in the survey methodology creates a serious question about the comparability of the 2007 and 2011/12 data despite the best efforts made to correct for this. If there are concerns about consumption having been more accurately captured at the bottom end of the distribution in 2011/12 compared with 2007, then this would affect both the shape of the GICs, and the estimates of reduction in poverty which would turn out to be overestimates. Clearly, it will be important that the consumption data are collected in a fully comparable way in future surveys.

The absence of adequate data to adjust for price changes compounds this. The survey-based deflators give a better indication of the pattern of change over this period than do national accounts or CPI-based deflators when the focus is on measuring poverty. At the same time, the survey-based deflator remains unsatisfactory because a single number for inflation or food price inflation is assumed for the entire country, which is implausible.

What we have attempted here is to make the best possible overview of the change in poverty, given the available data. The clear result from the analysis and the common thread to all the discussion above is the slow growth in real per capita consumption, which translates into relatively small poverty 
reduction outside of Dar es Salaam. This is one result from the consumption poverty analysis of which we can be reasonably confident.

\subsection{The Non-monetary Poverty Story}

We now complement the monetary poverty review by a brief analysis of trends in various non-monetary measures of deprivation. The data used are taken from the Tanzania Demographic and Health Survey (TDHS) conducted in the years 1991/2, 1996, 2004/5, and 2010 (National Bureau of Statistics and Macro International 1993, 1997, 2005, 2011). A nationally representative sample for the whole country, including Zanzibar, was taken in each case; the sample sizes were respectively 8,327, 7,969, 10,312, and 10,300 households.

From these micro data we capture the non-monetary multidimensional nature of poverty by identifying five binary welfare indicators at the household level based on the Bristol Indictors (Gordon et al. 2003), taken as water, sanitation, shelter, education, and information. A household is waterdeprived if the main source of drinking water is not from a pipe, tap, or well. For sanitation, the household is deprived if it has no flush toilet or ventilated improved pit toilet. A household is shelter-deprived if the main floor material is dirt, sand, dung, or planks. A household is education-deprived if the household head has not completed at least primary school. The household is information-deprived if it does not have a functioning radio or television.

Table 11.5 presents the percentage of households not deprived in each dimension, comparing the first and last year of the DHS surveys and comparing by region of the country. To start, the results show significant heterogeneity between urban and rural areas and across regions. Yet, almost all

Table 11.5. Households not deprived by welfare indicator, per cent

\begin{tabular}{|c|c|c|c|c|c|c|c|c|c|c|}
\hline & \multicolumn{2}{|c|}{ Water } & \multicolumn{2}{|c|}{ Sanitation } & \multicolumn{2}{|c|}{ Shelter } & \multicolumn{2}{|c|}{ Education } & \multicolumn{2}{|c|}{ Information } \\
\hline & 1992 & 2010 & 1992 & 2010 & 1992 & 2010 & 1992 & 2010 & 1992 & 2010 \\
\hline Nation & 64.5 & 71.2 & 2.9 & 11.7 & 18.6 & 30.5 & 31.8 & 56.2 & 36.7 & 64.3 \\
\hline Rural & 56.3 & 67.0 & 1.3 & 3.1 & 9.0 & 16.6 & 27.1 & 49.4 & 29.6 & 59.5 \\
\hline Urban & 92.3 & 85.3 & 8.2 & 40.3 & 51.6 & 76.7 & 47.7 & 78.5 & 60.8 & 80.4 \\
\hline Western & 56.6 & 77.1 & 3.2 & 6.5 & 9.6 & 15.0 & 23.4 & 45.6 & 30.5 & 64.5 \\
\hline Northern & 57.8 & 62.8 & 3.9 & 11.0 & 26.3 & 36.8 & 38.3 & 62.5 & 48.0 & 64.2 \\
\hline Central & 73.5 & 63.3 & 2.5 & 4.9 & 12.3 & 13.0 & 29.4 & 51.4 & 27.9 & 50.9 \\
\hline S. Highlands & 60.0 & 66.5 & 1.2 & 9.8 & 13.9 & 32.0 & 33.2 & 59.4 & 32.5 & 65.7 \\
\hline Lake & 51.2 & 70.7 & 2.7 & 12.7 & 12.0 & 25.7 & 30.4 & 51.1 & 32.9 & 64.1 \\
\hline Eastern & 84.9 & 79.0 & 4.5 & 23.8 & 38.9 & 59.1 & 40.3 & 69.0 & 50.4 & 77.3 \\
\hline Southern & 72.4 & 69.2 & 1.0 & 6.7 & 12.5 & 19.1 & 25.2 & 58.8 & 24.6 & 52.1 \\
\hline Zanzibar & 90.3 & 98.4 & 3.3 & 27.6 & 34.0 & 66.5 & 33.3 & 50.1 & 55.1 & 75.5 \\
\hline
\end{tabular}


indicators demonstrate substantial improvements between 1992 and 2010, with the exception of water in several locations. Sanitation facilities improved from a very low starting value of 3 per cent in 1992 to reach 12 per cent in 2010. Water, sanitation, shelter, education, and information all show improvements at national level by respectively $7,8,12,24$, and 27 percentage points.

Setting aside water for a moment, changes in these indicators were more pronounced in urban areas compared with rural areas, and increases are observed in every region of the country. There is significant heterogeneity by zone in the extent of change; in sanitation and shelter, for example, large improvements are seen over this period in the Eastern zone and in Zanzibar, while changes are small in the Central zone. In relation to water, the pattern is more diverse; some zones such as Western, Northern, Southern Highlands, Lake, and Zanzibar see improvements, while others such as the Central, Eastern, and Southern zones have deterioration in water access.

The national-level figure on water access is sensitive to constraints on the time it takes to retrieve water. When we restrict not deprived in water to households within thirty minutes of the water source, water access only improves from 53 to 55 per cent. When being not deprived in water is restricted to sources within fifteen minutes, the situation shows progress is limited to a change from 39 per cent in 1992 to 35 per cent in 2010. The situation is even more pronounced in urban areas.

Different measures of deprivation are defined for under-five-year-old children, where the focus is on water, sanitation, nutrition, mothers' education, and location of delivery as the main welfare indicators. Children under five are education-deprived if their mothers have not completed at least primary school. Children under five are nutrition-deprived if the child is more than two standard deviations below the median of the reference population in at least one of the following anthropometric measures: weight for age, height for age, weight for height. Children under five are delivery-deprived if the child was delivered in a home rather than a health facility. Sanitation is as defined before.

Table 11.6 shows that the percentage of the under-fives not deprived in each dimension has improved significantly for all indicators. Between 1992 and 2010, water, sanitation, nutrition, and education improved by seven, six, thirteen, and thirteen percentage points respectively, while delivery improved by five percentage points from 55 to 50 per cent, suggesting the share of women delivering at home has decreased. Examination of zones reveals that sanitation, nutrition, and education improved everywhere, though by varying extents, while there was substantial heterogeneity in the performance of the delivery indicators ranging from significant improvements to a few deteriorations. 
Table 11.6. Children under five (0-4 years) not deprived by welfare indicator, per cent

\begin{tabular}{|c|c|c|c|c|c|c|c|c|c|c|}
\hline & \multicolumn{2}{|c|}{ Water } & \multicolumn{2}{|c|}{ Sanitation } & \multicolumn{2}{|c|}{ Nutrition } & \multicolumn{2}{|c|}{ Education } & \multicolumn{2}{|c|}{ Delivery } \\
\hline & 1992 & 2010 & 1992 & 2010 & 1992 & 2010 & 1992 & 2010 & 1992 & 2010 \\
\hline Nation & 64.0 & 70.6 & 2.5 & 8.6 & 45.5 & 59.0 & 46.9 & 59.6 & 55.0 & 49.6 \\
\hline Rural & 56.9 & 67.5 & 1.1 & 2.0 & 44.1 & 56.7 & 42.7 & 55.1 & 46.7 & 41.8 \\
\hline Urban & 91.4 & 83.7 & 8.0 & 36.4 & 50.9 & 68.8 & 63.3 & 78.3 & 86.5 & 82.6 \\
\hline Western & 57.0 & 76.4 & 2.4 & 4.6 & 50.7 & 61.8 & 33.0 & 48.3 & 50.8 & 35.2 \\
\hline Northern & 58.6 & 59.0 & 5.5 & 7.7 & 47.3 & 57.1 & 60.5 & 66.2 & 63.9 & 51.2 \\
\hline Central & 72.2 & 59.9 & 1.7 & 2.9 & 41.3 & 49.3 & 51.3 & 58.1 & 57.5 & 46.9 \\
\hline S. Highlands & 61.5 & 65.6 & 1.2 & 9.5 & 40.7 & 52.7 & 50.2 & 66.4 & 53.1 & 50.0 \\
\hline Lake & 53.4 & 71.8 & 1.9 & 9.1 & 51.0 & 63.5 & 39.2 & 57.5 & 40.6 & 44.4 \\
\hline Eastern & 80.8 & 79.9 & 3.2 & 18.4 & 45.7 & 66.0 & 53.7 & 67.0 & 65.4 & 74.4 \\
\hline Southern & 73.3 & 71.1 & 0.7 & 6.0 & 34.2 & 55.6 & 47.7 & 65.6 & 70.0 & 69.0 \\
\hline Zanzibar & 88.9 & 98.3 & 2.7 & 26.3 & 39.1 & 60.8 & 42.8 & 57.2 & 32.5 & 48.8 \\
\hline
\end{tabular}

Source: As for Table 11.5

The story over this eighteen-year period in Tanzania is one of overall improvements in most key non-monetary indicators, with the exception of water in urban areas. A more detailed analysis of these non-monetary indicators, including considering multiple deprivations, is undertaken by Arndt et al. (2014).

\subsection{Conclusions}

While the process has been long, Tanzania has registered more impressive economic progress over the past fifteen years than in the 1980s and 1990s. Economic growth has favoured urban zones, especially Dar es Salaam, with rural areas in general and the agricultural sector in particular lagging behind. Consequently, monetary poverty remains high in rural areas, where the large majority of poor people reside; and progress in poverty reduction has been slow outside of Dar es Salaam. In addition to the pattern of growth, the impact of the world food and fuel price shocks may also have been an important factor over the period considered here.

Except for Dar, survey-based estimates of growth in real household consumption have fallen far below the reported economic growth rates, and what poverty reduction there has been has mostly taken place in the capital too. The question is not why poverty reduction is slow given the fast overall growth rate; it is rather why household consumption has grown so slowly.

The patterns of change in monetary poverty presented in this chapter remain subject to uncertainty, both in relation to the comparability of the consumption data between the latest two rounds and in relation to the price adjustment which it has been possible to make. The best assessment we are 
able to make with the existing data shows slow poverty reduction from 1992/3 to 2007 , which seems to have increased a little in more recent years, including in rural areas. The rate of decline remains slow; and the slightly more rapid poverty reduction experienced recently still needs to be verified and adequately explained, particularly the observation that poorer households appear to have experienced better relative consumption growth than less poor households. In addition, it is too early to judge how sustainable the recently observed (still modest) rural poverty reduction may be, unless policy focus is put squarely on rural sector advance. A much stronger focus on agriculture must play a key role in accelerating rural poverty reduction.

Tanzania's historical record in relation to non-monetary poverty is one of progress, one positive legacy of the Nyerere era. These indicators also confirm a pattern of general improvement between 1992 and 2010 for households as a whole and in relation to young children, though not all indicators improve. These changes are less directly related to growth and more to public service provision. We do note as well that these improvements remain relatively slow. Tanzania's record on non-monetary indicators is not particularly impressive compared with neighbouring countries, and is disappointing in some regions of the country. In other words, it would appear that the extent and efficiency of public service provision still needs to improve significantly.

On a parallel note, we wish to conclude by stressing that the present state of lack of clarity and consistency as regards basic data should be a matter of concern to both policymakers and those who wish a sound evidence base for supporting future progress.

\section{References}

Adam, C., D. Kwimbere, W. Mbowe, and S. O'Connell (2012). 'Food Prices and Inflation in Tanzania', International Growth Centre Working Paper, London/Oxford, July.

Arndt, C., M. Azhar Hussain, V. Leyaro, E. Jones, and F. Tarp (2013). 'Poverty and Growth in Tanzania'. Paper presented at the Conference on Inclusive Growth in Africa: Measurement, Causes and Consequences, 20-1 September 2013, Helsinki (draft dated August 2013).

Arndt, C., V. Leyaro, and K. Mahrt (2014). 'Multi-dimensional Poverty Analysis for Tanzania: First Order Dominance Approach with Discrete Indicators', UNU-WIDER Working Paper 2014/146. Helsinki: UNU-WIDER.

Arndt, C., S. Jones, and V. Salvucci (2015). 'When Do Relative Prices Matter for Measuring Income Inequality? The Case of Food Prices in Mozambique', Journal of Economic Inequality, 13(3): 449-64.

Atkinson, A. B. and M. A. Lugo (2010). 'Growth, Poverty and Distribution in Tanzania', International Growth Centre Working Paper 10/0831 (November). London and Oxford: LSE and University of Oxford. 
Deaton, A. (2005). 'Measuring Poverty in a Growing World (or Measuring Growth in a Poor World)', Review of Economics and Statistics, 87: 1-19.

Demombynes, G. and J. G. Hoogeveen (2007). 'Growth, Inequality and Simulated Poverty Paths for Tanzania, 1992-2002', Journal of African Economies, 16: 596-628.

Eele, G., J. Semboja, S. Likwelle, and S. Ackroyd (2000). 'Meeting International Poverty Targets in Tanzania', Development Policy Review, 18(1): 63-83.

Gordon, D., S. Nandy, C. Pantazis, S. Pemberton, and P. Townsend (2003). Child Poverty in the Developing World. Bristol: Policy Press.

Government of Tanzania (2009). Household Budget Survey 2007-Tanzania Mainland. Dar es Salaam: National Bureau of Statistics.

Hoogeveen, J. and R. Ruhinduka (2009). 'Poverty Reduction in Tanzania since 2001: Good Intentions, Few Results'. Paper prepared for the Research and Analysis Working Group of the MKUKUTA Monitoring System. Dar es Salaam: Ministry of Finance and Economic Affairs.

Jerven, M. (2011). 'Growth, Stagnation or Regression? On the Accuracy of Economic Observations, Tanzania, 1961-2001', Journal of African Economies, 20(3): 377-94.

Kessy, F., O. Mashindano, A. Shepherd, and L. Scott (eds) (2013). Translating Growth into Poverty Reduction: Beyond the Numbers. Dar es Salaam: Mkuki na Nyota.

Mashindano, O., K. Kayunze, L. da Corta, and F. Maro (2011). 'Agricultural Growth and Poverty Reduction in Tanzania 2000-2010: Where Has Agriculture Worked for the Poor and What Can We Learn from This?', Chronic Poverty Research Centre, Working Paper No. 208 (June).

Mkenda, A., E. Luvanda, and R. Ruhinduka (2010). 'Growth and Distribution in Tanzania: Recent Experience and Lessons', Interim Report to REPOA (Policy Research for Development).

National Bureau of Statistics and Macro International (1993). 'Demographic and Health Survey, 1991-92'.

National Bureau of Statistics and Macro International (1997). 'Demographic and Health Survey, 1996'.

National Bureau of Statistics and Macro International (2005). 'Demographic and Health Survey, 2004-5'.

National Bureau of Statistics and Macro International (2011). 'Demographic and Health Survey, 2010'.

Osberg, L. and A. Bandara (2012). 'Why Poverty Remains High in Tanzania: And What to Do About It?', Special Paper 12/3. Dar es Salaam: REPOA (Policy Research for Development).

Pauw, K. and J. Thurlow (2011). 'Agricultural Growth, Poverty, and Nutrition in Tanzania', Food Policy, 36: 795-804.

Ravallion, M. (2001). 'Measuring Aggregate Welfare in Developing Countries: How Well Do National Accounts and Surveys Agree?', Policy Research Working Paper No. 2665 (August).

Sandefur, J. (2013). 'Africa Rising? Using Micro Surveys to Correct Macro Time Series'. Mimeo, Center for Global Development.

World Bank (2007). Sustaining and Sharing Economic Growth in Tanzania, ed. Robert J. Utz. Washington, DC: World Bank. 
World Bank (2012). 'Tanzania Economic Update. Spreading the Wings: From Growth to Shared Prosperity', Poverty Reduction and Economic Management Unit, Issue 2. Washington, DC: World Bank.

World Bank (2013). 'Tanzania Economic Update. Raising the Game: Can Tanzania Eradicate Extreme Poverty?', Poverty Reduction and Economic Management Unit, Issue 4. Washington, DC: World Bank.

World Bank (2015). 'Tanzania Mainland Poverty Assessment'. Washington, DC: World Bank. 


\title{
12
}

\section{Assessing Progress in Welfare Improvements in Zambia}

\author{
A Multidimensional Approach
}

\author{
Gibson Masumbu and Kristi Mahrt
}

\subsection{Introduction}

Throughout the 2000s, Zambia achieved robust economic growth with real gross domestic product (GDP) growing at an average annual rate of 7 per cent, making Zambia one of the fastest-growing economies in southern Africa (AFDB 2013; World Bank 2014) and boosting Zambia from low-income to middle-income country status. This economic achievement is remarkable in that it follows more than twenty years of economic decline whereby GDP per capita fell from US\$1,070 at independence to US\$582 in 1994 (World Bank 2013), rural extreme consumption poverty peaked in 1993 at 84 per cent (CSO 2005), and life expectancy fell from 53 years in 1987 to 48 years in 1992 (Bonnick 1997). Despite this sustained, strong macroeconomic performance returning per capita GDP to its level at independence, Zambia's growth has not proven to be inclusive and has not translated into significant consumption poverty reduction.

The Zambian government has prioritized poverty reduction since the 2002 adoption of the interim Poverty Reduction Strategy Paper (PSRP) and the subsequent Fifth and Sixth National Development Plans (FNDP and SNDP). Yet, despite targeted planning and robust growth, 2010 national consumption lines indicate that 60 per cent of the population still lives in poverty with 42 per cent living in extreme poverty (CSO 2010b). With population growth, the absolute number of poor increased from approximately 5 million in 1993 to 8 million in 2010 (CSO 2010b). Poverty is overwhelmingly concentrated 
in rural areas where the consumption poverty rate remains persistently high at 77 per cent (compared to only 27 per cent in urban areas). Ninety per cent of Zambians living below the extreme poverty line reside in rural areas (CSO 2010b). Despite disappointing trends in monetary poverty, the Human Development Index (HDI) suggests recent improvements in non-monetary poverty indicators. The 2013 HDI classifies Zambia as a middle human development country with a rank of 141 out of 187 countries (UNDP 2014), an improvement compared to its 2010 classification as a low-development country with a rank of 164 (UNDP 2011). Nonetheless, the country's slow progress in meeting the Millennium Development Goals provides evidence that Zambia continues to lag behind in crucial areas of basic human development, including the provision of health and education services as well as infrastructural related services such as water, sanitation, and electricity (UNDP 2013).

In this chapter, we analyse poverty in Zambia between 1996 and 2010. We review recent growth and consumption poverty trends, and in this context, we evaluate the distribution and evolution of multidimensional household welfare. Recognizing the importance of non-monetary dimensions of poverty, we employ the first-order dominance (FOD) approach to assessing multidimensional welfare developed by Arndt et al. (2012). FOD allows multidimensional welfare comparisons across populations without imposing assumptions about the relative importance of each welfare dimension. Applying the FOD methodology to the 1996, 2006, and 2010 Living Conditions Monitoring Surveys (LCMS), five household-level binary indicators measuring welfare in water, sanitation, shelter, energy, and education form the basis of analysis. FOD comparisons generate information about the relative welfare of the nine provinces of Zambia and their performance over time. In addition, we evaluate the welfare of households across rural agricultural strata and urban housing cost areas.

The chapter is structured as follows. Section 12.2 provides an overview of the country's economic performance, including recent economic achievements and consumption poverty trends. Section 12.3 elaborates on the FOD methodology and the primary data sources. Section 12.4 presents FOD spatial and temporal welfare comparisons for both provinces and rural and urban household strata. Finally, section 12.5 contextualizes the FOD results and concludes.

\subsection{Context}

\subsubsection{Economy and Growth}

Zambia has one of the richest mineral deposits on the continent and is the fourth largest copper producer in the world (Whitworth 2014). The nation is also endowed with both substantial land resources, of which 58 per cent is 
classified as having medium to high potential for agricultural production, and some of the best surface and underground water resources in Africa; yet only 15 per cent of arable land is currently in use (USAID 2011). At the time of independence in 1964, Zambia was a middle-income country with one of the fastest growing economies in the region (DiJohn 2010). Zambia's rich mineral wealth was well developed, and world market conditions were generally favourable, contributing to average annual growth rates in excess of 4 per cent through 1974 (de Kemp, Faust, and Leiderer 2011; World Bank 2014). The country's fortunes began to change as a result of external shocks in the early 1970s. In 1973, oil prices quadrupled (de Kemp et al. 2011), leading to a sharp rise in the prices of imports (Ndulo and Mudenda 2004). In 1974, copper prices dropped by 40 per cent and remained weak and unstable through the mid-1990s (Ndulo and Mudenda 2004). Since copper accounted for 90 per cent of Zambia's export revenue, the economy experienced severe difficulties adjusting to this long-lasting deterioration in terms of trade. The economy's weaknesses due to dependence on a single commodity began to show. With a weak manufacturing base, an underdeveloped agricultural sector, and a rapid opening of the economy, the effects of the shock were transmitted to all sectors of the economy, resulting in severely reduced and even negative growth (Figure 12.1). By 1975, Zambia faced a sharp decline in government revenue and a serious balance of payments problem. The government, on the other hand, continued a programme of heavy public spending financed by massive external borrowing. By the early 1980s, the economy was under serious stress.

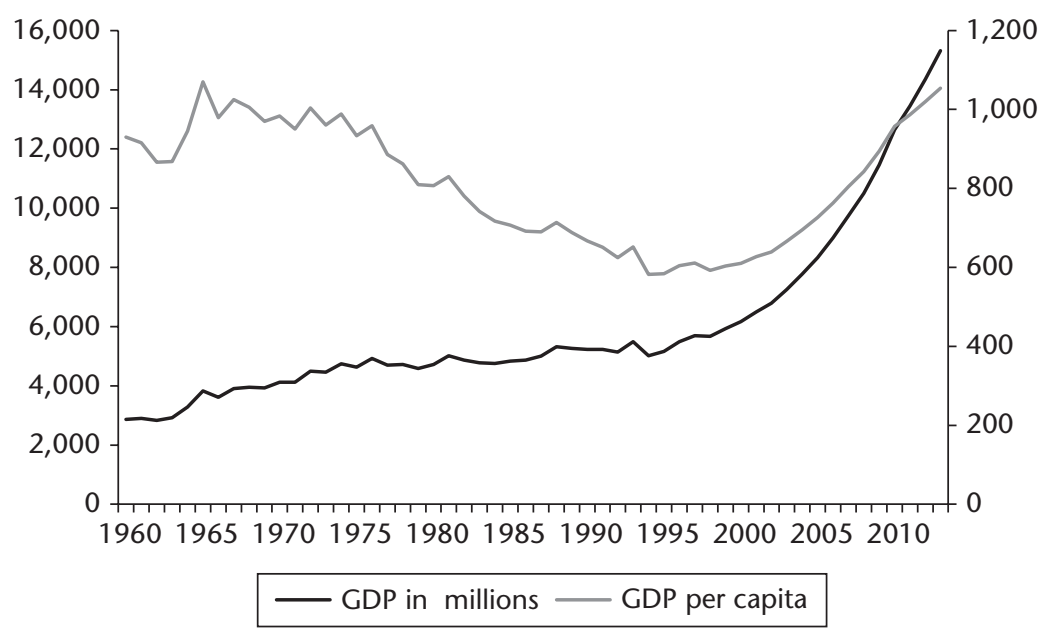

Figure 12.1. GDP and GDP per capita (constant 2005 US\$), 1960-2013 Source: World Development Indicators (World Bank 2014) 
In 1991, the country experienced a major political regime shift. The new government began implementing structural adjustment reforms sponsored by the Bretton Woods Institutions. Reforms notwithstanding, economic malaise continued throughout the 1990s. Average annual GDP growth fell from 1.6 per cent in the 1970 s to 1.4 per cent in the 1980 s and 1.3 per cent in the 1990 s, implying negative growth in per capita terms (World Bank 2014). The country performed poorly in many other economic indicators, including those related to basic macroeconomic control such as inflation and the fiscal deficit (see Table 12.1). In the 1970s, inflation averaged about 10 per cent but this increased steadily over the years and hit its peak in the 1990s when it exceeded 100 per cent. The government's fiscal deficit averaged about 2 per cent of GDP during the late 1990s. By 2000, it stood at about 5.4 per cent (de Kemp, Faust, and Leiderer 2011).

With rising copper prices and sounder economic policy, Zambia's economy began to turn around in the late 1990s and has continued to grow rapidly (Figure 12.1). Between 2000 and 2013, Zambia maintained an average annual GDP growth rate of 7 per cent, making it among the fastest-growing economies in Africa (AFDB 2013; World Bank 2014). Improved economic performance has been fuelled by, among other factors, the cancellation of the country's debt stock in 2005 under the Heavily Indebted Poor Countries (HIPC) Initiative. The debt stock had reached approximately US\$7 billion and was reduced to less than US\$1 billion before it began to increase in 2011/12. In addition, an upswing in copper prices led to increased foreign direct investment in the mining sector. Over a sustained period of time, the government managed to contain the budget deficit, reduce inflation to single digit levels, and stabilize exchange rates (Table 12.1). Foreign exchange reserves have accumulated to an excess of three months' import cover for the first time since the 1970s.

Table 12.1. Key macroeconomic indicators, annual averages, 1964-2011

\begin{tabular}{|c|c|c|c|c|c|c|c|c|c|c|}
\hline & 1964-9 & 1970-4 & 1975-9 & 1980-4 & 1985-9 & 1990-4 & 1995-9 & 2000-4 & 2005-9 & 2010-11 \\
\hline $\begin{array}{l}\text { Real GDP } \\
\text { Growth rate } \\
\text { (\% change) }\end{array}$ & 5.3 & 3.9 & -0.6 & 0.8 & 2.1 & -0.8 & 3.4 & 5.5 & 8.1 & 8.3 \\
\hline $\begin{array}{l}\text { Real GDP (US\$ } \\
\text { billions) }\end{array}$ & 3.8 & 4.4 & 4.7 & 4.8 & 5.1 & 5.2 & 5.6 & 6.9 & 9.8 & 13 \\
\hline $\begin{array}{l}\text { Real GDP per } \\
\text { capita (US\$) }\end{array}$ & 999 & 977 & 890 & 775 & 698 & 635 & 599 & 648 & 806 & 972 \\
\hline $\begin{array}{c}\text { Inflation (annual } \\
\text { average, \%) }\end{array}$ & n.a & n.a & n.a & n.a & 69.3 & 121.7 & 30.7 & 21.8 & 12.8 & 7.8 \\
\hline $\begin{array}{l}\text { Official nominal } \\
\text { exchange } \\
\text { rate (ZK per } \\
\text { US\$) }\end{array}$ & 0.7 & 0.7 & 0.7 & 1.1 & 8.5 & 278 & 1,527 & 4,127 & 4,172 & 4,829 \\
\hline
\end{tabular}

Source: Constructed from World Bank WDI (2014) and IMF WEO data by Cheelo and Muchimba (2012) 
Structural adjustment led to significant and lasting changes to the composition of the Zambian economy (see Figure 12.2); however, Resnick and Thurlow (2014) argue that structural changes, thus far, have had little impact on overall welfare. Economic liberalization in the 1990s led to a booming service sector, which by the mid-1990s became the biggest contributor to GDP and the greatest source of growth. Fuelled by large publicly funded infrastructure projects, as well as private projects and mining developments (Cardozo et al. 2014), construction expanded by an average of 15 per cent annually in the 2000s. This significant growth did not translate to social transformation, as employment creation was limited to low-wage, insecure informal trade as well as high-wage service and construction employment primarily benefitting urban high-income groups (Resnick and Thurlow 2014). Though large inflows of foreign direct investment, as well as relatively high copper prices, contributed to 10 per cent annual growth in the mining and quarrying sector, the sector's capital intensity meant little employment creation. In contrast, factors including privatization and trade liberalization hit manufacturing hard in the 1990s and the sector struggled to rebound with only low growth in the 2000s. While government agricultural supports and good weather patterns led to recent bumper maize crops, productivity has remained low and agriculture's contribution to GDP has declined since 1999.

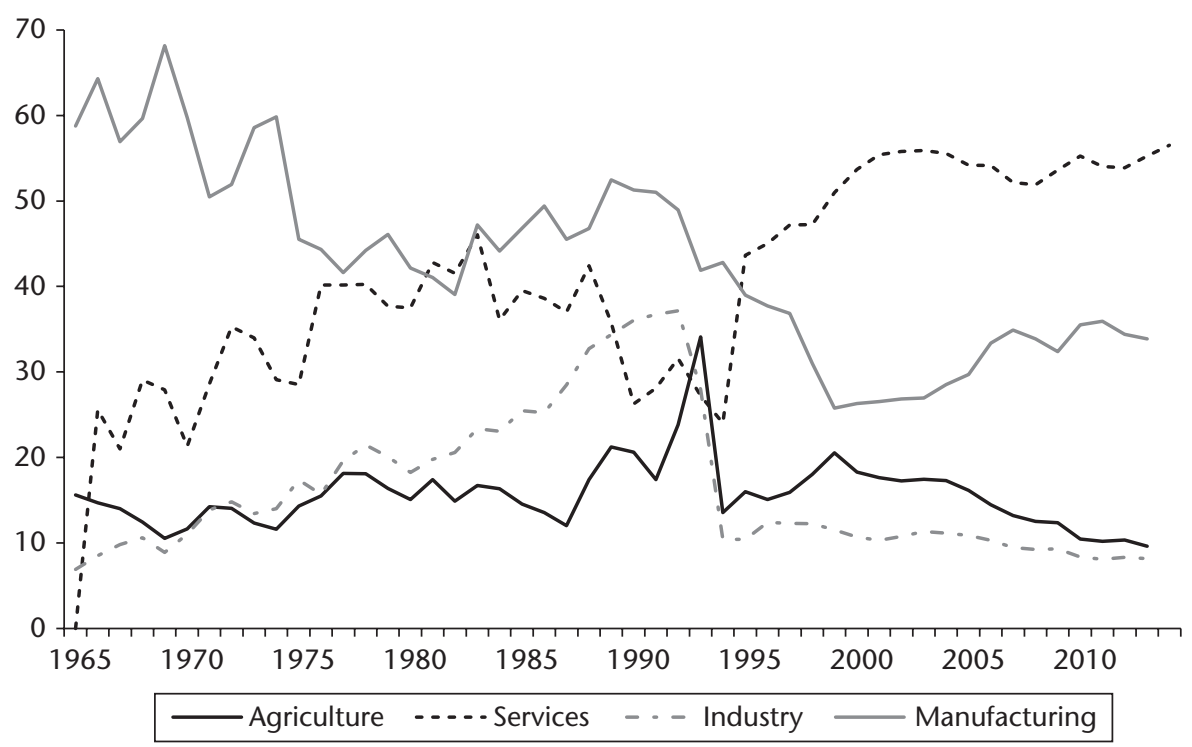

Figure 12.2. Value added as a percentage of GDP, 1965-2013

Source: World Development Indicators (World Bank 2014) 


\subsubsection{Poverty Trends}

Table 12.2 presents the national and provincial poverty headcount rates using the national consumption poverty line (CSO 2005, 2012). Unfortunately, assessment of long-run trends is complicated by differences in methodology. ${ }^{1}$ Nevertheless, it is useful to review the figures as they form a basis for much of the understanding of poverty dynamics in Zambia. Based on these figures, the national poverty headcount declined from 69 per cent in 1996 to 61 per cent in 2010, a change driven by large improvements in urban areas, which corresponds with rising GDP per capita (Figure 12.1). In 1996, 46 per cent of the urban population was poor compared to 28 per cent in $2010 .^{2}$ In rural areas, where 61 per cent of the population resides, poverty has remained stubbornly high. In 1996, 82 per cent of the rural population lived in poverty. Corresponding to a period of 3 per cent average annual growth in agricultural value added, rural poverty declined by four percentage points to 78 per cent in 2004 . However, between 2004 and 2010 the agricultural sector declined by an average annual rate of 2 per cent and rural poverty did not budge, ending the period with a rural poverty rate of 78 per cent. With rural poverty levels hovering around 80 per cent, the majority of people in rural areas have hardly reaped the benefits of buoyant economic growth.

At the provincial level, the gap between the more highly developed Copperbelt and Lusaka provinces and all other provinces widened between 1996 and

Table 12.2. Poverty headcount rates by area, 1991-2010

\begin{tabular}{lccccc}
\hline & 1996 & 1998 & 2004 & $2006^{*}$ & $2010^{*}$ \\
\hline National & 69 & 73 & 68 & 63 & 61 \\
Rural & 82 & 83 & 78 & 80 & 78 \\
Urban & 46 & 56 & 53 & 30 & 28 \\
Central & 74 & 77 & 76 & 71 & 61 \\
Copperbelt & 56 & 65 & 56 & 37 & 34 \\
Eastern & 82 & 79 & 70 & 79 & 78 \\
Luapula & 78 & 82 & 79 & 74 & 81 \\
Lusaka & 38 & 53 & 48 & 25 & 24 \\
Northern & 84 & 81 & 74 & 79 & 75 \\
Northwestern & 80 & 77 & 76 & 71 & 67 \\
Southern & 76 & 75 & 69 & 73 & 68 \\
Western & 84 & 89 & 83 & 83 & 80 \\
\hline
\end{tabular}

Note: *The 2006 and 2010 poverty rates are not comparable. These rates were calculated using year-specific Engel ratios to derive food shares; previous years used a fixed ratio.

Source: CSO $(2005,2012)$

${ }^{1}$ Specifically, poverty rates in 2006 and 2010 are not directly comparable to previous years. In 2006 and 2010 food shares are derived using year-specific Engel ratios while prior years used a fixed ratio.

${ }^{2}$ This could be explained by the change in the methodology used to compute poverty statistic in the 2006 and 2010 reports. 
Table 12.3. Poverty headcount rates by stratum, 1996-2010

\begin{tabular}{lccccr}
\hline & 1996 & 1998 & 2004 & $2006^{*}$ & $2010^{*}$ \\
\hline Low-cost housing & 58 & 61 & 58 & 35 & 35 \\
Medium cost & 43 & 50 & 46 & 14 & 9 \\
High-cost housing & 36 & 33 & 30 & 5 & 5 \\
Small-scale farms & 88 & 84 & 79 & 82 & 80 \\
Medium-scale farms & 73 & 72 & 73 & 70 & 70 \\
Large-scale farms & 22 & 16 & 37 & 33 & 25 \\
Non-agricultural & 80 & 80 & 69 & 68 & 59 \\
\hline
\end{tabular}

Note: *The 2006 and 2010 poverty rates are not strictly comparable with earlier years. These rates were calculated using year-specific Engel ratios to derive food shares, whereas previous years used a fixed ratio. This methodology shift may underlie the declines observed by housing cost between 2004 and 2006.

Source: CSO $(2005,2012)$

2010. For example, 34 per cent of the population in Copperbelt is poor compared to the next well-off province, Central, where 61 per cent of the population is poor. The poorest provinces, Eastern, Luapula, and Western, saw little to no improvement, with approximately 80 per cent of the population living in poverty in 2010 . Table 12.3 reports consumption poverty rates by urban housing cost areas and rural agricultural strata. Though urban poverty fell over the period, the large divide between low- and high-cost urban housing areas increased from twenty-two percentage points in 1996 to thirty percentage points in 2010. But this difference is dwarfed by the forty-five and seventy-five percentage point gap between the poverty rates in low- and high-cost urban housing areas compared to small-scale farm households.

This gap in welfare between urban areas, Lusaka, and Copperbelt and all other areas is made manifest in one of the highest levels of inequality in the world (World Bank 2014). Inequality worsened from a Gini coefficient of 0.60 in 2006 to 0.65 in 2010 (CSO 2012). Furthermore, in 2010, the bottom 50 per cent of the Zambian population received a meagre 9.1 per cent of the country's total income compared to the top 10 per cent reaping 52.2 per cent (CSO 2012).

Interprovincial comparisons point to skewed economic development whereby predominantly rural provinces, such as Western, Northern, Luapula, and Eastern, are characterized by high poverty rates and low welfare compared to the more developed Copperbelt, Central, and Lusaka provinces. Stagnation in rural areas can be attributed in part to a persistent duality of the economic structure. At independence, the country inherited a lopsided economy based on the extraction of copper in the Copperbelt. Transportation infrastructure ran from Copperbelt, through Central province, Lusaka, and Southern province to Southern Rhodesia, and consequently commercial activities were concentrated in Copperbelt and what came to be known as the line of rail (Simson 1985). The newly independent government strove to redress imbalances and inequalities by increasing its role in economic management and 
planning, including state ownership and the delivery of free social services. The government built strategic industries in all provinces to provide employment in order to boost local economies. Free access to health care, education, and other social amenities was meant to reduce inequities between rural and urban areas (UNDP 2011). However, the economic downturn in the 1980s and 1990s and adherence to structural adjustment programmes drastically reduced the government's capacity to overcome socioeconomic imbalances. Withdrawal of public support resulted in the closure of nearly all industries away from the line of rail as well as reductions in social services and social protection programmes. During this period, poverty peaked and the nation's human development fell to its lowest levels (UNDP 2011).

With 61 per cent of the population living in rural areas where consumption poverty rates continue to hover near 80 per cent, the polarized socioeconomic structure of the Zambian economy remains central to poverty reduction efforts. Overall, the average salary of Zambian workers is lower than the national consumption poverty line, and of the working poor, 81 per cent are engaged in farming (AFDB 2013). With 60 per cent of Zambian workers engaged in agricultural activities, growth in the agricultural sector provides the greatest potential for inclusive growth and poverty reduction (AFDB 2013; Diao et al. 2010). Table 12.4 presents employment by area in the formal and informal sectors and the agricultural and non-agricultural sectors. The level of formal economic activity in rural areas is very low. Within rural areas, 95 per cent of workers are employed in the informal sector (compared to 69 per cent in urban areas), 81 per cent of whom are employed in agriculture-related activities. Overall, the provinces with the highest poverty rates in 2010,

Table 12.4. Employment by sector, 2012, per cent

\begin{tabular}{|c|c|c|c|c|c|c|}
\hline & \multicolumn{3}{|c|}{ Formal sector } & \multicolumn{3}{|c|}{ Informal sector } \\
\hline & $\%$ of total & non-agriculture & agriculture & $\%$ of total & non-agriculture & agriculture \\
\hline National & 15.4 & 89.7 & 10.3 & 84.6 & 40.1 & 59.9 \\
\hline Rural & 5.5 & 66.4 & 33.6 & 94.5 & 19.3 & 80.7 \\
\hline Urban & 31.3 & 96.3 & 3.7 & 68.7 & 86.3 & 13.7 \\
\hline Central & 16.8 & 72.4 & 27.6 & 83.2 & 38.1 & 61.9 \\
\hline Copperbelt & 30.1 & 96.1 & 3.9 & 69.9 & 69 & 31 \\
\hline Eastern & 6.7 & 75.5 & 24.5 & 93.3 & 11.6 & 88.4 \\
\hline Luapula & 4.0 & 79 & 21 & 96.0 & 20.5 & 79.5 \\
\hline Lusaka & 31.3 & 93.3 & 6.7 & 68.7 & 90.4 & 9.6 \\
\hline Muchinga & 6.1 & 92.9 & 7.1 & 93.9 & 19.3 & 80.7 \\
\hline Northern & 4.6 & 87.3 & 12.7 & 95.4 & 28.9 & 71.1 \\
\hline Northwestern & 13.8 & 84.7 & 15.3 & 86.2 & 23.8 & 76.2 \\
\hline Southern & 8.0 & 87.9 & 12.1 & 92.0 & 40.7 & 59.3 \\
\hline Western & 6.3 & 88.6 & 11.4 & 93.7 & 17.8 & 82.2 \\
\hline
\end{tabular}

Note: Muchinga province was created in 2011 from Eastern and Northern provinces.

Source: CSO (2013) 
Eastern, Luapula, Northern, and Western (Table 12.2), correspond to the provinces with the highest percentage of the population employed in the informal sector and in agriculture.

In 2002, the government reintroduced agricultural supports with the goals of increasing production of staple crops, particularly maize, and reducing rural poverty (Mason and Smale 2013). Between 2004 and 2011, subsidized seed and fertilizer distributed via the Farmer Input Support Programme (FISP, formally the Fertilizer Support Programme) and price supports via the Food Reserve Agency (FRA) together comprised the majority of agricultural-sector Poverty Reduction Programme spending, with FISP accounting for 30 per cent of the total agricultural budget (Mason et al. 2013). In 2011, FISP amounted to 0.8 per cent of GDP and reached approximately 900,000 beneficiaries (Mason et al. 2013), with the number of targeted beneficiaries increasing to 1,000,000 in 2014/15 (MAL 2014). However, recent studies suggest that disproportionate participation of wealthier, larger farm households in FISP has resulted in limited poverty reduction. Specifically, only 9, 11, and 30 per cent of Zambian smallholder households received subsidized fertilizer through FISP in 2002/3, 2006/7, and 2010/11, respectively; and only 1, 10, and 27 per cent of Zambian smallholders sold maize to the FRA in the 2003/4, 2007/8, and 2011/12 maize marketing years, respectively (Mason and Tembo 2014; Mason et al. 2015).

Among smallholder farm households, larger farms were more likely to receive FISP fertilizer (Mofya-Mukuka et al. 2013). Furthermore, wealthier farmers were not only over-represented but also received greater shares of FISP fertilizer, such that in 2002/3 and 2010/11 respectively, the programme distributed only 7 and 15 per cent of FISP fertilizer to the poorest two income quintiles of the smallholder population compared to 63 and 42 per cent to the richest quintile (Mason and Tembo 2014). Poor targeting may have contributed to the measured lack of impact on poverty reduction. Programme efficiency may also be to blame. Mason and Tembo (2014) estimate that receipt of a $200 \mathrm{~kg}$ fertilizer pack only marginally reduces households' probability of falling below the US\$2/ capita/day poverty line by half a percentage point and reduces poverty severity by one percentage point. Mason and Smale (2013) find that a $10 \mathrm{~kg}$ seed pack more favourably reduces poverty severity by 0.7 percentage points and increases income by 1.1 per cent, suggesting high private and social costbenefit ratios for a range of prices and administrative costs.

\subsection{FOD Methodology and Data}

\subsubsection{Methodology}

In this analysis, we seek to better understand the nature of welfare dynamics during a period of high growth and relatively little monetary poverty 
reduction by evaluating the performance of Zambian households by province and urban and rural strata based on a set of non-monetary household outcomes. Despite the broad consensus on the multidimensional character of poverty, how to evaluate multiple dimensions in a single analysis remains a central topic of debate. The most common methods of evaluating multidimensional poverty rely on either arbitrary weighting schemes or assumptions regarding the nature of the welfare function. The FOD methodology developed by Arndt et al. (2012) advances multidimensional poverty analysis in its ability to compare the welfare of population groups without imposing arbitrary assumptions. Rather, the FOD criterion merely asserts that it is better to be not deprived than deprived in any dimension. ${ }^{3}$

Intuitively, consider a set of three ordinal, binary welfare indicators such that ' 0 ' indicates deprived and ' 1 ' indicates not deprived in each dimension. Each combination of welfare indicators is said to dominate, be dominated by, or be indeterminate relative to other combinations. The outcome $(1,1,1)$ clearly is better than or dominates $(0,0,0)$, since it is superior in every dimension. Furthermore, the outcome $(1,1,0)$ dominates $(0,1,0)$ because it is better to be not deprived than deprived in the first dimension. However, $(1,1,0)$ and $(0,0,1)$ are indeterminate outcomes; without imposing assumptions regarding the relative importance of or substitutability between each outcome, it cannot be determined if it is better to be not deprived in the first two dimensions or in the third dimension. Extending to two populations, $\mathrm{A}$ and $\mathrm{B}$, consider the distribution of individuals falling into each combination of welfare indicators. The FOD criterion can be described as follows: population A first-order dominates population B if one can generate distribution $\mathrm{B}$ by transferring probability mass (i.e. moving individuals) from better to unambiguously worse outcomes within A, where better is defined as above.

While FOD analysis allows for comparison across populations without imposing subjective restrictions, the criterion is strict and comes at a cost. Specifically, FOD comparisons frequently result in indeterminate outcomes and do not provide a sense of the extent of domination. Arndt et al. (2012) employ repeated bootstrap samples drawn from each population such that resulting FOD comparisons can be interpreted as empirical probabilities of domination. Not only do probabilities of domination reduce the possibility of indeterminate outcomes, but they also provide evidence of the extent to which a population dominates another. Furthermore, bootstrap probabilities allow populations to be ranked.

\footnotetext{
${ }^{3}$ For a detailed theoretical discussion of the FOD methodology, refer to Arndt et al. (2012).
} 
Though FOD comparisons frequently result in indeterminate outcomes, it should be noted that this shortcoming is countered by the strength of a dominant result. A dominant result requires superior welfare outcomes to be registered throughout the population and across indicators, meaning an indeterminate result could stem from relatively poor outcomes in a single indicator within a small section of the population. Thus, a dominance result provides a robust indication of broad-based superiority through time or across space (Arndt et al. 2012).

\subsubsection{Data}

FOD indicators are defined using the 1996, 2006, and 2010 Zambia Living Conditions Monitoring Surveys (LCMS) conducted by the Central Statistical Office (CSO). These nationally representative surveys allow for welfare comparisons at the provincial and urban/rural levels. The sampling method also allows for analysis of households by urban housing cost areas (low, medium, and high cost), and rural agricultural activities (non-agricultural, small-scale farm, medium-scale farm, and large-scale farm households). The total number of households surveyed increased over the study period from 11,787 in 1996 to 18,662 in 2006 and 19,397 in 2010. In urban areas, 65, 20, and 15 per cent of the 2010 sample reside in low-, medium-, and high-cost areas, respectively. In rural areas, approximately 75, 10, and 15 per cent of the 2010 sample are engaged in small-scale farming, medium-scale farming, or non-agricultural activities, respectively. Fewer than sixty large-scale farming households were included in each sample, and therefore this stratum is excluded from analysis.

\subsubsection{FOD Indicators}

We define welfare in terms of five household indicators inspired by the national development goals as outlined in the Sixth National Development Plan (GRZ 2011) and Vision 2030 (GRZ 2006): water, sanitation, ${ }^{4}$ housing, energy, and education. Given the government's prioritization of development goals, it becomes logical to use indicators directly associated with these expenditure priorities such that the welfare comparisons inform the allocation of public expenditure (Arndt et al. 2013). Table 12.5 defines each indicator in terms of deprivations.

\footnotetext{
${ }^{4}$ MDG definitions of improved water and sanitation (WHO and UNICEF 2014) provided a framework for defining the water and sanitation indicators.
} 
Table 12.5. FOD indicators

\begin{tabular}{ll}
\hline Indicators & Definitions \\
\hline $\begin{array}{l}\text { Sanitation } \\
\text { Water }\end{array}$ & $\begin{array}{c}\text { Deprived if household does not have a flush toilet or covered/uncovered latrines. }{ }^{\text {a }} \\
\text { Deprived if main source of drinking water } \\
\text { spring, is not supplied by a tap, pipe, protected well or }\end{array}$ \\
Housing & $\begin{array}{c}\text { Deprived if main flooring material is mud. } \\
\text { Deprived if household's cooking fuel source is firewood, charcoal, or crop/livestock } \\
\text { material. }\end{array}$ \\
Education & \begin{tabular}{c} 
Deprived if household head has not completed primary school. \\
\hline
\end{tabular}
\end{tabular}

Notes: ${ }^{a}$ The use of uncovered latrines should be considered a deprivation; however the 1996 and 2006 LCMS do not distinguish between covered and uncovered latrines.

b The 1996 LCMS collected data on drinking water supply in the dry and wet seasons. The water indicator reflects drinking water supply in the dry season.

${ }^{c}$ While water purchased from vendors is generally excluded from improved water sources, water kiosks differ in the formal provision of safe water at regulated prices. Only the 2010 LCMS reports drinking water supply from water kiosks; however, this does not create inconsistency since the kiosks were first introduced in 2006.

Source: Authors' definitions

\subsection{Assessing the Progress in Improving Welfare}

This section presents an assessment of Zambia's household welfare in 1996, 2006, and 2010. ${ }^{5}$ We strive to place multidimensional welfare in context with monetary poverty headcount trends as well as provide analysis pertinent to evaluating the impact of Zambia's national development programmes. We begin with a discussion of trends in each of the FOD indicators and then present spatial and temporal FOD results.

\subsubsection{Levels of Deprivation}

Figure 12.3 displays deprivation in each of the five indicators at the national, urban, and rural levels and Table 12.6 presents the evolution of deprivations across urban housing cost areas, rural agricultural strata, and all aggregate areas. Overall deprivation in access to water, sanitation, and education significantly declined over the period while only modest declines were registered in deprivations in shelter and cooking fuel. In comparison to progress in reducing rural consumption poverty (Table 12.2), this set of indicators provides evidence of improved welfare driven by gains in rural areas whereas urban welfare essentially stagnated. Further, in contrast to consumption poverty rates by stratum (Table 12.3), small-scale farm households achieved notable welfare gains in water, sanitation, and education. On the other hand, consistent with a large decline in consumption poverty rates, non-agricultural households also achieved significant welfare gains in every indicator except shelter. Over the study period, a great disparity persisted in deprivation levels of

\footnotetext{
${ }^{5}$ Population weights are used throughout the analysis.
} 


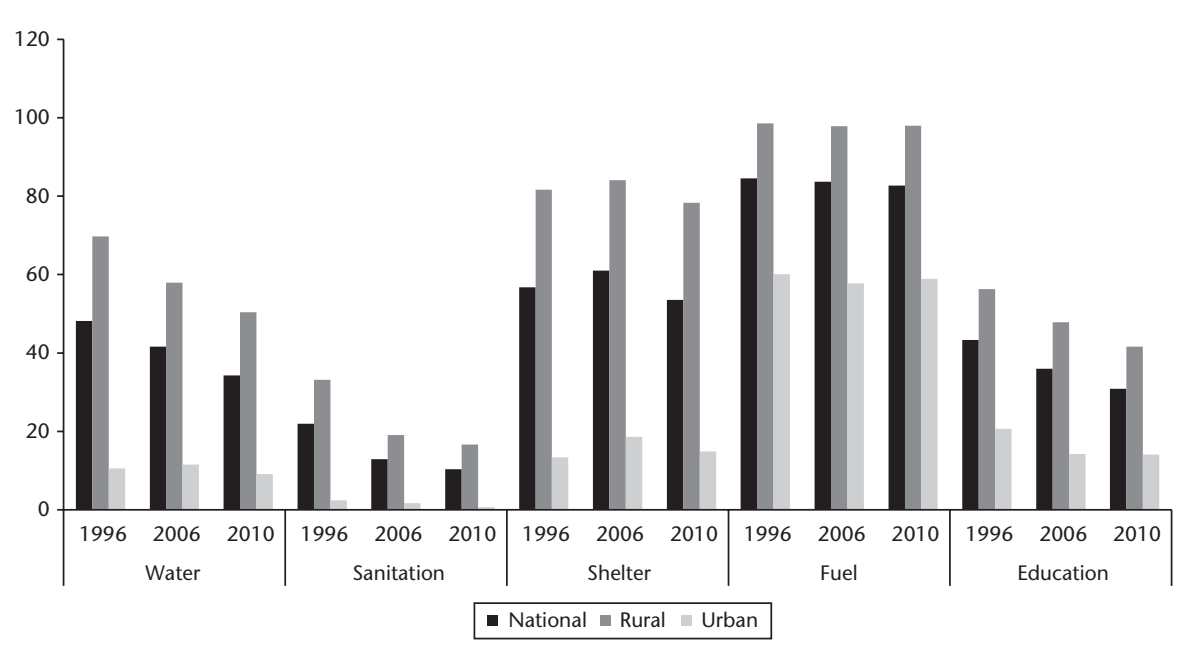

Figure 12.3. Deprivation by welfare indicator and area aggregate, per cent Source: Authors' calculations based on the CSO $(1996,2006$, and 2010) LCMS datasets

households residing in low-cost areas compared to medium- and high-cost areas. However, low-cost areas outperformed all rural strata in every indicator by a large margin. Though rural areas achieved notable gains, both the deprivation rates and the gap between urban and rural deprivation levels remained high.

While very little progress occurred in improving the quality of shelter and cooking fuel over the fourteen-year period in any area or strata, the share of the population with household heads who did not complete primary school declined in every area and household stratum. In contrast, changes in access to improved water and flush toilets or latrines varied substantially. In both cases, little change occurred in urban areas whereas rural access improved by twenty and sixteen percentage points, respectively. Improvements in rural water access were concentrated among small farm and non-farm households and rural sanitation access improved across all rural household strata. Interestingly, provinces performing well in access to water do not necessarily correspond to provinces with low levels of sanitation deprivation. For instance, substantial strides were made to reduce water deprivation in Southern and Eastern provinces by seventeen and twenty-two percentage points, putting these provinces on par with Copperbelt. However, Southern and Eastern provinces have two of the highest sanitation deprivation rates. Despite Luapala and Northern provinces also achieving reductions in water deprivation close to twenty percentage points, deprivation remained extremely high at nearly 70 per cent. Yet, Luapala and Northern province have among the lowest deprivations in sanitation. Nonetheless, provincial 


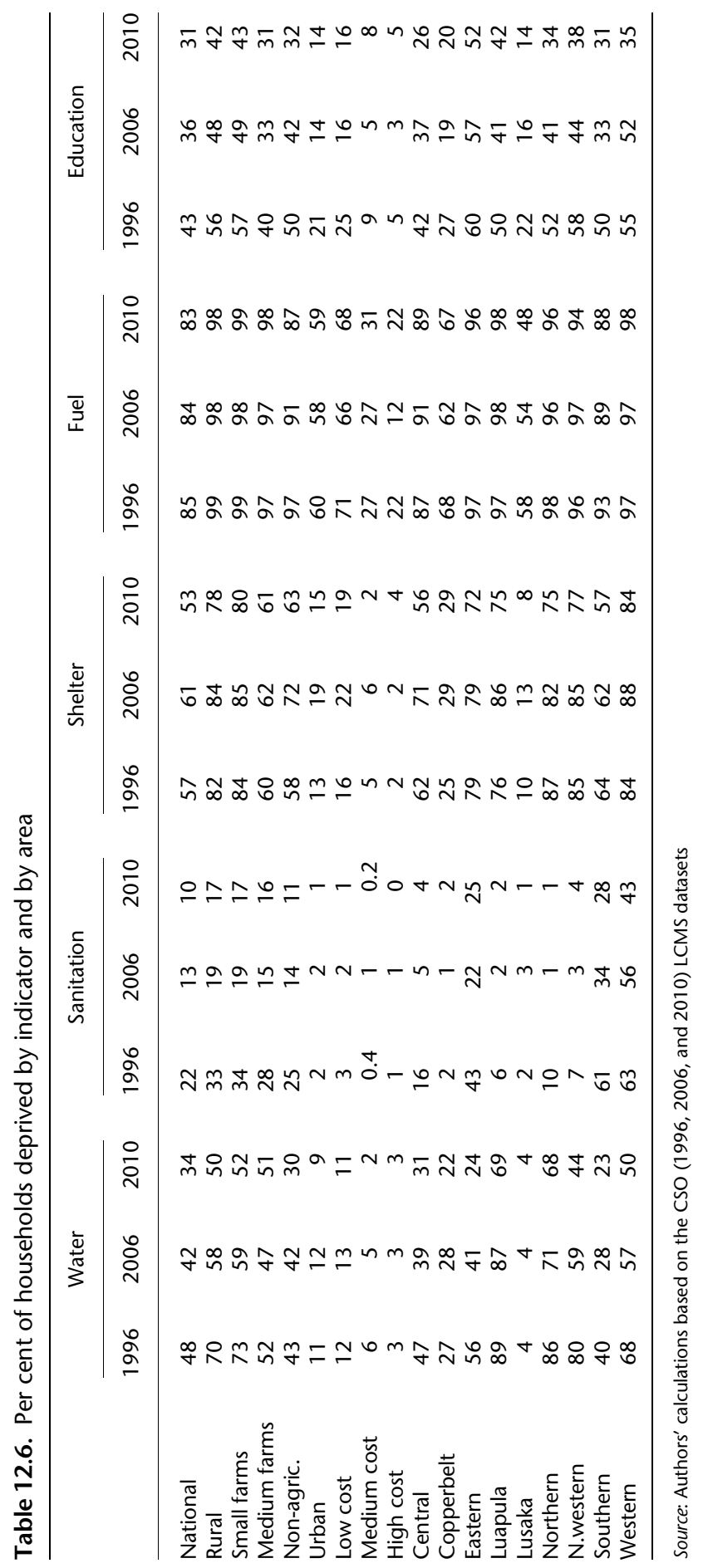


disparities remain large in both indicators at a maximum of sixty-five and forty-two percentage points for water and sanitation respectively.

\subsubsection{Number of Deprivations}

Table 12.7 presents the total number of deprivations faced by households at the national, rural, urban, and provincial levels and provides a sense of the depth of overall household deprivation over time and across regions. Predominately rural provinces (Eastern, Luapula, Northern, Northwestern, and Western) follow the pattern of rural areas with the greatest shares of households facing two, three, or four deprivations in 2010, while over the study period, the shares of severely deprived households (facing four or five deprivations) declined by more than twenty percentage points. Within rural areas, all household strata follow this pattern. This decline in severely deprived rural households was driven by gains attained by small-scale farm and non-farm households. Households in Central and Southern provinces face fewer deprivations with the greatest share of households facing one, two, or three deprivations and respectively 10 and 11 per cent of households not deprived in any indicator. Finally, the largest share of households not deprived in any indicator or deprived in only one indicator reside in urban areas (38 and 35 per cent) and Copperbelt (30 and 29 per cent) and Lusaka provinces (49 and 33 per cent). Though little improvement occurred between 1996 and 2010 within urban areas, households in low-cost housing areas accounted for the bulk of this change.

\subsubsection{Temporal FOD Comparisons}

This section discusses temporal FOD results for areas and rural and urban strata. FOD results are presented as the net probability of domination, which measures the probability the welfare of an area or strata improves between two years net of any probability of regression. Positive values indicate the probability of advancement in welfare and negative values indicate the probability of regression.

Table 12.8 displays the net temporal FOD results for each aggregate area and province. At the aggregate level, FOD comparisons indicate significant probabilities of advancement at the national level over time. National welfare in 2010 based on the five FOD indicators dominated the welfare profiles of both 2006 and 1996 with a probability of 63 and 72 per cent. Rural areas advanced between 1996 and 2010 with a probability of 76 per cent. At the provincial level, Central, Eastern, Lusaka, Northern, Northwestern, and Southern provinces all exhibit notable probabilities of welfare improvements in 2010. The remaining provinces have positive probabilities of advancing from 2006-10 or 


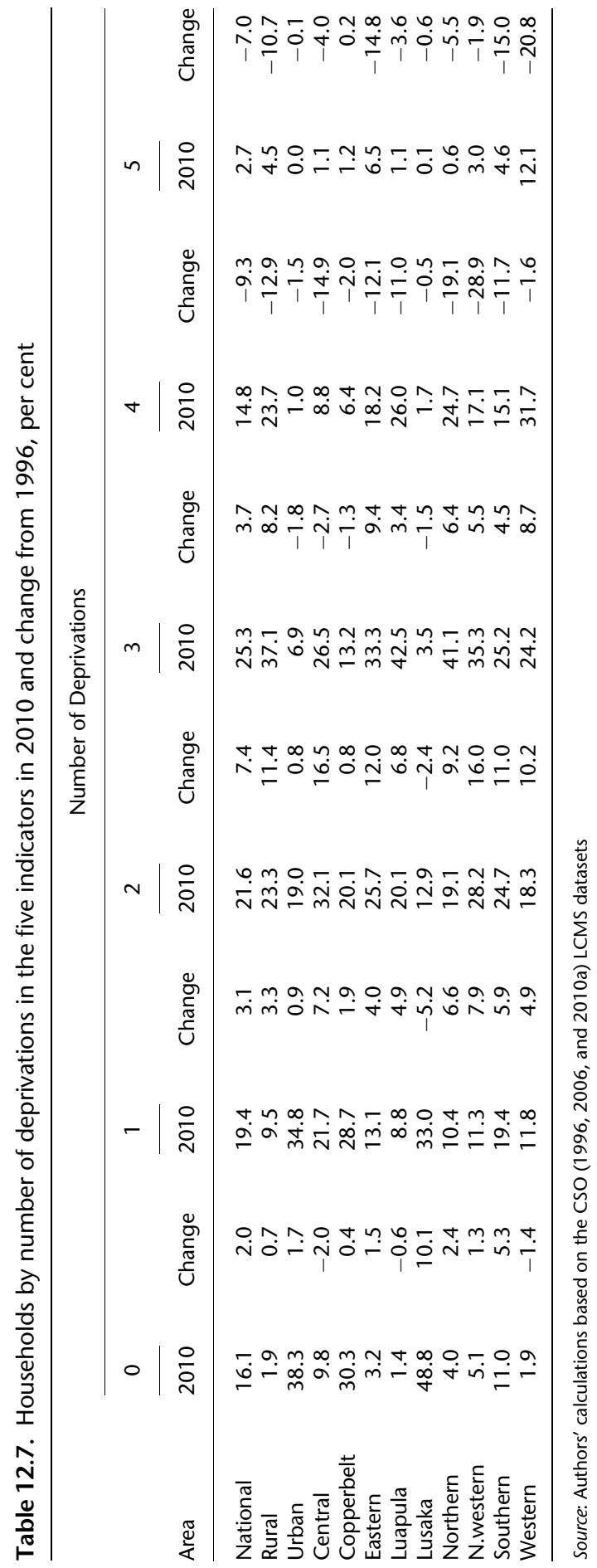


Table 12.8. Temporal net FOD comparisons by aggregate area and province (probabilities)

\begin{tabular}{lccc}
\hline & 2006 FOD 1996 & 2010 FOD 2006 & 2010 FOD 1996 \\
\hline National & 0.20 & $\mathbf{0 . 6 3}$ & $\mathbf{0 . 7 2}$ \\
Rural & 0.09 & 0.30 & $\mathbf{0 . 7 6}$ \\
Urban & & 0.30 & 0.19 \\
Central & 0.02 & 0.57 & 0.25 \\
Copperbelt & 0.22 & -0.23 & 0.21 \\
Eastern & 0.43 & 0.06 & 0.61 \\
Luapula & & 0.15 & 0.27 \\
Lusaka & 0.06 & 0.33 & 0.48 \\
Northern & 0.80 & 0.04 & 0.95 \\
Northwestern & 0.18 & 0.46 & 0.73 \\
Southern & 0.63 & 0.24 & 0.17 \\
Western & 0.07 & & \\
\hline
\end{tabular}

Note: Values in bold indicate domination in the static case (FOD without bootstrapping).

Source: Authors' calculations based on the CSO (1996, 2006, and 2010a) LCMS datasets

1996-2010, though the probabilities are lower (less than 30 per cent in all cases). Copperbelt is the only province registering a probability of decline, with a 21 per cent probability of regression between 2010 and 2006; however Copperbelt is equally likely to have advanced from 1996 to 2006 and from 1996 to 2010, respectively.

Measured changes in consumption or monetary poverty as per official sources are not closely related to improvements in non-monetary poverty as measured by the FOD. For instance, none of the areas with the greatest probability of advancement between 1996 and 2010 (national, rural, Eastern, Northern, and Southern) reduced consumption poverty over the same period by more than 10 per cent (see Table 12.2); whereas the areas with the greatest declines in monetary poverty (urban areas, Central, and Copperbelt) have among the lowest probabilities of welfare advancement between 1996 and 2010, according to the FOD. Western province stands out as the only area with very low consumption poverty reduction and very little probability of advancing in FOD comparisons.

Table 12.9 displays the net temporal FOD results for each aggregate urban and rural stratum. FOD comparisons suggest that no urban stratum was likely to have achieved welfare improvements over time. In contrast, welfare improvements in rural areas are likely. Households engaged in non-agricultural activities had a 79 per cent likelihood of advancing between 2006 and 2010 and smallscale farms had a 55 per cent chance of advancing between 1996 and 2010. Interestingly, though measured monetary poverty in rural areas has been sticky overall and for small-scale farm households in particular, over the study period (see Table 12.3), welfare as defined by the FOD indicators is quite likely to have improved. 
Table 12.9. Temporal net FOD comparisons by urban and rural strata (probabilities)

\begin{tabular}{lccc}
\hline & 2006 FOD 1996 & 2010 FOD 2006 & 2010 FOD 1996 \\
\hline Urban low-cost housing & & 0.17 & 0.10 \\
Urban medium-cost housing & & 0.04 & \\
Urban high-cost housing & 0.03 & 0.02 & 0.55 \\
Small-scale farms & 0.05 & -0.03 & 0.02 \\
Medium-scale farms & & 0.79 & 0.18 \\
Rural non-agricultural & & & \\
\hline
\end{tabular}

Note: Values in bold indicate domination in the static case (FOD without bootstrapping).

Source: Authors' calculations based on the CSO (1996, 2006, and 2010a) LCMS datasets

\subsubsection{Spatial FOD Comparisons}

In each year, FOD comparisons are made between all areas to determine the degree of domination of each aggregate area and province. Tables 12.10 and 12.11 report the results of the 1996 and 2010 spatial FOD bootstrap comparisons. Higher row averages are associated with relatively better-off regions (likely to dominate) while higher column averages are associated with relatively worse-off regions (likely to be dominated). Row by row, values in the inner table represent the probability that a row region dominates the corresponding column region. ${ }^{6}$ FOD comparisons are also conducted between each urban and rural stratum and results are presented in ranking tables in the following section.

In all three years, column averages indicate that urban areas, Copperbelt, and Lusaka dominated all other areas with a high degree of probability. The probability of Copperbelt dominating other areas diminished over time from 80 per cent in 1996 to 54 per cent in 2010. The probability of Lusaka and urban areas dominating other areas held fairly steady at 84 and 85 per cent in 1996 and 80 and 89 per cent in 2010, respectively. Rural areas and Western province exhibit the highest average probability of being dominated (near 50 per cent) in both 1996 and 2010. The lack of relative progress in Western province is consistent with both small gains in poverty rates and low probability of welfare advancement in temporal FOD comparisons. Eastern province also has a relatively high average probability of being dominated in 1996 (43 per cent) but this average falls in 2010 (27 per cent). Finally, Northern province experienced a notable decline in the probability of domination from 29 per cent in 1996 to 16 per cent in 2010. The gains in Eastern and Northern provinces indicate an improvement relative to other areas and are consistent with temporal results indicating a 61 and 95 per cent probability of advancing over the same period.

\footnotetext{
${ }^{6}$ Note that bootstrap sampling introduces a degree of randomness into the results and care must be taken not to place too much importance on very small probabilities.
} 


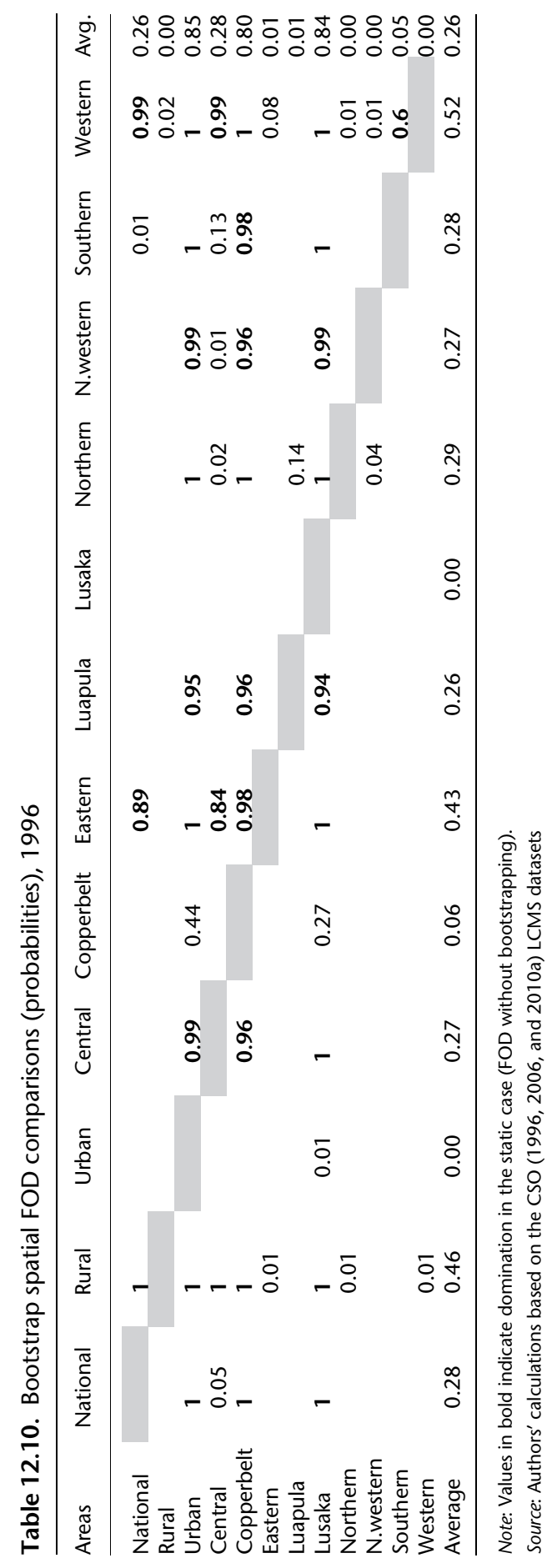




\subsubsection{Ranking of Provinces}

Spatial net domination scores provide a basis for ranking provinces and conveniently presenting a more detailed perspective on the evolution of relative well-being. Referring to Tables 12.10 and 12.11 , net domination measures the probability that an area dominates other areas (row averages) minus the probability it is dominated by other areas (column averages). Table 12.12 presents area rankings and Table 12.13 presents urban and rural stratum rankings. It is worth noting that the difference in net domination scores is often insufficiently large to distinguish between differences in welfare outcomes and variability introduced through random bootstrapping. To avoid misinterpreting rankings within the tables, shading identifies clusters with similar net domination scores. Within these clusters, ranks cannot be established with confidence.

Table 12.12 presents the ranking of the provinces based on net domination scores. Little change in ranking occurs between 1996 and 2010. At first glance, it appears as though a large degree of change takes place in 2006 relative to 1996 and 2010, but these changes are not generally robust. Rearranging provinces within shaded areas could produce orderings in 2006 quite close to those in 1996 and 2010. As indicated in the previous section, urban areas, Lusaka, and Copperbelt are ranked in the top and rural areas and Western provinces are ranked at the bottom, in all three years. Consistent with temporal results, Copperbelt's ranking robustly improved in 2006 and then worsened again in 2010. Northern province is likely to have increased in rank between 1996 and 2006 and 2010 from a rank as low as ninth in 1996 to a rank as high as fifth in 2010, a result also consistent with temporal results. Eastern province improved substantially in the extent to which it is dominated by other areas, and its ranking improved from as low as eleventh to as high as eighth position between 1996 and 2010, though this change in ranking is less robust.

Table 12.13 presents rankings by urban housing cost areas and rural agricultural activity based on net domination scores. Very little difference exists in the welfare of households residing in medium- and high-cost housing areas based on these indicators. Households in medium- and high-cost housing areas strongly outperform households in low-cost housing areas. Households located in low-cost housing areas, in turn strongly outperform the national aggregate and all rural strata. Medium-scale farm households and nonagricultural households attain similar welfare rankings in 1996 and 2006, but non-agricultural farm households significantly outperform mediumscale farm households in 2010, an improvement consistent with the temporal advancement of non-agricultural households during 2006-10. Despite temporal evidence of advancement in the welfare of small farm households, this 


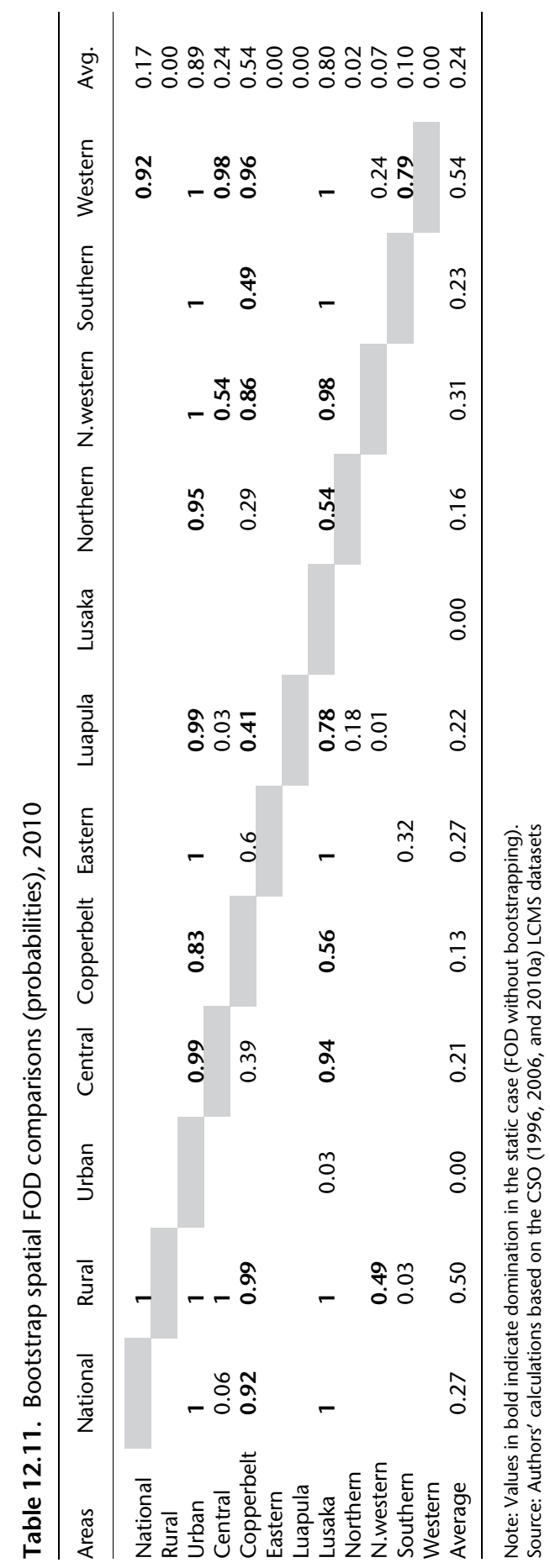


Table 12.12. Area rankings by probability of net domination

\begin{tabular}{|c|c|c|c|c|c|c|c|c|}
\hline \multicolumn{3}{|l|}{1996} & \multicolumn{3}{|l|}{2006} & \multicolumn{3}{|l|}{2010} \\
\hline & Domination & Rank & & Domination & Rank & & Domination & Rank \\
\hline Urban & 0.85 & 1 & Copperbelt & 0.73 & 1 & Urban & 0.88 & 1 \\
\hline Lusaka & 0.84 & 2 & Urban & 0.68 & 2 & Lusaka & 0.80 & 2 \\
\hline Copperbelt & 0.74 & 3 & Lusaka & 0.58 & 3 & Copperbelt & 0.41 & 3 \\
\hline Central & 0.01 & 4 & Central & -0.01 & 4 & Central & 0.03 & 4 \\
\hline National & -0.01 & 5 & Northern & -0.01 & 5 & National & -0.10 & 5 \\
\hline Southern & -0.23 & 6 & National & -0.05 & 6 & Southern & -0.12 & 6 \\
\hline Luapula & -0.25 & 7 & Northwestern & -0.14 & 7 & Northern & -0.15 & 7 \\
\hline Northwestern & -0.26 & 8 & Southern & -0.14 & 8 & Luapula & -0.22 & 8 \\
\hline Northern & -0.29 & 9 & Luapula & -0.22 & 9 & Northwestern & -0.24 & 9 \\
\hline Eastern & -0.42 & 10 & Eastern & -0.37 & 10 & Eastern & -0.27 & 10 \\
\hline Rural & -0.46 & 11 & Rural & -0.47 & 11 & Rural & -0.50 & 11 \\
\hline Western & -0.52 & 12 & Western & -0.58 & 12 & Western & -0.54 & 12 \\
\hline
\end{tabular}

Note: Areas grouped in shaded cells have net domination scores too close to distinguish between differences in welfare and differences in bootstrap variation. Therefore, shaded rankings must be interpreted with caution.

Source: Authors' calculations based on the CSO $(1996,2006$, and 2010a) LCMS datasets

advancement was not sufficient to change rankings of relative well-being. Though welfare improved, small-scale farm households remain severely deprived relative to all other household strata, as evidenced by net domination scores of 0.9 in both 1996 and 2010. In other words, small-scale farms were dominated in almost every comparison to all other household strata in all bootstrap samples.

\subsection{Discussion}

Zambia has made strides in revitalizing its economy over the last twenty years. The country rebounded from low and even negative growth in the 1980s and 1990s to a high average annual growth rate of 7 per cent in the 2000s. Both external and internal factors boosted economic rehabilitation and growth, including copper prices and debt cancellation along with consistent fiscal discipline and economic liberalization policies. Despite strong growth, structural changes over the last twenty years have brought little social transformation or employment creation (Resnick and Thurlow 2014). Though agricultural productivity rose in recent years, productivity remains low with agriculture's contribution to GDP steadily declining. Consequently, impressive economic growth, structural changes, and even the targeted rural farm support programmes of the 2000s did not translate to substantial monetary poverty reduction in the agriculture-dependent rural areas, according to official statistics. 


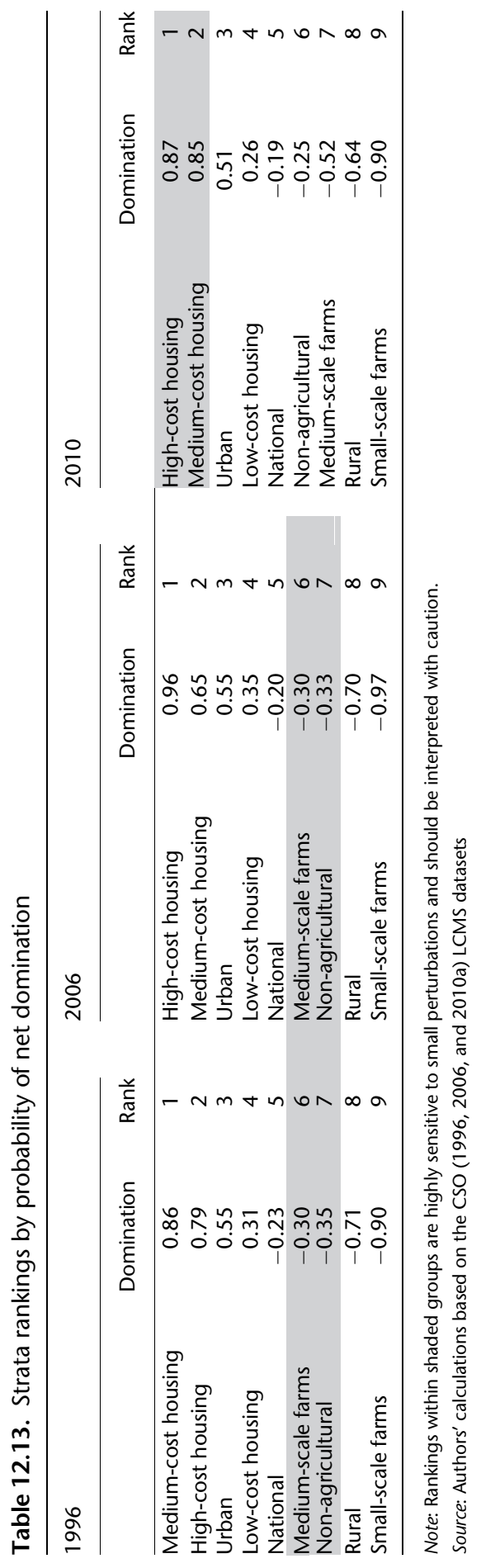


In contrast to the monetary poverty figures, FOD results provide robust evidence of broad-based gains in household welfare in Zambia between 1996 and 2010, with advancement based substantially on improved rural household welfare. Temporal FOD results suggest small farm and non-agricultural rural households drove advancements in rural welfare. Temporal FOD also provides robust evidence of advancement in Central, Eastern, Lusaka, Northern, Northwestern, and Southern provinces, with these results also driven by improvements in rural household welfare. Nonetheless, rural households continued to lag significantly behind their urban counterparts. Even with broad improvements in other regions, Lusaka, Copperbelt, and urban areas maintained vastly superior levels of well-being, though this relative superiority weakened somewhat for Copperbelt. The contrast between measured monetary poverty and FOD analysis extends into urban areas. The published urban poverty headcount rate declined over the fourteen-year period of analysis, but FOD provides only weak support for urban welfare gains.

Despite the broad-based welfare gains (based on FOD) achieved by much of the nation, including rural households and small farmers as a group, substantial gains eluded the two provinces with the highest monetary poverty headcount rates in 2010, Luapula and Western provinces. Temporal FOD indicates only relatively weak probabilities of advancement of 27 per cent in Luapula between 1996 and 2010 and 24 per cent in Western between 2006 and 2010; in other words, the probability of no change or indeterminate outcomes is relatively high at approximately 75 per cent.

As noted, small-scale farm households in particular and rural households in general remain notably worse off compared with other household strata. Nevertheless, the results indicate that, in terms of the multidimensional indicators employed, some of the fruits of the improved growth performance since the mid-1990s have been translated into real progress in important development indicators on the ground.

In terms of future research, three areas are suggested. First, further analysis is warranted to identify the extent to which FOD results are sensitive to data restrictions and indicator choices. For instance, the Zambian government has prioritized building covered latrines in rural areas. Yet, Living Conditions Monitoring Surveys prior to 2010 do not distinguish between covered and uncovered latrines and thus the sanitation indicator employed in this study classifies all households using any latrines as not deprived. As a result, FOD analysis could not capture improvements in sanitation for those moving from uncovered to covered latrines and therefore welfare gains may be underrepresented. Applying FOD analysis to the 2010 and 2013 Zambia Demographic and Health Surveys would permit a more relevantly defined sanitation indicator. Furthermore, considering alternative indicators measuring aspects of welfare such as health, nutrition, or access to information would better our 
understanding of the sensitivity of results to indicator selection as well as deepen our knowledge of the evolution of welfare in Zambia.

Second, the disconnect between the monetary poverty results and the FOD merits further scrutiny. Detailed analysis of consumption levels is hampered by the absence of quantity data within the household survey. It may (or may not) be possible to marry the detailed consumer price index data, which Zambia possesses, with the expenditure data from household consumption surveys in order to get a more accurate fix on trends in consumption including consumption poverty. This possibility should be investigated. Finally, while the Zambian government can be credited with having converted a period of relatively favourable commodity prices into some social gains, the economy remains unbalanced, with large gaps in welfare between rural and urban areas, and vulnerable to commodity price swings, particularly declines in the price of copper. Policies to enhance inclusion and address commodity price vulnerability should remain in focus.

\section{References}

AFDB (African Development Bank) (2013). 'Development Effectiveness Review 2013: Zambia'. Tunis: African Development Bank.

Arndt, C., R. Distante, M. A. Hussain, L. P. Østerdal, P. Huong, and M. Ibraimo (2012). 'Ordinal Welfare Comparisons with Multiple Discrete Indicators: A First Order Dominance Approach and Application to Child Poverty', World Development, 40(11): 290-301.

Arndt, C., A. Hussain, V. Salvucci, F. Tarp, and L. Østerdal (2013). 'Advancing Small Area Estimation', WIDER Working Paper No. 2013/051. Helsinki: UNU-WIDER.

Bonnick, G. G. (1997). 'Turning an Economy Around: Zambia Country Assistance Review'. Washington, DC: World Bank.

Cardozo, A., G. Masumbu, C. Musonda, and G. Raballand (2014). 'Growth, Employment, Diversification, and the Political Economy of Private Sector Development in Zambia', in C. S. Adams, P. Collier, and M. Gondwe (eds), Zambia: Building Prosperity from Resource Wealth. Oxford: Oxford University Press, 30-55.

CSO (Central Statistical Office) (1996). 'Living Conditions and Monitoring Survey'. Lusaka: CSO.

CSO (Central Statistical Office) (2005). 'Living Conditions and Monitoring Survey Report, 2004'. Lusaka: CSO.

CSO (Central Statistical Office) (2006). 'Living Conditions and Monitoring Survey'. Lusaka: CSO.

CSO (Central Statistical Office) (2010a). 'Living Conditions and Monitoring Survey'. Lusaka: CSO.

CSO (Central Statistical Office) (2010b). 'Living Conditions and Monitoring Survey Report, 2006 \& 2010'. Lusaka: CSO. 
CSO (Central Statistical Office) (2012). 'Census of Population and Housing Report'. Lusaka: CSO.

CSO (Central Statistical Office) (2013). 'Zambia Labour Force Survey Report'. Lusaka: CSO.

Cheelo, S. and L. Muchimba (2012). 'Zambia's Case Study on Economic Transformation'. Lusaka: Zambia Institute for Policy Analysis and Research.

De Kemp, A., J. Faust, and S. Leiderer (2011). 'Between High Expectations and Reality: An Evaluation of Government Support in Zambia, Synthesis Report'. The Hague: Ministry of Foreign Affairs of the Kingdom of the Netherlands.

Diao, X., P. Hazell, and J. Thurlow (2010). 'The Role of Agriculture in African Development', World Development, 38(10): 1375-83.

DiJohn, J. (2010). 'State Resilience against the Odds: An Analytical Narrative on the Construction and Maintenance of Political Order in Zambia since 1960', Crisis States Research Centre Working Papers Series 2, 75. London: Crisis States Research Centre, London School of Economics and Political Science.

GRZ (Government of the Republic of Zambia) (2006). 'Vision 2030: A Prosperous Middle-Income Nation by 2030'. Lusaka: GRZ.

GRZ (Government of the Republic of Zambia) (2011). 'Sixth National Development Plan (SNDP), 2011-2015'. Lusaka: GRZ.

Mason, N. M., T. S. Jayne, and R. Mofya-Mukuka (2013). 'Zambia's Input Subsidy Programs', Agricultural Economics, 44: 613-28.

Mason, N. M., T. S. Jayne, and R. J. Myers (2015). 'Smallholder Supply Response to Marketing Board Activities in a Dual Channel Marketing System: The Case of Zambia', Journal of Agricultural Economics, 66(1): 36-65, February 2015.

Mason, N. M. and M. Smale (2013). 'Impacts of Subsidized Hybrid Seed on Indicators of Economic Well-being among Smallholder Maize Growers in Zambia', Agricultural Economics, 44: 659-70.

Mason, N. M. and S. T. Tembo (2014). 'Do Input Subsidies Reduce Poverty among Smallholder Farm Households? Evidence from Zambia'. Paper presented the Agricultural and Applied Economics Association's Annual Meeting, Minneapolis, MN, 27-9 July 2014.

MAL (Ministry of Agriculture and Livestock) (2014). Ministerial statement on the 2014/ 15 Farmer Input Support Program (FISP), the 2014/15 maize marketing season, and an update on the status of maize products, by Honourable Wylbur C. Simuusa, MP, Minister of Agriculture and Livestock, 19 June, MAL, Lusaka.

Mofya-Mukuka, R., S. Kabwe, A. Kuteya, and N. M. Mason (2013). 'How Can the Zambian Government Improve the Targeting of the Farmer Input Support Program?', Working Paper No. 53,.Lusaka: Indaba Agriculture Research Institute.

Ndulo, M. and D. Mudenda (2004). 'Trade Policy Reform and Adjustment in Zambia', United Nations Conference on Trade and Development, <http://www.unctad.info/ upload/TAB/docs/TechCooperation/zambia_study.pdf $>$.

Resnick, D. and J. Thurlow (2014). 'The Political Economy of Zambia's Recovery: Structural Change without Transformation?', Discussion Paper No. 01320. Washington, DC: International Food Policy Research. 
Simson, H. (1985). Zambia: A Country Study. Uppsala: Scandinavian Institute of African Studies.

UNDP (United Nations Development Programme) (2011). 'Zambia Human Development Report, 2011'. Lusaka: UNDP.

UNDP (United Nations Development Programme) (2013). 'Millennium Development Goals: Progress Report, Zambia 2013'. Lusaka: UNDP.

UNDP (United Nations Development Programme) (2014). 'Human Development Report 2014: Sustaining Human Progress: Reducing Vulnerabilities and Building Resilience'. New York: UNDP.

USAID (United States Agency for International Development) (2011). 'Zambia Country Development Strategy: 2011-2015'. Washington, DC: USAID.

Whitworth, A. (2014). 'Explaining Zambia's Poverty: A History of (Non-agricultural) Economic Policy since Independence', Journal of International Development, doi: 10.1002/jid.3049.

World Bank (2013). 'Zambia's Jobs Challenge: Realities on the Ground', Zambia Economic Brief, Issue 2, available at <http://www.worldbank.org/content/dam/Wor ldbank/document/Africa/Zambia/Report/zambia-economic-brief-october-2013. pdf $>$.

World Bank (2014). World Development Indicators, available at < data.worldbank.org $>$. WHO (World Health Organization) and UNICEF (2014). 'Progress on Drinking Water and Sanitation-2104 Update'. Geneva: WHO. 



\section{Part 3}

Uninspiring/Negative Growth and Poverty Reduction 



\section{3}

\section{Slow Progress in Growth and Poverty Reduction in Cameroon}

Samuel Fambon, Andy McKay, Joseph-Pierre Timnou, Olive Stéphanie Kouakep, Anaclet Désiré Dzossa, and Romain Tchakoute Ngoho

\subsection{Introduction}

Cameroon is a country in Central Africa stretching over an area of 475,000 $\mathrm{km}^{2}$, with a population of about 22.5 million inhabitants in 2013 and a density of about 39.7 inhabitants per $\mathrm{km}^{2}$. It is a member country of the Franc Zone. ${ }^{1}$ Its currency, the franc of the Communauté Financière en Afrique Centrale (the CFAF), is issued by Banque des États de l'Afrique Centrale (BEAC), ${ }^{2}$ and pegged to the euro at the fixed parity of $€ 1=$ CFAF655.55. Cameroon is endowed with huge potentialities not only in agriculture, but also in minerals. In addition, the country has oil resources at its disposal, which contributed about 43 per cent of its exports in 2004, and accounted for 11.1 per cent of its GDP (IMF 2005). Compared with other sub-Saharan Africa (SSA) countries, Cameroon has a relatively diversified production base and resources, for it produces and exports a wide range of non-oil products. ${ }^{3}$ Although the country has been a producer and net exporter of oil since 1978, agriculture remains the pillar of the economy and employs about 70 per cent of the labour force.

It has the largest population by some margin in the Central African region and is the region's leading economy. In its first twenty-six years after

\footnotetext{
${ }^{1}$ Cameroon is also a member of the Communauté Economique et Monétaire de l'Afrique Centrale, of the Commonwealth, and of the Communauté Economique des États d'Afrique Centrale.

2 The BEAC is the central bank of six Central African countries, namely: Cameroon, the Central African Republic, Congo, Gabon, Equatorial Guinea, and Chad. The other members of the CFAF currency area are: Benin, Burkina Faso, Côte d'Ivoire, Niger, Senegal, Togo, and since 1984, Mali, whose common central bank is the Banque des États de l'Afrique de l'Ouest.

${ }^{3}$ These products are mainly cocoa, coffee, cotton, palm oil, bananas, rubber, and aluminium, etc.
} 
independence in 1960 its per capita GDP in 2005 US\$ grew at 2.5 per cent per year, reaching a maximum value of US\$1,356 in 1986. At that point it was among the wealthiest SSA countries outside South Africa. This, however, was not a case of consistent GDP growth over this period. Per capita growth between 1960 and 1977 averaged only 0.4 per cent per annum, but with the discovery of oil and the start of its production from 1978 per capita growth between 1977 and 1986 averaged 5.4 per cent per annum. This growth burst was not sustained, and ever since 1986 Cameroon's per capita GDP has been significantly lower. The following twenty-eight years were not a case of consistent decline; but since 1990 Cameroon has not had a per capita GDP level in excess of US $\$ 1,000$. It still remains relatively well-off among countries in SSA; and it has not been significantly affected by conflict as have some of its neighbours. But given its resources, its economic achievement has been disappointing.

This chapter focuses predominantly on Cameroon's record in terms of poverty reduction. But this needs to be understood in the context of its overall economic performance. Hence, in this chapter we begin by reviewing some of the factors accounting for its growth performance (section 13.2), summarizing the situation in different subperiods, and then drawing in particular on the insights of the AERC study of Kobou et al. (2008). In section 13.2 we use household data to look at the country's record in reducing monetary poverty and at the distributional pattern of growth (section 13.3). This is then complemented by analysing its record in terms of non-monetary outcomes (section 13.4). In this analysis a strong emphasis is placed on regional differences in this spatially diverse country. Section 13.5 concludes.

\subsection{The History of Growth Performance in Cameroon}

The growth history of Cameroon from its independence in 1960 to date is conveniently summarized by Figure 13.1, which shows the evolution of per capita GDP in local currency values. This is a case of a slow gradual growth, averaging 0.6 per cent a year over the full period, but punctuated by a relatively short-lived growth surge over the period 1976-85 during which per capita growth averaged 6.3 per cent. The growth surge is relatively straightforwardly explained: it reflects the discovery and production of oil, at a time when the initial oil price was high. The long-run performance calls for a more detailed explanation, but has been the subject of a detailed and authoritative political economy analysis by Kobou et al. (2008) on which we draw in sections 13.2.5 and 13.2.6.

To first summarize the history of Cameroon over this period, it is convenient to subdivide into four distinct sub-periods: (i) 1960-77, before the 


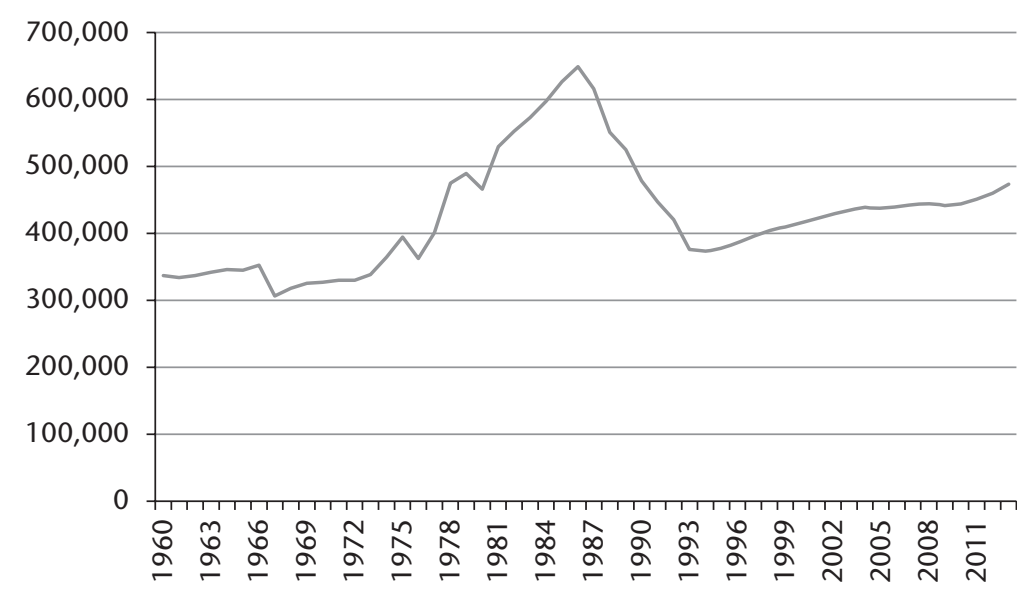

Figure 13.1. GDP per capita of Cameroon in constant local currency values Source: World Development Indicators, 2014

exploitation of oil; (ii) 1978-86, when the oil sector played a major role in the country's economy; (iii) 1987-93 during which the economy witnessed a serious economic crisis; and (iv) the period from 1994 to date, or the CFAF post-devaluation sub-period relative to the French franc. The following paragraphs briefly present Cameroon's economic performance over each of these sub-periods.

\subsubsection{Prior to Oil Exploitation: 1960-77}

Following independence in 1960, Cameroon adopted an interventionist approach to industrialization and economic development. Trade policy kept import prices high, terms of trade were stable, and there was a rapid expansion of agricultural exports. Real GDP grew at an average rate of 3.1 per cent over this period, but as the accompanying population growth averaged 2.4 per cent, the per capita growth rate was much smaller. Growth was also quite volatile during this time. The private investment/GDP ratio rose from 11 per cent in 1963 to about 19 per cent in 1977; by contrast, public investment as a percentage of GDP remained very low at 2 per cent. Government revenues during this sub-period accounted for about 18 per cent of GDP, and the average total budget deficit was low at about 1 per cent of GDP (Ghura 1997).

\subsubsection{The Arrival of Oil: 1978-86}

This sub-period starts with the production and exportation of oil in 1978. Real GDP rose by about 8.8 per cent per year during this sub-period, driven to a 
significant extent by the increase in oil production, which grew from less than 5 million barrels in 1978 to more than 66 million barrels in 1986. The oil sector also contributed significantly to the budget of the state, with oil receipts rising from less than CFAF 20 billion (1.4 per cent of GDP and 9 per cent of total revenues) in 1980 to CFAF 330 billion in 1985 (9 per cent of GDP and 41 per cent of total revenue). Total government revenues rose from an average of about 17 per cent of GDP over the sub-period 1965-77 to 21 per cent over the sub-period 1978-86 (Ghura 1997).

When the government officially announced the discovery and exploitation of important oil fields in Cameroon, it made a conscious effort to avoid contracting 'Dutch Disease'. This risk was reduced in the first instance by the fact that a large proportion (about three-quarters) of oil revenues were saved abroad. Oil receipts were excluded from the normal budgetary process and a special off-budget account created for oil revenues, which was directly managed by the Presidency of the Republic. The government sought to pursue the Green Revolution. And traditional exports, such as cocoa and coffee, which might lose out in such circumstances, benefitted from the government using its liquidity position to increase agricultural export prices. The government sought to keep the real exchange rate from appreciating.

But at the same time, taking advantage of the rise in public resources, the government, like those of many other oil-producing countries at the time, embarked between 1980 and 1984 on an expansionary fiscal policy characterized by significant consumption and investment spending. ${ }^{4}$ Ambitious development programmes were initiated in economic and social infrastructures, notably in transport, communications, health, education, and housing. The rise in budgetary and extra-budgetary resources generated by the oil sector made it possible to increase the investment rate and to control the level of the country's indebtedness. A large amount of money was spent on capital outlays using domestic resources with very little foreign borrowing. During this subperiod, external funding accounted for only 6 per cent of total expenditure, while the external debt amounted to only 27 per cent of GDP in 1988/9 (World Bank 1989).

Dutch Disease effects may have been relatively mild over this period, but at the same time policy was inconsistent with sustained growth (Kobou et al. 2008). During this time there was an accumulation of poor performances of public enterprises whose continued survival came to depend increasingly on government subsidies - a situation which led to serious public finance

\footnotetext{
4 A large number of public agencies, marketing boards, and public enterprises were set up and developed in all the sectors of the economy, often supported by government subsidies. Moreover, the transport sector suffered from the strong intervention of the government and was dominated by publicly owned rail, urban, air, and maritime transport enterprises, including road maintenance, etc.
} 
imbalances. ${ }^{5}$ A coup attempt was experienced in 1984 which turned out to be a prelude to the decline which was to follow shortly.

\subsubsection{The Economic Crisis: 1987-93}

The sub-period 1987-93 was marked by a severe economic crisis in which there was a 40 per cent fall in real GDP. Economic activity shrank in several sectors, in particular in the construction and public works sectors, but also in cash crops, retail trade, and oil. Three major factors account for the deterioration of the economic and financial situation in Cameroon during this subperiod: (i) the persistent and concomitant fall of the US\$ and the prices of export products such as oil, cocoa, coffee, and cotton; (ii) the associated appreciation of the effective real exchange rate against the US\$; and (iii) the decline in the country's oil output.

Between 1986 and 1992 the terms of trade declined by about 40 per cent (Ghura 1997), while the effective real exchange rate appreciated by about 40 per cent on a cumulative basis between 1985 and 1992. This was due to inflation triggered by expansionary fiscal policies and the appreciation of the French franc (Ghura 1997). To these causes must be added lax macroeconomic management. As a result of increased government spending in this period and a fall in revenue, the budgetary balance showed an average deficit of 7 per cent of GDP between 1987 and 1993, compared with a surplus of 1 per cent during the sub-period 1978-86. External and internal borrowing as well as external arrears essentially financed the budget deficit, and debt increased sharply. Investment plummeted by more than 70 per cent between 1985/6 and 1992/3, and consumption per head fell by nearly 40 per cent.

Enterprises faced serious problems of payment arrears due to external creditors and domestic suppliers, as well as failures to reimburse debts to domestic banks. The deterioration of financial conditions during the sub-period 1987-93 revealed the problems facing many domestic banks which were found to be undercapitalized, poorly managed, and only marginally profitable (Doe 1995). This situation worsened before and after the highly contested presidential elections of October 1992 when serious confrontations occurred between the government and the opposition (Fambon 2010). These incidents were further aggravated when opposition leaders adopted civil disobedience as their movement's call for action, and instructed their members and the population at large to stop paying taxes. The result was that the government became financially handicapped and was unable to honour its financial commitments, including its payroll.

\footnotetext{
5 It is estimated that the amount of subsidies disbursed to public enterprises in 1984/5 comes to CFAF 150 billion (Tchoungui et al. 1995).
} 
To reverse this downward trend, the government attempted by the late 1980s and early 1990s to stimulate the economy with the help of a strategy based only on domestic adjustment measures. ${ }^{6}$ Given the need to maintain the common parity of the CFAF, the key elements of this strategy were to reduce the budget deficit by raising tax rates; to cut salaries and subsidies to public enterprises; and to restore external competitiveness by reducing domestic costs and restructuring public enterprises. But given the extent of macroeconomic imbalances, it became apparent by the end of 1993 that strategies solely based on internal adjustment would not be sufficient to shift the economy back to a sustained growth recovery path. It was not possible to restore competitiveness given that domestic prices (including salaries and producer prices) had displayed significant downward rigidities. Moreover, owing to declining government revenues, fiscal adjustment mainly consisted of deep cuts in investment budgets and non-salary spending on maintenance and other essential services, which was harmful to Cameroon's economic growth.

\subsubsection{The Post-Devaluation Period (1994 to Date)}

While the domestic adjustment strategies by themselves failed to stem the crisis and revitalize the economy, the devaluation on 14 January 1994 of the CFAF vis-à-vis the French franc by 50 per cent provided a major opportunity. At the time the government adopted stabilization and structural reform programmes supported by the IMF and the World Bank, which sought to control inflation and re-establish growth, based on expectations that the competitiveness of exports from the rural and urban sectors could provide adequate primary and total budget surpluses likely to boost public savings to finance high-priority public and social spending. A second programme followed in August 1997 (which became the Poverty Reduction and Growth Facility (PRGF) in November 1999). ${ }^{7}$ The combined effects of these measures succeeded in restoring the country's economic growth starting in 1995 after almost a decade of economic decline. Considerable improvements were achieved in the export and public finance sectors.

\footnotetext{
${ }^{6}$ It is opportune to note that, when faced with unfavourable economic circumstances, Cameroon's public authorities first committed themselves in 1987 to an adjustment policy supported by an autonomous programme, and without the intervention of Bretton Woods institutions. This programme aimed to reduce government spending and to alleviate the weight of the public sector broadly defined. These measures turned out to be inadequate in stemming the economic crisis. Thus, the government ended up adopting an IMF stand-by agreement and a structural adjustment credit from the World Bank.

7 This programme was supported by a Structural Adjustment Credit of the World Bank and the Structural Adjustment Programme II of the Development Aid Fund.
} 
With Cameroon's external competitiveness restored and growth reestablished, GDP per head increased by about 1.6 per cent annually while inflation remained moderate at a rate of about 2 per cent per year during the same period. Private investment rose from 11 per cent to 13 per cent of GDP over 1996-2000. In addition, the fiscal reforms initiated in 1994 boosted nonoil revenues by two percentage points of GDP, owing mainly to improvements in tax administration and the introduction of the value added tax in 1999. Balance of payments stability was maintained with a current account deficit of 3.2 per cent of GDP on average during 1998-2000. Furthermore, the satisfactory execution of the reform programme gradually restored Cameroon's creditworthiness vis-à-vis the international financial community. In the context of these various reforms, the public authorities were able to finalize the country's Poverty Reduction Strategy Paper (PRSP), an interim version of which was adopted in August 2000 (Government of Cameroon 2003). The finalization of the PRSP in 2003 made it possible for the authorities to negotiate the completion point of the enhanced Heavily Indebted Poor Countries (HIPC) initiative, and completion was achieved in April 2006.

Since then, the economy has generally experienced macroeconomic stability with moderate inflation and reasonable economic growth. Growth has slowed down in recent years, though-for instance falling from 2.9 per cent in 2008 to around 2 per cent in 2009. This slowdown in growth might be attributed to the deterioration of the country's trade balance, the stagnation of the international economic climate, and to fiscal problems linked to the combined effects of the international economic and financial crisis, the food crisis, and the energy deficit. In view of this situation, the government took emergency measures to stimulate the agricultural sector, by giving priority to the production of food crops such as maize, rice, potatoes, and plantain bananas. The economy has performed better in the last few years.

To sum up, it may be said that economic growth in Cameroon was quite variable over the period, notably with major changes in economic policy orientations and the vagaries of domestic and external shocks. Poor macroeconomic management in the oil windfall period led to subsequent longlasting problems in later years.

\subsubsection{Sources of Growth and Total Factor Productivity}

Kobou et al. (2008) conducted a growth accounting analysis of Cameroon from 1960 to 2000 and showed that economic growth in Cameroon was basically driven by the major factors of production without showing any impact of technical progress (Table 13.1). Thus, for an average annual GDP growth rate of 1.16 per cent per head, the physical capital ratio recorded an average annual growth rate of 1.6 per cent versus 0.29 per cent for the human 
Table 13.1. Contribution of factors to growth in Cameroon

\begin{tabular}{lrccc}
\hline Subperiod & $\begin{array}{l}\text { Real GDP } \\
\text { per worker }\end{array}$ & $\begin{array}{l}\text { Contribution of } \\
\text { capital per worker }\end{array}$ & $\begin{array}{l}\text { Contribution of } \\
\text { education per } \\
\text { worker }\end{array}$ & $\begin{array}{l}\text { Contribution of global } \\
\text { productivity of factors }\end{array}$ \\
\hline $1960-77$ & 1.41 & 1.40 & 0.22 & -0.22 \\
$1978-85$ & 7.66 & 3.17 & 0.47 & 4.01 \\
$1986-2000$ & -2.58 & 1.00 & 0.28 & -3.86 \\
Mean & 1.16 & 1.61 & 0.29 & -0.74 \\
\hline
\end{tabular}

Source: Data based on Kobou et al. (2008)

capital ratio. The average annual growth rate of total factor productivity (TFP) was negative and stood at -0.74 per cent during the period 1960-2000.

However, this overall view of the period 1960-2000 conceals some contrasts that appear in sub-periods. Between 1960 and 1985, the physical and human capital ratios contributed two-thirds of per capita GDP growth, while TFP contributed the remaining one-third, but the positive TFP contribution occurred only in the 1978-85 period. This change of factors in the growth process may be linked to the deliberate action of decision-makers who sought to provide Cameroon with appropriate infrastructure and production units likely to contribute significantly to large-scale industrialization. But between 1986 and 2000 the pattern is very different. The capital and labour ratios increased at an average annual rate of 1.28 per cent, but which was lower than the rates previously recorded, but TFP was shrinking at an average annual rate of -3.86 per cent, which weighed heavily on the growth process. Between 1960 and 2000 economic growth was driven by both capital and labour, but more by capital. Under these conditions the country could not achieve sustained growth, since it is productivity rather than the capital stock which is crucial in the growth process.

The authors combined this framework with a regression model to provide a comprehensive picture of the macroeconomic factors which affect economic growth, analysing the roles by the macroeconomic framework, investment, and human capital. ${ }^{8}$ By concentrating on the variables of the 'new' growth theories (see, for instance, Easterly et al. 1991; Renelt 1991; Levine and Renelt 1992), the authors found that Cameroon's per capita GDP growth rate stood at 1.37 percentage points below the world average over the entire period of the study. Their analysis showed that unproductive government expenditure had

\footnotetext{
8 It should be noted that several other studies have been carried out on Cameroon's economic growth, but they do not take account of the variables of the new theory of economic growth. In effect, the study by Amin (2002) indicates that labour and capital inputs are the main factors which affect economic growth in Cameroon. Mbaku (1993) and Most and Van Den Berg (1996) show that domestic savings have a stronger impact on growth.
} 
a particular negative influence on growth, contributing -0.34 percentage points to the deviation of the growth rate.

Finally, the trend in the contribution of the different sectors to GDP has changed over time. The agriculture sector was the sole engine of growth and foreign exchange earnings until the late 1970s when oil became the primary engine of growth. By contrast, the analysis of the evolution of real GDP by sector of activity clearly shows that between 2000 and 2007, economic growth was above all driven by the service sector, and notably by telecommunications which achieved a growth rate exceeding 25 per cent per year during this period. The contribution of this sector to growth in this period is more important than that of the primary and secondary sectors combined.

\subsubsection{Policy and Political Economy Factors, Sources of Growth, and Total Factor Productivity}

Kobou et al. (2008) present a detailed analysis of the factors which have underlain Cameroon's ultimately disappointing growth performance. Some of the key messages have already been discussed in section 13.2.3. Cameroon has access to foreign exchange through natural resources such as timber and oil, but also through agricultural exports. To some extent, the combined use of these different resources has helped the country to shield itself against adverse shocks, with Cameroon often increasing its exports of timber when revenue from oil exports fell. But its economic performance remains very responsive to terms of trade fluctuations. In addition, and as seen in section 13.2.3, this resource wealth has been associated with lax macroeconomic management, notwithstanding the potential advantages of the fixed exchange rate.

They argue that markets for goods and services, as well as labour, fail to function well in Cameroon as a result of extensive government intervention. Farmers have often adopted a survival strategy, failing to use purchased inputs and often withdrawing from cultivating cash crops. The manufacturing sector was very highly protected until the late 1980s, but as a result it displayed a very low productivity, and the environment was not conducive to the conduct of business. Small firms, which potentially could be more dynamic, particularly faced numerous sources of disadvantage. This all created a very difficult environment for the conduct of economic activity. As noted in section 13.2.5, more recent growth has occurred mostly in the services sector, with agriculture and manufacturing continuing to perform poorly. Boosting productivity will require institutions and policies which affect the incentive to generate and disseminate innovations in the country.

The political economy context is also very important, with Kobou et al. (2008) arguing that this has been a major constraint on growth. Governments in Cameroon have faced a continual challenge to seek to maintain peace in a 
context of ethnic and regional tensions. The country has avoided open conflict, but peacebuilding has been a permanent focus of the government. Kobou et al. (2008) identify at least four groups in the population: the North, the Centre and South, the West, and the English-speaking regions of the Southwest and Northwest. To add to this are religious differences with the country approximately equally divided between Christianity, Islam, and traditional beliefs. To seek to maintain social cohesion in this environment has been a major focus of all governments. The authors argue that this has led to some suboptimal decisions; for instance, they contend that both ministerial appointments and employment in the public sector have been seen much more as a means of sharing power and resources among different interest groups. The public-sector payroll was used as a means of creating employment for these groups. While this may have maintained peace, it has failed to provide effective service delivery.

To sum up this review, growth performance has been disappointing for most of the period since independence with the exception of the relatively short-lived and ultimately unsustainable growth burst the country experienced between 1978 and 1986. Ineffective management of the natural resource wealth was definitely a major part of the explanation; but even aside from the resource wealth, weak institutions and poor implementation of policy would appear to have been a common theme in Cameroon.

\subsection{National-Level Patterns of Changes in Poverty, Inequality, and Household Welfare}

\subsubsection{Data Sources and Consumption Trends}

What have been the consequences of the above record of economic performance for the evaluation of poverty and living conditions in Cameroon? The investigation begins in this section and the next with the analysis of monetary poverty and inequality, for which the data come from the three ECAM (Enquête Camerounaise Auprès des Ménages) household surveys from 1996, 2001, and 2007 (Institute of Statistics 1996, 2001, 2007). This then corresponds entirely to the last of the four sub-periods described in section 13.2. There is little comparable data before this period.

The three ECAM surveys collect similar data, which includes detailed information on consumption. The ECAM2 and ECAM3 surveys have samples of 10,992 and 11,369 households, while the ECAM1 sample contains only 1,731 households. Household welfare is measured here as household consumption expenditure per adult equivalent; further detail on the precise definition is provided in Appendix 1 of Fambon et al. (2014). A poverty line for Cameroon was set in 2001 based on a consumption basket comprising sixty-one food items which provided 2,900 kcal per adult equivalent; the non-food 
Table 13.2. Average consumption in Cameroon in ECAM surveys

\begin{tabular}{|c|c|c|c|c|c|}
\hline & \multicolumn{3}{|c|}{ Average consumption per adult } & \multirow[b]{2}{*}{$\begin{array}{c}\text { Annualized growth, } \\
\text { 1996-2001, \% }\end{array}$} & \multirow[b]{2}{*}{$\begin{array}{c}\text { Annualized growth, } \\
2001-7, \%\end{array}$} \\
\hline & 1996 & 2001 & 2007 & & \\
\hline Cameroon & 310.5 & 391.7 & 411.6 & 4.8 & 0.8 \\
\hline Urban & 400.6 & 484.4 & 515.4 & 3.2 & 1.0 \\
\hline Rural & 235.0 & 315.0 & 280.4 & 4.9 & -1.9 \\
\hline Adamaoua & & 314.3 & 361.8 & & 2.4 \\
\hline Centre & & 337.2 & 320.6 & & -0.8 \\
\hline Coast & & 321.8 & 340.5 & & 0.9 \\
\hline Douala & & 538.4 & 621.5 & & 2.4 \\
\hline East & & 371.3 & 359.2 & & -0.6 \\
\hline Far North & & 344.5 & 310.5 & & -1.7 \\
\hline North & & 357.3 & 328.0 & & -1.4 \\
\hline Northwest & & 327.9 & 378.4 & & 2.4 \\
\hline South & & 358.0 & 428.5 & & 3.0 \\
\hline Southwest & & 413.9 & 464.0 & & 1.9 \\
\hline West & & 348.8 & 341.5 & & -0.4 \\
\hline Yaoundé & & 584.8 & 649.3 & & 1.8 \\
\hline
\end{tabular}

Source: Computed by the authors from ECAM1, ECAM2, and ECAM3 survey data (National Institute of Statistics 1996, 2001, and 2007)

component of the line was determined by a regression of the food share on the logarithm of the ratio of total household expenditures over the food poverty threshold, and other household consumption variables.

We begin by analysing the change in household consumption between the survey years, which are presented in Table 13.2. Household consumption grew by 26.2 per cent in total between 1996 and 2001 and 5.1 per cent between 2001 and 2007; over the same periods the changes in per capita GDP were 9.6 per cent and 4.7 per cent. Between 1996 and 2001 annualized growth rates of consumption were high in both urban and rural areas, especially in the latter, but between 2001 and 2007 consumption fell sharply in rural areas, while it continued to rise, though at a slower rate, in urban areas. By region there was quite a big diversity in growth rates between 2001 and 2007. There were quite fast positive growth rates in Douala, the South, Adamaoua, the Northwest, and Yaoundé, but in other regions growth was negative, especially in the North and Far North, which were among the poorer regions to begin with.

\subsubsection{Patterns of Monetary Poverty}

Summary poverty indices for the national level are presented in Table 13.3. The national poverty headcount fell significantly between 1996 and 2001 from 53.3 per cent to 40.2 per cent, a period over which per capita GDP 
Table 13.3. Trends in monetary poverty in Cameroon, 1996-2007

\begin{tabular}{lccc}
\hline & \multicolumn{3}{c}{ Survey period } \\
\cline { 2 - 4 } & 1996 & 2001 & 2007 \\
\hline$P_{0}$ & 0.533 & 0.402 & 0.399 \\
& & $(0.0146)$ & $(0.0134)$ \\
$P_{1}$ & $(0.0326)$ & 0.141 & 0.123 \\
$P_{2}$ & 0.191 & $(0.0085)$ & $(0.0062)$ \\
\multirow{2}{*}{ Watts } & $(0.0167)$ & 0.070 & 0.050 \\
& 0.090 & $(0.0061)$ & $(0.0031)$ \\
& $(0.0095)$ & 0.2091 & 0.1611 \\
& 0.2665 & $(0.0174)$ & $(0.0086)$ \\
\hline
\end{tabular}

Note: Figures in parentheses represent standard errors.

Source: Computed by the authors from ECAM1, ECAM2, and ECAM3 survey data (National Institute of Statistics 1996, 2001, and 2007)

grew by about 10 per cent. The $P_{1}$ poverty measure showed a reduction of five percentage points during the period, falling from 19 per cent in 1996 to 14 per cent in 2001; and the severity index fell from 9 per cent in 1996 to 6.9 per cent in 2001, a decrease of two percentage points. But there was no significant change in the poverty headcount between 2001 and 2007, a period over which per capita GDP also increased less. The greater reduction of poverty over 1996-2001 compared to 2001-7 is seen for all indices presented in Table 13.3. This shows that the government did not take advantage of either the macroeconomic stability the country experienced during the period 2001-7, or of the opportunities offered during this period, notably by the resources released by the IMF and the World Bank following the achievement of the decision and completion point of the HIPC debt-relief initiative.

But the poverty severity measure $P_{2}$ does show a significant reduction between 2001 and 2007 from 7 per cent to 5 per cent; and the Watts index too shows a significant reduction. Thus, the poverty reduction which did happen over this period occurred mostly at the bottom of the distribution.

Poverty incidence curves (Figures 13.2 and 13.3) confirm the significant poverty reduction from 1996 to 2001 and the very limited progress between 2001 and 2007. These curves suggest that the patterns of changes in poverty discussed above are not likely to be sensitive to the precise location of the poverty line, in any reasonable range. But they do also show evidence of greater poverty reduction at the bottom of the distribution between 2001 and 2007.

These periods show substantially better progress in urban areas than rural areas, as seen in Table 13.4, even though poverty levels were significantly higher in the latter. This is in line with the results in section 13.3.1 on consumption growth rates. There was a significant reduction in urban poverty 


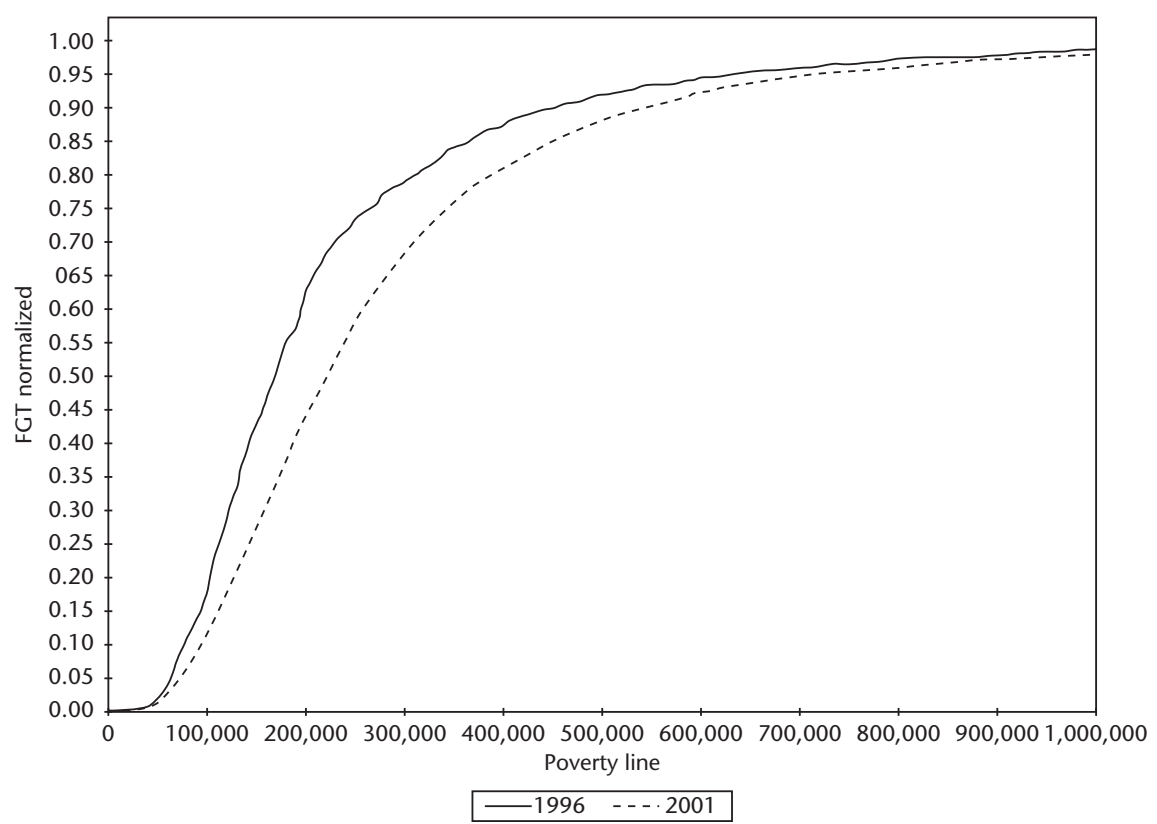

Figure 13.2. Poverty incidence curve for Cameroon, 1996-2001

Source: Computed by the authors from ECAM1 and ECAM2 data (National Institute of Statistics 1996 and 2001)

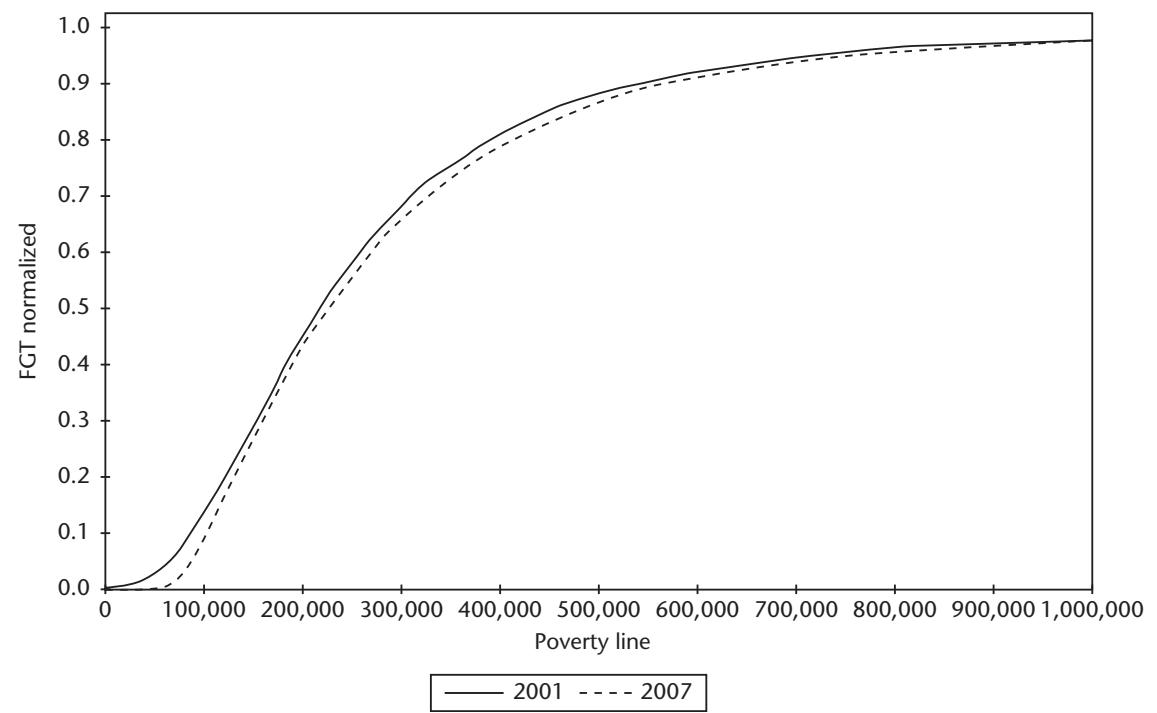

Figure 13.3. Poverty incidence curve for Cameroon, 2001-7

Source: Computed by the authors from ECAM2 and ECAM3 data (National Institute of Statistics 2001 and 2007) 
Table 13.4. Trends in monetary poverty in urban and rural areas, 1996-2007

\begin{tabular}{|c|c|c|c|c|c|c|}
\hline & \multicolumn{3}{|c|}{ Urban } & \multicolumn{3}{|c|}{ Rural } \\
\hline & 1996 & 2001 & 2007 & 1996 & 2001 & 2007 \\
\hline \multirow[t]{2}{*}{$P_{0}$} & 0.414 & 0.221 & 0.122 & 0.596 & 0.499 & 0.550 \\
\hline & $(0.030)$ & $(0.012)$ & $(0.008)$ & $(0.046)$ & (0.019) & $(0.018)$ \\
\hline \multirow[t]{2}{*}{$P_{1}$} & 0.147 & 0.063 & 0.028 & 0.214 & 0.183 & 0.175 \\
\hline & $(0.013)$ & (0.004) & $(0.002)$ & $(0.024)$ & $(0.012)$ & $(0.009)$ \\
\hline \multirow[t]{2}{*}{$P_{2}$} & 0.069 & 0.027 & 0.010 & 0.101 & 0.093 & 0.072 \\
\hline & $(0.007)$ & $(0.002)$ & $(0.001)$ & (0.014) & (0.009) & $(0.004)$ \\
\hline \multirow[t]{2}{*}{ Watts } & 0.205 & 0.085 & 0.035 & 0.299 & 0.275 & 0.230 \\
\hline & $(0.020)$ & $(0.006)$ & $(0.003)$ & $(0.036)$ & $(0.026)$ & $(0.012)$ \\
\hline $\begin{array}{l}\text { Average per adult } \\
\text { consumption }\end{array}$ & 400,607 & 484,450 & 515,391 & 235,881 & 315,012 & 280,224 \\
\hline
\end{tabular}

Note: Figures in parentheses represent standard errors.

Source: Computed by the authors from ECAM1, ECAM2, and ECAM3 survey data (National Institute of Statistics 1996, 2001, and 2007)

between 1996 and 2001 according to all indices, which continued between 2001 and 2007. Rural poverty fell less according to all measures between 1996 and 2001, while the rural poverty headcount increased significantly between 2001 and 2007. At the same time, though, the $\mathrm{P}_{1}$ and $\mathrm{P}_{2}$ measures fell in rural areas over this period, though not to a statistically significant extent. This again shows an improvement in the situation of the extreme poor in rural areas, a pattern confirmed by the rural growth incidence curve for this period (not presented here), which shows a very similar pattern to the national curve over the same years.

Similar information for the twelve commonly identified provinces of Cameroon for 2001 and 2007 is presented in Table 13.5. Consistent with the above results on both consumption growth rates and poverty, these data confirm that the two major cities of Yaoundé and Douala have by some way the lowest levels of poverty and have made the most progress between these years. Among the other regions, the Southwest, West, and South had the lowest levels of poverty in both 2001 and 2007, and poverty also fell over this period. The poorest provinces in both years were the North, Northwest, Adamaoua, the Far North, the Centre, and the East, though the ranking differs from year to year. Four of these provinces (the exceptions being the Centre and Northwest) showed increasing poverty headcounts between 2001 and 2007, this being large and statistically significant in the North and Far North (increases of 14.6 and 24.1 percentage points respectively). ${ }^{9}$ Poverty severity

\footnotetext{
9 It is opportune at this point to mention the fact that the region of the Far North has been for a decade the privileged target of poverty reduction projects and programmes, as well as actions for the benefit of women in the Far North province such as PREPAFEN, the programme for the
} 
Table 13.5. Poverty in Cameroon by region

\begin{tabular}{|c|c|c|c|c|c|}
\hline \multirow[b]{2}{*}{ Region } & \multirow[b]{2}{*}{ Population Share } & \multicolumn{2}{|c|}{2001} & \multicolumn{2}{|c|}{2007} \\
\hline & & $\mathrm{P}_{0}$ & $P_{2}$ & $P_{0}$ & $P_{2}$ \\
\hline Douala & 9.7 & $\begin{array}{c}0.186 \\
(0.016)\end{array}$ & $\begin{array}{c}0.020 \\
(0.003)\end{array}$ & $\begin{array}{c}0.055 \\
(0.012)\end{array}$ & $\begin{array}{c}0.002 \\
(0.001)\end{array}$ \\
\hline Yaoundé & 8.7 & $\begin{array}{c}0.183 \\
(0.020)\end{array}$ & $\begin{array}{c}0.021 \\
(0.003)\end{array}$ & $\begin{array}{c}0.059 \\
(0.012)\end{array}$ & $\begin{array}{c}0.002 \\
(0.001)\end{array}$ \\
\hline Adamaoua & 4.5 & $\begin{array}{c}0.458 \\
(0.049)\end{array}$ & $\begin{array}{c}0.067 \\
(0.010)\end{array}$ & $\begin{array}{c}0.530 \\
(0.044)\end{array}$ & $\begin{array}{c}0.054 \\
(0.010)\end{array}$ \\
\hline Centre & 7.8 & $\begin{array}{c}0.604 \\
(0.044)\end{array}$ & $\begin{array}{c}0.135 \\
(0.038)\end{array}$ & $\begin{array}{c}0.412 \\
(0.031)\end{array}$ & $\begin{array}{c}0.031 \\
(0.005)\end{array}$ \\
\hline East & 4.8 & $\begin{array}{l}0.47 \\
(0.051)\end{array}$ & $\begin{array}{c}0.077 \\
(0.019)\end{array}$ & $\begin{array}{c}0.504 \\
(0.052)\end{array}$ & $\begin{array}{c}0.062 \\
(0.011)\end{array}$ \\
\hline Far North & 17.7 & $\begin{array}{c}0.418 \\
(0.042)\end{array}$ & $\begin{array}{c}0.056 \\
(0.010)\end{array}$ & $\begin{array}{c}0.659 \\
(0.036)\end{array}$ & $\begin{array}{c}0.112 \\
(0.010)\end{array}$ \\
\hline Coast & 4.9 & $\begin{array}{c}0.441 \\
(0.047)\end{array}$ & $\begin{array}{c}0.088 \\
(0.020)\end{array}$ & $\begin{array}{c}0.308 \\
(0.027)\end{array}$ & $\begin{array}{c}0.027 \\
(0.004)\end{array}$ \\
\hline North & 7.3 & $\begin{array}{c}0.491 \\
(0.034)\end{array}$ & $\begin{array}{c}0.069 \\
(0.007)\end{array}$ & $\begin{array}{c}0.637 \\
(0.039)\end{array}$ & $\begin{array}{c}0.086 \\
(0.008)\end{array}$ \\
\hline Northwest & 11.5 & $\begin{array}{c}0.528 \\
(0.052)\end{array}$ & $\begin{array}{c}0.143 \\
(0.029)\end{array}$ & $\begin{array}{c}0.5100 \\
(0.034)\end{array}$ & $\begin{array}{c}0.068 \\
(0.008)\end{array}$ \\
\hline West & 12.1 & $\begin{array}{c}0.381 \\
(0.030)\end{array}$ & $\begin{array}{c}0.050 \\
(0.006)\end{array}$ & $\begin{array}{c}0.290 \\
(0.029)\end{array}$ & $\begin{array}{c}0.023 \\
(0.004)\end{array}$ \\
\hline South & 3.4 & $\begin{array}{c}0.386 \\
(0.082)\end{array}$ & $\begin{array}{c}0.052 \\
(0.016)\end{array}$ & $\begin{array}{c}0.292 \\
(0.047)\end{array}$ & $\begin{array}{c}0.026 \\
(0.006)\end{array}$ \\
\hline Southwest & 7.5 & $\begin{array}{c}0.35 \\
(0.057)\end{array}$ & $\begin{array}{c}0.069 \\
(0.019)\end{array}$ & $\begin{array}{c}0.275 \\
(0.038)\end{array}$ & $\begin{array}{c}0.025 \\
(0.006)\end{array}$ \\
\hline Cameroon & 100 & $\begin{array}{c}0.402 \\
(0.015)\end{array}$ & $\begin{array}{c}0.070 \\
(0.006)\end{array}$ & $\begin{array}{c}0.399 \\
(0.013)\end{array}$ & $\begin{array}{c}0.050 \\
(0.003)\end{array}$ \\
\hline
\end{tabular}

Note: Figures in parentheses represent standard errors.

Source: Computed by the authors from ECAM2 and ECAM3 survey data (National Institute of Statistics 1996, 2001, and 2007)

was particularly high in the Far North and the North in 2007. The worse situation of these two northern provinces is consistent with the consumption growth data presented in section 13.3.1. Thus there is some evidence of increasing spatial differentiation over this period, with the north of the country in particular becoming worse off relative to the rest, aligning with one of the social divides noted above and in Fambon et al. (2014).

The significant poverty increase in the Far North province may be due to situational obstacles such as the advent of floods and invasions of granivorous birds in this province of the country in 2007, which resulted in a serious loss of goods and harvests that negatively affected the population. In addition, structural obstacles such as anarchic agricultural practices and the chronic rainfall deficit contributed to the fall in agricultural production and the aggravation of 
food insecurity. Moreover, the peasants are victims of an inability to store which leads them to sell the bulk of their agricultural output at harvest time, only to borrow money during hard times at high interest rates to buy vital commodities to make ends meet. ${ }^{10}$ In the East province, the increase in poverty may be explained by the slowdown in forestry activity which is very important in this region. Moreover, some companies in the timber industry were delocalized to establish their headquarters in Douala, a move likely to limit the employment opportunities of the population and the tax revenues of the municipalities of the province. The poverty increase in the regions of Adamaoua and the North may be due to the loss of earnings in terms of revenues caused by the completion of the construction work of the DobaKribi pipeline. ${ }^{11}$ Regional-level inequality data are not presented here, but generally show reductions over this period, many statistically significant, but inequality in the North and Far North does not show a statistically significant change during this time.

A decomposition of changes in poverty between 2001 and 2007 into growth and redistribution components using the technique developed by Datt and Ravallion (1992) (not presented here) shows that the growth effect plays an important part in accounting for urban poverty reduction and rural poverty increase, but that there is also a strong poverty-reducing redistribution effect in urban areas. By-province growth effects contribute to strong poverty reduction in Douala, Yaoundé, the Centre, and the South, and there are strong poverty-reducing redistribution effects in Douala, Yaoundé, the Southwest, Coast, and the Centre. The increase in poverty in the northern provinces of the North and the Far North reflects sharply adverse growth and redistribution effects; in Adamaoua there is also an adverse redistribution effect. A similar decomposition by the main activity of the household shows a sharp poverty reduction among those in non-farm activities, both formal and informal though faster in the latter, but a sharp poverty increase among those working in agriculture. These changes predominantly reflect growth effects.

\subsubsection{Distributional Pattern of Change}

Values of summary inequality measures for Cameroon for the three years are summarized in Table 13.6, which also includes separate values for urban and rural Gini coefficients. The overall pattern shown in this table is of no

${ }^{10}$ In addition, the slowdown of the activity of the Société d'Expansion et de Modernisation de la Riziculture in the plain of Yagoua (SEMRY) and the cessation of that of the Programme National de Vulgarisation et Recherche Agricole (PNVRA), which supervise the peasants, further complicated the situation of households in this region of the country.

${ }^{11}$ It can be noted that this type of project offered in 2001 both the possibilities of direct incomes and of incomes mainly induced in the informal sector of the regions concerned. 
Table 13.6. Trends in inequality in Cameroon, 1996-2007

\begin{tabular}{lccc}
\hline & \multicolumn{3}{c}{ Survey period } \\
\cline { 2 - 4 } & 1996 & 2001 & 2007 \\
\hline Gini coefficient & 0.406 & 0.408 & 0.390 \\
& $(0.0169)$ & $(0.0078)$ & $(0.0060)$ \\
Urban Gini & 0.449 & 0.406 & 0.352 \\
& $(0.0203)$ & $(0.0096)$ & $(0.0075)$ \\
Rural Gini & 0.346 & 0.369 & 0.322 \\
& $(0.0310)$ & $(0.0161)$ & $(0.0065)$ \\
GE(0) & 0.272 & 0.291 & 0.248 \\
& $(0.0227)$ & $(0.0142)$ & $(0.0077)$ \\
GE(1) & 0.317 & 0.316 & 0.279 \\
& $(0.0300)$ & $(0.0155)$ & $(0.0106)$ \\
GE(2) & 0.544 & 0.556 & 0.445 \\
& $(0.0786)$ & $(0.0528)$ & $(0.0286)$ \\
\hline
\end{tabular}

Note: Figures in parentheses represent standard errors.

Source: Computed by the authors from ECAM1, ECAM2, and ECAM3 data (National Institute of Statistics 1996, 2001, and 2007)

significant change in inequality at the national level between 1996 and 2001 according to the Gini coefficient or Generalized Entropy (GE) Indices, but there were significant reductions in all these measures of inequality between 2001 and 2007. Looking at the urban-rural disaggregation, urban inequality consistently and significantly fell over this period. In rural areas, however, inequality increased between 1996 and 2001, before falling back significantly between 2001 and 2007. These patterns may seem difficult to reconcile with the regional patterns of change seen in Table 13.5, but are consistent with the poverty incidence curves showing better progress at the bottom between 2001 and 2007.

The growth incidence curve (GIC) comparing 1996 and 2001 shows positive growth throughout most of the distribution except at the very bottom and top (Figure 13.4). On the other hand, the GIC for 2001-7 (Figure 13.5) shows very little growth in consumption, but a pro-poor pattern of change with the only positive change being seen in the first quintile. This is consistent with the reduction in inequality in this period, with little change in the incidence of poverty, but a reduction in the severity of poverty associated with the improving outcomes for the poorest.

\subsection{Changes in Non-monetary Poverty}

The main source for the analysis of non-monetary measures of poverty is the Demographic and Health Surveys conducted in 1991, 1998, 2004, and 2011. 


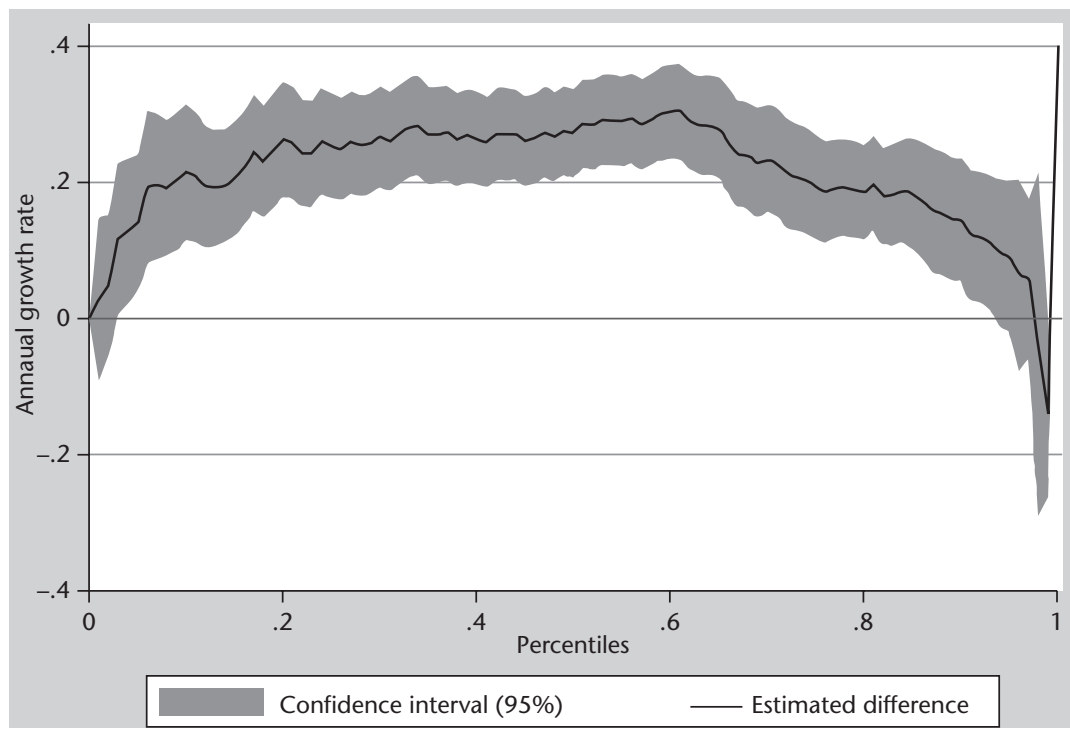

Figure 13.4. Cameroon growth incidence curve, 1996-2001

Source: Computed by the authors from ECAM1 and ECAM2 data (National Institute of Statistics 1996 and 2001)

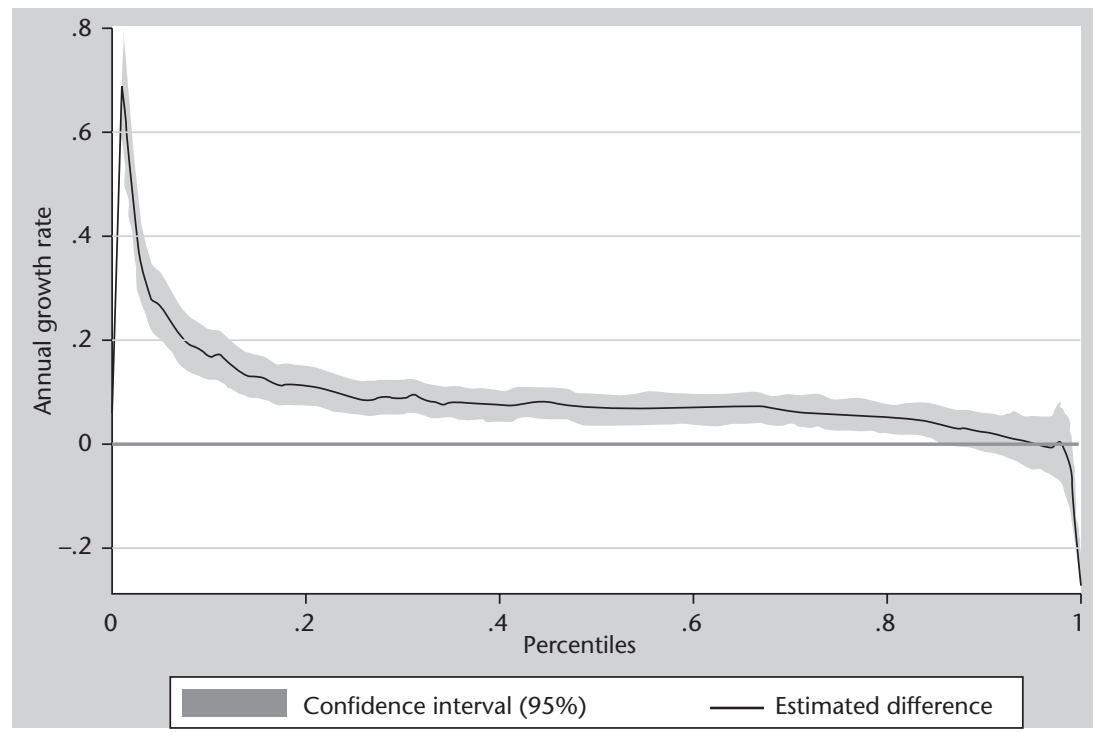

Figure 13.5. Cameroon growth incidence curve, 2001-7

Source: Computed by the authors from ECAM2 and ECAM3 data (National Institute of Statistics 2001 and 2007) 
Table 13.7. Summary national-level indicators from DHS surveys

\begin{tabular}{lrrrr}
\hline Indicator & 1991 & 1998 & 2004 & 2011 \\
\hline Under-five mortality rate & 144 & 146 & 148 & 128 \\
\% of children fully vaccinated & 40.0 & 35.8 & 48.2 & 53.2 \\
Height-for-age below -2 SD & 22.9 & 29.3 & 29.7 & 24.1 \\
Weight-for-height below -2 SD & 3.8 & 5.9 & 6.7 & 6.2 \\
Weight-for-age below -2 SD & 16.3 & 22.2 & 19.4 & 18.1 \\
\% of respondents with secondary education or above & 26.5 & 33.3 & 39.1 & 46.2 \\
Fertility rate & 5.8 & 4.8 & 5.0 & 5.1 \\
\% of households with electricity & 29.0 & 40.7 & 47.1 & 53.7 \\
\% of households with adequate drinking water source & 63.9 & 64.2 & 71.6 & 74.4 \\
\% of households owning radio & 54.0 & 52.5 & 62.5 & 56.1 \\
\% of households owning bicycle & 15.7 & 13.3 & 18.2 & 14.7 \\
\hline
\end{tabular}

Source: Computed by the authors from DHS surveys

Some summary national-level figures, including heath indicators (mortality, malnutrition, and vaccination), education, ownership of durable goods, and housing amenities, are presented in Table 13.7.

Cameroon's under-five mortality rate remains high for a middle-income country, and did not fall at all during 1991-2004. Only since then has the mortality rate fallen, though it still remains at 128 per thousand live births. In terms of malnutrition, the numbers of those stunted and underweight are also quite high; and malnutrition if anything worsened over the 1991-2004 period. Again, since then the situation has moderately improved, though the rates still remain quite high. And while the situation in relation to the number of children under 12 months, who had been fully vaccinated, improved over the 1998-2011 period, by 2011 nearly half of children in this age range still were not fully vaccinated. This suggests significant questions about the coverage or effectiveness of the health care system in Cameroon. Fertility remains high in Cameroon, but decreased from 5.8 in 1991 to 4.8 in 1998, remaining more or less at that level since.

Education, however, improved significantly over this period; by 2011 the proportion of the population who had secondary education or more almost doubled compared to twenty years before. The number of households with access to electricity also increased substantially over this period, though there was a much more modest improvement in the proportion having access to an adequate drinking water source. Ownership of durable goods did not increase much over this time, except for the percentage of households having a refrigerator, this presumably also being linked to the greater access to electricity. In short, many of these indicators give an impression of very slow improvement over most of this period, though the situation in relation to health indicators in particular improved more noticeably in recent years. But the absolute level of outcomes remains disappointing for a country with Cameroon's level of per capita GDP. 
The time pattern of change here is somewhat different from what was seen for consumption poverty. For the latter, the situation improved between 1996 and 2001, but made limited progress between 2001 and 2007. The DHS indicators by contrast show least progress between 1991 and 2004, but quite good progress between 2004 and 2011. However, this difference is not surprising; the surveys relate to different years, and consumption estimates in particular can be quite sensitive to the economic conditions when the surveys were carried out. In addition, there is no reason why monetary and different non-monetary measures should show the same trends.

We now turn to a disaggregated analysis of some of these indicators. Here, the 2004 and 2011 DHS surveys enable an estimation of indicators at the level of the twelve provinces of Cameroon, but the smaller sample size in 1991 and 1998 means that disaggregation is only possible into five regions, which are an aggregation of the twelve regions. To enable comparability, the tables show figures for these five regions for each of the four survey years, in addition to the more detailed figures for the last two survey years. In some cases, other forms of disaggregation will be shown, for instance by urban/rural or by wealth quintile defined using the DHS asset indices.

Table 13.8 presents data for under-five mortality. Mortality rates are higher for boys than girls. Over time, mortality rates change very little (in fact slightly worsen) between 1991 and 2004, before finally falling between 2004 and

Table 13.8. Disaggregated under-five mortality rates for Cameroon

\begin{tabular}{lrrrr}
\hline & 1991 & 1998 & 2004 & 2011 \\
\hline By location & & & & \\
Region: Yaoundé/Douala & 103 & 91 & 93 & 75 \\
Yaoundé & & & 112 & 76 \\
Douala & & & 74 & 75 \\
Region: Adamaoua/North/Far North & 199 & 202 & 186 & 171 \\
Adamaoua & & & 136 & 129 \\
North & & & 204 & 191 \\
Far North & 124 & 146 & 185 & 168 \\
Region: Centre/Southeast & & & 120 & 110 \\
Centre & & & 153 & 103 \\
South & 109 & 91 & 123 & 101 \\
East & & & 126 & 99 \\
Region: West/Coast & & & 113 & 105 \\
West & 87 & 98 & 116 & 93 \\
Coast & & & 98 & 68 \\
Region: Northwest/Southwest & & & 143 & 127 \\
Northwest & 144 & 148 & 154 & 135 \\
Southwest & 143 & 144 & 141 & 122 \\
Boy & 144 & 146 & 148 & 128 \\
Girl & & & & \\
Total & & & & \\
\hline & & & & \\
\hline
\end{tabular}

Source: Computed by the authors from DHS surveys 
2011. By region, sharp differences are seen; in particular mortality rates are much higher in the Adamaoua, North, and Far North provinces in all four years and the detailed data for 2004 and 2011 confirm that it is in the North and Far North provinces that rates are highest. These rates are twice as high as those in the region with the best mortality outcomes, the main cities of Douala and Yaoundé. It is clear from these figures that the high nationallevel mortality figure reflects in particular very poor outcomes in the northern part of the country. The other regions have mortality rates more similar to those of the main cities, though even here important differences are apparent, notably between the Northwest (where rates in 2011 are lowest in the country) and the adjacent Southwest (where rates are much higher). The patterns of change in most regions are similar to the national pattern, with the only improvements coming between 2004 and 2011, and this improvement is less in the Adamaoua, North, and Far North provinces.

Malnutrition levels are also highest by some magnitude in the same northern regions, as demonstrated on Table 13.9 reporting on the case of stunting. Improvements over time are also lower in this region compared to others.

Table 13.9. Percentage of under-three-year-olds with height-for-age $Z$ score less than -2

\begin{tabular}{|c|c|c|c|c|}
\hline \multicolumn{5}{|c|}{$\%$ with height-for-age $Z$ score less than -2} \\
\hline & 1991 & 1998 & 2004 & 2011 \\
\hline \multicolumn{5}{|l|}{ by location } \\
\hline Region: Yaoundé/Douala & 8.7 & 14.7 & 19.6 & 10.2 \\
\hline Yaoundé & & & 13.7 & 11.0 \\
\hline Douala & & & 25.0 & 9.4 \\
\hline Region: Adamaoua/North/Far North & 29.0 & 35.6 & 34.5 & 32.7 \\
\hline Adamaoua & & & 25.5 & 25.9 \\
\hline North & & & 42.0 & 34.8 \\
\hline Far North & & & 32.5 & 32.9 \\
\hline Region: Centre/South/East & 23.0 & 30.8 & 27.6 & 20.6 \\
\hline Centre & & & 25.9 & 14.8 \\
\hline South & & & 27.7 & 21.9 \\
\hline East & & & 30.1 & 29.4 \\
\hline Region: West/Coast & 23.0 & 21.2 & 27.5 & 21.6 \\
\hline West & & & 29.3 & 22.1 \\
\hline Coast & & & 22.4 & 20.2 \\
\hline Region: Northwest/Southwest & 22.7 & 25.8 & 30.2 & 22.7 \\
\hline Northwest & & & 30.0 & 25.5 \\
\hline Southwest & & & 30.6 & 18.7 \\
\hline \multicolumn{5}{|l|}{ by wealth quintile } \\
\hline Lowest & 31.7 & 36.4 & 35.4 & 36.8 \\
\hline Second & 29.1 & 32.2 & 33.5 & 31.4 \\
\hline Middle & 30.8 & 31.9 & 33.6 & 21.6 \\
\hline Fourth & 17.3 & 26.0 & 25.4 & 17.0 \\
\hline Highest & 9.1 & 15.3 & 13.5 & 9.9 \\
\hline Total & 22.9 & 29.3 & 29.7 & 24.1 \\
\hline
\end{tabular}

Source: Computed by the authors from DHS surveys 
Again the best outcomes are seen in the main cities. An analysis by wealth quintile shows (i) very large gaps by quintile; and (ii) that the improvements between 2004 and 2011 are largely confined to the top three quintiles, with the situation in the poorest quintile actually worsening over this period. Other malnutrition indicators show the same patterns (Fambon et al. 2014).

In relation to health inputs, the analysis of Fambon et al. (2014) shows that vaccination rates are consistently much lower in Adamaoua/North/Far North, and especially in the latter two provinces, and the rate actually fell in the Far North between 2004 and 2011. Rates in the lowest quintile are less than half of those in the richest quintile, and again the outcome worsened between 2004 and 2011 in the first quintile. Here, the best outcomes are actually not in the big cities, but rather in the Northwest and Southwest, both of these regions showing a big improvement between 2004 and 2011.

In relation to education (Table 13.10), the same regional pattern is apparent in all tables so far, with significantly worse outcomes in all the northern provinces especially in the North and Far North. By 2011, fewer than 12 per cent of respondents had secondary education or above; this contrasts dramatically with Douala/Yaoundé where an impressive 79 per cent are educated to this level. Education levels are much higher in other regions compared to the northern regions, but range from 69.7 per cent in the South to 44.8 per cent in the Northwest. All regions show the same pattern of consistent improvement

Table 13.10. Percentage of respondents with secondary education or above

\begin{tabular}{|c|c|c|c|c|}
\hline \multicolumn{5}{|c|}{ Percentage of respondents with secondary education or above } \\
\hline & 1991 & 1998 & 2004 & 2011 \\
\hline \multicolumn{5}{|l|}{ By location } \\
\hline Region: Yaoundé/Douala & 62.5 & 72.8 & 71 & 79.3 \\
\hline Yaoundé & & & 74.6 & 79.5 \\
\hline Douala & & & 67.7 & 79.1 \\
\hline Region: Adamaoua/North/Far North & 3.7 & 5.8 & 7.7 & 11.8 \\
\hline Adamaoua & & & 20.3 & 22.6 \\
\hline North & & & 6.6 & 12.6 \\
\hline Far North & & & 5.2 & 7.9 \\
\hline Region: Centre/South/East & 34.4 & 38.1 & 46.7 & 55.3 \\
\hline Centre & & & 46.7 & 57.5 \\
\hline South & & & 60.7 & 69.4 \\
\hline East & & & 34.5 & 42 \\
\hline Region: West/Coast & 32.7 & 45.2 & 47.3 & 58.8 \\
\hline West & & & 45 & 56.9 \\
\hline Coast & & & 52.9 & 63.8 \\
\hline Region: Northwest/Southwest & 22.8 & 32 & 37.9 & 48.7 \\
\hline Northwest & & & 31.6 & 44.8 \\
\hline Southwest & & & 47 & 53.8 \\
\hline Total & 26.5 & 33.3 & 39.1 & 46.2 \\
\hline
\end{tabular}

Source: Computed by the authors from DHS surveys 
in education rates over the period analysed here, but the gaps between regions remain constant or in some cases widen.

Tables for other non-monetary indicators presented by Fambon et al. (2014) mostly show the same patterns of regional difference. Big spatial differences are apparent in most indicators to the disadvantage of the north of the country, and in most cases the indicators stagnated between 1991 and 2004, only starting to improve since.

\subsection{Conclusions and Policy Priorities}

The overall pattern coming from this analysis is of good progress in reducing monetary poverty between 1996 and 2001, which then slowed down or stopped between 2001 and 2007. In terms of non-monetary measures of poverty there was very little progress over the 1991-2004 period except in education, but indicators then improved between 2004 and 2011. In both cases there has been progress for part of the period but this has not been sustained over the full time. Overall progress has been disappointing and this is in line with disappointing growth performance. Given the rates of growth over the period, the rate of change in monetary poverty is not very surprising; Cameroon has failed to reduce poverty because of poor growth performance which is a consequence of many of the factors highlighted in this chapter, including weak institutions and poorly formulated policies.

In addition to this, given Cameroon's income level, and comparison with other countries in SSA, the levels of the outcomes of the non-monetary indicators do raise serious questions about the effectiveness of public service delivery in health and education, among other areas. The main cities may have respectable outcomes in these indicators but much of the rest of the country lags significantly behind. There has been progress in recent years, but the levels of mortality and malnutrition remain high for a middle-income country.

Also striking in these results is the extent and consistency of spatial inequality shown by both monetary and non-monetary welfare measures. Again, the difference between Yaoundé and Douala compared to the rest of the country is striking; but perhaps the most striking feature is that the northern parts of the country are so much more deprived compared to the rest of the country. Even if successive governments have been concerned to limit regional divergences, this does not seem to have been particularly successful, in particular in relation to the north of the country where some of the non-monetary outcomes compare with levels in much poorer countries in SSA. These regions in particular appear not to have benefitted from economic growth or effective service delivery. The extent of divergence could be a potential source of increased tension in the future. 
In terms of priorities, Cameroon's seeming inability to sustain a reasonable growth rate seems to be one key factor; better and more effective policy formulation would seem to be a major policy priority here. This chapter suggests that this raises quite fundamental questions, not just about the effective management of resource wealth but also putting in place institutions that would support faster sustained growth. The fixed exchange rate is potentially an advantage, but with other institutional and policy weaknesses this is not sufficient by itself. Putting in place an appropriate framework for business, reducing support to public enterprises, addressing market failures including those in the financial sector, and prioritizing agricultural production would appear to be important early priorities.

An equally important priority is to address what appears to be a chronic problem of effective delivery of public services; this can offer benefits for growth as well as for social outcomes. Progress may have been made recently, but the overall outcomes in terms of non-monetary indicators, especially in the poorer regions, remain disappointing for a country with the overall income level which Cameroon has.

\section{Acknowledgements}

The authors would like to thank UNU-WIDER's Growth and Poverty Project for supporting this work, and Cameroon's National Institute of Statistics for providing the household survey data used in this analysis. They are also grateful to Macro International Inc. for making available the Cameroonian DHS data used in this study.

\section{References}

Amin, A. A. (2002). 'An Examination of the Sources of Growth in Cameroon's Economy', AERC Research Paper 116. Nairobi, Kenya: African Economic Research Consortium.

Datt, G. and M. Ravallion (1992). 'Growth and Redistribution Components of Changes in Poverty Measures: A Decomposition with Applications to Brazil and India in the 1980s', Journal of Development Economics, 38: 275-85.

Doe, L. (1995). 'Managing Cameroon's Banking Sector-In and Out of Crisis: The Role of the Government', African Development Review, 7: 103-66.

Easterly, W., R. King, R. Levine, and S. Rebelo (1991). 'How Do National Policies Affect Long-Run Growth: A Research Agenda', Working Paper WPS 794. Washington, DC: World Bank.

Fambon, S. (2010). 'Poverty and Growth in Cameroon during the Post-Devaluation Period (1996-2001)', Journal of African Studies and Development, 2(4): 81-98. 
Fambon, S., A. McKay, J.-P. Timnou, O. S. Kouakep, A. Dzossa, and R. Tchakoute (2014). 'Growth, Poverty, and Inequality: The Case Study of Cameroon', WIDER Working Paper 2014/154.

Ghura, D. (1997). 'Private Investment and Endogenous Growth: Evidence from Cameroon', IMF Working Paper WP/97/165. Washington, DC: International Monetary Fund.

Government of Cameroon (2003). Poverty Reduction Strategy Paper. Yaoundé: Government of Cameroon.

IMF (2005). 'Cameroon: Ex Post Assessment of Longer-Term Program Engagement', IMF Report No. 05/189. Washington, DC: International Monetary Fund.

Kobou, G., D. Njinkeu, and B. Powo Fosso (2008). 'The Political Economy of Cameroon's Post-Independence Growth Experience', in B. J. Ndulu, S. A. O'Connell, J.-P. Azam, R. H. Bates, A. K. Fosu, J. W. Gunning, and D. Njinkeu (eds), The Political Economy of Economic Growth in Africa, 1960-2000, vol. 2: Country Case Studies. Cambridge: Cambridge University Press, 547-87.

Levine, R. and D. Renelt (1992). 'A Sensitivity Analysis of Cross-Country Growth Regressions', American Economic Review, 82(4): 942-63.

Mbaku, J. M. (1993). 'Foreign Aid and Economic Growth in Cameroon', Applied Economics, 25: 1309-14.

Most, S. J. and H. Van Den Berg (1996). 'Growth in Africa: Does the Source of Investment Financing Matter?', Applied Economics, 28(9): 1427-33.

National Institute of Statistics (1996). Database of ECAM1. Republic of Cameroon, Ministry of Economic Affairs, Programming, and Regional Development.

National Institute of Statistics (2001). Database of ECAM2. Republic of Cameroon, Ministry of Economic Affairs, Programming, and Regional Development.

National Institute of Statistics (2007). Database of ECAM3. Republic of Cameroon, Ministry of Economic Affairs, Programming, and Regional Development.

Renelt, D. (1991). 'Economic Growth: A Review of the Theoretical and Empirical Literature', Working Paper No. 678. Washington, DC: World Bank.

Tchoungui, R., S. Gartlan, J.-A. Mopo Simo, F. Sikod, A. Youmbi, and M. Ndjatsana (1995). 'Structural Adjustment and Sustainable Development in Cameroon: A World Wide Fund for Nature Study', ODI Working Paper No. 83. London: Overseas Development Institute.

World Bank (1989). 'Memorandum and Recommendation of the President of the International Bank for Reconstruction and Development to the Executive Directors on a Proposed Loan of US\$150 Million Equivalent to the Republic of Cameroon for the Structural Adjustment Program', Report No. P-5079-CM. Washington, DC: World Bank. 


\title{
14
}

\section{The Fall of the Elephant}

\author{
Two Decades of Poverty Increase \\ in Côte d'Ivoire, 1988-2008
}

Denis Cogneau, Kenneth Houngbedji, and Sandrine Mesplé-Somps

\subsection{Introduction}

After having been praised as a model to follow, at the turn of the twenty-first century, Côte d'Ivoire (Ivory Coast) began to stand as a counter-example for those eager to find auspicious signs of the 'emergence' of Africa. For now, the case of this country is perhaps a reminder to others that some golden ages may end in nightmares. In 2012, Côte d'Ivoire had just emerged from a contested presidential election that came close to turning into a civil war between the followers of the incumbent (Laurent Gbagbo) and the challenger (Alassane Ouattara). For five years between the end of 2002 and 2007, the country had also been partitioned between North and South, with UN-mandated forces interposing between legalists and rebels. And in 1999, a coup by General Robert Gueï had expelled the president Henri Konan Bédié from power. When did it all start? Even on that point, different readings of history already disagree; furthermore, it is certainly possible to find roots of such a great crisis in the distant past, dating back at least to the colonial period (Dozon 2011). However, opting for a narrative that is not too deterministic, it is safe to say that bad economic and political conditions started to combine between 1990 and 1993. Macroeconomic imbalances and growth failures appeared in the mid-1980s, the first structural adjustment programme (SAP) being launched as early as 1981; still, the halving of cocoa producer prices was delayed until 1990, and this delay can be seen as symptomatic of a kind of denial of macroeconomic issues by the government (Berthélemy and Bourguignon 
1996; Cogneau and Mesplé-Somps 2002a, 2002b). In the same year, the first multi-party presidential election was conceded and won by the father of the nation Félix Houphouët-Boigny, who had ruled the country since independence (1960), and who died in December 1993. The death of the 'vieux' (old man) raised the last obstacle to the CFA franc devaluation in January 1994, illustrating how economics could be determined by politics (Jones and Olken 2005). Reciprocally, it can be argued that neoliberal economic reforms undermined the country's capacity to preserve a fragile political equilibrium, in particular between Northern and Southern elites (Boone 2007).

This chapter proposes a retrospective analysis of the evolution of living standards in Côte d'Ivoire over two decades, from the end of the 1980s until the end of the 2000s. It focuses on income distribution and monetary poverty, but also looks at access to education and to health. This is made possible by the exploitation of the large sample household surveys that were implemented at various times during that period. Our analysis also makes use of available national accounts, as well as of regional and sectoral price data. To our knowledge, the most recent past decade has not yet been analysed in those terms, and no such historical perspective has yet been tried. This chapter is organized as follows. Section 14.2 is a background section that reviews the main lines of Ivorian economic history from the colonial era until the 1980s. Section 14.3 then presents the data and the analytical methodology, further details being given in Cogneau et al. (2014). Section 14.4 reviews the first decade of uncertainties (1988-98), inaugurated by the great cocoa shock (1989-93) and followed by the devaluation bounce-back (1994-8). Section 14.5 then delves into the less-studied decade of the civil war (1998-2008), which we divide again into two halves. The first half saw three presidents follow one another into power (Konan Bédié, Gueï, Gbagbo) until the partition of the country in 2002. The second half ended in 2007 after the signature of the Ouagadougou agreements between Northern rebels and legalist forces. We then briefly discuss recent developments between 2008 and 2013, and set out a few prospects for the ten years to come. Section 14.6 concludes.

\subsection{The Rise of the Elephant until the End of the 1980s}

The present-day territory of Côte d'Ivoire was first constituted as a colony of France in 1899. Côte d'Ivoire became independent in 1960, like all the French colonies of West and Equatorial Africa. Before 1899, the French already had established trade posts on the coast of the Gulf of Guinea, in particular on the (Ébrié) lagoon in the Southwest (Grand-Bassam), close to the future capital of Abidjan, and not too far from the Gold Coast (Ghana) border where the British 
were settled. They also arrived in the North, coming from the coasts of Senegal; at the present-day Northern borders of the country with Guinea, Mali, Burkina Faso, and Ghana, they fought a series of wars against the Diula leader Almami Samori Ture, that ended with his capture in 1898. Before the arrival of the French, the most structured pre-colonial polities were the kingdoms located in the North; from West to East: the Senufo kingdom of Kenedugu, whose capital city was Sikasso (in today's Mali), the Kong and Buna kingdoms (with eponymous capital towns in today's Côte d'Ivoire), and the Gyaman kingdom (around Bonduku). Other small polities (Sefwi, Indenie, Sanwi) along the border with Ghana were under the dominion of the Ashanti Empire, whose capital Kumasi lay in central Ghana. Economically speaking, the Northern kingdoms were mostly based on trade with trans-Saharan caravans, which exchanged salt, cattle, and a few manufactured goods for the gold from the Northern mines and the kola nuts bought from the people of the Southern forests. The slave trade was also present in the Northeast and along the border with Ghana (the Ashanti Empire was based on gold and slave trades), but this affected the populations of Côte d'Ivoire to a relatively small degree.

During the colonial era, Côte d'Ivoire did not receive more investment than other comparable areas like Guinea or Dahomey (today's Benin), but much less than Senegal, which was the central seat of the government of former French West Africa (Huillery 2009). Cocoa production only took off after the Second World War, in the 1950s, and this drove urbanization (Jedwab 2011). It started at the border of Ghana, which was the world's first producer of cocoa at that time, as Akan planteurs (cocoa growers) imitated their co-ethnic neighbours. A Baule physician and cocoa grower, Felix Houphouët-Boigny, was elected to the French National Assembly in 1945, and occupied a series of ministerial positions in the governments of the French Fourth Republic. After having turned into an independentist leader, he became the first president of Côte d'Ivoire in 1960 and, as 'father of the nation', stayed in power until his death in December 1993. HouphouëtBoigny consolidated his rule by making a political alliance with Northern leaders (a Centre-East/North axis), allowing him to counterbalance the influence of non-Baule Akan kings and chiefs (Southeast) and to downplay the opposition of $K r u$ leaders (Centre West). ${ }^{1}$

At the same time, he preserved very strong links with the French, becoming one of the main actors of what would later be called the 'Françafrique'. He was

\footnotetext{
${ }^{1}$ Baules are part of the larger Akan ethnic group. This political equilibrium fell apart after his death in 1993, because of the individual competition between the Northerner Ouattara, prime minister, and the Baule Konan Bedie, president of the National Assembly.
} 
rewarded by high levels of French foreign aid, as well as by the allocation of French engineers and administrators to key technical positions within the Ivorian administration.

In the 1960s and 1970s, the 'Ivorian miracle' was built upon the two pillars of cocoa and French aid. The Baule planteurs colonized forested areas to plant cocoa and coffee trees, moving the cocoa frontier progressively from the East (Ghana border) to the West (Guinea border), where it had arrived by the end of the 1990s. Part of the sharecropper labour force for cocoa was provided by very large migration flows from Northern neighbours, first Burkina Faso and then Mali. According to the 1998 census, 26 per cent of residents were 'foreigners', even if half of them were actually born in the country (Tapinos et al. 2002). Cotton production was developed in the North, and kept increasing until the end of the 1990s as well. Administered producer prices were managed by parastatals as an implicit taxation on farmers, so that cocoa, coffee, and cotton income became central in the government revenue. With growing fiscal resources and generous amounts of aid, the Ivorian state could invest in roads and transportation infrastructures and in the construction of schools, and could also pay high wages to its civil servants, including teachers. Growing cocoa income spurred urbanization (Jedwab 2011). Great emphasis was placed on education, and Côte d'Ivoire succeeded in catching up with neighbouring Ghana in terms of literacy, where it was very much lagging behind at the end of the colonial era (Cogneau and Moradi 2014). Houphouët nicknamed Côte d'Ivoire the 'République des bons élèves' (Republic of the good pupils), paraphrasing the name 'République des professeurs' (Republic of the teachers) that was used to refer to the French Third Republic.

Figure 14.1 illustrates how growth was determined by income from cash crops, in particular cocoa. Between 1960 and the beginning of the 1970s, real GDP per capita rose by around 50 per cent, from 600 to 900 dollars (in constant 2000 US\$). In 1974-5, the international prices of cocoa, coffee, and cotton followed the boom in oil prices and other raw materials, and internal producer prices were dramatically increased as well, bringing GDP per capita to the heights of US\$1,100. Côte d'Ivoire overtook Ghana as the world's largest cocoa producer in 1977 (Eberhardt and Teal 2010). However, this price boom did not last very long, and with the first adjustment programme in 1981 also came disillusion with growth. The short-lived bounce of international prices in 1985-6 allowed macroeconomic stabilization to be postponed for a while; in 1987, Côte d'Ivoire failed to influence cocoa international prices by accumulating stocks. At the end of the 1980s, the growing deficits of the state budget and of the cocoa and coffee marketing board could no longer be sustained, and a large cut of producer prices was finally implemented in 1989. 


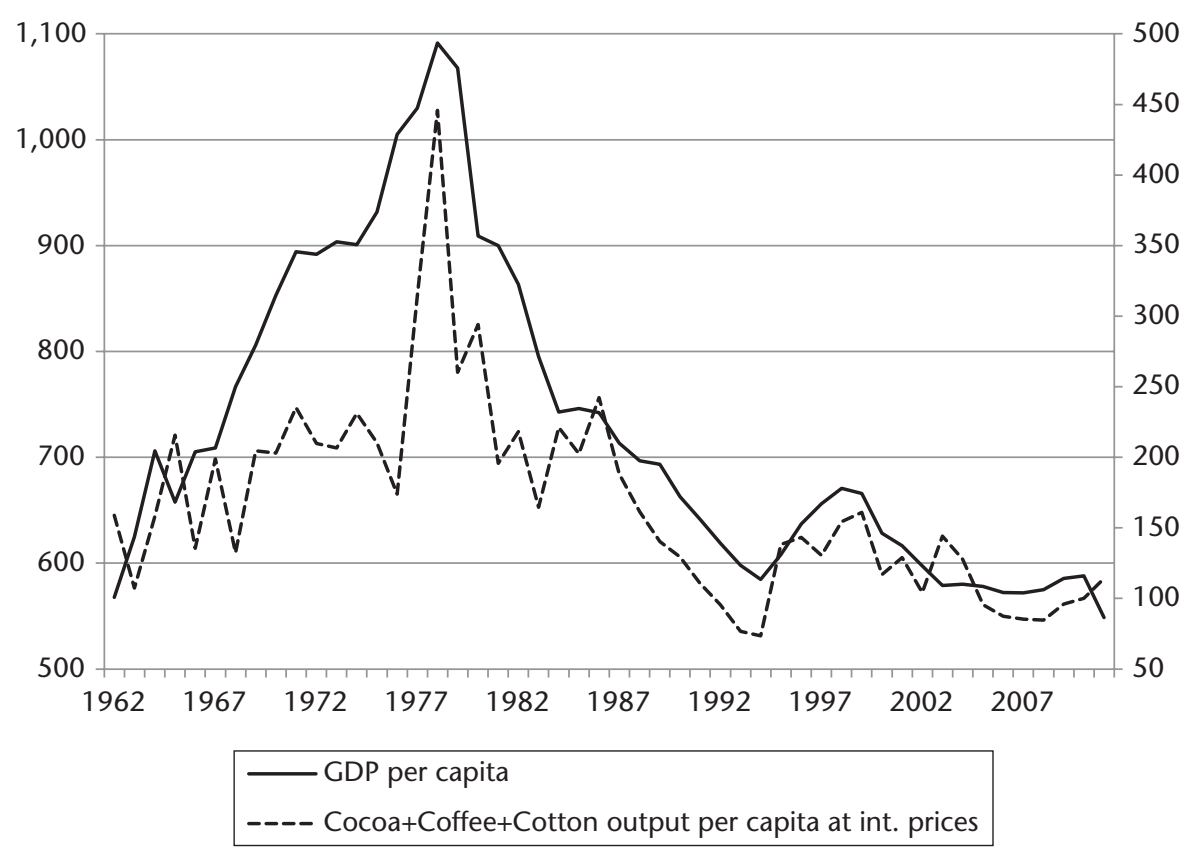

Figure 14.1. GDP per capita and cash crop income, 1960-2010

Note: In plain line and on left scale, gross domestic product per capita in 2000 US\$. In dotted line and on right scale, sum of cocoa beans, green coffee, and cotton seeds output, valued at international prices, deflated by GDP deflator, converted in 2000 US $\$$ and lagged by one year. Source: Authors' elaboration based on data from World Bank (2012) and FAOSTAT (2012)

Figure 14.2 provides a kind of summary of the Ivorian miracle and reversal of fortune, using height data covering eighty-five years (1903-88). For the early period (1903-40), we use recently collected military data on conscripts in the French army; data on conscripts' height gains connects nicely with data from the 1985-8 and 2008 surveys in which the heights of males aged twenty years and over were measured. ${ }^{2}$

The graph reveals the impressive height gain of four centimetres that was obtained in the first three-quarters of the twentieth century. This gain compares well with Fogel's (1994) figures for twentieth-century France or United Kingdom ( $6 \mathrm{~cm}$ over the $1875-1975$ period). For cohorts born after 1975, i.e. when GDP per capita began its great decline, we observe a significant fall in stature, of around $1.5 \mathrm{~cm}$.

\footnotetext{
${ }^{2}$ In retrospective survey data, the heights of the oldest cohorts are affected by old-age shrinkage. See Cogneau and Rouanet (2011) for an analysis of 1925-85 height evolutions and a comparison with Ghana.
} 


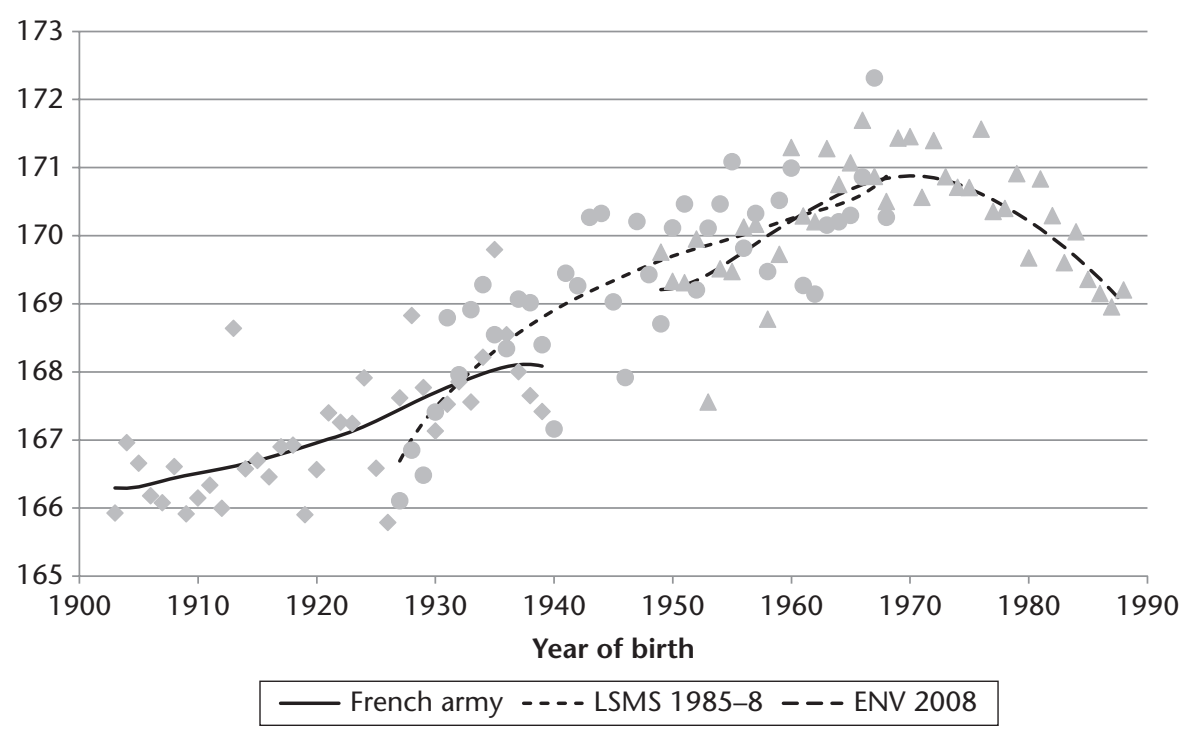

Figure 14.2. Average height stature of males aged 20-59 years, 1900-90

Note: Grey diamonds, circles, and triangles are average height of birth year cohorts, drawn from three distinct data sources. Lines are locally weighted regressions of average height on year of birth. 'French army' (diamonds): Data from a 10,000 sample of conscripts (aged around 20 years) and volunteers in the French army (1923-60). 'LSMS 1985-8' (circles): Males aged 20-59 years from CILSS 1-4 household surveys (1985-8). 'ENV 2008' (triangles): Males aged 20-59 years from ENV1 (2008) household survey.

Source: Authors' elaboration based on data from French army (indigenous soldiers born in Côte d'Ivoire), CILSS household surveys 1-4 (1985-8) and ENV1 (2008)

\subsection{Data Description and Methodology}

This section presents the main choices that were made in terms of measurement of living standards and poverty. ${ }^{3}$

\subsubsection{Construction of the Consumption Variable}

The consumption variable is the sum of consumption of own food production, food expenditures, and sufficiently frequent non-food expenditures like

\footnotetext{
3 The working paper version of this chapter (Cogneau et al. 2014) provides a presentation of the main data sources used in this study (five nationally representative household surveys conducted by the Institut National de la Statistique de Côte d'Ivoire in 1988, 1993, 1998, 2002, and 2008). Please refer to section 3.1 of this chapter for a discussion of the accuracy of the sample designs of household surveys, and in particular the statistical representation of people born in Burkina Faso and Mali. Refer as well to Appendix A1 of this chapter for more details on the construction of variables from micro data (consumption, durable goods ownership, school enrolment), and to Appendix A2 on macroeconomic indicators drawn from national accounts.
} 
housing, education, clothing, transport, and communication. We paid great attention to the comparability of all the components across surveys. For instance, we realized that imputed rent estimations could change significantly depending on how the number of rooms had been reported (e.g. whether toilet and bathroom were included or not).

Consumption of food products accounts for more than 50 per cent of total consumption. Food expenditures and consumption of own food production are recorded in two separate parts of survey questionnaires. Surveys do not use diaries, and instead ask about consumption over a product-specific recall period; not all surveys cover the whole year, and when they do, different households are surveyed in successive waves. We identified four features in survey questionnaires that could threaten comparability across time: (i) changes in the selection of goods for which expenditures were recorded; (ii) changes in recall periods for some goods; (iii) modifications in survey duration and controls for seasonality of consumption; and (iv) differences in the detail of goods. In their methodological experiment on the measurement of consumption in Tanzania, Beegle et al. (2012) identify the same strategic dimensions. Their results suggest that, when compared with the benchmark of individual diaries, a detailed list of products with short recall periods is preferable. Appendix A1 in Cogneau et al. (2014) explains in detail the way we computed non-food and food consumption aggregates and the potential bias induced by the changes to questionnaire designs since 1988. We produced four estimates for total consumption, which vary according to recall periods and declared frequency of consumption within these periods. Even if levels may differ very much, reassuringly enough, the time pattern of consumption is quite consistent across estimates. ${ }^{4}$

\subsubsection{Consumer Prices}

It has been revealed to be impossible to derive reliable/comparable unit prices from surveys. Quantities are declared in units that can be very heterogeneous across space, like bags or basins; furthermore, many times, units are not specified.

For both the 1988-96 and the 1996-8 periods, disaggregated consumer price levels in Abidjan, along with budget coefficients, were communicated by the Ivorian National Institute of Statistics (INS). Unfortunately, the 1988-96 price

\footnotetext{
4 Dabalen and Paul (2013) propose a reweighting procedure in order to account for changes in questionnaire designs between the 1985-8 surveys and the 1993-2008 surveys. The assumptions implied by their methodology are questionable, as they themselves acknowledge, in particular that of stability in the distribution of sociodemographic variables over twenty years. Further, the correction they make appears relatively limited, and provides estimates that are rather consistent with ours.
} 
data proved to be very inconsistent with the World Bank figures (World Bank 2008), as well as with the IMF figures (IMF 2013), in particular with respect to the high inflation following the CFA franc devaluation of 1994. The communicated price data showed very modest inflation in 1994 and 1995, in contrast with World Bank or IMF figures, which record a 26 per cent inflation rate for 1994 and 14 per cent for 1995. The cumulated 1996-2008 inflation from INS data was also lower, compared to other sources: the World Bank, IMF, and even Afristat, the regional statistical office. We could not elucidate the origin of such discrepancies.

In order not to run the risk of underestimating inflation, we resolved to stick with the consumer price index drawn up for the African Development Indicators (World Bank 2008). Household consumption is deflated by this national consumer price index, with 2005 as the base year, and translated into 2005 international dollars using World Development Indicators (World Bank 2012) purchasing power parity exchange rates for the year 2005. The poverty line chosen to compute poverty indicators is US\$1.25 (at the $2005 \mathrm{PPP}$ level).

We only used the disaggregate price data to analyse the potential impact of a change in consumer baskets. For instance, we computed another consumer price index using the budget coefficients of the average household in the first quartile of consumption per capita as of 1998. This 'poverty-oriented' price index showed little difference from the consumer price index computed with average budget coefficients. We also varied the consumer baskets according to the region of residence (North, East Forest, West Forest, Abidjan) and found little difference in aggregate price evolutions (keeping in mind that only prices collected in Abidjan were available).

Last, sparse data on price levels were also obtained for some provincial capital cities other than Abidjan, and for two or three years lying between 1998 and 2008. Due to the disruptions of civil war, Northern provinces have no data at all. In Southern provinces differences in price levels were found to be small and no correction was made.

\subsection{The Decade of Uncertainties: 1988-98}

\subsubsection{The Great Cocoa Shock: 1988-94}

By all accounts, the 1988-94 period was the turning point when macroeconomic crisis spread all over the country, reaching the still relatively protected cocoa growers and formal wage earners. A fourth structural adjustment programme was signed with the International Monetary Fund, involving very large cuts to public wages and expenditures, and a halving of cocoa and coffee producer prices. Félix Houphouët-Boigny had already been struck by cancer, 


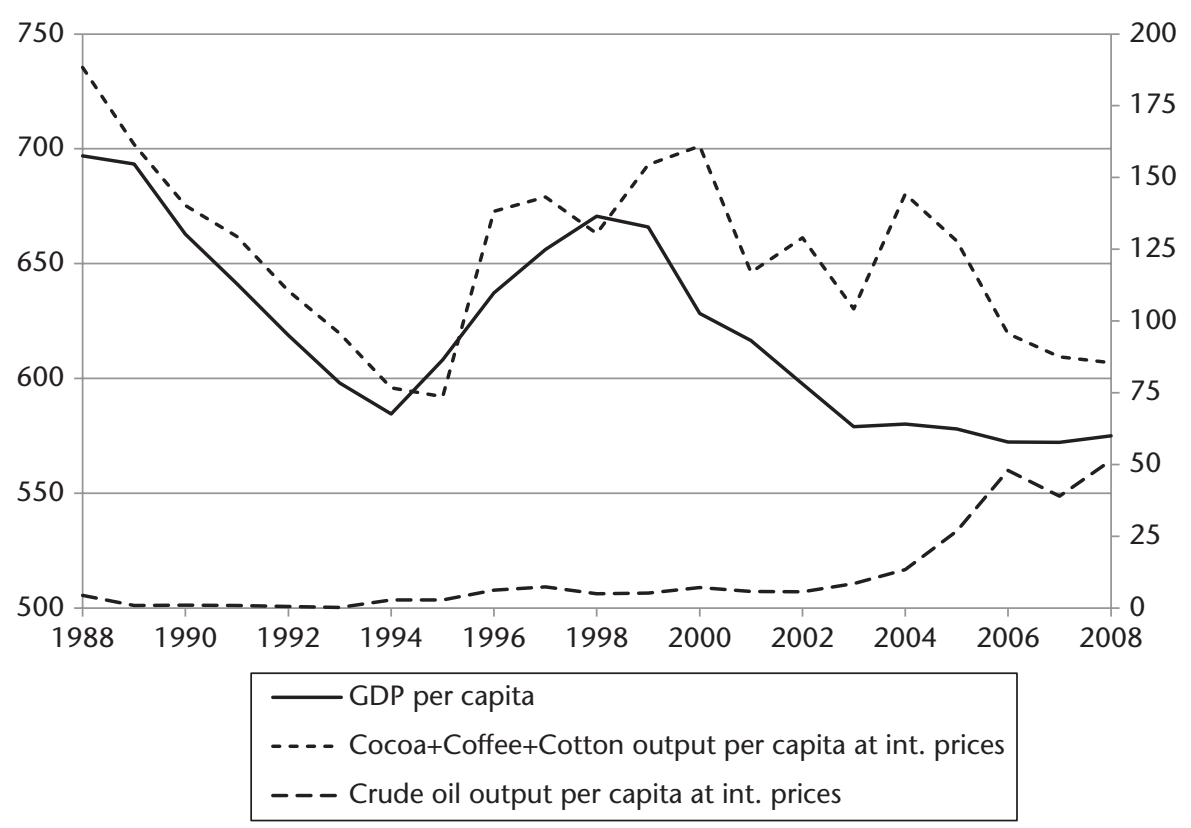

Figure 14.3. GDP per capita, cash crop income, and oil income, 1988-2008

Note: GDP per capita and Cocoa+Coffee+Cotton: see Figure 14.1. Crude oil output is valued at international prices lagged by one year, deflated by GDP deflator, and converted in 2000 US\$.

Source: Authors' elaboration based on data from World Bank (2012) and FAOSTAT (2012)

and Alassane Ouattara, the first prime minister since 1960, was in practice ruling the country. Social unrest and insecurity developed, with a series of street demonstrations, the occupation of Abidjan University, and a mutiny within the army. In the first multi-party election held in 1990, Houphouët-Boigny still beat his younger opponent Laurent Gbagbo, with more than 80 per cent of votes.

Between 1988 and 1993, according to national accounts, GDP per capita again fell by US $\$ 100$ (see Figure 14.3) and final private consumption per capita was reduced by 16 per cent. Our survey data indicates an even more dramatic collapse of household consumption per capita, from US\$2.92 to US\$2.02 per capita and per day respectively (constant 2005 international dollars), i.e. a 31 per cent reduction. As a result, the US\$1.25 poverty headcount almost doubled, from 20 to 38 per cent (Table 14.1). All regions in the country were evenly affected; whereas poverty had formerly been absent from the capital city Abidjan, 13 per cent of its inhabitants could be counted as poor in 1993.

In 1988, welfare was unambiguously much higher on the Eastern side of Côte d'Ivoire, at the border with Ghana. In 1993, the border differences in income or in child nutrition had become much smaller, even if, thanks to past investments, a significant Ivorian advantage in public utilities (electricity, water) remained (Cogneau et al. 2015). 
Table 14.1. Daily consumption per capita and poverty measures over time across regions, 1988-2008

\begin{tabular}{|c|c|c|c|c|c|}
\hline & 1988 & 1993 & 1998 & 2002 & 2008 \\
\hline \multicolumn{6}{|l|}{ Panel A: North } \\
\hline Consumption per capita & $\begin{array}{c}2.06 \\
(0.10)\end{array}$ & $\begin{array}{c}1.49 \\
(0.02)\end{array}$ & $\begin{array}{c}1.81 \\
(0.12)\end{array}$ & $\begin{array}{c}2.17 \\
(0.10)\end{array}$ & $\begin{array}{c}1.41 \\
(0.03)\end{array}$ \\
\hline Poverty headcount & $\begin{array}{c}0.33 \\
(0.02)\end{array}$ & $\begin{array}{c}0.52 \\
(0.01)\end{array}$ & $\begin{array}{c}0.47 \\
(0.02)\end{array}$ & $\begin{array}{c}0.40 \\
(0.01)\end{array}$ & $\begin{array}{c}0.62 \\
(0.01)\end{array}$ \\
\hline $\mathrm{N}$ & 416 & 2,527 & 977 & 2,611 & 3,622 \\
\hline \multicolumn{6}{|l|}{ Panel B: East Forest } \\
\hline Consumption per capita & $\begin{array}{c}2.68 \\
(0.09)\end{array}$ & $\begin{array}{c}1.99 \\
(0.03)\end{array}$ & $\begin{array}{c}2.07 \\
(0.06)\end{array}$ & $\begin{array}{c}2.34 \\
(0.04)\end{array}$ & $\begin{array}{c}1.87 \\
(0.03)\end{array}$ \\
\hline Poverty headcount & $\begin{array}{c}0.10 \\
(0.02)\end{array}$ & $\begin{array}{c}0.34 \\
(0.01)\end{array}$ & $\begin{array}{c}0.33 \\
(0.02)\end{array}$ & $\begin{array}{c}0.31 \\
(0.01)\end{array}$ & $\begin{array}{c}0.39 \\
(0.01)\end{array}$ \\
\hline $\mathrm{N}$ & 400 & 2,414 & 934 & 2,604 & 3,003 \\
\hline \multicolumn{6}{|l|}{ Panel C: West Forest } \\
\hline Consumption per capita & $\begin{array}{c}2.29 \\
(0.16)\end{array}$ & $\begin{array}{c}1.62 \\
(0.02)\end{array}$ & $\begin{array}{c}1.91 \\
(0.04)\end{array}$ & $\begin{array}{c}1.75 \\
(0.05)\end{array}$ & $\begin{array}{c}1.69 \\
(0.02)\end{array}$ \\
\hline Poverty headcount & $\begin{array}{c}0.29 \\
(0.02)\end{array}$ & $\begin{array}{c}0.46 \\
(0.01)\end{array}$ & $\begin{array}{c}0.38 \\
(0.01)\end{array}$ & $\begin{array}{c}0.50 \\
(0.01)\end{array}$ & $\begin{array}{c}0.47 \\
(0.01)\end{array}$ \\
\hline N & 479 & 2,885 & 1,417 & 3,533 & 3,864 \\
\hline \multicolumn{6}{|l|}{ Panel D: Abidjan } \\
\hline Consumption per capita & $\begin{array}{c}5.59 \\
(0.28)\end{array}$ & $\begin{array}{c}3.39 \\
(0.09)\end{array}$ & $\begin{array}{c}3.77 \\
(0.12)\end{array}$ & $\begin{array}{c}4.29 \\
(0.11)\end{array}$ & $\begin{array}{c}3.96 \\
(0.09)\end{array}$ \\
\hline Poverty headcount & $\begin{array}{c}0.00 \\
(0.00)\end{array}$ & $\begin{array}{c}0.13 \\
(0.01)\end{array}$ & $\begin{array}{c}0.05 \\
(0.01)\end{array}$ & $\begin{array}{c}0.09 \\
(0.01)\end{array}$ & $\begin{array}{c}0.09 \\
(0.01)\end{array}$ \\
\hline$N$ & 304 & 1,676 & 860 & 1,970 & 1,968 \\
\hline \multicolumn{6}{|l|}{ Panel E: All regions } \\
\hline Consumption per capita & $\begin{array}{c}2.92 \\
(0.08)\end{array}$ & $\begin{array}{c}2.02 \\
(0.02)\end{array}$ & $\begin{array}{c}2.31 \\
(0.04)\end{array}$ & $\begin{array}{c}2.47 \\
(0.04)\end{array}$ & $\begin{array}{c}2.14 \\
(0.02)\end{array}$ \\
\hline Poverty headcount & $\begin{array}{c}0.20 \\
(0.01)\end{array}$ & $\begin{array}{c}0.38 \\
(0.00)\end{array}$ & $\begin{array}{c}0.32 \\
(0.01)\end{array}$ & $\begin{array}{c}0.35 \\
(0.00)\end{array}$ & $\begin{array}{c}0.41 \\
(0.00)\end{array}$ \\
\hline$N$ & 1,599 & 9,502 & 4,188 & 10,718 & 12,457 \\
\hline
\end{tabular}

Note: Daily consumption expenditures per capita are in constant 2005 US\$ PPP and the poverty line used is US\$1.25 PPP a day. Standard errors in parentheses.

Source: Authors' calculation based on data from CILSS 4 and ENV1-4 household surveys

All social classes were affected: the consumption growth incidence curve is nearly flat, meaning that proportional decreases in consumption per capita were evenly spread across the income distribution (Figure 14.5).

For the first time, net primary school enrolment fell from 56 to 47 per cent (see Appendix Table 14.A1). Early-age child nutrition deteriorated, especially among small cocoa and coffee producers (Cogneau and Jedwab 2012). This is also when the AIDS epidemics began to spread (Cogneau and Grimm 2008).

During the fifteen years that followed, the country would never recover from this great shock, and poverty would mainly oscillate around the 1993 level, even reaching 41 per cent in 2008 (see also the cumulative distribution 


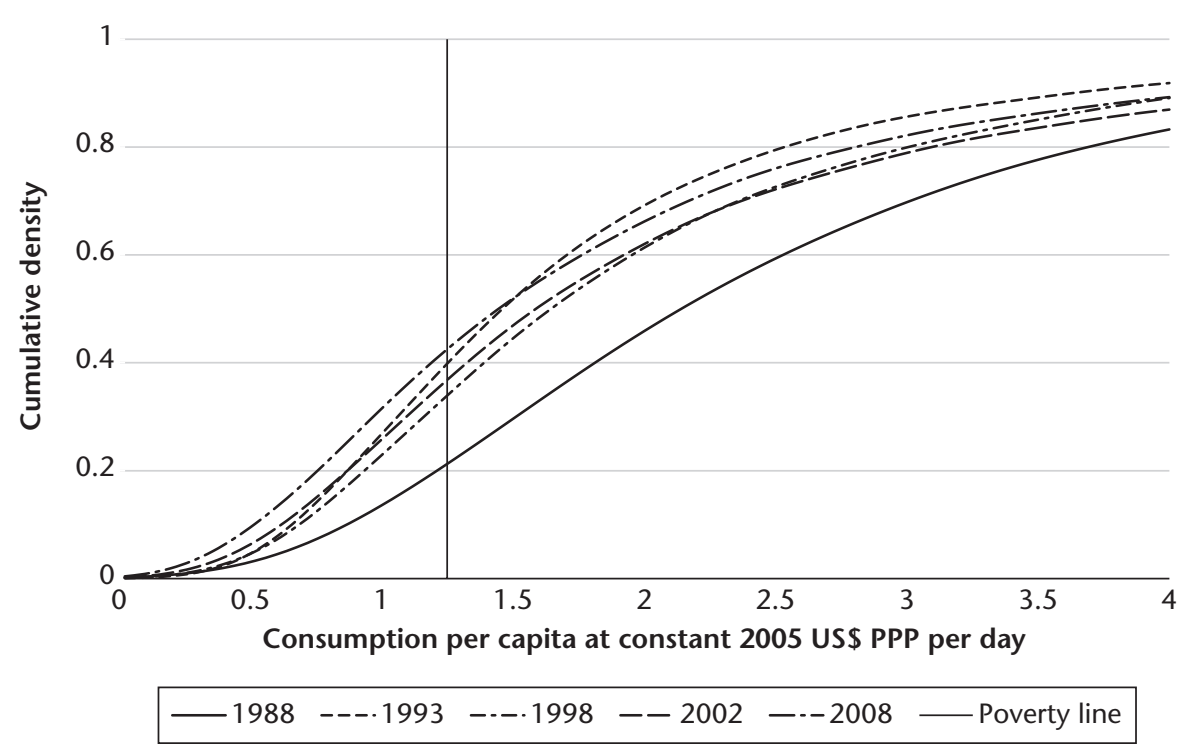

Figure 14.4. Cumulative distribution function of consumption per capita across time Note: Percentage of people whose consumption per capita and per day lies below the level on the horizontal axis. Vertical bar is the US\$1.25 poverty line.

Source: Authors' elaboration based on data from CILSS 4 and ENV1-4 household surveys

function curves in Figure 14.4). Figure 14.2 suggests that cohorts affected by early-age stunting and height losses had not entirely recovered from these effects when they reached adult age. The results of Demographic and Health Surveys for the years 1994, 1998, and 2012 suggest that early-age stunting has stayed on the increase throughout the last two decades (Coulibaly and N'Dri 2012). However, aside from consumption or nutrition, after having fallen back, primary school enrolment recovered in 1998 and carried on increasing in 2002. Secondary school enrolment exhibited continuous progresses (Appendix Table 14.A1). Finally, on the side of durable goods, households benefitted from the price decreases in radio and TV sets, and, most impressively, in mobile phones (Appendix Table 14.A2).

\subsubsection{The CFA Franc Devaluation Bounce-Back: 1994-8}

After the 1993 legislative elections in France, the new French Prime Minister Edouard Balladur aligned his position with those of the IMF and the World Bank regarding the need for a devaluation of the CFA franc. Côte d'Ivoire being the most important economy of the Franc Zone, the death of Houphouët-Boigny in December 1993 removed the last obstacle to its implementation, given the oath made by President Mitterrand to the old leader not to devalue the CFA franc. The CFA franc was immediately devalued by 50 per 


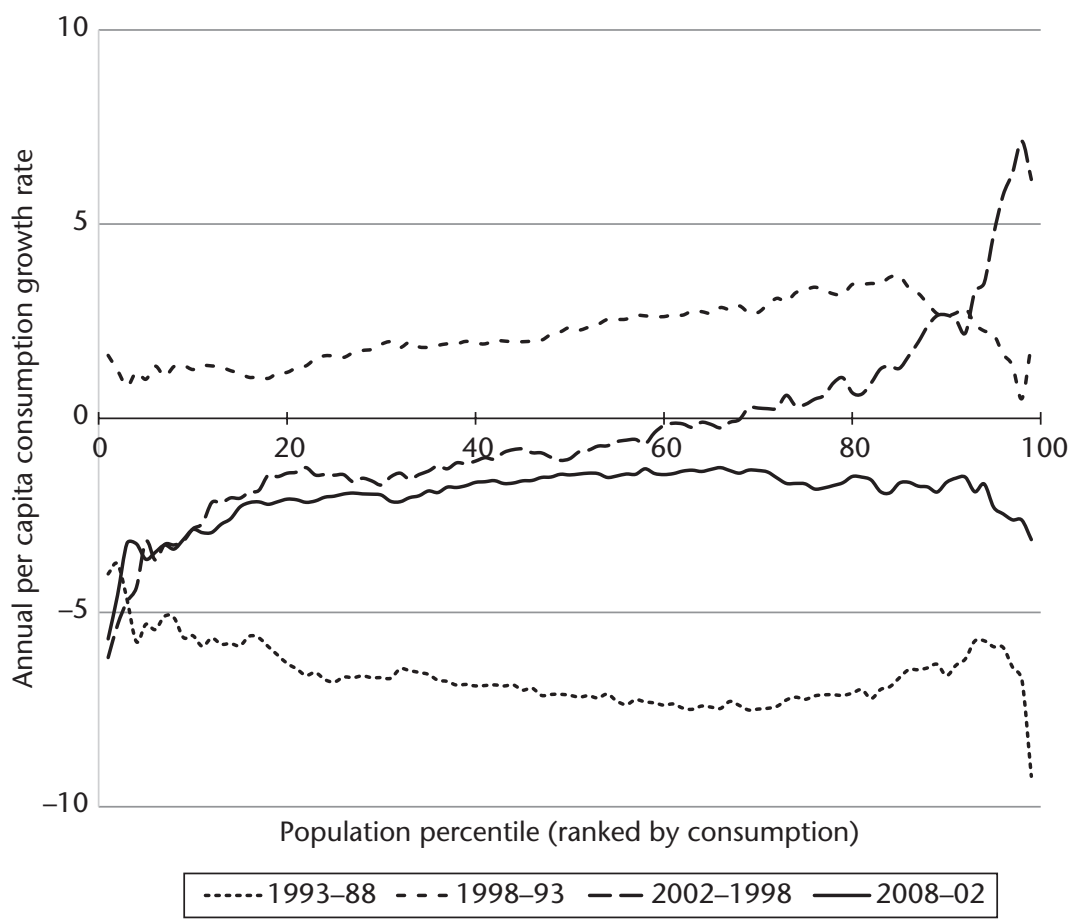

Figure 14.5. Growth incidence curves

Note: Average growth in consumption per capita for each percentile of consumption per capita in the initial year.

Source: Authors' elaboration based on data from CILSS 4 and ENV1-4 household surveys

cent in January 1994-meaning an ex ante doubling of import prices. The objective of this devaluation was the reduction of public deficits, through the reduction of the public wage bill in real terms, as well as increased fiscal revenue from import tariffs and duties on cocoa. Consumer price inflation stayed under control (around 30 per cent in 1994), so that a large real depreciation was achieved. In terms of macroeconomic stabilization, and according to the criteria set by the Bretton Woods institutions, the CFA franc devaluation was to some extent a success (Cogneau and Collange 1998).

In terms of income growth and poverty, fortunately enough, international commodity prices bounced back concomitantly, allowing increases in real producer prices of coffee and cotton; however real cocoa prices were kept constant, so that the marketing board deficits could be cleared (see Appendix Figure 14.A1). Fortunately again, national cocoa output reached a historical record (over 1.2 million tons), thanks in particular to trees reaching maturity in the West Forest, and perhaps also to increased collection effort. In the 
North, farmers planted more cotton (Appendix Figure 14.A2). Further, the new structural adjustment programme was backed by large amounts of foreign aid, translating into a doubling of public investment in infrastructure; private capital also flowed back to the country and the construction sector boomed.

According to national accounts, in 1998 consumption per capita had returned to its pre-shock level of 1988. Survey data are much less optimistic: household consumption per capita reached US\$2.31 per capita per day, i.e. only 80 per cent of the 1988 value. Compared to 1993, the poverty headcount at the US\$1.25 level was reduced by six percentage points. Consumption growth incidence was even slightly distorted towards upper-middle income levels (Figure 14.5), so that poverty was reduced to a lesser extent than an evenly distributed consumption growth would have allowed. Indeed, in rural areas, cash crop evolutions benefitted more the 'gros planteurs' (large cash crop growers), as illustrated by the high consumption growth among farmers (+17 per cent) that contrasts with the modest poverty decrease of four percentage points (Table 14.2 Panel A). In cities, informal workers benefitted from the boom in investment and from the recovery of household consumption (Table 14.2 Panel B). Civil servants, however, suffered as their wages were not indexed to inflation; this most likely explains why the consumption growth was very much mitigated in the top decile (Table 14.2 Panel C).

On the political side, in accordance with the Constitution, the president of the National Assembly, Henri Konan Bédié, became the new president of the country in 1994; he was a Baule and a Christian, like Houphouët-Boigny. This came to the disappointment of former Prime Minister Alassane Ouattara, a Northern Diula and Muslim. The political competition between the two heirs broke the Houphouëtian political equilibrium that relied on the alliance between Centre South Baule elites and Northern elites. To bar Ouattara's ambitions, Konan Bédié and his followers resurrected the theme of Ivorian national identity ('Ivoirité') that Houphouët's opponent Laurent Gbagbo, a Kru Southwest leader, had already promoted in the 1990 elections. Prior to the October 1995 presidential elections, the National Assembly passed an antiOuattara amendment in the Constitution, according to which presidential candidates ought to have two parents of 'Ivorian nationality' and should not have served as officials in another country, two criteria that Ouattara did not meet. The 1995 elections were also boycotted by Gbagbo, giving Konan Bédié an easy victory.

Strengthened by this victory and good economic conditions, Konan Bédié and Prime Minister Daniel Kablan Duncan launched a vast programme of public investment called the '12 works of the African elephant', meant to transform Côte d'Ivoire into an emerging 10 per cent growth country by the 
Table 14.2. Poverty measures by socioeconomic status of the household head

\begin{tabular}{|c|c|c|c|c|c|}
\hline & 1988 & 1993 & 1998 & 2002 & 2008 \\
\hline \multicolumn{6}{|c|}{ Panel A: Household head is a farmer } \\
\hline Consumption per capita & $\begin{array}{c}1.99 \\
(0.05)\end{array}$ & $\begin{array}{c}1.45 \\
(0.02)\end{array}$ & $\begin{array}{c}1.69 \\
(0.06)\end{array}$ & $\begin{array}{c}1.67 \\
(0.05)\end{array}$ & $\begin{array}{c}1.39 \\
(0.02)\end{array}$ \\
\hline Poverty headcount & $\begin{array}{c}0.30 \\
(0.02)\end{array}$ & $\begin{array}{c}0.52 \\
(0.01)\end{array}$ & $\begin{array}{c}0.48 \\
(0.01)\end{array}$ & $\begin{array}{c}0.51 \\
(0.01)\end{array}$ & $\begin{array}{c}0.59 \\
(0.01)\end{array}$ \\
\hline $\mathrm{N}$ & 800 & 4,277 & 1,908 & 4,744 & 4,675 \\
\hline \multicolumn{6}{|c|}{ Panel B: Household head is self-employed } \\
\hline Consumption per capita & $\begin{array}{c}3.38 \\
(0.16)\end{array}$ & $\begin{array}{c}2.37 \\
(0.06)\end{array}$ & $\begin{array}{c}2.49 \\
(0.07)\end{array}$ & $\begin{array}{c}2.78 \\
(0.08)\end{array}$ & $\begin{array}{c}2.44 \\
(0.04)\end{array}$ \\
\hline Poverty headcount & $\begin{array}{c}0.08 \\
(0.02)\end{array}$ & $\begin{array}{c}0.26 \\
(0.01)\end{array}$ & $\begin{array}{c}0.22 \\
(0.01)\end{array}$ & $\begin{array}{c}0.26 \\
(0.01)\end{array}$ & $\begin{array}{c}0.32 \\
(0.01)\end{array}$ \\
\hline $\mathrm{N}$ & 249 & 1,885 & 835 & 1,950 & 3,388 \\
\hline \multicolumn{6}{|c|}{ Panel C: Household head is a civil servant } \\
\hline Consumption per capita & $\begin{array}{c}4.28 \\
(0.23)\end{array}$ & $\begin{array}{c}3.49 \\
(0.15)\end{array}$ & $\begin{array}{c}3.46 \\
(0.21)\end{array}$ & $\begin{array}{c}4.09 \\
(0.27)\end{array}$ & $\begin{array}{c}3.92 \\
(0.18)\end{array}$ \\
\hline Poverty headcount & $\begin{array}{c}0.06 \\
(0.02)\end{array}$ & $\begin{array}{c}0.10 \\
(0.01)\end{array}$ & $\begin{array}{c}0.07 \\
(0.02)\end{array}$ & $\begin{array}{c}0.10 \\
(0.01)\end{array}$ & $\begin{array}{c}0.07 \\
(0.01)\end{array}$ \\
\hline $\mathrm{N}$ & 208 & 627 & 216 & 543 & 447 \\
\hline \multicolumn{6}{|c|}{ Panel D: Household head is a private-sector wage-earner } \\
\hline Consumption per capita & $\begin{array}{c}4.85 \\
(0.37)\end{array}$ & $\begin{array}{c}2.94 \\
(0.07)\end{array}$ & $\begin{array}{c}3.04 \\
(0.10)\end{array}$ & $\begin{array}{c}3.40 \\
(0.09)\end{array}$ & $\begin{array}{c}3.12 \\
(0.07)\end{array}$ \\
\hline Poverty headcount & $\begin{array}{c}0.02 \\
(0.01)\end{array}$ & $\begin{array}{c}0.17 \\
(0.01)\end{array}$ & $\begin{array}{c}0.14 \\
(0.01)\end{array}$ & $\begin{array}{c}0.18 \\
(0.01)\end{array}$ & $\begin{array}{c}0.21 \\
(0.01)\end{array}$ \\
\hline $\mathrm{N}$ & 218 & 1,876 & 883 & 2,321 & 2,510 \\
\hline \multicolumn{6}{|c|}{ Panel E: Household head is not working } \\
\hline Consumption per capita & $\begin{array}{c}3.51 \\
(0.56)\end{array}$ & $\begin{array}{c}2.07 \\
(0.06)\end{array}$ & $\begin{array}{c}2.85 \\
(0.24)\end{array}$ & $\begin{array}{c}3.09 \\
(0.10)\end{array}$ & $\begin{array}{c}2.39 \\
(0.06)\end{array}$ \\
\hline Poverty headcount & $\begin{array}{c}0.18 \\
(0.03)\end{array}$ & $\begin{array}{c}0.34 \\
(0.02)\end{array}$ & $\begin{array}{c}0.22 \\
(0.02)\end{array}$ & $\begin{array}{c}0.22 \\
(0.01)\end{array}$ & $\begin{array}{c}0.31 \\
(0.01)\end{array}$ \\
\hline $\mathrm{N}$ & 124 & 837 & 346 & 1,160 & 1,437 \\
\hline
\end{tabular}

Note: Daily consumption expenditures per capita are in constant 2005 US\$ PPP and the poverty line used is US\$1.25 PPP a day. Standard errors in parentheses.

Source: Authors' calculation based on data from CILSS 4 and ENV1-4 household surveys

2025 horizon. It was mostly based on colossal and costly infrastructures centred around the capital city Abidjan (new airport, highways, urban train, new thermal plant, etc.), relying on Build-Operate-Transfer agreements with private firms; in 1999, only four projects had effectively started. Capital-intensive industrial projects were also envisaged, in particular for the transformation of cocoa. In the meantime, the liberalization of the economy accelerated. Non-tariff barriers as well as internal price controls (on e.g. rice, transport) were eliminated. More liberal regulations were adopted for private investment, mines, labour, and telecommunications. The privatization of the cotton parastatal in 1997 was followed by the liberalization of the coffee (1998) and cocoa sectors (1999). Around 60 public firms were privatized, in diverse industries from sugar through telephones to railways. 


\subsection{The Erratic Civil War: 1998-2012}

With the prospect of the presidential elections of 2000, political tensions carried on increasing. In 1998, a new law on land was passed that introduced not only unequal rights for nationals and foreigners, but also a notion of autochthony; it was hardly applied in the years that followed, but contributed to violence around access to land and land rights (e.g. Chauveau 2010). Electoral lists were also scrutinized in order to exclude voters whose Ivorian nationality could be contested. At the same time, growth slowed down, and Konan Bédié was accused of stratospheric corruption. A scandal around the embezzlement of European aid in the health sector erupted in 1998. On Christmas Eve, 1999, a military coup overthrew Konan Bédié and called to power Robert Gueï, the chief of the army under Houphouët, whom Konan Bédié had forced into retirement in 1997. This event inaugurated a period of erratic civil conflict, punctuated by intermittent episodes of hard political violence.

\subsubsection{The Elephant Falling Down: 1998-2002}

General Robert Gueï committed to organizing elections, first declared he would not present himself, then changed his mind. Ouattara's candidature was again barred by the new 2000 Constitution and Konan Bédié was exiled to Ghana, so that only Laurent Gbagbo and Robert Gueï competed in the 2000 elections. Turnout was very low at 37 per cent. Yet Gueï was defeated and ousted from power by street demonstrations by Gbagbo partisans; he was later assassinated in Abidjan after the coup attempts of 2002. Political violence reached a peak as fights also arose between Ouattara and Gbagbo followers-in particular, a mass grave was found in the outskirts of Abidjan (Yopougon). The long-term opponent of Félix Houphouët-Boigny then became the third president of the Ivorian Republic. Gbagbo quickly endorsed the topic of 'Ivoirité', trying to build an alliance of Southern 'autochthons' (Krus of the Southwest, non-Baule Akans of the Southeast), orthogonal to the Houphouettian alliance, based on long-lasting resentments dating from the colonial and early post-colonial times (Dozon 2011).

Liberalization had not reduced corruption, nor increased fair competition in markets, as it was not accompanied by progress in the enforcement of the law (Cogneau and Mesplé-Somps 2002a, 2002b). No export diversification took place. Besides, following the liberalization of the marketing of coffee, producer prices collapsed. Foreign aid was cut following the military coup, resulting in public and private investment collapse. At the same time, public wages were increased by 15 per cent over the period, perhaps to buy loyalty from civil servants and the military in times when political legitimacy was undermined. 
Over the period 1998-2002, national accounts data on final consumption stagnated in per capita terms, while our survey aggregate increased by a small 6 per cent, from 2.31 to 2.47 (2005 international dollars per capita per day). Despite this sluggish growth, the poverty headcount increased by three percentage points, from 32 to 35 per cent. The consumption growth incidence was indeed strongly anti-redistributive and urban-biased (Table 14.4 and Figure 14.5). Coffee producers, food crop farmers, and the poorest informal

Table 14.3. Poverty measures in households headed by a farmer

\begin{tabular}{|c|c|c|c|c|c|}
\hline & 1988 & 1993 & 1998 & 2002 & 2008 \\
\hline \multicolumn{6}{|c|}{ Panel A: Cocoa and coffee farmers } \\
\hline Consumption per capita & $\begin{array}{c}2.14 \\
(0.06)\end{array}$ & $\begin{array}{c}1.51 \\
(0.02)\end{array}$ & $\begin{array}{c}1.66 \\
(0.05)\end{array}$ & $\begin{array}{c}1.60 \\
(0.03)\end{array}$ & $\begin{array}{c}1.46 \\
(0.03)\end{array}$ \\
\hline Poverty headcount & $\begin{array}{c}0.24 \\
(0.02)\end{array}$ & $\begin{array}{c}0.49 \\
(0.01)\end{array}$ & $\begin{array}{c}0.47 \\
(0.02)\end{array}$ & $\begin{array}{c}0.52 \\
(0.01)\end{array}$ & $\begin{array}{c}0.53 \\
(0.01)\end{array}$ \\
\hline $\mathrm{N}$ & 476 & 2,147 & 953 & 2,206 & 2,015 \\
\hline \multicolumn{6}{|l|}{ Panel B: Cotton farmers } \\
\hline Consumption per capita & $\begin{array}{c}1.47 \\
(0.10)\end{array}$ & $\begin{array}{c}1.35 \\
(0.04)\end{array}$ & $\begin{array}{c}1.32 \\
(0.08)\end{array}$ & $\begin{array}{c}2.22 \\
(0.46)\end{array}$ & $\begin{array}{c}1.20 \\
(0.16)\end{array}$ \\
\hline Poverty headcount & $\begin{array}{c}0.56 \\
(0.05)\end{array}$ & $\begin{array}{c}0.54 \\
(0.02)\end{array}$ & $\begin{array}{c}0.64 \\
(0.03)\end{array}$ & $\begin{array}{c}0.50 \\
(0.03)\end{array}$ & $\begin{array}{c}0.76 \\
(0.04)\end{array}$ \\
\hline $\mathrm{N}$ & 113 & 398 & 206 & 387 & 136 \\
\hline \multicolumn{6}{|l|}{ Panel C: Other farmers } \\
\hline Consumption per capita & $\begin{array}{c}1.98 \\
(0.15)\end{array}$ & $\begin{array}{c}1.38 \\
(0.03)\end{array}$ & $\begin{array}{c}1.91 \\
(0.14)\end{array}$ & $\begin{array}{c}1.65 \\
(0.03)\end{array}$ & $\begin{array}{c}1.33 \\
(0.03)\end{array}$ \\
\hline Poverty headcount & $\begin{array}{c}0.23 \\
(0.03)\end{array}$ & $\begin{array}{c}0.58 \\
(0.01)\end{array}$ & $\begin{array}{c}0.43 \\
(0.02)\end{array}$ & $\begin{array}{c}0.50 \\
(0.01)\end{array}$ & $\begin{array}{c}0.64 \\
(0.01)\end{array}$ \\
\hline $\mathrm{N}$ & 211 & 1,732 & 749 & 2,151 & 2,524 \\
\hline \multicolumn{6}{|l|}{ Panel D: All farmers } \\
\hline Consumption per capita & $\begin{array}{c}1.99 \\
(0.05)\end{array}$ & $\begin{array}{c}1.45 \\
(0.02)\end{array}$ & $\begin{array}{c}1.69 \\
(0.06)\end{array}$ & $\begin{array}{c}1.67 \\
(0.05)\end{array}$ & $\begin{array}{c}1.39 \\
(0.02)\end{array}$ \\
\hline Poverty headcount & $\begin{array}{c}0.30 \\
(0.02)\end{array}$ & $\begin{array}{c}0.52 \\
(0.01)\end{array}$ & $\begin{array}{c}0.48 \\
(0.01)\end{array}$ & $\begin{array}{c}0.51 \\
(0.01)\end{array}$ & $\begin{array}{c}0.59 \\
(0.01)\end{array}$ \\
\hline $\mathrm{N}$ & 800 & 4,277 & 1,908 & 4,744 & 4,675 \\
\hline
\end{tabular}

Note: Daily consumption expenditures per capita are in constant 2005 US\$ PPP and the poverty line used is US $\$ 1.25$ PPP a day. Standard errors in parentheses.

Source: Authors' calculation based on data from CILSS 4 and ENV1-4 household surveys

Table 14.4. Decomposition of changes in poverty headcount, 1988-2008

\begin{tabular}{lrrrr}
\hline & $1988-93$ & $1993-8$ & $1998-2002$ & $2002-8$ \\
\hline Changes in poverty headcount & 18.26 & -6.06 & 3.38 & 5.64 \\
Growth & 20.81 & -8.45 & -3.72 & 6.72 \\
Redistribution & -0.41 & 2.35 & 6.86 & -2.36 \\
Residual & -2.14 & 0.04 & 0.24 & 1.27 \\
\hline
\end{tabular}

Note: The poverty line is set at 2005 US $\$ 1.25$ PPP per day.

Source: Authors' calculation based on data from CILSS 4 and ENV1-4 household surveys 
workers lost, while skilled civil servants gained (Tables 14.2 and 14.3). In the North, very good cotton yields (Appendix Figure 14.A2 and Table 14.2 Panel C) also very much reduced poverty in this area. Could it be that this sudden inflow of income helped the rebels to arm themselves?

\subsubsection{A Country Split in Two: 2002-8}

In September 2002, military insurgents made coup attempts in the main cities of Abidjan, Bouake, and Korhogo, and invaded the North of the country. They were rising up from within the country and also coming from Southern Burkina Faso and Mali where they had organized and trained; two other movements also crossed the border of Liberia and took control of the cities of Man and Odienne in the Northwest. The UN mandated French and Economic Community of West African States (ECOWAS) troops to interpose between rebels and loyalists. In January 2003, the belligerents signed the Marcoussis agreement according to which a 'national union government' had to be formed, with the Ministries of Defence and of the Interior given to rebel representatives, and the participation of all political parties. The agreement failed, as members of the coalition withdrew or were dismissed. Another reconciliation meeting was organized in Accra in June 2003, according to which Laurent Gbagbo was expected to prepare new presidential elections while also changing the eligibility conditions that were barring the candidature of Ouattara. The country remained split in two, with French, ECOWAS, and UN troops seated along an East-West interposition line. In November 2004, loyalist planes bombed Bouake and French troops that had settled in the airport; French planes retaliated and destroyed the Ivorian airforce. Gbagbo's partisans then held large street demonstrations and began attacking French citizens, whom French forces tried to evacuate; the Ivorian and French governments blamed each other for murders committed during these days. Some French, Lebanese, and other foreigners left the country towards the end of 2004. Thabo Mbeki, the president of South Africa, was then mandated by the African Union to act as a mediator. Under strong international pressure, a change in the constitution was finally adopted at the beginning of 2005 , allowing the candidature of Alassane Ouattara in future presidential elections. A political 'détente' process ensued, which resulted in the Ouagadougou agreements that were signed in March 2007, and the nomination of Guillaume Soro, head of the rebels, as prime minister. Presidential elections were, however, delayed every year until 2010.

Figure 14.6 presents the timeline of these events, along with the Armed Conflict Location and Event Data Project's (ACLED) count of political violence. It illustrates that the two household surveys we use, carried out in 2002 and 2008, lie at the two ends of this second phase of the civil war. The ENV3 


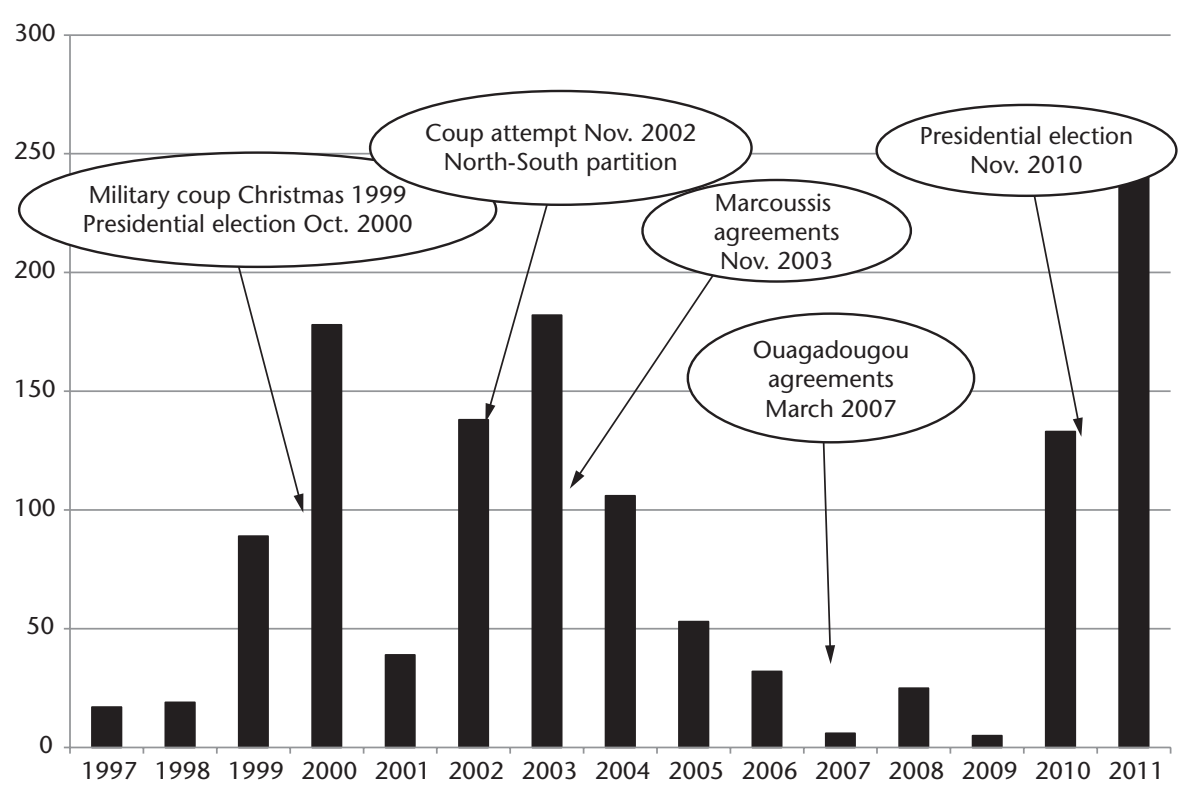

Figure 14.6. Civil conflict

Note: Number of political violence events, 1997-2011. Political violence events reported are violence against civilians that occurs during civil and communal conflicts, battles, and riots or protests. Source: Authors' elaboration based on data from ACLED (2013)

2002 survey was implemented between May and July, hence just before the September rebellion, while the ENV4 2008 (June-August 2008) came after the Ouagadougou agreements had brought some peace to the country.

Between 2002 and 2008, national accounts of consumption per capita fell by 11 per cent, and rather consistently the household survey mean dropped by 13 per cent. According to our estimates, the national poverty headcount increased by six percentage points, from 35 to 41 per cent, i.e. the highest figure ever recorded over the past two decades, and most likely even before that: GDP per capita fell below the level of 600 dollars (constant 2000 US\$), as it had done in 1993, falling back to the level of the early 1960s. Very strikingly, the Northern areas that were cut from the 'legal country' suffered a lot economically: the poverty headcount increased by twenty-two percentage points, skyrocketing to 62 per cent. Cotton production collapsed; as of 2008, only 1 per cent of households were still growing this crop; aggregate figures suggest that cotton production only started its recovery in 2010-11 (Appendix Figure 14.A2). Other areas instead experienced little change in poverty, or in the case of East Forest, a limited increase, so that the bulk of poverty increase stemmed from the impact of the partition on the North. 


\subsubsection{The Last Episode of Civil War (2008-11)}

Presidential elections were finally organized at the end of 2010. The two former heirs of Houphouët-Boigny, who had been enemies throughout the 1990s, Konan Bédié and Ouattara, formed an alliance against Gbagbo, and hence reconstructed the Centre-North alliance of the past. Alassane Ouattara opposed Laurent Gbagbo in the second round, and both candidates claimed victory. A last episode of civil war erupted, causing the deaths of between 900 and 3,000 and the displacement of 1 million people (IDMC 2012). With support from French troops, the incumbent Laurent Gbagbo was arrested in his palace in April 2011 and presented to the International Court of Justice in The Hague in December. Since 2012, progress towards national reconciliation has been limited. The Commission for Dialogue, Truth, and Reconciliation, launched in July 2011, has been criticized for its slowness and partiality: to date, only crimes by Gbagbo supporters have been judged, while Ouattara's partisans also committed reprehensible acts of violence. Whereas the most influential leaders of Gbagbo's political party (the Ivorian Popular Front (FPI)) went into exile in Ghana, the FPI refused to participate in any official reconciliation committee and boycotted the municipal elections of April 2013. Security in the country depends on the reintegration into civil society of thousands of former members of armed militia. On the economic side, Ouattara's government benefits from the strong support of international donors: a substantial reduction in external debt stock was obtained, and budget support of around 7 per cent of GDP has been received each year since 2011. After limited growth in 2010 ( 2 per cent), and a fall of 5 per cent in 2011, growth in 2012 was estimated at around 8.6 per cent (IMF 2012). This quick recovery is the result of public reconstruction programmes and the revival of formal economic activities.

After around two decades of political and economic turmoil, from the mid1960s to the mid-1980s, it took some time for neighbouring Ghana to finally reconstruct a stable democracy and a buoyant economy, at the turn of the twenty-first century (Eberhardt and Teal 2010). In the case of Côte d'Ivoire, getting back to (political and economic) 'business as usual' will probably not be sufficient. In the short run, new rents from natural resources like oil or minerals could enable the restoration of the political and economic equilibrium of the old days, involving a cautious balance in the distribution of state resources: jobs and public investments. In the longer run, the burning issues that fuelled the conflict will have to be addressed, at the least, the acquisition of nationality and the regulation of land allocation. Further, in the context of the exhaustion of the 'rent' from the forest, the intensification of smallholder practices should become an urgent necessity, if only to enable preservation of the high level of cocoa output that still makes up the wealth of Côte d'Ivoire (Gockowski and Sonwa 2011). Dark predictions regarding the impact of 
climate change on the conditions for cocoa growing even suggest that shifting away from cocoa could become an obligation (Läderach 2011).

\subsection{Conclusion}

At the end of the 1980s, Côte d'Ivoire entered a deep macroeconomic crisis that put an end to the often-praised 'Ivorian miracle'. After the death of the founding father Houphouët-Boigny, unrestrained political competition was combined with bad economic conditions and led to the nightmare of civil war. Drawing from a series of five household surveys covering two decades (1988-2008), we have told the story of this descent into hell from the standpoint of poverty and living standards. Despite the bounce-back allowed by the CFA devaluation in 1994, the country could never recover from the initial shock created by the halving of cocoa producer prices and huge budget cuts. In 2008, after five years of civil war and with another episode yet to come (2010-11), the extreme US\$1.25 poverty headcount had reached a historical record for poverty, with Northern areas deeply impoverished by the partition of the country.

\section{Appendix}

Table 14.A1. School net attendance rates over time

\begin{tabular}{|c|c|c|c|c|c|}
\hline & 1988 & 1993 & 1998 & 2002 & 2008 \\
\hline \multicolumn{6}{|c|}{ Panel A: Primary school ${ }^{\mathrm{a}}$} \\
\hline Girls & $\begin{array}{c}0.48 \\
(0.02)\end{array}$ & $\begin{array}{c}0.42 \\
(0.01)\end{array}$ & $\begin{array}{c}0.51 \\
(0.01)\end{array}$ & $\begin{array}{c}0.55 \\
(0.01)\end{array}$ & $\begin{array}{c}0.56 \\
(0.01)\end{array}$ \\
\hline Boys & $\begin{array}{c}0.64 \\
(0.01)\end{array}$ & $\begin{array}{c}0.51 \\
(0.01)\end{array}$ & $\begin{array}{c}0.58 \\
(0.01)\end{array}$ & $\begin{array}{c}0.63 \\
(0.01)\end{array}$ & $\begin{array}{c}0.62 \\
(0.01)\end{array}$ \\
\hline Net rate & $\begin{array}{c}0.56 \\
(0.01)\end{array}$ & $\begin{array}{c}0.47 \\
(0.00)\end{array}$ & $\begin{array}{c}0.54 \\
(0.01)\end{array}$ & $\begin{array}{c}0.59 \\
(0.00)\end{array}$ & $\begin{array}{c}0.59 \\
(0.01)\end{array}$ \\
\hline $\mathrm{N}$ & 1,985 & 11,439 & 4,504 & 9,980 & 9,479 \\
\hline \multicolumn{6}{|c|}{ Panel B: Secondary school ${ }^{\mathrm{b}}$} \\
\hline Girls & $\begin{array}{c}0.10 \\
(0.01)\end{array}$ & $\begin{array}{c}0.12 \\
(0.00)\end{array}$ & $\begin{array}{c}0.16 \\
(0.01)\end{array}$ & $\begin{array}{c}0.16 \\
(0.01)\end{array}$ & $\begin{array}{c}0.21 \\
(0.01)\end{array}$ \\
\hline Boys & $\begin{array}{c}0.17 \\
(0.01)\end{array}$ & $\begin{array}{c}0.22 \\
(0.01)\end{array}$ & $\begin{array}{c}0.26 \\
(0.01)\end{array}$ & $\begin{array}{c}0.22 \\
(0.01)\end{array}$ & $\begin{array}{c}0.29 \\
(0.01)\end{array}$ \\
\hline Net Rate & $\begin{array}{c}0.14 \\
(0.01)\end{array}$ & $\begin{array}{c}0.17 \\
(0.00)\end{array}$ & $\begin{array}{c}0.21 \\
(0.01)\end{array}$ & $\begin{array}{c}0.19 \\
(0.00)\end{array}$ & $\begin{array}{c}0.25 \\
(0.00)\end{array}$ \\
\hline $\mathrm{N}$ & 1,550 & 10,399 & 4,443 & 9,892 & 9,231 \\
\hline
\end{tabular}

Note: Attendance rate is estimated using the highest grade completed at the time of the survey. ${ }^{\text {a }}$ The sample is restricted to children aged 6-11 years at the time of the survey. ${ }^{\mathrm{b}}$ The sample is restricted to children aged 12-18 years at the time of the survey.

Source: Authors' calculation based on data from CILSS 4 and ENV1-4 household surveys 
Table 14.A2. Durable goods ownership

\begin{tabular}{|c|c|c|c|c|c|}
\hline & 1988 & 1993 & 1998 & 2002 & 2008 \\
\hline \multicolumn{6}{|l|}{ Panel A: National } \\
\hline Cooker & 10.7 & 10.0 & 11.8 & 13.9 & 14.4 \\
\hline Fridge & 20.7 & 18.1 & 18.4 & 17.0 & 15.6 \\
\hline Radio & 57.8 & 60.0 & 64.6 & 67.4 & 74.7 \\
\hline TV & 26.7 & 29.2 & 31.1 & 34.9 & 45.3 \\
\hline Bike or motorbike & 35.6 & 33.7 & 33.5 & 35.6 & 53.2 \\
\hline Car & 4.6 & 5.2 & 4.7 & 5.8 & 3.4 \\
\hline Phone & & & 6.5 & 20.0 & 65.5 \\
\hline \multicolumn{6}{|l|}{ Wealth score ${ }^{a}$} \\
\hline Mean & 1.6 & 1.6 & 1.6 & 1.7 & 2.1 \\
\hline Std. Dev. & 1.4 & 1.4 & 1.4 & 1.4 & 1.1 \\
\hline $\mathrm{N}$ & 1,600 & 9,599 & 4,200 & 10,800 & 10,958 \\
\hline \multicolumn{6}{|c|}{ Panel B: Urban areas } \\
\hline Cooker & 25.1 & 21.2 & 22.0 & 30.4 & 30.8 \\
\hline Fridge & 45.1 & 37.6 & 32.7 & 34.3 & 29.8 \\
\hline Radio & 71.3 & 76.8 & 69.9 & 75.0 & 74.9 \\
\hline TV & 57.2 & 57.2 & 52.9 & 61.3 & 73.9 \\
\hline Bike or motorbike & 17.8 & 20.1 & 18.7 & 20.1 & 26.0 \\
\hline Car & 10.6 & 10.4 & 8.5 & 11.9 & 6.7 \\
\hline Phone & & & 13.0 & 41.8 & 89.4 \\
\hline \multicolumn{6}{|l|}{ Wealth score ${ }^{a}$} \\
\hline Mean & 2.3 & 2.2 & 2.0 & 2.3 & 2.4 \\
\hline Std. Dev. & 1.6 & 1.5 & 1.6 & 1.5 & 1.3 \\
\hline $\mathrm{N}$ & 736 & 5,360 & 1,919 & 4,980 & 6,119 \\
\hline \multicolumn{6}{|l|}{ Panel C: Rural areas } \\
\hline Cooker & 1.6 & 1.4 & 3.6 & 1.4 & 1.6 \\
\hline Fridge & 5.2 & 3.3 & 6.8 & 3.9 & 4.5 \\
\hline Radio & 49.3 & 47.2 & 60.3 & 61.6 & 74.5 \\
\hline TV & 7.5 & 8.1 & 13.3 & 14.9 & 23.0 \\
\hline Bike or motorbike & 46.9 & 43.9 & 45.5 & 47.4 & 74.4 \\
\hline Car & 0.8 & 1.3 & 1.6 & 1.1 & 0.8 \\
\hline Phone & & & 1.1 & 3.4 & 46.8 \\
\hline \multicolumn{6}{|l|}{ Wealth score ${ }^{a}$} \\
\hline Mean & 1.1 & 1.1 & 1.3 & 1.3 & 1.8 \\
\hline Std. Dev. & 1.0 & 1.0 & 1.1 & 1.0 & 0.9 \\
\hline $\mathrm{N}$ & 864 & 4,239 & 2,280 & 5,820 & 4,839 \\
\hline
\end{tabular}

Note: Share of individuals living in a household with at least one of the durable goods listed.

a Wealth score: Sum of cooker, fridge, radio, TV, bike, motorbike, and car per capita

Source: Authors' calculation based on data from CILSS 4 and ENV1-4 household surveys 


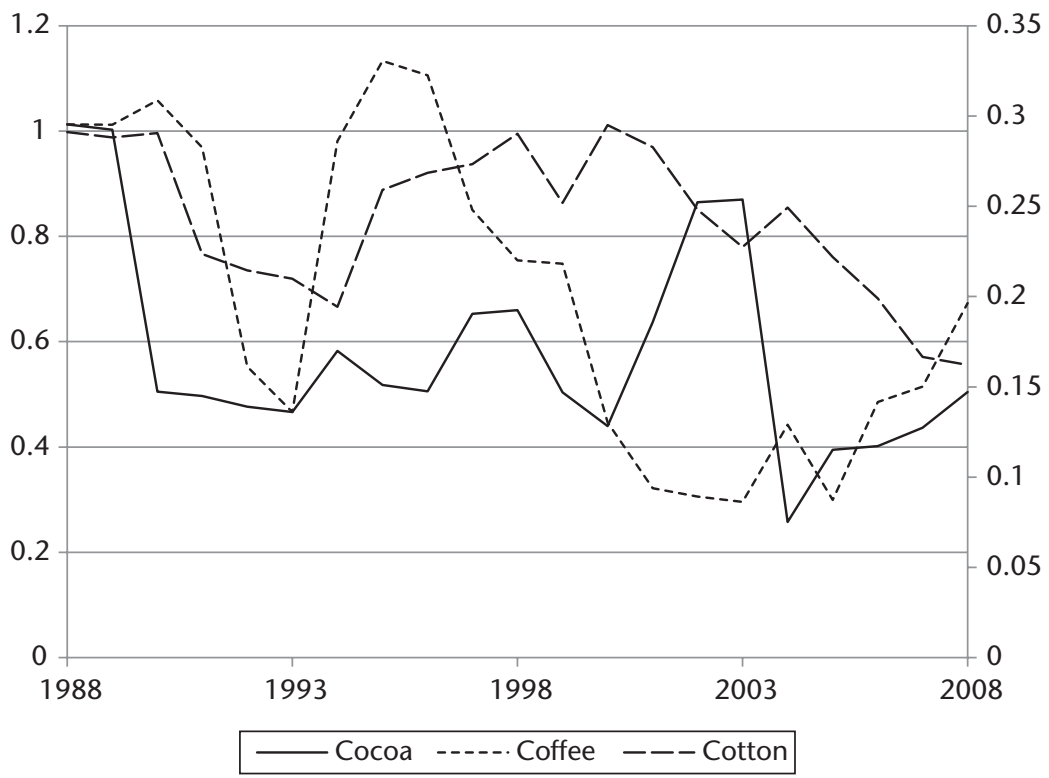

Figure 14.A1. Real producer prices for cash crops

Note: Real producer prices: nominal producer prices deflated by consumer price index and converted in 2000 US\$. Cocoa and coffee prices on left scale, cotton prices on right scale (2000 US\$ per kilogram).

Source: Authors' elaboration based on data from World Bank (2012) and FAOSTAT (2012)

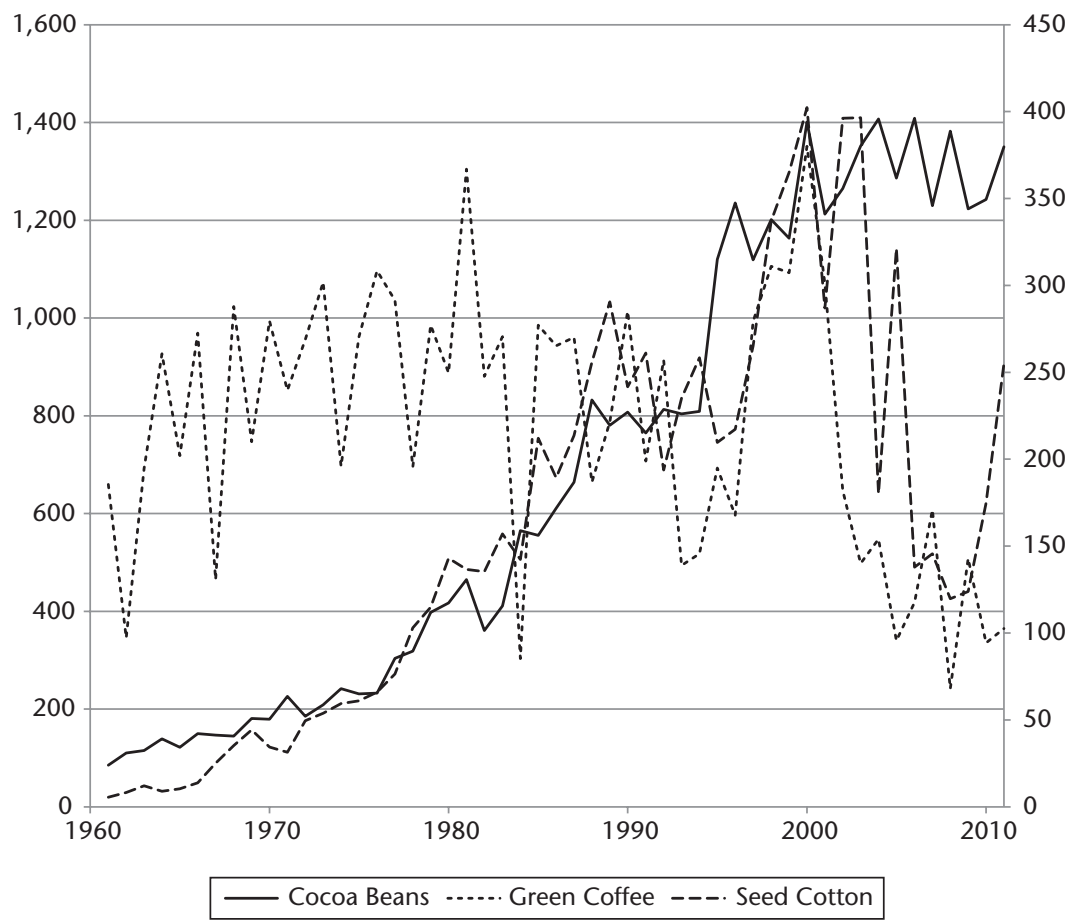

Figure 14.A2. Cocoa, coffee, and cotton output

Note: Output in thousands of tons. Cocoa on left scale, coffee and cotton on right scale. Source: Authors' elaboration based on data from FAOSTAT (2012) 


\section{Acknowledgements}

We thank Siriki Coulibaly (Afristat) and Jonas Yao N'Dri (Institut National de la Statistique-Côte d'Ivoire) for their contributions to this study. We thank the National Institute of Côte d'Ivoire for giving us access to the survey data. We also thank workshop participants at UNU-WIDER, especially Channing Arndt, Michael Grimm, Murray Leibbrandt, Andy McKay, and James Thurlow. The usual disclaimer applies.

\section{References}

ACLED (2013). 'Armed Conflict Location and Event Dataset'. Available at <http://www. acleddata.com/data/africa/>, accessed June 2013.

Beegle, K., J. De Weerdt, J. Friedman, and J. Gibson (2012). 'Methods of Household Consumption Measurement through Surveys: Experimental Results from Tanzania', Journal of Development Economics, 98(1): 3-18.

Berthélemy, J.-C., and F. Bourguignon (1996). Growth and Crisis in Côte d'Ivoire. Washington, DC: World Bank.

Boone, C. (2007). 'Africa's New Territorial Politics: Regionalism and the Open Economy in Côte d'Ivoire', African Studies Review, 50(1): 59-81.

Chauveau, J.-P. (2010). 'La loi de 1998 sur le domaine rural dans l’histoire des politiques foncières en Côte d'Ivoire: Une économie politique des transferts de droits entre "autochtones" et "étrangers" en zone forestière', in J.-P. Colin, P.-Y. Le Meur, and E. Léonard (eds), Les politiques d'enregistrement des droits fonciers: Du cadre légal aux pratiques locales. Paris: Karthala, 105-40.

Cogneau, D. and G. Collange (1998). 'Les effets à moyen terme de la dévaluation des FCFA: Une comparaison Cameroun/Côte d'Ivoire', Revue d'Économie du Développement, 3-4 (December): 125-47.

Cogneau, D. and M. Grimm (2008). 'The Impact of AIDS Mortality on the Distribution of Income in Côte d'Ivoire', Journal of African Economies, 17(5): 688-728.

Cogneau, D., K. Houngbedji, and S. Mesplé-Somps (2014). 'The Fall of the Elephant: Two Decades of Poverty Increase in Côte d'Ivoire (1988-2008)', UN-WIDER WP/ 2014/144.

Cogneau, D. and R. Jedwab (2012). 'Commodity Price Shocks and Child Outcomes: The 1990 Cocoa Crisis in Côte d'Ivoire', Economic Development and Cultural Change, 60(3): 507-34.

Cogneau, D. and S. Mesplé-Somps (2002a). 'Les illusions perdues de l'économie ivoirienne et la crise politique', Afrique Contemporaine, 206: 87-104.

Cogneau, D. and S. Mesplé-Somps (2002b). 'L'économie ivoirienne, la fin du mirage?', DIAL Document de travail 2002/18. Paris: DIAL.

Cogneau, D., S. Mesplé-Somps, and G. Spielvogel (2015). 'Development at the Border: Economic Integration in Côte d'Ivoire and its Neighbors', World Bank Economic Review, 29(1): 41-71. 
Cogneau, D. and A. Moradi (2014). 'Borders that Divide: Education and Religion in Ghana and Togo since Colonial Times', Journal of Economic History, 74(3): 694-728.

Cogneau, D. and L. Rouanet (2011). 'Living Conditions in Côte d'Ivoire and Ghana, 1925-1985: What Do Survey Data on Height Stature Tell Us?', Economic History of Developing Regions, 26(2): 55-82.

Coulibaly, S. Z. and J. Yao N'Dri (2012). 'Evolution de la situation nutritionnelle en Côte d'Ivoire de 1994 à 2012, à partir des données des enquêtes démographiques et de santé'. Mimeo. Mali: Afristat.

Dabalen, A. L. and S. Paul (2013). 'Recovering Comparable Poverty Estimates in Côte d'Ivoire', Journal of Development Studies, 49(10): 1412-26.

Dozon, J.-P. (2011). Les clefs de la crise ivoirienne. Paris: Karthala.

Eberhardt, M. and F. Teal (2010). 'Ghana and Côte d'Ivoire: Changing Places', Revue Internationale de Politique de Développement, 1: 33-49.

FAOSTAT (2012). Food and Agriculture Organization of the United Nations, Statistics Division, <http://faostat3.fao.org/home/index.html>, accessed December 2012.

Fogel, R. W. (1994). 'Economic Growth, Population Theory and Physiology: The Bearing of Long-Term Processes on the Making of Economic Policy', American Economic Review, 84(3): 369-95.

Gockowski, J. and D. Sonwa (2011). 'Cocoa Intensification Scenarios and their Predicted Impact on $\mathrm{CO}_{2}$ Emissions, Biodiversity Conservation, and Rural Livelihoods in the Guinea Rain Forest of West Africa', Environmental Management, 48: 307-21.

Huillery, E. (2009). 'History Matters: The Long-Term Impact of Colonial Public Investments in French West Africa', American Economic Journal: Applied Economics, 1(2): 176-215.

IDMC (2012). 'Côte d'Ivoire: Les personnes déplacées à l'intérieur de leur propre pays tentent de refaire leur vie sur fond de paix fragile', <www.internal-displacement. org/assets/library/Africa/Cote-dIvoire/pdf/201211-af-cotedivoire-overview-fr.pdf>, accessed June 2012.

IMF (2012). 'Côte d'Ivoire: Second Review under the Three-Year Arrangement under the Extended Credit Facility, Request for Modification of Performance Criteria, and Financing Assurances Review-Staff Report', IMF Country Report 12/332. Washington, DC: International Monetary Fund.

IMF (2013). World Economic and Financial Surveys: World Economic Outlook Database. Available at <http://www.imf.org/external/pubs/ft/weo/2013/02/weodata/ index.aspx>, accessed June 2012.

Jedwab, R. (2011). 'Why Is African Urbanization Different? Evidence from Resource Exports in Ghana and Ivory Coast'. Unpublished, Paris School of Economics.

Jones, B. and B. Olken (2005). 'Do Leaders Matter? National Leadership and Growth since World War II', Quarterly Journal of Economics, 120(3): 835-64.

Läderach, P. (2011). 'Predicting the Impact of Climate Change on the CocoaGrowing Regions in Ghana and Cote d'Ivoire'. Report for the Bill and Melinda 
Gates Foundation. Managua, Nicaragua: International Center for Tropical Agriculture (CIAT).

Tapinos, G., P. Hugon, and P. Vimard (eds) (2002). La Côte d'Ivoire à l'aube du XXIème siècle. Paris: Karthala.

World Bank (2008). 'African Development Indicators'. Washington, DC: World Bank. World Bank (2012). 'World Development Indicators'. Washington, DC: World Bank. 


\section{5}

\section{Incomes, Inequality, and Poverty in Kenya}

\section{A Long-Term Perspective}

Arne Bigsten, Damiano Kulundu Manda, Germano Mwabu, and Anthony Wambugu

\subsection{Introduction}

This study aims to provide consistent estimates of what has happened to national income, inequality, and poverty in Kenya over time, and to explain why they evolved in the way they did. The primary focus is on the most recent period for which we have household survey data, but first we review (in section 15.2) the evidence on long-term changes in inequality and poverty in Kenya. In section 15.3 we discuss the problems of measuring income changes. We present evidence on changes in incomes, employment, and economic structure in section 15.4 , and on poverty and inequality in section 15.5 . In section 15.6 we discuss policy challenges and in section 15.7 we conclude.

\subsection{The Evolution of Kenyan Incomes, Inequality, and Poverty during the Twentieth Century}

One can distinguish four types of determinants of changes in the structure of production and incomes. These are, first, changes in the factor endowments of the economy. The key to growth is capital deepening, which will occur if there is a high rate of investment in people and machinery. Second, there are the effects of changes in output prices. The domestic prices of tradeable commodities are largely exogenous, but they are also affected by government interventions. Third, technical progress is important for growth and leads to higher 
factor rewards. Finally, changes in the level of distortions or government policies affect factor prices and thus incomes.

During the twentieth century, there were dramatic changes in the structure of Kenya's economy and in the sectorial allocation of labour. Kenya started out with almost the whole of its labour force in agriculture and related activities; but a century later more than half of the labour force is in formal or informal non-agricultural activities. There has been an even more drastic shift in the structure of output. The share of agriculture in gross domestic product (GDP) has fallen from above three-quarters to about a quarter. This structural transformation has driven the changes in incomes, income distribution, and poverty.

\subsubsection{The Period up to the First World War}

Until the arrival of the British colonialists at the end of the nineteenth century, the Kenyan inland was little integrated with the outside world, while there were long-distance trading activities along the coast. The inland households were pastoralists, settled farmers, small craftsmen, or traders, but generally there was limited specialization. Individuals had generally enough land to ensure a standard of living roughly comparable to that of the other members of the community; regional differences in welfare levels that are so conspicuous today were small.

With the completion of the railway in 1901, the inland was opened up to trade and settlement. The railway construction was undertaken by Indian workers, and about 6,500 remained in the country. The majority set up small commercial stores, while some took up intermediate-level positions in private industry or the public sector. A rapid increase in the numbers of Asians and Europeans followed in the colony. By 1914 there had already been a considerable expansion of formal wage employment (Bigsten 1984). Another category of workers was engaged in settler agriculture, either as squatters or as contract labour. A class of African traders and businessmen emerged. This group was engaged in stock trading, maize milling, butchering, the selling of food and drink, and small-scale retail trade (Kitching 1980). Finally, the period before and during the First World War also saw an expansion of cash crop production on African farms and an increase in the cultivated area. The increasing differentiation in agricultural activities started to increase income inequality.

\subsubsection{The Interwar Period}

By the First World War, pass laws had been introduced, and in the highlands the Africans could only work as contract or resident labour. The measures were 
instituted to increase the supply of African labour, since the Europeans were unwilling to pay competitive wages. By restricting the scope for development on the African farms, the supply price of labour was reduced, and through various forms of coercion and through hut and poll taxes the Africans were made to work for still less. Asians were not allowed to own land, and Africans were not allowed to grow a number of cash crops.

By the mid-1920s, a three-class society had been established along racial lines, with whites monopolizing export crop agriculture, the higher administrative posts, and the professions; the Asians trade, commerce, and the middle reaches of the bureaucracy; and the Africans left with unskilled wage employment, smallholder farming, petty trade at the village level, and the lower-level clerical posts in the administration (Collier and Lal 1986: 38). Still, African cash crop agriculture expanded in spite of the restrictions imposed by the government, and there was a growing domestic market for food crops.

Like other countries, Kenya was hit hard by the Depression of 1929. Since most of the produce of the settlers went for export, several estates went bankrupt, although many were saved by loans from the colonial government. The squatters could supplement their income by production on their own plots, but their standard of living deteriorated for a few years. When the effects of the Depression receded, employment started to increase again. The economic decline during the Depression meant that the major market for African food crops was curtailed, but African agriculture acreage still expanded during the 1930s. The process of commercialization of African agriculture continued and it accelerated during the Second World War. The labour movements also gained in importance (Bigsten 1984).

Inequality among African smallholders increased, and the major differentiating factor was access to land. Those who had large landholdings in areas where cash crops could be produced improved their relative position. Ruralurban differences in living standards emerged; a rural elite was buying up land for commercial farming (Kitching 1980), and an African trade and business class was established. The most rapidly changing regions in the country were Central and Nyanza provinces. During the Second World War, agriculturalists as well as traders made considerable profits. Obviously, Europeans and Asians still dominated commerce and industry, but African businessmen and traders were making noticeable progress.

\subsubsection{The Post-War Period, 1945-63}

After the Second World War, wage employment was quite extensive, but much of it was still of a temporary nature. Labour migration was very common, and African wage employment increased rapidly in the 1950s. The 
growth of agricultural employment in the 1950s reflected an increase in labour demand due to rising producer prices and switches to new crops such as tea and pyrethrum. The government also changed its policy towards African small farmers, who were now allowed to grow coffee. During the period 1960-7, employment in modern agriculture fell because of the breaking up of estates, which reduced demand for agricultural wage labour. Nonagricultural employment declined in the run-up to independence due to rapid increases in real wages, which among other things were due to government efforts to increase minimum wages.

During the 1940s there was a considerable gap between agricultural and non-agricultural wages, but this was to some extent offset by higher costs of living and fewer opportunities in urban areas for supplementing wage incomes with farm incomes. The gap increased rapidly during the 1950s. Real wages in agriculture rose rapidly in the 1960s due to increasing commercialization of agriculture, but non-agricultural real wages increased even faster. Thus, during the 1950s and 1960s the gap between agricultural and nonagricultural wages increased dramatically.

\subsubsection{The First Post-Independence Period, 1963-76}

The coming of independence in Kenya in 1963 implied a change in the interracial distribution of both political power and incomes. The income structure change was limited, but employment was no longer as systematically racially segregated.

With the coming of independence there was a great need for qualified manpower in the public sector. To satisfy this need the public sector increased its relative wages dramatically. Between 1963 and 1965 public-sector real wages increased by 48 per cent, while they increased by a mere 6 per cent in the private sector (Collier and Lal 1986). In 1968 wages by skill were higher in the public sector than in the private sector, although private-sector wages started to increase rapidly from 1966. Another factor that continued to be of importance for income distribution during the first years of independence was the increase in minimum wages.

During the first decade after independence many smallholders experienced marked improvements, but there were significant differences among them. However, there remained a hard-core group of rural poor consisting of smallholders (a) with little land or with land of low potential; (b) with inadequate access to off-farm income or urban markets; or (c) who were reluctant to innovate. There were also landless workers and pastoralists with little or no education. 


\subsubsection{Economic Inequality and Poverty, 1914-76}

There were large changes in the collection of national statistics in the mid1970s; in particular, the racial breakdown of employment statistics was abandoned. Therefore we are forced to break this historical account of the Kenyan economy in 1976, and show how the income distribution in the country evolved between 1914 and 1976 (see Bigsten 1986 for a detailed presentation of the approach). ${ }^{1}$ The estimated growth rate for Kenya for the whole period, 1914 to 1976, was a respectable 5 per cent per year. The data for the pre-war period are very shaky, but for the period 1946-76, for which the database is better, the recorded growth rate is 6.6 per cent per year (compared to 3.7 per cent per year for the 1914-46 period). It therefore seems fairly safe to conclude that income growth in Kenya was quite high during the first three-quarters of the twentieth century.

During this period, the structure of incomes by source changed significantly (Figure 15.1). We see that smallholder agriculture declined in importance until 1950 , but then its share in incomes remained practically constant. The shares of wage earnings and operating surplus stayed around the level of 1960 until 1976. Structural change was thus not as dramatic in the 1960s and 1970s as it had been previously.

The income shares of different income groups depend on the number of people engaged in different activities and their income levels. The incomes of African businessmen and own-account workers grew very rapidly from independence. Agricultural wage employees had a very uneven increase in their wages, while the wage rates of African private employees increased rapidly from the Second World War until 1970, but then declined. There was a similar pattern for public employees, although their wages jumped immediately after independence and their real wages were more resistant during the 1970s.

The gap between African and Asian per capita incomes declined slowly until independence, but then increased again. The racial income gaps remained very large, although the relative European incomes were much higher in the colonial period. The level of the African per capita incomes increased with the most rapid increase during the 1950s and 1960s. During the period 1970-6,

\footnotetext{
1 The basic principle was to start from the national income estimate and then to disaggregate this by income groups by sector and race. After estimating the number of persons in each group, one estimated the average income of each group within which the income distribution was assumed to be lognormal. Information from available sources was then used to estimate the variance of incomes in each group. It was used to distribute income receivers around the mean income. Once this is done one could count the number of income receivers in each category with an annual income in a certain range. The Gini coefficients could then be derived for each group and any aggregation of groups. We should note that the Gini tends to become significantly higher by this approach than when estimated from household budget surveys. One reason is that capital income is more clearly accounted for and survey estimates use consumption instead of income, and the former tends to be more equally distributed.
} 


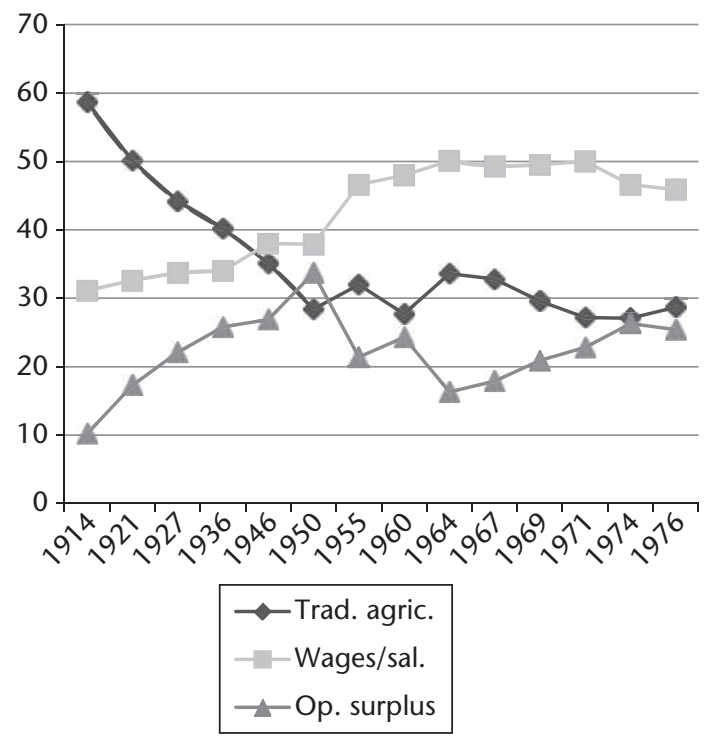

Figure 15.1. Incomes by source, per cent Source: Based on Bigsten (1986) data

the economic situation deteriorated and African per capita incomes declined. Still, the overall effect of these changed factor returns and in particular changes in the relative sizes of the three groups meant that the African share of incomes increased (see Figure 15.2). ${ }^{2}$ It has certainly continued to do so after 1976, but we have no data to analyse this breakdown beyond this time.

Overall inequality according to these estimates increased until 1950, then fluctuated and finally declined slightly during the 1970s (see Figure 15.3). Between 1950 and 1955 the Gini coefficient declined from 0.70 to 0.63 , while the variance within the thirteen income categories ${ }^{3}$ changed very little. The reason for the decline in inequality was that smallholder incomes increased at a higher rate than those of other groups. During 1955-60, overall inequality increased strongly again, while inequality both in the modern and the traditional sector changed very little. This was largely due to the fact that traditional (mainly smallholder agriculture) incomes fell to 17 per cent of modern incomes. Between 1960 and 1964, the modern-traditional gap again decreased and so did the Gini coefficient. The same pattern repeats itself for the whole period up to 1976 . When the modern-traditional gap increases,

\footnotetext{
2 The shares of Europeans and Asians in the labour force peaked around 1960 at 0.8 per cent and 1.6 per cent respectively. By 1976 their shares had declined to 0.2 per cent and 0.5 per cent.

3 The categories for Africans, Europeans, and Asians were self-employed, agricultural wage employees, non-agricultural wage employees, and public employees. The final category was African smallholders.
} 


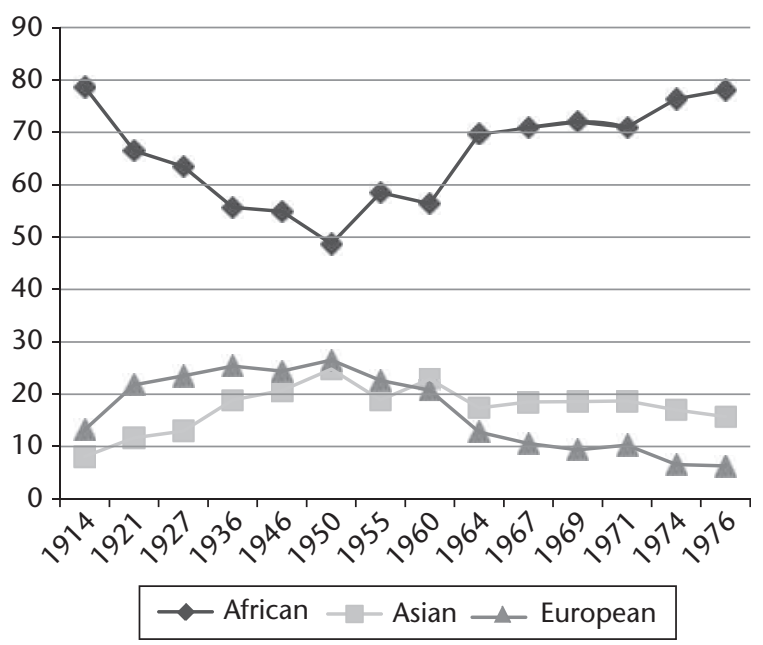

Figure 15.2. Percentage distribution of income by race Source: Based on Bigsten (1986) data

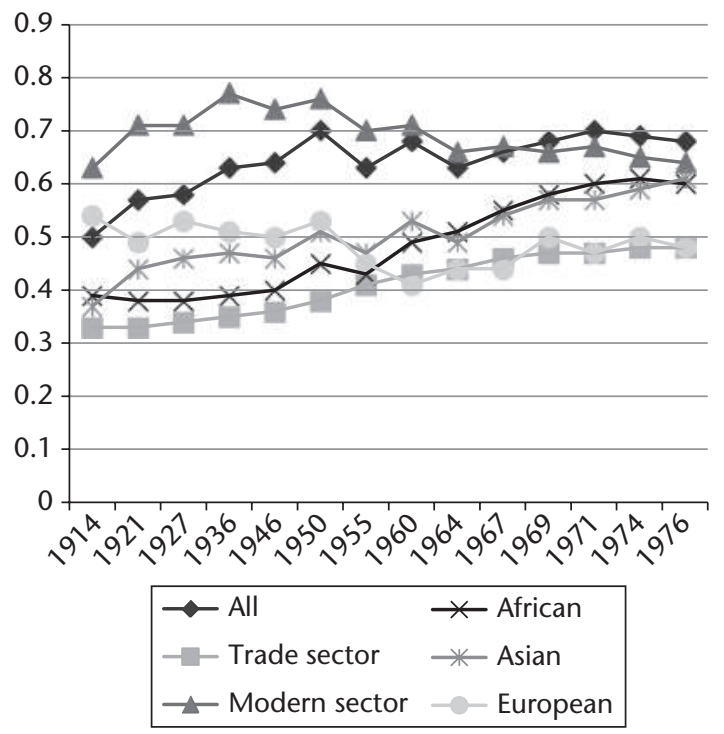

Figure 15.3. Gini coefficients, 1914-76

Source: Based on Bigsten (1986) data

the Gini coefficient goes up, and vice versa. Overall inequality increased between 1964 and 1971 and then fell between 1971 and 1976.

There was a long-term increase in inequality in the traditional (largely agricultural) sector. This is consistent with increased diversification within agriculture. When we consider the modern sector, the opposite pattern 


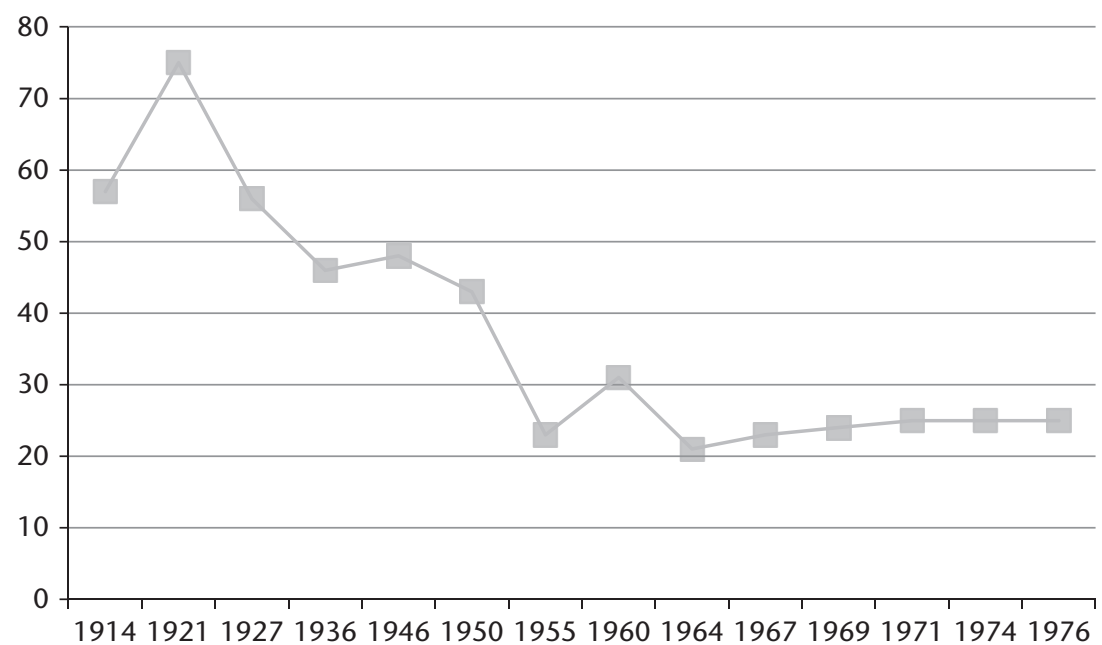

Figure 15.4. Income poverty in Kenya (Sen's Index), 1914-76 Source: Based on Bigsten (1986) data

emerges. Here inequality declined. This is consistent with the view of increasing integration and homogenization of the modern sector. The fact that we do not measure income by households here does, however, create a problem. Since many households have incomes from a variety of sources, the distribution over families might look somewhat different. The trends over time should, nevertheless, be reasonably well captured.

Overall inequality in Kenya thus increased until about 1950 and then stagnated at a high level. The result is similar, whether we use the modern versus traditional income gap or the Gini coefficient as our measure of inequality.

We can also look at the evolution of poverty. The regions with the highest poverty rates at the time are still the poorest today, suggesting that poverty can persist in a region or country for centuries. Figure 15.4 shows Sen's Poverty Index for Kenya over the period 1914-76. This index is essentially the headcount ratio weighted by two parameters, (a) the Gini for the poor and (b) the normalized poverty gap. We see that the income poverty rates as measured by Sen's Poverty Index are initially very high, but from 1950 income poverty declined for a short period before rising again and remaining nearly constant during the first decade of independence.

Bigsten (1986) argues that the sectorial inequality in incomes is a good proxy for inequality in the overall distribution of income among workers or individuals. This conclusion is confirmed by the correlation coefficient between the sectorial inequality and the Gini, which is as high as 0.70. Accordingly, the Gini is strongly negatively correlated with the narrowing of 
the income gap between rural (traditional) and urban (modern) sectors. As this gap increases, that is, as the low, rural incomes increase faster than the urban incomes (see Bigsten 1986), the Gini coefficient falls.

\subsubsection{Factor Incomes, 1964-2000}

During the first years after independence Kenya grew quite fast, but from the early 1970s, the country experienced increasing macroeconomic imbalances, which were not addressed effectively. In the beginning of the 1980s, the government embarked on a series of structural adjustment programmes. By 1993-4 it had achieved extensive trade liberalization, and the country became an open economy according to the criteria set up by Sachs and Warner (1995).

Bigsten and Durevall $(2006,2008)$ evaluated the role of endowments (capital, K; labour, L; and land, T) and openness for the evolution of relative factor prices from independence until 2000. Their estimates of factor endowment ratios, K/L, T/L, and $\mathrm{K} / \mathrm{T}$, are shown in Figure 15.5 . The $\mathrm{K} / \mathrm{L}$ ratio is very important for the pattern of specialization, the factor price outcomes, and incomes. We see that the ratio increased until 1982, but that the trend was

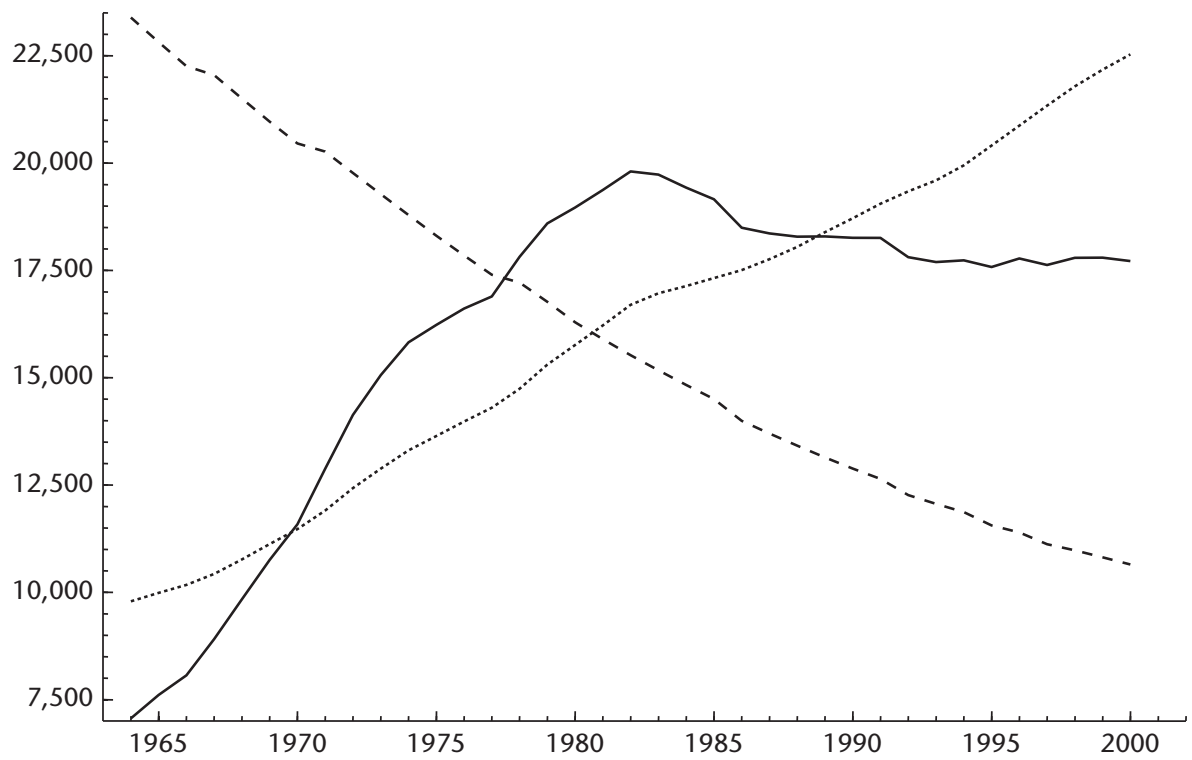

Figure 15.5. Relative factor endowments in Kenya, 1964-2000

Note: $\mathrm{K} / \mathrm{L}=\ldots \ldots \mathrm{T} / \mathrm{L}=\ldots \ldots+\mathrm{K} / \mathrm{T}=\ldots \ldots \ldots$ The variables have been mean- and variance- adjusted to increase the readability of the graph.

Source: Bigsten and Durevall (2008). Figure reproduced with permission of Journal of Development Studies 
then reversed. The capital-land ratio grew and the land-labour ratio declined continuously.

Labour supply growth outstripped formal-sector job creation and the use of minimum wages to push up real formal-sector wages became increasingly ineffective, and private-sector real wages fell. From 1968 onwards the labour market can be characterized as competitive, although various labour market controls remained until the 1990s. Trade unions were allowed to seek full compensation for price increases from 1994, and the relaxation of wage guidelines made it possible for firms and employees to negotiate wages on the basis of productivity considerations rather than cost-of-living indices (Ikiara and Ndung'u 1997). It also became easier to shed labour.

The evolution of real wages is shown in Figure 15.6 alongside estimates for returns to capital and land. Real wages are measured as labour earnings, including allowances, of employees in the private sector divided by the GDP deflator. Real wages increased by about 25 per cent from the mid-1960s until the beginning of the 1970s. This was followed by a slow decline until 1995, when real wages started to increase rapidly. The growth of private-sector real earnings between 1994 and 2000 was 65 per cent. This may have been due to the lifting of labour market controls (IMF 2003). Real returns to land have

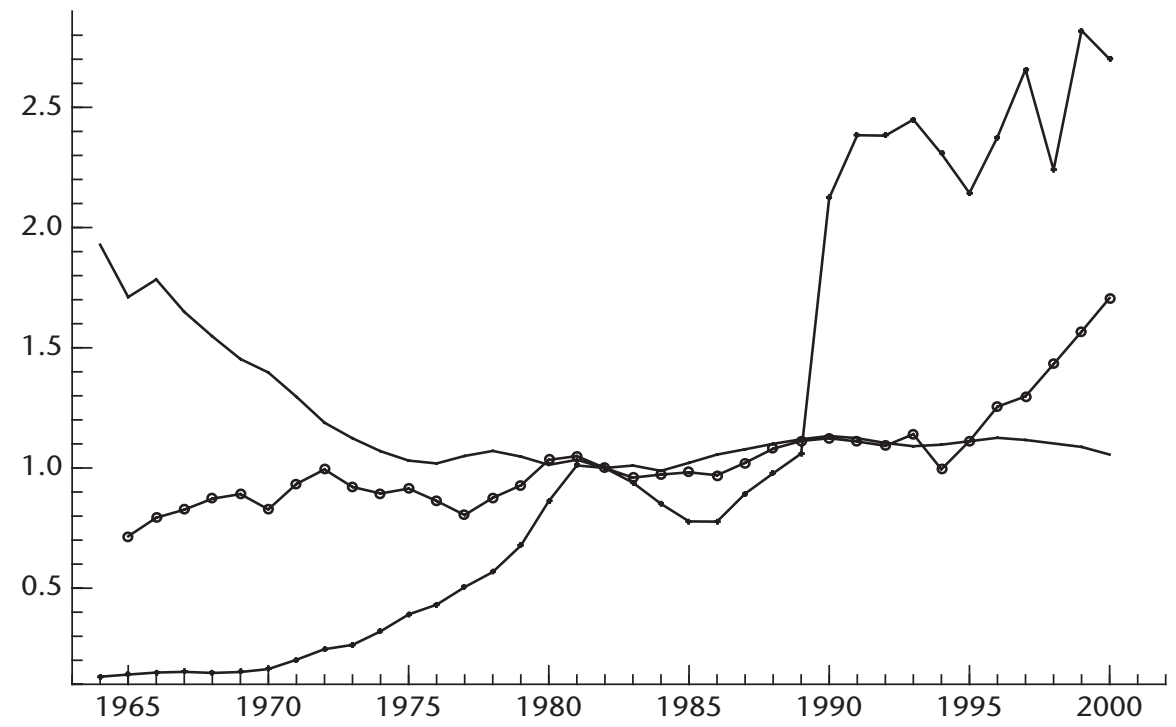

Figure 15.6. Indexes of real returns to factors in Kenya, 1964-2000

Note: Real return to capital $=$ ; real return to labour $=0 \ldots$

The GDP deflator was used to calculate the real values of earnings and land prices. The base year is $1982=1$. The series for land prices is the moving average of the actual series.

Source: Bigsten and Durevall (2008). Figure reproduced with permission of Journal of Development Studies 
increased sharply since independence. Returns to capital declined from 1964 to the mid-1970s; in total, a reduction of 50 per cent. Since 1975 it has fluctuated slightly.

The main empirical regularity for the period $1965-2000$ is that factor price movements were driven by changes in factor endowments, while in this regard the removal of trade restrictions had a limited effect. Changes in income inequality have been strongly influenced by the long-term process of structural change. The rapid increase in real wages that started in the mid1990s and lasted into the next decade could have been driven by labour policy reforms, though.

\subsection{Measurement Challenges}

One of the challenges encountered when trying to measure growth and income distribution in African economies is that the data are weak and inconsistent. The first challenge for our more detailed analysis of recent developments is to get measures of the growth of GDP.

Kenya's GDP is measured from both the production side and the expenditure side, and the accounts show some discrepancy (expenditure figures are typically up to 5 per cent larger). The Kenya National Bureau of Statistics (KNBS) relies mostly on the production approach. To get income shares, the KNBS measures labour incomes and then deducts these from GDP to get operating surplus, which includes capital and rental incomes.

There are two GDP time series (with different base years) that cover parts of the relevant time period. The first series is based on 1982 prices, while the other series is based on 2001 prices. KNBS also switched from the 1969 system of national accounts (SNA) to SNA 1993, which implied some definitional changes. KNBS re-estimated GDP back to 1996 using the 2001 weights. There are considerable differences between the two series both in terms of levels and growth rates.

The 2001 rebasing used information from the Household Budget Survey (HBS) of 1997 extensively. New rebased series should be better than the old ones, and they typically increase the level of GDP. We note that in the rebasing in 2001 GDP estimates increased very significantly (at most 50 per cent for 2001; Muchiri and Audi n.d.), because of changes in definitions and methods, changes in data sources, and improved coverage. For example, output of construction is considerably higher in the new series, which also means that fixed capital formation becomes larger. ${ }^{4}$

\footnotetext{
${ }^{4}$ For further discussion of estimation procedures, see Bigsten et al. (2014).
} 
Table 15.1. Growth rates (per cent) for 1997-2002 using 1982 and 2001 prices

\begin{tabular}{lcrrrrrr}
\hline & 1997 & 1998 & 1999 & 2000 & 2001 & 2002 & Average \\
\hline At 1982 prices & & & & & & & \\
Agricultural growth & 1.0 & 1.5 & 1.2 & -2.1 & 1.3 & 0.7 & 0.6 \\
Manufacturing growth & 1.9 & 1.4 & 1.0 & -1.4 & 0.8 & 0.5 & 0.7 \\
GDP growth & 2.4 & 1.8 & 1.4 & -0.2 & 1.2 & 1.1 & 1.3 \\
At 2001 prices & & & & & & & \\
Agricultural growth & -3.2 & 8.4 & 6.4 & -1.2 & 10.5 & -3.0 & 3.0 \\
Manufacturing growth & 0 & -1.8 & -4.1 & 1.0 & 1.6 & 0.1 & -0.5 \\
GDP growth & 0.3 & 3.4 & 2.1 & 0.5 & 4.5 & 0.6 & 1.9 \\
\hline
\end{tabular}

Source: KNBS data

There is an overlap between the two GDP series for seven years, making it possible to compare growth rates for six years. In Table 15.1 we show growth rates of GDP and the two components of agriculture and manufacturing. We see that there are considerable differences in the aggregate growth estimates between the two series. The new series gives higher GDP growth rates for all years except the first and the last. The average growth rates over the six years are 1.3 per cent and 1.9 per cent, respectively. Comparing growth rates in agriculture and manufacturing, we see that the differences for individual years are even larger.

So why are the differences so large between the old and the new series? One reason is that the relative weights of the different sectors have changed. The share of manufacturing fell drastically with the new prices. For 2001 it fell from 13 per cent of GDP to 9.6 per cent of GDP. This kind of change can explain why the aggregate growth rates can be quite different when we have different sectorial developments. It is harder to understand how the sectorial growth rates can vary as dramatically as they do.

\subsection{The Evolution of GDP, Factor Proportions, and Employment, 1994-2012}

As noted, we have contradictory growth estimates depending on whether we use the old GDP series (1982 base) or the newer series (2001 base). Table 15.2 shows how the two series differ in terms of GDP growth rates and investment shares (GFCF). The columns for capital formation are included because differences in capital formation estimates underlie differences in the GDP estimates, but also because investment rates are of interest when we are trying to explain growth variations. The new series is supposedly the better one, so we rely on this as much as possible. The last column gives our preferred estimates of per 
Table 15.2. GDP growth in new and old series, 1994-2012

\begin{tabular}{|c|c|c|c|c|c|c|c|}
\hline & $\begin{array}{l}\text { GDP growth } \\
\text { (new series) } \\
(\%)\end{array}$ & $\begin{array}{l}\text { GDP } \\
\text { growth } \\
\text { (old series) } \\
(\%)\end{array}$ & $\begin{array}{l}\text { GFCF \% of } \\
\text { GDP current } \\
\text { prices (new } \\
\text { series) }\end{array}$ & $\begin{array}{l}\text { GFCF \% of } \\
\text { GDP } \\
\text { current } \\
\text { prices (old } \\
\text { series) }\end{array}$ & $\begin{array}{l}\text { Per capita } \\
\text { income } \\
\text { growth } \\
\text { (new } \\
\text { series) }\end{array}$ & $\begin{array}{l}\text { Per capita } \\
\text { income } \\
\text { growth } \\
\text { (old series) }\end{array}$ & $\begin{array}{l}\text { 'Best' } \\
\text { estimates of } \\
\text { per capita } \\
\text { income } \\
\text { growth }\end{array}$ \\
\hline 1994 & & 3.0 & & 18.9 & & 0.1 & 0.1 \\
\hline 1995 & & 4.8 & & 21.4 & & 1.9 & 1.9 \\
\hline 1996 & & 4.6 & 16.0 & 19.8 & & 0.5 & 0.5 \\
\hline 1997 & 0.3 & 2.4 & 15.5 & 17.6 & -2.6 & -0.6 & -2.6 \\
\hline 1998 & 3.4 & 1.8 & 15.6 & 16.4 & 0.5 & -0.6 & 0.5 \\
\hline 1999 & 2.1 & 1.4 & 15.5 & 15.2 & -0.8 & -0.8 & -0.8 \\
\hline 2000 & 0.5 & -0.2 & 16.8 & 14.6 & -2.4 & -2.9 & -2.4 \\
\hline 2001 & 4.5 & 1.2 & 18.2 & 12.8 & 1.6 & -0.8 & 1.6 \\
\hline 2002 & 0.6 & 1.1 & 17.4 & 12.9 & -2.3 & -1.1 & -2.3 \\
\hline 2003 & 2.9 & & 15.8 & 12.5 & 0.0 & & 0.0 \\
\hline 2004 & 5.1 & & 16.3 & & 2.0 & & 2.0 \\
\hline 2005 & 5.8 & & 18.7 & & 2.9 & & 2.9 \\
\hline 2006 & 6.4 & & 19.1 & & 3.5 & & 3.5 \\
\hline 2007 & 7.0 & & 19.4 & & 4.0 & & 4.0 \\
\hline 2008 & 1.5 & & 19.4 & & -1.0 & & -1.0 \\
\hline 2009 & 2.7 & & 19.6 & & 0.1 & & 0.1 \\
\hline 2010 & 5.8 & & 20.3 & & 3.7 & & 3.7 \\
\hline 2011 & 4.4 & & 20.0 & & 1.6 & & 1.6 \\
\hline 2012 & 4.6 & & 20.4 & & 1.7 & & 1.7 \\
\hline
\end{tabular}

Source: Republic of Kenya, Statistical Abstract (annual); Republic of Kenya, Economic Survey (annual)

capita income growth. After a long period of virtual stagnation, the Kenyan economy went through a strong growth phase in 2003-7, as the rate of economic growth accelerated up to 7 per cent. During the same period, total factor productivity in manufacturing increased by as much as 20 per cent (World Bank 2007). Aggregate capital formation increased to 19 per cent in 2006 and over 20 per cent of GDP in 2010. This is high by Kenyan standards, but pales in comparison with that of its Asian competitors. Manufacturing growth followed more or less the same pattern as GDP, which meant that its share of GDP remained at slightly below 10 per cent of GDP. There has not been any take-off for manufacturing production in Kenya.

Our main concern is to understand what has happened to the incomes of individuals and households. We see that per capita income growth was weak and fluctuating between 1994 and 2002. Incomes fell in 2000, which was a drought year, and in 2002, which was an election year. Then growth stabilized, but we note a drop in 2008, because of the civil conflict following the December 2007 disputed election.

We have compared the growth of GDP per capita from the national accounts, with the evolution of mean consumption spending according to household surveys. Between 1994 and 2005/6 GDP per capita grew by 
3 per cent, while mean consumption (per adult equivalent) fell by 1.2 per cent. There was furthermore a 4 per cent increase in the share of GDP going to investment over the period. So we think we can say that the aggregate GDP estimates square well with the aggregate household estimates.

Factor quantity series are of interest to us, since we know (Bigsten and Durevall 2008) that changes in factor abundance have been a crucial determinant of the pattern of specialization and factor prices (and thus inequality and poverty). The most noteworthy development is that labour force growth has outpaced the growth of capital from the 1980s onwards. The country has not been able to pursue a strategy of capital deepening. This has had great implications for how the reallocation of labour in the economy has evolved. The labour pressure on land increases, continuously pushing labour off the land. This labour could have been absorbed by capital-intensive activities if capital had been accumulated at a sufficiently rapid rate. But since this has not happened, labour has had to move into activities that use little capital, that is, the informal sector and various forms of low-productivity self-employment. It is clear that it is mainly changes in factor endowments that drive structural change in the Kenyan economy.

To illustrate changes in factor endowments during the period under study we have extended the $\mathrm{K} / \mathrm{L}, \mathrm{K} / \mathrm{T}$, and $\mathrm{L} / \mathrm{T}$ estimates of Bigsten and Durevall (2006) to 2011 (Figure 15.7). Since the investment rate continued until 2004 at about the same rate as 1994-2000, we assume that the capital stock continued to grow at 1.7 per cent per year until 2004. We assume that the upward shift of the investment rate by 2 per cent of GDP from 2005 led to an increase of the capital stock by 2.2 per cent per year until 2011. The labour force growth

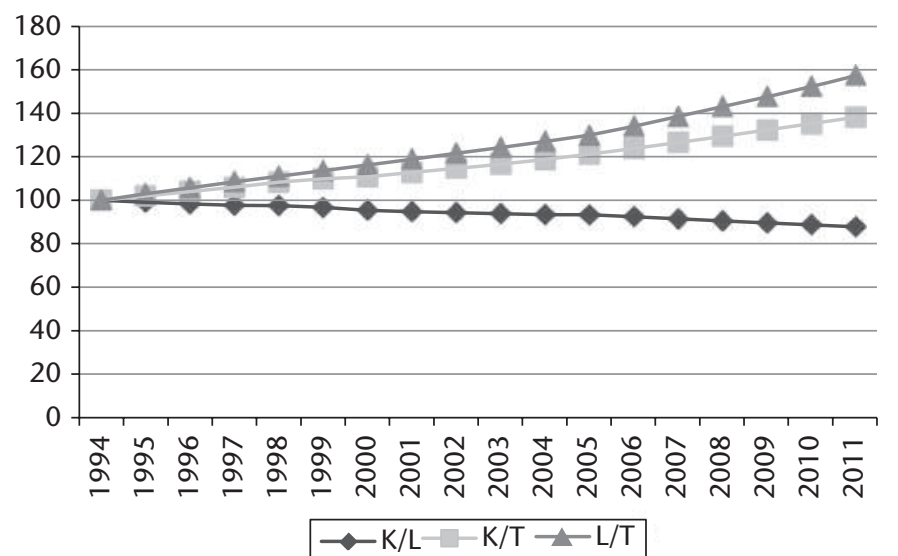

Figure 15.7. Factor proportions, 1994-2011

Note: $\mathrm{K}=$ capital; $\mathrm{L}=$ labour; $\mathrm{T}=$ land

Source: Authors' calculations based on KNBS data 
estimates are taken from the World Bank's World Development Indicators (over 3 per cent growth annually), while the estimate of agricultural land is kept constant (possibly some new land came under cultivation, but this would not change our estimates substantially).

The capital/labour ratio has continued to shrink in the new millennium, meaning that it has been impossible for the formal sector to absorb a major part of the labour that enters the labour market. The majority of labour market entrants have moved into the informal sector, which consequently has exploded in numbers. Part of the reported increase in informal-sector growth is certainly due to improved data coverage, but it is clear that the vast majority of labour outside agriculture is in the informal rather than the formal sector.

The government has had the ambition to try to attract more foreign direct investment (FDI), but so far it has not been very successful (less than 1 per cent of GDP). The oil and water discoveries in northern Kenya might change this. So far, there has been FDI in relation to telecom privatization and investments in railways, whereas not much has happened in manufacturing.

Kenya's share of world exports had fallen from 0.085 per cent in 1980 to 0.035 per cent by the year 2000; thus Kenya became increasingly marginalized in the world market during this period. Over the same period, its share of world GDP fell from 0.066 per cent to 0.040 per cent. However, Kenya's share of world exports has increased since 2000. There has been some diversification in terms of export destinations, but there has not been any significant diversification of Kenyan exports in terms of products.

One important determinant of overall inequality is the factorial income distribution. We have noted that the KNBS constructs estimates of labour income and GDP, where the income to capital and land is computed as the difference between the two. What we can check about factor distribution is thus whether the reported labour share has changed over time. In Table 15.3 we show the series from 1976 (when the initial story with the old data design ended). We see that there have been some changes over time, but there is no trend. The series starts at a 40 per cent share and ends there as well. This is a lower share than in richer countries, but if smallholder agriculture incomes are excluded the share should be at least 50 per cent. We can conclude that there is no long-term trend in the distribution of income between capital (and land) and labour.

The stability of the factorial distribution should contribute to keeping the overall distribution stable, but inequality can of course still increase if the distribution within the categories becomes more uneven. We have no information about the distribution of capital incomes, but we have some data on labour incomes. The Kenyan labour force has changed structure over recent decades. There has been a strong decline in the proportion of employees with 
Table 15.3. Labour income share in GDP, 1976-2012

\begin{tabular}{llll}
\hline & \multicolumn{3}{c}{ Remuneration/total factor income } \\
\hline & & 2000 & 45.9 \\
1976 & 39.8 & 2001 & 46.9 \\
1980 & 40.9 & 2002 & 48.3 \\
1985 & 42.1 & 2003 & 41.6 \\
1990 & 42.1 & 2004 & 37.2 \\
1992 & 41.0 & 2005 & 41.5 \\
1993 & 39.6 & 2006 & 42.4 \\
1994 & 43.1 & 2007 & 42.1 \\
1995 & 45.5 & 2008 & 38.6 \\
1996 & 43.5 & 2009 & 39.6 \\
1997 & 42.1 & 2010 & 42.3 \\
1998 & 43.5 & 2011 & 40.0 \\
1999 & 45.1 & 2012 & 39.6 \\
\hline
\end{tabular}

Source: Republic of Kenya, Economic Survey (ES) (annual until 2013)

Table 15.4. Growth of formal and informal employment and real earnings of formal labour, 1994-2012

\begin{tabular}{lrrr}
\hline & $\begin{array}{l}\text { Real average earnings } \\
\text { growth (\%) }\end{array}$ & $\begin{array}{c}\text { Formal employment } \\
\text { growth (\%) }\end{array}$ & $\begin{array}{l}\text { Informal employment } \\
\text { growth (\%) }\end{array}$ \\
\hline 1994 & 8.3 & 2.0 & 11.9 \\
1995 & 19.8 & 3.4 & 25.0 \\
1996 & 11.7 & 4.0 & 18.0 \\
1997 & 8.5 & 1.8 & 13.0 \\
1998 & 11.2 & 1.1 & 12.2 \\
1999 & 8.0 & 0.6 & 11.5 \\
2000 & 4.7 & 0.4 & 11.0 \\
2001 & 8.7 & -1.1 & 7.7 \\
2002 & 12.7 & 1.3 & 10.0 \\
2003 & -2.7 & 1.5 & 8.6 \\
2004 & 9.9 & 2.1 & 8.0 \\
2005 & 2.4 & 2.9 & 6.7 \\
2006 & 1.3 & 2.8 & 6.6 \\
2007 & 4.5 & 2.6 & 6.1 \\
2008 & -10.2 & 1.8 & 5.3 \\
2009 & -4.7 & 2.8 & 7.9 \\
2010 & -0.4 & 2.9 & 7.6 \\
2011 & -8.1 & 3.4 & 6.3 \\
2012 & -4.8 & 3.1 & 6.0 \\
\hline
\end{tabular}

Source: Republic of Kenya, Economic Survey (annual until ES 2013)

no education and an increase in the proportion with primary education (Bigsten and Wambugu 2010). This reflects the near-universal primary education in the country. Wages differ very much by levels of education (Bigsten 1984; Knight and Sabot 1990; Söderbom et al. 2006).

Table 15.4 shows the growth rates of formal and informal employment for 1994-2012. We see that very many of the new jobs were in the informal 
Table 15.5. Labour earnings in the formal and informal sectors (KSh per month), 1998/9-2005/6

\begin{tabular}{|c|c|c|c|c|}
\hline \multirow[b]{2}{*}{ Sector } & \multicolumn{2}{|c|}{$\begin{array}{l}\text { Integrated Labour Force } \\
\text { Survey (1998/9) }\end{array}$} & \multicolumn{2}{|c|}{$\begin{array}{l}\text { Kenya Integrated Household } \\
\text { Budget Survey }(2005 / 6)\end{array}$} \\
\hline & Mean & Median & Mean & Median \\
\hline Formal & $\begin{array}{l}8,152 \\
(6,212)\end{array}$ & $\begin{array}{c}6,105 \\
(4,652)\end{array}$ & $\begin{array}{c}22,813 \\
(10,264)\end{array}$ & $\begin{array}{c}8,000 \\
(3,599)\end{array}$ \\
\hline Informal & $\begin{array}{c}5,147 \\
(3,922)\end{array}$ & $\begin{array}{c}2,800 \\
(2,133)\end{array}$ & $\begin{array}{l}15,403 \\
(6,930)\end{array}$ & $\begin{array}{c}4,000 \\
(1,791)\end{array}$ \\
\hline Total & $\begin{array}{c}6,208 \\
(4,730)\end{array}$ & $\begin{array}{c}3,000 \\
(2,286)\end{array}$ & $\begin{array}{l}19,697 \\
(8,872)\end{array}$ & $\begin{array}{l}6,000 \\
(2,699)\end{array}$ \\
\hline
\end{tabular}

Note: Real earnings in parentheses, deflated using Consumer Price Index (CPI) (1994 prices).

Source: Republic of Kenya (2003a, 2008a)

sector. This means that the share of formal employment has fallen to about a fifth of total employment outside smallholder agriculture. There are no solid data indicating the trend in the unemployment rate, but the measured rate of open unemployment is nearly constant. In Kenya, as in other African countries, the unemployment rate is relatively small because the majority of the population must work to survive. The main labour market problem in Kenya is not open unemployment but rather a large number of working poorsubsisting in the informal sector and smallholder agriculture.

Table 15.4 also shows the evolution of real earnings in the formal sector since 1994. What we see here is a remarkable growth of earnings during the period that is the focus of our study, followed by dramatic declines from 2008 onwards. The start of this drop coincided with the civil strife of $2007 / 8$, but continues until the end of our data period in 2012.

There are no systematic income data for the informal sector. The little data we have are from surveys for 1998/9 and 2005/6. Looking at the evolution of formal and informal median earnings it seems as if the gap between the two sectors has been fairly constant (Table 15.5). We do not have any clear picture as to why real wages in the formal sector suddenly started to fall from 2008 onwards.

\subsection{The Evolution of Poverty and Inequality, 1980s-2000s}

In this section, we analyse the evolution of inequality and poverty over the past two decades. The aim is to provide evidence on changes in level and distribution of household welfare over a period for which nationally representative datasets are available (Republic of Kenya 1996, 1998a, 2007). 


\subsubsection{Monetary Measures}

Tables 15.6-15.12 show recent trends in and patterns of poverty and inequality in Kenya from the 1980s using a variety of methods and datasets (Mukui 1994; Republic of Kenya 1996, 1998a, 2007). ${ }^{5}$

The Kenya economy was on a recovery path in 2005 after the poor performance it recorded in the 1990s, and poverty declined between 1997 and 2005/6. The region with the lowest poverty rates is Central, which got an early start in development as we pointed out in our historical review. We may also note that the capital city, Nairobi, has the lowest poverty rate in the country despite its large in-migration.

We computed income inequality (Gini coefficient) using per adult equivalent expenditures and organized around region (province) and area (rural/ urban) (Table 15.7). The national Gini coefficient increased from 0.428 in 1994 to 0.516 in 2005 . This was driven by three forces. First, the urban share of households increased, which meant that a larger share of households were in the high-inequality region. Second, urban income inequality rose between 1994 and 2005. And finally, the urban-rural gap in inequality increased between the two periods.

In the historical section we saw that the national Gini was driven by changes in the urban-rural gap. Here we are able to examine Kenya's ruralurban disparity in per adult equivalent consumption from 1994 to 2005 . We compare the average consumption expenditure of rural and urban residents using our household surveys. Table 15.8 presents average per adult equivalent consumption expenditure for 1994 and 2005 and the rural/urban expenditure ratios. These show that the average rural consumption expenditure was 46 per cent of the average urban consumption expenditure in 1994, while it had declined to 33 per cent by 2005. Thus, at least during this period the increase in the overall Gini is correlated with the increase in the rural-urban gap. The increase in urban inequality also contributed to the overall increase. Due to data limitations, the situation for the recent period could not be assessed, but it is possible that the redistribution and devolution initiatives started during the Kibaki government (2003-13), especially the cash transfer programmes and the 2010 constitutional reform, have reduced the rural-urban consumption disparity.

\footnotetext{
5 A special model was developed for this UNU-WIDER project, which would make it possible to adjust the poverty lines to account for relative price changes. We were able to get the required price data for 2005/6, and to run the full programme for this year. It is reassuring to find that the national poverty rate for 2005 estimated with the new toolkit (47 per cent), was not substantially different from the estimate (46 per cent) obtained with the official constant bundle, despite notable regional variations in the two sets of estimates. Relative price changes do not seem to be of first-order importance for the estimates of poverty change during this period.
} 


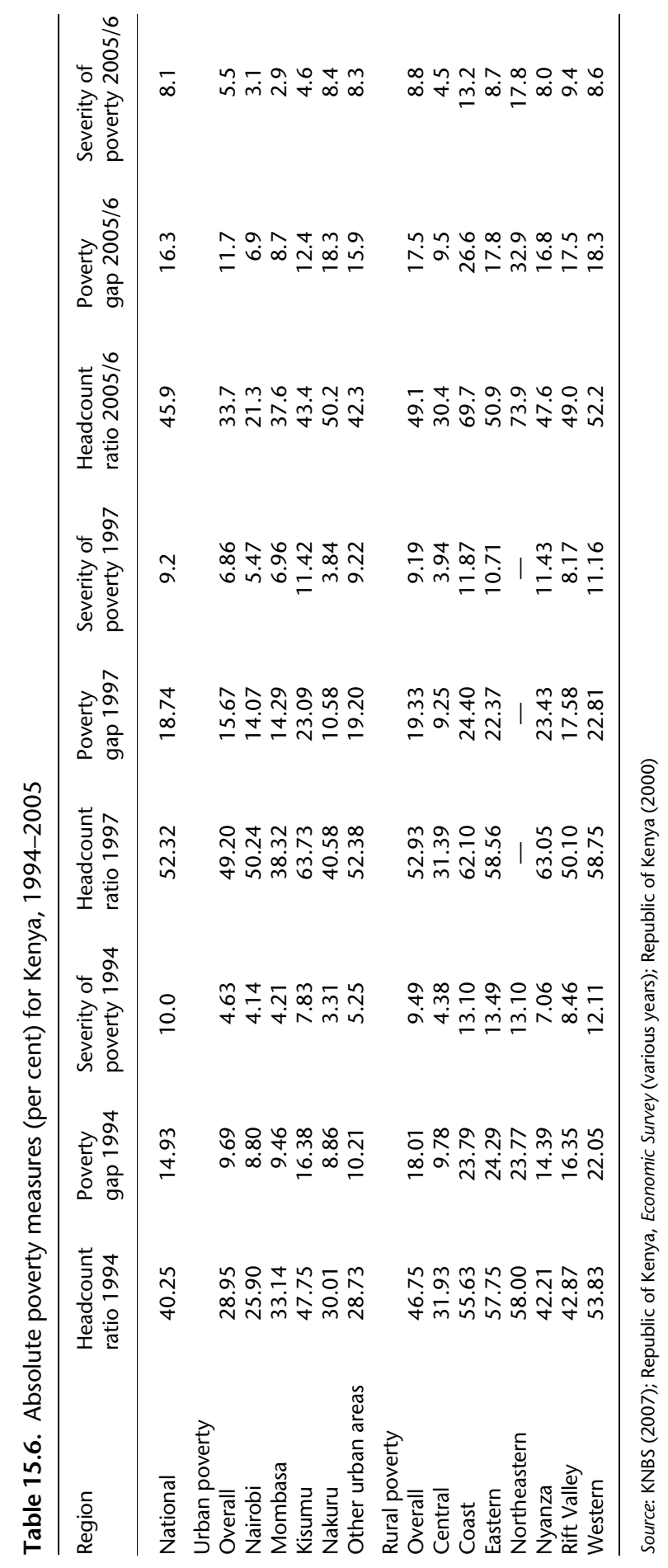


Table 15.7. Regional welfare inequality (Gini coefficient) in Kenya, 1994-2005

\begin{tabular}{lcc}
\hline Region/Area & 1994 & 2005 \\
\hline Nairobi & 0.526 & 0.581 \\
Central rural & 0.330 & 0.350 \\
Central urban & 0.350 & 0.390 \\
Coast rural & 0.417 & 0.355 \\
Coast urban & 0.339 & 0.390 \\
Eastern rural & 0.428 & 0.387 \\
Eastern urban & 0.396 & 0.422 \\
Northeastern rural & 0.420 & 0.371 \\
Northeastern urban & 0.411 & 0.368 \\
Nyanza rural & 0.385 & 0.359 \\
Nyanza urban & 0.380 & 0.374 \\
Rift Valley rural & 0.394 & 0.407 \\
Rift Valley urban & 0.343 & 0.431 \\
Western rural & 0.398 & 0.350 \\
Western urban & No data & 0.382 \\
National & 0.428 & 0.516 \\
Total rural & 0.395 & 0.385 \\
Total urban & 0.426 & 0.497 \\
\hline
\end{tabular}

Source: Authors' computations from household survey data (Republic of Kenya 1996, 2007)

Table 15.8. Average annual expenditure of rural and urban residents in Kenya, 1994-2005

\begin{tabular}{lcccc}
\hline Area/Year & $\begin{array}{l}\text { Number of } \\
\text { observations }\end{array}$ & $\begin{array}{l}\text { Mean expenditure per } \\
\text { adult equivalent (Ksh) }\end{array}$ & Std. Dev. & $\begin{array}{l}\text { Rural/Urban } \\
\text { expenditure ratio }\end{array}$ \\
\hline 1994 & & & & \\
Rural & 9,171 & 16,030 & 13,533 & 0.4585 \\
Urban & 1,455 & 34,951 & 44,989 & \\
Total & 10,626 & 18,621 & 21,848 & \\
2005 & & & & 0.3262 \\
Rural & 8,473 & 25,730 & 121,629 & \\
Urban & 4,682 & 78,866 & 78,939 & \\
Total & 13,155 & 44,642 & & \\
\hline
\end{tabular}

Source: Authors' computations based on household survey data (Republic of Kenya 1996, 2007)

\subsubsection{Non-monetary Poverty Measures}

The most common metric of poverty is some threshold level of income or consumption expenditure. However, poverty is multidimensional and goes beyond the conventional single-index metrics, which ignore many wider aspects of poverty. Empirical studies have shown that using the monetary approach alone may be deceptive and needs to be complemented with nonmonetary measures. Poverty is associated not only with insufficient income or consumption but also with insufficient health, nutrition, and literacy, and 
Table 15.9. Health poverty

\begin{tabular}{|c|c|c|c|c|c|}
\hline Year and welfare indicators & 1989 & 1993 & 1998 & 2003 & 2008 \\
\hline Neonatal mortality (per 1,000 births) & 28.2 & 25.7 & 25 & 35 & 31 \\
\hline Post-neonatal mortality (per 1,000 births) & 35.2 & 35.9 & 34 & 32 & 21 \\
\hline Infant mortality rate (per 1,000 live births) & 62 & 63 & 71 & 75 & 59 \\
\hline $\begin{array}{l}\text { Child mortality rate (per 1,000 children surviving to } \\
12 \text { months of age) }\end{array}$ & 36.7 & 28.1 & 37 & 29 & 23 \\
\hline Under-five mortality (per 1,000 live births) & 113 & 96.1 & 112 & 115 & 74 \\
\hline Maternal mortality ratio (per 100,000 births) & 365 & 423 & 590 & 414 & 488 \\
\hline Life expectancy at birth in years & 60 & 57 & 51 & 47 & 55 \\
\hline $\begin{array}{l}\text { Vaccination coverage (\% of children } 12-23 \text { months fully } \\
\text { vaccinated) - proxy for access to medical services }\end{array}$ & 44 & 79 & 65 & 57 & 77 \\
\hline
\end{tabular}

Source: Republic of Kenya (1989, 1993, 1998b, 2003a, 2008b)

with deficient social relations, insecurity, and low self-esteem and powerlessness (Hulme et al. 2001). In order to capture the multidimensional nature of poverty, we will consider some key non-monetary indicators of well-being. We analyse the trends of the non-monetary indicators of poverty in Kenya using data from the various Demographic Health Surveys (DHS for 1989, 1993, 1998, 2003, 2008). The non-monetary indicators of welfare we use include measures of health, education, environment, and nutrition.

The indicators for health poverty presented in Table 15.9 include neonatal mortality, post-neonatal mortality, infant mortality, child mortality, underfive mortality, and maternal mortality.

Health status in Kenya has on the whole been improving since 1989. In particular, most forms of mortality have declined. However, the trend in life expectancy is irregular, perhaps due to effects of HIV/AIDS, the timing of antiretroviral treatments, and access to water and sanitation over the period analysed (State of World Population 2011). Access to medical services as proxied by the vaccination coverage improved from 44 per cent in 1989 to 79 per cent in 1993 then declined to 57 per cent in 2003. Between 2003 and 2008 , it improved by twenty percentage points, indicating that Kenya is on a good track to universal health care coverage. In general, the year 2003 saw bad performance in many of the indicators, such as infant mortality rates and life expectancy, due to extreme weather conditions, including drought, landslides, and floods that were widespread in that year, leading to food deficits in most parts of the country (Republic of Kenya 2004).

Table 15.10 indicates that the fraction of people without access to safe drinking water in Kenya decreased from about 55 per cent in the late 1980s, stabilized in 2002, and remained more or less constant between 2004 and 2008. The general trend in access to water is not clear. However, the emerging picture is that there is a slight improvement in access to safe drinking water in the country. As can be seen from Tables 15.10 and 15.11, data on mortality, 
Table 15.10. Percentage of people without access to improved drinking water

\begin{tabular}{lccccccc}
\hline Year and welfare indicators & 1989 & 1994 & 2000 & 2002 & 2004 & 2005 & 2008 \\
\hline $\begin{array}{l}\text { Access to safe/improved drinking water } \\
\text { (\% not using any improved source of } \\
\text { drinking water) }\end{array}$ & 55 & 47 & 51 & 38 & 39 & 44 & 41 \\
\hline
\end{tabular}

Source: Constructed from <www.worldwater.org/data.html> (Pacific Institute n.d.)

Table 15.11. Percentage of children under five years classified as malnourished, 1993-2008

\begin{tabular}{lrrrr}
\hline Year and welfare indicators & 1993 & 1998 & 2003 & 2008 \\
\hline Height-for-age stunting & 32.7 & 35.3 & 30.3 & 29.6 \\
Weight-for-height stunting & 5.9 & 6.0 & 5.6 & 5.8 \\
Weight-for-age underweight & 22.3 & 21.2 & 19.9 & 20.3 \\
Children stunted (\% overall) & 31.2 & 30.9 & 30.1 & 29.8 \\
Children underweight (\% overall) & 23.3 & 21.5 & 20.1 & 19.5 \\
\hline
\end{tabular}

Source: Republic of Kenya (1989, 1993, 1998b, 2003a, 2008b)

life expectancy, and access to clean water do not yield the same trend in nonincome poverty profiles. Thus, there is a need to combine these metrics in the measurement of population welfare.

The main nutritional indicators in Kenya and elsewhere are child anthropometrics. They include height-for-age stunting (percentage of children under five years classified as malnourished); weight-for-height wasting (percentage of children under five years classified as malnourished); weight-for-age underweight (percentage of children under five years classified as malnourished); children stunted (percentage overall); and children underweight (percentage overall). These are standard indices of physical growth that describe the nutritional status of children. Children falling below the cut-off point of minus two standard deviations ( $-2 \mathrm{SD}$ ) from the median of the reference population are classified as stunted (Republic of Kenya 2008b).

Table 15.11 shows the nutritional status of children under five for the DHS surveys. The nutritional status of children under five has improved somewhat since the early 1990s. The height-for-age stunting declined from 32.7 per cent in 1993 to 29.6 per cent in 2008 . The weight-for-height stunting has remained more or less constant during this period, while weight-for-age underweight declined from 22.3 per cent in 1993 to 20.3 per cent in 2008 .

Education level is a key measure of non-income poverty. School enrolment rates, dropout rates, and literacy rates are good indicators of non-income poverty. School enrolment rates tend to be higher in rich households and lower in income-poor households. However, this enrolment-income gradient 
Table 15.12. Indicators of access to education

\begin{tabular}{lrrrrr}
\hline Year and welfare indicators & 2000 & 2002 & 2004 & 2006 & 2009 \\
\hline Primary gross enrolment (\%) & 95.20 & 91.46 & 107.05 & 105.38 & 113.27 \\
Primary net enrolment (\%) & 65.08 & 61.72 & 73.53 & 75.13 & 82.78 \\
Secondary gross enrolment (\%) & 39.20 & 40.81 & 46.94 & 49.85 & 60.17 \\
Secondary net enrolment (\%) & 33.23 & 34.51 & 38.97 & 42.07 & 50.03 \\
Tertiary gross enrolment (\%) & 2.75 & 2.82 & 2.92 & 2.96 & 4.03 \\
\hline
\end{tabular}

Source: UNESCO (2010)

Table 15.13. Literacy rates

\begin{tabular}{llllll}
\hline Year/Indicators & 1995 & 2003 & 2008 & 2009 & 2010 \\
\hline $\begin{array}{l}\text { Literacy rate (\% of population aged } 15 \text { and } \\
\text { above who can read and write) }\end{array}$ & 78.1 & 85.1 & 86.5 & 87.1 & 87.4 \\
\hline
\end{tabular}

Source: World Bank (various years), <www.worldbank.org >

does not always hold. Table 15.12 shows enrolment rates for the period 2000 to 2009.

The school enrolment rates for both primary and secondary schools improved between 2000 and 2009. Primary gross enrolment has been on the rise since the year 2000. However, between 2004 and 2009, the gross enrolment rate increased due to the introduction of free primary education. Net primary enrolment has also increased steadily in the last decade, with the lowest being recorded in 2002, while the peak was in 2009. Both gross and net secondary enrolments have increased since the year 2000. This can be attributed to subsidized secondary school education which was commenced in the year 2008 .

Table 15.13 shows that the literacy rates have been improving for the last fifteen years or so. The proportion of people who can read and write was 78.1 per cent in 1995 but steadied at an average of about 86 per cent between 2003 and 2010.

Overall, the social indicators show a moderate positive trend, which is consistent with the moderate increase in incomes and the reduced poverty rates after 1997.

\subsection{Policy Challenges}

We have presented different measures of the level and distribution of the standard of living in Kenya for the period 1900-2012. Over the past century, 
low growth, limited transformation of the economy, high inequality, and poverty have been the dominant features of the Kenyan economy. What can be expected of the economy over the next 100 years? What policies can be pursued over that time horizon to accelerate growth, reduce poverty, improve equity, and transform the economy's informal and agrarian activities into high-productivity manufacturing enterprises?

The main aim of current Kenyan economic policy is to reduce poverty. Success in this endeavour will depend on growth and changes in income distribution. The quality of economic and political governance is probably the main determinant of the extent to which Kenya will be able to create an inclusive growth process that would increase the incomes of the poor.

One aspect of development that is important for income distribution is regional integration or the lack thereof. The Kenyan economy is characterized by large regional differences in welfare (Bigsten 1980), which is also politically problematic since it more or less also reflects ethnic differences across regions. A lot of the politics in Kenya is played along ethnic lines, with detrimental effects on equity and economic efficiency. Regional inequality in Kenya is caused by agro-climatic conditions, weak institutional and infrastructural developments, fragmented domestic markets, and ethnic politics. Income inequality arising out of regional differences makes a substantial contribution to overall inequality.

To reduce inequality and poverty, Kenya must continue the transformation of its economy from a dual economy to a more integrated and modern economy. This requires a continued shift of labour from agriculture into preferably well-paying formal-sector jobs. In recent decades the investment rate has been too low to increase the amount of capital per worker. This has meant that the number of jobs in the formal and relatively capital-intensive sector has stagnated, while the labour force increase has had to be absorbed by the informal sector. This is where many of the new entrants to the labour market end up, and the income level is often modest. Still, this sector is currently an indispensable part of the process of structural transformation and the shift in the labour force out of agriculture. And the pace of this shift is crucially important for the sustained growth of the Kenyan economy and for the eventual integration of different sectors and thereby a more even distribution of income.

What does all this imply for policymaking? First, on the macro level there is a need to bring about a shift to a policy that is credible to domestic as well as foreign investors. Formal firms have been confronted with all kinds of problems in dealing with governments, such as regulatory red tape, corruption, and lack of security. Thus, part of a policy to bring about a shift of firms to the formal sector is to clean up the way the government deals with formal-sector firms to reduce the incentives for firms to take shelter in the informal sector. 
To bring about informal-sector growth and absorption into the formal sector, the government needs to design its general policies so that they are relevant also for informal firms, and design specific programmes targeting informal firms. The skill levels and policy environment of informal firms need to be improved to make it possible for them to graduate to the formal sector.

\subsection{Concluding Remarks}

The chapter has analysed incomes, poverty, and inequality in Kenya over a period long enough to permit identification of key determinants of these welfare indicators. In contrast to previous studies in this area that have relied on single data sources and methods, the chapter has used multiple datasets and different methods to assess the development process in Kenya over a period of 100 years. We find that irrespective of the data type and measurement method, poverty and inequality in Kenya are high, and have been persistently high for a long time. Moreover, and importantly, the structure of the economy has not changed enough to make a real dent in poverty levels. At the beginning of the new millennium, Kenya remained an agrarian economy, with a large and rapidly expanding informal sector. The capital/labour ratio is still declining, and the manufacturing sector is small and stagnant, which is why few good jobs are being created for the rapidly increasing labour force. The main labour market problem is that of the working poor, rather than that of the openly unemployed. Thus, there is a need to implement short-run policies to increase labour incomes in agriculture and the informal sector. The slow progress in terms of poverty reduction is clearly linked to the slow growth of the formal sector. High growth and poverty reduction can only be achieved through productivity-enhancing transformation of the economy.

\section{References}

Bigsten, A. (1980). Regional Inequality and Development: A Case Study of Kenya. Farnborough: Gower.

Bigsten, A. (1984). Education and Income Determination in Kenya. Aldershot: Gower.

Bigsten, A. (1986). 'Welfare and Economic Growth in Kenya 1914-1976', World Development, 14(9): 1151-60.

Bigsten, A. and D. Durevall (2006). 'Openness and Wage Inequality in Kenya, 1964-2000', World Development, 34(3): 465-80.

Bigsten, A. and D. Durevall (2008). 'Factor Proportions, Openness and Factor Prices in Kenya, 1965-2000', Journal of Development Studies, 44(2): 289-310. 
Bigsten, A., D. K. Manda, G. Mwabu, and A. Wambugu (2014). 'Incomes, Inequality, and Poverty in Kenya: A Long-Term Perspective', WIDER Working Paper 2014/126. Helsinki: UNU-WIDER.

Bigsten, A. and A. Wambugu (2010). 'Kenyan Labour Market Challenges', in C. Adam, P. Collier, and N. S. Ndung'u (eds), Kenya: Policies for Prosperity. Oxford: Oxford University Press, 267-92.

Collier, P. and D. Lal (1986). Poverty and Labor in Kenya 1900-1980. Oxford: Oxford University Press.

Hulme, D., K. Moore, and A. Shepherd (2001). 'Chronic Poverty: Meanings and Analytical Frameworks', CPRC Working Paper 2. Manchester: Chronic Poverty Research Centre.

Ikiara, G. K. and N. Ndung'u (1997). Employment and Labor Market during Adjustment: The Case of Kenya. Geneva: International Labour Organization.

IMF (International Monetary Fund) (2003). 'Kenya: Selected Issues and Statistical Appendix', Country Report 03/200. Washington, DC: IMF.

Kitching, G. (1980). Class and Economic Change in Kenya: The Making of an African PetiteBourgeoisie. New Haven and London: Yale University Press.

KNBS (Kenya National Bureau of Statistics) (2007). Basic Report on Well-being in Kenya: Based on Kenya Integrated Household Budget Survey-2005/06. Nairobi: Ministry of Planning and National Development.

Knight, J. and R. Sabot (1990). Education, Productivity, and Inequality: The East African Natural Experiment. New York: Oxford University Press.

Muchiri, B. and P. Audi (n.d.). Statistical Measures of Growth and their Changes over Time. Nairobi: Kenya National Bureau of Statistics.

Mukui, J. T. (1994). Kenya: Poverty Profiles, 1982-1992. Nairobi: Ministry of Planning and National Development.

Pacific Institute (n.d.). 'Data'. Available at <www.worldwater.org/data.html>, accessed 14 November 2013.

Republic of Kenya (1989). Kenya Demographic and Health Survey. Nairobi: Government Printer.

Republic of Kenya (1993). Kenya Demographic and Health Survey. Nairobi: Government Printer.

Republic of Kenya (1996). Welfare Monitoring Survey II: Basic Report. Nairobi: Government Printer.

Republic of Kenya (1998a). Welfare Monitoring Survey III: The Second Report on Poverty in Kenya: Poverty and Social Indicators. Nairobi: Government Printer.

Republic of Kenya (1998b). Kenya Demographic and Health Survey. Nairobi: Government Printer.

Republic of Kenya (2000). Second Report on Poverty in Kenya, vol. I: Incidence and Depth of Poverty. Nairobi: Ministry of Finance and Planning.

Republic of Kenya (2003a). The 1998/9 Labor Force Survey Report. Nairobi: Central Bureau of Statistics.

Republic of Kenya (2003b). Kenya Demographic and Health Survey. Nairobi: Government Printer. 
Republic of Kenya (2004). National Policy on Disaster Management (Revised Draft). Nairobi: Government Printer.

Republic of Kenya (2007). Kenya Integrated Household Budget Survey: Basic Report, Revised Edition. Nairobi: Government Printer.

Republic of Kenya (2008a). Labor Force Analytical Report: Based on the Kenya Integrated Household Budget Survey 2005/06. Nairobi: Kenya National Bureau of Statistics.

Republic of Kenya (2008b). Kenya Demographic and Health Survey. Nairobi: Government Printer.

Republic of Kenya (various years). Economic Survey. Nairobi: Government Printer.

Republic of Kenya (various years). Statistical Abstract. Nairobi: Government Printer.

Sachs, J. and A. Warner (1995). 'Economic Reform and the Process of Global Integration', Brookings Papers on Economic Activity, 1: 1-118.

Söderbom, M., F. Teal, A. Wambugu, and G. Kahyarara (2006). 'The Dynamics of Returns to Education in Kenyan and Tanzanian Manufacturing', Oxford Bulletin of Economics and Statistics, 68(3): 261-88.

State of World Population (2011). People and Possibilities in a World of 7 Billion. New York: United Nations Population Fund.

UNESCO (2010). Education for All Global Monitoring Report. Paris: Institute for Statistics.

World Bank (2007). Kenya Investment Climate Assessment. Draft. Washington, DC: World Bank.

World Bank (various years). 'Data'. Available at <http://data.worldbank.org/>, accessed 14 November 2013.

World Bank (various years). 'World Development Indicators'. Washington, DC: World Bank. 


\title{
16
}

\section{Utility-Consistent Poverty in Madagascar, 2001-10}

\author{
Snapshots in the Presence of \\ Multiple Economy-Wide Shocks
}

David Stifel, Tiaray Razafimanantena, and Faly Rakotomanana

\subsection{Introduction}

By all estimates, Madagascar is one of the poorest countries in the world, with macroeconomic indicators suggesting that the nation is poorer today than it was over forty years ago. Average real per capita income in 2010 was approximately one-third of what it was in 1960. Yet our understanding of poverty in Madagascar is incomplete because it is hampered by issues with data and methodology. This is not surprising given the complexity of measuring poverty in a manner that is consistent over time and space, yet is also sensitive to local conditions. The contemporary literature on poverty in Madagascar has stressed consistency over time by focusing on the comparability of the survey instruments used to estimate nominal household consumption aggregates, the key welfare measure used in calculating poverty (Paternostro et al. 2001; Amendola and Vecchi 2007). Evidence that differing commodity lists (Pradhan 2000) and recall periods (Scott and Amenuvegbe 1990) affect the levels of reported consumption from household surveys led Malagasy statisticians to make every effort to ensure that the survey instruments used to measure poverty were comparable from 2001 onward.

The nominal household consumption aggregate, however, is but one admittedly important component of poverty measurement. Another is the poverty line. The appropriate estimation of poverty lines is essential not only to gauge 
a poverty threshold, but also as a cost-of-living index that allows interpersonal welfare comparisons when the costs of consuming basic needs vary over time and space (Ravallion 1998). The challenge is to estimate poverty lines that are consistent over time and space (i.e. the reference standard of living is fixed), and yet are also characterized by specificity in which the poverty lines reflect local consumption patterns and norms (Ravallion and Bidani 1994).

In this chapter, we analyse poverty in Madagascar between 2001 and 2010 by starting with a series of surveys for which a comparable set of survey instruments were used, and applying to those surveys Arndt and Simler's (2010) utility-consistent approach to calculating cost-of-basic-needs (CBN) poverty lines. These consistent yet specific poverty lines, along with consumption aggregates calculated from comparable survey instruments, form the basis of the poverty analysis in this chapter.

Another conceptual issue that arises when analysing trends in poverty is that poverty estimates are based on nationally representative household surveys that are not typically conducted every year. As such, they represent snapshots of poverty during the particular years in which the survey took place. The challenge is to disentangle the long-term poverty trends from the short-term shocks that may affect poverty estimates in a particular year. This is particularly the case for Madagascar given that two major political crises, along with a rice price crisis and multiple cyclones, hit the country during the first decade of the twenty-first century. As such, we place the monetary poverty measures in context by comparing them to other macro- and microeconomic indicators. While recognizing that short-term shocks may also affect the long-term structure of the economy, we conclude that the poverty estimates for Madagascar are more of a reflection of short-term shocks than of long-term trends.

The structure of this chapter is as follows. In section 16.2, we elaborate on the methodology used to calculate poverty and describe the primary data sources. Section 16.3 provides a description of the political and economic context in which the surveys took place to better understand the long-term trends and short-term shocks. In section 16.4, we present the estimates of poverty and inequality based on the utility-consistent approach to calculating poverty lines, and triangulate these results with other monetary and nonmonetary indicators. Section 16.5 provides concluding remarks.

\subsection{Data and Poverty Lines}

The primary data sources used in this analysis are the 2001, 2005, and 2010 Madagascar Enquête Périodique auprès des Ménages (EPM). The EPM are generalpurpose LSMS-type cross-section surveys conducted by the Institut National 
de la Statistique (INSTAT). They are nationally representative, stratified, and clustered surveys conducted over three-month periods at the end of the calendar year, and contain information on household characteristics, expenditure, activities, and infrastructure. Detailed consumption information is collected for the purpose of constructing welfare measures.

Over the course of the three surveys, the sample size grew from 5,080 in 2001 to 11,781 in 2005 , and to 12,460 in 2010 . This reflects the need for the latter two surveys to be representative, at the urban and rural levels, of each of the twenty-two administrative regions created in 2004 as part of the government's decentralization programme. Fortunately, the forty-four strata in these 2005 and 2010 surveys can be grouped to represent the same twelve strata in the 2001 survey (urban and rural for six provinces). Further, while slight changes were made to the questionnaire in response to demands from the government and from donors who financed the surveys, INSTAT's efforts over the years to maintain comparability for welfare measurement-reflected in the nearly identical questionnaire modules for food and non-food expenditures, education and health expenditures, housing values and characteristics, ownership of durable goods, gifts and remittances, and in-kind payments-bode well for consistent poverty and inequality measurement.

The utility-consistent regional poverty lines estimated from the EPM (Table 16.1) show that between 2001 and 2010, the costs of basic needs have risen by over 116 per cent (an average of 8.0 per cent per year). In some regions, such as urban Mahajanga, they have risen even further (200 per cent). Rising costs of basic non-food items drove the rise in overall basic needs costs between 2001-5, while rising costs of basic food items were more responsible for rising overall basic needs costs in rural areas between

Table 16.1. Original and utility-consistent (UC) poverty lines, Madagascar, 2001-10

\begin{tabular}{|c|c|c|c|c|c|c|}
\hline & \multicolumn{3}{|c|}{ Ariary per person per day } & \multicolumn{3}{|c|}{ Relative to Urban Antananarivo } \\
\hline & 2001 & 2005 & 2010 & 2001 & 2005 & 2010 \\
\hline Antananarivo (urban) & 358 & 646 & 866 & 100.0 & 100.0 & 100.0 \\
\hline Antananarivo (rural) & 340 & 536 & 770 & 94.9 & 82.9 & 89.0 \\
\hline Fianarantsoa (urban) & 326 & 521 & 851 & 91.2 & 80.6 & 98.3 \\
\hline Fianarantsoa (rural) & 301 & 451 & 762 & 84.0 & 69.8 & 88.0 \\
\hline Toamasina (urban) & 362 & 572 & 937 & 101.0 & 88.4 & 108.3 \\
\hline Toamasina (rural) & 333 & 501 & 789 & 93.0 & 77.5 & 91.1 \\
\hline Mahajanga (urban) & 338 & 574 & 922 & 94.4 & 88.8 & 106.5 \\
\hline Mahajanga (rural) & 347 & 514 & 748 & 96.9 & 79.5 & 86.4 \\
\hline Toliara (urban) & 406 & 502 & 940 & 113.4 & 77.6 & 108.6 \\
\hline Toliara (rural) & 338 & 498 & 819 & 94.4 & 77.1 & 94.6 \\
\hline Antsiranana (urban) & 473 & 718 & 1,080 & 132.1 & 111.1 & 124.8 \\
\hline Antsiranana (rural) & 420 & 593 & 920 & 117.4 & 91.8 & 106.3 \\
\hline
\end{tabular}

Source: Authors' calculations from EPM data 
2005 and 2010. The poverty lines also illustrate substantial regional variation in costs of basic needs. For example, in 2005 the rural Fianarantsoa poverty line was 30 per cent below the urban Antananarivo poverty line, while in 2011 the urban Antsiranana poverty line was 25 per cent higher than in urban Antananarivo. In short, the different poverty lines and differential changes in these poverty lines lend credence to the need for specificity in constructing poverty lines.

\subsection{Context}

The first decade of the twenty-first century was a tumultuous one for Madagascar, with important political and economic shocks hampering gains made during the intervening years. It is thus important to place the snapshots of poverty as measured in the 2001, 2005, and 2010 EPM in the broader context of the events that took place in Madagascar during this time period and the decades leading up to it. In this section, we lay the groundwork for the poverty analysis by describing the general political and economic environment since independence and focus particularly on the first decade of the twenty-first century to relate this to the timing of the EPM surveys.

Madagascar gained independence from France in 1960. Nonetheless, colonial influence remained strong for a decade under the new Philbert Tsiranana government as a robust French military presence remained, foreign trade regulations favoured French business interests and trade with France, and the country maintained its membership in the Franc Zone (and consequently had no independent central bank) (Pryor 1990). As illustrated in Figure 16.1, per capita GDP grew by roughly 10 per cent over the first decade of independence. But this growth fell short of expectations and was not shared by all. This contributed to a growing nationalist movement that demanded economic independence from France and eventually toppled the government in 1972. The policies of the transitional government of Gabriel Ramanantsoa (1972-5) that restricted trade and led to the departure from the Franc Zone (France no longer guaranteed convertibility of the new Malagasy currency) disrupted the economy and began a long period of economic decline (Figure 16.1).

The perceived failure of President Tsiranana's economic policies discredited liberal policies and gave credence to a more ardent form of socialism that gained favour under President Didier Ratsiraka in 1975 and lasted until 1985. Importantly for rural dwellers at this time, nationalized enterprises to purchase crops were established, displacing private rural traders and leading to the 'disintegration' of agricultural markets (Pryor 1990). Further, the combination of nationalizing foreign enterprises and removing colonial-era poll and cattle taxes placed strains on the public purse. This did not stop the 


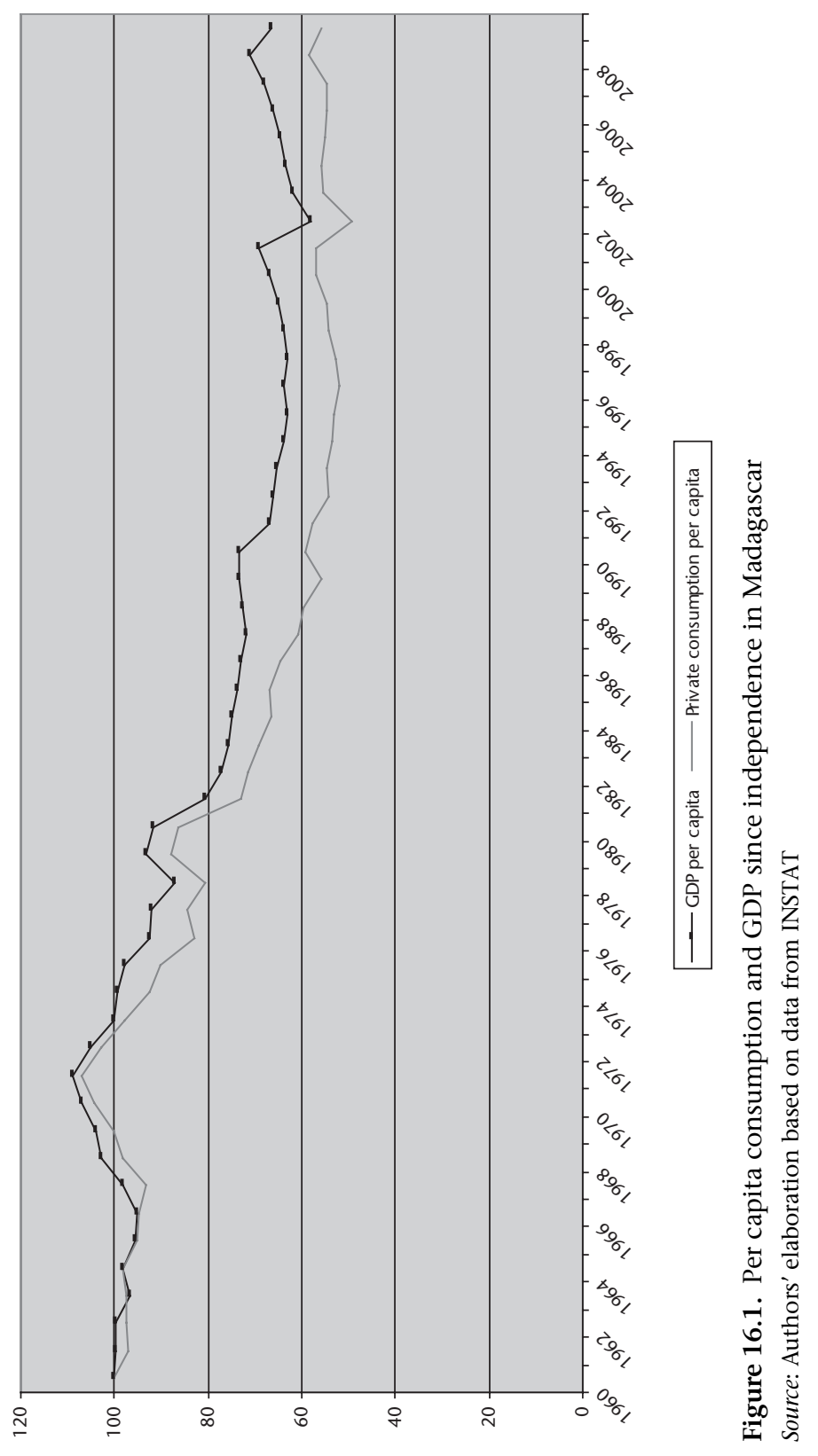


government in the late 1970s, however, from investing heavily in ill-chosen projects that had limited effect on the economy and that were financed by short-term debt (Pryor 1990). By 1984, real GDP per capita had fallen by over 20 per cent, leading the cash-strapped government to agree in 1985 to a liberalization plan as a condition for structural adjustment loans from the IMF and World Bank. Although moderate recovery followed, the adverse social effects of the stabilization plan along with growing demand for political freedoms resulted in a political crisis that toppled the Ratsiraka government and resulted in a fall in per capita GDP growth that did not recover until Ratsiraka was re-elected in 1997 (see Figure 16.1) on a platform of continued liberal reforms.

By the turn of the millennium, Madagascar had experienced its fair share of economic mismanagement and political shocks that resulted in per capita GDP levels that were roughly 40 per cent below what they were at the time of independence (Figure 16.1). Nonetheless, there was much hope that the next decade would not resemble the previous ones as liberalization reforms began to take hold. This was not to be, however, as the decade was also characterized by economic and political shocks that disrupted what could have potentially been a long-term turnaround. It is in this setting that the period of analysis in this chapter takes place.

The 2001 EPM survey was conducted at the end of 2001, just prior to the 16 December national elections. As such, it provides a reflection of livelihoods in Madagascar during the year prior to the negative fallout of the disputed elections. This was a year in which the IMF and the World Bank approved US\$819 million worth of debt relief for the country, and in which Madagascar qualified for the United States African Growth and Opportunity Act (AGOA) and 'Wearing Apparel' provisions. Growth of real per capita income in this year was a modest 3.1 per cent, driven largely by increased production in the industrial and service sectors (Table 16.2).

The year immediately following the survey, however, was one of economic and social disruption due to a disputed presidential election. Supporters of the incumbent president, Didier Ratsiraka, effectively blockaded the capital of Antananarivo by blowing up six bridges in protest against a 29 April ruling by the constitutional court that the challenger and former mayor of the capital city, Marc Ravalomanana, had won the first round of the election outright. By August, Ratsiraka had fled the country to live in exile in France, and the international community pledged US\$2.3 billion in support to the newly instated Ravalomanana government. But the damage had been done. The first eight months of the year witnessed tourism drying up, textile exports halting, some thirty textile factories shuttering their doors, fuel and foodstuff prices skyrocketing in the capital due to shortages, and foreign investors staying away. As a result, real per capita gross domestic product (GDP) shrank 
Table 16.2. Production and inflation in Madagascar, 2001-10

\begin{tabular}{|c|c|c|c|c|c|c|c|c|c|c|}
\hline & 2001 & 2002 & 2003 & 2004 & 2005 & 2006 & 2007 & 2008 & 2009 & 2010 \\
\hline $\begin{array}{l}\text { Per capita GDP } \\
\text { (thousands of } 2010 \\
\text { Ariary) }\end{array}$ & 984 & 836 & 893 & 914 & 930 & 951 & 982 & 1,024 & 955 & 933 \\
\hline $\begin{array}{l}\text { of real per } \\
\text { GDP }\end{array}$ & 3.1 & -15.0 & 6.8 & 2.4 & 1.8 & 2.2 & 3.3 & 4.2 & -6.7 & -2.3 \\
\hline $\begin{array}{l}\text { GDP (billions of } 2010 \\
\text { Ariary) }\end{array}$ & 15.0 & 13.1 & 14.4 & 15.2 & 15.9 & 16.7 & 17.7 & 19.0 & 18.2 & 18.3 \\
\hline -Pri & 4.7 & 4.6 & 4.7 & & & 5.1 & & & 5.8 & 5.6 \\
\hline$-\ln$ & 1. & 1. & 1. & & & 1.5 & & & 2.0 & 2.0 \\
\hline$-\mathrm{Se}$ & 7. & 6. & 6. & 2 & 7.7 & 8.3 & 8. & 9.6 & 8.9 & 9.0 \\
\hline & 6. & -12 & & & & & & & -4.1 & 0.4 \\
\hline & 4.0 & -1 & 1. & 3. & 2.5 & 2.1 & & 2.9 & 8.5 & -3.4 \\
\hline —Indus & 7.6 & -20.8 & 14.6 & 6. & 3.0 & 3.5 & $9.8-2-10$ & 3.6 & -7.8 & 0.2 \\
\hline & 6.1 & -15 & & & 6.1 & 7.4 & & & -7.5 & 1.7 \\
\hline $\begin{array}{l}\text { Rice (paddy) price } \\
\text { inflation }\end{array}$ & -16.4 & -0.8 & -5.3 & 50.6 & 33.6 & 18.3 & 33.1 & -16.2 & 14.3 & -4.9 \\
\hline General inflation & 7.4 & 16.5 & -1.7 & 14.0 & 18.4 & 10.8 & 10.3 & 9.2 & 9.0 & 9.2 \\
\hline
\end{tabular}

Note: Shaded areas indicate years during which EPM surveys were conducted.

Source: Authors' elaboration based on data from INSTAT and FAOSTAT

by 15 per cent over the course of the year, and by the end of 2002 the general price level was 16.5 per cent higher than in the previous year (Table 16.2). The industrial and service sectors were hardest hit, with production shrinking by 20.8 per cent and 15.0 per cent respectively. Given the remoteness that is characteristic of much of the agricultural sector, however, production in the primary sector fell by only 1.3 per cent. Clearly urban areas were hit hardest by the 2002 political crisis.

While 2003 was a year of recovery and of implementation of the country's first Poverty Reduction Strategy, 2004 was characterized by yet another crisis. This time, however, the origin was economic in nature, though it was likely exacerbated by the government's response. The combination of a 58 per cent depreciation of the Malagasy currency relative to the US dollar, along with a 43 per cent rise in the Bangkok US dollar price of rice in 2004, meant that domestic rice prices rose as the rice import parity rose substantially for a country that typically imports rice, its main staple crop. Coupled with uncertainty over government intentions and the harassment of rice importers, private-sector traders were discouraged and rice imports ended up being only 151 thousand tonnes in 2004, compared to 254 thousand tonnes in the previous year (Minten and Dorosh 2006). The reduction in the supply of rice in the domestic market manifested itself in an average increase in paddy rice prices of 50 per cent. Given the importance of rice in the Malagasy consumption basket and given the exchange rate depreciation, this also meant that general inflation was high at 14 per cent in 2004 (Table 16.2). 
The 2005 EPM was conducted during a period of political stability and continued overall growth led primarily by services and industry. This growth however was moderate and per capita incomes did not recover to pre-political crisis levels until 2007. Inflation remained high during this period, led largely by rapid rice price inflation, as changes in domestic rice prices in the latter half of the decade reflected changes in international rice prices. Tight monetary policy prevented general inflation from being even higher. This was also a period when Rio Tinto invested over US\$500 million in an ilmenite mine in southern Madagascar, and when a consortium led by Sherrit International initiated the construction of a US $\$ 4.76$ billion nickel laterite mine in the eastern part of the country. Further, while the textile sector benefitted from exports growth under AGOA and the preferential access Madagascar had to European markets under the Lomé Convention, textile exports did take a hit from the dismantling of the Multi-Fibre Agreement in March 2005 (Africa Confidential 2005).

The government of Marc Ravalomanana was generally viewed favourably by the international community as it made strides to attract foreign investment. Madagascar joined the South African Development Community (SADC) in 2005, and was the first country to sign a compact with the United States Millennium Challenge Account (MCA) when it signed a US\$110 million poverty reduction agreement in April 2005. Following his re-election in 2006, Ravalomanana's government developed its second poverty reduction strategy, dubbed the Madagascar Action Plan, in consultation with the international financial institutions. Under his watch, the economy continued its steady growth as per capita incomes grew annually by 2 to 4 per cent through 2008.

On the domestic front, however, resentment began to build over the president's potential conflicts of interest with respect to his agro-industrial corporation, his attempts to rapidly reform the army, the government's purchase of a luxurious official airplane, and the government's 2008 agreement to lease 1.3 million hectares of arable land to the South Korean conglomerate, Daewoo, for ninety-nine years. Protests in the streets of the capital, led by the president's rival and mayor of Antananarivo, Andry Rajoelina, and supported by factions of the army, led to Ravalomanana's eventual ousting in March 2009.

Unlike the 2002 political crisis when the international donors rallied around the new government by rapidly recognizing it and by providing US $\$ 2.3$ billion in support, the 2009 political crisis was followed by a slashing of aid. The ascendency of Rajoelina to Madagascar's top office was officially viewed by most of the international community as effectively a coup d'état. As such, most donors cut all but humanitarian assistance, as net official development assistance receipts fell from US\$843 million in 2008 to US\$444 million in 2009 (OECD-DAC 2013). Further, Madagascar was suspended from 
SADC and had its AGOA access terminated by January 2010. As a consequence, the 6.7 per cent fall in per capita income during 2009 was not followed by a recovery as seen in 2003 , but rather by a stagnation of total GDP and a further 2.3 per cent fall of per capita GDP, negating all of the gains made after 2005. It is this environment of stagnation following the 2009 crisis (some would say 'continued crisis') that is characterized by the 2010 EPM.

\subsection{Poverty and Inequality in the 2000s}

It is within the context of these multiple political and economic shocks that we analyse snapshots of poverty and inequality in Madagascar in the first decade of the 2000s. As illustrated in Figure 16.2, if we simply compare real per capita incomes during the EPM survey years (2001, 2005, 2010), we would conclude that the decade was characterized by stagnation and a persistent deterioration of well-being. However, when the intervening years are included, the picture becomes one of growth interrupted by political and economic shocks. As such, once we have described poverty and inequality levels using utility-consistent poverty lines for the three household survey years, we complement the analysis with indicators from other data sources to substantiate the consistency of these poverty and inequality estimates with the broader dynamic picture.

\subsubsection{Monetary Poverty and Inequality}

Poverty rates in Madagascar are high and rose over the course of the three survey periods (Table 16.3). In 2001, 57.8 per cent of the population was poor, compared to 59.1 per cent in 2005, and 61.7 per cent in 2010. Although poverty is largely a rural phenomenon, with over 63 per cent of the rural population below the poverty line, it is also becoming increasingly urban. The urban headcount ratio rose by a substantial 9.6 percentage points, from 34.2 per cent in 2001 to 43.8 per cent in 2010 .

The more distribution-sensitive measures of poverty reveal that the headcount ratios alone mask important distributional differences in changes in poverty. Indeed there is little change in the depth and severity of national poverty over the decade, and the changes that are observed indicate a slight reduction, not an increase. The poverty incidence curves shown in Figure 16.2 illustrate this graphically, as the crossing curves indicate no first-order dominance. For example, the real per capita household consumption levels (temporally and spatially deflated by the poverty lines to 2010 urban Antananarivo values) of the richest 55 per cent of the population fell between 2001 and 2005 (dark solid line above the light solid line), and did so again slightly between 
Table 16.3. Monetary poverty in Madagascar, 2001-10

\begin{tabular}{|c|c|c|c|c|c|c|}
\hline & \multicolumn{3}{|c|}{ Levels } & \multicolumn{3}{|c|}{ Changes } \\
\hline & 2001 & 2005 & 2010 & $2001-5$ & 2005-10 & $2001-10$ \\
\hline \multicolumn{7}{|l|}{ National } \\
\hline Headcount ratio $\left(\mathrm{P}_{0}\right)$ & 57.8 & 59.1 & 61.7 & 1.2 & 2.6 & 3.9 \\
\hline Depth of poverty $\left(\mathrm{P}_{1}\right)$ & 24.8 & 23.3 & 23.4 & -1.5 & 0.1 & -1.4 \\
\hline Severity of poverty $\left(P_{2}\right)$ & 13.4 & 12.0 & 11.6 & -1.4 & -0.4 & -1.8 \\
\hline \multicolumn{7}{|l|}{ Urban } \\
\hline Headcount ratio $\left(\mathrm{P}_{0}\right)$ & 34.2 & 42.7 & 43.8 & 8.4 & 1.2 & 9.6 \\
\hline Depth of poverty $\left(\mathrm{P}_{1}\right)$ & 12.8 & 15.4 & 16.0 & 2.5 & 0.7 & 3.2 \\
\hline Severity of poverty $\left(P_{2}\right)$ & 6.5 & 7.6 & 7.8 & 1.1 & 0.2 & 1.3 \\
\hline \multicolumn{7}{|l|}{ Rural } \\
\hline Headcount ratio $\left(\mathrm{P}_{0}\right)$ & 64.6 & 63.7 & 66.2 & -0.9 & 2.5 & 1.6 \\
\hline Depth of poverty $\left(\mathrm{P}_{1}\right)$ & 28.2 & 25.5 & 25.3 & -2.7 & -0.2 & -2.9 \\
\hline Severity of poverty $\left(P_{2}\right)$ & 15.4 & 13.3 & 12.6 & -2.1 & -0.7 & -2.8 \\
\hline
\end{tabular}

Note: Poverty measures are multiplied by 100 .

Source: Authors' calculations from EPM data

2005 and 2010 (dashed line above the dark solid line). At the same time, the poorest 40 per cent of the population experienced slight improvements in real consumption. Because the standardized poverty line ${ }^{1}$ is above the consumption level for the 45 th percentile, the headcount ratio captures the deteriorating consumption levels for those above this level. The improvements in consumption levels of the poorest 40 per cent of the population are not captured by the headcount ratio because these households remain poor throughout the decade. Nonetheless, these improved living standards for the poorest 40 per cent are captured by the decreases in the depth and severity of poverty. In short, the well-being of the poorest of the poor improved. It was just not enough to raise them out of poverty.

In urban areas, all of the poverty measures show a worsening of poverty, with the bulk of the change occurring between 2001 and 2005 (an 8.4 percentage point increase, compared to a 1.2 percentage point increase between 2005 and 2010). This is illustrated graphically in Figure 16.3a, where the poverty incidence curves for 2005 and 2010 are substantially higher than for 2001 for all but the poorest 10 per cent of the population. As noted in section 16.3, urban areas were hit hardest by the 2002 political crisis. The poverty

\footnotetext{
1 Because all per capita household consumption aggregate values are converted into 2010 urban Antananarivo values by using the regional poverty lines, the 2010 urban Antananarivo poverty line represents the standardized poverty line for all households in each survey year.
} 


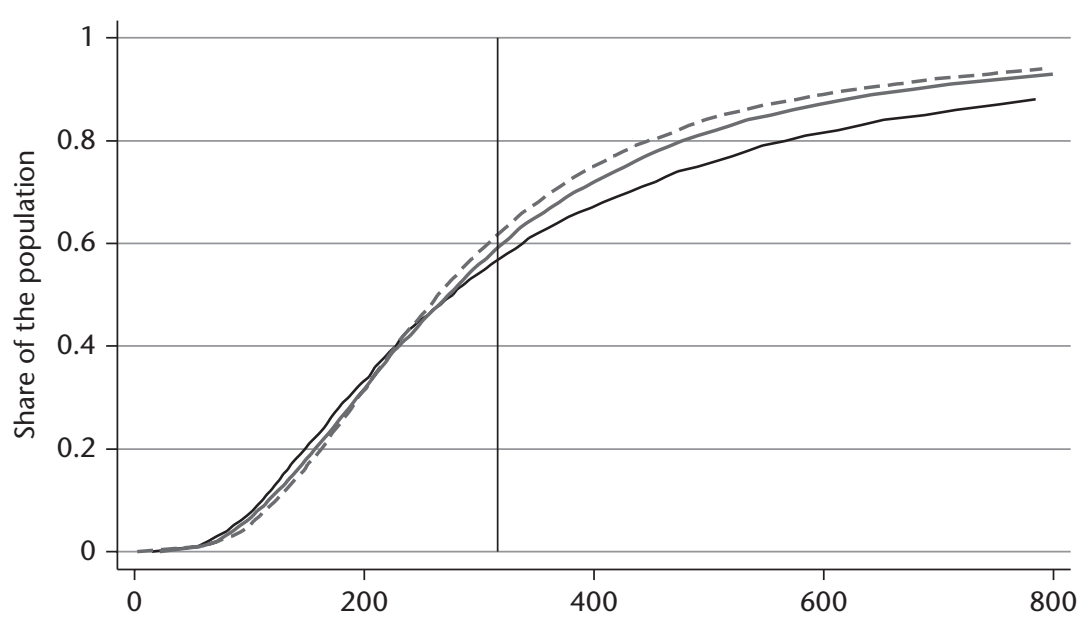

Thousands of 2010 urban Antananarivo Ariary per person per year

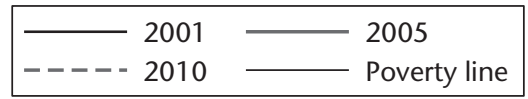

Figure 16.2. Poverty incidence curves, Madagascar, 2001-10 Source: Authors' calculations from EPM data

incidence curves in Figure 16.3a suggest that these areas had not recovered from the crisis by 2005, and that the 2009 crisis prevented real urban consumption levels from sustainably returning to 2001 levels. Higher levels of urban poverty, along with lower consumption levels among the non-poor, are arguably the legacy of the political and economic shocks that hit the country during this period.

Despite a greater percentage of the rural population falling below the poverty line over the course of the decade, the rural poor for the most part fared slightly better. As illustrated by the declining poverty depth and severity measures and by the improvements in the poverty incidence curves (lower) among the poorest 55 per cent of the rural population, the poorest half of the rural population was slightly better off at the end of the decade than it was at the beginning (Figure 16.3b). Nonetheless, although rural areas weathered the storm better than urban areas, rural poverty remains high by any measure.

Further disaggregation of poverty by region reveals some interesting messages. First, in 2001, urban poverty rates in all six of the provinces were lower than the poverty rates in all of the rural areas, with the exception of rural Antananarivo (Table 16.4). The 45.3 per cent of the rural Antananarivo population that was poor was lower than the 46.8 and 50.2 per cent in urban Toamasina and Toliara, respectively. The spillovers from the national capital and major market centre in urban Antananarivo, and the corresponding lower prices of 


\section{a.Urban}

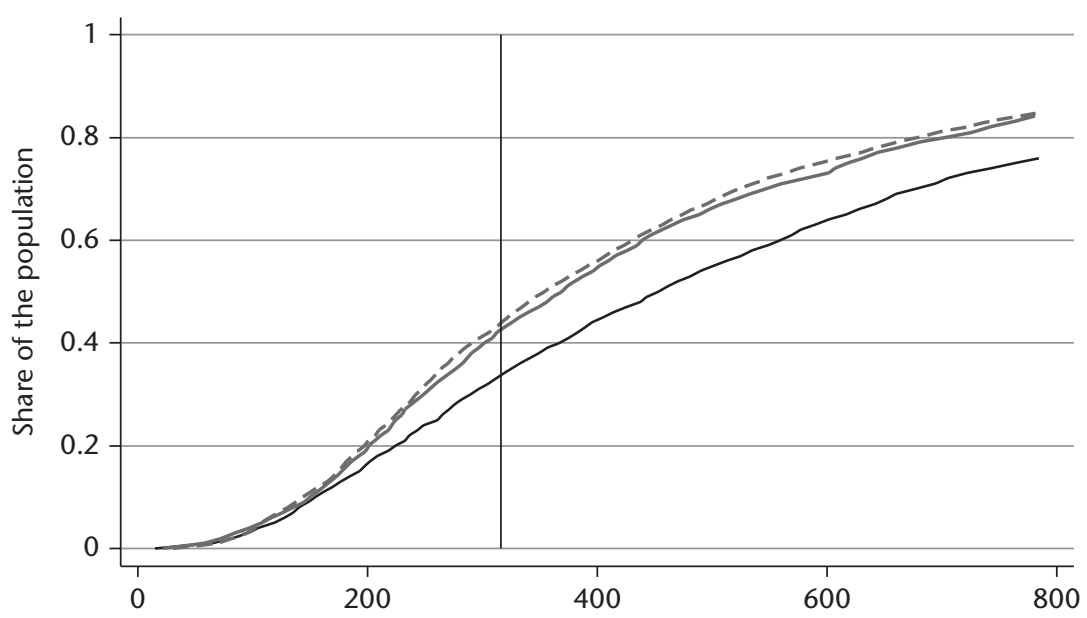

Thousands of 2010 urban Antananarivo Ariary per person per year

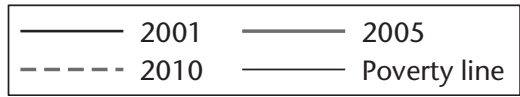

b.Rural

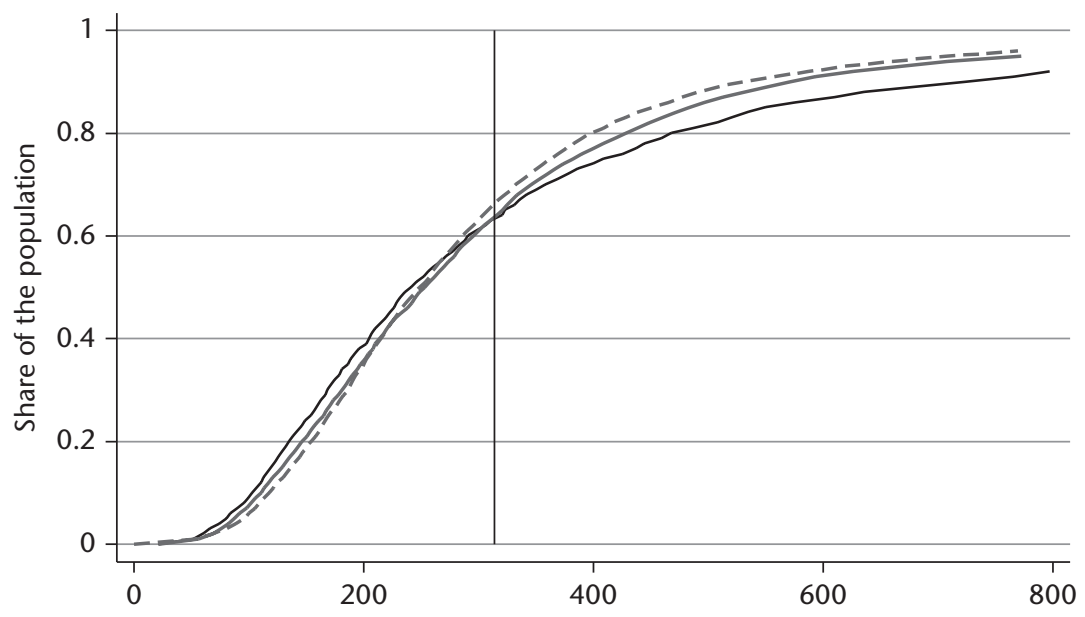

Thousands of 2010 urban Antananarivo Ariary per person per year

\begin{tabular}{|ll|}
\hline-2001 & 2005 \\
-----2010 & Poverty line
\end{tabular}

Figure 16.3. Poverty incidence curves, Madagascar, 2001-10 Source: Authors' calculations from EPM data 
Table 16.4. Regional poverty in Madagascar, 2001-10

\begin{tabular}{|c|c|c|c|c|c|c|}
\hline & \multicolumn{4}{|c|}{ Per cent poor } & \multicolumn{2}{|c|}{ Changes } \\
\hline & 2001 & 2005 & 2010 & $2001-5$ & 2005-10 & $2001-10$ \\
\hline Antananarivo (urban) & 21.1 & 37.3 & 35.1 & 16.2 & -2.2 & 14.0 \\
\hline Antananarivo (rural) & 45.3 & 64.2 & 53.1 & 18.9 & -11.2 & 7.7 \\
\hline Fianarantsoa (urban) & 42.5 & 59.7 & 54.7 & 17.2 & -5.0 & 12.3 \\
\hline Fianarantsoa (rural) & 74.3 & 65.9 & 77.4 & -8.5 & 11.5 & 3.1 \\
\hline Toamasina (urban) & 46.8 & 44.3 & 45.8 & -2.5 & 1.5 & -1.0 \\
\hline Toamasina (rural) & 74.2 & 62.4 & 65.1 & -11.8 & 2.7 & -9.1 \\
\hline Mahajanga (urban) & 36.5 & 37.8 & 45.9 & 1.3 & 8.2 & 9.5 \\
\hline Mahajanga (rural) & 71.8 & 62.4 & 60.5 & -9.4 & -1.9 & -11.3 \\
\hline Toliara (urban) & 50.2 & 43.7 & 57.1 & -6.5 & 13.4 & 6.9 \\
\hline Toliara (rural) & 70.5 & 65.0 & 72.9 & -5.5 & 7.9 & 2.5 \\
\hline Antsiranana (urban) & 21.9 & 27.8 & 27.8 & 5.9 & 0.0 & 5.9 \\
\hline Antsiranana (rural) & 60.0 & 54.1 & 68.1 & -5.9 & 14.0 & 8.2 \\
\hline Urban & 34.2 & 42.7 & 43.8 & 8.4 & 1.2 & 9.6 \\
\hline Rural & 64.6 & 63.7 & 66.2 & -0.9 & 2.5 & 1.6 \\
\hline National & 57.8 & 59.1 & 61.7 & 1.2 & 2.6 & 3.9 \\
\hline
\end{tabular}

Source: Authors' calculations from EPM data

non-food items there, were likely responsible for the relatively low level of poverty in rural Antananarivo. The relatively high poverty rate in urban Toamasina is somewhat surprising given that this area includes one of the most important ports in the country, though the region is particularly susceptible to the adverse effects of annual cyclones given its location along the east coast.

Second, in 2001, poverty rates were lowest in urban Antananarivo (location of the capital) and urban Antsiranana, at 21.1 and 21.9 per cent, respectively. This is not surprising given that the national capital is in the former, and given the importance of the deep-water port, vanilla exports, and tourism in the latter. The poorest regions in the country, rural areas in Toliara, Mahajanga, Toamasina, and Fianarantsoa, were considerably poorer (more than 70 per cent of the populations) than urban Antsiranana and urban Antananarivo.

Third, the changes in regional poverty over the three survey years were not uniform, nor were they necessarily consistent with the observed changes at the more aggregated urban and rural levels. For example, while the rural headcount ratio rose by some sixteen percentage points in rural Antananarivo between 2001 and 2005, they actually fell in the three poorest regions-rural Mahajanga, Toamasina, and Fianarantsoa. In urban areas, poverty rates rose by over nine percentage points overall during the period, while falling in urban Toamasina and Toliara. At the same time, urban poverty rose by over sixteen percentage points in Antananarivo and Fianarantsoa. This pattern is consistent with the directed and lasting effects of the blockade of the highlands (Antananarivo and Fianarantsoa) in 2002. 
Table 16.5. Inequality in Madagascar, 2001-10

\begin{tabular}{lccc}
\hline & 2001 & 2005 & 2010 \\
\hline $\begin{array}{l}\text { Gini coefficient } \\
\quad \text { National }\end{array}$ & 0.454 & 0.410 & 0.393 \\
$\quad$ Urban & 0.427 & 0.431 & 0.426 \\
$\quad$ Rural & 0.438 & 0.383 & 0.365 \\
Theil index & & & \\
$\quad$ National & 0.370 & 0.341 & 0.330 \\
Urban & 0.319 & 0.354 & 0.356 \\
$\quad$ Rural & 0.352 & 0.306 & 0.295 \\
Per cent due to & & & \\
$\quad$ Within-group inequality & 92.1 & 93.9 & 94.7 \\
$\quad$ Between-group inequality & 7.9 & 6.1 & 5.3 \\
\hline
\end{tabular}

Source: Authors' calculations from EPM data

Clearly, the differing poverty rates indicate that not all regions in Madagascar are equal. We now turn to how that translates into overall inequality of household consumption in the country as well as in urban and rural areas. The first thing to note is that the degree of inequality in Madagascar is typical of many African countries (World Bank 2011), as the Gini coefficient was 0.45 in 2001 (Table 16.5). Second, inequality fell over the course of the decade, as indicated by the Gini coefficient falling from 0.45 in 2001 to 0.39 in 2010, and the Theil index falling from 0.37 to 0.33 . This is not surprising, given the compression of the consumption distribution observed in Figure 16.1, as the top half of the population experienced worsening conditions while the bottom half saw marginally improved conditions.

The degree of inequality in rural areas was higher than in urban areas in 2001. But due to declining rural inequality, urban inequality was greater by 2010. As with national inequality, the fall in rural inequality over the three survey periods is also consistent with the compression of the poverty incidence curves in Figure $16.2 \mathrm{~b}$ as the poorest half of the population witnessed improved conditions alongside the worsening conditions of the richest 40 per cent. Unlike rural inequality, urban inequality worsened. It first rose between 2001 and 2005, but the change was ambiguous between 2005 and 2010. The Gini coefficient, for example, suggests that urban inequality fell back to 2001 levels by 2010, while the Theil index suggests that it rose further. This is consistent with crossing urban Lorenz curves during this time period (not shown here). However, what is clear about inequality in Madagascar is that it is driven primarily by inequality within urban and rural areas, rather than by the inequality between the two. Despite urban consumption levels being over 50 per cent higher on average than in rural areas, 94 per cent of total inequality is due to within-group inequality (Figure 16.5). This follows largely from the rural population accounting for roughly 80 per cent of the 
national population. As with poverty, rural inequality largely drives national inequality.

\subsubsection{Poverty and GDP}

National poverty rates in 2001, 2005, and 2010 are consistent with volatile trends in real per capita GDP over the decade. To illustrate this, we plot the poverty estimates from the EPM surveys along with real per capita GDP in Figure 16.4. What is clear from this graph is that the short-term shocks to the economy (primarily the 2002 and 2009 political crises, but the 2004 rice price crisis as well) appear to dominate long-term trends in growth and poverty. In short, the adverse consequences of the 2002 political shock between the 2001 and 2005 EPM surveys meant that despite the subsequent recovery, poverty rates were higher in 2005 than 2001. Similarly, given that the 2009 political crisis occurred between the 2005-10 EPM surveys, the gains in poverty reduction that likely occurred along with the persistent growth between 2005 and 2009 are not reflected in the 2010 headcount ratio, which is higher than in 2005. It would be a mistake to infer from these poverty estimates that there is a long-term trend of rising poverty in Madagascar. This is even more the case

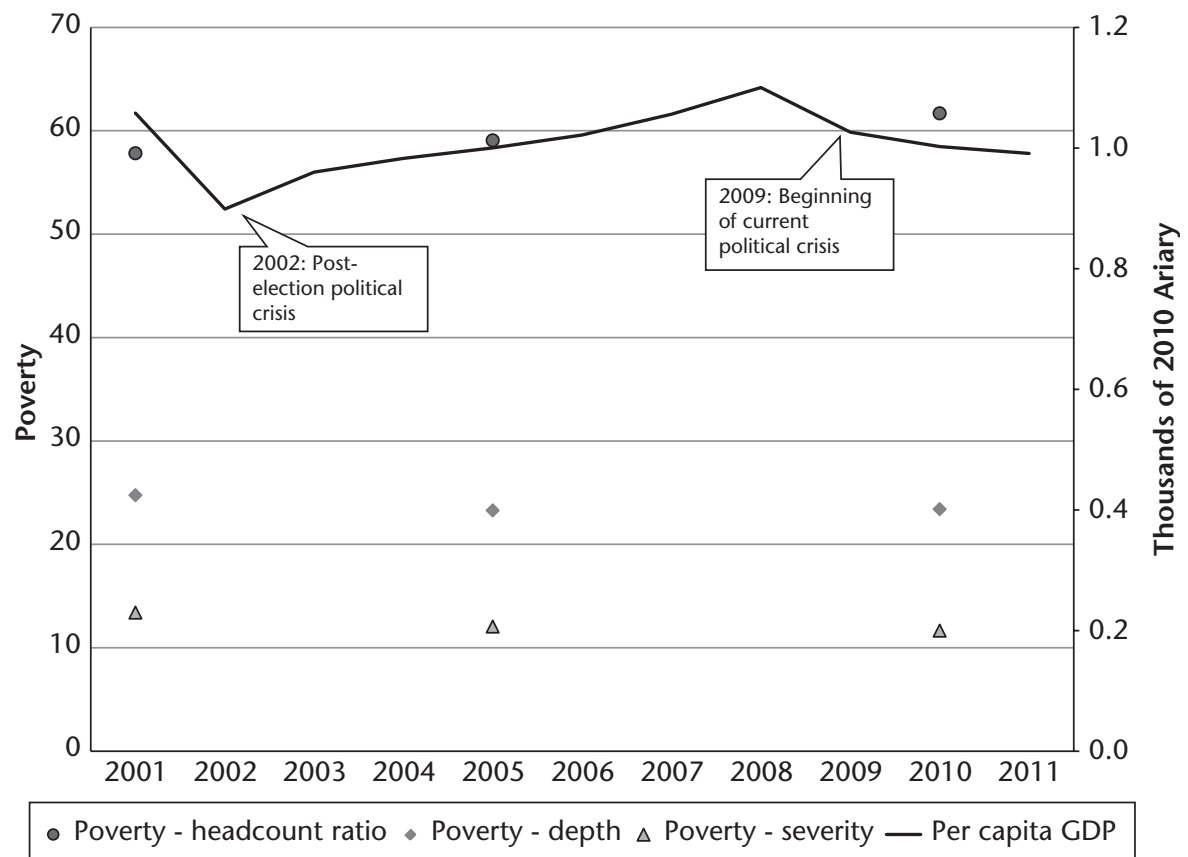

Figure 16.4. Poverty and real per capita GDP, Madagascar, 2001-10 Source: Authors' calculations from EPM data and INSTAT 
when we consider that the effects of the short-term shocks were not felt uniformly across the country. Indeed, the moderate and persistent increases in consumption levels of the poorer rural population throughout this time period (as illustrated in Figure 16.3b and as manifested by the slightly lower depth and severity of national poverty in Figure 16.4) suggest that poorer and more remote areas (Stifel and Minten 2008) fared better during this time period and were cushioned from the shocks that afflicted urban and less remote rural areas.

A sectoral breakdown of GDP is instructive vis-à-vis the differential impact of the shocks on poverty, and it provides insights into the sources of growth and the volatility of this growth. In Figure 16.5, we plot real GDP by sector along with regional poverty rates to illustrate the sectoral production trends and how they relate to poverty. We begin with the non-mining primary sector, given that it makes up 80 per cent of the labour force (Table 16.6), and given its strong link to the livelihoods of the poor (Randrianarison and Minten 2003; Stifel et al. 2007). Apart from the years directly affected by

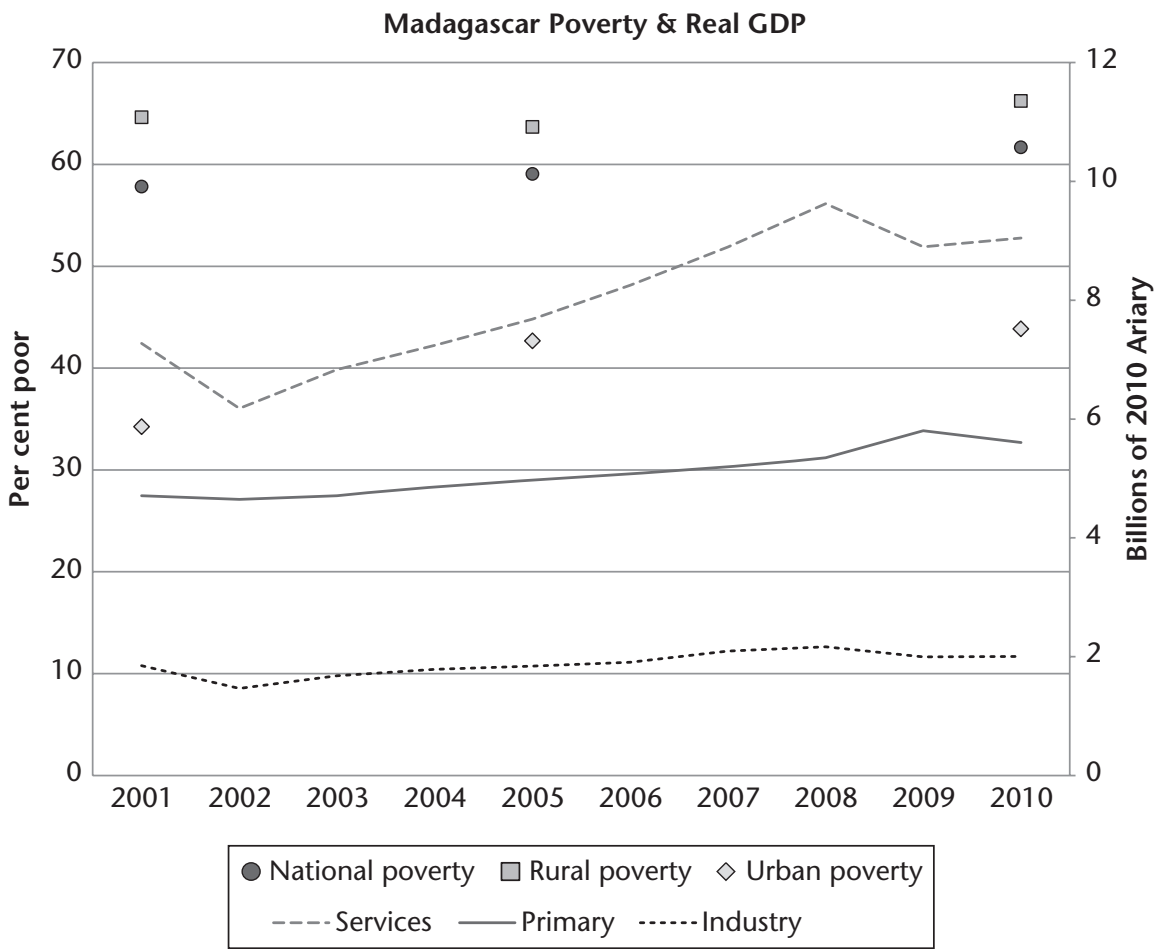

Figure 16.5. Poverty and real GDP by sector, Madagascar, 2001-10

Source: Authors' calculations from EPM data and INSTAT 
Table 16.6. Sectoral distribution of employment and the poor in Madagascar, 2001-10

\begin{tabular}{|c|c|c|c|c|c|c|c|c|c|}
\hline & \multicolumn{3}{|c|}{$\begin{array}{l}\text { Headcount ratio by } \\
\text { sector }\end{array}$} & \multicolumn{3}{|c|}{$\begin{array}{l}\text { Distribution of workers by } \\
\text { sector within residence }\end{array}$} & \multicolumn{3}{|c|}{$\begin{array}{l}\text { Distribution of workers by } \\
\text { residence within sector }\end{array}$} \\
\hline & 2001 & 2005 & 2010 & 2001 & 2005 & 2010 & 2001 & 2005 & 2010 \\
\hline \multicolumn{10}{|l|}{ National } \\
\hline Primary & 69.3 & 64.4 & 64.6 & 76.4 & 82.0 & 80.4 & 100 & 100 & 100 \\
\hline Industry & 22.6 & 31.1 & 38.0 & 6.8 & 3.4 & 4.6 & 100 & 100 & 100 \\
\hline Services & 19.3 & 30.5 & 30.1 & 16.8 & 14.6 & 15.0 & 100 & 100 & 100 \\
\hline Total & 57.8 & 59.1 & 61.7 & 100.0 & 100.0 & 100.0 & 100 & 100 & 100 \\
\hline \multicolumn{10}{|l|}{ Urban } \\
\hline Primary & 64.8 & 61.6 & 62.0 & 39.6 & 48.4 & 54.5 & 9.3 & 11.3 & 12.9 \\
\hline Industry & 16.2 & 29.6 & 24.7 & 17.1 & 11.0 & 9.8 & 44.9 & 61.6 & 40.6 \\
\hline Services & 17.0 & 26.0 & 20.0 & 43.4 & 40.6 & 35.7 & 46.1 & 53.3 & 45.1 \\
\hline Total & 34.2 & 42.7 & 43.8 & 100.0 & 100.0 & 100.0 & 17.9 & 19.2 & 19.0 \\
\hline \multicolumn{10}{|l|}{ Rural } \\
\hline Primary & 69.8 & 64.8 & 64.9 & 84.4 & 89.9 & 86.5 & 90.7 & 88.7 & 87.1 \\
\hline Industry & 27.8 & 33.5 & 47.2 & 4.6 & 1.6 & 3.4 & 55.1 & 38.4 & 59.4 \\
\hline Services & 21.3 & 35.6 & 38.5 & 11.1 & 8.5 & 10.2 & 53.9 & 46.7 & 54.9 \\
\hline Total & 64.6 & 63.7 & 66.2 & 100.0 & 100.0 & 100.0 & 82.1 & 80.8 & 81.0 \\
\hline
\end{tabular}

Source: Authors' calculations from EPM data

political crises, the primary sector experienced moderate growth that was slower than the industrial and service sectors (see also Table 16.2). Further, with the exception of 2009 when the growth rate was unexpectedly high, ${ }^{2}$ this growth was not enough to keep up the with the population growth rate. ${ }^{3}$ As such, while the primary sector did not serve as an engine for growth, it appears that it did, however, serve as a safety net for urban households who resorted to primary-sector activities in the wake of falling production in the service and industrial sectors during the crisis years. For example, the share of urban employment in the primary sector rose from 39.6 per cent in 2001 to 54.5 per cent in 2010 , while it fell in services and industry from 17.1 to 9.8 per cent, and 43.4 to 35.7 per cent, respectively. In rural areas, nonetheless, primary-sector growth did serve as a source of poverty reduction as the headcount ratio for rural households in this sector fell from 70 per cent to 65 per cent. Further, given the large portion of the rural population involved in agriculture, primary-sector growth likely contributed to the declining depth and severity of poverty illustrated in Figure $16.3 \mathrm{~b}$.

The service sector, which employs 15 per cent of the total labour force, accounts for the largest share of real GDP (54 per cent in 2010), and

\footnotetext{
2 According to FAO and Ministry of Agriculture data, the volume of rice production grew by 16 per cent in 2009 (see Figure 16.1), contributing significantly to the 10.7 per cent growth of agricultural production that year.

3 Estimated by INSTAT to be between 2.8 per cent and 3.1 per cent.
} 
experienced the most rapid intra-crisis growth rates. But it is also the sector that was most negatively affected by the political shocks. For example, real production in this sector fell by 1.1 billion Ariary in 2002, or roughly a 7 per cent fall in total real GDP. While industrial production also fell by 0.3 billion Ariary, it was the decline in service-sector production that contributed substantially to the increase in urban poverty observed between 2001 and 2005, despite the recovery in this sector beginning in 2003. This follows from the service sector accounting for the lion's share of urban employment (43.4 per cent in 2001), and the nine percentage point rise in the urban service-sector headcount ratio, even after 6 per cent of the labour in this sector shifted to agriculture. The impressive average annual 7.7 (6.8) per cent growth of service(industrial-)sector production between 2003 and 2008 undoubtedly contributed to the six percentage point decline (4.9 percentage point increase) in poverty in this sector between 2005 and 2010, though the decline would likely have been greater, and perhaps reduced poverty levels to 2001 levels, if not for the 2009 political crisis.

\subsubsection{EPM Poverty and Other Data Sources on Monetary Poverty}

Other non-nationally representative data sources show pictures of changes in poverty that are broadly consistent with those from the EPM. For example, a series of labour force surveys conducted in the capital Antananarivo, by Madio, show that wage poverty among formal-sector wage labourers rose significantly in the wake of the 2002 political crisis (Table 16.7), from 32 per cent to 38 per cent. These data also suggest, however, that by 2004 wage labourers in the capital had more than recovered as poverty for this group fell to less than 30 per cent. It is worth noting that these data did not include

Table 16.7. Urban labour poverty and rural household consumption in Madagascar, 2001-10

\begin{tabular}{|c|c|c|c|c|c|c|c|c|c|c|}
\hline & 2001 & 2002 & 2003 & 2004 & 2005 & 2006 & 2007 & 2008 & 2009 & 2010 \\
\hline \multirow{3}{*}{\multicolumn{11}{|c|}{$\begin{array}{l}\text { Urban poverty } \\
\text { Per cent of Antananarivo } \\
\text { workers who are poor } \\
\text { Rural household } \\
\text { consumption } \\
\text { (per capita) } \\
\text { Thousands of } 2001 \text { Ariary }\end{array}$}} \\
\hline & & & & & & & & & & \\
\hline & & & & & & & & & & \\
\hline Central (Itasy) & 61.0 & 66.1 & 74.2 & 126.6 & 158.1 & 115.8 & 119.8 & 115.6 & & \\
\hline South (Toliara) & 81.0 & 73.8 & 62.0 & 120.5 & & 167.9 & 150.1 & 127.7 & & \\
\hline Northeast (Fenerive) & 93.0 & 75.5 & 84.7 & 107.4 & 117.3 & 126.3 & & 107.8 & & \\
\hline Northwest (Marovoay) & 109.0 & 88.4 & 89.1 & 172.6 & 161.4 & 149.2 & & 150.5 & & \\
\hline
\end{tabular}

Notes: Shaded columns represent EPM survey years. * The 2010 survey includes both formal- and informal-sector labour. Source: Authors' calculation using data from Antananarivo Labour Force Survey and Réseaux Observitoires Ruraux 
formal-sector labour until the 2010 survey (note the considerably higher estimate of wage poverty that year), and that the higher 2005 urban Antananarivo poverty rate from the EPM, shown in Table 16.3, suggests that informal non-wage labour earnings were slower to recover.

Household per capita consumption measured from annual panel data from four rural communities collected from 1999 to 2008 (Réseaux Observitoires Ruraux), shows that although real per capita consumption levels fell during the 2002 political crisis for three of the four communities, they rose to above 2001 levels by 2005. This is consistent with the decline in rural poverty as measured by the depth and severity of poverty in rural areas in the EPM between 2001 and 2005.

\subsubsection{Poverty and Non-monetary Measures of Well-being}

The Demographic and Health Surveys (DHS) for Madagascar provide a nationally representative set of non-monetary indicators that complement the poverty estimates from the EPM. Although the timing of these surveys (1997, 2003-4, 2008-9, 2011) is not the same as the EPM $(2001,2005,2010)$, they nonetheless provide a rough sense of consistency with the trends in monetary poverty, and in some cases may indicate long-term trends in welfare. For example, stunting rates in children under five have declined over the period between the three years $(1997,2004$, and 2009) for which the DHS include anthropometric data for Madagascar (Table 16.8). While this high level of malnutrition-nearly half of all young children-is consistent with the high poverty rates in the country-over half of all individuals-the declines in

Table 16.8. Stunting rates in Madagascar

\begin{tabular}{lccc}
\hline & 1997 & 2004 & 2009 \\
\hline National & 48.3 & 47.3 & 45.4 \\
Gender & & & \\
Male & 51.8 & 48.5 & 47.6 \\
Female & 44.8 & 46.2 & 43.1 \\
Residence & & & \\
Urban & 41.3 & 37.0 & 34.3 \\
Rural & 49.2 & 48.9 & 46.4 \\
Province & & & \\
Antananarivo & 57.0 & 52.4 & 48.6 \\
Fianarantsoa & 51.6 & 47.8 & 48.3 \\
Toamasina & 47.8 & 47.3 & 30.3 \\
Mahajanga & 41.0 & 47.6 & 43.8 \\
Toliara & 36.5 & 40.5 & 33.3 \\
Antsiranana & 37.1 & 37.1 & \\
\hline
\end{tabular}

Note: Sample of children under age five

Source: Authors' calculations based on data from Madagascar DHS+ 
stunting are also potentially consistent with the snapshots of poverty measured in the EPM. Declines in monetary poverty after 1997 (Paternostro et al. 2001; Amendola and Vecchi 2007), along with over US\$100 million in donorsupported nutrition and health-sector projects, suggest that stunting rates likely fell between 1997 and 2001. These improvements, however, were interrupted by the political crisis in which skyrocketing fuel prices and road blockages led to farm incomes in 2002 falling by over 35 per cent (Randrianarison et al. 2002) and basic food prices more than doubling (Minten 2002), which disrupted household food consumption among rural households for an extended period of time and consequently worsened chronic child malnutrition (World Food Program 2002). Further, the 2004 rice price crisis, in which prices for the main staple crop rose by over 50 per cent, had detrimental effects on household rice consumption for net buyers of rice who tend to be the poor (Barrett and Dorosh 1996). As such, the 2004 stunting rates measured in the DHS would likely have been even lower had these two crises not occurred.

Birth history data collected in the 2004 and 2009 DHS enable us to construct retrospective estimates of infant (under age one) mortality rates (IMR) for each of the eight years prior to, but not including, the survey year. Plotting these IMRs shows two things (Figure 16.6). First, mortality rates are high, which is not surprising given high monetary poverty in Madagascar. For example, in 2001, roughly 60 children per 1,000 live births died before they reached their first birthday. Second, there is evidence of a long-term trend of improvements consistent with the stunting data. But unlike the stunting data, because we estimate IMR for each year, not just the survey years, we observe a sharp rise in mortality rates coinciding with the 2002 political crisis, and a levelling-out in 2004 during the rice price crisis.

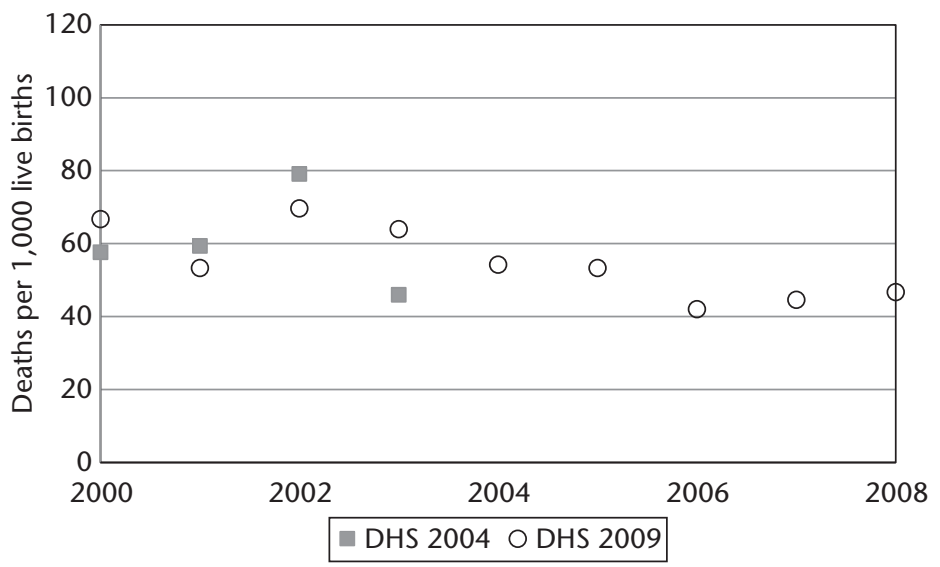

Figure 16.6. Annual infant mortality rates, Madagascar, 2000-8 Source: Authors' calculations based on data from Madagascar DHS+ 
Table 16.9. Net schooling enrolment rates in Madagascar, 2001-10

\begin{tabular}{|c|c|c|c|c|c|c|c|c|c|}
\hline & \multicolumn{3}{|c|}{ Total } & \multicolumn{3}{|c|}{ Boys } & \multicolumn{3}{|c|}{ Girls } \\
\hline & 2001 & 2005 & 2010 & 2001 & 2005 & 2010 & 2001 & 2005 & 2010 \\
\hline \multicolumn{10}{|l|}{ National } \\
\hline Primary & 49.4 & 66.2 & 73.4 & 50.6 & 65.9 & 72.4 & 48.2 & 66.4 & 74.5 \\
\hline Secondary (collège) & 6.4 & 12.9 & 22.7 & 5.4 & 12.3 & 21.0 & 7.5 & 13.4 & 24.5 \\
\hline Secondary (lycée) & 4.1 & 2.8 & 6.3 & 3.1 & 3.1 & 6.0 & 5.1 & 2.6 & 6.7 \\
\hline \multicolumn{10}{|l|}{ Urban } \\
\hline Primary & 67.5 & 72.5 & 80.1 & 63.8 & 71.5 & 78.9 & 70.9 & 73.6 & 81.4 \\
\hline Secondary (collège) & 15.6 & 24.0 & 37.8 & 15.4 & 22.1 & 33.7 & 15.8 & 25.9 & 42.3 \\
\hline Secondary (lycée) & 7.7 & 9.0 & 17.2 & 5.2 & 11.3 & 17.0 & 9.5 & 6.9 & 17.5 \\
\hline \multicolumn{10}{|l|}{ Rural } \\
\hline Primary & 45.0 & 64.7 & 71.9 & 47.5 & 64.6 & 70.8 & 42.7 & 64.8 & 73.0 \\
\hline Secondary (collège) & 3.7 & 9.9 & 19.2 & 2.7 & 9.7 & 18.0 & 4.9 & 10.0 & 20.4 \\
\hline Secondary (lycée) & 2.9 & 1.0 & 3.4 & 2.6 & 0.8 & 3.3 & 3.3 & 1.3 & 3.5 \\
\hline
\end{tabular}

Source: Authors' calculations from EPM data

Finally, as with other non-monetary measures of well-being, net schooling enrolment rates showed persistent improvement between 2001 and 2010 (Table 16.9), despite the increases in monetary poverty measured over the survey years. For example, the net primary enrolment rate rose from 49.4 per cent in 2001 to 73.4 per cent in 2010. In line with the Millennium Development Goal of equal access to education for girls, enrolment rates for girls rose faster than for boys over the decade. By 2010, girls' enrolment rates at all primary and secondary levels were higher than boys' enrolment rates regardless of area of residence. While more boys and girls attended school at the end of the decade, there is still considerable room for improvement. Only 6.3 per cent of upper-secondary school-aged (lycée) children were enrolled in school in 2010. This low level of human capital accumulation is going to prove challenging for future poverty reduction in Madagascar.

\subsection{Concluding Remarks}

In this chapter, we analyse poverty in Madagascar in 2001, 2005, and 2010 using Arndt and Simler's (2010) utility-consistent approach to calculating cost-of-basic-needs $(\mathrm{CBN})$ poverty lines. These consistent yet specific poverty lines, along with consumption aggregates calculated from comparable survey instruments, form the basis of the monetary poverty analysis in this chapter.

The Madagascar case is complicated by the fact that two major political crises along with a rice price crisis occurred between the survey periods. As such, the snapshots of national poverty rising from 57.8 per cent in 2001 to 
59.1 per cent in 2005, and to 61.7 per cent in 2010, are not necessarily indicative of a trend of persistently rising poverty. The challenge is to disentangle the long-term poverty trends from the short-term shocks that may affect poverty estimates in a particular year. Indeed, complementary data from the national accounts, non-nationally representative surveys, and nonmonetary measures of well-being suggest that in the time periods between the shocks, the well-being of the poorer segments of society improved. This evidence suggests that poverty estimates for Madagascar are more of a reflection of short-term shocks than of long-term trends.

\section{References}

Africa Confidential (2005). 'Madagascar: Joining the Club', Africa Confidential, 46(6). Amendola, N. and G. Vecchi (2007). 'Growth, Inequality and Poverty in Madagascar, 2001-2005'. Mimeo. Antananarivo, Madagascar: World Bank.

Arndt, C. and K. Simler (2010). 'Estimating Utility-Consistent Poverty Lines with Applications to Egypt and Mozambique', Economic Development and Cultural Change, 58(3): 449-74.

Barrett, C. and P. Dorosh (1996). 'Farmers' Welfare and Changing Food Prices: Nonparametric Evidence from Rice in Madagascar', American Journal of Agricultural Economics, 78(3): 656-69.

Minten, B. (2002). 'Study of the Impact of the Political Crisis through Price Analysis of Goods in Urban and Rural Areas', Programme ILO Political Crisis Policy Brief 4. Ithaca, NY: Cornell University.

Minten, B. and P. Dorosh (2006). 'Rice Markets in Madagascar in Disarray: Policy Options for Increased Efficiency and Price Stabilization', Africa Region Working Paper Series 101. Washington, DC: World Bank.

OECD DAC (Organization for Economic Cooperation and Development Development Assistance Committee) (2013). 'Aid Statistics', <http://www.oecd.org/dac/stats/>, accessed 17 May 2013.

Paternostro, S., J. Razafindravonona, and D. Stifel (2001). 'Changes in Poverty in Madagascar: 1993-1999', Africa Region Working Paper Series 19. Washington, DC: World Bank.

Pradhan, M. (2000). 'How Many Questions Should Be in a Consumption Questionnaire? Evidence from a Repeated Experiment in Indonesia', Cornell Food and Nutrition Policy Program Working Paper 112. Ithaca, NY: Cornell University.

Pryor, F. (1990). The Political Economy of Poverty, Equity, and Growth: Malawi and Madagascar. Oxford: Oxford University Press for the World Bank.

Randrianarison, L. and B. Minten (2003). 'La main-d'œuvre agricole à Madagascar'. Paper presented at the conference Agriculture et Pauvrete à Madagascar, 20 March, Antananarivo, Madagascar.

Randrianarison, L., J. Rarivoarivelomanana, and B. Minten (2002). 'Impact of the Political Crisis on the Agricultural Sector', Programme ILO Political Crisis Policy Brief 7. Ithaca, NY: Cornell University. 
Ravallion, M. (1998). 'Poverty Lines in Theory and Practice', Living Standards Measurement Study Working Paper 133. Washington, DC: World Bank.

Ravallion, M. and B. Bidani (1994). 'How Robust Is a Poverty Profile?', World Bank Economic Review, 8: 75-102.

Scott, C. and B. Amenuvegbe (1990). 'Effect of Recall Duration on Reporting of Household Expenditures: An Experimental Study in Ghana', Social Dimensions of Adjustment in Sub-Saharan Africa Working Paper 6. Washington, DC: World Bank.

Stifel, D. and B. Minten (2008). 'Isolation and Agricultural Productivity', Agricultural Economics, 39(1): 1-15.

Stifel, D., F. H. Rakotomanana, and E. Celada (2007). 'Assessing Labor Market Conditions in Madagascar, 2001-2005', Africa Region Working Paper Series 105. Washington, DC: World Bank.

World Bank (2011). World Development Indicators 2011. Washington, DC: World Bank. World Food Program (2002). 'WFP Assists 35,000 Malnourished Children Affected by Political Crisis in Madagascar'. Geneva: United Nations World Food Program. 


\title{
17
}

\section{Poverty, Inequality, and Prices in Post-Apartheid South Africa}

\author{
Murray Leibbrandt, Arden Finn, and Morné Oosthuizen
}

\subsection{Introduction}

The widespread poverty and extreme inequalities prevalent at the time of the democratic transition represented a key area of policy focus for the first democratic government, as well as one of the sets of outcomes against which its performance has often been judged. Poverty and inequality trends during the post-apartheid period have consequently been the subject of intensive analysis in South Africa. While little data on household incomes and expenditures existed prior to the transition, regular nationally representative household surveys undertaken since the early 1990s by Statistics South Africa and other institutions have filled this gap. The availability of these data provided the platform for the research effort.

That said, the effect of prices on purchasing power is typically given only passing attention in the South African literature on poverty and inequality. Typically, incomes or expenditures are deflated by a scalar derived from some version of the consumer price index (CPI) in order to make comparisons over time. This leaves the effect of differential price movements across the distribution as a key gap. It is hoped that this chapter will contribute towards filling this gap by more purposefully considering the impact of prices on estimates of poverty and inequality.

The chapter starts by reviewing the received wisdom on post-apartheid growth and poverty well-being. It summarizes the secondary literature along with some new descriptive work that uses income data and non-money-metric sources. Section 17.3 reviews the available national expenditure data covering the past almost twenty years, with a view to choosing appropriate datasets for the analysis of the role of prices. It also considers the relevant available price 
data. The section goes on to assess in detail the sensitivity of poverty and inequality estimates to differential price movements over this period. The central task of section 17.4 of the chapter is to tease out which prices changes were particularly influential in driving these findings. Section 17.5 concludes by summarizing findings, paying particular attention to the implications for policies that have been put in place over the post-apartheid period to address the apartheid legacy of high poverty and inequality.

\subsection{Existing Evidence on the Evolution of Post-Apartheid Well-being}

\subsubsection{The Narrative}

South Africa's economy has undergone substantial changes since the advent of democracy in 1994. Economic growth stagnated during apartheid due to sanctions on international trade and investment, uncompetitive local industries, rigid exchange controls, restricted skills development, and high levels of poverty and inequality (Aron et al. 2008). After the first democratic election, economic sanctions were dropped, labour restrictions were lifted, and policies were put in place to advance the interests of African workers. South Africa has since had stable macro management and, as shown in Table 17.1, the economy has grown steadily both in real and nominal terms.

Over the same period, the schooling system was transformed from one characterized by highly skewed spending across racial groups to one based on equitable government funding. School enrolment rates rose, though learning achievements remain very poor in previously disadvantaged schools (Van der Berg 2007). The new, young labour market participants have more education, on average, than their parents. Two in five young adults graduate with

Table 17.1. South African macroeconomic trends, 1993-2012

\begin{tabular}{lcccc}
\hline & GDP (ZAR million) & GDP growth (\%) & GDP per capita & $\begin{array}{c}\text { GDP per capita } \\
\text { growth (\%) }\end{array}$ \\
\hline 1993 & $1,065,830$ & 1.2 & 28,277 & -0.9 \\
1997 & $1,214,768$ & 2.6 & 29,582 & 0.5 \\
2001 & $1,337,382$ & 2.7 & 30,024 & 0.8 \\
2005 & $1,571,082$ & 5.3 & 33,176 & 3.9 \\
2008 & $1,814,594$ & 3.6 & 36,392 & 2.3 \\
2010 & $1,842,052$ & 3.1 & 36,079 & 1.9 \\
2012 & $1,954,303$ & 2.5 & 37,476 & 1.5 \\
Avg. 1993-2012 & $1,470,001$ & 3.2 & 32,031 & 1.5 \\
\hline
\end{tabular}

Source: Updated from Leibbrandt et al. (2010); South African Reserve Bank (2013) 
Matric certificates (the qualification awarded to those who pass nationally set, standardized exams at the end of secondary schooling).

Other countries, such as Brazil and India, have seen education gains translate into productivity and employment growth, and large decreases in poverty and inequality. Job creation in a dynamic labour market served as the key pathway through which these societies generated high social returns to improved education and indirect benefits to social transfers.

South Africa has not made similar gains. Over the post-apartheid period, poverty has fallen only sluggishly. Eighteen years after the first democratic election, the share of people living below a US $\$ 2$ per day poverty line has declined by no more than four percentage points from 34 per cent in 1993 to 30 per cent in 2008. These gains are often attributed to social policy reforms (a massive expansion of cash grant transfers) rather than economic development (Leibbrandt et al. 2010). Of equal concern is the fact that inequality has risen further from its very high levels under apartheid (Leibbrandt et al. 2010).

Just as the labour market was the key intermediary in the successes in Brazil and India, so the unsatisfactory performance of the labour market sits centre stage in South Africa's disappointing development outcome. A total of 2.74 million jobs (net) were created between 1993 and 2008, of which 2.5 million were targeted at skilled labour, while unskilled workers lost a total of 770,000 jobs (net). Over the same period, unemployment rates more than doubled from 14 per cent in 1993 to a peak of 29 per cent in 2001, before declining to 23 per cent in 2008. By the time of the economic crisis in 2010, the unemployment rate had risen to 25 per cent, using the narrow definition of unemployment (National Treasury 2011). If discouraged workers-those who have stopped looking for work 'because they do not anticipate finding any'-are included in this definition, the figure is substantially higher at about 32 per cent (Statistics South Africa 2012b). Of the total population of four million unemployed, 75 per cent are long-term unemployed and many young job seekers report having limited or no formal work experience, even at age 30 (National Treasury 2011). The informal sector is small, with only 6 per cent of South Africans in self-employment. The supply of labour is therefore primarily directed at jobs in the formal sector.

In general, this labour market situation has had a negative impact on poverty because of the failure to pull individuals from poor households into employment. Leibbrandt et al. (2010) show that, in 2008, 32 per cent of South Africa's 13.2 million households were no-worker households. The same figure was 26 per cent in 1993, implying an increase over the last fifteen years in the number of households relying on assistance, especially child support grants, as their main form of income. Indeed, the improved aggregate poverty situation is due to increased support from social grants, and not from the labour market. Even in one-worker households, the poverty incidence remains high 
as many workers are in low-paid employment. Clearly an employed person within a household does not a guarantee an escape from poverty.

The poverty impacts of pervasive unemployment are compounded by a social protection gap that exists for unemployed adults, as social cash grants target people who are not expected to be economically active: children, pensioners, and people with disabilities. This leaves unemployed adults deeply dependent on goodwill transfers from within their communities, placing a large care burden on communities and deepening poverty.

Leibbrandt et al. (2010) show that these same labour market dynamics have played a dominant role in driving inequality over the post-apartheid period. Even though the average share of wage income in total income has remained constant at around 70 per cent, wage income has contributed 85-90 per cent of the total inequality in household income. In contrast, state transfers are shown to be mildly redistributive or to have a neutral impact on the overall Gini coefficient.

\subsubsection{Trends in Money-Metric Poverty and Inequality}

Most of the analysis of poverty and inequality in post-apartheid South Africa has used income as the welfare measure. Leibbrandt et al. (2010) use household income per capita to track changes in inequality and poverty between 1993 and 2008, and include a short section on the comparability of income and expenditure in the datasets that were used. It is understood that the expenditure data in 1993 are not as reliable as the income data, thus motivating the focus on an income-based comparison.

We briefly present some of the quantitative analysis that has been undertaken in support of the above narrative using income data from national household surveys. Figure 17.1 shows three post-apartheid real income per capita densities as an example of extensive empirical work that has been undertaken on the distribution of income (Fedderke et al. 2003; Simkins 2004; Hoogeveen and Özler 2006; Van der Berg et al. 2006, 2008). It provides a representative snapshot of the weight of evidence. ${ }^{1} \mathrm{~A}$ poverty line is inserted on the graph as a reference point. It is a cost-of-basic-living poverty line developed by Hoogeveen and Özler (2006) and has a real value of ZAR573 per person per month.

The graph shows that the distribution of real income shifted rightwards at almost all points between 1993 and 2010. At the bottom of the distribution, the major shift took place between 1993 and 2000, with relatively little movement between 2000 and 2010. This pattern is reversed as we move up

\footnotetext{
1 This section is based on Finn et al. (2014).
} 


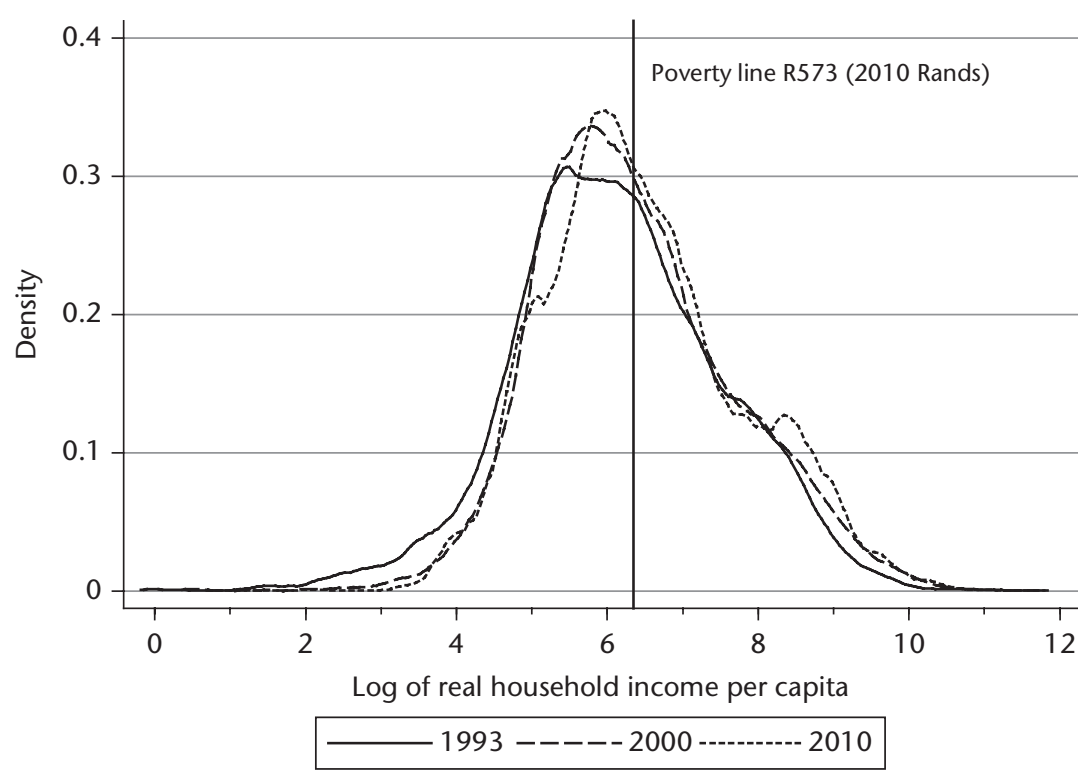

Figure 17.1. Distributions of income, 1993, 2000, and 2010

Source: Authors' illustration based on data from PSLSD 1993, Income and Expenditure Survey (IES) 2000, and NIDS Wave 22010

the distribution (but remain below the poverty line) where we see that there was a significant rightward shift from 2000 to 2010.

There is evidence of a significant rightward shift at the very bottom of the distribution, and poverty dominance analysis confirms a reduction in poverty. However, this is not a dramatic decrease in poverty. According to the poverty head count ratio-simply the proportion of the population living below the poverty line-the poverty rate at the lower poverty line stood at 56 per cent in 1993 and remained steady at around 54 per cent for the later years in our analysis. The reduction in poverty incidence using the upper poverty line also stands at two percentage points-from 72 per cent in 1993 to 70 per cent in the late 2000s. The rightward shift at the bottom of the distribution is reflected by consistent decreases in the poverty gap rate, which gives us a broad measure of the depth of poverty in society. The main driver behind increasing incomes at the bottom of the distribution is the rapid expansion of the government social support programme. The importance of state grants in raising these incomes is highlighted in Leibbrandt et al. (2010), who note that in 1993 one-fifth of households were beneficiaries of state grants, while in 2008 this proportion had climbed to one-half, and Leibbrandt and Levinsohn (2011), Bhorat and Van der Westhuizen (2011), and Woolard and Leibbrandt (2011) show clearly that social grants reduced both poverty and inequality. 
The expansion of government grants was not complemented by a reduction in the unemployment rate. The labour market is by far the most important factor to consider when decomposing poverty (see Leibbrandt et al. 2010). While the expansion of state support has helped to lower poverty, persistently high levels of unemployment have prevented poverty reduction on a substantial scale. In 1993, almost 90 per cent of individuals living in a workless household were living below the poverty line. This reduced somewhat to around 80 per cent in the period under study, but it remains very high. In fact, almost half of the poor in the country live in a workless household. This is in contrast to the poverty share of those living in households with two or more workers, which stands at around 17 per cent.

Leibbrandt et al. (2010) decompose poverty by different groups and reveal that the decrease in poverty in post-apartheid South Africa is driven mainly by a fall in the poverty incidence among Africans, and particularly African males. Poverty rates for this group fell from 66 per cent to 60 per cent, while the corresponding figures for African females are 72 per cent and 68 per cent. Despite these changes, the African share of overall poverty remained constant at 93 per cent in 1993, 2000, and 2010. This far outweighs the African share in the overall population, which is close to 80 per cent.

A great deal of rural-urban migration took place in South Africa in the period under study. Our data reflect that the share of urban residents in the population rose from 49 per cent in 1993 to 60 per cent in the late 2000s. As a result of this movement, the urban share of total poverty rose from 30 per cent to about 43 per cent. That said, the poverty rate in rural areas was higher than in urban areas for any choice of poverty line.

We move now to a discussion of inequality. At the start of the postapartheid period South Africa stood as one of the most unequal societies of all countries with reasonably good survey data. In panel A of Figure 17.2, we plot three Lorenz curves for 1993, 2000, and 2010.

All three Lorenz curves suggest the high level of inequality. The richest 20 per cent of people earn about 70 per cent of the total income, and the second richest about 20 per cent of total income. Thus the poorest 60 per cent together earn about 10 per cent of the total income in the population. This is approximately true regardless of which dataset is being used, and is exceptionally low by international standards. The primary observation is that the distributions do not vary much with time. In this case, the 2000 graph lies slightly below 1993, and the 2010 distribution almost perfectly overlaps with 1993. The big picture conclusion is that inequality has remained mostly stable and stubbornly high over the post-apartheid era (see Leibbrandt et al. 2010; Van der Berg 2011).

Whereas Lorenz curves are unaffected by the mean of the income distribution, the generalized Lorenz curves of panel B are shifted up by mean income. 


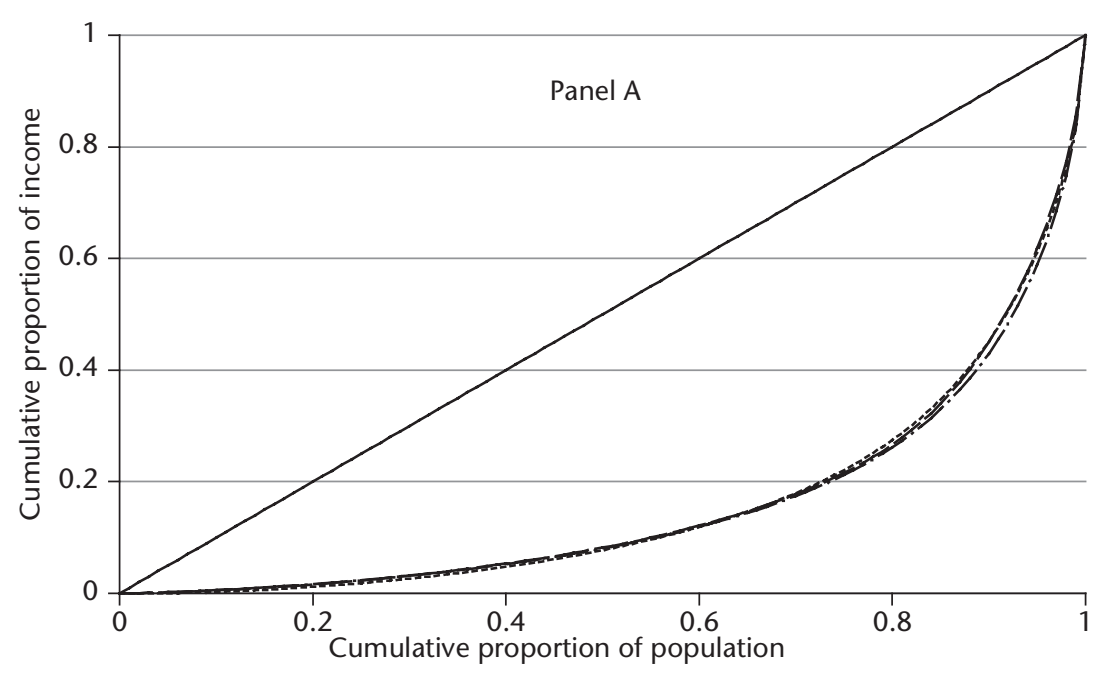

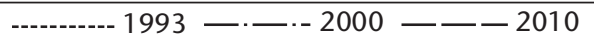

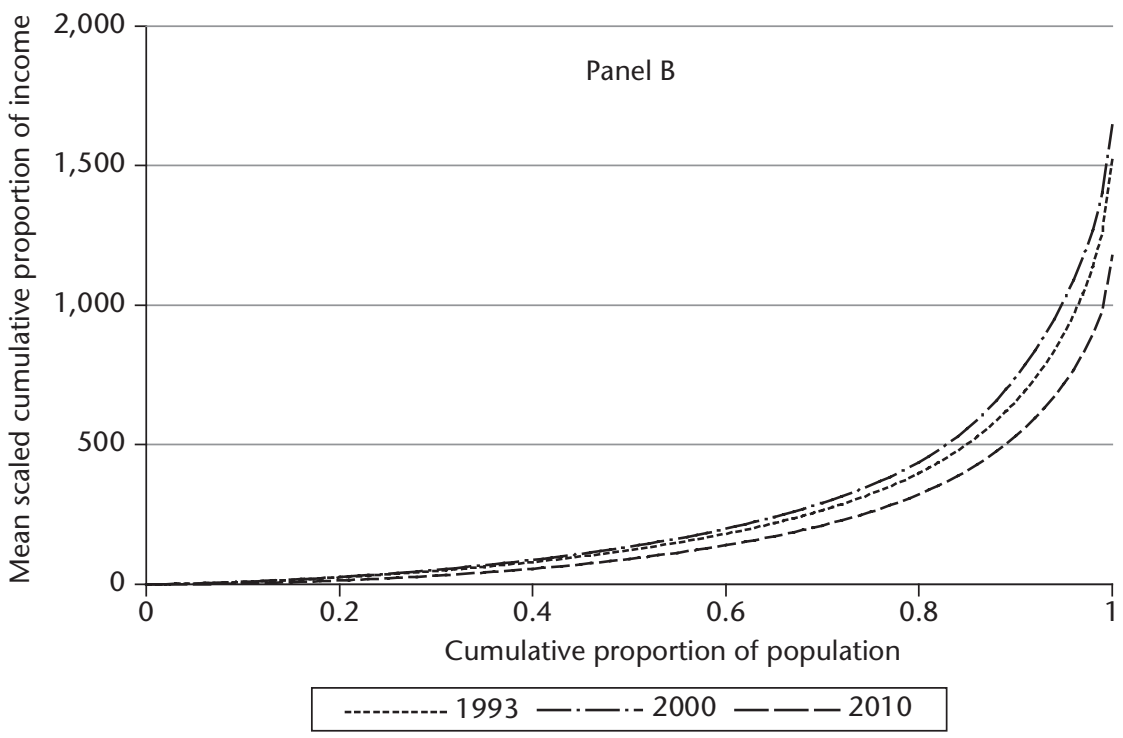

Figure 17.2. Lorenz curves, 1993, 2000, and 2010

Source: Authors' illustration based on data from PSLSD 1993, IES 2000, and NIDS Wave 2010

While the Lorenz curves give a graphical measure of income inequality, the latter provide a graphical measure of social welfare through the inclusion of both inequality and mean income. If everyone in a society earned twice as much as they previously did, the new generalized Lorenz curve would rotate upwards, whereas the corresponding Lorenz curve would remain unchanged. 
We observe from panel B that the 1993 distribution is always below the 2000 distribution, which in turn is always below the 2010 distribution. Thus, panels A and B together reflect a society with high but stable inequality and with rising mean incomes amounting to an improvement in aggregate welfare over this time period.

However, an increasingly pressing policy focus has developed as to why South Africa's inequality seems to be so stubbornly persistent. Some of the evidence points to the emergence of a small but well-paid black professional class. Hoogeveen and Özler (2006) find increases in inequality between 1995 and 2000, and attribute this mostly to increases in inequality among the African subpopulation. Using decomposition work, Leibbrandt and Levinsohn (2011) have emphasized the importance of unemployment and earnings. Pushing further down this road, a literature has highlighted the high rates of return to tertiary qualifications in conjunction with wide variations in the quality of primary and secondary schooling (Van der Berg 2009; Pellicer and Ranchhod 2012; Branson and Leibbrandt 2013a, 2013b).

Figure 17.3 follows on to provide a representative snapshot of the empirical work that has been undertaken to understand the drivers of these changes. It shows the share of income sources in total household income by income quintile in 2008. The proportion of income derived from wages increases linearly by income quintile. If a person is a member of a household situated in the poorest five deciles, the person is likely to receive relatively little wage income and to depend quite heavily on government grants and subsidies.

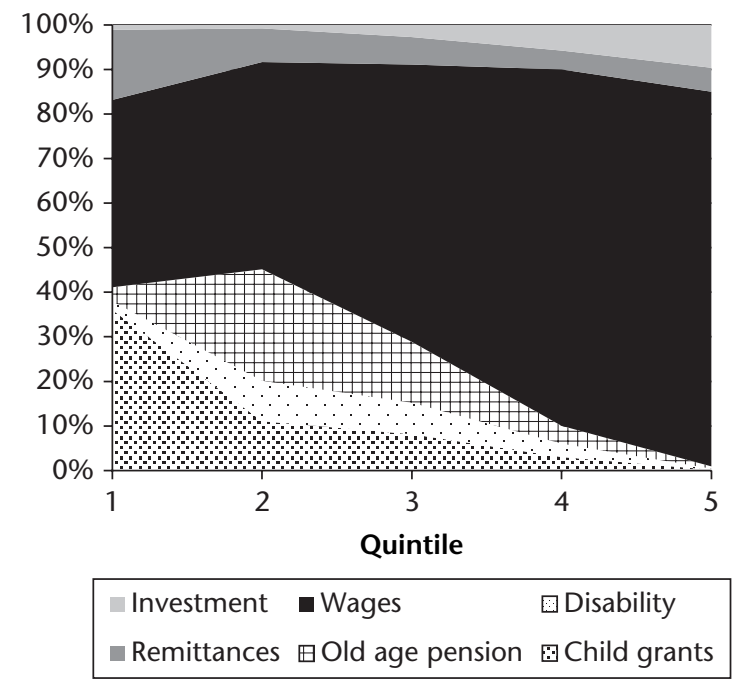

Figure 17.3. Share of household income from various sources, 2008 Source: Authors' illustration; see text 


\subsubsection{Trends in Non-Money-Metric Poverty}

The concept of welfare extends beyond the simple flow of income or expenditure into and out of a household and includes, among other things, the various assets accumulated by households over time. Further, in the context of public policy, many government interventions involve the transfer of assets and provision of services to households that are not picked up in income measures and are not necessarily easily valued in currency terms. Such assets include, for example, the provision of sanitation services or housing.

This makes the non-money-metric welfare story of the post-apartheid era considerably more straightforward than the money-metric story. These measures of non-money-metric welfare include a large number of services and assets that are directly impacted by the state's roll-out of services. The provision of low-cost housing, the provision of access to water, improved sanitation, and massive electrification of particularly poor township areas have been prioritized and have boosted access rates. As a result, all the studies point to declines in non-money-metric poverty and inequality irrespective of the period within the last twenty years since 1993.

Bhorat and Van der Westhuizen (2013), using factor analysis, construct an asset index and find significant declines in non-income poverty and inequality between 1993, 1999, and 2004. Non-income poverty rates and the nonincome poverty gap declined across a number of demographic covariates, with the results robust to the choice of poverty line (Bhorat and Van der Westhuizen 2013: 18). The non-income measure included dwelling type (formal or not); construction materials for roofs and walls; water access; power sources for lighting and cooking; sanitation; access to telecommunications, to a vehicle, and to a television. While well-established South African patterns of deprivation are reaffirmed in the study-Africans, females, and rural dwellers are typically worst off-the authors find that improvements in asset poverty and inequality were concentrated in the immediate postapartheid period, rather than in the latter half of the period.

Bhorat et al. (2007) construct a so-called Comprehensive Welfare Index, as well as separate private and public asset indices. The Comprehensive Welfare Index is constructed to include both private and public assets, wage and nonwage income, and education levels. The analysis reveals that while poverty across all three of these indices declined between 1993 and 2005, the decline was more rapid for the Comprehensive Welfare and Public Asset indices between 1993 and 1999, and more rapid for the Private Asset Index between 1999 and 2005 (Bhorat et al. 2007: 48). Given increasing fiscal allocations towards public services and assets, this suggests that earlier interventions may have targeted 'low-hanging fruit', meaning they were simpler, cheaper, and had higher numerical impact. The later rapid improvements in the Private 
Asset Index were underpinned by the period's relatively good economic performance.

Wittenberg and Leibbrandt (2014) add a detailed discussion of asset inequality to this corpus. They begin by flagging the fact that it is hard to make comparisons of asset indices over the post-apartheid period because a standard asset bundle changes substantially between the beginning and the end of the period. Nonetheless, after extensive sensitivity checks to settle on a defensible set of asset bundles, they affirm the fact that these bundles show real welfare gains for South Africans over the period. They then use these asset indices and recently derived methods to estimate changes in asset inequality over time. This shows a clear and marked fall in asset inequality over the post-apartheid period.

Finn et al. (2013) construct a multidimensional poverty index (MPI) and compare measures of multidimensional poverty from the 1993 PSLSD (SALDRU 1994a, 1994b) and the second wave of NIDS (SALDRU 2008; Brown et al. 2012) in 2010/11. The index comprises three dimensions-education, health, and living standards-which themselves contain nine indicators. Some examples of indicators include school attendance, child mortality, nutrition, access to water and electricity, as well as an asset index. Using an MPI poverty line of deprivation in at least one-third of weighted indicators, the authors calculate multidimensional headcount rates of 37 per cent in 1993 and 8 per cent in 2010. The proportion of the population in severe MPI poverty also dropped substantially from 17 per cent to 1 per cent. This strong decrease is reflected in the MPI measure itself (the MPI headcount multiplied by the intensity of poverty), which fell from 0.17 to 0.03 over the period. The largest drivers of the reduction in multidimensional poverty were access to water and electricity. The authors compare the drop in MPI poverty to money-metric poverty between 1993 and 2010, and demonstrate that MPI improvements were notably larger.

The consensus is that non-income measures of poverty and inequality tell a more positive story of the post-apartheid period, and one that does not appear to be materially impacted by the choice of base year for comparison. Asset poverty and inequality levels have declined as the state actively intervened to uplift poor and marginalized communities through the provision of basic services and improved housing. Importantly, the evidence suggests that demographic and locational markers of disadvantage are being eroded quite significantly over time, as within-group differences explain an increasing proportion of inequality.

\subsection{Poverty, Inequality, and Prices}

\subsubsection{The Availability of Data to Assess the Role of Prices}

The above story of slight declines in money-metric poverty, stronger declines in asset poverty, and persistently high inequality is consistent with a large 
body of evidence and is pretty settled. However, expenditure patterns differ considerably across the distribution as do the price indices for different consumption components (Oosthuizen 2007; Finn, Leibbrandt, and Oosthuizen 2014). The impact of these relative price changes and relative inflation rates is a near unexplored aspect of these changes in well-being. This is despite the fact that the way in which price changes are accounted for may impact on the observed rankings themselves, as well as the rankings relative to the poverty line, distorting the chosen measures of poverty and inequality.

The analysis in this chapter thus far has used the headline CPI to deflate nominal household incomes and expenditures to 2008 prices. However, this implies that each expenditure item or category within the aggregate has experienced identical price changes. Even a cursory glance at the various published product indices will confirm that is contentious. In combination with differences in consumption bundles across households, this means that a single deflator is unable to adequately account for price changes for all households. Indeed, household-specific inflation rates can vary quite substantially in a given period. Between January 1998 and December 2008, for example, it is estimated that an average of one-third of urban South African households actually experienced rates of inflation within one percentage point of the overall urban inflation rate (Oosthuizen 2013).

Various household surveys collecting information on household expenditures have been conducted in the past twenty years in South Africa, varying in level of detail, geographical coverage, and representivity. Moreover, the expenditure data in these various datasets reveal some awkward anomalies that complicate comparisons over time (Finn, Leibbrandt, and Oosthuizen 2014). Taking these expenditure datasets at face value results in a volatile picture of poverty and inequality trends that lacks plausibility when benchmarked against the the extensive money-metric and non-money-metric literature. Given the similarities in methodology, Statistics South Africa's Income and Expenditure Surveys (IES) of 2005/6 (Statistics South Africa 2008) and 2010/11 (Statistics South Africa 2012a) and Living Conditions Survey (LCS) of 2008/9 (Statistics South Africa 2011) seem to provide a coherent and plausible picture of the most contemporary period. Therefore we use them for the analysis that follows. Unfortunately, this analysis deems that there is not a 1990s dataset that is a plausible comparative baseline of the early post-apartheid period. The chosen period of analysis also coincides with a period in which the geographical coverage and classification system of the CPI is generally consistent. Going forward, we make use of official price indices for all urban areas. $^{2}$

\footnotetext{
${ }^{2}$ Since price data at the product level are not publicly available, the approach taken here is to use price indices at the most detailed level of disaggregation available (typically at a product group level).
} 


\subsubsection{Does Accounting for Price Changes Affect Poverty Trends?}

Different households consume different baskets of goods and experience differing rates of inflation over time. How important were price changes for headcount poverty rates in South Africa between 2005 and 2010? In answering the question, we compare CPI-adjusted cumulative distribution functions (CDFs) to percentile-specific price inflation indices (PCPI) CDFs. In all cases we are converting nominal expenditures for 2005 and 2010 into 2008 real Rand equivalents. For the CPI CDFs we deflate (2010) or inflate (2005) each percentile of the entire distributions using the same headline CPI price index. For the PCPIs we deflate or inflate each percentile of the expenditure distribution for each period by its own price index.

Constructing the PCPI involves two steps. First, we calculate the share of each expenditure item in total consumption expenditure for each percentile in 2008, and then assign this share as the weight for each relevant item. This is done at the most detailed level of disaggregation for which Statistics South Africa publishes price indices. Second, we multiply the weight by the price change for each item and then sum across each item for each percentile to arrive at the PCPI. So, for example, the percentile-specific inflation faced by percentile $x$ at time $t$ across items $i$ to $k$ is:

$$
\text { PCPI }_{x, t}=\left[\sum_{i}^{k} w_{i, x} \frac{p_{i, t-1}}{p_{i, t}}\right]^{-1}
$$

where $w_{(i, x)}$ is the weight of expenditure item $i$ for percentile $x$ and $p_{i}$ is the price of item $i$. For comparability with the CPI-adjusted CDFs and in order to focus on price changes, the weights were held constant across the years, and were based on the shares derived from the 2008 LCS dataset.

A quick way of graphically assessing the impact of percentile-specific price changes on poverty is to compare CDFs where expenditure is inflated or deflated by CPI in one case and by PCPI in the other. This is what is shown in Figure 17.4. In the upper panel representing the 2005 situation, the solid line inflates the 2005 expenditure distribution into a 2008 real equivalent, assuming that each good consumed by anyone anywhere along the distribution experienced the same price change between 2005 and 2008-namely, that represented by the increase in the CPI over the period. The PCPI adjusts expenditures using a percentile specific price index. The dashed line plots this CDF. It is nowhere below that of the solid line which corresponds to the CPI deflator. This implies higher proportions of the population have lower real expenditure levels when the PCPI is used compared to the CPI situation. The value of goods that 2005 expenditures can buy is less and headcount poverty rates are higher at the poverty line of ZAR6,084 or any other poverty line when percentile-specific price changes are taken into account. 


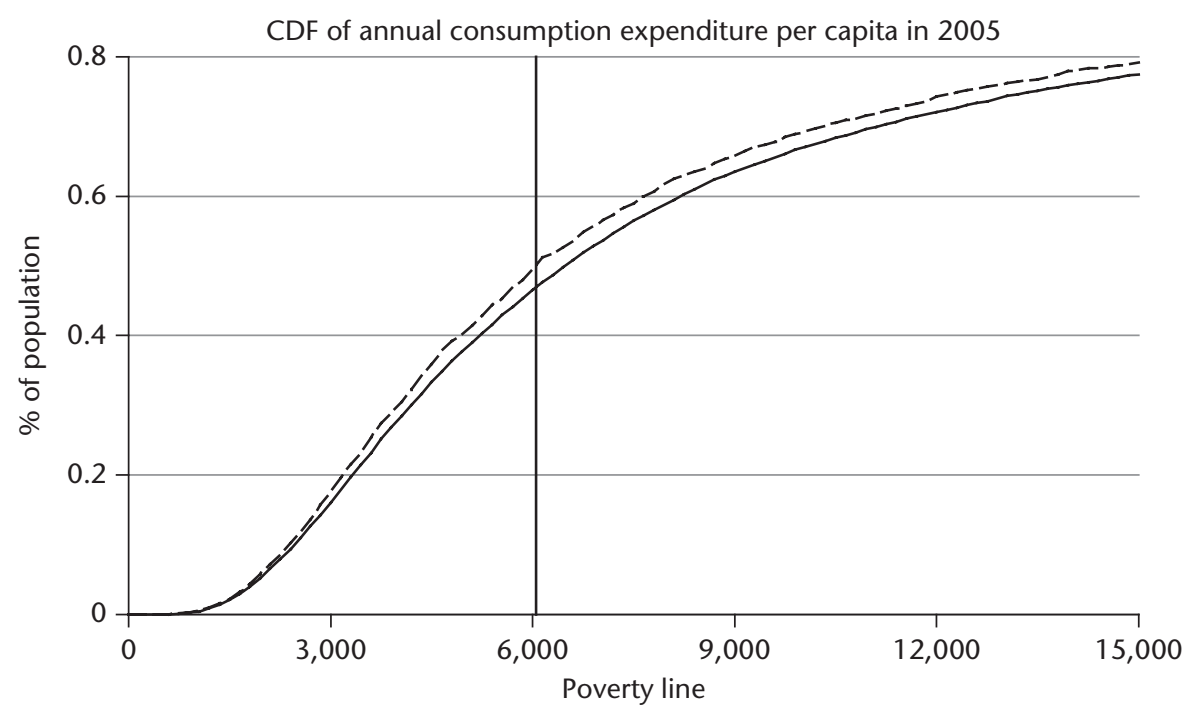

CPI deflator ----- PCPI deflator

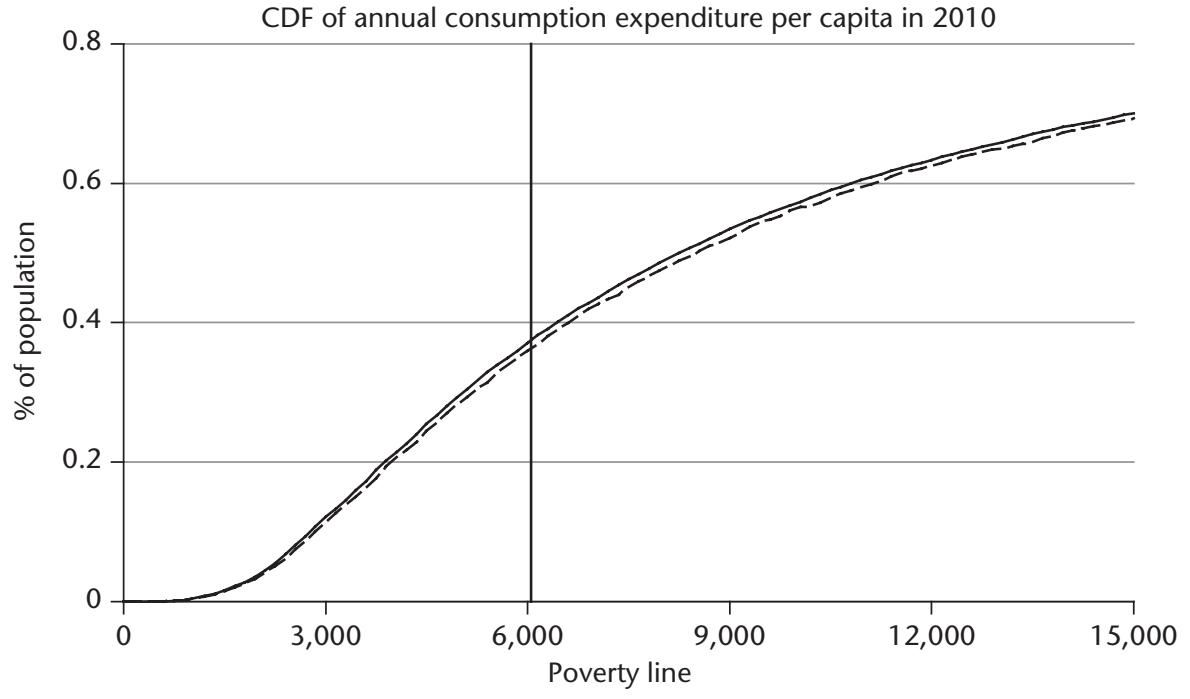

$$
\text { CPI deflator } \quad----- \text { PCPI deflator }
$$

Figure 17.4. Impact of prices on poverty as demonstrated by CDFs

Source: Authors' illustration based on data from IES 2005/6, LCS 2008/9, IES 2010/11, and published price indices 
The lower panel shows that the situation is different in the IES 2010 data. Now, the CDFs deflating by the CPI and the PCPI overlap almost perfectly over the range R0 to ZAR15,000 of household expenditure per capita per year. Between 2008 and 2010 the magnitude of each percentile specific price change was slightly less but very close to the price change reflected in the overall CPI. As a consequence, headcount poverty is very close too at the poverty line of ZAR6,084 or any other poverty line.

Given that the 2005 PCPI CDFs are notably above their respective CPI equivalents whereas the 2010 PCPI CDFs are very close to their CPI equivalents, the net effect of percentile-specific inflation over the period 2005 to 2010 worsens poverty at any poverty line. Finn, Leibbrandt, and Oosthuizen (2014) illustrate this point by decomposing poverty changes at one specific poverty line into a growth component, a redistribution component, and a price component, making use of the Günther and Grimm (2007) extension of the Datt and Ravallion (1992) poverty decomposition. This analysis shows that over the period 2005-10, price changes were anti-poor whether measurement is at the national level or separated into urban and rural components. Indeed, the rural poor were particularly hard-hit.

\subsubsection{Does Accounting for Price Changes Affect Inequality Trends?}

The relationship between prices and consumption inequality is complicated by the fact that higher expenditure households have a larger weighting within the calculation of consumer price indices. As a result, the expenditure weights underlying the official CPI are biased towards higher expenditure groups and the 'representative household' that the CPI is meant to track may not be representative of the broader population.

Exactly where in the distribution the representative household is located depends on the extent of inequality: higher levels of inequality are associated with a location further up the distribution. For example, the representative household in Spain in the 1990s was located at the 61st percentile of the distribution (Izquierdo et al. 2003: 149) and in the 75th percentile in the United States in 1990 (Deaton 1998: 43). In Brazil, Colombia, Mexico, and Peru, the representative household is located between the 80th and 90th percentiles based on data between the 1980s and the early 2000s (Goni et al. 2006: 7). In South Africa, the representative household was located in the 95th percentile in 2000 (Oosthuizen 2007: 20). Conventional CPIs, therefore, do not track the experiences of what would be considered the 'average' household and provide an imperfect measure of the inflation experienced by poor households.

Not surprisingly therefore, visual inspection of Lorenz curves is very useful. In Figure 17.5, we compare Lorenz curves for 2005 and 2010. In each year, the 


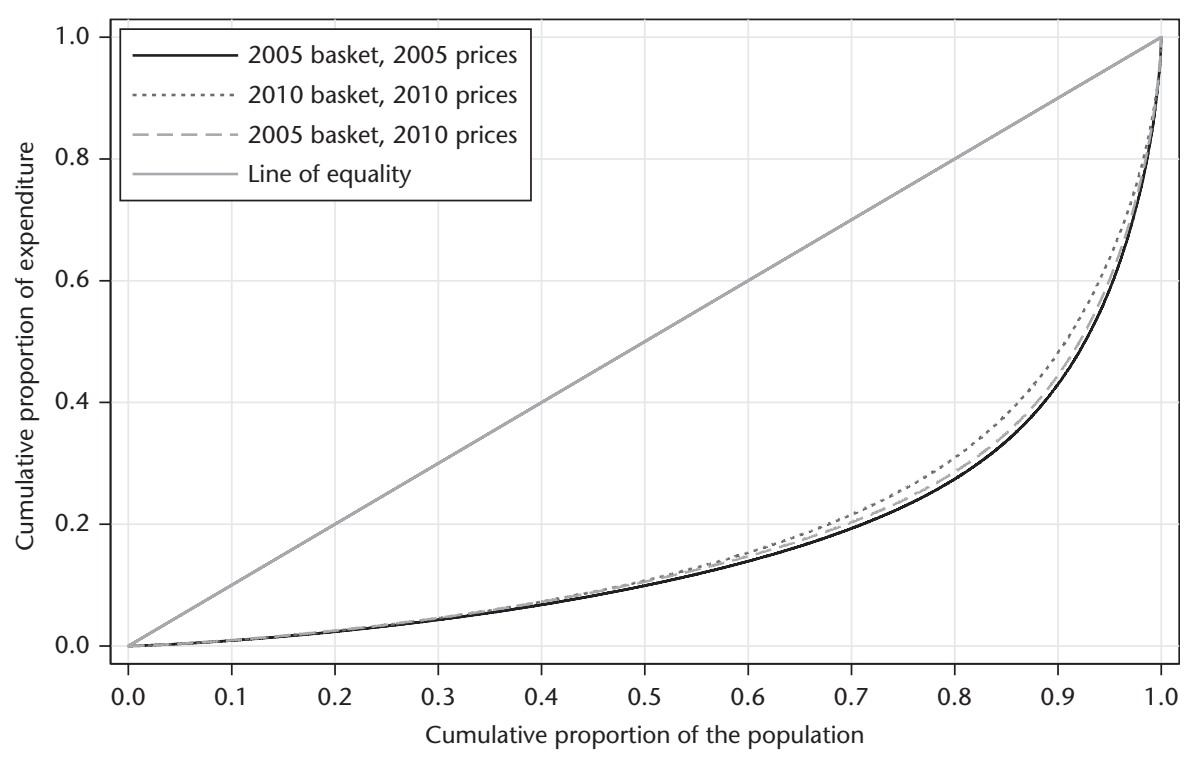

Figure 17.5. Impact of prices on inequality as demonstrated by Lorenz curves

Source: Authors' illustration based on data from IES 2005/6, IES 2010/11, and published price indices

Lorenz curves are plotted using nominal expenditure and, in 2005, we plot the 2005 expenditures in 2010 prices. Comparing the nominal Lorenz curves in the two years suggests that inequality declined between 2005 and 2010-the 2010 Lorenz curve lies closer to the line of equality than does the 2005 curve.

When the 2005 basket is priced in 2010 prices it is marginally closer to the line of equality at the lower end of the distribution and slightly further away from the line of equality for the richest quarter of households. The gap between the own-priced Lorenz curves for 2005 and 2010 reflects the total change in nominal inequality and is equivalent to comparing the Gini coefficients of the two nominal distributions. The gap between the two Lorenz curves based on 2010 prices and in which only the baskets differ offers a measure of the change in real inequality. The gap between the two Lorenz curves based on the 2005 basket-in which only the prices differ-corresponds to the effect of differential inflation.

The effect of prices on inequality measures can be estimated more precisely. Following Ruiz-Castillo et al. (2002) and Goni et al. (2006), we assume an inequality index, $\xi\left(x_{t}\right)$, in period $t$ to be an increasing function in the level of inequality. The vector $x_{t}$ measures nominal expenditures, i.e. $x_{t}=\left(x^{1}{ }_{t}, \ldots, x^{H}{ }_{t}\right)^{\prime}$ $=\left(p_{t}^{\prime} c^{1}{ }_{t} \ldots, p_{t}^{\prime} c^{H}{ }_{t}\right)^{\prime}$, where $p_{t}$ represents prices from period $t$ and $c_{t}$ represents household consumption, for all households (denoted by the superscripts 
$1, \ldots, H)$. If $x_{t, s}=\left(p_{t}^{\prime} c^{1}{ }_{s}, \ldots, p_{t}^{\prime} c^{H}\right)^{\prime}$ is the vector of household consumptions in periods evaluated at the prices of period $t$, then:

$$
\begin{aligned}
\Delta \xi & =\xi\left(x_{t}\right)-\xi\left(x_{t-1}\right) \\
& =\xi\left(x_{t, t}\right)-\xi\left(x_{t-1, t-1}\right) \\
& =\xi\left(x_{t, t}\right)-\xi\left(x_{t, t-1}\right)+\xi\left(x_{t, t-1}\right)-\xi\left(x_{t-1, t-1}\right) \\
& =\xi Q-\Delta \xi P
\end{aligned}
$$

The first pair of terms in Equation (17.2) refers to the difference in the inequality measure when the baskets from the two different periods ( $t$ and $t-1)$ are priced in terms of the prices of a single period (period $t$ ) - the only difference between the two sets of baskets being the quantities consumed. The second pair of terms refers to the change in the inequality measure when the base period baskets (i.e. period $t-1$ ) are priced using the sets of prices from each period. In this case, the only difference between the two sets of baskets is the prices at which they have been valued. Changes in nominal inequality may therefore be thought of as consisting of a component that reflects the effects of changes in quantities consumed $(\Delta \xi \mathrm{Q})$ and a component that reflects the effects of changing prices $(\Delta \xi \mathrm{P})$. Goni et al. (2006: 5) describe $\Delta \xi \mathrm{Q}$ as 'changing real inequality' and $\Delta \xi \mathrm{P}$ as 'inflation inequality'. In terms of the Lorenz curves presented in Figure 17.5, $\Delta \xi \mathrm{Q}$ corresponds to the comparison of the two baskets in 2010 prices, while $\Delta \xi \mathrm{P}$ corresponds to the comparison of the two Lorenz curves based on the 2005 basket.

Table 17.2 presents the decompositions for the $2005-10$ period as a whole, by repricing individual households' expenditure baskets using product category price indices. Estimates of inequality are estimates of nominal inequality. The percentage change in the estimates of inequality over the period is then decomposed into an inflation inequality component $(P \Delta)$ and a real inequality component $(Q \Delta)$. Since the chosen base period may impact on the results-the base period refers to the consumption basket used-the decomposition is performed using first the initial period and then the final period as the base period.

The data show that inequality declined in nominal terms between 2005 and 2010, with the Gini coefficient falling from 0.668 to 0.636 . However, in real terms, the decline has been smaller, with inflation inequality estimated to account for between 35 per cent and 56 per cent of the observed changes in nominal inequality, depending on the base and the inequality measure. For example, price changes are responsible for 2.1 percentage points or 1.7 percentage points of the almost 4.8 per cent decline in the level of the Gini coefficient between 2005 and 2010, depending on the base period.

This is not a positive situation. As $\Delta \xi \mathrm{P}$ is negative for the $2005-10$ period, price changes have been against those at the bottom of the distribution. 
Table 17.2. Distributional effects of inflation inequality, 2005-10

\begin{tabular}{|c|c|c|c|c|c|c|c|}
\hline \multirow[t]{2}{*}{ Measure } & \multirow[t]{2}{*}{$\begin{array}{l}\text { Initial } \\
\text { inequality }\end{array}$} & \multirow[t]{2}{*}{$\begin{array}{l}\text { Final } \\
\text { inequality }\end{array}$} & \multirow[t]{2}{*}{$\% \Delta$} & \multicolumn{2}{|c|}{$\begin{array}{l}\text { Base in initial } \\
\text { period } \\
\text { (percentage } \\
\text { points) }\end{array}$} & \multicolumn{2}{|c|}{$\begin{array}{l}\text { Base in final } \\
\text { period } \\
\text { (percentage } \\
\text { points) }\end{array}$} \\
\hline & & & & $\mathrm{P} \Delta$ & $\mathrm{Q} \Delta$ & $\mathrm{P} \Delta$ & $\mathrm{Q} \Delta$ \\
\hline \multicolumn{8}{|c|}{ National-2005 vs 2010} \\
\hline Gini coefficient & 0.668 & 0.636 & -4.77 & -2.10 & -2.67 & -1.68 & -3.09 \\
\hline Theil index & 0.957 & 0.829 & -13.37 & -5.33 & -8.05 & -5.08 & -8.29 \\
\hline Mean log deviation & 0.838 & 0.756 & -9.80 & -5.46 & -4.35 & -4.09 & -5.71 \\
\hline
\end{tabular}

Note: (a) Estimates of nominal inequality use prices from March 2006 for the 2005/6 IES expenditures, from March 2009 for the 2008/9 LCS expenditures, and from March 2011 for the 2010/11 IES expenditures. These months are the same as those used by Statistics South Africa as the base month for IES and LCS data. (b) Inequality measures are calculated on the basis of per capita household expenditure (i.e. these are individual-level measures).

Source: Authors' calculations

Differential price changes, therefore, created a 'wedge' between real inequality $(\Delta \xi \mathrm{Q})$ and nominal inequality $(\Delta \xi)$. For the period under review, the effect of prices has been to exaggerate the changes observed in terms of real inequality as both the real inequality and the inflation inequality effects were in the same direction. ${ }^{3}$ This finding is consistent with the finding of anti-poor price movements in terms of the above analysis of poverty.

\subsection{Which Prices Drove these Price Impacts on Poverty and Inequality?}

The poverty and inequality decompositions presented above confirm that differential inflation rates across the distribution matter for the measurement of poverty and inequality trends over time in South Africa. Both the poverty and the inequality decompositions characterize the 2005-10 period as one during which price changes were anti-poor, with inflation rates for poorer households typically exceeding those of better-off households. In this section we seek to understand these changes by probing the expenditure categories that have promoted a gap between the inflation rates of poor and non-poor households.

In order for poor households to experience higher average rates of inflation over a given period, poor households must be 'overexposed' to relatively highinflation items and 'underexposed' to relatively low-inflation items, with

\footnotetext{
3 Although not presented here, separate urban and rural decompositions are broadly consistent with these aggregate results. Results for urban and rural areas separately can be found in Finn, Leibbrandt, and Oosthuizen (2014).
} 


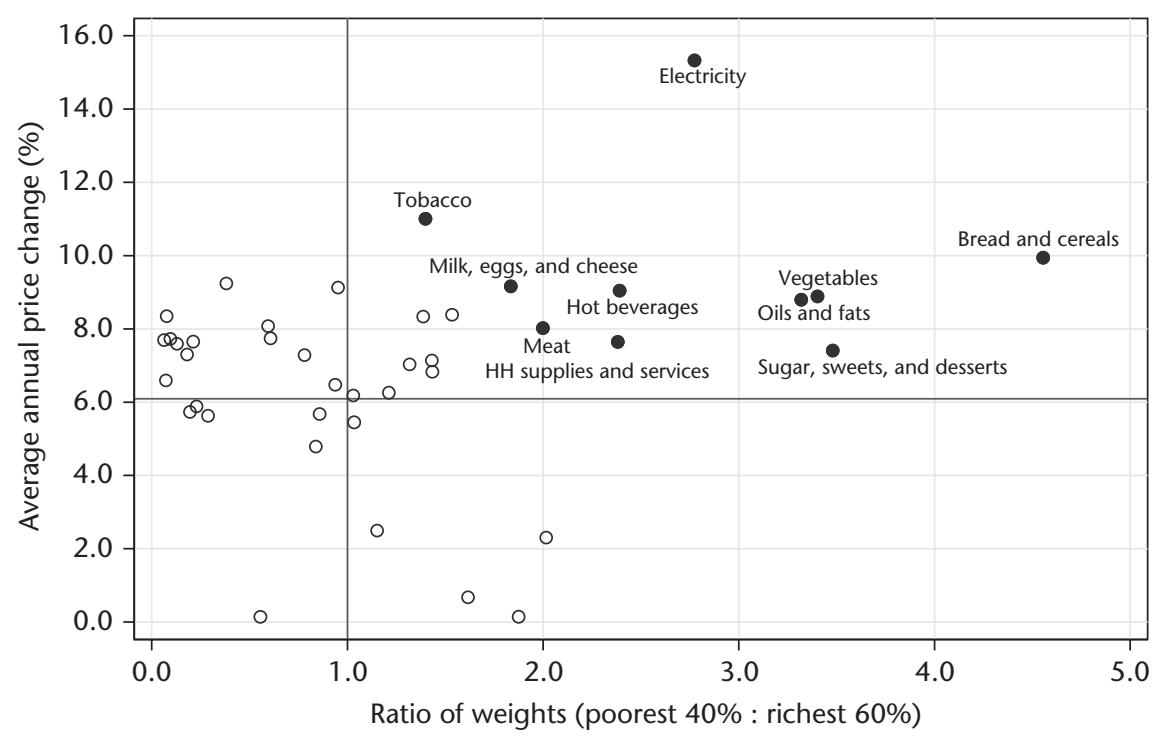

Figure 17.6. Poor households' exposure to high-inflation expenditure categories, 2005-10

Note: Four expenditure categories with negative overall price changes were omitted from the scatter plot. These are: postal services and telecommunication services ( -11.4 per cent per annum; 0.7 relative weight); furnishings, floor coverings, and textiles ( -2.1 per cent per annum; 1.1 relative weight); footwear ( -0.5 per cent per annum; 2.0 relative weight); and purchase of vehicles $(-0.5$ per cent per annum; 0.01 relative weight).

Source: Authors' illustration based on data from IES 2005/6, IES 2010/11, and published price indices

over- or underexposure defined in terms of these items' weights among poor relative to non-poor households. Figure 17.6 illustrates this by plotting the relative weights of each expenditure category in the CPI-calculated as the ratio between the weight for the poorest 40 per cent of households and the weight for the richest 60 per cent of households-against each category's average annual price change. The horizontal line indicates the average rate of inflation for the period and the vertical line shows the categories in which poor households are underexposed (to the left of the line) or overexposed (to the right of the line).

Expenditure categories with both high relative weights and above-inflation price increases over the period contribute to widening the gap in the price indices of poor and non-poor households. Ten of these have been highlighted. Of these, six are food categories and a seventh is a beverage category. The remaining three categories are electricity (a price regulated by government), tobacco (a price that is strongly affected by government, through taxation), and household supplies and services. At two extremes are electricity and bread and cereals. Bread and cereals have a very high relative weight-poor households spend 3.5 times more than non-poor on this expenditure category relative to 
their total expenditures - so that almost any rate of price increase above inflation would make this category a substantial contributor to the gap between poor and non-poor price indices. Electricity, on the other hand, has a moderately high relative weight-the weight for poor households is 2.8 times that for non-poor-but its rate of price increase has been particularly strong. In fact, electricity is by some margin the expenditure category with the highest rate of price increase, having increased by 15.3 per cent per annum over the five-year period.

While the figure highlights expenditure categories characterized by rapid price increases and relatively high expenditure weights for poor households, it does not show that the higher average rate of inflation experienced by poor households is also caused by poor households' underexposure to low-inflation items. The key items in this regard are purchase of vehicles; domestic worker wages; tertiary education fees; insurance; postal services and telecommunication services; and recreational and cultural services. Using more detailed price data for the 1997-2006 period and expenditure data for urban areas only, earlier work finds that purchases of vehicles, insurance of buildings, and computers and telecommunication equipment widen the gap between decile one and all urban households due to poor households' underexposure to low-inflation items (Oosthuizen 2007: 54). Paraffin, other tobacco products, matches, and candles were found to widen the gap through poor households' overexposure to these high-inflation items.

In Table 17.3 we investigate whether our analysis of the $2005-10$ period is likely to apply to the whole decade. We do this by determining if the inflation rate for poor households is higher than the overall inflation rate over the 2000s. If so, inflation can be said to be anti-poor, and vice versa. The table presents a matrix of income and/or expenditure datasets from the 2000s, which yield a number of periods based on comparisons between pairs of

Table 17.3. Patterns of inflation, 2000-13

\begin{tabular}{llllll}
\hline & IES 2000 & IES 2005/6 & LCS 2008/9 & IES 2010/11 & Census 2011 \\
\hline IES 2005/6 & Anti-poor & & & \\
LCS 2008/9 & Anti-poor + & Anti-poor & & \\
IES 2010/11 & Anti-poor + & Anti-poor & Pro-poor - & & \\
Census 2011 & Anti-poor + & Anti-poor & Neutral & Anti-poor - & Neutral \\
Oct. 2013 & Anti-poor + & Anti-poor & Anti-poor - & Anti-poor & Neut \\
\hline
\end{tabular}

Notes: (a) Base periods for prices are as follows: IES 2000-2000 (since total country price indices are not available prior to 2002); IES 2005/6-March 2006; LCS 2008/9-March 2009; IES 2010/11-March 2011; and Census 2011-October 2011. (b) 'Neutral' means that the gap between the All Items price index and the All Items index for the poorest 20 per cent of households is less than one point. 'Anti-poor +' means that the gap between the All Items price index and the All Items index for the poorest 20 per cent of households is greater than twenty points. A minus sign $\left({ }^{\prime}{ }^{\prime}\right)$ indicates that inflation is weakly pro- or anti-poor (i.e. the difference in indices is more than one but less than three index points).

Source: Authors' calculations 
datasets. Based on the datasets' respective base periods in terms of prices, the pattern of inflation in each period can be determined. We have chosen to compare quintile one households (i.e. the poorest 20 per cent of households) with the national average. Patterns of inflation are described as pro- or antipoor, or neutral. Inflation patterns are described as neutral when the difference between the two national indices and the quintile index is less than one point.

The table confirms that for most two-way comparisons between the five datasets (or points in time they represent), inflation was anti-poor. This means that conventional estimates of changes in poverty that deflate expenditures using the headline inflation rate would upwardly bias improvements in real incomes or expenditures for the bottom quintile. Similarly, not deflating expenditures or incomes (or using headline inflation to deflate) would overstate improvements in inequality or understate the extent of worsening real inequality. This effect would be quite strong when making comparisons between the IES 2000 and any of the later datasets. However, the effect would be much weaker when comparing any dataset from the LCS 2008/9 onwards with another later dataset. The effects here are typically weak and effectively neutral.

\subsection{Conclusion}

This chapter had two specific objectives. The first was to tell the story of the evolution of poverty and inequality in post-apartheid South Africa in a way that covers both money-metric and non-money-metric dimensions of wellbeing and teases out the drivers of these changes. For the most part, this was based on a review of an existing corpus. The second goal of the chapter was to assess the impact of prices on estimates of poverty and inequality, an issue that has received very little attention.

The post-apartheid narrative has to start with the inherited legacy of very high inequality and high poverty. Most obviously, the markers were the strong racial and spatial (rural) disadvantages associated with apartheid. Using income data from 1993 and an extensive literature that draws on these data, we detail the unequal human capital, asset, and labour market situation at the start of the post-apartheid period. At the broadest level, the specific intent of post-apartheid policymaking has been to confront and overturn this inherited situation. With the benefit of hindsight and our current knowledge about poverty traps, inequality persistence, and socioeconomic marginalization, we can understand how the pernicious correlation of these racial and spatial legacies with poorer human capital accumulation and poorer household and community assets presented the post-apartheid government with a most daunting set of constraints. 
Jumping ahead to the contemporary situation, we used comparable, national 2010 income data to show a somewhat improved money-metric poverty situation and an income inequality situation that is, at best, as unequal as the 1994 situation. This shows just how hard it has been to overturn the embedded apartheid dynamics of persistence poverty and inequality. That said, there are signs of progress. A comparison of multidimensional poverty indices shows that there have been improvements in human capital. Access to education and average years of schooling have expanded, and on the health side, there have been improvements in child mortality and nutrition. Plus there have been notable improvements in access to assets. Work on multidimensional poverty and the derivation of asset indices collectively show notable improvements in access to water and electricity, even for the poor. An analysis of asset indices shows improvements in access to sanitation and housing too. It is clear that asset inequality has fallen over the post-apartheid period.

These improvements in multidimensional poverty represent notable policy achievements. However, these achievements are not mirrored in equivalent money-metric improvements and this raises a fundamental question in understanding South Africa's post-apartheid performance. Why has South Africa not generated social returns from its investments in human capital and assets? We have some but not all of the pieces of this puzzle in place. Drawing on a decomposition literature we show that South Africa's failure to generate more jobs has been central to the inability to see improved human capital realized in more earners and in higher earnings for more productive workers. A dynamic labour market has to be the central mechanism through which a society transforms itself, through which assets embodied in people become livelihoods and income. The South African labour market has been very static and has not done this.

We reference a literature that situates some of this failure within the schooling system itself. This literature argues that the quality of schooling has declined. The apparent schooling improvements are a cruel mirage. This view needs to be balanced against the fact that the post-apartheid economy has operated in the global economic environment and a skills twist in the demand for labour. South Africa-along with all developed economies and many middle-income developing economies-has seen an increasing demand for skilled and semi-skilled labour and very flat demand for unskilled labour. What makes this skills' twist so pernicious in the South African context is that the improvements in years of schooling (from seven to ten years) lie in the zone of falling returns. We have yet to see large increases in complete secondary (twelve years) or tertiary education. The market has strongly dampened the returns to the improved educational access that has been achieved. 
Another dimension of the labour market failure is a sluggish employment response to economic growth. Partly this failure is about the levels of growth. Our growth rates have hovered just below 3 per cent for most of the postapartheid period. Nearly all planning models of the economy have been clear that we require growth rates in excess of 5 per cent to kickstart robust job creation. In the mid-2000s South Africa's growth rates inched upwards towards these levels only for the financial crisis to cut them back to close to zero in 2008. We show that growth has been pro-poor. However, the key mechanism has not been strongly inclusive employment creation. Rather, increased tax revenues have been used to finance significantly increased state expenditures on social grants. However, as with education and health, without a dynamic labour market, these grants remain remedial. They are not generating second-round effects or pathways out of poverty through financing labour market entry or through financing the creation of small enterprises.

Thus, there have been significant successes but the need to generate labour-absorbing growth is highlighted as a fundamental challenge to further reductions in poverty and to reducing inequality. Does this picture require significant adjustments when giving account to different consumption bundles across the distribution and the different prices and price changes of these bundles?

We explored the role of prices in driving expenditure-based poverty and inequality over the 2005-10 period using price/poverty decompositions and price/inequality decompositions. In line with our earlier analysis, we showed that both growth and redistribution were pro-poor. However, percentilespecific price indices dampen improvements in poverty. In addition, while measured inequality declined somewhat over this period, this decline is exaggerated by the fact that inflation was anti-poor. In other words, giving specific attention to what the poor and those at the bottom of the income distribution consume, and pricing this bundle as accurately as possible, we showed that these groups have to spend more than an average CPI adjustment would reveal on their consumption bundles. At the end of the day it is the consumption bundle that is the real measure of well-being and expenditure is merely a proxy measure. Indeed, the implication of our decomposition work is that some of the increase in the expenditures of the poor do not signal an increase in consumption and therefore in real well-being but rather an increase in the cost of the same consumption bundle.

Adding prices into the post-apartheid narrative does not make things look any better. Rather, it cautions that, over the 2000s, the real support for those at the bottom of the distribution has not been as substantial as usually indicated. Our detailed analysis signals the exposure that those at the bottom of the expenditure distribution have had and continue to have to food price 
movements. This would be true anywhere in the world; although the particular vulnerability of rural communities in South Africa flags the absence of support from subsistence food production. More novel is our finding that those at the bottom of the distribution have been relatively overexposed to high-inflation items such as electricity and food, and underexposed to lowerinflation items such as services generally and transport. Our review of nonmoney-metric well-being has shown evidence of the successful rollout of such services in the post-apartheid period. Success in the fight against poverty can be undermined by sharp increases in the pricing of such services. Moreover, basic foodstuffs and these services are more important components in the consumption bundles of those at the bottom of the distribution than those at the top. In the 2000s their prices rose more sharply than those goods consumed by the better-off, and this worsened inequality.

\section{References}

Aron, J., B. Kahn, and G. Kingdon (2008). 'South African Economic Policy under Democracy: Overviews and Prospects', in J. Aron, B. Kahn, and G. Kingdon (eds), South African Economic Policy under Democracy. Oxford: Oxford University Press, 1-27. Bhorat, H. and C. Van der Westhuizen (2011). 'Pro-Poor Growth and Social Protection in South Africa: Exploring the Interactions'. Unpublished submission to the National Planning Commission. Cape Town: Development Policy Research Unit, University of Cape Town.

Bhorat, H. and C. Van der Westhuizen (2013). 'Non-monetary Dimensions of Wellbeing in South Africa, 1993-2004: A Post-Apartheid Dividend?' Development Southern Africa, 30(3): 295-314.

Bhorat, H., C. Van der Westhuizen, and S. Goga (2007). 'Welfare Shifts in the PostApartheid South Africa: A Comprehensive Measurement of Changes', DPRU Working Paper 07/128. Cape Town: Development Policy Research Unit, University of Cape Town.

Branson, N. and M. Leibbrandt (2013a). 'Education Quality and Labour Market Outcomes in South Africa', OECD Economics Department Working Paper 1021. Paris: OECD Publishing.

Branson, N. and M. Leibbrandt (2013b). 'Educational Attainment and Labour Market Outcomes in South Africa, 1994-2010', OECD Economics Department Working Paper 1022. Paris: OECD Publishing.

Brown, M., R. C. Daniels, L. De Villiers, M. Leibbrandt, and I. Woolard (2012). National Income Dynamics Study Wave 2 Beta Release User Manual. Cape Town: Southern Africa Labour and Development Research Unit, University of Cape Town.

Datt, G. and M. Ravallion (1992). 'Growth and Redistribution Components of Changes in Poverty Measures: A Decomposition with Applications to Brazil and India in the 1980s', Journal of Development Economics, 38(2): 275-95. 
Deaton, A. (1998). 'Getting Prices Right: What Should Be Done?', Journal of Economic Perspectives, 12(1): 37-46.

Fedderke, J., J. Manga, and F. Pirouz (2003). 'Challenging Cassandra: Household and Per Capita Household Income Distribution in the October Household Surveys 1995-1999'. Unpublished mimeograph, University of Cape Town.

Finn, A., M. Leibbrandt, and M. Oosthuizen (2014). 'Poverty, Inequality, and Prices in Post-Apartheid South Africa', WIDER Working Paper 2014/127, October. Helsinki: World Institute for Development Economics Research.

Finn, A., M. Leibbrandt, and V. Ranchhod (2014). 'Post-Apartheid Poverty and Inequality Trends', in R. Kanbur (ed.), The Oxford Companion to the Economics of South Africa. Oxford: Oxford University Press, 291-7.

Finn, A., M. Leibbrandt, and I. Woolard (2013). 'What Happened to Multidimensional Poverty in South Africa between 1993 and 2010?', SALDRU Working Paper Series 99. Cape Town: Southern Africa Labour and Development Research Unit, University of Cape Town.

Goni, E., H. Lopez, and L. Serven (2006). 'Getting Real about Inequality: Evidence from Brazil, Colombia, Mexico, and Peru', World Bank Policy Research Working Paper 3815. Available at <http://documents.worldbank.org/curated/en/2006/01/6525971/gettingreal-inequality-evidence-brazil-colombia-mexico-peru>, accessed January 2013.

Günther, I. and M. Grimm (2007). 'Measuring Pro-Poor Growth When Relative Prices Shift', Journal of Development Economics, 82(1): 245-56.

Hoogeveen, J. and B. Özler (2006). 'Poverty and Inequality in Post-Apartheid South Africa: 1995-2000', in H. Bhorat and R. Kanbur (eds), Poverty and Policy in PostApartheid South Africa. Cape Town: HSRC Press, 59-94.

Izquierdo, M., E. Ley, and J. Ruiz-Castillo (2003). 'The Plutocratic Gap in the CPI: Evidence from Spain', IMF Staff Papers, 50(1): 136-55.

Leibbrandt, M. and J. Levinsohn (2011). 'Fifteen Years On: Household Incomes in South Africa', NBER Working Paper 16661. Cambridge, MA: National Bureau of Economic Research.

Leibbrandt, M., I. Woolard, A. Finn, and J. Argent (2010). 'Trends in South African Income Distribution and Poverty since the Fall of Apartheid', OECD Social, Employment and Migration Working Papers 101. Paris: OECD.

National Treasury (2011). 'National Budget Speech'. Available at <http://www.treasury.gov. za/documents/national\%20budget/2011/speech/speech2011.pdf $>$, accessed January 2013.

Oosthuizen, M. (2007). 'Consumer Price Inflation across the Income Distribution in South Africa', DPRU Working Paper 07/129. Cape Town: Development Policy Research Unit, University of Cape Town.

Oosthuizen, M. (2013). 'Inflation Inequality in South Africa', DPRU Working Paper 13/158. Cape Town: Development Policy Research Unit, University of Cape Town.

Pellicer, M. and V. Ranchhod (2012). 'Inequality Traps and Human Capital Accumulation in South Africa', SALDRU Working Paper Series 86. Cape Town: Southern Africa Labour and Development Research Unit, University of Cape Town.

Ruiz-Castillo, J., E. Ley, and M. Izquierdo (2002). 'Distributional Aspects of the Quality Change Bias in the CPI: Evidence from Spain', Economics Letters, 76(1): 137-44. 
SALDRU (Southern Africa Labour and Development Research Unit) (1994a). 'Project for Statistics on Living Standards and Development, 1994. South Africans Rich and Poor: Baseline Household Statistics'. Cape Town: SALDRU.

SALDRU (Southern Africa Labour and Development Research Unit) (1994b). 'Project for Statistics on Living Standards and Development'. Cape Town: SALDRU.

SALDRU (Southern Africa Labour and Development Research Unit) (2008). 'National Income Dynamics Study'. Cape Town: SALDRU.

Simkins, C. (2004). 'What Has Happened to the Distribution of Income in South Africa between 1995 and 2001?'. Mimeo, South African Regional Poverty Network (SARPN), Pretoria.

South African Reserve Bank (2013). 'Quarterly Bulletin Online Statistical Query'. Online database. Available at <http://www.reservebank.co.za/>, accessed June 2013.

Statistics South Africa (2008). 'Income and Expenditure of Households 2005/2006', Statistical Release P0100. Pretoria: Statistics South Africa. Available at $<\mathrm{http}: / / w w w$. statssa.gov.za/>, accessed January 2013.

Statistics South Africa (2009a). 'Consumer Price Index Collection Frequency'. Available at <http://www.statssa.gov.za/>, accessed January 2013.

Statistics South Africa (2009b). 'The South African CPI Sources and Methods Manual'. Pretoria: Statistics South Africa. Available at <http://www.statssa.gov.za/>, accessed January 2013.

Statistics South Africa (2011). 'Living Conditions of Households in SA: 2008/2009', Statistical Release P0310. Pretoria: Statistics South Africa.

Statistics South Africa (2012a). 'Income and Expenditure of Households 2010/2011', Statistical Release P0100. Pretoria: Statistics South Africa.

Statistics South Africa (2012b). 'Quarterly Labour Force Survey (2012Q1)', Statistical Release P0211. Pretoria: Statistics South Africa.

Van der Berg, S. (2007). 'Apartheid's Enduring Legacy: Inequalities in Education', Journal of African Economies, 16(5): 849-80.

Van der Berg, S. (2009). 'The Persistence of Inequalities in Education'. In J. Aron, B. Kahn, and G. Kingdon (eds), South African Economic Policy under Democracy. Oxford: Oxford University Press, 327-54.

Van der Berg, S. (2011). 'Current Poverty and Income Distribution in the Context of South African History', Economic History of Developing Regions, 26(1): 120-40.

Van der Berg, S., R. Burger, R. Burger, M. Louw, and D. Yu (2006). 'Trends in Poverty and Inequality since the Political Transition', DPRU Working Paper 06/104. Cape Town: Development Policy Research Unit, University of Cape Town.

Van der Berg, S., M. Louw, and D. Yu (2008). 'Post-Transition Poverty Trends Based on an Alternative Data Source', South African Journal of Economics, 76(1): 58-76.

Wittenberg, M. and M. Leibbrandt (2014). 'Measuring Inequality by Asset Indices: The Case of South Africa'. Paper delivered at the UNU-WIDER conference 'InequalityMeasurement, Trends, Impacts, and Policies', 5-6 September, Helsinki.

Woolard, I. and M. Leibbrandt (2011). 'The Role of Cash Transfers in Reducing Poverty and Inequality in South Africa over the Post-Apartheid Period'. Unpublished submission to the National Planning Commission. Cape Town: Southern Africa Labour and Development Research Unit, University of Cape Town. 

PART 4

Low-Information Countries 



\section{8}

\section{Growth and Poverty in the Democratic Republic of Congo}

\section{1 through 2013}

Malokele Nanivazo and Kristi Mahrt

\subsection{Introduction}

With the largest area in sub-Saharan Africa (2,344,858 square kilometres), the third largest population (76 million inhabitants) (CIA World Fact Book 2013), and nine bordering countries, the Democratic Republic of Congo (DRC) holds a position of influence in central Africa. According to the World Bank, with its 'immense and extraordinary agricultural and mineral resources, the DRC has the potential to become one of Africa's richest countries and one of the continent's key engines for growth' (World Bank 2013a). Twelve years after the end of the Second Civil War, ongoing local conflict and political instability have produced a precarious environment plagued by endemic corruption, an uncertain legal framework, lack of adequate infrastructure, and substandard macroeconomics policies. It is perhaps a measure of how far below potential DRC has sunk that, in spite of these unfavourable conditions, evidence suggests the DRC has begun a path to recovery. Since 2002, the DRC has sustained an estimated average annual growth rate of 6 per cent (World Bank 2014) and signs of economic recovery are evident in the agricultural, industrial, manufacturing, services, and mining sectors.

Despite improving economic conditions, high positive growth has not yet translated to corresponding reductions in consumption poverty and the majority of the population remains in a fragile position. The DRC remains one of the poorest countries in the world with a GDP per capita of only US \$288 (constant 2000 US\$) in 2013 (World Bank 2014). Based on national 
consumption poverty lines, 71 per cent of the population was poor in 2005 compared to 63 per cent in 2012 (UNDP 2014a). A disaggregation of the 2012 poverty rates reveals that the situation is worse in rural areas (65 per cent) compared to urban areas (60 per cent) (UNDP 2014a). Despite this reduction in consumption poverty, basic welfare continues to lag behind. This lack of progress is evident in the 2014 DRC Millennium Development Goals Report assertion that the DRC is unlikely to achieve any of the eight Millennium Development Goals (MDGs) by 2015 (UNDP 2014a).

It is worth emphasizing that data collection is a challenging endeavour in DRC. Given its recent tumultuous history, institutional weaknesses, and the lack of trust of the population vis-à-vis agents of the government (enumerators), the scope for non-sampling error is large. Even sample biases are difficult to control. All recent national surveys, the Demographic Health Survey (DHS), the Multiple Indicator Cluster Survey (MICS), and the Enquêtes 1-2-3, base their sample frames on combinations of the 1984 census and administrative censuses. This is well short of ideal. All surveys follow a similar sampling scheme with stratification by provinces as well as cities, towns, and rural areas. Sample sizes tend to increase over time such that the 2001 and 2010 MICS include 8,622 and 11,393 households, the 2007 and 2010 DHS include 8,886 and 18,171 households, and the 2005 and 2012 Enquêtes 1-2-3 include 12,098 and 21,454 households.

The Enquête 1-2-3 obtains consumption information that forms the basis for official poverty headcount measures and as such these figures should be interpreted with a degree of caution. In this uncertain and limited data environment, triangulating poverty estimations through the use of both an array of welfare measures and multiple data sources is essential.

This chapter seeks to provide a broader understanding of welfare in the DRC through an analysis of the distribution and evolution of multidimensional welfare for the eleven provinces over the twelve-year span from 2001 through 2013. We begin with a review of growth and consumption poverty trends on the basis of existing published figures. We then evaluate multidimensional welfare with a focus on indicators of relevance to children. For this purpose, we apply Arndt et al.'s (2102) first-order dominance (FOD) approach to assess child multidimensional poverty using ordinal, binary welfare indicators without imposing arbitrary assumptions regarding the relative importance of each indicator. Applying the FOD approach to the 2001 and 2010 MICS and the 2007 and 2013 DHS takes advantage of alternative data sources, while allowing for a thorough examination of the impact of macroeconomic policy on relevant welfare indicators over time and throughout the nation during key periods of transition, rebuilding, and reform.

The organization of this chapter is as follows. Section 18.2 provides an overview of the economic context since independence with a focus on reform 
and progress since 2001. Section 18.3 reviews both monetary and nonmonetary poverty measures. Section 18.4 presents the FOD methodology and the child welfare indicators. Section 18.5 presents the FOD results. Section 18.6 concludes and discusses key results.

\subsection{Economy and Growth}

\subsubsection{Independence to 2002: Instability and Recovery}

Since its independence (1960), the DRC's economic performance can be characterized by repeated cycles of instability driven by government failure, conflict, and ineffective macroeconomic policies. ${ }^{1}$ In the short period immediately following independence, the DRC experienced great political and civil upheaval, including three regime changes, resulting in a sharp initial decline in GDP (see Figure 18.1). The takeover of Joseph Mobutu in 1965 initially brought about a period of stability and growth as the state increased its economic presence through public investment, and later the nationalization of all mining and foreign enterprises (Zaireanization). This period was shortlived as capital flight, declining terms of trade, and mounting debt resulted in a sharp economic downturn and reduced spending on the maintenance of critical infrastructure and productive capital. From 1983 to 1989, the government implemented a number of policies to improve long-term economic

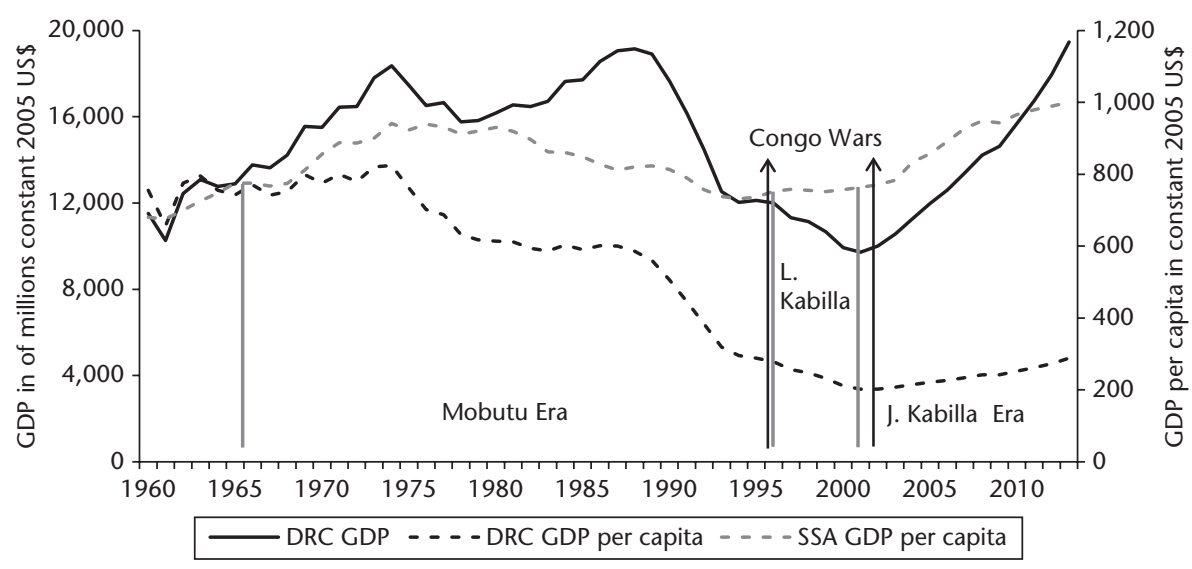

Figure 18.1. Evolution of GDP and GDP per capita with marked regime changes and wars, 1960-2013

Source: Authors' illustration based on World Bank (2014)

\footnotetext{
${ }^{1}$ For a detailed discussion of economic performance over this period, refer to Ulloa et al. (2009) and Akitoby and Cinyabuguma (2004) upon which this discussion is based.
} 
growth, including a structural adjustment programme, which, combined with a strong upturn in copper prices, spurred a period of recovery and growth. However, the recovery was short-lived. The subsequent decade brought political instability, the ousting of Mobutu, the takeover and assassination of Laurent Kabila, and the First (1996-7) and Second (1998-2002) Congo Wars, resulting in economic devastation. Over the period from 1990-2002, the economy contracted by approximately 40 per cent and GDP per capita declined by 60 per cent (World Bank 2014). GDP per capita declined to only 30 per cent of its value at independence. Ulloa et al. (2009) note that the contribution of industry and services to GDP plummeted proportionately as the economy reverted to subsistence agriculture.

\subsubsection{1-14: Recovery and Growth}

\subsubsection{REFORM STRATEGIES}

The transitional government of Joseph Kabila sought to reverse the effects of the worst economic and social crisis since independence. The government embarked upon macroeconomic and liberalization reforms in conjunction with the IMF. The formulation of the Interim Poverty Reduction Strategy Paper (I-PRSP 2001-2), the Government Economic Programme (PEG 2002-5), and the first Growth and Poverty Reduction Strategy Paper (GPRSP 1 2006-10) sought to implement economic reforms aimed at creating a conducive economic environment for growth and attracting private investment. The plans recognized the extent to which conflict, government failure, and economic collapse were interconnected. These plans aimed to promote good governance and peace through reformed institutions, macroeconomic stability, and growth.

\subsubsection{INFLATION}

With the implementation of the three reform programmes came an amelioration of economic growth and inflation rates. Annual GDP growth increased from -7 per cent in 2000 to 3 per cent in 2002 and was sustained at an average annual growth rate of 5 per cent in the 2000 s in contrast to -4 per cent in the 1990s. In addition, better public financial management and fiscal policies brought hyperinflation to a halt (see Fischer, Lundgren, and Jahjah 2013). Between 2000 and 2003, inflation as measured by the consumer price index (CPI) decreased from more than 500 per cent to about 13 per cent per annum (World Bank 2014). In 2004, the CPI returned to single digits for the first time in fourteen years.

\subsubsection{SECTORAL GROWTH}

The DRC has substantial potential for economic growth. The DRC's primarily untapped mineral endowment is among the richest in the world with 1,100 
minerals, precious metals, and crude oil. Historically, the mining sector was a key component of the economy with state-owned mining corporations controlling the majority of production. However, the mining sector's contribution to GDP fell from approximately 25 per cent in the mid-1980s to less than 10 per cent in 2001 (IMF 2005). This sharp decline is partly a statistical artifact as a consequence of official mining being replaced by unofficial mining activities (smuggling, unofficial trade, and artisanal and informal mining) due to factors including failed economic policies beginning with Mobutu's Zaireanization, deterioration of infrastructure, lack of fiscal capacity in tax and revenue collection, and conflict at the eastern border. The extent of the decline in official production can be seen in copper production by the stateowned firm GECAMINES dropping to 5 per cent of its 1980 output level, its cobalt production falling by 70 per cent, and its production of zinc coming to a halt by the 1990s (Akitoby and Cinyabuguma 2004).

In 2002, the DRC revised its mining laws, giving the state the role of regulator, facilitator, and taxer as opposed to the government's previous ownership role. Perhaps not surprisingly, government has had difficulty capturing revenue from unofficial mineral trade. Government mining revenue in 2002 and 2004 was extremely low, though it did increase from 0.18 per cent of GDP in 2002 to 0.24 per cent in 2004 (IMF 2005). The future ability to harness the full economic benefits of the mining sector remains a challenge due to weak institutions and the continued lack of fiscal capacity in revenue and tax collection.

The agricultural sector provides direct employment to more than 75 per cent of the labour force, accounts on average for about 45 per cent of real GDP (Akitoby and Cinyabuguma 2004), and represents the DRC's greatest potential source of inclusive growth and food security. The nation possesses more than 80 million hectares of fertile arable land, ranking DRC among the world's areas with the highest potential agricultural value for major crops (maize, palm oil, soybean, and sugarcane). Despite this potential, agricultural productivity in 2006 had fallen to 60 per cent of its 1960 level as the population reverted increasingly to subsistence agriculture (IMF 2013; Ulloa et al. 2009). As a result, the DRC is now dependent on imported food (World Bank 2013b).

\subsubsection{CHALLENGES TO GROWTH}

The recent progress realized in the DRC is threatened by insecurity created by sporadic fighting in its eastern provinces and the state's lack of legitimacy, sovereignty, and authority outside of the urban centres. International organizations and donors frequently point to a culture of corruption as a challenge to growth (AFDB 2013; USAID 2014). The DRC's inadequate infrastructure is a major constraint for economic growth and hampers efforts to sustain productive economic activities. Only 2 per cent of the 152,400 km long national road network and 11 per cent of the $86,821 \mathrm{~km}$ agricultural road network are in 
good condition (IMF 2013). In energy, the DRC has a hydroelectric power potential estimated at about 106,000 MW, equivalent to 66 million tons of oil per year or 13 per cent of global potential for hydroelectricity, nearly all of it unexploited (AFDB 2013; IMF 2013). According to the AFDB (2013), poor electrical supply is a major obstacle in sustaining small-scale enterprises.

\subsection{Poverty Profile}

\subsubsection{Monetary Poverty and Inequality}

The 2014 Human Development Report (UNDP 2014b) presents consumption poverty headcount figures based on national poverty lines calculated from the 2005 and 2012 DRC Enquêtes 1-2-3. In 2005, 71 per cent of the population was poor, compared to 63 per cent in 2012. This nine percentage point drop in poverty can be attributed to a decline in rural poverty from 76 to 65 per cent whereas urban poverty essentially stagnated at 61 and 60 per cent in 2005 and 2012, respectively. The depth and severity of poverty both decreased (six and eighteen percentage points, respectively). In the same period, the Gini index increased from 0.42 to 0.45 , indicating increased inequality in the country.

Table 18.1 shows the extent to which consumption poverty varies by provinces within and across years. In 2012, the four poorest provinces were Bandundu (75 per cent), Kasaï Oriental (79 per cent), Kasaï Occidental (75 per cent), and Equateur (77 per cent). Between 2005 and 2012 Kasai Occidental and Kasai Oriental experienced a significant increase in poverty of 34 and 26 per cent, respectively, whereas Sud Kivu and Nord Kivu saw the greatest declines in poverty of 28 and 29 per cent, respectively.

Table 18.1. Consumption poverty headcount in 2005 and 2012, per cent

\begin{tabular}{lrrrrrrr}
\hline & 2005 & Rank & 2012 & Rank & Change & Percent change & Change in rank \\
\hline National & 71.3 & 8 & 63.4 & 8 & -7.9 & -11.1 & 0 \\
Urban & 61.5 & 4 & 60.4 & 6 & -1.1 & -1.8 & 2 \\
Rural & 75.7 & 11 & 65.2 & 9 & -10.5 & -13.9 & -2 \\
Bandundu & 89.1 & 13 & 74.6 & 11 & -14.5 & -16.3 & -2 \\
Bas Congo & 69.8 & 7 & 56.9 & 3 & -12.9 & -18.5 & -4 \\
Equateur & 93.6 & 14 & 77.3 & 13 & -16.3 & -17.4 & -1 \\
Kasaï Occidental & 55.8 & 2 & 74.9 & 12 & 19.1 & 34.2 & 26.1 \\
Kasaï Oriental & 62.3 & 5 & 78.6 & 14 & 16.3 & -3.7 & 4 \\
Katanga & 69.1 & 6 & 66.6 & 10 & -2.5 & -11.5 & 0 \\
Kinshasa & 41.6 & 1 & 36.8 & 1 & -4.8 & 7.5 & 4 \\
Maniema & 58.5 & 3 & 62.9 & 7 & 4.4 & -28.1 & -7 \\
Nord Kivu & 72.9 & 9 & 52.4 & 2 & -20.5 & -24.7 & -6 \\
Orientale & 75.5 & 10 & 56.9 & 4 & -18.6 & -28.8 & -7 \\
Sud Kivu & 84.6 & 12 & 60.2 & 5 & -24.4 & & 4 \\
\hline
\end{tabular}

Source: DRC Enquêtes 1-2-3 reported in the DRC MDG Status Report (UNDP 2014a) 


\subsubsection{Non-monetary Poverty Profile}

Since poverty rates are limited to 2005 and 2012, non-monetary welfare indicators comprise an essential component of the DRC's poverty profile. The DRC's low ranking on various international poverty indices reflects the impact of years of political, social, and economic turmoil. For instance, in 2013, the DRC ranked 186th out of 187 countries based on the UNDP's Human Development Index. In 1980, the DRC's human development was on par with the UNDP's low Human Development Index; however, between 1980 and 2000, corresponding to a period of severe economic deterioration and civil wars, the DRC's human development sharply declined. Mirroring the restoration of relative peace and economic recovery, human development steadily improved throughout the 2000s but has yet to return to its 1980 value and remains significantly below that of sub-Saharan Africa and even the low Human Development Index (UNDP 2014b).

The MDGs provide another useful tool for monitoring the DRC's progress in improving eight key aspects of well-being. According to the most recent DRC MDGs report, the country is unlikely to meet any of the eight MDGs by 2015 (UNDP 2014a). Of particular concern, the 2013 infant and under-five mortality rates of 86 and 118 per 1,000 live births and maternal mortality rates of 730 per 100,000 live births (World Bank 2014) remain significantly higher than the MDG targets of 30 and 60 per 1,000 births and 322 per 100,000 live births, respectively (UNDP 2014a). The primary cause of infant and child death in the DRC is malaria. It is estimated that malaria strikes children with an average of ten episodes per year and kills between 150,000 and 250,000 children under five annually (IMF 2013).

Economic upheaval adversely affected the education system in terms of insufficient funding, dilapidated infrastructure, and inadequate facilities and materials, resulting in low school enrolment in secondary and tertiary levels, high dropout rates, and low completion rates. Gross school enrolment rates at the primary, secondary, and tertiary levels of education were $98,43.3$, and 8.2 per cent in 2012 and biased in favour of boys (UNDP 2014a; World Bank 2014). The DRC is unlikely to reach the MDG target of a one-to-one ratio of girls to boys in primary, secondary, and tertiary education as in 2012 these ratios were 0.87, 0.59, and 0.55, respectively (World Bank 2014). Other important indicators also remain low. In 2012, only 31 and 47 per cent of population had access to improved sanitation and water sources compared to the MDG goals of 71 and 55 per cent. There is a large disparity between the urban and rural areas' access to improved water sources (79 versus 29 per cent) and improved sanitation (29 versus 32 per cent) (World Bank 2014).

In the DRC, poverty has the face of a woman. The political, economic, and social constraints faced by women are captured in the DRC's gender inequality 
index score of 0.67 , ranking the country 147 th out of 151 countries (UNDP 2014b). With the decreased productivity of the agricultural sector, where 73 per cent of economically active women are employed, women face a greater risk of poverty (FAO 2011). The imbalanced school enrolment figures noted above substantially hamper the ability of women to move to other sectors or into the formal sector. Discrimination is reinforced by the legal and institutional framework, which incapacitates married women from participating in the labour force by requiring their husbands' authorization to work (AFDB 2013).

\subsection{FOD Methodology and Data}

\subsubsection{Methodology}

This study seeks to move beyond the examination of individual non-monetary indicators and analyse multidimensional poverty across time and the provinces of the DRC. Despite the broad consensus on the multidimensional character of poverty, how to evaluate multiple dimensions in a single analysis remains a central topic of debate. The most common methods of evaluating multidimensional poverty rely on either weighting schemes ${ }^{2}$ or the signs of the secondor higher-order cross-derivatives, ${ }^{3}$ yet the assumptions required by these approaches remain contentious. ${ }^{4}$ The FOD methodology developed by Arndt et al. (2012) advances multidimensional poverty analysis in its ability to compare the welfare of population groups across time and space without imposing arbitrary assumptions. Rather, the FOD criterion merely asserts that it is better to be not deprived than deprived in any dimension. ${ }^{5}$

Intuitively, consider a set of three ordinal, binary welfare indicators such that ' 0 ' indicates deprived and ' 1 ' indicates not deprived in each dimension. Each combination of welfare indicators is said to dominate, be dominated by, or be indeterminate relative to other combinations. The outcome $(1,1,1)$ clearly is better than or dominates $(0,0,0)$, since it is superior in every dimension. Furthermore, the outcome $(1,1,0)$ dominates $(0,1,0)$ because it is better to be not deprived than deprived in the first dimension. However, $(1,1,0)$ and $(0,0,1)$ are indeterminate outcomes; without imposing assumptions regarding the relative importance of or substitutability between each outcome, it cannot be determined if it is better to be not deprived in the first two dimensions or in the third dimension. Extending to two populations, A and B, consider the distribution of individuals falling into each combination of welfare indicators.

\footnotetext{
2 See Bourguignon and Chakravarty (2003); Alkire and Foster (2011a, 2011b).

3 See Duclos, Sahn, and Younger (2006), Atkinson (1987), and Foster and Shorrocks (1988a, 1988b, 1988c).

4 See, for example, Ravallion (2011).

5 For a detailed theoretical discussion of the FOD methodology, refer to Arndt et al. (2012).
} 
The FOD criterion can be described as follows: population A first-order dominates population $\mathrm{B}$ if one can generate distribution $\mathrm{B}$ by transferring probability mass (i.e. moving individuals) from better to unambiguously worse outcomes within A, where better is defined as above.

While FOD analysis allows for comparison across populations without imposing subjective restrictions, the criterion is strict and comes at a cost. Specifically, FOD comparisons frequently result in indeterminate outcomes and do not provide a sense of the extent of domination. Arndt et al. (2012) employ repeated bootstrap samples drawn from each population such that resulting FOD comparisons can be interpreted as empirical probabilities of domination. Not only do probabilities of domination reduce the possibility of indeterminate outcomes, but they provide evidence of the extent to which a population dominates another. Furthermore, bootstrap probabilities allow populations to be ranked.

Though FOD comparisons frequently result in indeterminate outcomes, it should be noted that this shortcoming is countered by the strength of a dominant result. A dominant result requires superior welfare outcomes to be registered throughout the population and across indicators, meaning an indeterminate result could stem from poor outcomes in a single indicator within a small section of the population. Thus, a dominant result provides a robust indication of broad-based superiority through time or across space (Arndt et al. 2012).

\subsubsection{Deprivation Indicators}

This analysis employs the FOD approach to empirically evaluate child wellbeing in the DRC among the eleven provinces and three aggregate areas (national, urban, and rural) in 2001, 2007, 2010, and 2013. Given the deep and extensive nature of poverty in the DRC, child well-being is defined in terms of severe lack of access to basic needs. Gordon et al. (2003a, 2003b) develop a set of severe deprivation indicators to measure child well-being, known as the 'Bristol Indicators'. In particular, Gordon defines severe deprivations as 'circumstances that are highly likely to have serious adverse consequences for the health, well-being, and development of children' (Gordon et al. 2003b: 5). The welfare indicators used in this analysis closely follow the 'Bristol Indicators' and are defined as follows.

1. Water deprivation: Children with only access to surface water for drinking or for whom the nearest source of water is more than a thirty-minute walking distance from their dwellings.

2. Sanitation deprivation: Children with no access to any kind of latrines or toilets. 
3. Shelter deprivation: Children living in dwellings with five or more people per room or with no flooring material (e.g. a mud floor).

4. Health deprivation: Children who did not sleep under a mosquito net the previous night. ${ }^{6}$

5. Information deprivation: Children who belong to a household where there is no access to a television, radio, or phone. ${ }^{7}$

6. Nutrition deprivation: Children whose Z-scores for any anthropometric measures (stunting, wasting, or underweight) are below three standard deviations from the mean of the reference population.

7. Education deprivation: Children who have never been to at least primary school or are not currently attending school.

\subsubsection{Data and Descriptive Statistics}

The deprivation indicators are drawn from the 2001 and 2010 DRC MICS and the 2007 and 2013 DRC DHS. Within each survey, we utilize three subsamples: (1) children under five years old, (2) children aged 7 through 17, and (3) children aged 0 through 17 . Child welfare for the three subsamples is measured in terms of access to water, sanitation, shelter, health, and information. In addition, the analysis of children under five incorporates the nutrition indicator and the analysis of children 7 through 17 includes education. ${ }^{8,9}$

Table 18.2 reports the percentage of children aged 0-17 not deprived in water, sanitation, shelter, health, and information by areas and years. Tables 18.3 and 18.4 present children under five not deprived in nutrition by gender and children aged 7-17 not deprived in education by gender. Though the deprivation indicators provide mixed evidence of advancement and stagnation, the overall picture is one of progress. All aggregate areas and provinces advanced in terms of bed net usage, primary school enrolment, malnutrition, and access to information. National use of bed nets more than tripled from 2007 to 47 per cent in 2013 by which time they were used nearly equally in urban and rural areas.

Nationally, access to information increased from 36 per cent in 2001 to 62 per cent in 2013, though the difference in urban and rural access increased to forty percentage points. The percentage of children categorized as not

\footnotetext{
6 The Bristol health indicator is defined in terms of immunizations. Due to the limited sample for which this data is available and the FOD requirement that no indicator has missing values, we define health in terms of the use of mosquito nets.

${ }^{7}$ Data on the possession of mobile phones was not collected in 2001. However, given the limited usage of mobile phones in 2001, this is not likely to significantly impact results.

8 The 2007 and 2013 DHS surveys collect anthropometric measures for a subsample of children under five and thus sample sizes are smaller for under-fives in these years.

9 Data on the use of mosquito nets was not collected for children older than 5 in 2001, thus the analysis of children aged 7-17 and children 0-17 is restricted to 2007, 2010, and 2013.
} 


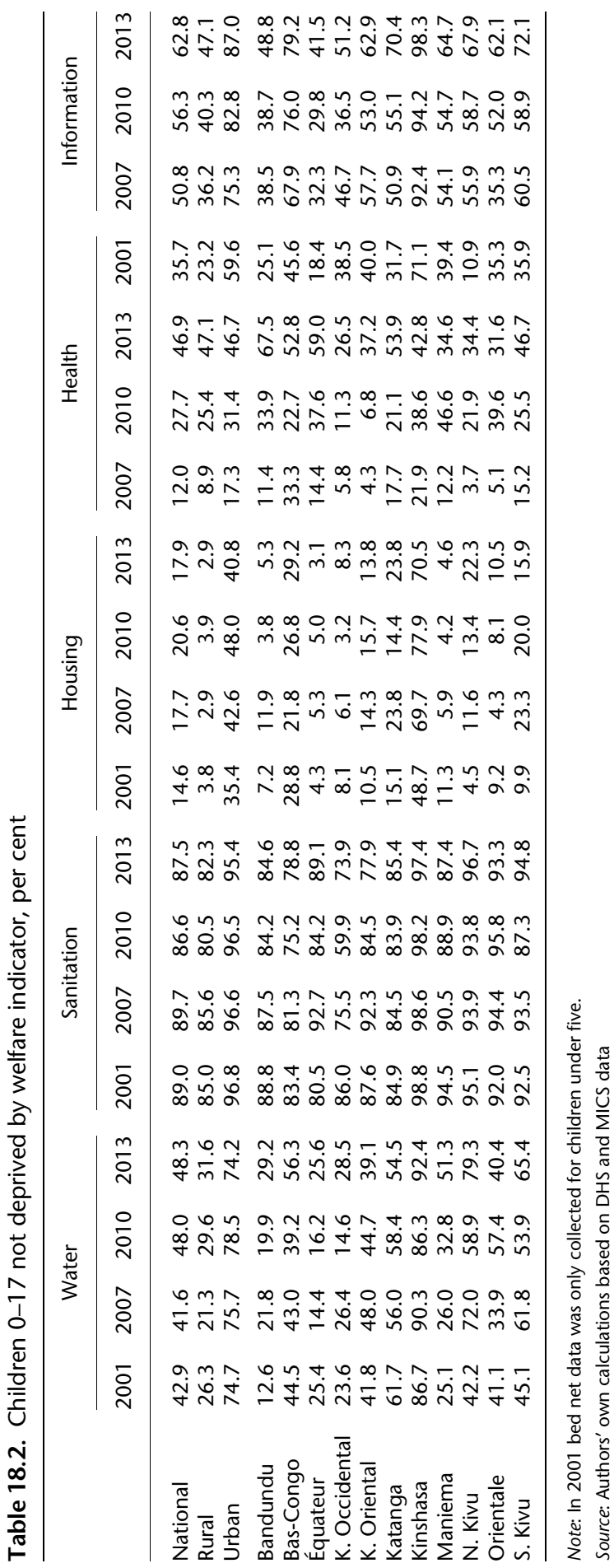




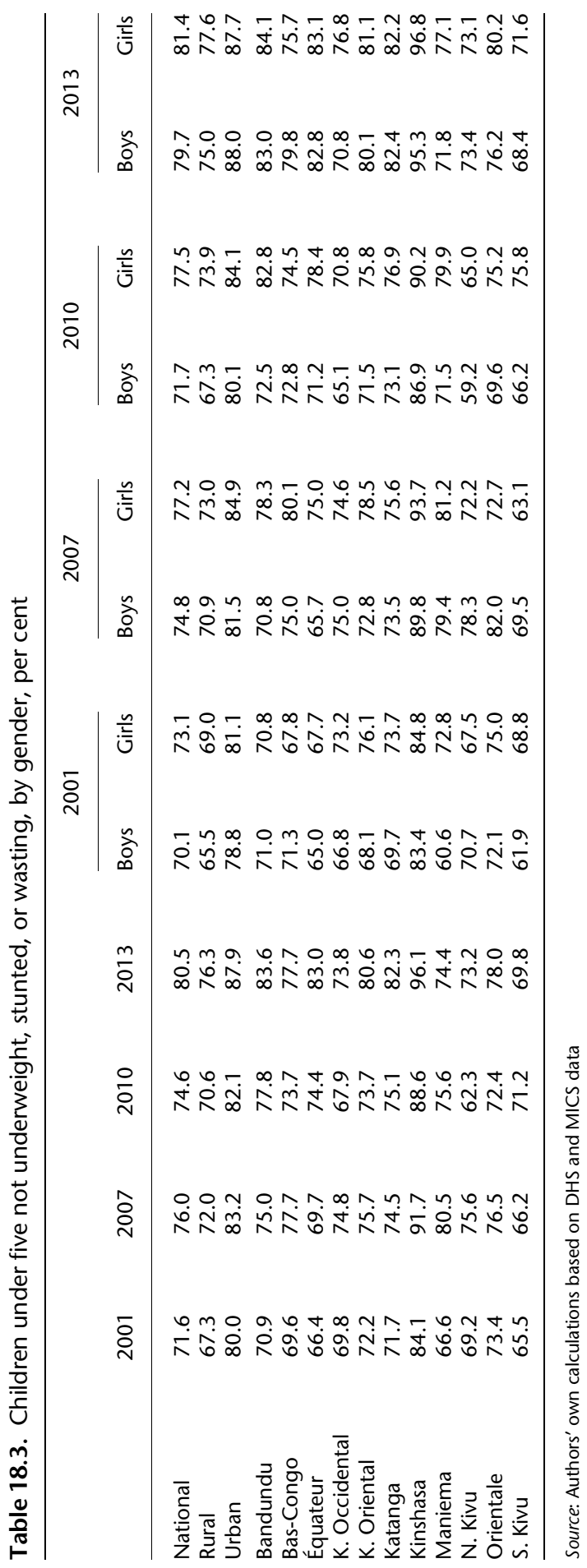




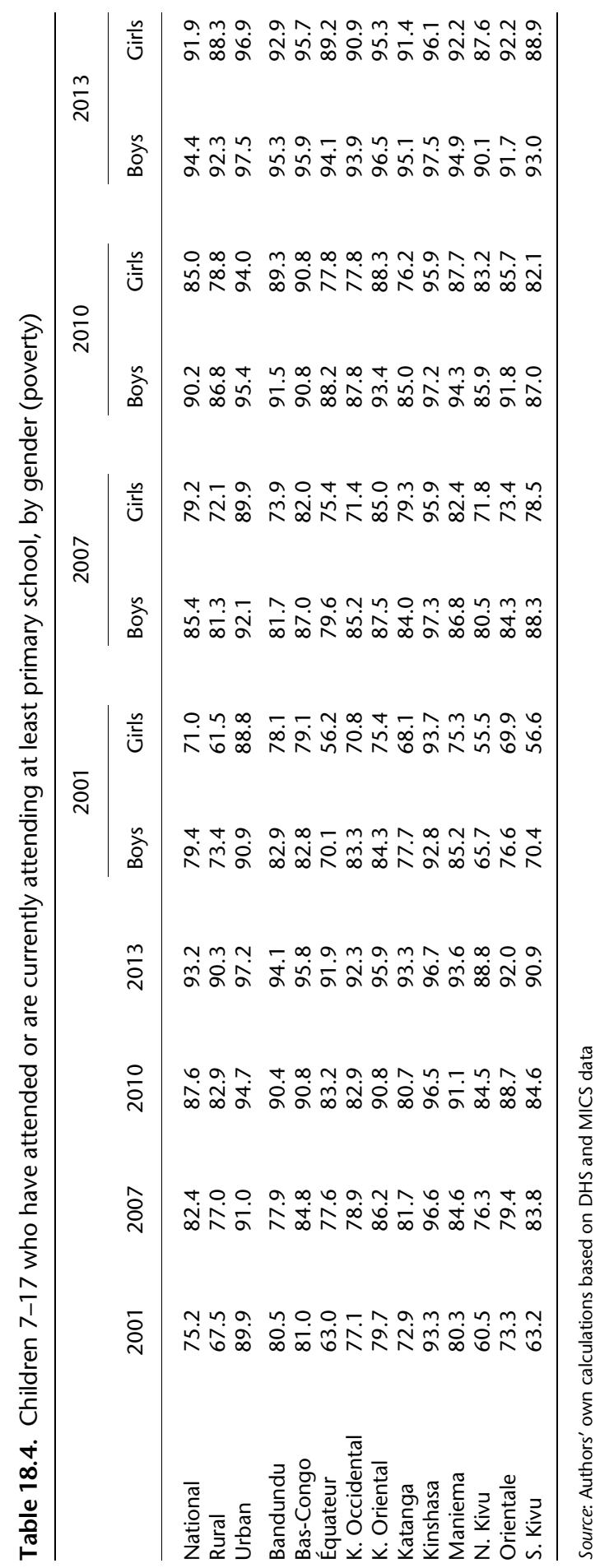


nutrition-deprived improved from 72 per cent in 2001 to 81 per cent in 2013 with a similar improvement occurring in both rural and urban areas..$^{10}$ Though the percentage of children identified not nutrition-deprived declined across all areas, comparing Kinshasa and Sud Kivu reveals that the provincial gap widened considerably to twenty-six percentage points. Finally, by 2013 the percentage of children who have ever attended primary school approached 90 per cent or greater in every area. Furthermore, the urban gender gap was nearly eliminated and the rural gap declined from twelve to four percentage points.

In contrast, access to water improved only in rural areas, quality of housing improved only in urban areas, and access to sanitation deteriorated slightly in both urban and rural areas. Progress in housing quality and access to water varied significantly among the provinces. For example, access to water nearly or more than doubled in Bandundu, Maniema, and Nord Kivu, but was stagnant and even declining in Equateur, Kasai Oriental, Katanga, and Orientale. Even within provinces progress was not consistent. Bandundu and Maniema, with the greatest advancements in water, were also the only two provinces with declining housing quality. Only Sud Kivu and Nord Kivu achieved an improvement in all seven indicators.

Table 18.5 presents the total number of deprivations faced by children at the national, rural, urban, and provincial levels and provides a sense of the depth of overall deprivation over time and across regions. For instance, the distribution of children across a number of deprivations highlights the DRC's rural/urban welfare divide. In 2013, 1 per cent of rural children were deprived in zero or in one indicator compared to 24 per cent of urban children, whereas 29 per cent of rural children were deprived in four or five indicators compared to 5 per cent of urban children. This pattern is even more extreme when comparing provinces. For example, in Kinshasa 42 per cent of children faced zero or one deprivation and virtually no children faced four or five deprivations. In stark contrast, 2 per cent of children face zero or one deprivation in Kasai Occidental.

\subsection{Results: FOD Comparisons}

This section reports the results of the temporal and spatial FOD bootstrap comparisons (Tables 18.6-18.10) and spatial rankings. For each subsample of children, temporal FOD comparisons are conducted between time periods for each area and spatial FOD comparisons are conducted between areas in each time period.

\footnotetext{
${ }^{10}$ Most areas experienced a temporary increase in malnutrition in 2010 explainable by high food prices (52 per cent increase in June 2009 compared to May 2008) and a reliance on diminishing food aid (Kandala et al. 2011).
} 


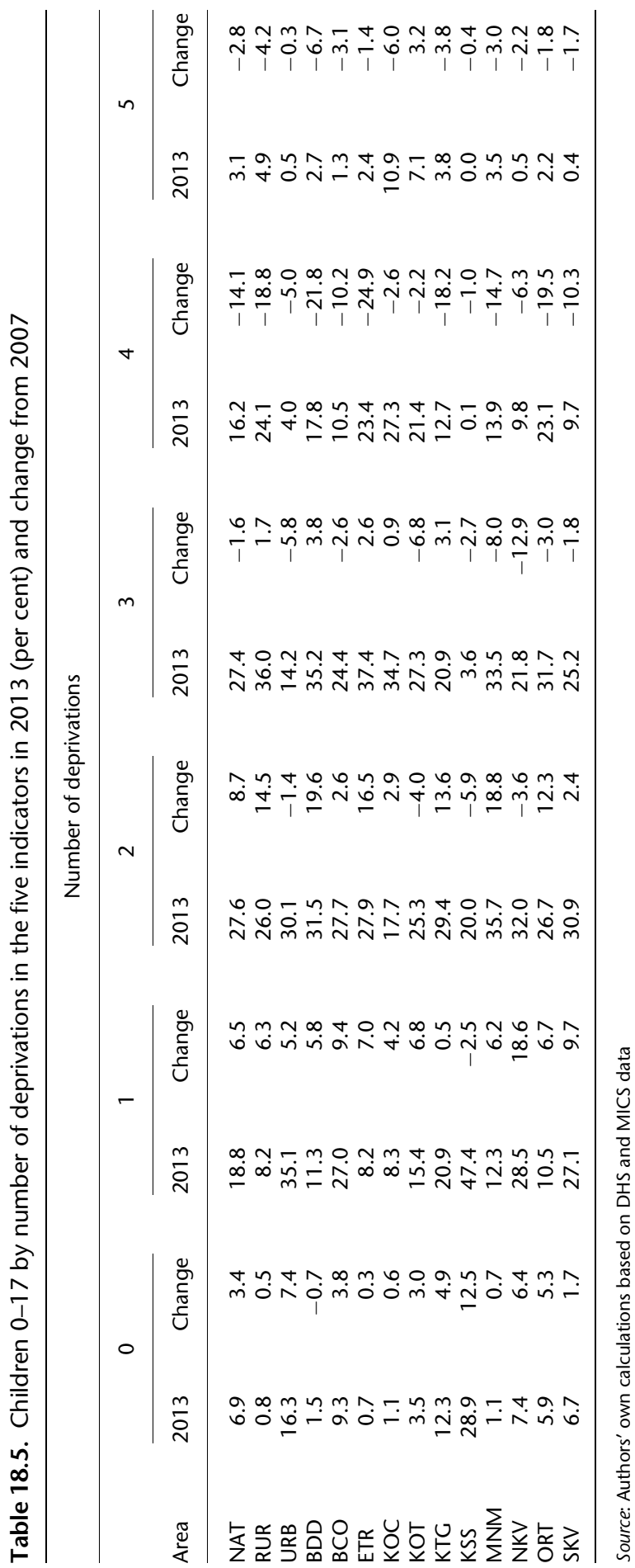




\subsubsection{Temporal Comparisons}

Table 18.6 reports temporal net domination results for children under five and children aged $0-7$. Temporal net domination measures the probability that an area advances between two years net of any probability of regression, such that positive values report the probability of advancement in welfare, blank cells suggest stagnation, and negative values report the probability of regression. Bold values indicate domination in the static case (FOD comparisons without bootstrapping).

FOD comparisons in the subsample of children aged 0-17 indicate significant probabilities of advancement between 2010 and 2013 in Kasai Occidental (65 per cent) and Nord Kivu (64 per cent), and between 2007 and 2013 in Nord Kivu (57 per cent). In addition, the under-five sample suggests a 42 per cent probability of advancement in Sud Kivu between 2001 and 2013. This evidence of improved welfare in Kasai Occidental between 2010 and 2013 is inconsistent with consumption poverty figures (Table 18.1), which indicate that poverty increased by twenty percentage points between 2005 and 2010 . The FOD results are likely due to the water, sanitation, and shelter indicators rebounding after deteriorating between 2007 and 2010 rather than a reflection of improvements in a broader context (Table 18.2). In contrast, the advancement in Nord and Sud Kivu is consistent with twenty and twenty-five percentage point reductions in the consumption poverty rates and significant and generally steady advances across all FOD indicators. Finally, FOD comparisons

Table 18.6. Temporal net FOD comparisons (bootstrap probabilities)

\begin{tabular}{|c|c|c|c|c|c|c|c|c|c|}
\hline & \multicolumn{5}{|c|}{ Children under five } & \multicolumn{4}{|c|}{ Children 0-17 } \\
\hline & $\begin{array}{l}2007 \\
\text { FOD } \\
2001\end{array}$ & $\begin{array}{l}2010 \\
\text { FOD } \\
2001\end{array}$ & $\begin{array}{l}2013 \\
\text { FOD } \\
2001\end{array}$ & $\begin{array}{l}2010 \\
\text { FOD } \\
2007\end{array}$ & $\begin{array}{l}2013 \\
\text { FOD } \\
2007\end{array}$ & $\begin{array}{l}2013 \\
\text { FOD } \\
2010\end{array}$ & $\begin{array}{l}2010 \\
\text { FOD } \\
2007\end{array}$ & $\begin{array}{l}2013 \\
\text { FOD } \\
2007\end{array}$ & $\begin{array}{l}2013 \\
\text { FOD } \\
2010\end{array}$ \\
\hline $\begin{array}{l}\text { National } \\
\text { Rural } \\
\text { Urban }\end{array}$ & $\begin{array}{l}0.03 \\
0.01\end{array}$ & 0.02 & $\begin{array}{l}0.11 \\
0.06 \\
0.01\end{array}$ & 0.01 & $\begin{array}{l}0.04 \\
0.07 \\
0.01\end{array}$ & 0.18 & $\begin{array}{l}0.01 \\
0.14\end{array}$ & $\begin{array}{l}0.01 \\
0.01 \\
0.01\end{array}$ & $\begin{array}{l}0.01 \\
0.12\end{array}$ \\
\hline $\begin{array}{l}\text { Bandundu } \\
\text { Bas-Congo } \\
\text { Équateur }\end{array}$ & $\begin{array}{l}0.05 \\
0.03\end{array}$ & & $\begin{array}{l}0.07 \\
0.32\end{array}$ & -0.03 & & $\begin{array}{l}0.19 \\
0.23\end{array}$ & $\begin{array}{r}0.03 \\
-0.04\end{array}$ & $\begin{array}{l}0.09 \\
0.21 \\
0.03\end{array}$ & $\begin{array}{l}0.27 \\
0.30 \\
0.03\end{array}$ \\
\hline $\begin{array}{l}\text { K. Occidental } \\
\text { K. Oriental }\end{array}$ & $\begin{array}{l}0.01 \\
0.07\end{array}$ & 0.01 & & & 0.03 & 0.65 & 0.01 & 0.12 & $\begin{array}{l}\mathbf{0 . 6 5} \\
0.03\end{array}$ \\
\hline Katanga & 0.03 & & 0.11 & & 0.15 & 0.21 & -0.02 & 0.15 & 0.19 \\
\hline Kinshasa & 0.08 & 0.10 & 0.17 & & & & 0.04 & 0.12 & \\
\hline Maniema & 0.01 & & & & & & 0.05 & 0.05 & \\
\hline N. Kivu & 0.38 & 0.01 & 0.36 & & 0.10 & 0.25 & 0.04 & 0.57 & 0.64 \\
\hline Orientale & & 0.02 & 0.15 & 0.06 & 0.33 & & 0.42 & 0.17 & \\
\hline S. Kivu & 0.12 & & 0.42 & & & 0.02 & & 0.04 & 0.10 \\
\hline
\end{tabular}

Note: Figures in bold indicate FOD in the static sample.

Source: Authors' own calculations based on DHS and MICS data 
indicate advancement, though probabilities are lower, in Bandundu, Bas Congo, Equateur, and Orientale, which correspond to the remaining provinces with a reduction in consumption poverty greater than ten percentage points.

\subsubsection{Spatial Comparisons}

Spatial results are quite similar among the three subsamples and therefore this section focuses on the subsample of children aged $0-17$. Tables 18.7 and 18.8 report the results of the 2007 and 2013 spatial FOD bootstrap comparisons, with values in bold indicating domination in the static sample. Row (column) averages display the probability that an area first-order dominates (or is dominated by) other regions. Therefore, regions that are relatively better off have larger row and lower column averages. ${ }^{11}$

Considering row averages, Kinshasa and urban areas have relatively higher welfare than other regions. Specifically, Kinshasa dominates all other regions with an average probability of 86 per cent in 2007. This row average declines to 38 per cent in 2013. Urban areas, of which Kinshasa is a major part, show similar trends with average probabilities of 68 and 40 per cent in 2007 and 2013 respectively. To a lesser extent, FOD also indicates that Sud Kivu is better off than other regions (row average probabilities of 37 and 23 per cent in 2007 and 2013). In 2013, Kinshasa, urban areas, and Sud Kivu dominate fewer regions and dominate to a lesser extent, suggesting that over time, the welfare gap between high-performing areas and all other areas narrowed.

Turning to column averages, in 2007 Kasai Occidental, rural areas, and Bandundu were relatively poor, with average probabilities of being dominated of 40, 39, and 27 per cent, respectively. Kasai Occidental and Kasai Oriental deteriorated relative to other regions, registering increased probabilities of being dominated in 2010 and 2013. On the other hand, in 2013, the probability of rural areas being dominated by other areas declined ( 23 per cent) and Bandundu registered zero probability of being dominated, a gain in welfare supported by temporal results.

\subsubsection{Spatial Rankings}

Spatial net domination provides a basis for ranking regions and conveniently presenting a more detailed perspective on the evolution of relative well-being. Net domination measures the probability that an area dominates other areas minus the probability it is dominated by other areas. Tables 18.9 and 18.10 present area rankings for the subsamples of children aged 0-17 and children

\footnotetext{
11 Note that bootstrap sampling introduces a degree of randomness into the results and care must be taken to not place too much importance on very small probabilities.
} 


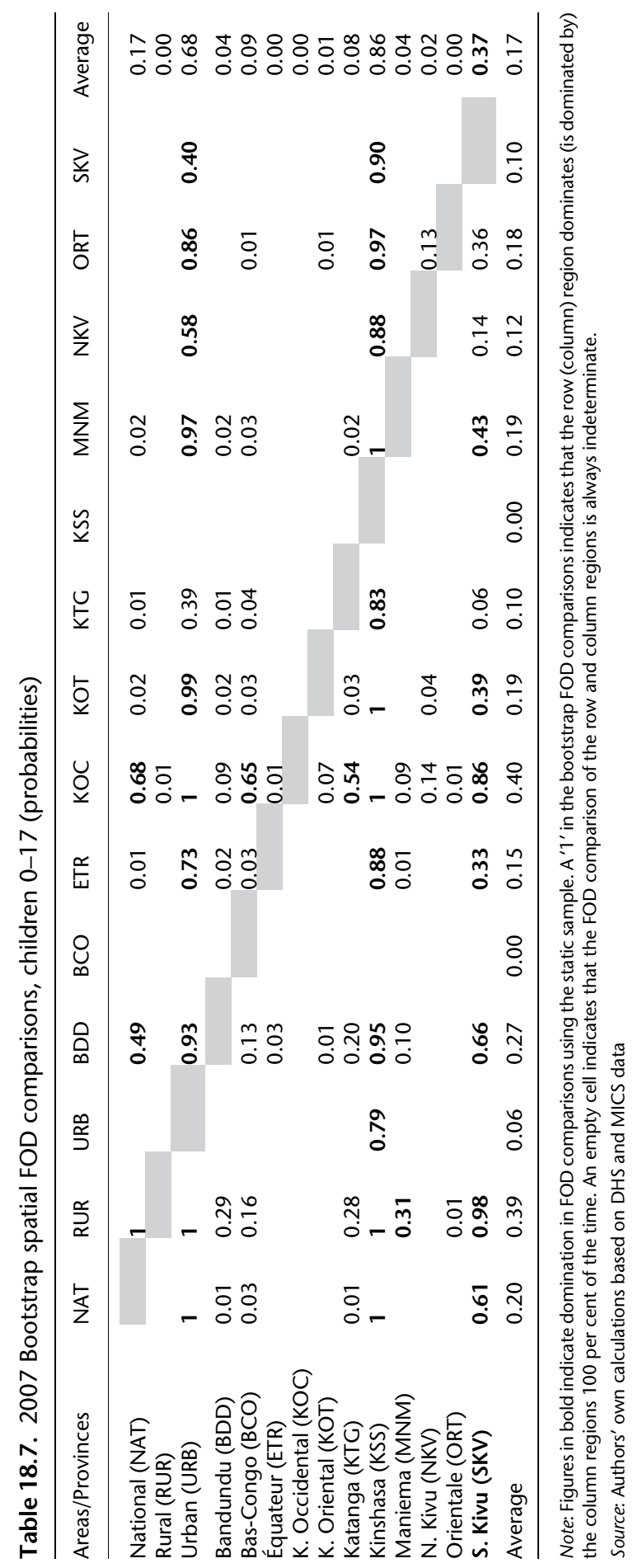




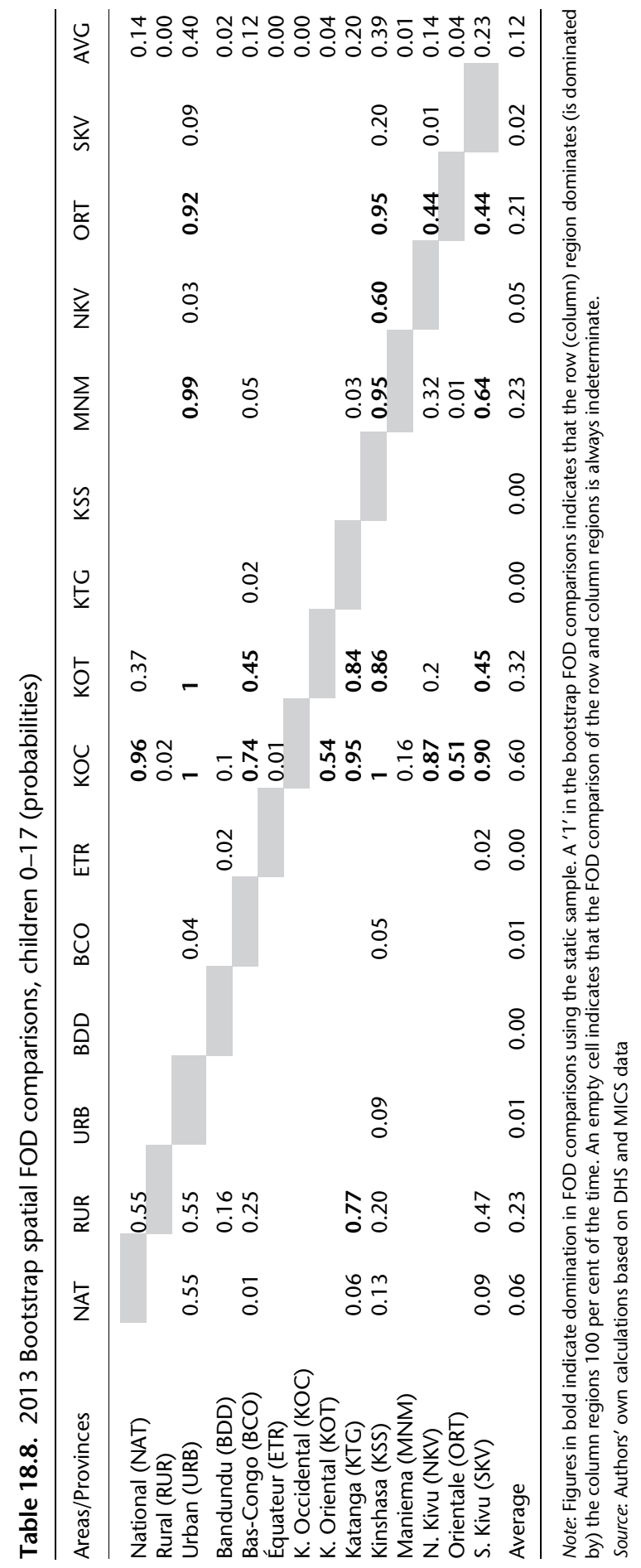


under five. Generally, the rankings are consistent between the three subsamples.

It is worth noting that the difference between net domination scores is often not sufficiently large to distinguish robustly between differences in welfare outcomes and variation introduced through random bootstrapping. To avoid misinterpreting rankings, within the tables, shading identifies clusters with similar net domination scores. Within these clusters, ranks cannot be established with confidence. Furthermore, for areas with similar scores, small changes in bootstrap probabilities may lead to disproportionately large rank changes. This sensitivity to small perturbations is a likely explanation for some of the fluctuations in rank changes among provinces.

Despite the need for caution in interpreting rankings, several conclusions can be drawn. Kinshasa and urban areas are ranked first or second throughout the twelve-year period. Kasai Occidental is ranked last or second to last in all years and is solidly last in 2103 in all subsamples. Katanga, Bandundu, and rural areas improved in rank, while Kasai Oriental deteriorated-results that are most decisively evident in the children aged 0-17 subsample.

It is noteworthy that specific FOD area rankings do not closely align with rankings based on consumption poverty rates (Table 18.1). For instance, in 2007 urban areas have slightly higher levels of consumption poverty (61 per cent) than Kasai Occidental (56 per cent) and Maniema (59 per cent) (UNDP 2014a). In contrast, in FOD comparisons, urban areas dominate both provinces in nearly every iteration. In the rankings, urban areas are ranked second compared to the Kasai Occidental and Maniema rankings of fourteenth and ninth. This difference in outcomes identifies fundamental differences in basic welfare not apparent in consumption poverty measures.

Though regional spatial FOD rankings and consumption poverty rankings do not closely correspond, some general trends are quite consistent. Between 2005 and 2012 the disparity between consumption poverty in urban and rural areas declined from fourteen percentage points to only five percentage points. In comparison, rural-urban relative trends are consistent in terms of narrowing of net domination scores with rural areas being dominated less often ( -39 and -23) and urban areas dominating less often (62 and 39) between 2007 and 2013 respectively.

Furthermore, FOD ranking suggest a narrowing in the welfare gap among regions. As noted, the extent to which Kinshasa dominates other areas significantly declined from 86 to 39 . This trend is further supported by the increase in the number of regions with positive net domination scores from four to nine between 2007 and 2013. Even though fewer regions were dominated in 2013 compared to 2007, the gap between the bottom regions (particularly Kasai Occidental) and all others widened, suggesting that the bottom echelon fell further behind. Again, this pattern is consistent with a 
narrowing in the range of consumption poverty rates at the provincial level along with the large increases in poverty in Kasai Occidental and Oriental.

\subsection{Discussion}

This chapter provides an evaluation of multidimensional welfare across regions in the DRC from 2001 to 2013, a time period corresponding to turmoil, restoration, reformation, and growth as well as declining rural consumption poverty. Applying FOD welfare analysis to 2001 and 2010 MICS and 2007 and 2013 DHS survey data allows the analysis of the welfare of children aged 0-17 in terms of deprivations in water, sanitation, shelter, health, and information. In addition, the analysis of children under five incorporates the nutrition indicator and the analysis of children aged 7-17 years includes education.

During the period of analysis, GDP grew at an average annual rate in excess of 5 per cent and since 2010 it accelerated to an average annual growth rate greater than 7 per cent. Over the same period, GDP per capita increased at an average annual rate of 3 per cent, rising from US\$201 in 2001 to US\$288 in 2013 measured in constant 2005 US\$ (World Bank 2014). Consumption poverty fell between 2005 and 2012 from 71 per cent to 63 per cent, a change driven by rural poverty declining nearly ten percentage points to 65 per cent while urban poverty hardly budged, remaining at 60 per cent in 2012 (UNDP 2014a).

Despite encouraging growth and consumption poverty trends, FOD temporal comparisons do not indicate broad-based advancement of welfare at the national, urban, or rural levels over the twelve-year period. This lack of multidimensional welfare advancement is likely due to inconsistent progress in the water, sanitation, and housing indicators. Nonetheless, all areas achieved significant reductions in the percentage of children deprived in bed net use, access to information, primary school enrolment, and malnutrition. Furthermore, FOD results do provide encouraging evidence of advancement in some provinces consistent with consumption poverty. Specifically, temporal FOD suggests that provinces with reductions in consumption poverty greater than ten percentage points (Bandundu, Bas Congo, Equateur, Orientale) also have a moderate probability of advancing welfare, and provinces with reductions in consumption poverty greater than 20 per cent (Nord and Sud Kivu) have significant probabilities of advancing welfare. FOD results also suggest a decline in the disparity between rural and urban areas and provinces. Specifically, net spatial domination scores indicate a narrowing between 2001 and 2013 in the extent to which Kinshasa and urban areas outperformed other areas, as well as the extent to which rural areas were outperformed by all other areas. 
Table 18.9. 2007, 2010, and 2013 area rankings by probability of net domination, children 0-17

\begin{tabular}{|c|c|c|c|c|c|c|c|c|c|}
\hline \multicolumn{3}{|c|}{2007} & \multicolumn{3}{|c|}{2010} & \multicolumn{4}{|c|}{2013} \\
\hline Area & Net Dom. & Rank & Area & Net Dom. & Rank & Area & Net Dom. & Rank & Change \\
\hline Kinshasa (KSS) & 0.86 & 1 & KSS & 0.84 & 1 & URB & 0.39 & 1 & -1 \\
\hline Urban (URB) & 0.62 & 2 & URB & 0.56 & 2 & KSS & 0.39 & 2 & 1 \\
\hline Sud Kivu (SKV) & 0.27 & 3 & ORT & 0.21 & 3 & SKV & 0.21 & 3 & 0 \\
\hline Bas Congo (BCO) & 0.09 & 4 & MNM & 0.11 & 4 & KTG & 0.20 & 4 & -1 \\
\hline Katanga (KTG) & -0.02 & 5 & NAT & 0.03 & 5 & $\mathrm{BCO}$ & 0.11 & 5 & 1 \\
\hline National (NAT) & -0.03 & 6 & SKV & 0.02 & 6 & NKV & 0.09 & 6 & -1 \\
\hline Nord Kivu (NKV) & -0.10 & 7 & NKV & -0.05 & 7 & NAT & 0.08 & 7 & 1 \\
\hline Équateur (ETR) & -0.15 & 8 & $\mathrm{BCO}$ & -0.07 & 8 & BDD & 0.02 & 8 & -4 \\
\hline Maniema (MNM) & -0.15 & 9 & KTG & -0.09 & 9 & ETR & 0.00 & 9 & 1 \\
\hline Orientale (ORT) & -0.18 & 10 & ETR & -0.11 & 10 & ORT & -0.17 & 10 & 0 \\
\hline Kasai Oriental (KOT) & -0.19 & 11 & BDD & -0.15 & 11 & MNM & -0.22 & 11 & 2 \\
\hline Bandundu (BDD) & -0.23 & 12 & КOT & -0.24 & 12 & RUR & -0.23 & 12 & -1 \\
\hline Rural (RUR) & -0.39 & 13 & RUR & -0.36 & 13 & КOT & -0.28 & 13 & 2 \\
\hline $\begin{array}{l}\text { Kasai Occidental } \\
\text { (KOC) }\end{array}$ & -0.40 & 14 & $\mathrm{KOC}$ & -0.70 & 14 & $\mathrm{KOC}$ & -0.60 & 14 & 0 \\
\hline
\end{tabular}

Note: Rankings within shaded groups are highly sensitive to small perturbations and should be interpreted with caution. Source: Authors' own calculations based on DHS and MICS data

Table 18.10. 2001, 2007, 2010, and 2013 area rankings by probability of net domination, children under five

\begin{tabular}{|c|c|c|c|c|c|c|c|c|c|c|c|c|}
\hline \multicolumn{3}{|l|}{2001} & \multicolumn{3}{|c|}{2007} & \multicolumn{3}{|c|}{2010} & \multicolumn{4}{|c|}{2013} \\
\hline Area & $\begin{array}{l}\text { Net } \\
\text { Dom. }\end{array}$ & Rank & Area & $\begin{array}{l}\text { Net } \\
\text { Dom. }\end{array}$ & Rank & Area & $\begin{array}{l}\text { Net } \\
\text { Dom. }\end{array}$ & Rank & Area & $\begin{array}{l}\text { Net } \\
\text { Dom. }\end{array}$ & Rank & Change \\
\hline Kinshasa (KSS) & 0.90 & 1 & KSS & 0.79 & 1 & KSS & 0.86 & 1 & URB & 0.32 & 1 & -1 \\
\hline Urban (URB) & 0.53 & 2 & URB & 0.43 & 2 & URB & 0.54 & 2 & KSS & 0.31 & 2 & 1 \\
\hline Équateur (ETR) & -0.05 & 3 & $\mathrm{BCO}$ & 0.03 & 3 & MNM & 0.07 & 3 & KTG & 0.14 & 3 & -3 \\
\hline National (NAT) & -0.06 & 4 & SKV & -0.01 & 4 & ORT & 0.06 & 4 & NAT & 0.06 & 4 & 0 \\
\hline Maniema (MNM) & -0.08 & 5 & NKV & -0.05 & 5 & NAT & 0.00 & 5 & $\mathrm{BCO}$ & 0.03 & 5 & -2 \\
\hline Katanga (KTG) & -0.08 & 6 & NAT & -0.06 & 6 & ETR & -0.04 & 6 & SKV & 0.01 & 6 & -4 \\
\hline Bas Congo (BCO) & -0.10 & 7 & ETR & -0.07 & 7 & SKV & -0.06 & 7 & NKV & 0.00 & 7 & -4 \\
\hline Orientale (ORT) & -0.12 & 8 & KTG & -0.08 & 8 & $\mathrm{BCO}$ & -0.06 & 8 & $\mathrm{BDD}$ & 0.00 & 8 & -1 \\
\hline Bandundu (BDD) & -0.12 & 9 & MNM & -0.10 & 9 & KTG & -0.07 & 9 & ETR & 0.00 & 9 & 6 \\
\hline Sud Kivu (SKV) & -0.13 & 10 & KOT & -0.11 & 10 & BDD & -0.08 & 10 & ORT & -0.07 & 10 & 2 \\
\hline Nord Kivu (NKV) & -0.13 & 11 & BDD & -0.13 & 11 & NKV & -0.13 & 11 & RUR & -0.11 & 11 & -3 \\
\hline $\begin{array}{l}\text { Kasai Oriental } \\
\text { (KOT) }\end{array}$ & -0.17 & 12 & ORT & -0.16 & 12 & KOT & -0.16 & 12 & MNM & -0.15 & 12 & 7 \\
\hline $\begin{array}{l}\text { Kasai Occidental } \\
\quad(\text { KOC) }\end{array}$ & -0.18 & 13 & $\mathrm{KOC}$ & -0.21 & 13 & RUR & -0.30 & 13 & KOT & -0.17 & 13 & 1 \\
\hline Rural (RUR) & -0.23 & 14 & RUR & -0.27 & 14 & $\mathrm{KOC}$ & -0.64 & 14 & $\mathrm{KOC}$ & -0.37 & 14 & 1 \\
\hline
\end{tabular}

Note: Rankings within shaded groups are highly sensitive to small perturbations and should be interpreted with caution. Source: Authors' own calculations based on DHS and MICS data 
Only Kasai Occidental, Kasai Oriental, and Maniema provinces experienced an increase in consumption poverty between 2005 and 2012, which was accompanied by stagnating or declining relative welfare. Specifically, probabilities of being dominated in spatial FOD comparisons confirm a lack of improvement in relative welfare in Kasai Oriental and Maniema and a significant decline in Kasai Occidental relative to other areas. In contrast, Nord and Sud Kivu exhibit the most encouraging signs of improvement with reductions in consumption poverty greater than twenty percentage points. They are the only provinces with gains in the percentage of children not deprived in every deprivation indicator. Furthermore, temporal FOD comparisons indicate that the greatest probabilities of advancement in any area occur in Nord and Sud Kivu.

Even though rural consumption poverty declined and the relative welfare of rural areas exhibits positive signs of improvement, great strides still must be made to reduce severe deprivations in rural areas where 60 per cent of the population resides. The rural population depends heavily on the agricultural sector, yet the lack of infrastructure, the closure of large farms, low levels of technology adoption, and the lack of private investment have hampered productivity in this sector. The government's prioritization of agricultural and rural sectors appears to have produced some initial gains, yet efforts must continue towards achieving the DRCs agricultural potential and further advancing the welfare of rural populations.

In addition to low agricultural productivity, increasing consumption poverty and declining relative welfare in Kasai Occidental and Kasai Oriental are likely due to the region's large rural population and dependence on the informal mining sector, particularly diamond mining. The IMF estimates that artisanal diamond mining contributed to one fifth (about two millions carats) of total diamond output in the DRC (2005), yet because most artisanal mines operate illegally often by parties not present in the local area, the benefits are not captured in the local economy or in local or national government revenues. Local miners earn about US\$1 a day, which is less than the private-sector minimum wage (Global Witness 2004 cited in IMF 2005). A commitment to carry out current mining reform laws is crucial to lift these mineral-rich provinces out of a precarious state.

\section{References}

African Development Bank (2013). 'African Development Fund Democratic Republic of Congo 2013-2017 Country Strategy Paper'. Tunis: African Development Bank.

Akitoby, B. and M. Cinyabuguma (2004). 'Sources of Growth in the Democratic Republic of the Congo: A Cointegration Approach', International Monetary Fund Working Paper WP/04/114. Washington: International Monetary Fund. 
Alkire, S. and J. Foster (2011a). 'Understandings and Misunderstandings of Multidimensional Poverty Measurement', Journal of Economic Inequality, 9(2): 289-314.

Alkire, S. and J. Foster (2011b). 'Counting and Multidimensional Poverty Measurement', Journal of Public Economics, 95(7): 476-87.

Arndt, C., R. Distante, M. A. Hussain, L. P. Østerdal, P. L. Huong, and M. Ibraimo (2012). 'Ordinal Welfare Comparisons with Multiple Discrete Indicators: A First-Order Dominance Approach and Application to Child Poverty', World Development, 40(11): 2290-301.

Atkinson, A. B. (1987). 'On the Measurement of Poverty', Econometrica, 55(4): 749-64.

Bourguignon, F. and S. R. Chakravarty (2003). 'The Measurement of Multidimensional Poverty', Journal of Economic Inequality, 1(1): 25-49.

Central Intelligence Agency (2014). 'The World Fact Book: The Democratic Republic of Congo'. Available at <https://www.cia.gov/library/publications/the-world-factbook/ geos/cg.html>, accessed 4 October 2014.

Duclos, J.-Y., D. E. Sahn, and S. D. Younger (2006). 'Robust Multidimensional Poverty Comparisons', Economic Journal, 116: 943-68.

FAO (2011). 'The State of Food and Agriculture 2010-2011. Women in Agriculture: Closing the Gender Gap for Development'. Rome: FAO.

Fischer, F., C. Lundgren, and S. Jahjah (2013). 'Making Monetary Policy More Effective: The Case of the Democratic Republic of the Congo', WP/13/226. Washington, DC: International Monetary Fund.

Foster, J. E. and A. F. Shorrocks (1988a). 'Poverty Orderings', Econometrica, 56(1): 173-7.

Foster, J. E. and A. F. Shorrocks (1988b). 'Poverty Orderings and Welfare Dominance', Social Choice and Welfare, 5(2-3): 179-98.

Foster, J. E. and A. F. Shorrocks (1988c). 'Inequality and Poverty Orderings', European Economic Review, 32(2): 654-61.

Global Witness (2004). 'Same Old Story: A Background Study on Natural Resources in the Democratic Republic of the Congo'. Washington, DC: Global Witness Publishing.

Gordon, D., S. Nandy, C. Pantazis, S. Pemberton, and P. Townsend (2003a). Child Poverty in the Developing World. Bristol: Policy Press.

Gordon, D., S. Nandy, C. Pantazis, S. Pemberton, and P. Townsend (2003b). 'Using Multiple Indicator Cluster Survey (MICS) and Demographic and Health Survey (DHS) Data to Measure Child Poverty'. Paper presented at the UNICEF MICS Conference.

IMF (International Monetary Fund) (2005). 'Democratic Republic of the Congo: Selected Issues and Statistical Appendix', IMF Country Report No. 05/373. Washington, DC: International Monetary Fund.

IMF (International Monetary Fund) (2013). 'Democratic Republic of the Congo: Poverty Reduction Strategy Paper Second Generation 2011-2015', IMF Country Report No. 13/226. Washington, DC: International Monetary Fund.

Kandala, N. B., T. P. Madungu, J. B. O. Emina, K. P. D. Nzita, and F. P. Cappuccio (2011). 'Malnutrition among Children under the Age of Five in the Democratic Republic of Congo (DRC): Does Geographic Location Matter?', Public Health, 11(261), doi: 10.1186/1471-2458-11-261.

Ravallion, M. (2011). 'On Multidimensional Indices of Poverty', Journal of Economic Inequality, 9(2): 235-48. 
Ulloa, A., F. Katz, and N. Kekeh (2009). 'Democratic Republic of the Congo: A Study of Binding Constraints'. Cambridge, MA: Harvard University.

UNDP (United Nations Development Programme) (2014a). 'Democratic Republic of Congo Millennium Development Goals Status Report 2012'. Kinshasa: United Nations Development Programme.

UNDP (United Nations Development Programme) (2014b). 'Human Development Report 2014. Sustaining Human Progress: Reducing Vulnerabilities and Building Resilience'. New York: United Nations Development Programme.

USAID (United States Agency for International Development) (2014). 'Democratic Republic of the Congo Country Development Strategy: 2015-2019'. Washington, DC: USAID.

World Bank (2013a). 'Democratic Republic of Congo Overview'. Available at: <http:// www.worldbank.org/en/country/drc/overview>, accessed 22 January 2014.

World Bank (2013b). 'International Development Association International Finance Corporation and Multilateral Investment Guarantee Agency Country Assistance Strategy for the Democratic Republic of Congo for the Period FY2013-FY2016', Report No. 66158-ZR. Washington, DC: World Bank.

World Bank (2014). World Development Indicators. Available at $<$ data.worldbank. org>, accessed 18 May 2014. 



\section{Index}

Note 1: Entries within tables, figures, boxes and footnotes are indicated by $\mathrm{t}, \mathrm{f}, \mathrm{b}$ and $\mathrm{n}$ following the page number. The entry may also be in the text on the same page in which case it will be entered again with just the page number.

Note 2: As each chapter (except the first two) pertains to a particular country, the sub-headings for each country have not been double-entered as main entries, so the reader is advised to locate main entries of interest under the country headings.

Adam, C. 248

administrative data $22 \mathrm{~b}$

African Development Bank (AFDB) 426

African Economic Research Consortium (AERC) 4

Agricultural Development-Led Industrialization (ADLI) 26

agricultural productivity growth 27

agricultural sector 26-8, 36, 37

statistics 21, 22b, 28b

aid flows 31

Alfani, F. 202

Alkire, S. 219

Amin, A.A. 300n

Annim, S. 70

Appleton, S. 140

Arndt, C. 43, 63, 90, 98-9, 157, 218, 264, 272, $371,390,438-9$

Aryeetey, E. 70, 72

assets ownership 25, 33

Atkinson, A.B. 248

Ayalew, A.D. 114

Balladur, E. 328

Barrett, C.B. 153

Basinga, P. 114

Batana, Y.M. 224

Baur, R.F. 28

Bédié, H.K. 318, 330, 332, 336

Beegle, K. 324

Belgium: Department for Development Cooperation (DGOS) 126

Bellemare, M. 57n

Benin, S. 26n

Besley, T. 163n

Bhorat, H. 401

Bidani, B. 139, 142
Bird, K. 147

Blackwell, B. 129

Booth, D. 113

Bourguignon, F. 12-15, 192, 201, 224

Brazil 395, 406

Bretton Woods institutions 190, 266, 329 see also International Monetary Fund (IMF); World Bank

Burkina Faso 18, 22-3, 27, 163-87

agricultural sector $163-4,174,175 f, 177-8$, 178t, 180, 186

auto-adjustment programmes $164 \mathrm{n}$

birth rate $175 \mathrm{n}$

cereal crops $165-6,167 \mathrm{n}, 168 \mathrm{n}, 169,172$, $173 t, 179 t, 181-4,181 f, 182 t$

CFA franc zone 164-5

Compaoré, B. 166

Consumer Price Index (CPI) 167, 168n, 169-72, 173t, 174, 181-3, 181f, 183t consumption bundles 171,173

cotton 164-5, 177-80, 178t, 179t, 187

country context and background 164-7

credits, access to 180

Demographic Health Surveys (DHS) 184

education/educational attainment 166n, 182t, 183t, 187

employment and patterns of population $178 \mathrm{t}$

Enquête Agricole Permanente (EAP) 179

expenditure distributions 187

external aid 164

farmers' market integration (budget shares) $182 \mathrm{t}$

fertility rates $175 \mathrm{n}$

fertilizer use 180, 187

food crisis (2008) 165-6, 183

food crops 181f, 182t, $183 \mathrm{t}$ 
Burkina Faso (cont.)

food imports $184 \mathrm{f}$

food prices $164-6,169,172,181-7$

forestry sector 180

formal sector $178,178 \mathrm{t}$

fuel subsidies 166

GDP 163, 180

GDP deflators 172, 173t, 187

GDP per capita $173,175,177$

GDP per capita constant prices $165 \mathrm{f}$

GDP per capita growth $3 \mathrm{t}$

GDP per capita, sectoral 175f, $176 \mathrm{f}$

Gini coefficient 167

growth, inequality and poverty dynamics (1994-2003) 167-71

growth, inequality and poverty dynamics (2003-9) 172-4

headcount index $169,171 \mathrm{t}$

health care $182 \mathrm{t}, 183 \mathrm{t}$

Heavily Indebted Poor Country (HIPC)

Initiative 165

household expenditure 167, 169

implicit price deflator 170

imports $184 \mathrm{f}$

income distribution 166,170

income, income inequality, and income poverty $168 \mathrm{t}, 173 \mathrm{t}$

industry (secondary sector) 174, 175f, 177

inflation $164,169-72,173 t, 174,181-4$, 181f, 186-7

informal sector 164, 178, 178t, 186

International Monetary Fund (IMF) 164, 166-7

labour 186

land expansion 181, 186

land use development, production and productivity in food and cotton production $179-80,179 \mathrm{t}$

Laspeyres index 168n

liberalization 164-5

livestock production 180

living standards $167,172,184$

malnutrition $164,184-5,186,186 \mathrm{t}$

market integration 184

migration $163,165,175,177,186$

mortality rates $164,184-5,186,186 \mathrm{t}$

national accounts (NA) $167 \mathrm{n}$

National Institute of Statistics and

Demography (INSD) 166-7, 172-3, 173t, 185

non-food items $182 \mathrm{t}, 183 \mathrm{t}$

non-poor category 171

output 180

policy perspectives $185-7$

population growth $164,174-5,176 t, 181$, 184f, 186

post-Malthusian equilibrium $186-7$
Poverty Reduction Strategy Paper (PRSP) 165

private consumption deflator $173 \mathrm{t}$

private sector $178,178 \mathrm{t}$

privatization 164

productivity growth 181,184

public sector $178,178 \mathrm{t}$

purchasing power 181, 184, 186

QUIBB surveys 166n, 177-8

real GDP per capita 164-5, 167, 173t, 174

relative prices 30

rent and utilities $182 \mathrm{t}, 183 \mathrm{t}$

rural/urban areas 163-4, 168t, 169, 174-5, $176 \mathrm{t}, 177,178 \mathrm{t}, 181-3,184 \mathrm{f}, 185,186 \mathrm{t}$

sectoral analysis 174-8

standard of living 166

state-owned marketing board (SOFITEX) 180n

structural reforms 164, 165, 166

stunting 185

technology 187

total GDP 174

trade and services (tertiary sector) 174 , $175 \mathrm{f}, 177$

transfers made $182 \mathrm{t}, 183 \mathrm{t}$

transport $183 \mathrm{t}$

triple poverty decomposition $170-1$

wasting 185

weather conditions, adverse 164, 165, 167, $169,181,185$

World Bank 164, 167

World Health Organization (WHO) standard 185

Byekwaso, N. 141

Cameroon 17b, 19, 293-316

agricultural sector 293, 299, 301, 308

balance of payments 299

budget deficit 295, 297, 298

capital 300, 300t

cash crops 297

CFA zone 293, 298

cocoa prices 297

coffee/coffee prices 296-7

communications 296

construction and public works sectors 297

consumption bundles 302

consumption trends 302-3, 303t

cotton prices 297

current account deficit 299

Demographic Health Surveys (DHS) 309, $311 t, 312$

development programmes 296

distributional pattern of change 308-9

durable goods ownership 311, 311t

ECAM household surveys 302, 303t

economic crisis (1987-93) 297-8 
education/educational attainment 296, 300t, 311, 311t, 314-15, 314t

effective real exchange rate 297

electricity, access to $311,311 \mathrm{t}$

exports/export prices 293, 296-8

external debt 296

external funding 296-7

fertility rates $311,311 \mathrm{t}$

fiscal policies, expansionary 296-7

fixed exchange rate 316

food crops 299

forestry 308

formal sector 308

GDP growth 293, 299

GDP per capita 3t, 294, 295f, 299, 300, 303-4, 311

gender factors $312 \mathrm{t}$

Generalized Entropy Indices 309

Gini coefficient 308, 309t

global productivity $300 \mathrm{t}$

government revenues/GDP ratio 295-6

government subsidies 296

Green Revolution 296

growth, contribution of factors to $300 \mathrm{t}$ growth incidence curves (GIC) 309, 310 f

growth performance 294-302

growth rate per capita 294, 295

growth, sources of 299-302

health care 296, 311, 314, 315

Heavily Indebted Poor Countries (HIPC) Initiative 299, 304

household consumption 297, 302-3

housing 296

human capital ratio 299-300

income levels 315

inequality trends $309 \mathrm{t}$

inflation 297, 299

informal sector 308

internal adjustment 298

internal borrowing 297

International Monetary Fund (IMF) 298, 304

investment 295, 297, 299

labour ratios 300, 300t

Logone and Chari project $307 \mathrm{n}$

macroeconomic management 297, 304

malnutrition 311, 313-15

manufacturing sector 301

minerals sector 293

monetary poverty trends $303-8,304 t$, $306 \mathrm{t}, 315$

mortality rates (under-five) 311-12, 311t, $312 t, 315$

national-level patterns of changes in poverty, inequality, and household welfare 302-9, 311t

data sources and consumption trends 302-3 distributional patterns of change 308-9

monetary poverty, patterns of $303-8$

new growth theories 300

non-farm activities 308

non-food consumption 302-3

non-monetary poverty 309-15

oil/oil prices 293, 294, 295-7, 301

PARFAR 307n

payment arrears 297

physical capital 299, 300

PNVRA 308n

policy and political economy factors 301-2

policy priorities $315-16$

population growth 295

post-devaluation period (1994 to

date) 298-9

poverty by region $307 \mathrm{t}$

poverty incidence curves $305 \mathrm{f}$

Poverty Reduction and Growth Facility (PRGF) 298

Poverty Reduction Strategy Paper (PRSP) 299

poverty severity measure 304

PREPAFEN 306n

price data $29 \mathrm{~b}$

prior to oil exploitation (1960-77) 295

real GDP 295, 297

real GDP per capita $300 t$

redistribution effect 308

regions/provinces 302-3, 303t, 306, 307t, $308,312 t, 313,313 t, 314 t, 315$

regression model 300

retail sector 297

rural/urban areas 298, 303-4, 303t, 306, 306t, 308-9, 309t, 312

SEMRY 308n

service sector 301

shocks 299

structural reform programmes 298, 298n

stunting $311,311 \mathrm{t}, 313,313 \mathrm{t}$

telecommunications 301

terms of trade 297

total factor productivity (TFP) 299-302

transport 296

vaccination coverage $311,311 t, 314$

wasting $311,311 \mathrm{t}$

water, access to $311,311 \mathrm{t}$

Watts index 304

World Bank 298, 304

Structural Adjustment Credit 298n

Central Asia $5 \mathrm{f}$

Chakravarty, S. 224

Chen, S. 32

China 6, 7f

Coleman, S. 71

Colombia 406

commodity prices 35

Compaoré, B. 166 
Comprehensive African Agricultural Development Programme (CAADP): Senior Policy Seminar (2015) 27 conflict avoidance 20

Congo, Democratic Republic 11, 19, 421-43 African Development Bank (AFDB) 426 agricultural sector $424,425,428,443$ bootstrap samples $429,434,436 \mathrm{t}, 437,438 \mathrm{t}$, $439 t, 440$

Bristol Indicators 429, 430n

censuses 422

children 429-30, 434, 437, 440-1

area rankings by probability of net domination $442 \mathrm{t}$

bootstrap spatial first-frder dominance (FOD) comparisons 438t, 439t

by number of deprivations in five indicators $435 \mathrm{t}$

in education by gender $433 \mathrm{t}$

not deprived by welfare indicator $431 \mathrm{t}$

not underweight, stunted or, wasting by gender $432 t$

temporal net first-order dominance (FOD) comparisons (bootstrap probabilities) $436 \mathrm{t}$

civil conflict and political instability 421 , 423-4

cobalt production 425

Consumer Price Index (CPI) 424

consumption poverty 440-1, 443

copper production/prices 424,425

cross-derivatives, second- or higherorder 428

Demographic Health Surveys (DHS) 422, 430, 441

deprivation indicators 429-30, 435t

diamond mining 443

economy and growth 423-6

2001-14: recovery and growth 424-6

growth, challenges to 425-6

independence to 2002: instability and recovery $423-4$

inflation 424

reform strategies 424

sectoral growth 424-5

education/educational attainment 427-8, 430, 431t, 433t, 434, 441

Enquêtes 1-2-3 422, 426

financial management 424

first-order dominance (FOD) 428-41, 443

bootstrap comparisons $437,438 t, 439 t$

deprivation indicators 429-30

methodology 428-9

spatial rankings 437-41

temporal comparisons 436-7, 436t, 441, 443

welfare analysis 441 fiscal policies 424

food prices $434 \mathrm{n}$

GDP 423f, 425, 441

GDP growth, annual 424

GDP per capita 3t, 421, 423f, 424, 425,441

GECAMINES 425

gender factors 427-8, 430, 433t, 434

Gini index 426

Government Economic Programme (PEG) 424

Growth and Poverty Reduction Strategy Paper (GPRSP) 424

growth rate 421

health care/health deprivation 430 , 431t, 441

housing indicators 434, 441

Human Development Report (UNDP) 426, 427

hydroelectricity 426

inflation 424

information, access to/deprivation 430 , 431t, 441

infrastructure 425-6

Interim Poverty Reduction Strategy Paper (I-PRSP) 424

International Monetary Fund (IMF) 424, 443

Kabila, J. 424

Kabila, L. 424

liberalization 424

macroeconomic reforms 424

malaria 427

Millennium Development Goals (MDGs) 422, 427

mining/minerals sector $424-5$ unofficial 425,443

Mobutu, J. 423, 424, 425

mortality rates:

infant and under-five 427

maternal 427

mosquito bed net use 430n, 441

multidimensional assessments 25

Multiple Indicator Cluster Survey (MICS) 422, 430, 441

nationalization-Zaireanization 423,425

net domination 436-7, 440-1, 442t

non-monetary welfare indicators 427

non-sample error 422

nutrition deprivation/malnutrition 430 , $431 \mathrm{t}, 434,441$

oil sector 425

political turmoil 427

poverty profile $426-8$

headcount $426 \mathrm{t}$

monetary poverty and inequality 426

non-monetary poverty profile $427-8$

real GDP 425 
regions/provinces $426,426 \mathrm{t}, 431 \mathrm{t}, 432 \mathrm{t}$, 433t, 434, 435t, 436t, 437, 438t, 439t, $440-1,442 \mathrm{t}, 443$

rural/urban areas $422,426-7,426 \mathrm{t}, 429-30$, 431t, 432t, 433t, 434, 435t, 436t, 437, $438 \mathrm{t}, 439 \mathrm{t}, 440-1,442 \mathrm{t}, 443$

sample biases/sizes 422

sanitation facilities/sanitation deprivation 427, 429-30, 431t, 434, 436, 441

school enrolment 441

shelter provision/shelter deprivation 430, 431t, 436, 441

spatial rankings 434

structural adjustment programmes 424

vaccination coverage $430 \mathrm{n}$

water, access to/water deprivation 427 , 429-30, 431t, 434, 436, 441

weighting schemes 428

welfare indicators 422, 427-9, 432t, 441

well-being 427, 429

World Bank 421

zinc production 425

consistency versus specificity 29-30

consumer durables, ownership of 32

Consumer Price Index (CPI) 29b

consumption 14

bundles 29-30

inadequate 25

threshold 13

see also household consumption

Cord, L.J. 163n

Côte d'Ivoire 12, 19, 20, 34, 81, 164, 318-39

African Development Indicators 325

Afristat 325

agricultural sector 331t, 333

AIDS epidemics 327

Armed Conflict Location and Event Data Project (ACLED) count of political violence $334-5$

Balladur, E. 328

Bédié, H.K. 318, 330, 332, 336

Bretton Woods institutions 329

Build-Operate-Transfer agreements 331

cash crops 322f, 326f, 330, 339f

Centre-North alliance 336

CFA franc devaluation bounce back (1994-8) 328-31

civil war (1998-2012) 332-7

1998-2002 332-4

2002-8 334-5

2008-11 336-7

civil conflict time line $335 \mathrm{f}$

clothing 324

cocoa/cocoa prices $318,320-1,322 \mathrm{f}, 325-8$, 326f, 333t, 336-7, 339f coffee/coffee prices 321, 322f, 326f, 329, $331-3,333 \mathrm{t}, 339 \mathrm{f}$

colonial rule $319-20$

Commission for Dialogue, Truth and Reconciliation 336

communication 324

construction sector 330

Consumer Price Index (CPI) 325

consumer prices $324-5,329$

consumption growth incidence 333

consumption per capita $327 \mathrm{t}, 328 \mathrm{f}$, 330, 331t

consumption variable, construction of 323-4

cotton/cotton prices $321,322 \mathrm{f}, 326 \mathrm{f}$, 329-31, 333t, 334-5, 339f

Demographic Health Surveys (DHS) 328

Duncan, D.K. 330

durable goods ownership 328, 338t

Economic Community of West African States (ECOWAS) 334

economic turmoil 336

education/educational attainment 319, 321, $324,327-8$

elections 332, 336

electricity, access to 326

ENV3 and ENV4 surveys 334-5

fiscal revenue 329

food consumption 324

foreign aid 321,330

formal sector $331 \mathrm{t}$

Gbagbo, L. 318, 326, 330, 332, 334, 336

GDP per capita 3t, 322, 322f, 326f, 335

gender factors $337 \mathrm{t}$

growth incidence curve $327,329 \mathrm{f}$

Gueï, R. 318, 332

health care 319

height stature of males $322,323 \mathrm{f}, 328$

Houphouët-Boigny, F. 319-21, 325-6, 328,337

housing 324

import prices 329

income 319, 326, 329

independence 319-20

inflation 325,329

informal sector $330,333-4$

infrastructure $321,330,331$

International Monetary Fund (IMF) 325, 328

investment 320, 330-1

Ivorian Popular Front (FPI) 336

liberalization 331,332

literacy rates 321

macroeconomic stabilization 329

Mbeki, T. 334

migration 321

Mitterand, F. 328

national accounts of consumption 335 
Côte d'Ivoire (cont.)

National Institute of Statistics (INS) 324-5

neoliberal reforms 319

non-food consumption 324

nutrition $326,327-8$

oil/oil prices $321,326 \mathrm{f}$

Ouagadougou agreements 334-5

Outtara, A. 318, 326, 330, 332, 334, 336

political violence/social unrest 326, 332, 336

poverty headcount $327 t, 331 t, 333 t$

poverty measures $331 t, 333 t$

private capital 330

private consumption 326-7

private sector $331 \mathrm{t}$

privatization 331

public deficits 329

public sector $331 \mathrm{t}$

public wage bill 329

purchasing power parity exchange rates 325

real GDP per capita 321

regions/provinces 320, 325

rural/urban areas 330

school attendance rates $337 \mathrm{t}$

self-employment $331 \mathrm{t}$

Soro, G. 334

structural adjustment programmes

(SAP) $318,321,325,330$

stunting 328

transport 324

Ture, A.S. 320

'12 works of the African elephant' (public investment programme) 330-1

unemployed/not working 331t

water, access to 326

World Bank 325, 328, 329

Coulombe, H. 70

country typologies 12-19

categorization 15-19

difficulties $17 \mathrm{~b}$

inequality measurement $16 \mathrm{~b}$

poverty, growth, and inequality triangle 12-15

cross-country studies 31-4

Cudgoe, G. 70

Dabalen, A.L. 324n

Daniels, L. 141, 144

data collection and analysis $22 \mathrm{~b}$

data issues 20-1

Datt, G. 170, 308, 406

Deaton, A. 246

Demographic Health Surveys (DHS) 16b, 21, 22b, 25, 28b, 31, 32

Dercon, S. 58, 147

distribution parameter (inequality) 32

dominance test, third-order $65 \mathrm{f}$

donor funding 14
Dorosh, P. 46, 64

Duclos, J.-Y. 70, 224

Duncan, D.K. 330

Durevall, D. 351, 356

East Asia and the Pacific 4, 5f, 8

Easterly, W. 19

Economic Community of West African States (ECOWAS) 334

economic growth rates 34

education/educational attainment $6,14,25$, $31,32-3,37$

see also school enrolment/attendance

Egypt 99

employment creation 37

employment problems 36

Engel's Law 102

Ethiopia 11, 16, 27, 34, 35, 43-65

Agricultural Development-Led

Industrialization (ADLI) 46-7

agricultural sector 26, 26b, 47, 55t, 56

between-group inequality 54

birth history data 59

cash or food transfers 48

Central Statistical Agency (CSA) 44

cereal production $47,56 \mathrm{f}$

communication infrastructure/

telecommunications 48

comparability issues 44,45

consistency 43, 64

consumption bundles 43,64

consumption levels $53-4$

context 46-8

cooperatives, government-established 47

cost of basic needs (CPN) poverty lines 43 , $45-6,64$

data collection method 44-5

Demographic Health Survey (DHS) 58, 59

education/educational attainment 60-2

electricity, access to $62 \mathrm{t}, 63$

extension agents 47

fertilizer use 47

food codes 45

food consumption aggregate 45

food inflation $55 \mathrm{t}$

food insecurity 48

food prices/food price shocks 24, 57, 58

GDP 54-7, 55t

GDP per capita growth $3 t$

gender factors $59 \mathrm{t}, 60 \mathrm{t}, 61 \mathrm{t}, 62$

Gini coefficient 53-4

headcount ratio $49 \mathrm{t}, 58 \mathrm{t}$

health care 63

Household Income, Consumption and Expenditure Surveys (HICES) 43-5, 57-8, 64

hydroelectric dams $47-8$ 
industry sector $55 \mathrm{t}$

infant mortality rates (IMRs) 59-60, 60f, 63

inflation $45,46,54-7,55 \mathrm{t}$

infrastructure $47-8$

item codes 45

literacy rates $61-2,61 t$

macro- and microeconomic indicators 44

malnutrition 59

maximum entropy approach 43, 64

Millennium Development Goals (MDGs) 60

monetary poverty and inequality $44,48-54$, $49 t, 54,54 t, 57-8$

non-food inflation $55 \mathrm{t}$

non-monetary measures of well-being 58-62

Other Food Security Program 48

political instability 46

political risk 20

poverty depth and severity $49 \mathrm{t}, 58 \mathrm{t}$

poverty incidence curves $50 \mathrm{f}, 51 \mathrm{f}$

price volatility 57

producer prices 57

production $55 \mathrm{t}$

Productive Safety Nets Programme (PSNP) 48

public goods, access to $62-3,62 \mathrm{t}$

real consumption levels 50

real GDP per capita $54,55 \mathrm{t}$

regional poverty lines $46 \mathrm{t}, 52 \mathrm{t}$

regions/provinces $45-6$

revealed preference conditions 43, 64

Road Sector Development Program 47-8

Rural Household Survey (ERHS) 24, 30, 57-8

rural/urban areas 49-50, 49t, 52-4, 58t, 59, $59 \mathrm{t}, 60 \mathrm{t}, 61-4$

sanitation facilities, access to $62-3$

school enrolment rates 59-61, 60t

seasonality 45

second-order dominance test $65 \mathrm{f}$

sensitivity analysis 45

services sector $55 \mathrm{t}, 56-7$

specificity 64

stunting rates $59,59 \mathrm{t}, 63$

Theil index 53-4

toilet facilities, access to $62 \mathrm{t}$

utility-consistent approach 43, 63-4

water, access to $62 \mathrm{t}, 63$

weather conditions, adverse $24,46,54,58$

Welfare Monitoring Surveys (WMS) 44, 59,63

well-being 58-62

within-group inequality 54

Europe $5 \mathrm{f}$

expenditure and quantity information $29 \mathrm{~b}$

exports 14

fertility rates 6

Fogel, R.W. 322 food $29 b, 37$

consumption (staples) 30

prices $14,30,35$

Food and Agriculture Organization (FAO) 386n

maize production data 21

Statistics (FAOStat) 204t, 206

food, fuel, and financial crisis (2008) 2, 3, 30

Foster, J. 99, 169n, 219

fuel prices 14

Galor, O. 186-7

Gbagbo, L. 318, 326, 330, 332, 334, 336

GDP 31, 37

growth 14-15, 18, 21, 33, 35

low 13

measurement $16 \mathrm{~b}$

per capita/growth $3,3 t, 4$

scale parameter 32

gender factors 6

Ghana 16-17, 20, 34, 35, 69-87

agricultural sector $26,71,74,74 t, 75 t, 82$, $82 \mathrm{t}, 86-7,92 \mathrm{f}$

aid flows 31

balance on goods and services $74 t, 75 t$

between-group inequality 83

capital formation $74 t, 75 t$

cocoa exports 73

consumer demand system-based simulations 70

Consumer Price Index (CPI) 70, 95t

consumer price inflation 75

consumption distribution functions $105 \mathrm{f}$

consumption expenditure $74 t, 75 t, 77,79$

consumption growth 70,74

consumption per capita $78 \mathrm{t}$

consumption poverty $75-83$

democratic transition 72,85

Demographic Health Surveys (DHS) 69, 71

district-level inequality using GLSS3-5 70

econometric analysis 70

economic developments and policies for poverty reduction $71-3$

economic growth (trends) $73 \mathrm{f}$

economic mismanagement 73

economic performance 72

Economic Recovery Programme (ERP) 72

education/educational attainment 71 , $84,84 \mathrm{t}$

electricity, access to $84 \mathrm{t}$

energy sector 75

Enhanced Heavily Indebted Poor Countries (HIPC) facility 72

expenditure overshooting 73

exports of goods and services $74 t, 75 t$

fiscal deficits 72

fiscal policy management 75,85

food price crisis (2007-8) 70 
Ghana (cont.)

food prices/inflation 70-1, 75, $76 f$

formal sector $82 \mathrm{t}$

Foster-Greer-Thorbecke poverty index 81

GDP deflator 70

GDP growth 74

GDP growth rates (sectoral) and contributions to change $92 \mathrm{t}$

GDP per capita/growth 3t, 69, 73f, 74t, 78-9, 83,85

gender factors $80 t, 84,86 t$

generalized entropy inequality indices $82-3$

Gini coefficient 82

gold exports 73

government consumption expenditure $74 \mathrm{t}, 75 \mathrm{t}$

growth incidence curves $77,78 \mathrm{f}, 79 \mathrm{f}$

growth and poverty trends 91-4

health care 71

household consumption expenditure $74 \mathrm{t}$, $75 \mathrm{t}, 77,79$

household surveys 71

imports of goods and services $74 t, 75 t$

industry sector $74 \mathrm{t}, 75 \mathrm{t}$

inequality indices 83

inflation 70-1, 75, 76f, 85, 95t

informal sector $82 \mathrm{t}$

infrastructure 71

International Monetary Fund (IMF) 72, 73, 75,85

investment 74,85

liberalization 72

Livelihood Empowerment Against Poverty

(LEAP) cash transfer programme 72

Living Standards Survey (GLSS) 69-70, 75, 77,81

macroeconomic performance $73-5,85$

maize yields by region $92 \mathrm{f}$

manufacturing sector $74 \mathrm{t}, 75 \mathrm{t}, 85-6$

monetary poverty analysis $100-5$

mortality rates (infant and under-five) 83 , $84,84 \mathrm{t}, 85 \mathrm{t}$

national accounts aggregates $74 \mathrm{t}$

national inequality 70

Nkumah, K. 71

non-manufacturing industries 74

non-monetary poverty analysis $83-5,84 \mathrm{t}$, 105-7

non-working sector $82 \mathrm{t}$

north-south disparities $83,83 t, 86-7$

nutrition 84

oil production/prices/shocks 72-4, 85

political stability/instability 71-3, 85

poverty estimates $105 \mathrm{f}$

poverty headcount:

by main economic activity $82 \mathrm{t}$

changes in and elasticity calculations $78 \mathrm{t}$ disaggregated $80 t$

rates $93 \mathrm{f}$

rates and changes in poverty $103 \mathrm{t}$

Poverty Reduction Strategy (GPRS I

and II) 72

price data $29 \mathrm{~b}$

private consumption 74,79

private investment 85

private sector $82 \mathrm{t}$

Programme of Actions to Mitigate the Social Costs of Adjustment (PAMSCAD) 72

public sector $82 \mathrm{t}$

Rawlings, J. 71

real GDP growth $73 f, 74 t, 75 t$

real GDP per capita $78 \mathrm{t}$

regional poverty lines 94-100

Consumer Price Index (CPI) estimates 95t

food, non-food, and overall 101t

inflation estimates $95 \mathrm{t}$

preferences 96-100

prices and poverty 94-6

regions 96-100

utility consistency 96-100

regions/provinces $80-4,80 \mathrm{t}, 83 \mathrm{t}, 87$

relative mean deviation 82

repatriation of Ghanaians from Nigeria 72

retired/non-active sector $82,82 \mathrm{t}$

rural/urban areas 70-1, 79-80, 80t, 84, 85t

school attendance rates $83,86 \mathrm{t}$

self-employed sector $82,82 \mathrm{t}$

services, access to 83

service sector $74,74 t, 75 t$

Shared Growth Development Agenda (GSGDA) 72

shocks 72

Statistical Service (GSS) 70, 77

structural change 74-5

stunting 70,84

summary inequality indices 82

survey consumption per capita $78 \mathrm{t}$

terms of trade 73

Theil index 82

toilet facilities, access to $84 \mathrm{t}$

unemployment $82,82 \mathrm{t}, 87$

utility consistency 96-100

vaccination coverage $84 \mathrm{t}$

Vision 202072

water, access to $84 \mathrm{t}$

weather conditions, adverse 72,73

well-being, subjective $107 \mathrm{t}$

within-district inequality 70

World Bank 72

Gibson, J. 142

Gini coefficient 16b, 18, 32

Goldberg, D.P. 129

Golooba-Mutebi, F. 113

Goni, E. 407 
Gordon, D. 429

governance quality $25-6$

government spending 14

Grimm, M. 406

growth performance 14

growth recovery 3-4

Guariso, A. 114

Gueï, R. 318, 332

Günther, I. 166-7, 168n, 170, 172, 174, 406

Hanlon, J. 214-15

Headey, D. $45 \mathrm{n}$

health care $6,14,25,32$

access to 35

aid flows 31

see also life expectancy; malnutrition; mortality; nutrition

Heavily Indebted Poor Countries (HIPC) Initiative:

Burkina Faso 165

Cameroon 299, 304

Ghana 72

Zambia 266

Hoogeveen, J. 396, 400

Houphouët-Boigny, F. 319-21, 325-6, 328,337

household budget surveys 30

household consumption 34

household consumption expenditure per capita $8 \mathrm{f}$

household consumption surveys:

periodicity $22 \mathrm{~b}$

price data $29 \mathrm{~b}$

household demographics 32

household income 13, 25

household-level insecurity 24

housing quality 32

Howe, G. 128

human capital 37

Human Development Index (HDI) 264

Human Development Report (UNDP) 426, 427

human welfare 5

Ichoku, H.E. 233

imports 14

income 13,25

India $6,7 f, 395$

inequality $21,22 \mathrm{~b}$

data $31-2$

measurement $16 \mathrm{~b}$

information systems $25,36-7$

infrastructure 37

Ingelaere, B. 125

International Comparisons Project 9

International Monetary Fund (IMF):

Burkina Faso 164, 166-7

Cameroon 298, 304
Congo, Democratic Republic 424, 443

Côte d'Ivoire 325, 328

Ghana 72, 73, 75, 85

Madagascar 375

Tanzania 238, 248

investment 14

Jamal, V. 140

Jedwab, R. 74-5

Jerven, M. 17

Johnston, D. 17

Kabano, I.H. 114

Kabila, J. 424

Kabila, L. 424

Kakande, M. 141

Kalk, A. 114

Kasirye, I. 157

Katsouris, C. $221 \mathrm{n}$

Kaufmann, D. 132

Kenya $19,35,153,343-67$

absolute poverty measures $361 \mathrm{t}$

agricultural sector $344-9,348 f$, 354t, 357,359

capital 343, 351-2, 356-7, 356f, 367

cash crops 344-5

cash transfer programmes 360

coffee 346

colonial rule 344

consumption expenditure 360

correlation coefficient 350-1

Demographic Health Surveys (DHS) 363, 364

economic inequality and poverty (1914-76) 347-51

education/educational attainment 346,358 , $363-5,365 t$

employment (1994-2012) 354-9

expenditure $353,362 t$

exports 357

factor endowments 343-4, 351, 351f, 353,356

factor incomes (1964-2000) 351-3

factor prices 344,353

factor proportions 354-9, 356f

factor quantity series 356

first post-independence period (1963-76) 346

foreign direct investment (FDI) 357

formal sector $344,352,357-8,358 \mathrm{t}, 359 \mathrm{t}$, 366-7

GDP 354-9

GDP deflator 352

GDP growth $353,354 t, 355 t$

GDP per capita growth $3 \mathrm{t}, 344$

Gini coefficient 348, 349f, 350-1, 360

government policy distortion 344 
Kenya (cont.)

growth distribution 353

growth rates $354 \mathrm{t}, 366$

growth rates and investment shares

(GFCF) 354, 355t

health care 363

HIV/AIDS 363

Household Budget Surveys (HBS) 353

income:

by source $348 \mathrm{f}$

distribution 344, 346-7, 349f, 353, 357,366

growth $355 \mathrm{t}$

structure 346

income, inequality, and poverty 343-53, $350 f, 360$

informal sector 344, 356-7, 358, 358t, 366-7

Integrated Household Budget Survey $359 \mathrm{t}$

Integrated Labour Force Survey $359 t$

interracial distribution/racial income

gaps 346-7, 348n, 349f

interwar period $344-5$

investment 356, 366

Kibaki government 360

labour 344-5, 351, 352, 356f, 357, 359t, 367

allocation 344

force $356-8$

income share in GDP $358 \mathrm{t}$

movements 345

prices 345

land $351,352,356 \mathrm{f}$

liberalization 351

life expectancy 363-4

literacy rates $365 t$

macroeconomic imbalances 351

malnutrition $364 \mathrm{t}$

manufacturing sector 354t, 355, 367

measurement challenges 353-4

minimum wages 352

modern-traditional gap increases $348-51$

monetary measures 360-2

mortality rates 363

national accounts 355

National Bureau of Statistics (KNBS) 353, 357

non-agricultural sector $344,346,348$ n

non-monetary poverty measures $362-5$

nutrition 363, 364

oil sector 357

openness 351

output prices 343

pass laws 344

period up to First World War 344

policy challenges 365-7

political conflict/civil unrest 20, 355

post-war period (1945-63) 345-6

poverty gap $361 \mathrm{t}$ poverty headcount $361 \mathrm{t}$

poverty and inequality

(1980s-2000s) 359-65

monetary measures 360-2

non-monetary poverty measures $362-5$

poverty severity $361 \mathrm{t}$

private sector $346,347,352$

production side 353

public sector $346,347,348$ n

railway 344

real returns to factors, indices of $352 \mathrm{f}$

real wages 352

regional integration 366

regional welfare inequality $362 \mathrm{t}$

regions/provinces 345,360

returns to capital 353

rural/urban areas 345, 346, 360, 361t, $362 \mathrm{t}$

sanitation facilities, access to 363

self-employment 348n, 356

Sen's Poverty Index 350, 350f

standard of living 344,345

structural adjustment programmes

(SAPs) 351, 353, 366

stunting $364,364 t$

system of national accounts (SNA) 353

technical progress 343-4

three-class society 345

total factor productivity 355

tradeable commodities 343

trade unions 352

unemployment 359

UNU-WIDER project 360n

vaccination coverage 363

wages $345,346,358$

wasting $364,364 t$

water, access to $363,364 t$

weather conditions, adverse 363

well-being 363

World Bank World Development Indicators 357

Kiregyera, B. 205

Kobou, G. 294, 299, 301-2

Korea, Republic 16b

labour 37

Lanjouw, P. 149

Latin America and Caribbean $5 \mathrm{f}$

Levinsohn, J. 397, 400

life expectancy 25

Living Standards Measurement (LSMS) $16 \mathrm{~b}$

Lokshin, M. 142

'lost decade' 19

Loveridge, S. 125

Lugo, M.A. 248

macroeconomic management 14

Madagascar 19, 20, 34, 153, 370-91 
agricultural sector $376,387,389$

birth history data 389

CFA 373

colonial influence 373

commodity lists 370

context 373-8

cost of basic needs (CPN) 371, 372-3, 390

cost-of-living index 371

Daewoo 377

decentralization programme 372

Demographic Health Surveys (DHS) 388-9

economic policies 373

employment, sectoral distribution of and the poor $386 \mathrm{t}$

Enquête Périodique auprès des Ménages (EPM) monetary poverty and other data sources 371-3, 375, 377-8, 384, 387-9

exchange rate depreciation 376

Food and Agriculture Organization (FAO) 386n

food prices 389

foreign investment 377

foreign trade regulations 373

formal sector 387

GDP per capita 3t, 373, 374f, 375, 376t, 378, 384-5, 384f

gender factors $388 \mathrm{t}$

Gini coefficient 383t

health care 389

household consumption 370-1, 374f, 378, $383,387 \mathrm{t}, 388$

household surveys 371

human capital accumulation 390

income per capita 370,378

independence 373

industrial sector $376-7,376 \mathrm{t}, 385 \mathrm{f}$, 386-7, 386t

inequality $383 \mathrm{t}$

infant mortality rates (IMRs) 389, 389f

inflation 376-7, 376t

informal sector 388

INSTAT 371-2, 386n

International Monetary Fund (IMF) 375

labour force surveys $387,387 \mathrm{t}$

liberalization 375

living standards 379

Lomé Convention 377

Lorenz curves 383

LSMS-type cross-section surveys 371

malnutrition 388-9

Millennium Development Goals (MDGs) 390

Ministry of Agriculture 386n

monetary poverty and inequality 378-84, 379t

Multi-Fibre Agreement 377

nationalist movement 373 nationalization 373

nutrition 389

official development assistance 377

political crises $371,375-7,379,384,386-90$

political stability 377

population growth 386

poverty depth and severity $379 t, 384 f$

poverty and GDP 384-7

poverty headcount $379 t, 382,384 f$

poverty incidence curves $379-80$, 380f, 381f, 383

poverty lines and data $370-3,372 t$

poverty and real GDP by sector $385 \mathrm{f}$

poverty and real per capita GDP $384 \mathrm{f}$

poverty reduction strategy: Madagascar Action Plan 376, 377

primary sector $376,376 \mathrm{t}, 385,385 \mathrm{f}, 386 \mathrm{t}$

production and inflation $376 \mathrm{t}$

production trends, sectoral 385

Rajoelina, A. 377

Ramanantsoa, G. 373

Ratsiraka, D. 373, 375

Ravalomanana, M. 375, 377

real GDP per capita 375, 376t, 387

regions/provinces $372,380,382-3,382 t$, $387 \mathrm{t}, 388 \mathrm{t}$

relative prices 30

rice prices/rice price crisis $371,376-7,376 \mathrm{t}$, 384, 386n, 389-90

Rio Tinto 377

rural/urban areas 372-3, 372t, 376, 378-80, $379 t, 380 f, 381 f$, 382-4, 382t, 383t, 385f, $386-8,386 \mathrm{t}, 387 \mathrm{t}, 388 \mathrm{t}, 390 \mathrm{t}$

sample size 372

school enrolment rates $390 t$

services sector $376-7,376 \mathrm{t}, 385 \mathrm{f}, 386-7,386 \mathrm{t}$

Sherrit International 377

shocks, political and economic 371, 373, $375,378,380,384-5,391$

South African Development Community (SADC) 377-8

stabilization plan 375

structural adjustment loans 375

stunting 388-9, 388t

textiles sector 377

Theil Index 383t

total GDP 378

United States African Growth and Opportunity Act (AGOA) 375, 377, 378

United States Millennium Challenge Account (MCA) 377

utility-consistent approach 371, 390

wage poverty $387-8$

'Wearing Apparel' provisions 375

weather conditions, adverse 371

well-being measures $379,388-90$

World Bank 375 
Malabo declaration 27

Malawi 16, 17-18, 27, 34, 89-109

agricultural sector 89-94, 92t, 107-9

amenities 93

annual GDP 89

cash transfers 109

clothing inadequacy 106, 107t

clothing prices 101-2

confidence interval value 103

Consumer Price Index (CPI) 95, 101-2, 108-9

consumption-based approach 105

consumption bundles 90, 94, 96-9, 102, 108

consumption conversion factors 108

consumption expenditure 96, 106

consumption per capita 93, 98

conversion factors 90

cost estimates 98

crop estimates 109

cumulative distribution functions 104-5

demographic composition 96

econometric model 93

economic growth 90, 93-4

education/educational attainment 93, 105,106

employment 93

empowerment and freedom of association 105, 106

entropy-based approach 90, 99

externalities 106

extreme poverty 104

Farm Input Subsidy Program (FISP) 26, 89-92, 94, 109

fertilizer subsidies 28b, 91, 101, 107

food inadequacy $107 \mathrm{t}$

food products $95-6$

food security 89

footwear prices 101-2

GDP 90, 92, 107

GDP per capita/growth 3t, 108

general equilibrium model 93

Gini coefficient 94, 108

government services $92 \mathrm{t}$

health care/health care inadequacy 93, 105, $106,107 \mathrm{t}$

household demographics 93

household durable consumer goods 96, 106

household surveys 93

housing quality $93,106-7,107 \mathrm{t}$

housing (rental value) 96

income levels 105, 106

inflation 94-6, 100-2, 108-9

Integrated Household Surveys (IHSs) 90 93-4, 96-7, 106, 108

iterative process $90,98-9$ maize production 89-90, 91, 108

markets, incomplete 106

mining, industry and construction sectors $92 \mathrm{t}$

money-metric approach 106

national GDP 92t

national poverty 108

national rates $93 \mathrm{f}$

National Statistical Office (NSO) 90, 93-105, 101t, 108-9

non-food consumption 104

non-food share of expenditure 102-4

no trickle-down effect hypothesis 108

nutrition 106

poverty gap 99-100

poverty headcount $99-100$

poverty lines:

national 90-1, 100-1

non-food 100-1

regional 90-1, 97, 100

rural 100

price data $29 \mathrm{~b}$

private services $92 \mathrm{t}$

public goods 106

real GDP 109

regions/provinces 90-1, 97, 100-1, 101t

relative prices of commodities 30,96

revealed preference conditions 99

rural/urban areas 91, 93f, 94-6, 100-5, 101t, $103 \mathrm{t}, 105 \mathrm{f}, 107 \mathrm{t}, 108-9$

social support 109

squared poverty gap 99-100

stunting 106

subsidy programme 101

tobacco sector 91

trade and transport sectors $92 \mathrm{t}$

ultra-poor 104, 109

utility consistency 99

wasting 106

water, access to and clean water provision 106

weather conditions, adverse 91

welfare aggregates 104

Welfare Monitoring Surveys (WMSs) 93

well-being, subjective 106-7

World Bank 95

Mali 20

malnutrition $6,25,35$

manufacturing value-added 37

market information system data $29 \mathrm{~b}$

Mason, N.M. 271

Mbaku, J.M. 300n

Mbeki, T. 334

Mexico 406

Middle East $5 f$

Millennium Development Goals (MDGs):

Congo, Republic 422, 427 
Ethiopia 60

Madagascar 390

Rwanda 132

Zambia 264

Minot, N. 141, 144

Minten, B. $47 \mathrm{n}$

Mitterand, F. 328

Mixed Indicators Cluster Survey (MICS) 25

Mkenda, A. 247

mobile phone subscriptions 6,33

Mobutu, J. 423, 424, 425

monetary poverty indicators $7-9,34$

monetary poverty, volatility of $21-5$

data collection and analysis 22b

sources of variation in measures $23 \mathrm{~b}$

Morocco 28b

mortality rates 5

child 5,5 f, 35

maternal 5

premature 25

Most, S.J. 300n

Mozambique 18, 20, 24, 27, 34, 99, 190-216

absorption components 206

agricultural sector/agricultural productivity growth 23, 192, 202-3, 205-6, 209-16, $210 \mathrm{t}, 212 \mathrm{f}$

Agricultural Surveys (TIAs) 202-5, 204t

aid flows $31 \mathrm{n}$

armed conflict 190

assets ownership 193-6

basic accounts 200-2

Bretton Woods Institutions 190

capital-intensive activities 191

cereal crops 203, 204t, 205-6, 206f

computable general equilibrium (CGE) model 210-12

Consumer Price Index (CPI) 208, $208 f$

consumer prices 213

consumption patterns 201, 202, 206-10, $210 \mathrm{t}, 212 \mathrm{f}$

core food products $207-8,208 \mathrm{f}$

credit, access to 203

current perspectives 214-16

Demographic Health Surveys (DHS) 199

durable consumer goods 194-6, 195f, $195 \mathrm{t}, 214$

Economic Rehabilitation Programme 190 education/educational attainment 191, 196-7, 197f, 209, 210, 212f, 214

employment creation 216

exports 201, 202, 209, 210t, 216

farm-gate prices 213

farm size 203

Food and Agriculture Organization (FAO) maize production data 21

Food and Agriculture Organization Statistics (FAOStat) 204t, 206 food consumption $207,209,210,212 \mathrm{f}$

food crops 204t, 211, 215

food prices $23,206-7,213$

food security unit 205

foreign ownership 191, 215

Frelimo party 190-1

fuel and food price crisis (2008) 215

fuel prices 23, 206f, 207, 209-10, 212f, 213

GDP/growth 191-3, 201, 205-6, 210-11, $210 t, 214$

GDP per capita growth $3 \mathrm{t}$

Gini coefficient 213

government 201, 210t

health care 196-8, 198f, 199f, 214

Household Budget Survey (IOF) 199, 201f, 211

household budget surveys 192, 198-9, 211

household-specific price indices 208

housing/housing quality indicators 193-4, 194t, 207, 214

human capital 214

imports 201-2, 209, 210t, 213

industry sector $210,210 \mathrm{t}$

inequality 207-9

informal sector 216

infrastructure 215,216

international real price indices $206 \mathrm{f}$

investment 201, 210t

job creation in enterprise sector 215

labour force growth 209-10, 212-13

living standards 192

luxuries and necessities 207

macroeconomic consistency 200-14

absorption components 206

basic accounts 200-2

consumption and poverty headcount estimates 202

formal assessment of macroeconomic factors 209-14

GDP growth 202-6

inequality 207-9

terms of trade 206-7

maize 21

malnutrition 198-200, 200f, 201f, 214

Ministry of Agriculture 203

monetary measures of poverty 23b, 191-3

mortality rates (infant/child) 191-2

Multiple Indicator Cluster Survey

(MICS) 199, 201f

national accounts 205, 211

National Institute of Statistics 205

National Resistance Movement

(Renamo) 190, 215

natural resources exploitation 215

net enrolment rate (NER) 196-7

Nkomati Accord 190

nominal per capita consumption $209 \mathrm{f}$ 
Mozambique (cont.)

non-core foods $207-8,208 \mathrm{f}$

non-foods 207-8, 208f

non-monetary poverty measures $193-200$

assets ownership 193-6

education, access to $196,197 \mathrm{f}$

health services and clean water, access to $196-8,198 f, 199 f$

well-being: anthropometric

measures 198-300

nutrition 198

oil prices 207, 215

per capita growth in GNP 192

population growth 191, 193, 197, 203, 209-11

poverty, growth, and inequality

triangle 192-3, 201

poverty headcounts 192t, 202

poverty rates $211 \mathrm{t}, 212 \mathrm{f}$

price data $29 \mathrm{~b}$

price indices $209 \mathrm{f}$

processed food prices $206 \mathrm{f}$

production volatility 204

productivity-enhancing inputs (pesticides, fertilizers) 203

productivity growth 215

purchasing power 207

real trade balance 202

relative prices 30

rural/urban areas 192-4, 192t, 194t, 195f, 195t, 196-7, 197f, 198f, 199f, 202, 207-8, 211-12, 211t

school enrolment 196-7

services $210,210 t$

shocks 215-16

social indicators 193

Statistical Yearbook 205

structural adjustment programme (SAP) 191

stunting $200 f$

tax burdens 191

technology innovation 203, 215

terms of trade 206-7, 211, 213, 215

transport costs 213

wasting $200 \mathrm{f}$

water, access to 196-8, 198f, 199f, 214

weather shocks $23,205,209-10,212 \mathrm{f}$, 213,215

welfare measures 214

well-being 193-4, 198-200, 202-3

Muellbauer, J. 207

Muhoza, D.N. 114

multidimensional assessments, importance of $25-6$

multi-purpose household surveys $28 \mathrm{~b}$

national accounts $22 \mathrm{~b}$

Nigeria $8,11,20,27,34,35-6,81,218-34$ absolute poverty $221 \mathrm{n}$

agricultural sector 221f, 223

aid flows 31

approach 224-6

basic needs approach $221 \mathrm{n}$

bootstrapping approach 219, 225, 229, 230, 230t, 231t

child poverty 219

communication sector 221

Core Welfare Indicator Survey 219

counting approach 219

data sources 226

Demographic Health Surveys (DHS) 219, 226-7, 229, 230t, 231t, 233t

deprivation 227, 229, 233

distance function method 224

distribution of households by number of deprivations $229 \mathrm{t}$

economic growth and stagnation 219-21

education/educational attainment 226, 227, $228 \mathrm{t}, 234$

electricity, access to 226, 227, 228t, 234

factor analysis 224

first-order dominance (FOD) method 218-19, 225-6, 229-34, 230t, $231 \mathrm{t}, 232 \mathrm{f}, 233 \mathrm{t}$

fuzzy set approach 224

GDP per capita growth $3 \mathrm{t}$

Gini coefficient 218, 223

global financial crisis 218

Harmonized Nigeria Living Standard Survey (HNLSS) 221n, 222

income inequality 222-3, 223t

inertia approach 224

information theory approach 224

linear programming 225

living standards 222, 224

macroeconomic policies 220

manufacturing sector $221 \mathrm{f}$

mining sector $221 \mathrm{f}$

multidimensional welfare combinations 25 , 224-5, 227-9

National Bureau of Statistics (NBS) 218, 221n

General Household Surveys (GHS) 222

Nigeria Economic Report (2014) (World Bank) 16b, 18

Nigeria Poverty Profile Report 222

non-oil sectors 220-1

oil sector 220-1, 221f, 223

one-dimensional approaches 224

political instability 219

population of households not deprived 228t

poverty incidence $221-4,222 t$

real GDP growth rate 220f, $221 \mathrm{f}$

reform agenda 220 
regions/provinces $219,221,222 \mathrm{t}, 223 \mathrm{t}$, 225-6, 228t, 229, 229t, 230t, 231t, 232, 232f, 233t, 234

relative poverty $221 \mathrm{n}$

rural/urban areas 219, 222-3, 222t, 223t, 225-7, 228t, 229t, 230, 230t, 231t, 232, 232f, 233t, 234

sanitation facilities, access to $226-7$, $228 \mathrm{t}, 234$

services $221 \mathrm{f}$

shelter 226-7, 228t

social instability 219

structural reforms 220

subjective poverty $221-2 \mathrm{n}$

water, access to $226,227,228 \mathrm{t}, 234$

weather conditions 221

welfare indicators $25,219,224-9$

World Bank 221, 222

Nkumah, K. 71

Nkurunziza, J. 114

non-monetary poverty indicators $5-7,34$

non-sampling error 23b, 25

North Africa $5 \mathrm{f}$

nutrition 6,32

see also malnutrition

Nyerere, J. 238

oil prices $30,35,36$

Orazem, P.F. 28

Osei, R. $74-5$

Outtara, A. 318, 326, 330, 332, 334, 336

Oyekale, T.O. 219

Özler, B. 396, 400

Paul, S. 324n

Penn World Tables 32

Peru 406

Pinkovskiy, M. 16, 31-2, 187

political stability/instability 19-20, 34

population growth rates $6,7 \mathrm{f}, 35$

poverty, growth, and inequality triangle $12-15$

poverty headcounts 8

poverty lines 1,9

poverty rates $23 \mathrm{~b}$

price data/statistics $21,22 \mathrm{~b}$

pricing surveys, village-level $29 \mathrm{~b}$

public services, distance to and use of 25

purchasing power parity (PPP) 9, 31-2

Radelet, S. 4

Rajoelina, A. 377

Ramanantsoa, G. 373

Ratsiraka, D. 373, 375

Ravallion, M. 32, 90, 98, 139, 142, 149, 170, $246,308,406$

Ravalomanana, M. 375, 377

Rawlings, J. 71 relative prices $28-30,29 \mathrm{~b}$

Resnick, D. 267

Rozelle, S. 142

Ruiz-Castillo, J. 407

rural/urban areas 5

Rwanda 16, 34, 35, 112-33

abject poverty category 133

adult equivalence scale 119

agricultural sector $26,112-14,119$, 122-7, 131

asset holdings $116 \mathrm{t}, 117-18$, $130 \mathrm{t}, 131$

cereals, pulses, and roots 124

child anthropometric outcomes 125-6

civil war 114

coercion/fines 125

coffee sector 114

Consumer Price Index (CPI) 119

consumption poverty and inequality trends 118-26, 131-2

changes in poverty by district $124 \mathrm{f}$

consumption bundles 120

consumption and consumption poverty by province $120 \mathrm{t}$

growth incidence curves $122 \mathrm{f}$

pattern of poverty by district $123 \mathrm{f}$

cost-of-living index 119

country context $112-14$

cultivation patterns 126

Demographic Health Surveys (DHS) 114, $117,118 \mathrm{t}, 123,126,131$

durable goods (household) 116t, 117

economic performance 112-14

education/educational attainment 113-15, $116 t, 118-19,125,131-2$

electricity, access to $116 \mathrm{t}, 117,119$

environmental degradation 112

family size 125

farm size 112

fertility rates $114,115,116 \mathrm{t}, 118$

fertilizer use 127

food price index 119

food rich category 128, 133

GDP growth 121

GDP per capita/growth 3t, 112

gender factors $113,114,115$

General Health Questionnaire (GHQ-12) 129

genocide 20,114

Gini coefficient 116, 121, 127

growth performance 114

happiness 129-30, 130t

health care $113-15,116 \mathrm{t}, 118-19,118 \mathrm{t}, 125$, 131-2

Household Living Conditions Survey

(EICV) 119, 120, 125

household mobility analysis $126-30$ 
Rwanda (cont.)

happiness and mean income, assets, and income change by happiness $130 \mathrm{t}$ income and land values $127 \mathrm{f}$

mobility matrix of self-reported social categories $128 \mathrm{t}$

social mobility between $u b u d e h e$ categories: self-reported reasons $129 \mathrm{f}$

housing characteristics/conditions 115, 116t, 117-19, 131

human development outcomes 131

income $126-31,127 \mathrm{f}, 130 \mathrm{t}$

land ownership 128, 130

land size 126

livestock ownership 127-8

Millennium Development Goals (MDGs) 132

mobile phone ownership $117 \mathrm{n}$

money rich category 128,133

mortality rates $115,116 \mathrm{t}, 131$

mosquito bed net usage $116 \mathrm{t}, 118 \mathrm{t}$

National Institute of Statistics of Rwanda poverty report 119

non-farm activity 122,125

non-farm self-employment 127

non-farm wage employment 127

non-monetary measures $114-18,116 \mathrm{t}$

nutrition $115,116 \mathrm{t}$

participatory poverty assessment (PPA, ubudehe) 127, $129 \mathrm{f}$

performance-based financing 113-14, 118,132

political risk 20

poor category 133

population growth 113

price data $29 \mathrm{~b}$

principal component analysis 117

production factors 128-9

questionnaire design 114-15

real per capita GDP $113 \mathrm{f}$

refugee crisis 114

regression analysis 127

resourceful poor category 128, 133

richest 20 per cent and poorest 20 per cent of sample population $118 \mathrm{t}$

rural/urban areas $117,118,121$

school attendance 116-17, 116t, 118t

self-employment 122,127

services sector $112-13$

social categories 127-8, 133

stunting $115,116 \mathrm{t}$

toilet facilities, access to $117 \mathrm{n}$

vaccination coverage $115,116 \mathrm{t}, 117,118 \mathrm{t}$

very poor category 128,133

violent conflicts $112,114-18$

wage work 122-3, 125, 127

wasting $115,116 \mathrm{t}$ water, access to $117 \mathrm{n}, 119$

weather conditions 125,127

well-being 114-18, 116t, 130, 131

World Bank 127

World Health Organization (WHO) 129n

Sachs, J. 351

Sahn, D. 33

Saksena, P. 114

Sala-i-Martin, X. 16, 31-2, 187

sampling error 23b, 25

Sandefur, J. 248

sanitation facilities, access to $5-6,14,25,35$

Sayne, A. 221n

Schmidt, E. 46, 64

school enrolment/attendance $6,25,35$

selection bias 20

Sen, A.K. 12, 106

Simler, K. 30, 43, 63, 90, 98-9, 371, 390

Smale, M. 271

Smart, T. 214-15

Somalia 20

Soro, G. 334

South Africa 11, 15, 17b, 19, 33n, 34n, 35-6, $393-415$

aid flows 31

asset ownership 401-2, 412, 413

Census (2011) 411t

child grants $400 \mathrm{f}$

Comprehensive Welfare Index 401

Consumer Price Index (CPI) 393, 403-4, 405f, 406, 410, 414

consumption bundles 414-15

cost-of-basic-living poverty line 396

cumulative distribution functions (CDFs) 404, 405f, 406

disability benefits $400 \mathrm{f}$

economic crisis 395

education/educational attainment 394-5, 400, 401, 402, 413

electricity, access to 401, 402, 410-11, 413

employment creation 414

factor analysis 401

first-order dominance (FOD) 401

food categories 410

food prices $414-15$

formal sector 395

GDP/GDP growth 394t

GDP per capita/GDP per capita growth $3 t$, $394 \mathrm{t}$

gender factors 398,401

Gini coefficient 396, 407, 408, 409t

goodwill transfers 396

government grants and subsidies 397-8, 400

government interventions 401

growth component 406

growth rates 414 
health care 402,413

high-inflation expenditure categories $410 \mathrm{f}$ household consumption 407-8

housing 401, 402, 413

human capital 412,413

income 396, 399, 400, 400f, 401

income distribution 396-7, 397f

Income and Expenditure Surveys (IES) 403, $411 \mathrm{t}, 412$

inequality $407-9,409 t$

infant mortality rates (IMRs) 413

inflation 403-4, 406-9, 409t, 410f, 411t, $412,414-15$

informal sector 395

investment $400 \mathrm{f}$

labour market 395-6, 398, 412, 413-14

Living Conditions Survey (LCS) 411t, 412

living standards 402

Lorenz curves 398-9, 399f, 406, 408

macroeconomic trends $394 \mathrm{t}$

migration 398

money-metric poverty and inequality trends 396-400

multidimensional poverty index (MPI) 402,413

National Income Dynamics Study (NIDS) 402

non-money-metric poverty 401-2

nutrition 413

old age pension $400 \mathrm{f}$

percentile-specific price inflation indices

(PCPI) 404, 405f, 406

poverty dominance analysis 397

poverty headcount 402, 406

poverty line 395,396

price changes $403,406,408-9$

price impacts on poverty and

inequality 409-12

price/inequality decomposition 414

price/poverty decomposition 414

prices, poverty, and inequality 402-9

accounting for prices and effect on poverty trends 404-6

data availability to assess role of prices $402-3$

price changes and effect on inequality trends 406-9

price/inequality as demonstrated by

Lorenz curves $407 \mathrm{f}$

price/poverty as demonstrated by cumulative distribution functions (CDFs) $405 \mathrm{f}$

prices, relative 30

Private Asset Index 401-2

Project for Statistics on Living Standards and

Development (PSLSD) 402

redistribution component 406 remittances $400 \mathrm{f}$

representative household 406

rural/urban areas 398, 403, 406, 409n, 411-12

sanitation facilities, access to 401,413

self-employment 395

social grants 414

social support programmes 395-6, 397, 399

Statistics South Africa 95, 393, 404

Theil index 409t

unemployment 395-6, 398, 400

wage income $396,400 f$

water, access to $401,402,413$

well-being 394-402, 403, 414-15

South African Development Community (SADC) 377-8

South Asia 4, 5f, 6, 8

Southern African Development Community (SADC) 238

Spain 406

Ssewanyana, S.N. 157

Stifel, D. 33

Sudan 20

system of national accounts (SNA) $16 \mathrm{~b}$

Tanzania 17b, 18, 20, 27, 238-60, 324

agricultural sector 243, 255-6, 259, 260

asset ownership 255, 256

balance of trade 241

Bristol Indicators 257

communications 243

community infrastructure 256

comparability issues 249

Consumer Price Index (CPI) 247n, 248-9

consumer prices 247

consumption 239, 241-2, 245-9, 254f, 255

Demographic Health Surveys (DHS) 239,257

deprivation measures (children under-five) 258-60, 259t

East African Community 238

education/educational attainment 257, $257 \mathrm{t}, 258,259 \mathrm{t}$

exports 241

financial, food, and fuel crises 240

financial intermediation 243

food consumption 253

food price inflation 248, 255

food prices/shocks 239, 251, 259

food shares $256 \mathrm{t}$

fuel prices/shocks 239, 251, 259

GDP deflator 247-9

GDP elasticity 239

GDP per capita 3t, 239, 245

Gini coefficient 250, 250t

growth incidence curves 251f, 252f, 253f, 255-6 
Tanzania (cont.)

growth patterns 240-3

Household Budget Surveys (HBS) 239-40, 243, 245-9, 252, 255

household characteristics 255

households not deprived by welfare indicator $257 \mathrm{t}$

imports 241

industry/construction sector 243

inflation 248, 249, 255

information 257-8, 257t, 259t

International Monetary Fund (IMF) 238, 248

investment 241, 256

kernel density plots 252

location of delivery $258,259 t$

manufacturing, trade, and repairs sector 243

micro-level evidence on consumption poverty and responsiveness to growth 243-9

mining and quarrying sector 243

national accounts data 239, 240-1, 245-8, 255

National Bureau of Statistics 243, 249

natural gas 241

non-food data 253

non-food price inflation 248

non-monetary poverty 239, 257-9, 260

Nyerere, J. 238

population growth 240

poverty change pattern 249-57

poverty headcounts $244 \mathrm{t}, 250 \mathrm{t}$

price data 29b, 249

price deflators 247

public service provision 260

real GDP 242t, 243, 249

real local currency per capita GDP, growth of $241 \mathrm{f}$

regions/provinces $257 \mathrm{t}, 258,259 \mathrm{t}$

rural/urban areas 243, 250, 250t, 251f, 252f, 253f, 256, 256t, 257t, 258-60, 259t

sanitation facilities, access to $257,257 \mathrm{t}$, $258,259 t$

savings and investment 256

services sector 243

shelter $257-8,257 \mathrm{t}, 259 \mathrm{t}$

social development 238

Southern African Development Community (SADC) 238

survey-based deflator 248, 256

water, access to $257,257 \mathrm{t}, 258,259 \mathrm{t}$

welfare indicators 257

well-being 248-9

World Bank 238, 243, 248

Poverty Assessment 249

World Development Indicators on real GDP 240

tax revenue $14,22 \mathrm{~b}$ technological advances in location and imaging technologies $28 \mathrm{~b}$

Tembo, S.T. 271

Thurlow, J. 267

time use 32

trade and growth 4,14

Tsui, K. 224

Ture, A.S. 320

Uganda 16, 34, 137-58

activity 151-2

age of household head 149

agricultural sector 26, 149, 151, 152t, 158

agro-climatic diversity 157

asset-based poverty trap 155

Bureau of Statistics (UBOS) 138, 140, 143

child dependency ratios 149-50, 150f, 158

chronic poor category $145-7,147 \mathrm{f}, 148 \mathrm{f}$, 149-50, 150f, 151t, 152t, 153t, 154f, $155 \mathrm{t}, 156 \mathrm{f}, 157-8$

civil strife $155 \mathrm{t}, 156$

consistency 142

Consumer Price Index (CPI) 141

consumption bundles/food baskets 139 , 141-2, 145, 157

cultural diversity 157

death of a family member 155t, 156

Demographic Health Surveys (DHS) 141

dependency ratios 149

dietary diversity 140, 145

education/educational attainment 152-3, 158

employment 157

escape from poverty category $146,147 \mathrm{f}$, 149-50, 150f, 151t, 152t, 153t, 154f, $155 \mathrm{t}, 156 \mathrm{f}, 158$

falling into poverty category $146,147 \mathrm{f}$, $150 f, 151 \mathrm{t}, 152 \mathrm{t}, 153 \mathrm{t}, 154 \mathrm{f}, 155 \mathrm{t}$, $156 \mathrm{f}, 158$

food consumption 149

GDP per capita growth $3 \mathrm{t}$

gender factors 149,158

health care $153-5,158$

distance to health infrastructure $154 \mathrm{f}$

maternal health 157

number of days per year inactive due to illness $154 \mathrm{f}$

household demographics 149-51, 158

household head 149, 152

human capital 155

income 152t, 158

inequality 145

inflation 140, 141, 144

infrastructure 147

literacy rates 141,157

location 146-9

marital status $149,151 \mathrm{t}, 158$ 
migration 157

minimum cross-entropy approach 143

Monitoring Survey data 139

national accounts $26 \mathrm{n}$

National Household Survey (UNHS) $137 n$, 138n, 141, 143, 157

National Panel Survey (UNPS) 138, 143, 145,153

never poor category $149-50$

non-agricultural enterprises 152t, 158

non-food requirements 139

non-poor category $145,147,147 f, 148 f, 149$, $150 f, 151 \mathrm{t}, 152 \mathrm{t}, 153 \mathrm{t}, 154 \mathrm{f}, 155 \mathrm{t}, 156 \mathrm{f}$, 157,158

nutrition 157

organizational support $152 \mathrm{t}$

per capita expenditures 143

policy changes 137

poverty headcounts $140 \mathrm{t}, 144 \mathrm{t}$

production 149

property income $152 \mathrm{t}$

rationality assumption 142

real GDP 137

reassessment of poverty and its evolution 143-5

regions/provinces 140t, 141, 143, 144t, 145 , 147f, 148, 158

relative prices 30

robbery and theft $155 \mathrm{t}, 156$

rural/urban areas 139, 140t, 143-4, 144t, 147

seed quality $155,155 \mathrm{t}$

self-employed sector 152

shocks and coping 155-8, 155t, 156f

sliding into poverty 149-50, 157

social capital 152, 157

spatial differences $139,143-4$

standard of living 142

staple cereal crops 140, 142, 157

stunting 157

transaction costs 147

transfers $152 \mathrm{t}$

trends and controversies 139-41

utility-consistent poverty lines using revealed preferences $141-3$

utility maximization 142-3

vulnerable category 146, 147f, 148f, 150f, $151 \mathrm{t}, 152 \mathrm{t}, 153 \mathrm{t}, 154 \mathrm{f}, 155 \mathrm{t}, 156 \mathrm{f}, 157-8$

wage employment $151,152 t$

water, access to $141,148-9,148 \mathrm{f}$

weather conditions, adverse $155,155 \mathrm{t}$

welfare indicators 139,142

well-being 146, 157

World Bank 137

Living Standards Measurement Study (LSMS) 138

World Health Organization (WHO) estimates 139
Ulloa, A. 424

United Nations:

medium variant population projection 6

Secretary General's High-Level Panel of Eminent Persons on the Post-2015 Development Agenda 21

United States 406

African Growth and Opportunity Act (AGOA) 375, 377, 378

Millennium Challenge Account (MCA) 377

orange production forecasts $28 \mathrm{~b}$

UNU-WIDER 360n

Growth and Poverty Project (GAPP) 2

World Income Inequality Database (WIID) 16b, 32

Van Den Berg, H. 300n

Van der Westhuizen, C. 401

Van Landeghem, B. 130

Verduzco-Gallo, I. 97, 102, 108

vulnerability 30

Warner, A. 351

water, access to 5-6, 14, 25, 35

Weil, D.N. 186-7

welfare 5

well-being 32

Westoff, C. 114

Wittenberg, M. 402

Wodon, Q. 70, 165

Woolard, I. 397

World Bank 1, 24, 32

Burkina Faso 164, 167

Cameroon 298, 298n, 304

Congo, Democratic Republic 421

Côte d'Ivoire 325, 328, 329

Ghana 72

global monetary poverty figures 8

Kenya 357

Madagascar 375

Malawi 95

Nigeria 221, 222

Rwanda 127

Tanzania 238, 240, 243, 248, 249

Uganda 137, 138

World Development Indicators (WDI) 1, 2 $3,4,5,15,17 \mathrm{~b}, 240,357$

World Health Organization (WHO) 129n, 139,185

Young, A. 26, 31-3, 187

Zambia 18, 27, 34, 263-87

agricultural sector/small-scale farm households $265,267-8,267 \mathrm{f}, 269 \mathrm{t}$, 270-1, 270t, 273-4, 277, 279, 282, 284,286 
Zambia (cont.)

aid flows 31

balance of payments 265

bootstrapping 272, 280, 281t, 282, 283t, 284

Bretton Woods Institutions 266

Central Statistical Office (CSO) 273

commodity price vulnerability 287

construction sector 267

Consumer Price Index (CPI) 287

consumption poverty rate 264

copper prices 264-7, 269, 284, 287

debt stock cancellation 266, 284

Demographic Health Surveys (DHS) 286

deprivation, levels of 274-7, 275f, 276t,

$277,278 \mathrm{t}$

duality of economy structure 269

economy and growth 264-7

education/educational attainment 264, 270, $273,274 \mathrm{t}, 275 \mathrm{f}, 276 \mathrm{t}$

electricity, access to $264,273,274 t$

employment by sector $270 \mathrm{t}$

exports 265

external borrowing 265

external factors 284

external shocks 265

Farmer Input Support Programme (FISP) 271

Fertilizer Support Programme 271

Fifth National Development Plan (FNDP) 263

first-order dominance (FOD) 264, 272-4 $274 t, 277-82,279 t, 280 t, 281 t, 283 t$ $284,284 t, 285 t, 286-7$

fiscal deficit 266

fiscal discipline 284

Food Reserve Agency (FRA) 271

foreign direct investment (FDI) 266, 267

foreign exchange reserves 266

formal sector $270 \mathrm{t}$

fuel $275 \mathrm{f}, 276 \mathrm{t}$

GDP 265f, 266, 267, 271

GDP per capita 3t, 265f, 268

Gini coefficient 269

health care 264, 270, 286

Heavily Indebted Poor Countries (HIPC)

Initiative 266

household consumption surveys 287

housing 269, 269t, 273, 274t

Human Development Index (HDI) 264

imports 265

industry sector $267 \mathrm{f}$

inflation 266, 266t

informal sector 270t, 271

information, access to 286

infrastructure projects 267,269

internal factors 284 land resources 264-5

liberalization 267,284

life expectancy 263

Living Conditions Monitoring Surveys (LCMS) 264, 273, 286

macroeconomic indicators $266 \mathrm{t}$

manufacturing sector $265,267,267 \mathrm{f}$

methodology 271-3

Millennium Development Goals (MDGs) 264

mineral wealth 265

mining and quarrying sectors 266, 267

multidimensional assessments 25

nominal exchange rate $266 t$

non-agricultural households 269t, 270t, 273-4, 277, 279, 282, 286

non-monetary poverty indicators 264, 272

nutrition 286

oil prices 265

population growth 263

poverty headcount rates 268t, 269t

Poverty Reduction Programme 271

Poverty Reduction Strategy Paper (PSRP) 263

poverty trends 268-71

price data $29 \mathrm{~b}$

privatization 267

real GDP/real GDP per capita 263, 266t

regions/provinces 268t, 270t, 276t, 277 $278 t, 279 t, 281 t, 282-4,283 t, 284 t, 286$

rural/urban areas $264,268-70,268 \mathrm{t}, 270 \mathrm{t}$, $272-5,276 t, 277,278 t, 279 t, 280 t, 281 t$, 282, 283t, 284t, 285t, 286-7

salary (average) 270

sanitation facilities, access to $264,273,274 t$, 275f, 276t, 286

seed and fertilizer subsidies 271

service sector $267,267 \mathrm{f}$

shelter 264, 275f, 276t

Sixth National Development Plan (SNDP) 263, 273

social protection programme 270

stagnation 269

staple crops 267,271

state ownership 270

structural adjustment reforms 266, 267, 270,284

value added as percentage of GDP $267 \mathrm{f}$

Vision 2030273

water, access to $264,265,273,274 t$, $275 \mathrm{f}, 276 \mathrm{t}$

weather conditions, adverse 267

weighting schemes or assumptions 272

welfare indicators 272

well-being 282, 284, 286

Zimbabwe 12, 20 